\title{
Coal Gasification: Direct Applications and Syntheses of Chemicals and Fuels
}

\author{
A Research Needs Assessment \\ by the \\ DOE Coal Gasification Research Needs \\ (COGARN) Working Group
}

June 1987

Prepared by:

S.S. Penner, Chairman of COGARN

Center for Energy and Combustion Research

and Department of Applied Mechanics and Engineering Sciences

University of California, San Diego

Lajolla, CA 92093

Under Contract No. DE-ACOI-85ER30076

Prepared for:

U.S. Depariment of Energy Office of Energy Research Office of Program Analysis Washington, DC 20545 



\section{DISCLAIMER}

This report was prepared as an account of work sponsored by an agency of the United States Government. Neither the United States Government nor any agency thereof, nor any of their employees, make any warranty, express or implied, or assumes any legal liability or responsibility for the accuracy, completeness, or usefulness of any information, apparatus, product, or process disclosed, or represents that its use would not infringe privately owned rights. Reference herein to any specific commercial product, process, or service by trade name, trademark, manufacturer, or otherwise does not necessarily constitute or imply its endorsement, recommendation, or favoring by the United States Government or any agency thereof. The views and opinions of authors expressed herein do not necessarily state or reflect those of the United States Government or any agency thereof. 


\section{DISCLAIMER}

Portions of this document may be illegible in electronic image products. Images are produced from the best available original document. 
COAL GASIFICATION:

DIRECT APPLICATIONS AND SYNTHESES OF CHEMICALS AND FUELS*

S.S. Penner, ${ }^{*}$ S.B. Alpert, ${ }^{a}$ J.M. Beér, ${ }^{b}$ M. Denn, ${ }^{c}$ W. Haag, ${ }^{d}$ R. Magee, ${ }^{e}$ E. Reichl, ${ }^{f}$ E.S. Rubin, ${ }^{g}$ P.R. Solomon, ${ }^{h}$ I. Wender, ${ }^{i}$ and K. Woodcock ${ }^{j}$

*Center for Energy and Combustion Research and Dept. of Appl. Mech. and Engin. Sc., Univ. of Calif., San Diego, La Jolla, CA 92093

${ }^{2}$ Adv. Power Systems Div., Electric Power Res. Inst., Palo Alto, CA 94303

${ }^{b}$ Dept. of Chem. Engin., Mass. Inst. Tech., Cambridge, MA 02139

${ }^{C}$ Dept. of Chem. Engin., Univ. of Calif., Berkeley, Berkeley, CA 94720

dCentral Res. Div., Mobil Res. and Dev. Corp., Princtón, NJ 08540

Radian Corporation, 8500 Shoa] Creek Rd., Austin, TX 78766

$f_{25}$ Lismore Lane, Greenwich, CT 06830

${ }^{g}$ Center for Energy and Envir. Studies, Carnegie Mellon Univ., Pittsburgh, PA 15213

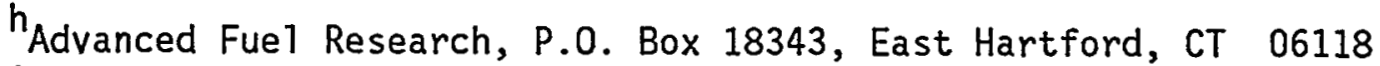

${ }^{i}$ Dept. of Chem. Engin., Univ. of Pittsburgh, Pittsburgh, PA 15261

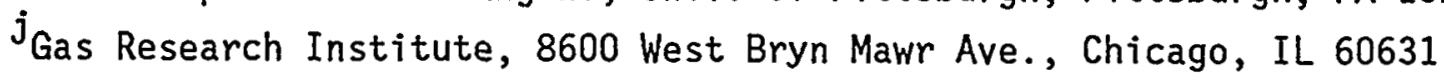

* This publication has been prepared by the US DoE Working Group on Research Needs for Advanced Coal-Gasification Techniques (COGARN). The Contract Sponsor was the DoE Office of Energy Research, Office of Program Analysis. The DoE technical project officer was F.D.

Freeburn; the DoE Contract Number is DE-AC01-85ER30076. S. S. Penner served as Chairman of COGARN and the other listed authors served as members of COGARN. 
The following people, who were not members of the COGARN Working Group, contributed to this publication and are appropriately identified as authors or coauthors of specific chapters or sections: A.J. Appleby, EPRI, Palo A1to, CA 94303; J.F. Elliott, Department of Mechanical Engineering, MIT, Cambridge, MA 02139; D.R. Hardesty, Combustion Research Facility, Sandia National Labs., Livermore, CA 94550; V.L. Hi11, Gas Research Institute, Chicago, IL 60631; J.C.W. Kuo, Mobil Research and Development Corp., Paulsboro, NJ 08066; J.P. Longwe11, Department of Chemical Engineering, MIT, Cambridge, MA 02139; D.K. Ottesen, Combustion Research Facility Sandia National Labs., Livermore, CA 94550; D. Pescarolo, Fluor Technology, Inc., 3333 Michelson Dr., Irvine, CA 92730; D. Rastler, EPRI, Palo Alto, CA 94303; M.T. Simnad, AMES, University of California, San Diego, La Jolla, CA 92093; S.P.N. Singh, Chemical Technology Division, ORNL, Oak Ridge, TN 37831; P.B. Tarman, Institute of Gas Technology, Chicago, IL 60616; D.F. Wiesenhahn, AMES, University of California, San Diego, La Jolla, CA 92093. 


\section{TABLE OF CONTENTS}

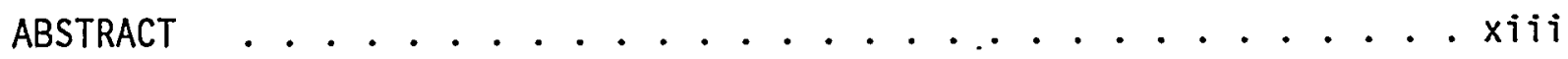

ACKNOWLEDGMENTS .................................

CHAPTER 1. SUMMARY OF RESEARCH RECOMMENDATIONS . . . . . . . . 1

CHAPTER 2. OVERVIEW OF COAL-GASIFICATION R\&D NEEDS ........ 5

2.1. Introduction ............. 5

2.2. Process Synthesis ........... 6

2.3. Gasifiers for Electricity Generation ...... 8

2.4. Gasification for Syngas Production ........ 9

2.5. Gasification for Syntheses of Fuels and Chemicals . . 10

2.6. Gasifiers for Fuel Cells (FCs) . . . . . . . 15

2.7. Gasification Catalysts ............ 15

2.8. Gas Cleanup ............. . . 16

2.9. Summary of Research Recommendations on

Environmental Issues ............ 21

2.10. Coal Beneficiation and Feed Preparation:

Solids Processing .......... . . 25

2.11. Applications of Advanced Diagnostics to Coal-

Gasification Systems .......... . 29

2.12. Fundamentals of Coal Conversion and Relation to

Coal Properties .............. 31

CHAPTER 3. GASIFICATION FOR ELECTRICITY GENERATION . . . . . . . 37

Sections 3.1 and 3.2 were written by S. B. Alpert,

S. S. Penner and D. F. Wiesenhahn, Sec. 3.3-3 by

P.B. Tarman, and the remaining subsections of Sec. 3.3, as well as Sec. 3.4 , by S. S. Penner and

D. F. Wiesenhahn with advice and inputs from correspondents identified in the subsections.

3.1. Integrated Coal-Gasification Combined Cycles (IGCC) . 37

3.1-1. Introduction . . . . . . . . . 37

$3.1-2$. IGCC System Status .......... 38

3.1-3. Advantages IGCCs . . . . . . . . 44 42

$3.1-4$. Future Utilization of IGCCs ....... 44

References for Section $3.1 \ldots . . . . .44$ 
3.2. The Cool Water IGCC ............ 44

3.2-1. General Features ........... 44

3.2-2. Process Description ......... 44 45

3.2-3. Performance Results ........ 47

References for Section 3.2 . . . . . . . . 49

3.3. Selected Gasifiers for IGCC Plants ........ 49

3.3-1. The Texaco Coal-Gasification Process (TCGP) . 49

3.3-2. The Shell Coal-Gasification Process (SCGP). . 53

3.3-3. The U-GAS Process ......... 58

3.3-4. Other Gasifiers .......... . 73

References for Section $3.3 \ldots . . . . .74$

3.4. Research Recommendations for Improving Gasifiers . . 74

3.4-1. Fouling and Slagging ........ . 74

3.4-2. Corrosion and Fatigue ........ . . 75

3.4-3. High-Temperature Sulfur Removal . . . . . 76

3.4-4. Gasifiers for Low-Rank Coals ...... . 76

3.4-5. Low-Cost Gas Separation and Air Enrichment. . 76

References for Section $3.4 \ldots . . . .76$

CHAPTER 4. COAL GASIFICATION FOR SNG PRODUCTION ......... 77

This chapter has been written by Kermit E. Woodcock and Vernon L. Hill.

4.1. Introduction ............. . . 77

4.1-1. The Great Plains Coal Gasification Plant (GPCGP) ............ 77

4.1-2. General Thermodynamic Considerations . . . . 78

4.1-3. General Flow Sheets ......... 81

4.2. Advanced Gasification Technology for SNG . . . . .83

4.2-1. BGC/Lurgi Slagging Gasifier . . . . . . . 84

4.2-2. KRW (Kellogg-Rust-Westinghouse) Ash-

Agglomerating, Fluidized-Bed Gasifier . . . . 85

4.2-3. Rheinbraun $A G$, Hydrogasification . . . . . 87

4.2-4. Catalytic Coal Gasification ....... . 90

4.3. Catalytic Methanation ............ 90

4.3-1. Chemistry and Thermodynamics ....... . 90

4.3-2. Catalysis ........... . . 92

4.3-3. Commercial Processes . . . . . . . . .94 94

4.3-4. Direct Methanation .......... . 94

4.3-5. Comflux Process (Fluid-Bed Methanation).. .98

4.3-6. HICOM ............ . . 99

4.3-7. Liquid-Phase Methanation . . . . . . . . 104 
4.4. Acid-Gas Removal ............... . . . . . . .

4.4-1. Commercial Processes ........... 105

4.4-2. Advanced Technologies ......... 106

4.5. SNG Economics ...............110

4.6. Research and Development Needs ... . . . . . .112

4.6-1. Engineering Development and Testing . . . . .112

4.6-2. Technology Base Data for Design .... . . .113

4.6-3. Basic Research Needs for Advanced Systems . .114

References.................. . . . . . . . . . .

CHAPTER 5. GASIFICATION FOR THE SYNTHESES OF FUELS -AND CHEMICALS . . .117

This chapter has been written by W. O. Haag, J. C. Kuo and I. Wender.

5.1. Cata7ytic Conversion of Synthesis Gas to Fuels and Chemicals ............. . . . 117

5.1-1. Introduction . . . . . . . . . . 117

5.1-2. Synthesis of Methanol and Higher Oxygenated Compounds . . . . . . . . . 120

5.1-3. SG as a Source of Chemicals . . . . . . 139

5.1-4. Fischer-Tropsch Synthesis . . . . . . . . . 144

5.1-5. Syntheses of Chemicals Using SG, CO or Methanol Plus Other Chemicals ....... 160

5.1-6. Other Chemicals from SG, Methanoi and $\mathrm{CO}$; Emerging Processes . . . . . . . . 164

5.2. Catalytic Processing of Synthesis-Gas-Derived

Products . . . . . . . . . . . . 168

5.2-1. Introduction . . . . . . . . . 168

5.2-2. Methanol-to-Gasoline (MTG) . . . . . . 169

5.2-3. Methanol Conversion to 0lefins and Diese1 . .173

5.2-4. Processing of Fischer-Tropsch Products . . .175

5.3. Interaction of Coal Gasifiers with Synthesis Gas

Conversion Processes . . . . . . . . . . . . 179

5.3-1. Introduction ............ . . . . . . .

5.3-2. $\mathrm{H}_{2}+$ CO Partial Pressure Requirements $\therefore 180$

5.3-3. $\mathrm{H}_{2} / \mathrm{CO}$ Ratio Requirement........ . 184

5.3-4. Purity Requirements for Synthesis Gas . . . 187

5.4. Zeolites as Shape-Selective Catalysts .......188

5.4-1. Introduction . . . . . . . . 188

5.4-2. Classification of Zeolites ....... 189

5.4-3. Intrinsic Catalytic Properties of Zeolites . 194

5.4-4. Shape Selectivity . . . . . . . . 194 
References ................. . . . . . . . . . . . .

CHAPTER 6. COAL GASIFICATION IN FUEL-CELL APPLICATIONS . . . . . . . .

6.1. Overview of FCs .............. . . . . . . .

This section has been written by A. J. Appleby.

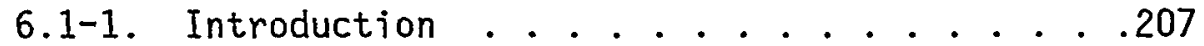

6.1-2. The $\mathrm{FC}$ as a Direct Energy-Conversion Device .209

6.1-3. Alkaline Fuel Cells (AFCs) ....... . 213

6.1-4. Acid Fuel Cells . . . . . . . . . 217

6.1-5. Molten Carbonate Fuel Cells (MCFCs) . . . .221

6.1-6. Solid Oxide Fuel Cells (SOFCs) . . . . . .226

6.1-7. Conclusions ............ . . 229

6.2 Coal Gasifiers for FCs . . . . . . . . . . . 230

This section has been abstracted by S. S. Penner and

D. F. Wiesenhahn from viewgraphs presented by

D. Rastler at the Second Technical Meeting of COGARN.

6.2-1. The Site-Specific UPA Design . . . . . . 230

$6.2-2$. The Site-Specific SCE Design . . . . . . 234

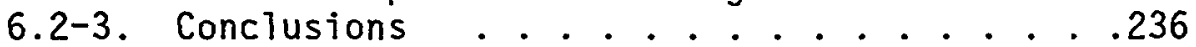

6.2-4. Research Needs on Gasifier-PAFC Systems . . .239

6.2-5. Other Gasifier-FC Systems . . . . . . . .239

References ................ . . . . . . . . . . .

CHAPTER 7 . USE OF CATALYSTS DURING GASIFICATION . . . . . . . . . 43

This chapter has been prepared by S. S. Penner and

D. F. Wiesenhahn.

7.1. Selected Examples of Current Research . . . . . 243

7.1-1. Introduction ............. . . . . . . . .

7.1-2. Results from the 1985 International Coal

Science Conference . . . . . . . . . . 244

7.1-3. Catalytic Conversions at Reduced

Temperatures ......... . . . 249

References for Section $7.1 \ldots .257$

7.2. The Exxon Process for Catalytic Coal Gasification . .258

7.2-1. Process Features . . . . . . . .258

7.2-2. Development Work ......... . . 261

7.2-3. Fluid-Bed Slurry Dryer (FBSD) . . . . . . .266

7.2-4. Mechanisms of Catalysis and Selection of

Alternative Catalysts ........ 266

7.2-5. Environmental Aspects of CCG . . . . . . . .270

7.2-6. Large Pilot Plant . . . . . . . . . 271

References for Section 7.2 . . . . . . . . 271 
7.3. Recommended Research for Syngas Production from Coal.271

CHAPTER 8. GAS-CLEANING PROCESSES FOR COAL GASIFICATION . . . . . . . .273

This chapter has been written by Robert A. Magee. The Appendix to this chapter has been written by J. F. Elliot.

8.1. Introduction .............. . . . . . . . . .

8.2. Gas Cleanup Systems ............ . . . 274

8.3. Quenching, Cooling and Heat Recovery ........276

8.4. Removal of Particles, Aerosols and Inorganic

8.5. Acid-Gas Removal and Sulfur Recovery . . . . . . . . . . .277

8.5-1. Solid Sorbents and In-Bed Desulfurization . .279

8.5-2. Sulfur-Redox Processes . . . . . . . 282

References ................ . . 283

Appendix: Slag for In-Bed Sulfur Removal . . . . . 285

CHAPTER 9. ENVIRONMENTAL ISSUES . . . . . . . . . . . . . . .

This chapter has been written by Edward S. Rubin.

9.1. Introduction ............... . . . . . . . .

9.2. Overview of US Regulatory Policy . . . . . . . 291

9.2-1. Trends in Environmental Regulation . . . . 291

9.2-2. Elements of Current Policy . . . . . . .292

9.2-3. Future Regulatory Directions . . . . . .293

9.3. Environmental Emissions from Coal Gasification . . 299

9.3-1. Process Overview . . . . . . . . . . 300

9.3-2. Recent Characterization Studies . . . . . .302

9.3-3. Methods of Environmental Control . . . . . .319

9.4. Experience at Commercial Facilities . . . . . . 324

9.4-1. The Great Plains Gasification Plant. . . . 324

9.4-2. The Cool Water Gasification Facility . . . 325

9.5. Research Needs and Priorities . . . . . . . . 327

9.5-1. Current Control Technology .........328

9.5-2. Future Environmental Requirements . . . . . .329

9.5-3. Advanced Control Technology . . . . . . .332

References ........................... 
CHAPTER 10. COAL BENEFICIATION ............................. . . . . . .

This chapter has been written By Suman P.N. Singh.

10.1. Background . . . . . . . . . . . . . 335

10.2. Current Commercial Practice . . . . . . . . . . . .338

10.3. Recent Advances in Coal Cleaning . . . . . . . . 343

10.4. Conclusions . . . . . . . . . . . . . . . 344

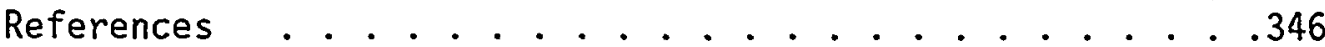

CHAPTER 11. OPTICAL DIAGNOSTICS FOR IN SITU MEASUREMENTS IN COMBUSTION ENVIRONMENTS CONTAINING COAL PARTICLES . . . . . .349

This chapter has been written by D. R. Hardesty and

D. K. Ottesen.

Abstract ............................. . . . . . . . .

11.1. Introduction . . . . . . . . . . . . . . 350

11.2. Diagnostics Requirements . . . . . . . . . . 350

11.2-1. Characteristics of Class I Flows . . . . . .351

11.2-2. Diagnostics Considerations for Class I

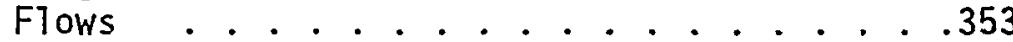

11.2-3. Characteristics of Class II Flows..... . . .355

11.2-4. Diagnostics Considerations for Class II

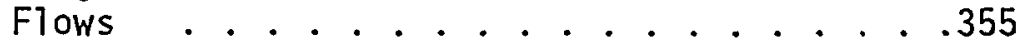

11.3. Gas-Phase Temperature Measurement . . . . . . . 356

11.3-1. Raman Scattering Techniques....... . . . . .

11.3-2. Fluorescence and Absorption Techniques . . .363

11.4. Gas-Phase Species Concentration Measurement . . . .366

11.4-1. Raman Scattering Techniques . . . . . . .366

11.4-2. Fluorescence and Absorption Techniques . . .367

11.5. Particle Size, Number Density and Temperature

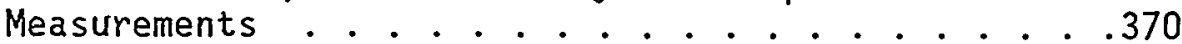

11.5-1. Single Particle Counter, SPC (Scattering)

Instruments . . . . . . . . . . . . . . .371

11.5-2. Imaging Methods for Single-Particle Counting. 378

11.5-3. Ensemble Methods for Analysis of

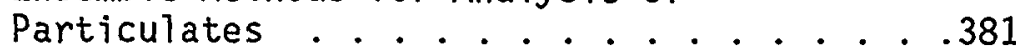

11.6. Velocity Measurements in Particle-Laden Flows . . . .383

11.6-1. Application of Laser-Doppler Velocimetry to Coal-Derived Flows . . . . . . . . 384

11.7. Particulate Composition Measurement by Laser-Spark

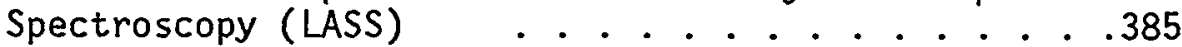


Referencess ................. . . . . . . . . . . .

CHAPTER 12. FUNDAMENTALS OF COAL CONVERSION AND RELATION TO

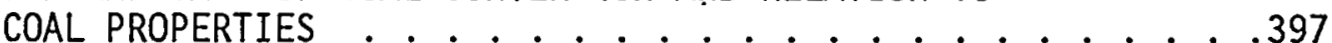

This chapter has been written by P. R. Solomon and

J. M. Beer. The Appendix is by J. P. Longwell.

12.1. Introduction . . . . . . . . . . . . . . . . . . . . . .

12.2. Coal Characterization .....................

12.2-1. Organic Structure (Functional Groups) . . . .399

12.2-2. Viscosity ........... . 400

$12.2-3$. Pyrolysis . . . . . . . . . 400

12.2-4. Reactivity ........... . . 400

12.2-5. Mineral Matter . . . . . . . . 401

12.3. Fundamental Processes in Gasification and Partial

Gasification ................ 402

12.3-1. Heat Transfer . . . . . . . . . . . 402

12.3-2. Pyrolysis Rates . . . . . . . . . . 406

12.3-3. Devolatilization: Formation of Gases, Condensables and Char .........408

12.4. The Behavior of Coa] Mineral Matter in Gasification .423

12.4-1. The Nature of Mineral Matter in Coal and Its Characteristics ............423

12.4-2. Behavior During Heating . . . . . . . 424

12.4-3. Mineralogical Transformations at High

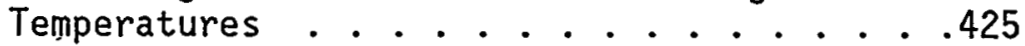

12.4-4. Ash Agglomeration . . . . . . . . .425

12.5. Mathematical Modeling ............426

12.5-1. Status of Mode1 Development . . . . . . 426

12.6. Research Recommendations ........... . . . . . . .

12.6-1. Coal Characterization .......... . 429

12.6-2. Fundamental Processes in Gasification and Partial Gasification ........ 430

12.6-3. Mathematical Modeling of Gasification

Processes ...............432

References ................ . . . . . . . . . .

Appendix: Effect of $\mathrm{CaO}$ on Combined Fluidized-Bed

Gasification and Pyrolysis ......... . 440 
CHAPTER 13. GAS SUPPLIES AND SEPARATION; ASH DISPOSAL; MATERIALS

FOR GASIFIERS . . . . . . . . . . . . . . . . 443

13.1. Gas Supplies and Separation . . . . . . . . . . 443

This section has been abstracted by S. S. Penner and D. F. Wiesenhahn from viewgraphs and references supplied by A. Smith.

13.1-1. Introduction .............443

13.1-2. Cryogenic Air Separation . . . . . . . .444

13.1-3. The MOLTOX System . . . . . . . . . . .446

13.1-4. Other Air-Separation Systems . . . . . . .450

13.1-5. Research Needs .. . . . . . . . . . .450

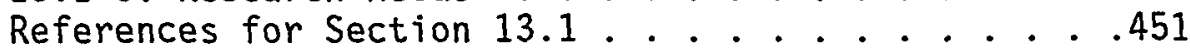

13.2. Utilization and Disposal of Ash from Gasifiers . . 452

This section has been written by S. B. Alpert.

13.2-1. Environmental-Impact Studies . . . . . .454

13.3. Construction Materials for Coal Gasification . . . 455

This section has been written by M. T. Simnad.

13.3-1. Introduction ............ . . . . . . . . . . 555

13.3-2. High-Temperature Corrosion . . . . . . .455

13.3-3. Low-Temperature Corrosion . . . . . . .463

13.3-4. Erosive Wear . . . . . . . . . . . .464

13.3-5. Mechanical Properties .......... . .465

13.3-6. Materials for Syngas Coolers of Slagging Gasifiers............. . . . 468

13.3-7. Nuclear Heat Steam-Gasification of Coal . . .470

References for Section 13.3 .......... . . . . . 775

CHAPTER 14. INTRODUCTION TO COSTING . . . . . . . . . . . . . . 477

This chapter has been written by D. Pescarolo.

APPENDIX: GENERAL REMARKS ON COAL-GASIFICATION SYSTEMS . . . . . . . 483

This Appendix has been prepared by S. S. Penner and

$D$. F. Wiesenhahn and is based on a presentation by

R. Shinnar.

A-1. Stoichiometry of Coal Conversion . . . . . . . .483

A-2. Gasifier Efficiency . . . . . . . . . . . . . . 486

A-3. Fluidized-Bed Gasifiers . . . . . . . . . . . 490

References ................. . . . . . . . . . .

GLOSSARY OF SYMBOLS AND ABBREVIATIONS . . . . . . . . . . . . . . .493

FORMAL REVIEWS OF THE COGARN REPORT . . . . . . . . . . . . . . . 499 


\section{ABSTRACT}

The DOE Working Group for an Assessment of Coal-Gasification Research Needs (COGARN - coal gasification advanced research needs) has reviewed and evaluated U.S. programs dealing with coal gasification for a variety of applications. Cost evaluations and environmental-impact assessments formed important components of the deliberations. We have examined in some depth each of the following technologies: coal gasification for electricity generation in combined-cycle systems, coal gasification for the production of synthetic natural gas, coal gasifiers for direct electricity generation in fuel cells, and coal gasification for the production of synthesis gas as a first step in the manufacture of a wide variety of chemicals and fuels. Both catalytic and non-catalytic conversion processes were considered. In addition, we have constructed an orderly, long-range research agenda on coal science, pyrolysis, and partial combustion in order to support applied research and development relating to coal gasification over the long term.

The COGARN studies were performed in order to provide an independent assessment of research needs in fuel utilization that involves coal gasification as the dominant or an important component. The findings and research recommendations of COGARN are summarized in this publication.

\section{ACKNOWLEDGEMENTS}

The COGARN discussions profited greatly from inputs provided by ex officio members: F.D. Freeburn (Mail Station G-225, ER-33, GTN, U.S. Department of Energy, Washington, DC 20545), F.M. Glaser (FE-14, GTN, Office of Technical Coordination, U.S. Department of Energy, Washington, DC 20545), J.S. Halow and M. Ghate (Coal Management Division, U.S. Department of Energy, Morgantown Energy Technology Center, P.0. Box 880, Morgantown, WV 26505), A.W. Hemenway (FE-24, GTN, Office of Surface Coal Gasification, U.S. Energy, Washington, DC 20545), J.M. Jennings (Office of Technical Coordination, FE-14, GTN, U.S. Department of Energy; Washington, DC 20545). The following people, among others, have contributed to our discussions, evaluations, and final recommendations: A.J. Appleby (EPRI), R.A. Bajura (METC), T. Bechtel (METC), E. Cairns (LBL), J. Callo (Brown Univ.), P. Cho (DOE), J.F. Elliott (MIT), M. Ghate (DOE), F.M. Glaser (DOE), D. Grether (LBL), D.R. Hardesty (SNL-L), H. Heinemann (UCB/LBL), V. Hili (GRI), J. Howard (MIT), G.Y. Jordy (DOE), J. Klosek (Air Products), J.C.W. Kuo (Mobil Corp.), D. Leppin (GRI), J.P. Longwell (MIT), H. Meyer (GRI), G.L. Miller (DOE), L. Monroe (MIT), T.F. Morton (Fluor), M. Nager (She11 0i1), C.R. Nelson (GRI), J. Notestein (METC), D.K. Ottesen (SNL-L), D. Pescarolo (Fluor), A.A. Pitrolo (METC), D. Rastler (EPRI), J. Rosenberg (GRI), W.G. 
Schlinger (Texaco), M.A. Serio (AFR), R. Shinnar (CUNY), M. Simnad (UCSD), S.P.N. Singh (ORNL), A. Smith (Air Products), D. Stevenson (DOE), E. Suuberg (Brown Univ.), P.B. Tarman (IGT), I. Thomas (DOE), G. Wheeler (DOE), P.R. Wieber (METC), and D.F. Wiesenhahn (UCSD). The authors are greatiy indebted to Annetta Whiteman for preparing this entire manuscript for publication. 


\section{CHAPTER 1:}

\section{SUMMARY OF RESEARCH RECOMMENDATIONS}

The COGARN studies on coal gasification encompass the use of gasifiers for a wide variety of applications. Specifically included are all direct uses of the gases produced from coal, as well as conversions of product gases to chemicals and liquid fuels (indirect coal liquefaction). The research priorities summarized in this chapter were arrived at by COGARN members working as a group and therefore represent a consensus on research needs. These listed research needs were defined after a 12-month period of intensive review and study involving six separate ful1-day meetings at different locations, where discussions were held with many coal-gasification experts after presentations of on-going research by resident scientists and engineers. The fifty experts who provided valuable inputs are identified in the contributor listing of the Acknowledgments. While the scope of our deliberations was broad, it was not encyclopedic. In order to provide balance and perspective, we have solicited external reviews to this study (cf. Formal Reviews of the COGARN Report) with the expectation that the expert reviewers would provide independent comments and highlight important omissions and possible bias.

The gasifier is part of a complex process, of an integrated system, and it must accordingly be optimized as a unit operation within the context of the overall system. The proper perspective is total economic return. Coal gasification is always performed in connection with a downstream process. The primary emphasis may be on electricity generation, on syngas production for pipeline applications, or on syntheses of fuels and chemicals.

Neither the gasification system nor a research recommendation should be viewed as affecting a single unit process (e.g., the gasifier) but rather as impacting an integrated system that handles coal, contains a gasification 
unit, and can ultimately produce an array of products for the fuel, chemical, gas, and electricity industries. The primary goal may involve one or more applications (e.g., electricity generation, electricity production with cogeneration of steam, production of multi-product slates of chemicals and fuels). The multi-product slates and opportunities for multiple applications make coal-gasification systems unique in the chemical process industries and offer important opportunities for cooperation in research between government and a variety of important US industries. This type of cooperative approach is required in order to assure a US competitive edge in domestic and international markets, particularly since potential foreign competitors appear to view coal-gasification systems from this same broad perspective.

In the absence of a quantitative procedure for optimizing process synthesis and because of the fact that experienced design engineers will remain, for some time to come, the most important element in the synthesis of a process flowsheet (compare Sec. 2.2), it appeared appropriate to ask members of the COGARN Working Group to identify primary areas for research emphasis in order to advance the art and science involved in the construction of improved coal-gasification systems. A random compendium of all of the three highest priority research tasks identified by COGARN members is summarized in the first column of Table ES-1 on pages $4 A$ and $4 \mathrm{~B}$. This list was distributed to COGARN members with a request to identify the top four priority items. The selections made and their weighted preferences (with.ten for first priority, five for second, two for third, and zero for fourth) are given in the last column of Table ES-1.

It will be noted that the entries in Table ES-1 are not listied according to the final weighted priority, which was arrived at according to the procedure described in the preceding paragraph. Thus, the initial random ordering of the first three choices made by individual COGARN members was retained deliberately in order to emphasize the fact that it is inappropriate to attach special significance to the listed numerical values because these numbers were arrived at by using the specified arbitrary weighting of $10,5,2$, and 0 for the first four choices in the final iist, respectively. Any different weighting of COGARN member priorities would have yielded different numbers for the final weighted priorities. The 
initial 33 different top three priority listings made by 11 COGARN members dealt with the 18 topical areas listed in Table ES-1, many of which represent first-priority choices for two or more COGARN members.

Examination of the data 1isted in Table ES-1 shows that all of the listed research and development areas have their proponents, which is inevitable in view of the procedure used to obtain this list of entries from COGARN members with diverse interests and responsibilities. Selection of items (8), (11) and (18) for first or second priority reflects the COGARN members' predilection for an integrated systems approach in arriving at optimized gasification processes, while emphasis on items (2) and (10) indicates preoccupation with environmental controls that have become a major cost item in synfuels technologies, in general, and in coal gasification, in particular.

A11 of the items listed in Table ES-1 are important and merit support. If such topics as (6), (7), (12), and (14)-(17) are not adequately funded, there is little hope for innovation based on new scientific information. If item (2) goes unfunded, near-term systems cost reductions may be in jeopardy; special opportunities for savings are associated with items (1), (5), and (9). High load factors and low operating costs may result from success with item (13), while optimal process synthesis itself depends on advances of the type specified in connection with topics (3) and (4). We may summarize the COGARN Working Group R\&D recommendations as follows:

(i) Each of the topics (1) to (18) represents a vital research area in the advancement and improvement of cost-effective coal-gasification systems.

(ii) Priority assignments reflect the background and problem areas faced by individual investigators and cannot be made in an absolute sense and in a manner acceptable to a diverse group such as the COGARN members.

(iii) We recognize the overriding importance of item (11) if we are to proceed from the laboratory to commercial operation in an orderly fashion and in an advantageous manner in international competition.

(iv) R\&D efforts merit support provided they (a) offer the promise of significant advances through innovative new approaches or (b) bring significant cost savings through incremental improvements in component 
operation that benefit overall systems performance through reductions in capital, operation and maintenance costs. There are no entries in Table ES-1 that do not meet one of these two requirements.

In the Overview of Chapter 2, we return to the more traditional approach of component optimization by summarizing briefiy the salient recommendations derived from the more detailed studies in Chapters 3 to 13 . It should be recalled that this Summary of Research Recommendations and Chapter 2 represent assessments by the COGARN Working Group as a whole, while Chapters 3 to 14 contain the views of individual identified authors. 
Table ES-1. Summary of the three highest priority research and development recommendations for long-range emphasis identified by individual COGARN members.

(1) Continue fundamental research aimed at improved un4.0 derstanding of the behavior of coals in gasifiers. This work should include a search for gasification catalysts and feed-preparation methods that improve gasifier performance and may reduce costs while increasing operating life; the selection and improvement of methods of coal feed for fixed-bed gasifiers require special attention.

(2) Develop hot-gas clean-up techniques (for $\mathrm{NH}_{3}$, alkalis, heavy metals) and especialiy hot sulfur-removal systems and in-bed sulfur capture (including in-bed use of zinc ferrite, lime/limestone/dolomite) and hot filters.

(3) Identify preferred gasifier configurations and perform needed materials research to handle high-s and high-Cl coals in IGCC systems producing electricity and other products.

(4) Develop and characterize slurry reactors to produce methanol and higher alcohols for fuels, together with electricity, from synthesis gas.

(5) Develop mass-production techniques for oxygen from 6.0 air separation at acceptable purity for gasification $(\sim 95 \%)$ in order to reduce oxygen-production costs.

(6) Develop and test diagnostic techniques for improved measurements of (a) inflows of solids and liquids and (b) local reactor conditions in gasifiers and auxiliary systems to define rates and mechanisms of fouling and to improve scale-up procedures of solidfeed reactors.

(7) Obtain expanded data for equilibria and kinetics involving sulfur compounds in alternate clean-up systems (including sulfur redox reactions in liquid aqueous and other solvents.)

(8) Evaluate the integrated performance characteristics of advanced (pressurized) gasification technologies 
in combination with alternate downstream processing for both oxygen- and air-blown systems.

(9) Improve and validate scale-up procedures for coal gasifiers.

(10) Develop a greatly expanded environmental data base for emissions, fates, and associated health hazards of trace constituents emanating (in gaseous, liquid, and solid wastes) from coal-gasification systems.

(11) Determine limiting capacities of individual equipment (gasifiers, etc.) in demonstration coal gasification facilities, such as Cool Water, Great Plains, etc., in order to obtain a needed data base for optimum design of future plants.

(12) Develop chemical and physical understanding of coalconversion phenomena and their relations to (a) char formation, (b) ash formation, (c) condensable products chemistry, and (d) catalytic effects.

(13) Develop comprehensive (numerical) models for gasifiers based on our best scientific knowledge of chemical and physical phenomena and validate and improve these models by performing appropriate laboratory and field measurements.

(14) Characterize the properties of gasification residues, 4.9 including chemical analyses, leachability, and disposal methods.

(15) Define new and better syntheses (especially of ethanol from syngas) and determine the suitability of $C_{1}$ to $C_{5}$ alcohols as fuels for transportation systems, with proper regard for costs, octane enhancement, toxicity, emissions, and distribution.

(16) Perform needed R\&D to define opportunities for di- 3.0 rect use of low $\mathrm{H}_{2}$ to $\mathrm{CO}$ ratios in chemical syntheses.

(17) Support needed research for total upgrading of Fischer-Tropsch products.

(18) Investigate the applicability of knowledge-based expert systems, artificial intelligence and advanced computational methods to the design of improved systems involving integrated coal-gasification plants. 
CHAPTER 2

OVERVIEW OF COAL-GASIFICATION R\&D NEEDS

\subsection{Introduction}

Estimates of US coal resources and reserves indicate ready avai1ability at current ( $\sim 933 \times 10^{6}$ tons in 1985) and anticipated future production rates for several centuries, although prices in constant dollars are expected to rise from depressed 1985 levels of about $\$ 20 /$ ton fob utilization representing about $78 \%$ of total US generating capacity.

Based on application of 1978 technology, world-wide coal reserves corresponded to about $3.04 \times 10^{12}$ bbl of oil equivalent, with the US share of $28 \%$ of the total exceeding that of Europe (20\%), the USSR (17\%), China (16\%), and other countries. Coals are characterized according to a variety of measures, with coal rank (roughly related to carbon content and heat of combustion) being a preferred measure in Western countries.

The direct utilization of coals currently dominates industrial and residential applications. This field has been examined in an antecedent study. 1 While direct utilization of coal has represented the lowest cost use and has therefore enjoyed the widest market penetration, the direct utilization of coals for electricity generation is being challenged by integrated coal-gasification combined cycle (IGCC) systems with gasification before combustion. When specified environmental standards must be met, IGCC systems may be competitive with or superior to direct coal use with required environmental control measures.*

The successful technologies that have been developed for coal gasification have opened up alternative markets that include not only gasifiers for IGCC systems but also gasifiers combined with fuel cells, gasification

* The Glossary should be consulted for definitions of abbreviations. 
to produce methane as a substitute for natural gas, and gasification for the production of syngas followed by syntheses of chemicals and fuels. The processes, science and technologies involved in these coal-utilization schemes are reviewed and evaluated in this study. The compilation is not meant to be encyclopedic and the discussion of selected topics, as well as the omission of others, represents neither more nor less than the opportunity for COGARN review and study of an important, albeit limited, subset of a vast data and information base.

We have structured this report by beginning with accounts of gasification for electricity generation, SNG production, syntheses of fuels and chemicals, and fuel-cell applications. Next, we comment on gasification catalysts, coal feed, beneficiation, and solids processing. We conclude with potential applications of advanced diagnostics to coal gasifiers and the scientific underpinnings of the entire field, namely, coal conversion and coal properties as determinants in the design and development of coalgasification systems. The concluding chapter deals with costing of coalgasification systems as an example of our estimating capabilities for synfuels production.

While our discussions of coal-gasification systems and applications may stress developments of unit processes or unit-process components, the thesis of this study remains the necessity to view coal-gasifiers as components of integrated systems and improvements in unit-process performance as elements in integrated systems performance. The true measure of system-component improvement remains the improvement of system economics.

\section{Reference for Section 2.1}

1. "Coal Combustion and Applications," a report prepared by the DOE Coal Combustion and Applications Working Group, Energy 9, 361-418 (1984); see al so Progr. Energy Combust. Sci. 10, 87-144 (1984).

\subsection{Process Synthesis}

In accord with the primary approach to gasification identified in the Executive Summary, we place very great importance on viewing gasifiers 
as components of integrated systems. The ultimate goal of a coal-conversion process is to produce a final product: power, chemical, fuels or any combination of these. Coal-conversion processes have in the past been discussed in terms of a sequence of unit operations, with attention focused on technical problems encountered in specific unit processes. This procedure reflects undue emphasis on specific unit operations that appear in existing flowsheets, rather than on process sythesis with primary identified goals. Experienced design engineers will remain, for some time to come, the most important element in the synthesis of a process flow sheet.

We note the growing use of computer-based design aids and even the beginnings of applications of artificial intelligence (AI) methods in the process synthesis of complex systems. Proponents of AI believe that its uses in synthesis and design in the process industries will become increasingly. important during the next two decades. It is clearly desirable to include coal-conversion processes, in general, and coal-gasification systems, in particular, within the category of complex process systems for which powerful new tools will be needed in order to assure an orderly approach to systems optimization.

One of the primary goals of research on process synthesis is to establish methodologies for determining optimal pathways from raw materials to final products. The current status of such techniques involves an interplay of heuristics, more formalized AI, and designer experience. Coalgasification development has generally emphasized optimization of obvious pathways through a process, rather than exploration of dramatic new routes to the final product.

Long-term advances in coal-gasification processes will undoubtedly rest on the development of process flowsheets that eliminate some of the currently-employed technology, i.e., some of the normal unit operations. clearly, the most advanced techniques of process synthesis should be utilized in the development of novel flowsheets. The present state of the art in the discipline of process synthesis is unlikely to bring about major advances in ways of thinking about coal-gasification processes. However, process synthesis is a dynamic field of research and can be expected to move quickly. Coal gasification contains features that are uncommon in other process industries, while the latter have been providing technical 
motivation for ongoing research. The nature of gas-cleanup requirements is a particularly cogent example of technological differences. The often unique features of the coal-gasification system may require emphases in process-synthesis research that would not be driven by other processindustry needs. It is therefore appropriate that some financial support be directed towards research in the area of process synthesis from those interested in the development of optimal coal-gasification flowsheets in order to ensure that new methodologies will be applied promptiy and properly to coal-gasification systems.

\subsection{Gasifiers for Electricity Generation}

Coal gasifiers are easily incorporated into an integrated gasifier combined-cycle (IGCC) system producing electricity. From a utility perspective, this system has many advantages over traditional electricity-generation systems: low pollutant emissions, modular installment capability, relatively high energy-conversion efficiency and, in some cases, a lower net electricity cost.

Cool Water is a demonstration plant producing over 100 MWe of power. The successful operation of this plant has raised the level of confidence within the utility industry to the point where several large IGCC systems are being considered or planned. Utilities can expand or replace obsolete equipment by first installing turbines (with or without combined cycles) fired by $N G$ and, at an appropriate time, installing coal-gasification units. This route avoids a full-scale commitment to both technology and capital investment and may therefore be a preferred strategy for utilities facing uncertain rates of return and capacity requirements.

Key research recommendations for improving entrained-flow gasifiers of the type used at Cool Water relate to the control of fouling and slagging and of corrosion and fatigue, high-temperature sulfur removal, gasifiers for low-rank coals, and low-cost gas separations and air enrichment. These are detailed in Sec. 3.4 The U-GAS system represents one of a number of alternate gasification schemes and is discussed in Sec. 3.3-3.

Our selection of gasifiers for detailed description is illustrative rather than exhaustive and does not represent a value judgement of 
preferred technologies for IGCC applications.

\subsection{Gasification for Syngas Production}

The research and development needs associated with the long-range objectives of the gas industry in coal gasification cover a broad spectrum of activities, ranging from engineering studies to basic research. These needs include operational and economic data on large, integrated coalgasification plants, expanded engineering data bases, and the development of fundamentally-oriented information on the rate-controlling steps in the various process elements. While the gas industry needs are focused on coal gasification related to the production of high-Btu syngas or SNG, many of the process steps are generic and will be useful in a variety of coalgasification applications. Needs relate to engineering development, a technology data base and fundamental research.

Engineering development requires: (i) large-scale operational and performance data on integrated coal-gasification plants such as the Cool Water integrated coal-gasification combined-cycle power-generation plant and the Great Plains coal-to-SNG plant; ( $i j$ ) expanded engineering data bases for oxygen-blown, ash-agglomerating fluidized-bed gasifiers to optimize designs for specific processes or applications (high-pressure operations, fines collection and recycle, coal types, in-bed desulfurization); (iii) scale-up data for emerging technologies such as the direct methanation concept and the CNG advanced acid-gas removal concept; (iv) integrated performance evaluations of advanced gasification technologies such as the BGC/Lurgi slagging gasifier and the ash-agglomerating, fluidized-bed process with advanced downstream processing concepts such as direct methanation and CNG acid-gas removal processes; $(v)$ development and validation of scale-up models with particular emphasis on coal gasifiers; ( $v i$ ) exploratory studies to develop initial data bases for new or advanced process concepts for gasification and downstream processing; ( $v i i)$ improved, high-temperature heat recovery systems; ( $v i i i$ ) expanded environmental data bases for advanced technologies in the areas of trace-constituent production, fate, control, and disposal or treatment. 
The technology data base requires: (i) development of metal alloys for high-temperature heat-recovery applications; ( $i$ i) development of improved ceramics for high-temperature applications (i.e., particulate filters, valves); ( $i j i$ ) expanded data bases on the erosion-corrosion behavior and resistance of metals and ceramics in coal-gasification environments; (iv) long-term corrosion data (for $>10,000 \mathrm{hr}$ ) in coal-gasification environments, $i . e .$, in the presence of alkali metals, sulfidation, and chlorine compounds; (v) vapor-1iquid equilibrium data at elevated pressures and temperatures for selected multicomponent systems involoving synthesis gas, steam, heavy oils (tars), light aromatics, phenolics, fatty acids, $\mathrm{CH}_{4}, \mathrm{H}_{2} \mathrm{~S}$, $\mathrm{CS}_{2}, \mathrm{COS}$, mercaptans, $\mathrm{NH}_{3}, \mathrm{HCl}, \mathrm{HCN}, \mathrm{AsH}_{3}, \mathrm{SeH}_{2}, \mathrm{Hg}, \mathrm{Zn}, \mathrm{Pb}, \mathrm{Cd}$; (vi) transport data (thermal conductivities, viscosities, diffusivities) for tars and slurries, especially in mixtures of solids with oils, tars and water; (vii) thermodynamic data (free energies of formation, heats of formation, entropies, specific heats) for all important constituents; (vii) vaporTiquid equilibrium data in sour-water strippers for $\mathrm{H}_{2} \mathrm{O} / \mathrm{NH}_{3} / \mathrm{CO}_{2} / \mathrm{H}_{2} \mathrm{~S}$ systems at 0 to $100 \mathrm{psig}$ and 70 to $400^{\circ} \mathrm{F}$; ( $i x$ ) improved correlations for predicting mass-transfer coefficients and other engineering design parameters in multicomponent systems.

Basic research needs include: (i) improved understanding of the chemical processes associated with and controlling the fragmentation/gasification of coal; ( $i j$ ) improved models for predicting vapor-liquid equilibria in multicomponent systems.

\subsection{Gasification for Syntheses of Fuels and Chemicals}

\section{5-1. Overview}

\section{Chemicals constitute only about $7 \%$ of production from fossil}

fuels. However, manufacturing and marketing of high-value chemicals has a major impact on the US economy and our balance of trade. Although it is traditional to separate the fuels (utility, transportation and industria1) and chemical businesses, the production of synthesis gas (SG) is common to both the fuels and chemicals industries. 
The distinction between fuels and many chemicals has become blurred for the following reasons: (i) Any utility plant based on SG will also be a potential source of SG for the production of chemicals and fuels. (ii) Any plant for the synthesis of chemicals from SG is a potential source of clean utility, transportation or industrial fuels. (iii) SASOL converts SG to more than $3 \times 10^{6}$ TPY of motor fuels but also produces more than 0.65 $x 10^{6}$ TPY of chemicals such as ethylene, ammonia, and polymers in the product slate. (iv) The Mobil methanol-to-gasoline (MTG) process has been commercialized in New Zealand with conversion of off-shore NG to over 4000 TPD of methanol, which is then converted to 14,500. BPD of high octane gasoline. Methanol may be used as a peaking or transportation fuel. In the MTO pro-cess, Mobil has converted methanol to $\mathrm{C}_{2}-\mathrm{C}_{4}$ olefins (chemicals, monomers) at high yields (56-81\%) using a 100 BPD semi-works plant in the FRG, which was previously used for the fluidized MTG process. Mobil is also converting olefins from the MTO and FT processes into gasoline and diese] fuel with over 95wt\% selectivity. Al1 of the Mobil processes involve use of the shape-selective zeolite catalyst ZSM-5. In New Zealand, the MTG process has been used to obtain high yields of durene, which is unwanted in gasoline but is an excellent source of the valuable monomer pyromellitic anhydride. Gasoline made via the MTG process contains about 38wt\% of BTX (benzene, toluene and $x y$ lenes); these compounds are petrochemical feedstocks and can be made in about 60 wt\% yield via ZSM-5 for use as chemicals. (v) SG is the primary source of $\mathrm{H}_{2}$, which is a fuel and is also used in making chemicals (ammonia, nylon) or fuels (hydrocracking, upgrading of heavy oils, hydrogenation of materials for fuels or for chemicals, potential use in direct liquefaction of coal, etc.). (vi) $\mathrm{CO}$ is an excellent fuel and is also used in carbonylation reactions to make chemicals [acetic acid, phosgene, methyl acetate (also a fuel), ethanol (a desirable fuel), etc.]. (vii) A medium-BTU gas mixture of $\mathrm{CO}$ and $\mathrm{H}_{2}$ is an excellent clean fuel, that may be pipelined for over 100 miles. (viji) Tennessee Eastman makes methanol (a fue1, chemical) and acetic anhydride (a chemica1). Surplus SG is available as an industrial or utility fuel via an IGCC plant. (ix) Northern Great Plains makes methane (a fuel) and methanol. ( $x$ ) The Ube (Japan) Texaco gas- 
ifier is used to make ammonia (a chemical); an IGCC plant is being considered for utility use. ( $x i$ ) Japan and France have a 7000 BPD plant in Japan to make $C_{1}-C_{5}$ alcohols from $S G$. ENI (Italy) produces $C_{1}-C_{5}$ alcohols from $S G$ for fuel use. ( $x i i$ ) Research is needed to synthesize ethanol directly from SG. Ethanol has usually been classified as a chemical but has also been used as an additive in transportation fuels (gasohol). The 1986 General Motors manual honors car guarantees with designated methanol and ethanol additives to gasoline.

The future prosperity of the utility industry may well depend on the flexible use of clean energy sources (i.e., IGCCs) as at Cool Water and Dow. The plant may use NG, petroleum or coal-gasification products interchangeably. As in the petroleum industry, the use of SG for electricity production will spawn plants for manufacturing transportation fuels and chemicals. Similarly, chemical plants using SG will spawn plants for power production.

The three main pathways for SG utilization are: (i) fuels and chemicals made directly (Table 2.5-1), (ii) fuels made via methanol by indirect syntheses (Table 2.5-2), and (iii) a long list of products from the reaction of $S G$ or $C O$ with another chemical, some of which are listed in Table 2.5-3.

Table 2.5-1. Principal fuels and chemicals made directly from SG.

ammonia, methanol, hydrogen, carbon monoxide, gasoline, diesel fuel, methane, isobutane, ethylene, C1-C5 alcohols, ethanol, ethylene glycol, C2-C4 olefins

Table 2.5-2. Principal fuels and chemicals made via methanol (indirect synthesis).

formaldehyde, acetic acid, gasoline, diesel fuel, methyl formate, methyl acetate, acetaldehyde, acetic anhydride, vinyl acetate, ethylene, propylene, ethanol, $\mathrm{C} 1-\mathrm{C5}$ alcohols, propionic acid, benzene, toluene (BTX), xylenes, ethyl acetate, a methylating agent 
Table 2.5-3. Some products from the reaction of $S G$ or $C O$ with a chemical not derived from SG.

\begin{tabular}{|c|c|c|}
\hline methanol + isobutane & $\mathrm{H}+$ & methyl tert-butyl-ether \\
\hline olefins $+\mathrm{H}_{2}+\mathrm{CO}$ & $\mathrm{CO}_{2}(\mathrm{CO}) 8$ & aldehydes and alcohols \\
\hline olefins $+\mathrm{CO}+\mathrm{H}_{2}$ & $\mathrm{H}+$ & highly branched acids \\
\hline chlorine + $\mathrm{CO}$ & $\longrightarrow$ & CoC12 (phosgene) \\
\hline methanol + $\mathrm{HCl}$ & $\longrightarrow$ & chloromethanes \\
\hline methanol $+x N H 3$ & $\longrightarrow$ & methylamines \\
\hline methanol & $\longrightarrow$ & single cell protein \\
\hline toluene + methanol & zeolite & styrene \\
\hline methyl propionate $+\mathrm{HCHO}$ & bases & methyl methacrylate \\
\hline $\begin{array}{l}\text { nitrobenzene }+ \text { methanol }+\mathrm{Co} \\
\text { terephthalic acid + methanol }\end{array}$ & & $\begin{array}{l}\text { isocyanates (_ urethanes) } \\
\text { dimethyl terephthalate }\end{array}$ \\
\hline
\end{tabular}

\section{5-2. Research Recommendations}

The use of $S G$ for fuels and chemicals is the wave of the future. By the year 2010, this country will be well on its way to an economy built largely on the use of clean fluid fuels, with coal gasification as a primary component. The acid-rain problem and transportation-fuel shortages may be solved by the use of $S G$. The following are research requirements: (i) Additional research is needed on the synthesis of ethanol from SG. Present selectivity to ethanol from $S G$ is approaching $70 \%$. Ethanol is used as an octane enhancer (gasohol has $10 \%$ of ethanol in gasoline); it is used neat in Brazil. Since the federal subsidy for fermentation ethanol may soon be removed, there is increased urgency for a better synthesis from SG. (ii) The direct production of $\mathrm{C}_{2}-\mathrm{C}_{5}$ alcohols also suffers from a lack of selectivity and poor understanding of conditions and catalysts needed for synthesis. The $C_{2}-C_{5}$ alcohols may be used directly as transportation fuels but are more 
likely to be employed for blending with methanol as an octane enhancer or in the production of tertiary ethers (these are excellent octane enhancers). (iii) There is great uncertainty about the use of alcohol fuels, especially methanol and $\mathrm{C}_{2}-\mathrm{C}_{5}$ alcohols. Blending characteristics of these fuels in gasoline or the use of neat alcohols are not understood. Determination of the suitability of alcohols as transportation fuels or additives is needed, with emphasis on costs, octane enhancement, automobile compatibility, distribution problems, toxicity, and emissions. (iv) Methods for separating $\mathrm{CO}_{2}$ in coal gasification with $<10 \mathrm{ppm}$ of $\mathrm{H}_{2} \mathrm{~S}$ are needed. Trillions of SCF of $\mathrm{CO}_{2}$ are needed in enhanced oil recovery; it is also useful in supercritical extraction, refrigeration, carbonation, polymer production, etc. ( $v \mathrm{CO}_{2}$ is the intermediate in the commercial synthesis of methanol using $\mathrm{Cu} / \mathrm{ZnO} / \mathrm{Al}_{2} \mathrm{O}_{3}$ catalyst. Clarification of the role of $\mathrm{CO}_{2}$ in methanol synthesis may lead to processes with reduced $\mathrm{CO}$ to $\mathrm{H}_{2}$ ratios, with $\mathrm{CO}_{2}$ replacing large amounts of $\mathrm{CO}$. (vi) Studies should be conducted to identify major potential cost savings resulting from integration of the gasifier with down-stream processing. Thus, oxygen-purity requirements to minimize the cost of the overall process should be examined. (vii) Research is needed on the direct use of low $\mathrm{H}_{2} / \mathrm{CO} S G$ in slurry $\mathrm{FT}$ processes. (viii) Improvements are needed in low-temperature, sulfur-tolerant water-gas-shift (WGS) efficiencies and economies to make either high $\mathrm{H}_{2} / \mathrm{CO} \mathrm{SG}$ or $\mathrm{H}_{2}$ by minimizing excess steam requirements. (ix) FT reactor design, as in the slurry reactor, should be improved. ( $x$ ) Continued exploration is needed on homogeneous and heterogeneous low-temperature/high-activity methanol synthesis catalysts. ( $x i$ ) Work should be continued on the development of SG conversion catalysts that tolerate higher feed impurities (e.g. S compounds). (xii) Studies should be continued on the direct upgrading of the total vaporous FT-reactor effluents through improved catalyst design. (xiii) Improved FT catalysts are needed, especially catalysts with higher activity for FT and WGS and higher stability in producing lower light HC yields. (xiv) Investigations should be performed to obtain improved methods for upgrading FT wax via new catalysts and processes. 


\subsection{Gasifiers for Fuels Cells (FCs)}

An overview of current and developing FCs is presented in Sec. 6.1 while Sec. 6.2 deals with special features of coal gasifiers for FC applications. The principal conclusions reached, insofar as the gasifier is concerned, are the following: (i) Site-specific emission requirements can be easily met and by-products must be properly eliminated. (ii) The plant configuration is modular and can be erected and on-stream within a 3-4 year period. (iii) The coal-gasifier-FC-system is expected to be economically competitive in the 100-150 MWe range.

The coal-gasifier unit should be a modular 20-50 MWe unit producing $\mathrm{H}_{2}$ and $\mathrm{CO}$. An atmospheric-pressure air-blown unit is acceptable but a pressurized gasifier would be preferable. The gasifier must be reliable for operation on a wide range of coals. It should produce $\mathrm{H}_{2}$-Co mixtures with high efficiency, yield minimal amounts of tar and oils in the raw-gas condensate, and become commercially available between the early and mid-1990s.

Since candidate gasification systems include units such as Shell, Texaco, Lurgi, KRW, KGN, MHI, and U-GAS, we recommend that the role of DOE, if any, be confined to cost-sharing with EPRI of an appropriate utilitydevelopment program. No long-range research to develop gasifiers specifically for FCs appears to be required.

\subsection{Gasification Catalysts}

Section 7.1-1 contains brief summaries of examples of current research on gasification catalysts used in the reactor itself for the temperature range 800 to $900^{\circ} \mathrm{C}$.

Catalysis at much lower temperatures is also being investigated (cf. Sec. 7.1-2) and holds the promise of far greater cost reductions for capital equipment and operations. A currently pursued research area involves catalysts constructed by combining $\mathrm{KOH}, \mathrm{CsOH}, \mathrm{NaOH}$, or $\mathrm{LiOH}$ with mixtures of transition-metal oxides. Significant conversions have been observed in the laboratory on time scales of hours at temperatures near 
$525^{\circ} \mathrm{C}$ and above. Empirical classification of efficiencies of transitionmetal oxides has shown, for example, that $\mathrm{NiO}$ is the most effective metal oxide tested thus far in combination with $\mathrm{KOH}$ and that the combination of $\mathrm{KOH}$ with $\mathrm{NiO}$ is far more effective than either $\mathrm{KOH}$ or $\mathrm{NiO}$ alone in the conversion of graphite according to the overall process $2 \mathrm{C}+2 \mathrm{KOH}$

$\rightarrow 2 \mathrm{COK}+\mathrm{H}_{2}$. A similar result was observed for gas production from Montana subbituminous coal. For coals, $\mathrm{H}_{2}$-production rates are high initially and then decay with time. The mechanisms of catalysis for transition-metal oxides mixed with $\mathrm{KOH}$ are under active study. It has been found from XPS diagrams that the binding energies for $\mathrm{NiO}-\mathrm{KOH}$ mixtures do not show the same resonances as $\mathrm{NiO}$ alone, whereas the $\mathrm{KOH}$ resonances are not materially changed. Fundamental work directed at finding low-T catalysts is clearly worth pursuing.

Section 7.2 deals with the development of the Exxon process for catalytic coal gasification (CCG) in the presence of 10 to $20 \% \mathrm{~K}$. The work was carried through successfully to a PDU ( $1 \mathrm{mt} / \mathrm{day}$ ) before termination. Long-term process and equipment performance data are needed on a large pilot plant before scale-up to commmercial plant sizes. Also needed are results for a variety of coals. Environmentally acceptable performance over a long period of time remains to be demonstrated. Required research areas include the following: ( $i$ ) definitions of optimal coal-pretreatment conditions for different coals and catalysts; ( $i i)$ studies of rates and mechanisms of salt leaching from coal ash during counter-current washing for catalyst recovery and studies to reduce costs of the recycle system; (iii) identification of lower-cost, environmentally-benign, throw-away catalysts; (iv) identification of catalysts for operation at reduced $T$.

\subsection{Gas Cleanup}

Process designs for producing gaseous fuels or synthesis gas from the gasification of coal with steam and air/oxygen usually include one or more process units to treat the gas exiting from the primary reactor in order to bring the gas to the specifications imposed by its intended use. 
These process functions are included in the gas clean-up system. The design may call for: (i) quench cooling (possibly with heat recovery); (ii) particulate removal (including removal of tars/oils); (iii) composition adjustment; (iv) acid-gas removal (usually with sulfur recovery).

These processing functions may be performed in various sequences and by using a wide variety of specific process configurations. For example, the quench/cooling step is often combined with particulate removal in a direct aqueous scrubbing step that also removes gaseous contaminants such as $\mathrm{NH}_{3}$, chlorides, sulfur-containing gases, and cyanides. Waste materials from the process units may be treated in a variety of processes or disposed of directly, depending on the gasification reactor, coal type, and discharge or waste-handling restrictions. The capital investment costs of these gascleanup systems generally represent $35 \%$ to more than $40 \%$ of the total capital cost of the gasification plant (exclusive of the end-use processes).

A summary of commercial and near commercial technologies is presented in Chapter 8. A review of this material leads to the important conclusion that the most probable source of significant economic advances in the gas-cleaning area results from elimination of one or more entire process units. Therefore, DOE research should emphasize approaches which are most likely to allow the elimination of process units or the combination and simplification of process units. The gas-cleanup functions most likely to yield benefits through elimination of units or significant simplification in the overall process are acid-gas removal and sulfur recovery.

The most common commercial design approach to acid-gas removal and sulfur recovery is a two- or three-step process in which acid gases (predominantly $\mathrm{CO}_{2}$ and sulfur species) are adsorbed from the process gas and subsequently desorbed to produce a concentrated acid-gas waste stream. Sulfur is then removed from this waste stream until levels are reached that meet required environmental restrictions prior to gas discharge. Two approaches currently being investigated have the potential to eliminate at least one of these process steps: (i) hot-gas cleanup through the use of solid sorbents, with or without gasifier in-bed sulfur capture and (ii) liquid redox technologies that remove sulfur from the gas and convert it to elemental sulfur in the same unit. 


\section{8-1. Hot-Gas Cleanup and In-Bed Sulfur Capture}

The use of solid sorbents to remove sulfur from the raw product gas formed in coal gasification provides the following process advantages: (i) delivery of the gas to the treatment system at temperatures in the $800-1200^{\circ} \mathrm{F}$ range may allow elimination of all or part of the quench/cooling processes and reduce or eliminate condensate normally produced during gas cooling, thus significantly reducing wastewater-treatment requirements and organic condensate handling and disposal, while retaining much of the thermal energy of the hot product gases, at increased thermal process efficiency; ( $i i)$ very high sulfur-capture efficiencies may result, which are relatively independent of the distribution of sulfur among the possible gas-phase sulfur species; (iii) sulfur will appear in concentrated solid form, which may be disposed of or reacted to regenerate the sorbent and produce a concentrated waste stream.

Research to date has led to identification of six key issues requiring resolution if hot-gas cleanup with solid sorbents is to be economically and technically viable. These are: (i) high-temperature particulate removal; (ii) reduced sorbent cost; ( $i i i)$ increased sorbent durability during multiple regeneration cycles; (iv) improved sorbent capacity; (v) treatment or disposal of regeneration off-gases; ( $v i$ ) disposal of spent sorbent.

Particulates entrained in the raw product gas will degrade the sorbent by obscuring its surface or plugging the gas paths through the reactor. Removal of particulates at high temperature has been accomplished with cyclones. However, the collection efficiency for cyclones is highly dependent on the aerodynamic efficiency for particles of different sizes and drops off rapidly for very small particles. Other approaches that are in the developmental stages involve the use of metal and ceramic filters, ceramic-based filters and high-temperature scrubbers.

Sorbent cost, durability and capacity are obviously closely coupled since less expensive sorbents may become economically viable, even with reduced durability during regeneration. An inexpensive sorbent might be acceptable as a nonregenerable sorbent which is disposed of after a single 
use. The three most extensively characterized sorbent materials are activated carbon, calcium oxide (or carbonate) and zinc ferrite. Activated carbon exhibits limited capacity, must operate at relatively low temperatures and has limited durability. Calcium oxide is inexpensive and has high capacity, but its performance is highly dependent on the process-gas composition and it requires relatively long contact times. Zinc ferrite is relatively expensive but has high sorption capacity; its durability must be improved to compensate for its cost.

Further investigation of the identified sorbents, as well as evaluation of alternate sorbent materials, sorbent-preparation techniques and sorbent-regeneration conditions may serve to overcome current technology limitations. In addition, phase diagrams of the primary compounds involved in the adsorption and desorption cycles for candidate sorbents should be obtained to provide a basis for the selection of optimal adsorption and regeneration conditions and definition of the optimum form of sorbent materials.

The potential for in-bed sulfur capture through the addition of solid reactants to the gasification reactor is closely related to hot-gas cleanup using solid sorbents. In-bed sorbents must be codisposable with the ash. Therefore, candidate materials must be inexpensive and produce an inert residue, i.e., they must be classified as nonhazardous under current and future RCRA regulations. Sulfur-capture efficiency is directly related to the temperature, residence time, and gas-composition profile experienced by the sorbent as it passes through the reactor. Thus, the configuration and operating conditions of the gasifier are major determining factors in sorbent performance. Both dolomite (a mixture of magnesium and calcium oxides) and lime have been tested as reagents for in-bed sulfur capture. A1though other alkali oxides are potential candidates, most lead to significant problems with disposal or to high costs.

Investigations should include the development of reaction data defining both equilibrium compositions and kinetics as functions of gas composition and temperature in order to relate sulfur-capture potential to gasifier configuration and operation. Many of these data are available for lime and dolomite. Development of recovery techniques for reagents that 
have higher sulfur capacity but are more expensive would greatly enhance the range of options that may become economically viable for in-bed sulfur capture.

\section{8-2. Liquid Redox Processes}

Absorption of reduced sulfur compounds in solution, followed by chemical oxidation of the sulfur to elemental sulfur in the solution, provides a one-step approach to the removal and recovery of sulfur from gasification-process gases. If the reagents can be oxidized to their original form, a closed-1oop process may be operated. This approach has the following advantages: (i) a single process unit may be used for both removal and recovery; ( $i i)$ low reagent replacement-costs may result, depending on efficiency of reagent regeneration; (iii) high sorption efficiency is achieved using established liquid/gas contacting technology.

Commercial appiications of the redox approach to sulfur removal and recovery involve aqueous solutions and operate at essentially atmospheric temperature and pressure. Low temperatures are maintained in order to minimize the rates of side reactions that produce non-regenerable compounds. There are reports on the impact of high-pressure operations but these are limited in scope, content and detait.

Experience with several liquid redox processes has led to identification of the following areas requiring further investigation and development: (i) absorber blockage; ( $i$ ) improving the quality of the sulfur product; ( $i i i)$ study of the complex redox chemistry of sulfur with possible multiple oxidation states for the element; (iv) low sulfur-adsorption efficiency; ( $v$ ) potential for side reactions that reduce the efficiency of elemental sulfur production and reagent recovery; ( $i$ ) high pumping and reagent costs; (vii) simplification of the complicated process control that is needed because of the occurrence of complex chemical equilibria and kinetics. Areas of recommended research include: (i) detailed investigation of sulfur redox chemistry; ( $i i)$ determination of the precipitation kinetics of elemental sulfur; (iii) investigation of sulfur reaction and reoxidation chemistry 
of candidate redox agents or catalysts, including $\mathrm{Va}, \mathrm{Fe}, \mathrm{Co}$, quinones, etc.; (iv) investigations of high-temperature and high-pressure operations; (v) investigations of alternate solvents for redox reactions of sulfur at higher temperatures and pressures than are possible in aqueous solutions.

\subsection{Summary of Research Recommendations on Environmental Issues}

Research recommendations related to the environmental control of coal-gasification processes are framed by several general questions regarding the methods and cost of meeting current and future environmental control requirements. These are: (i) Are adequate control technologies available to meet current environmental control requirements for surface coal-gasification facilities? Can the performance of such technology be predicted reliably to assure compliance with current requirements for air, water and solid waste emissions from commmercial gasification processes? (ii) What are the anticipated trends in future environmental control requirements, and how will these affect future gasification technology in various applications? Are adequate technology and information available to handle potential future situations? ( $i j i)$ What are the potentials for reducting the costs of environmental controls significantly through new process development and/or the development of improved control technology? What research is needed to pursue these opportunities?

Each of the specified issues is addressed briefly in the following paragraphs.

\subsubsection{Understanding Current Technology}

Much of the environmental research on coal-gasification processes conducted over the past decade has been directed at characterizing the chemical compositions of gaseous, liquid and solid waste streams from various types of gasifiers. This procedure has aided the design of technology for air-pollution control and waste-water treatment, with the result that current environmental control requirements are generally met, albeit by often using empirical design criteria rather than fundamental understanding. 
There are, however, some notable exceptions, which underscore the continuing need for more fundamental research on process factors related to environmental controls. Perhaps the most prominent example is the Great Plains gasification facility in North Dakota, which does not yet comply with $\mathrm{SO}_{2}$ emission regulations because of the inexplicably poor performance of the commercial sulfur-removal unit (Stretford process). It is generaliy believed that the problem is related to trace compounds in the gas stream, which alter the chemistry and catalytic processes significantly, as compared to the less complex gas mixtures typically treated with this process. No solution has as yet been found.

In contrast to Great Plains, sulfur removal and recovery systems at Cool Water have performed well on both high- and low-sulfur coals. Selexol for sulfur removal is followed by. a modified SCOT plant and a Claus unit for sulfur recovery. Some gasifier trace compounds, which do not pose environmental or health hazards, are operational nuisances because they slowly contaminate the Selexol and SCOT solvents. Cool Water has only minimal wastewater-treatment facilities since the plant is located in an arid region where natural evaporation is effective for disposing of process blowdown water. This treatment and process-water system now perform wel1, after some stream rerouting during start-up. Most future commercial plants will not be located in an arid climate where natural evaporation is a practical method for process waste-water disposal.

Problems with environmental control-system performance often reflect a lack of understanding of process and chemistry details relating to environmental control-system design and performance. The following research recommendations are thus suggested: (i) Basic research is needed in order to obtain better understanding of process chemistry related to the control of gaseous pollutants. The chemistry of sulfur removal from complex gas mixtures, including the effects of trace compounds found in coal-gasification processes, are of particular concern. (ii) Fundamental research is also needed on gasification-process-water chemistry, particularly in the context of waste-water recycle systems which offer the potential for waste elimination. This research should provide a basic understanding 
of the reactions of species and the fates of contaminants common to coal-gasification process condensates and waste waters.

\section{9-2. Future Environmental Requirements}

During the past two decades, there has been a clear and continuing trend toward more stringent environmental control requirements for energy-conversion processes of all types. In recent years, environmental requirements have become more comprehensive in scope, covering emissions to all environmental media (air, water and 1and). At the same time, the level of sophistication with which potential pollutants are identified, measured, and regulated has also increased. While the nature of future environmental requirements inevitably remains speculative, several general trends are likely to affect coal-gasification processes. These include the following: (i) Control of traditional criteria air pollutants (those originally regulated by the 1970 Clean Air Act are $\mathrm{SO}_{2}$, particulate matter, $\mathrm{NO}_{\mathrm{x}}$, hydrocarbons and photochemical oxidants) will continue to be important. Recent trends in New Source Performance Standards (NSPS), such as those for combustion-related pollutants, have tended to become more stringent as control-technology capabilities have improved. In terms of future developments, the recent commercialization of technology to reduce emissions of $\mathrm{NO}_{x}$ greatly may compel further tightening of current NSPS requirements. Toxic air pollutants are likely to become more heavily regulated in response to concerns over their health and ecological impacts. In the context of coal-gasification processes, this development could affect emissions of heavy (trace) metals and organic compounds emitted in small quantities. (iii) Zero discharge of waste-water contaminants can be expected to continue to be the prevailing philosophy guiding regulatory requirements at the federal, state and local levels. This development could have significant implications for commercial coal-gasification facilities located in parts of the country where traditional methods such as solar evaporation ponds cannot be used. (iv) The disposal of solid as well as of liquid wastes will come under increasing scrutiny to make certain that waste materials, by-products, 
and potential leachates are environmentally benign. Criteria defining hazardous and toxic substances are likely to evolve as new measurement techniques and research results become available.

Research recommendations derived from these observations include the following: (i) Sustained research is needed to characterize trace metals and other potentially hazardous or toxic emissions to air, water and land emanating from coal-gasification process streams, control technologies and fugitive sources such as cooling towers. (ii) Continued research is also needed in the areas of solid and liquid waste management, particularly the utilization of solid residues as by-products (rather than wastes). Better understanding is required of the fates of organic and inorganic contaminants in the environment (both near-source reactions and long-range transport should be explicated).

\section{9-3. Advanced Control Technology}

Environmental control systems currently account for a significant portion of total coal-gasification process costs. Therefore, high priority must be assigned to novel or advanced methods for reducing these co:sts while maintaining environmental quality standards.

The ability to eliminate or substantially simplify environmental control processes will depend, in part, on the gasifier design and, more substantially, on process application. Thus, processes producing gas to be used at room temperature invariably produce condensates requiring some degree of waste-water treatment in addition to gaseous pollutant removal, a1though gasifier types such as entrained beds produce inherently cleaner condensates than others (e.g., tar-producing fixed-bed gasifiers).

Gasifier applications for electric power generation offer the potential for significant simplification of environmental control systiems by using hot-gas cleanup. Removal of pollutants at high temperatures, followed by combustion of the gaseous products, not only yields improved process efficiency but also eliminates several unit operations that are required for low-temperature processing (e.g., waste-water treatment). The ongoing DOE 
research program on hot-gas cleanup offers an'excellent opportunity for major improvements of this nature. The associated research recommendations are: (i) Current DOE research on hot-gas cleanup is important, generally well-focused, and deserving of strong continued support. Key research needs have been identified and are being pursued to develop viable means for particulate and sulfur removal at high temperatures using gas treatment and/or in-bed removal processes. (ii) Additional research is needed to ensure that $\mathrm{NO}_{\mathrm{X}}$ emissions with hot-gas cleanup systems can be controlled to the same degree that is achievable with current low-temperature coal-gasification systems and combustion-gas treatment devices.

\subsection{Coal Beneficiation and Feed Preparation; Solids Processing}

A cost item in the utilization of coal gasifiers is coal cleanup to meet applicable environmental regulations. One of the procedures that is widely employed for this purpose is pre-combustion cleanup or coal beneficiation, the purpose of which is to prepare as-mined coal and make it suitable for desired end uses. Coal preparation, cleaning and washing are required to meet environmental constraints at minimal costs and also to improve downstream equipment performance.

Beneficiation applied to gasification parallels its use in combustion. The cost of beneficiation may be balanced by savings in the gasifier or combustion equipment. In the same fashion, the size of the coal fed to the two types of processes must be properly selected to fit the peculiar needs of the specific gasifier or furnace. Technology for size reduction and size-classification is generally well developed, although a useful research area has been identified for counter-current, moving-bed gasifiers.

\subsection{0-1. Beneficiation}

The process of coal beneficiation includes size reduction, size classification, removal of impurities, and drying. Table 2.10-1 contains a 
summary of currently used commercial procedures for physical or mechanical coal cleaning.

The levels of coal cleaning vary from minimal to full at reduced yields and energy recovery; simultaneously, sulfur levels may be reduced. Costs vary from low to high as the level of cleaning is augmented.

A number of novel physical beneficiation processes have been or are under active development. We refer to Chapter 10 for a description of these techniques. Some of the beneficiation processes have reached developmental status.

Coal beneficiation may become competitive with combustion clean-up of coal and with post-combustion clean-up of effluents. The extent to which one or more of these techniques is employed in any particular gasification process depends on overall costs, including estimates for equipment failures and plant downtimes. While some preparation, cleaning and washing are used almost universally, applications of more sophisticated beneficiation procedures have generally not been judged to be cost-effective.

The development and assessment of the practical utility of coal-beneficiation procedures has been and continues to be of direct interest to DOE, especially in connection with direct coal-combustion technologies, and is viewed by the members of COGARN as a lower priority effort for coal-gasification technologies than for combustion systems.

Table 2.10-1. Currently used procedures for physical or mechanical coal cleaning.

Process

Size reduction

Size classification

Cleaning

Drying
Techniques

Rotary beakers, impact mills, singleand double-roli crushers

Vibrating screens, sieve bends, classifying cyclones

Magnetic separation, concentratirg tables, jigs, hydrocyclones, heavymedia cyclones, froth flotation

Screens, filters, centrifuges, thermal dryers 


\subsection{0-2. Feed Preparation}

Occasionally, new approaches are proposed to surface comminution, such as the use of chemicals to loosen coal particles along their cleavage planes, new machines for preparing micron-sized coal, etc. However, no useful procedure has been found around the basic laws relating to energy requirements for comminution in commercial application. Similarly, improved classification equipment continues to reach the market, including screens and elutriators of various types. This development results from a general trend to use ever finer size fractions in newer gasification and combustion equipment.

There is, however, one type of gasifier, historically the dominant system, which presents special R\&D opportunities, namely, the moving-bed reactor. The apparatus requires passage of the upward-flowing gasifying medium (air, oxygen, steam, and $\mathrm{CO}_{2}$ ) through the downward-moving bed of coal. To assure free and even flow and good contact requires special qualities of the solid feed. The ideal feed would have the following characteristics: (i) a preferred, coarse size which may range from $1 / 4^{\prime \prime}$ to $2^{\text {" }}$ or more; (ii) a minimum strength, which remains in effect as the lumps move down through the reactor and are consumed by the reaction; ( $i i j$ ) absence of caking or softening as the temperature increases, thereby preventing melting of the solid and plugging of the reactor; (iv) good reactivity with steam and $\mathrm{CO}_{2}$ at rates over the temperature range encountered in the gasifier; ( $v$ ) ash behavior (softening/fusion) which allows the reactor to operate either in the dry or slagging mode, even in the highest temperature zone (bottom); ( $i$ ) in most situations, preferably no release of condensable heavy hydrocarbons or tars as the temperature is elevated. There are, unfortunately, no coals found in nature which fulfill this wishlist. It therefore remains a challenge to the engineer to devise a gasifier which can accommodate the properties of the coals which are available in practice.

There are two models of moving-bed gasifiers which may be viewed as extremes and span the range of approaches. First, there is the modern blast furnace. Here, the feed-preparation step (the coke oven) virtually 
dominates the system, but the gasifier feed (coke) complies with every one of the listed needs except for reactivity, which is not important in slagging reactors because of the high temperatures involved $\left(>2,700^{\circ} \mathrm{F}\right)$. As a result, the gasifier, which is the blast furnace, has been developed up to $55 \mathrm{ft}$ in diameter with 5-6,000 ton/day of coke-gasification capacity and stable, uninterrupted operation over 2-3 years. No other reactor comes even close to this performance. But the cost of feed preparation involved (the coking of coal) is prohibitively high.

The second model is the modern, high-pressure Lurgi gasifier, 15 to $16 \mathrm{ft}$ in diameter, which can accommodate unbeneficiated coal down to $1 / 4$ " size. The units have up to 1,000 ton/day capacity, depending on reactivity, and high ash-fusion temperatures. The same reactor will accept coals with a wide range of caking properties when using agitation in the critical temperature zone $\left(600-1,200^{\circ} \mathrm{F}\right)$. By operating in a slagging mode, the range of coals is greatly extended to cover even strongly caking (greater than 25,000 Gieseler-degree) coals and coals with low ash-softening points.

A11 moving beds have the requirement that most of the feed must be of lump size and coarse. Since modern mining equipment tends increasingly to produce coal with less than $1 / 4^{\prime \prime}$ size, this requirement calls for feed preparation to increase size, such as pelletizing, briquetting, extrusion; these are relatively costly steps, although they are well developed and in wide commercial use.

The preceding statements suggest an area for R\&D, which is best summarized as feed preparation for moving-bed gasifiers. These gasification systems have moved into the foreground as gasification regains the position it once had. Of particular interest here is work which deals specifically with the use of lime to control caking properties and reduce the evolution of tar while simultaneously increasing reactivity. In spite of progress already made, more fundamental research on coal properties and surface behavior may lead to further advances. The counter-currency of moving beds is unique among gasifiers and makes these thermally most efficient, with tremendous gasification potential, as has been shown for the blast furnace. Effective system utilization requires a substantial advance in the 
feed-preparation area. R\&D on this subject could have a major pay-off.

\subsection{0-3. Gasification as a Solids-Processing Technology}

Gasification of coal is, by definition, a solids processing operation. This operation requires intimate and efficient contact of solids with gas over a substantial pressure range and also involves major input of energy to the reactor at high temperatures.

It is important to recognize the unique problems associated with handling and converting (processing) solids. Physical and mechanical difficulties rather than process chemistry may be the determinant factors in gasifier performance. This is a significant observation regarding gasification and it is appropriate that the DOE R\&D program reflects the special problems of solids processing.

Applications of new or improved diagnostics are needed that will help the engineer to design better reactors, which will function smoothly and reliably. The needed measurements will assist the operator in monitoring solids behavior on-line and within the gasifiers.

\subsection{Applications of Advanced Diagnostics to Coal-Gasification Systems}

Two primary discoveries and developments have occurred during about the last 20 years that may be expected, in time, to change chemical process technologies, in general, and coal-gasification technologies, in particular, from applications of intuition-based art to quantitative science. These advances relate to (a) computers and numerical analyses and (b) advanced diagnostic techniques. The current status of diagnostics for coal-gasification systems is summarized in Chapter 11 . The subject of numerical gasifier modeling is discussed in Chapter 12; it should be noted that this type of quantitative description almost always forms an integral component of current industrial development programs. The pacing items in obtaining improved numerical modeling relate to data inputs and verification of model assumptions. Modern diagnostic techniques play a key role in this 
program.

Quantitative measurements for coal-gasification systems are required to improve our understanding of fundamental processes. Continuous monitoring of system operations is needed for on-line utility plants and other chemical process units utilizing coal gasifiers. Advanced diagnostics offer significant promise, including high spatial and temporal resolution and also the opportunity to probe highly-turbulent, multiphase flow's. These techniques are non-intrusive and generally costly and challenging to apply. In fact, it is likely that successful field adaptation of any of the advanced techniques will require close long-term cooperation between instrument developers and system engineers dealing with such complex process technologies as coal gasifiers.

Existing advanced techniques have been shown to be useful for the measurement of essentially any desired parameter in combustion systems. In Chapter 11, Hardesty and Ottesen begin their overview on diagnostics by identifying the primary flow regimes in gasifiers and then describing these by identifying characteristics such as well-mixed gaseous regions, regions with minimal concentrations of particles, heavy particle loadings, strong gradients, highly turbulent flows, multiphase flows, etc. Each region presents special challenges for applications of diagnostics that support quantitative modeling and monitoring.

Among the advanced techniques that yield data with high spatial and temporal resolution and are likely to find wide field applications are the following: measurements of velocity components, temperatures, particulate loadings, atomization rates, species concentrations, rates of deposit build-up on walls and protruding surfaces, and others that are of special interest because they may influence successful operation or determine gasifier $1 \mathrm{ife}$.

Effective applications of sophisticated diagnostics to coal-processing units have been notably slow to materialize. There are two reasons for this slow progress: developers generally do not know what critical questions can be resolved by using advanced techiniques and, even if the problems have been properly identified, they may be reluctant to utilize 
costly procedures that have previously been employed successfully only by researchers working on idealized systems in clean laboratories.

This issue could be profitably addressed by DOE, which has been funding the development of laser-diagnostic techniques for combustion applications for some years. What is required are first increased use of advanced diagnostics in laboratory systems of modest size. Subsequently, a user task group should be created, i.e., a group of well-trained people should devote their skills to instrumenting industrial plants and demonstrating incisive required measurements on these practical systems.

The view is often expressed that commercial instruments will be developed when they are needed. The fallacy with this argument in the present case is that users do not know what they need until they realize the very great value of improved diagnostics in process control and modeling. It is in this area that a DOE-sponsored program on technology transfer is most likely to be useful.

\subsection{Fundamentals of Coal Conversion and Relation to Coal Properties}

In order to develop reliable coal-conversion technology, it is important to have knowledge of the conversion behavior of coal and the relationship of conversion behavior to some measurable set of coal properties. Required are answers to such questions as the effects on gasifier performance of normal variations in organic and mineral properties of a coal from a single mine, of variations in coal particle size, and of switching coals. Unscheduled shutdowns of coal plants are often caused by unexpected and uncontrolled behavior of the coal. What will be the effect of instituting pollution-control strategies such as the injection of sorbents? Can slagging and fouling behavior be predicted from the coal mineral distribution and the process conditions? Can the concentration of tars and fines exiting the gasifier be predicted and controlled?

The design of new processes or scaling up is improved by the availability of good predictive capability. For example, to design a process for producing condensable products by mild gasification involving 
incomplete reaction, knowledge of the product slate from devolatilization (condensables, char and gas species) and of the secondary reactions of the condensables is needed. The objective of work on fundamentals of coalconversion behavior should be the development of accurate predictive capabilities to put gasification technology on a sound engineering foundation. The steps toward achieving this goal are: (i) development of chemical and physical understanding of coal-conversion phenomena and their relation to coal properties; ( $i$ i) reduction of data and mechanisms to the form of engineering correlations and submodels; ( $i i i$ ) development of comprehensive computer-simulation codes for gasification processes incorporating the submodels.

Fundamentals of coal conversion involve coal characterization, gasification steps relating to the organic structure of coal, processes relating to the inorganic mineral matter, and the status and needs of computer modeling of gasifiers for monitoring, control and scale-up. Recommendations for research in these areas are listed in the following paragraphs.

\subsection{2-1. Coal Characterization}

While there are a number of standard characterization procedures for coal, they often do not provide information appropriate to advanced processes. Methods are needed to provide parameters from which coal behavior in gasification can be accurately predicted. (i) NMR and FTIR techniques promise to provide needed information on functional groups. The remaining problems are calibration, e.g., what percentages of carbons are seen and what are applicable absorption coefficients? Repeated parallel experiments on identical coal samples would help to resolve these issues. (ii) Validation is needed of methods for measuring coal viscosity at high heating rates and high temperatures. These measurements should be related to swelling and agglomeration phenomena observed under gasifier operating conditions. (iii) Standard pyrolysis tests need to be defined to provide extensive devolatilization data that are applicable to high heating rates at high temperatures. (iv) Work is required to define a reactivity test and methodol- 
ogy to relate the test results to reactivity under gasifier operating conditions. (v) Work is required to define mineral characterization procedures and methodology to relate the test results to ash behavior under gasifier operating conditions.

\subsection{2-2. Fundamental Processes in Gasification and Partial Gasification}

For gasification, the objective is to gasify coals of different rank in the shortest time at the lowest severity conditions, with small amounts of tars or fines exiting from the reactor. For mild gasification to produce co-products, the objective is high yields of quality products. These factors are controlled by heat transfer, pyrolysis rates, devolatilization processes, gasification of char, and secondary reactions of condensables and gases. Research needs for these areas follow.

There is a lack of data on the fundamiental parameters involved in heat transfer (heat capacities, emissivities, heats of reaction, effects of volatile evolution on convective heat transfer). Heat-transfer calculations employing the measured parameters should be validated under typical gasification conditions by employing well instrumented laboratory-scale experiments, which allow coal-particle temperature measurements.

Accurate determinations are needed of the important chemicalkinetic rates in pyrolysis. In these experiments, coal-particle temperatures should be directly measured or accurately determined by indirect means. At high heating rates above $10,000^{\circ} \mathrm{C} / \mathrm{sec}$, attention must be given to temperature gradients within the particle. Experiments should be analyzed by using an agreed-upon standard model so that results can be directly compared. This model should provide rate expressions which are independent of heating rate or experimental geometry. The use of a small set of standard coal samples by several investigators should be encouraged.

Work should proceed towards finding an acceptable standard model to describe the devolatilization process. Experimental and theoretical work is especially needed on sulfur evolution, tar formation and char viscosity (including depolymerization, mass transport, and crosslinking processes), 
and on the formation of chars (swelling, pore structure and reactivity).

There is a need to develop a better understanding of the chemical factors (i.e., functional-group composition, minerals) which influence intrinsic reactivity and how the observed reactivity is affected by physical factors (pore structure). For catalytic gasification, the dispersion of catalyst in the char is an important issue, along with interactions of added catalysts with minerals already present in the char. The elutriation of highly unreactive carbon in the form of fines from gasifiers is a problem which could benefit from a more fundamental understanding of gasification reactions.

There is a need for kinetic data and models of product evolution for the gas-phase cracking of tars from a range of coals. There is also a need for information on the kinetics of soot formation from tar. In addition, we require information on mechanisms and kinetics of secondary repolymerization reactions of tars which occur on surfaces inside and outside of the parent coal particle. This information is needed in order to understand the yields and quality of co-products generated in mild gasification.

Both mechanisms and rates should be determined for important mineral transformations in coals.

\subsection{2-3. Transformation of Coal Mineral Matter}

When the mineral constituents of coal are heated, they undergo thermal decomposition that is usually associated with weight loss. During these reactions, the mineral components of the ash (the major ones of which are compounds of silicon, aluminum, iron, and calcium) may form new eutectics with lower melting points and these new melts can mix with and dissolve in other molten mineral compounds. The practical significance of the behavior of the ash in gasification processes relates to (a) the desired trouble-free removal of ash or slag from the process and (b) ash deposition on heat-exchange surfaces downstream of the gasifjer by semi-molten ash particles carried over by the product-gas stream. 
The specific requirements for information on ash behavior vary with the particular.conditions of the gasification process, e.g., in fluidized-bed gasifiers, a controlled amount of ash agglomeration may be favored but semi-molten ash particles can cause significant problems in process cyciones, with the recycling of carried-over, partially-gasified char particles into the fluidized bed. In slagging gasifiers, on the other hand, slag viscosity-temperature relationships must be known to ensure liquid-slag removal over a range of operating conditions. When the gasifier is coupled directly with a gas-turbine plant, the condensation of vapor phase alkali species in the gas turbine may cause corrosion.

Traditionally, ash chemistry was used for coal mineral-matter characterization. In recent years, new analytical methods have become available, which are capable of yielding much more detailed and useful characterizations, including the types, amounts, size distributions, and structures of inorganic matter in coal. Theoretical and experimental studies are in progress under the sponsorship of DOE PETC, DOE METC, and EPRI to improve our understanding of the transformation of coal mineral matter under combustion conditions (high temperature oxidizing atmosphere) but little or no research effort is devoted to studies which pertain to conditions typical of those occurring in the various types of gasifiers.

It is recommended that fundamental studies of ash sintering, agglomeration, slagging, and partial vaporization be carried out under reducing conditions and in the temperature range typical of gasification processes. Furthermore, a data base on ash behavior should be created for the most important American coal types in gasification processes.

\subsection{2-4. Mathematical Modeling of Gasification Processes}

Development of coal-reaction process models should continue and should focus on entrained, fixed and fluidized beds in a coordinated manner. Work on gasification and combustion should be closely coordinated, since a given model generally has areas of applicability in both systems. Increased near-term emphasis should be given to model evaluation and application. 
On-going development and improvement of submodels, particularly those related to coal and residue properties, should be continued. Basic work should be pursued in such areas as turbulence-flame interactions and multi-phase flows.

Support should be provided for selected, well instrumented and flexible laboratory-scale experiments that can be employed to validate selected aspects of the comprehensive codes. 
CHAPTER 3:

GASIFICATION FOR ELECTRICITY GENERATION *

3.1. Integrated Coal-Gasification Combined Cycles (IGCC)

3.1-1. Introduction

Because of the huge US coal reserves (estimated to last at least 200-300 years), the preferred use of the cheapest available energy source, the stalemate faced by the nuclear industry, and the uncertainty of future natural gas (NG) prices, it is likely that coal will continue to be the major fuel for electric utilities in the future.

Integrated coal-gasification combined cycle (IGCC) systems offer many advantages over conventional pulverized-coal combustors. These advantages include higher energy-conversion efficiency, reduced pollutant emissions, lower financial risks associated with staged capacity additions, and the relatively small modular unit size used, as well as the ability to accept a variety of feedstocks.

An IGCC power plant involves the coupling of a coal-gasification system producing a clean fuel gas to combustion and steam turbines that generate electric power. A schematic diagram of a unit of this type is illustrated in Fig. 3.1-1. To illustrate the important features of an IGCC, the Cool Water Coal Gasification Program (CWCGP), which is an actually operating IGCC plant, will be described in Sec. 3.2 .

Sections 3.1 and 3.2 were written by S.B. Albert, S.S. Penner and D.F. Weisenhahn; Sec. 3.3-3 by P.B. Tarman, and the remaining subsections of Sec 3.3 , as well as Sec. 3.4 by S.S. Penner and D.F. Wiesenhahn with the advice and inputs from correpondents identified in the subsections. 


\subsubsection{IGCC System Status**}

Development of a number of advanced coal-gasification systems has been progressing at a rapid pace (compare Table 3.1-1). Uncertainty regarding conventional fuels (NG and $0 i 1$ ), environmental regulations that represent increasingly tight standards, and uncertainties regarding nuclear power deployment in a number of countries have spurred commercial developments of coal-gasification systems for diverse applications such as (a) electricity generation, (b) fertilizer, hydrogen and organic chemicals production, and (c) generation of hot water for district heating, et.c.

Coal-gasification systems may be classified according to the type of gasifier used in which coal is contacted and reacted with an oxidant (air or oxygen) to produce the desired fuel gas. If the system is blown with air, the fuel gas is low-Btu gas; if the system is blown with oxygen, the fuel gas is medium-Btu gas. Three types of contacting devices are moving beds, fluidized beds, and entrained flows.

In moving beds, a descending bed of coal, usually of $1 / 8$ to 1 inch in coal, is fed by a pressurized lockhopper system to the top of a shaft. Reactant gaseous oxygen (or air) and steam enter the bottom of the vessel. As coal descends, it is devolatilized; then, pyrolysis reactions occur and finally carbon is gasified. The raw product gas contains tars and oils, which need to be condensed and removed. The ash may be withdrawn as a dry solid or as molten slag. In some moving-bed versions, tars, oils, and coal fines are recycled to extinction.

In fluidized-bed reactors, coal is ground to produce a fluid-bed grind (ca 8 mesh or less). The oxidant gas (and some steam) are introduced through a perforated deck or grind at the bottom of a vessel. The flow rate of the reactants is high enough to suspend the coal particulates but not blow them out of the vessel. A uniform temperature is obtained as the result of the mixing that occurs. Depending on the temperature, tars and oils can be avoided but fines carryover and ash slagging limit conversion of some coals to $80-90 \%$ of the carbon. In order to overcome this limitation, the carbon-containing ash may be processed in an additional vessel or the unconverted carbon can be recycled to the gasifier.

\footnotetext{
This section is reproduced from Ref. 1 .
} 
In entrained-flow systems, a relatively fine grind of coal (ca $75 \%$ through 200 mesh) is fed either as a dry solid or as a water and coal mixture to a short-residence time reactor. Contacting with the oxidant is achieved by means of a nozzle arrangement. At the high velocities and temperatures used in entrained systems $\left(2000\right.$ to $\left.3000^{\circ} \mathrm{F}\right)$, no tars or $0 i 1 \mathrm{~s}$ are produced. Carbon burn-out is nearly complete and the product gas is essentially a mixture of $\mathrm{CO}$ and $\mathrm{H}_{2}$.

In the US and abroad, advanced coal-gasification technologies have been under development for the last decade. Several technologies have been supported by EPRI: (i) Texaco technology represents an entrained system that features a coal-water slurry feeding the pressurized, oxygen-blown gasifier. It is the farthest advanced in that three commercial or demonstration plants are in operation. Two of these plants are located in the US and one in Japan. A plant in the FRG will start up in late 1986 to produce organic chemicals and hot water for district heating. Projects have also been announced for China and Sweden. (ii) The Shell coal-gasification unit is under construction at 250/400 TPD

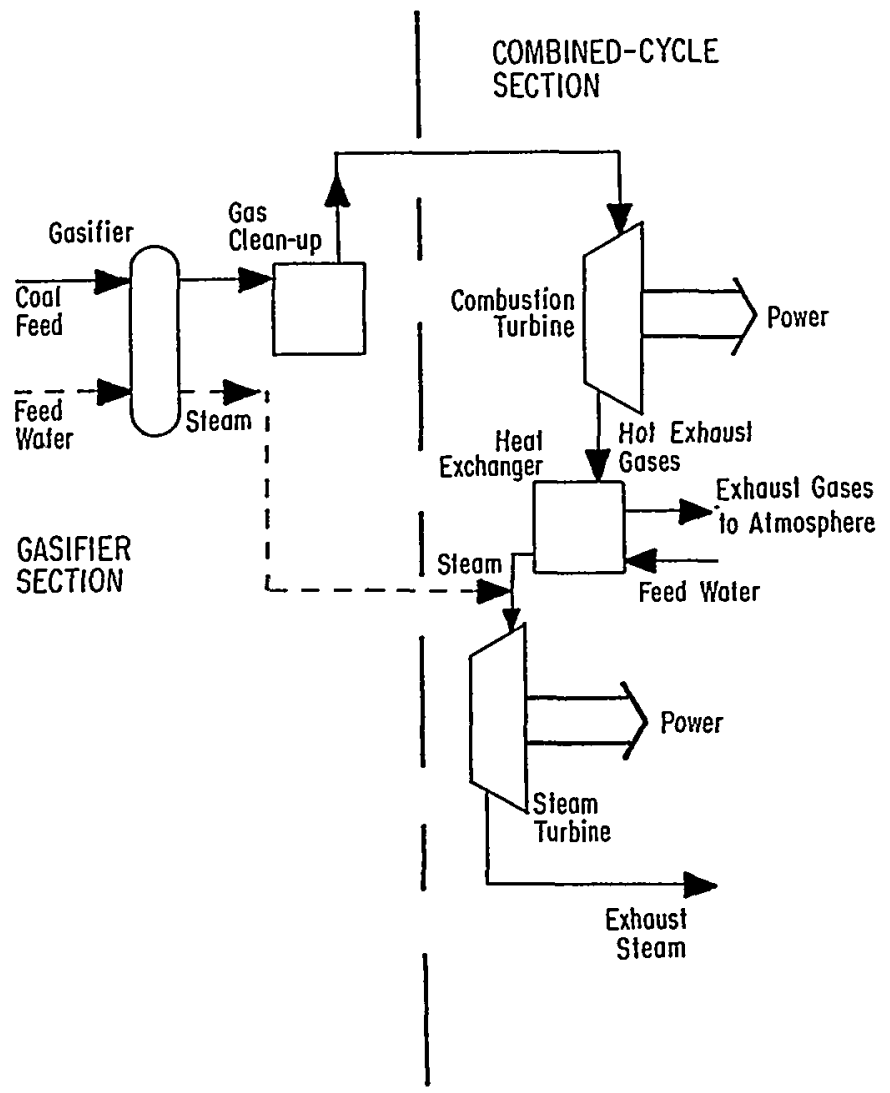

Fig. 3.1-1. Schematic drawing showing a generic IGCC system. 
Table 3.1-1. Status of selected coal-gasification technologies.

\begin{tabular}{|c|c|}
\hline Manufacturer & Operating Plants \\
\hline Texaco & $\begin{array}{l}\text { Cool Water: } 2 \times 1000 \mathrm{TPD} ; 117 \mathrm{MW} ; \\
\text { Ube: } 4 \times 500 \text { TPD; Tennessee Eastman: } \\
2 \times 900 \text { TPD; Ruhrchemie: } 1 \times 600 \mathrm{TPD}\end{array}$ \\
\hline Shell & 250 TPD pilot plant in TX \\
\hline Dow & $\begin{array}{l}160 \mathrm{MW}_{\mathrm{e}} \text { IGCC at Plaquemine, LA; } \\
1 \times 2,500 \mathrm{TPD} \text { gasifiers }\end{array}$ \\
\hline BGC/Lurgi & 600 TPD at Westfield, Scotland \\
\hline Al1is-Chalmers & 600 TPD at Wood River \\
\hline $\mathrm{KRW}$ & $\begin{array}{l}35 \text { TPD at Waltz Mills; } 500 \text { TPD in } \\
\text { China (1989 start-up) }\end{array}$ \\
\hline IGT & $\begin{array}{l}40 \text { TPD at Chicago; } 200 \text { TPD proposed } \\
\text { for France }\end{array}$ \\
\hline
\end{tabular}

pilot-plant scale at their research center in Deer Park, Texas, and is expected to lead to commercial designs in the late 1980s. The Shell process features a dry-feed, entrained gasifier system that operates at elevated temperature and pressure. Current studies with US electricity companies are defining commercial opportunities. (iii) The British Gas Corporation and Lurgi GmbH have jointly developed a slagging, moving-bed gasifier system. A commercial gasifier prototype (600 TPD) will be started up at Westfield, Scotland, in early 1986. Virginia Power is considering installation of a coal-gasification system for a 200-MW IGCC power plant based on the $\mathrm{BGC} /$ Lurgi technology. (iv) An air-blown, rotary, ported kinn (similar to a moving-bed device) is under development by Allis Chalmers Corporation. A 600 TPD prototype is located at an Illinois Power Co. power station. (v) The Dow Chemical Company is installing a 160-MW IGCC plant in Louisiana that will produce electricity and synthesis gas for industrial chemicals. Details of the system are proprietary, but it features a coal-water--slurry-fed 
entrained gasifier. Price supports of $\$ 620$ million from the Synthetic Fuels Corporation have been obtained for the project.

Other gasification-systems technologies have been evolving, including the Kellogg-Rust-Westinghouse gasifier and the Institute of Gas Technology U-GAS system. These are representative of ash-agglomerating fluid-bed systems. Advanced fluid-bed systems are also being developed in Japan. A Winkier demonstration fluid-bed system operating at elevated temperature and pressure is being started up in the FRG by Rheinische Braunkohle. The Winkler system will handle 700 TPD of coal to produce industrial chemicals and electric power.

Other projects that are at the pilot-plant stage of development include a 50 TPD pressurized pilot plant by GKT-Krupp. The Vereinigte Elektrizitatswerke Westfalen (VEW) has started up a 250 TPD pressurized pilot plant that partially converts coal (60\% conversion) to low-Btu gas for power generation. Lurgi has gasified lignite in an atmospheric-pressure, circulating fluid bed in their 15 TPD pilot plant in Frankfurt, FRG.

In Japan, several pilot-plant programs are also underway, including development of a molten-iron gasification system. A 250 TPD pilot plant is under construction in Sweden by Sumitomo-KHD; in this unit, sulfur is captured in the slag.

Development of advanced combustion turbines is also proceeding rapidly. The efficiency of combined-cycle equipment is increasing because of the ability to operate at higher firing temperatures. In utility applications, firing temperatures of $2,000^{\circ} \mathrm{F}$ are conventionally used and higher temperatures of $2,300^{\circ} \mathrm{F}$ may be expected before 1990. Developments in the areas of reheat, materials, and advanced cooling methods promise additional improvements in efficiency in the 1990s.

Table 3.1-2. Future goals for 500-600 MW IGCC plants; reproduced from Ref. 3. Comparisons refer to conventional coal-fired plants as baseline.

About $10 \%$ higher efficiency, i. e., heat rates of $9000-9100 \mathrm{Btu} / \mathrm{kWh}$, corresponding to $37.5-37.9 \%$ efficiency.

Lower pollutant emissions, $33 \%$ less water consumption, reduced wastewater treatment and formation of non-hazardous, useful by-products.

A $15 \%$ reduction in levelized electricity costs.

More rapid and cheaper construction of smaller modular units. 


\section{1-3. Advantages of IGCCs}

High efficiencies are obtained in combined-cycle operation because efficient combustion turbines are combined with steam turbines. The gas turbine converts high temperature $\left(\sim 2300^{\circ} \mathrm{F}\right)$ heat efficiently while the steam turbine utilizes low-temperature heat efficiently in the form of steam $\left(\sim 1050^{\circ} \mathrm{F}\right)$. Figure $3.1-1$ shows a schematic drawing of a generic IGCC system.

Low pollutant-emission levels result from the combustion of a clean fuel. Pollutants are removed before combustion by using gas-purification systems tested in other industries. Combined-cycle systems yield very low emissions when NG is burned. Water consumption of IGCC systems is also substantially lower ( 33\%) than for pulverized-coal combustors. Thus, coal-gasification systems are environmentally superior to other alternate coal-utlization technologies and will meet rigorous environmental standards for $S$ and $\mathrm{NO}_{x}$, as well as particulates.

Compared to conventional coal-combustion plants, IGCCs have both

lower capital and lower operating costs, ${ }^{2}$ resulting in lower net electricity costs to consumers. Compared to conventional or combined-cycle systems burning $N G$, the econonic benefits based on current costs (ca $\$ 2 / \mathrm{million}$ Btu) are not so clear. ${ }^{2}$ When $N G$ prices are very low, as at present, it is the preferred fuel for power generation.

Because of its modular design, an IGCC system may be phased in at different stages of plant construction, as is illustrated in Fig. 3.1-2. Each stage has a short construction time. The use of small capacity additions eliminates the need for large, high-risk capital investments. This aspect of IGCC units is especially attractive to utilities with uncertain future demand requirements. The last step (addition of the gasifier) may be delayed until fuel prices make this addition economically attractive.

A properly designed IGCC system will have the flexibility of accepting many different types of feedstocks, including such low-rank coals as lignites, as well as petroleum coke. Additionally, gasification systems may be configured to produce other industrial chemical products, which adds a desirable degree of flexibility. 
(a)

Phase 1

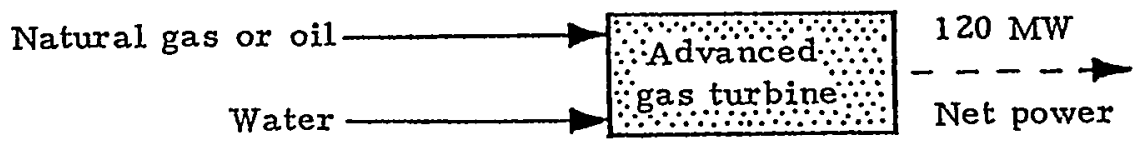

(b)

Phase 2

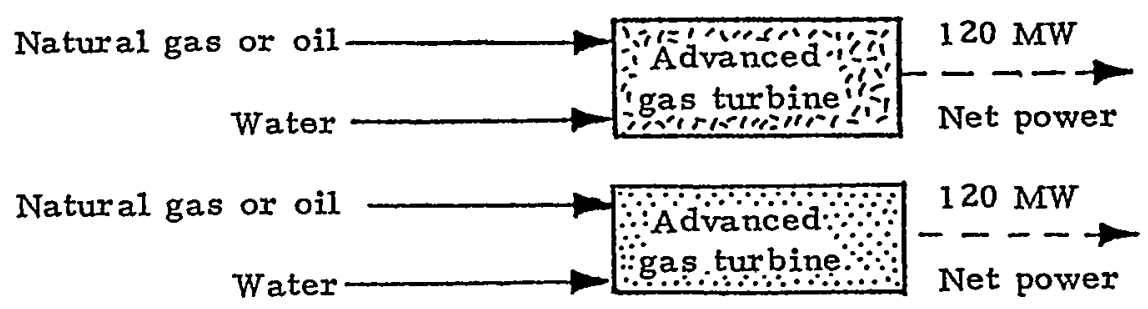

(c)

Phase 3

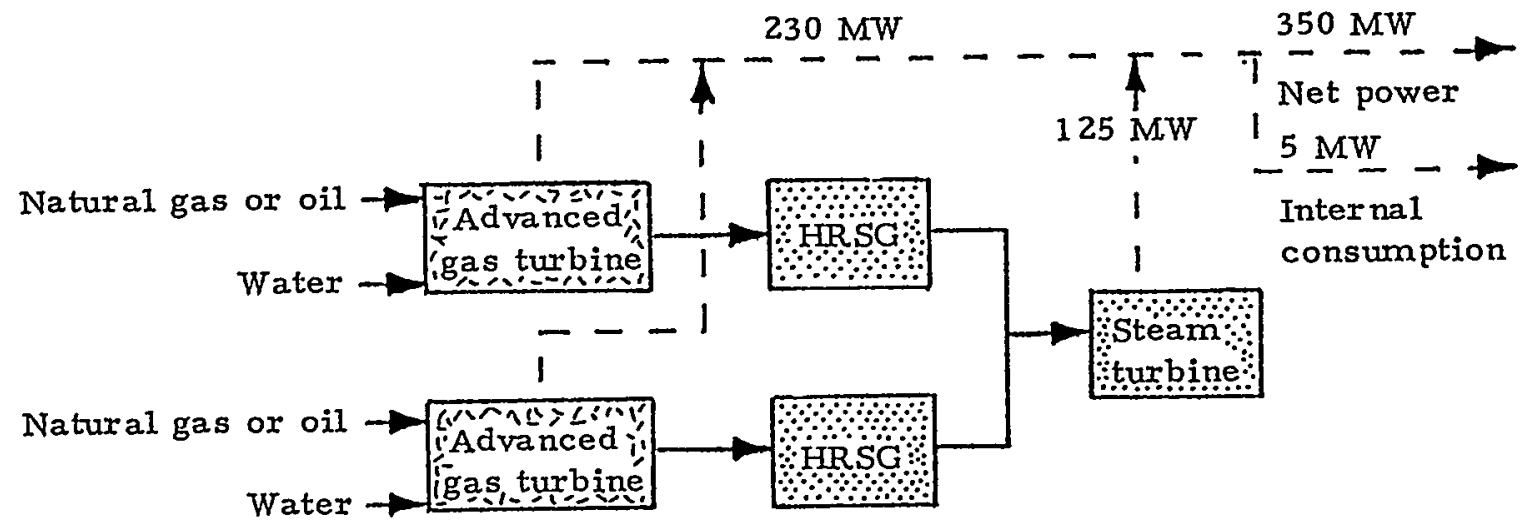

(d)

Phase 4

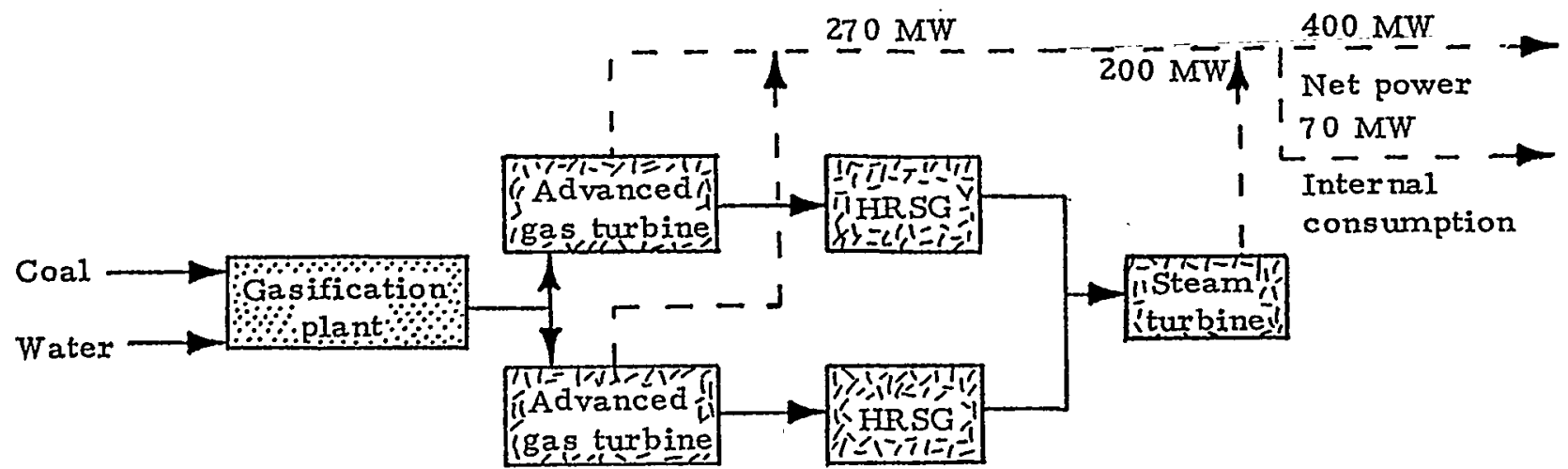

Fig. 3.1-2. Four installation stages of a phase-in IGCC system; reproduced from Ref. 2. The existing capacity is designated Prision and newly installed capacity by 


\section{1-4. Future Utilization of IGCCS}

Table 3.1-2 is a summary of future goals for 500-600 MW $\mathrm{IGCC}_{1}$ plants. Research needs relate especially to studies designed to reduce capital and operating costs.

Among existing coal technologies for electricity generation, the IGCC may well represent a superior choice. The most serious 1 imitation for IGCC use is its cost when compared with the use of NG and petroleum at currently low prices in conventional electricity generation units. Continuing research to reduce system costs is recommended.

\section{References for Section 3.1}

1. D.F. Spencer, S.B. Alpert and M.J. Gluckman, "Integrated Coal Gasification Combined Cycles (IGCC) an Emerging Commercial Option for the Power Industry," paper presented at a 1985 ACS meeting, EPRI, Palo Alto, CA (1986).

2. D.F. Spencer, "The Commercial Implications of the Cool Water Project for the Electric Power Industry," EPRI, Palo Alto, CA (1986), unpublished.

3. W.N. Clark, "Remarks at Alternative Coal Tests Press Briefing," Cool Water Coal Gasification Plant, Daggett, CA (April 4, 1986).

\subsection{The Cool Water IGCC}

\section{2-1. General Features}

The Cool Water Coal Gasification Program (CWCGP) utilizes a $100 \mathrm{MW}_{\mathrm{e}}$ IGCC plant located in Daggett, CA. It has a coal capacity of 1000 TPD and is located adjacent to a $600 \mathrm{MW}_{\mathrm{e}} \mathrm{NG}-$ fired plant of the Southern California Edison Co. Construction was started on December 15, 1981, and first electricity production occurred on May 20, 1984. The CWCGP was completed ahead of schedule and below budget. ${ }^{1}$ The total capital cost was $\$ 263$ million.

There are six participants, each contributing a minimum of $\$ 25$ million: Texaco Inc. ( $\$ 45$ million), Southern California Edison Co. ( $\$ 25$ million, EPRI ( $\$ 69$ million), Bechtel ( $\$ 30$ million), General Electric Co. 
( $\$ 30$ million), and the Japanese Cool Water Program Partnership ( $\$ 30$ million). Additional $\$ 5$ million contributions came from the Empire State Energy Research Corp. and the Sohio Alternate Energy Dev. Co.; there was also a $\$ 24$ million loan.

\section{2-2. $\quad$ Process Description}

The CWCGP is shown schematically in Fig. 3.2-1. More detailed diagrams can be found in Ref. 2 .

Coal is brought by rail cars, stored in two large storage silos (1), and transferred to be ground and slurried (2). A $60 / 40 \%$ coal-water slurry is normally used. The slurry is reacted with $\mathrm{O}_{2}$ in the gasifier (3). Oxygen is supplied from an over-the-fence plant (4). A Texaco gasifier is used (compare Sec. 3.3-1). If the gasifier operates in the heat-recovery mode, the hot gases are collected in a heat exchanger and high pressure steam $(\sim 100 \mathrm{~atm})$ is raised.

Slag is removed with a lockhopper system (5); ash and water from the gasifier are separated (6). Some solids are recycled back to the grinding and slurrying processes (2). Solid slag is presently stored in speciallylined landfills. Recently, however, the EPA and the State of California Health Department have determined that this slag is non-hazardous. Studies of markets for concrete or asphalt applications are being undertaken. The product gases are scrubbed to remove particulates (3) and are then transferred to the syngas cooler (7) and the sulfur removal unit (8). Sulfurcompounds $\left(\mathrm{H}_{2} \mathrm{~S}\right.$ and $\left.\mathrm{COS}\right)$ are sent to the sulfur recovery unit (9), where the sulfur is converted to elemental form and sold (currently at $\$ 100 /$ ton). Sulfur removal is accomplished by the Selexol process; sulfur recovery from $\mathrm{H}_{2} \mathrm{~S}$ and $\mathrm{COS}$ is implemented by using the Claus system. Waste acid-gases from the Claus unit are cleaned by the SCOT process.

The clean syngas is saturated (10) to control $\mathrm{NO}_{\mathrm{x}}$ emissions prior to combustion and power generation in the General Electric combustion turbine (1). The combustion-turbine exhaust gases are sent to the Heat Recovery Steam Generator HRSG (12), and vented to the atmosphere. In the HRSG, heat from the hot combustion gases is used to make steam. This steam is combined with the steam made by cooling of the syngas (3) (if applicable) and is then passed through the steam turbine (13). At cool Water, the 


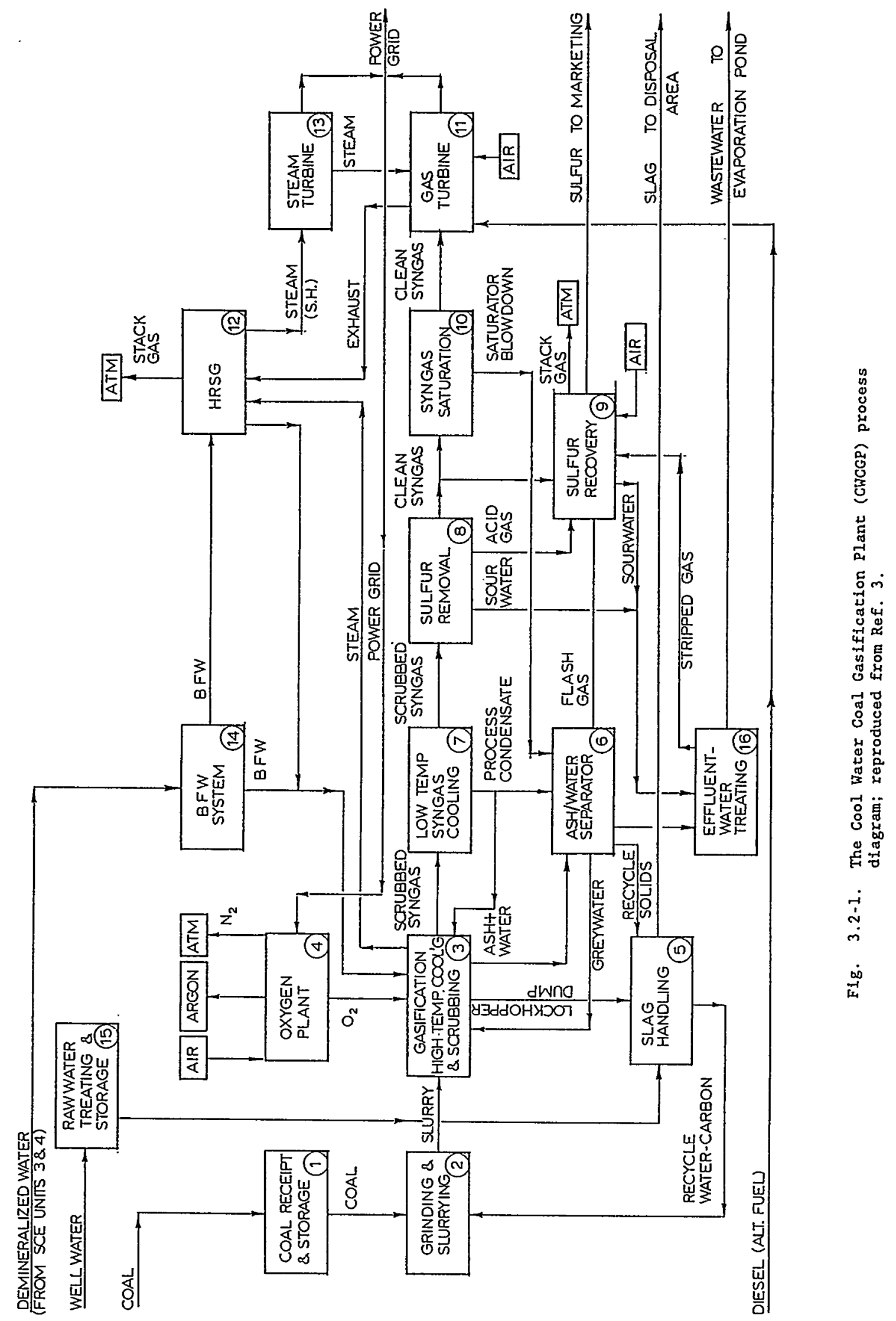


combustion turbine generates $65 \mathrm{MW}$ and the steam turbine $55 \mathrm{MW}$ for a total capacity of $120 \mathrm{MW}$.

Boiler feedwater (14) for the steam turbine is supplied from the adjacent Southern California Edison plant. Well water (15) is used for slag processing (5). Waste-water is treated (16) and sent to on-site evaporation ponds.

\section{2-3. Performance Results}

Some of the design goals and actually achieved performances are listed in Table 3.2.-1.

Three representative coals have been gasified so far. The plant has met all of the design goals. The performance of the CWCGP is very good for the coals that have been tested. Illinois No. 6 and the Pittsburgh No. 8 coals with sulfur contents of 3.1 and $2.9 \mathrm{wt} \%$, respectively, have been handled. Plans call for the testing of additional coals, including an Australian coal.

Because of the high carbon-conversion efficiency, the carbon recycling system illustrated in Fig. 3.2-1 has not been used. Refractory wear in the gasifier has exceeded expectations. Minor problems encountered were wear and plugging of the slag-handling system, difficulty in keeping the lockhopper valves operating smoothly, and fine slag particles remaining in the gas-scrubbing system: ${ }^{1}$ All of these problems were resolved by making minor modifications -in-plant operation or-design

Pollutant-emission results are given in Table 3.2-2. Actual emission levels were always well below requirements, even with high-sulfur Eastern coals. The environmental requirements listed in Table 3.2-2 are the strictest for any coal-burning power plant in the US.

Both modes of gasifier operation have been utilized: gasifier heat recovery and direct quenching (compare Sec. 3.3-1). Capacity factors have met targets expected for the first 2 years of operation and have been generally equal to or superior to targeted goals. It is expected that a multi-purpose IGCC will have a capacity factor greater than $80 \%$. 
Table 3,2-1. Design and actual performance for the CW CGP; reproduced from Ref. 4.

\begin{tabular}{|c|c|c|c|c|}
\hline Performance Parameter & Design ${ }^{\dagger}$ & \multicolumn{3}{|c|}{ Actual Performance } \\
\hline Coal type & SUFCO & SUFCO & $\begin{array}{l}\text { Illinois } \\
\text { No. } 6\end{array}$ & $\begin{array}{l}\text { Pittsburgh } \\
\text { No. } 8\end{array}$ \\
\hline Sulfur content ( $w t \%)$ & 0.48 & 0.4 & 3.1 & 2.9 \\
\hline HHV (Btu/lb) & 12,300 & 12,300 & 12,800 & 13,700 \\
\hline Coal-feed rate (TPD) & 1000 & 1000 & 1000 & 1000 \\
\hline Oxygen consumption (TPD) & 962 & 908 & 885 & 979 \\
\hline Gross power production $\left(\mathrm{MW}_{\mathrm{e}}\right)$ & 114 & 116 & 120 & 125 \\
\hline Byproduct sulfur produced (TPD) & 4.6 & 3.8 & 30 & 27 \\
\hline Coal/water slurry concentration (wt\% solids) & 60 & 60 & 64 & 62 \\
\hline Carbon conver sion (\%) & 98.3 & 98.3 & 96.6 & 99.1 \\
\hline Gasifier/syngas coolex efficiency (\%) & 90.3 & 91.5 & 88.5 & 91.6 \\
\hline Gasifier refractory life (yr) & 1.0 & 2.6 & 1.1 & $\neq$ \\
\hline Overall heat rate $(B t u / k W h)^{\S}$ & 11,500 . & 11,300 & 12,000 & $11 ; 600$ \\
\hline Efficiency (\%) & 29.7 & 30.2 & 28.4 & 29.4 \\
\hline \multicolumn{5}{|c|}{$\begin{array}{l}\dagger \text { Design parameters based on SUFCO coal. } \\
\oint \text { Data not yet available. } \\
\text { The heat rates were not optimized and are expected to be reduced by } \sim 2,500 \mathrm{Btu} / \mathrm{kWh} \text { in future } \\
\text { plants. }\end{array}$} \\
\hline
\end{tabular}

Table 3.2-2. Allowed pollutant levels and actual CW CGP pollutant emissions measured at the HRSG. All units are lbs/ $10^{6}$ Btu; from Ref. 4.

\begin{tabular}{|c|c|c|c|c|c|}
\hline $\begin{array}{l}\text { Coal } \\
\text { Type }\end{array}$ & Pollutant & $\begin{array}{l}\text { Permit \& } \\
\text { Regulation } \\
\text { Limits } \\
\text { (a) }\end{array}$ & $\begin{array}{l}1985 \\
\text { EPA } \\
\text { Test }\end{array}$ & $\begin{array}{c}\text { Preliminary } \\
\text { Test } \\
\text { Results }\end{array}$ & $\begin{array}{c}\text { Federal } \\
\text { NSPS } \\
\text { (b) }\end{array}$ \\
\hline $\operatorname{SUFCO}(0.5 \% \mathrm{~S})$ & $\begin{array}{l}\mathrm{SO}_{2} \\
\mathrm{NO}_{x} \\
\mathrm{CO}\end{array}$ & $\begin{array}{l}0.033 \\
0.13 \\
0.07\end{array}$ & $\begin{array}{l}0.018 \\
0.07 \\
0.004\end{array}$ & & $\begin{array}{l}0.24(c) \\
0.6 \\
\text { NS (e) }\end{array}$ \\
\hline $\begin{array}{l}\text { Illinois No. } 6 \\
(3.0 \% \mathrm{~S})\end{array}$ & $\begin{array}{l}\mathrm{SO}_{2} \\
\mathrm{NO}_{x} \\
\mathrm{CO} \\
\text { Particulates }\end{array}$ & $\begin{array}{l}0.16 \\
0.13 \\
0.07 \\
0.01\end{array}$ & & $\begin{array}{l}0.076 \\
0.094 \\
0.004 \\
0.009\end{array}$ & $\begin{array}{l}0.6(d) \\
0.6 \\
\text { NS } \\
0.03\end{array}$ \\
\hline $\begin{array}{l}\text { Pittsburgh No. } 8 \\
(2.9 \% \mathrm{~S})\end{array}$ & $\begin{array}{l}\mathrm{SO}_{2} \\
\mathrm{NO}_{x} \\
\mathrm{CO}\end{array}$ & $\begin{array}{l}0.16 \\
0.13 \\
0.07\end{array}$ & & $\begin{array}{l}0.086 \\
0.09 \\
0.004\end{array}$ & $\begin{array}{l}0.6(d) \\
0.6 \\
\text { NS }\end{array}$ \\
\hline
\end{tabular}

(a) Emission requirements for the HRSG Stack from limiting permit and regulatory emission criteria.

(b) New Source Pexformance Standards for a coal-fired power burning equivalent coal as CW CGP.

(c) $0.8 \mathrm{lb} / 10^{6}$ Btu uncontrolled emissions $\times 0.30$ for controlled emissions.

(d) Emissions controlled to $0.6 \mathrm{lb} / 10^{6} \mathrm{Btu}$.

(e) NS: No standard. 
1. D.F. Spencer, S.B. Alpert and H.H. Gilman, Science 232, 609 (1986).

2. Electric Power Research Institute, "Cool Water Coal Gasification Program - First Annual Report," Report No. EPRI AP-2487, Palo Alto, CA. (1982).

3. Ref. 2 of Sec. 3.1.

4. Ref. 3 of Sec. 3.1 .

\subsection{Selected Gasifiers for IGCC Plants}

The following coal-gasification systems represent important developments in gasification technology. The systems are designed to handle a wide variety of coals and to be useful in both combined-cycle gasification systems for electricity generation or for the production of pipline-quality SNG.

3.3-1. The Texaco Coal-Gasification Process (TCGP) ${ }^{*}$

\section{3-1A. Introduction}

The Texaco Coal Gasification Process (TCGP) has the following design features: (a) a pressurized reaction vessel; (b) a downward loading, entrained flow, slagging reactor; (c) air-or $\mathrm{O}_{2}$-blown gasification; (d) high operating temperatures; (e) flexible feeds of fuels and output products; ( $f$ ) system coupling for cogeneration (i.e., using the excess heat produced in the gasifier to generate electricity).

The development schedule for the TCGP is summarized in Table 3.3-1.

\section{3-1B. Process Description}

Two configurations of the TCGP are shown in Fig. 3.3-1, depicting two different gas-cooling methods. The TCGP is designed to operate at

* The radiant section is necessary to cool the gases below the sticking temperature of the slag before entering the convective cooler. 
pressures between 20 and $80 \mathrm{~atm}$ and at temperatures between 1200 and $1500^{\circ} \mathrm{C}$.

Table 3.3-1. Development of the TCGP; taken from Ref. 1.

\begin{tabular}{|c|c|c|c|c|c|c|}
\hline Owner & i $\begin{array}{c}\text { Type } \\
\text { of Plant }\end{array}$ & Location & $\begin{array}{l}\text { Coal } \\
\text { Capacity, } \\
\text { TPD }\end{array}$ & $\begin{array}{l}\text { Start- } \\
\text { Up }\end{array}$ & Gas Cooling & Product \\
\hline Texaco, Inc. & pilot & Califor nia & 15 & 1973 & direct quench (d.q.) & - \\
\hline Texaco, Inc. & pilot & California & 15 & 1978 & d.q./heat recovery & - \\
\hline Texaco, Inc. & pilot & California & 15 & 1981 & d. q. & - \\
\hline $\mathrm{RAG/RCH}$ & $\begin{array}{l}\text { demon- } \\
\text { stration }\end{array}$ & W. Germany & 165 & 1978 & heat recovery & oxso-chemicals \\
\hline $\begin{array}{l}\text { Dow } \\
\text { Chemical }\end{array}$ & $\begin{array}{l}\text { demon- } \\
\text { stration }\end{array}$ & Louisiana & 400 & 1979 & - & $\begin{array}{l}\text { synthesis gas } \\
\text { for electric } \\
\text { power }\end{array}$ \\
\hline IVA & $\begin{array}{l}\text { demon- } \\
\text { stration }\end{array}$ & Alabama & 190 & 1982 & d. q. & arnmonia \\
\hline $\begin{array}{l}\text { Tennessee- } \\
\text { Eastman }\end{array}$ & $\begin{array}{l}\text { com- } \\
\text { mercial }\end{array}$ & Tennessee & 900 & 1983 & d. q. & $\begin{array}{l}\text { acetic } \\
\text { anhydride }\end{array}$ \\
\hline $\begin{array}{l}\text { Southern } \\
\text { Calif. } \\
\text { Edison Co., } \\
\text { etc. (Cool } \\
\text { Water) }\end{array}$ & $\begin{array}{l}\text { com- } \\
\text { mercial }\end{array}$ & California & 1,000 & 1984 & $\begin{array}{l}\text { heat recovery or } \\
\text { d.q. }\end{array}$ & $\begin{array}{l}\text { synthesis gas } \\
\text { for electric } \\
\text { power }\end{array}$ \\
\hline Ube & $\begin{array}{l}\text { com- } \\
\text { mercial }\end{array}$ & Japan & 1,650 & 1984 & d. q. & arnmonia \\
\hline SAR & $\begin{array}{l}\text { com- } \\
\text { mer cial }\end{array}$ & W. Germany & 800 & 1986 & d.q./heat recovery & $\begin{array}{l}\text { oxo-chemical/ } \\
\mathrm{H}_{2}\end{array}$ \\
\hline
\end{tabular}

The coal is wet-ground (1) and slurried with oil or water (2). If (molten) coal-liquefaction residues are used, these steps are omitted.

Typical slurry feeds have between 60 and $70 \mathrm{wt} \%$ of solids. The slurry is mixed with $\mathrm{O}_{2}$ or air in the gasifier-burner (3). For gasification of an oil slurry, steam or another temperature moderator is added to the burner stream; water serves this purpose for water slurries. By properly adjusting the $\mathrm{O}_{2}$ /slurry ratio, temperatures are maintained above ash-fluid temperatures.

After leaving the gasifier (burner), the gases are cooled (4), either by direct contact with quenching water [Fig. 3.3-1(a)] or by passing through a radiative cooler ${ }^{*}$ and then a convective cooler [Fig. 3.3-1(b)]. In the latter case, heat is recovered from these gases (and from the gasifier) in the form of high-pressure steam, which can be used to generate electric power. The former method is preferred when the output is $\mathrm{NH}_{3}$ or 

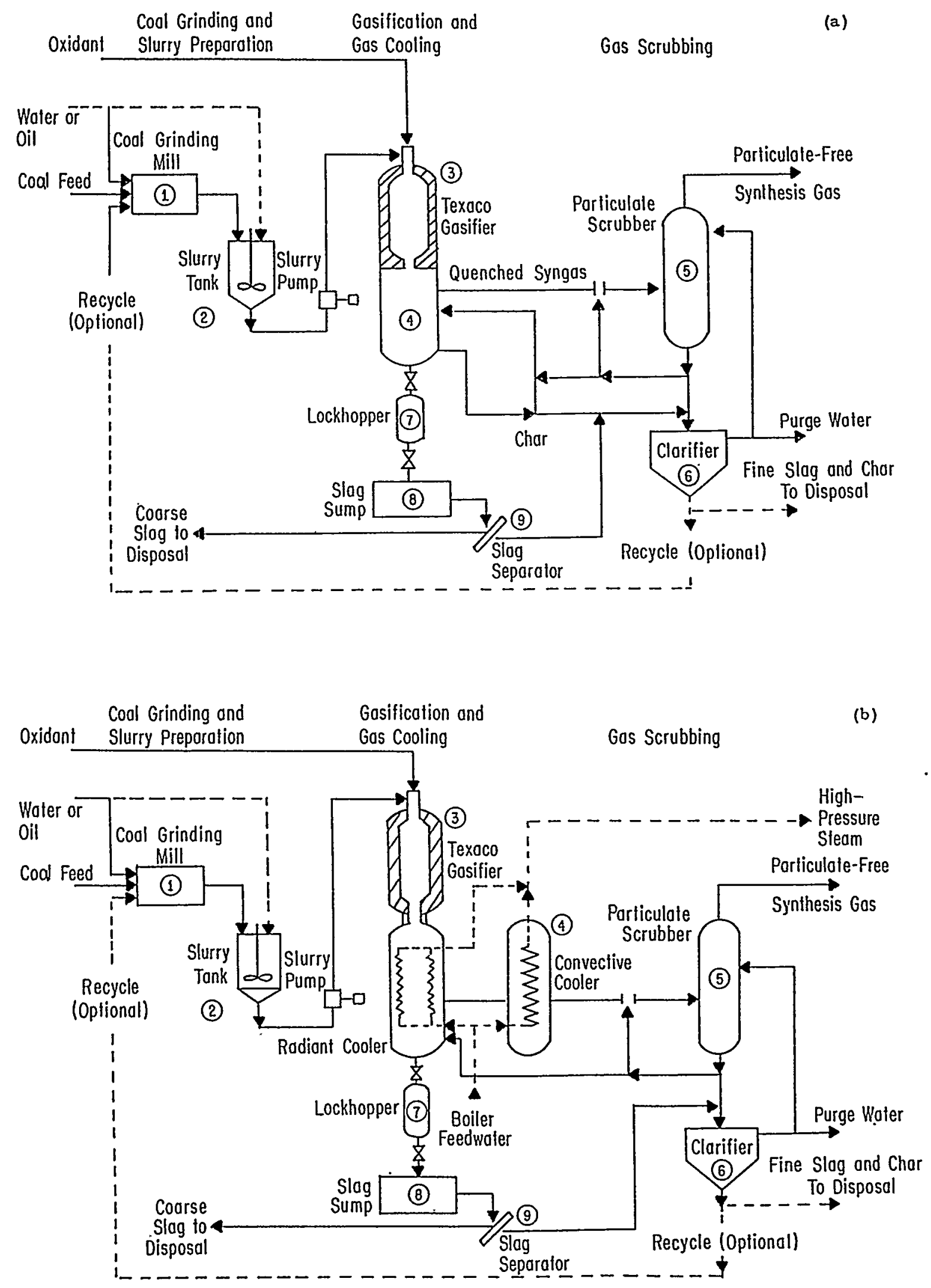

Fig. 3.3-1. The process diagram for the TCGP is shown for two gas-cooling rodes: (a) direct quench and (b) waste-heat recovery; reproduced, with minor modification, from Ref. 1 . 
$\mathrm{H}_{2}$, since the required shift reactor is easily integrated in the quench mode; also, heat transfer from the gases to the quenching water produces steam, which is used downstream to increase the $\mathrm{H}_{2}$ yield.

After cooling, the gases enter a water scrubber (5), where char and fly-ash are removed from the product gas. If necessary, the product gases also undergo sulfur cleanup (not shown) using commercially available technology. The scrubbing water is sent to the clarifier (6) and is then recycled to the particulate scrubber (5), thus forming a closed loop. Some of the recycled water is purged to prevent scaling and to control the level of dissolved solids. A small amount of make-up water is needed. Most of the ash from the gasifier (3) is removed as a quenched slag through a water-sealed depressurizing lockhopper system (7) and is then sent to the siag-collection sump (8). Fines from the slag separator (9) are pumped to the clarifier (6) for recycle or disposal while the coarse slag from the separator is removed.

The product gases leaving the particulate scrubber (5) contain $\mathrm{H}_{2}$, $\mathrm{CO}, \mathrm{CO}_{2}, \mathrm{H}_{2} \mathrm{O}$, and traces of $\mathrm{Ar}, \mathrm{N}_{2}, \mathrm{CH}_{4}, \mathrm{H}_{2} \mathrm{~S}$, and $\mathrm{COS}$. The amounts of the two sulfur pollutants present depend on the sulfur contents of the feed fuels $s^{2}$. There is no detectable amount of $\mathrm{NO}_{X}$ formed, ${ }^{2}$ and it is stated that no $\mathrm{SO}_{\mathrm{x}}$ is produced. ${ }^{1}$ Generally, very low pollutant levels result from the TCGP in both the gaseous and wastewater streams. A detailed analysis of all pollutant levels is given in Ref. 2 . The observed excellent gasifier performance is attributed to the high reaction temperatures ${ }^{2}$ and the highly-reducing environment used in the process. ${ }^{1}$

A number of different products have been prepared in commercial plants (compare Table 3.3-1). These include $\mathrm{H}_{2}, \mathrm{NH}_{3}$, fuel gas for electricity generation, and synthesis gas $\left(\mathrm{CO}\right.$ and $\mathrm{H}_{2}$ ) for the production of methanol or other oxo-products.

Many different types of fuels have been successfully gasified in the TCGP. According to Texaco, any carbonaceous material that may be formed into a pumpable, concentrated slurry can be gasified. A summary of the types of coals, cokes and 7 iquefaction residues that have been gasified in the Texaco pilot plants is given in Table 3.3-2. Free-swelling indices ranging between 0 and 8 have been handled at the RAG/RCH plant in FRG. 1 In Ref. 3, the conversion of petroleum coke to synthesis gas in a 30 TPD plant in Ube City, Japan, is described in detail. This plant has been operating since 1982 . 
Table 3.3-2. Examples of feedstocks gasified in the Texaco Montebello plants.

Coals: anthracites, semi-anthracites, bituminous and subbituminous coals, and lignites.

Petroleum cokes: fluid, delayed, calcined, fluid from tarsands bitumens.

Coal liquefaction residues: formed from solvent refined coal (SRC I and II), H-coal, and in the Exxon donor solvent (EDS) process.

others: Lurgi tar/oil.

\section{3-2. The Shell Coal-Gasification Process (SCGP)}

\section{3-2A. Introduction}

The past and current development schedules of the SCGP are summarized in Table 3.3-3. The SCGP is described as a "highty efficient

Table 3.3-3. Milestones in the SCGP development.

\begin{tabular}{l|c|l}
\hline \multicolumn{1}{c|}{ Date } & Scale of Operation & \multicolumn{1}{c}{ Location } \\
\hline 1972 & development initiation & \\
1976 (start-up) & 6 TPD pilot plant & Amsterdam, Holland \\
1978 (start-up) & 150 TPD experimental unit & Harburg, FRG \\
1987 & SCGP-1 ( -1/5 of commercial & near Houston, TX \\
& Size): 250 TPD of high- & \\
& TPD of wet, high-ash & \\
& lignites & \\
\hline
\end{tabular}

* This is a brief summary of technical material provided by Heitz and Nager. ${ }^{4}$ It has been reviewed and approved for accuracy by M. Nager (She11 0il Company) to whom we are greatly indebted for advice and assistance. 
process with demonstrated feedstock flexiblity from lignites to coke. "4 4 The SCGP-1 demonstration unit is expected to be completed during the fourth quarter of 1986, with plant start-up scheduled for the first half of 1987.4 It is being developed by several Shell $0 i 1$ units, in collaboration with EPRI and Lummus Crest (a Combustion Engineering subsidiary). The initial application of this technology is expected to be to electric power generation.

An evaluation of the 6 TPD SCGP in Amsterdam is given in Ref. 5. Two coals were tested: Illinois No. 5 and a Texas lignite. Further information on the SCGP, including an economic assessment of an IGCC system utilizing the Shell gasifier, may be found in Ref. 6 .

\section{3-2B. Process Description}

The process diagram for the 6 TPD process-development unit is reproduced in Fig. 3.3-2 from Ref. 5. Pulverized coal is sieved over a vibrating screen with $1 \mathrm{~mm}$ openings to remove the coarse materials. It is then pressurized in a lockhopper system (1) and is pneumatically transported from the feed vesse1 (2) to the reactor (3), which consists of two oppositely-fired burners.

Temperatures in the reactor are sufficientiy high to melt the coal ash and produce a liquid slag. A dense, non-leachable slag is formed as the liquid slag leaves the reactor through the slag tap and falls into a water bath 4 .

The reactor product gas and fly slag (which is comprised mostly of residual carbon and partially molten ash) is quenched (5) with recycled product gas to about $350^{\circ} \mathrm{C}$. Primary separation of fly slag from product gas occurs in a cyclone (6). Further separation is accomplished in the venturi scrubber (7), the separator vessel (8), and the packed-bed scrubber (9). The product gas is now free of solids ( $<1 \mathrm{mg}$ of solids $/ \mathrm{Nm}^{3}$ ). Some of this gas leaves the plant as high-pressure product gas (10), while some is recycled to the quench section (5). Before this recycle gas reaches the quench section, it passes through a condenser (11), separator vessel (12), recycle-gas compressor (13), and buffer vessel (14). 


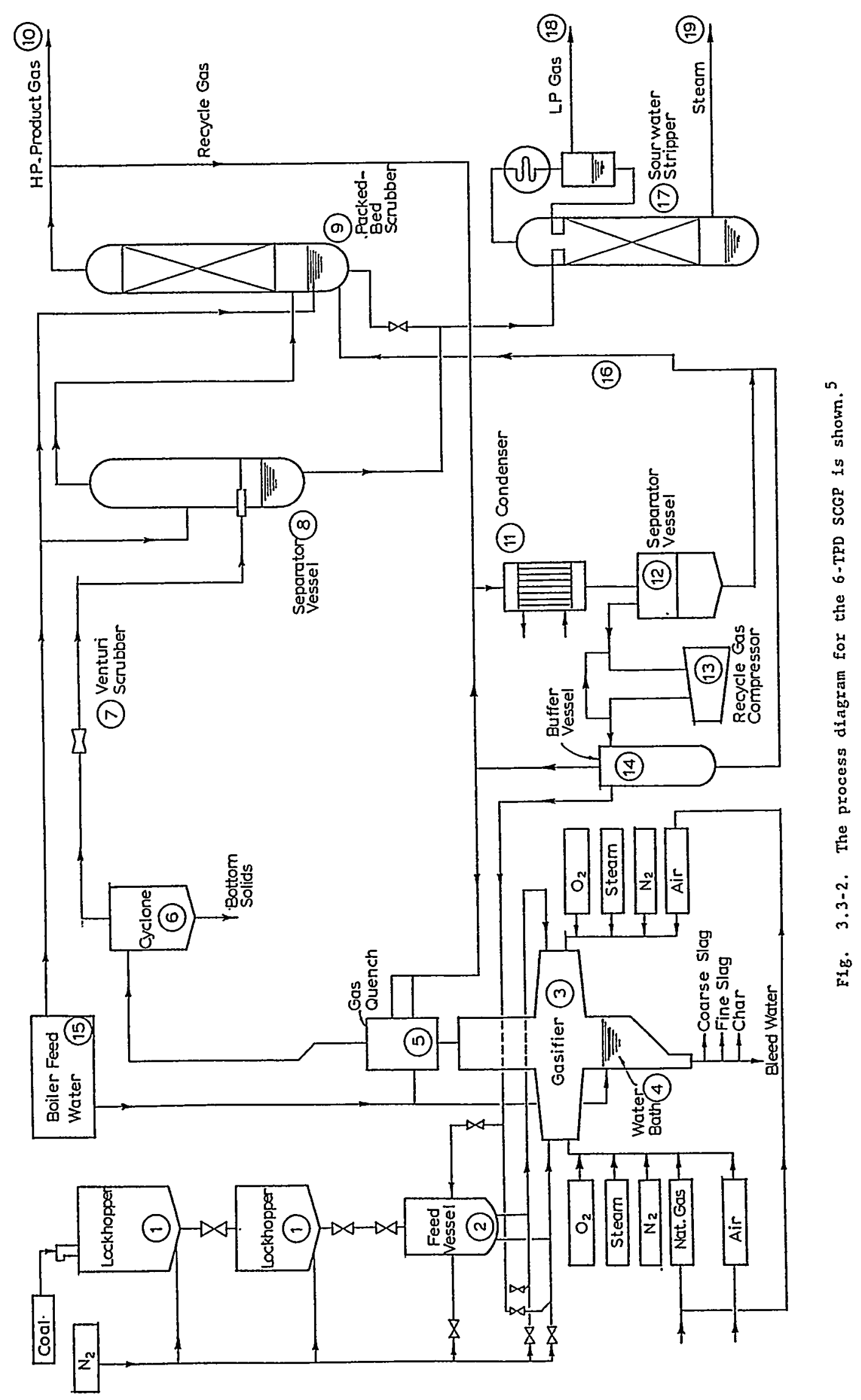


Boiler feed-water (15) enters the system through the separator (8) and the packed-bed scrubber (9). Water from the recycle-gas clean-up section (16) is also admitted to the packed-bed scrubber. The water is finally passed through the sour-water stripper (17), where low-pressure gas (18) and steam (19) are produced.

The 250 TPD SCGP-1 has been described ${ }^{4}$ as substantially different from the 6-TPD pilot plant, with improvements derived from results of continuing research at the She11 Research Laboratory in Amsterdam and the 150 TPD Harburg plant.

In the pilot plant, nitrogen is typically employed to transport coal to the gasifier. However, recycle product gas may also be used when a product gas essentially free of nitrogen is desired. Typical gas concentrations are given in Table 3.3-4 and indicate that $\mathrm{N}_{2}$ comprises around 14 or $15 \%$ of the product gas. In larger-scale systems, a denser flow of solids can be handled, thus reducing the carrier-gas flow-rate. These product gases have high $\mathrm{CO}$ and $\mathrm{H}_{2}$ but $10 \mathrm{~W} \mathrm{CO}_{2}$ and $\mathrm{CH}_{4}$ concentrations. This desirable feature is attributed to the dry feed and high temperature in the Shell gasifier. The gas composition on a dry, nitrogen-free basis expected from the SCGP-1 is given in Table 3.3-5 for comparison. Trace components for both processes are similar and compounds such as naphtha, phenols, tars, and other HCS do not survive the gasifier.

Other design improvements are aimed at potential economies of scale, improved stream factors and careful component optimization.

According to Heitz and Nager, ${ }^{4}$ it is expected that units processing 2500 TPD or more will be shop-fabricated and transportable by rail in the US. The SCGP-1 will be used to confirm equipment life and to provide needed information for commercial designs. Key components for evaluation include the feed system, gasifier, and syngas cooling system. Environmental data will be obtained for feedstocks designated by the participants, with the acid-gas removal system designed to meet applicable strict environmental control legislation. A gas-treating slip-stream unit will be operated to test cleanup options.

Computerized data-acquisition and handling systems are being installed.

For further details and information on project management and related topics, we refer to Heitz and Nager. 4 
Table 3.3-4. Representative product-gas compositions (in vol\%) obtained at the SCGP in Amsterdam; from Ref. 5.

\begin{tabular}{c|c|c}
\hline \multirow{2}{*}{ Component } & \multicolumn{2}{|c}{ Coal Type } \\
\cline { 2 - 3 } & Illinois No. 5 & Texas Lignite \\
\hline $\mathrm{H}_{2}$ & 26.78 & 26.49 \\
$\mathrm{CO}$ & 52.24 & 52.43 \\
$\mathrm{CO}_{2}$ & 5.14 & 6.61 \\
$\mathrm{CH}_{4}$ & 0.02 & 0.13 \\
$\mathrm{H}_{2} \mathrm{~S}_{2}$ & 0.77 & 0.27 \\
$\mathrm{~N}_{2}{ }^{\dagger}$ & 14.98 & 14.01 \\
& 7.38 & 9.35 \\
\hline
\end{tabular}

Table 3.3-5. Typical treated product-gas composition anticipated for the SCGP-1; reproduced from Ref. 4.

\begin{tabular}{c|c}
\hline Component & \% by volume $\left(\mathrm{N}_{2}\right.$-free $)$ \\
\hline $\mathrm{H}_{2}$ & 30 \\
$\mathrm{CO}$ & 69 \\
$\mathrm{CO}_{2}$ & 0.1 \\
$\mathrm{H}_{2} \mathrm{~S}$ & $<0.01$ \\
$\mathrm{COS}$ & $<0.01$ \\
$\mathrm{HCN}$ & $<0.001$ \\
$\mathrm{NH}_{3}$ & $<0.001$ \\
$\mathrm{HCl}$ & $<0.001$ \\
$\mathrm{HF}$ & $<0.001$ \\
$\mathrm{CH}_{4}$ & 0.03 \\
$\mathrm{H}_{2} \mathrm{O}$ & 0.6 \\
$\mathrm{Ar}^{2}$ & 0.2 \\
\hline
\end{tabular}




\section{3-3. The U-GAS Process *}

\section{3-3A. Introduction}

The Institute of Gas Technology (IGT) has developed the U-GAS process to produce gas from coal in an efficient economic, and environmentally acceptable manner. The product gas from the process may be used to produce low-Btu gas, medium-Btu gas, and substitute NG for use as fuels, or chemical products such as ammonia, methanol, hydrogen, and oxo-chemicals, or electricity generated by a combined cycle or a fuel cell. The three main goals for developing a new gasification process have been economical handling of large volumes of gas throughput, high carbon conversion of coal to gas without producing tar or oil by-products, and minimum damage to the environment.

The U-GAS process has been developed in a multiphase program over a period of 8 years and has utilized skills and expertise evolving from earlier coal-gasification projects at IGT that date back to 1950. The process has been extensively tested in a pilot plant to establish process feasibility and provide a large data base for scale-up and design of the first commercial plant. The U-GAS process is considered to be one of the more flexible, efficient, and economical coal-gasification technologies developed in the US during the last decade. The U-GAS technology is currently available for licensing from GDC, Inc., a wholly owned subsidiary of IGT.

\section{3-3B. Process Description}

The U-GAS process accomplishes four important functions in a single-stage, fluidized-bed gasifier (Fig. 3.3-3): it decakes coal, devolatilizes coal, gasifies coal, and agglomerates and separates ash from

* Prepared by P.B. Tarman, Vice President, Research and Development, IGT, 3424 South State St., Chicago, IL 60616. 
char. Other characteristics of the process are shown in Table 3.3-6. In the process, coal (1/4 inch $\times 0)$ is dried only to the extent required for handling purposes. It is pneumatically injected into the gasifier through a lockhopper system. Within the fluidized bed, coal reacts with steam and oxygen (air can be substituted for oxygen) at a temperature of 1750 to $2000^{\circ} \mathrm{F}$. The temperature of the bed depends on the type of coal feed and is controlled to maintain nonslagging conditions for ash. The operating pressure of the process depends on the ultimate use of product gas and may vary between 50 and $350 \mathrm{psi}$. The pressure must be optimized for a

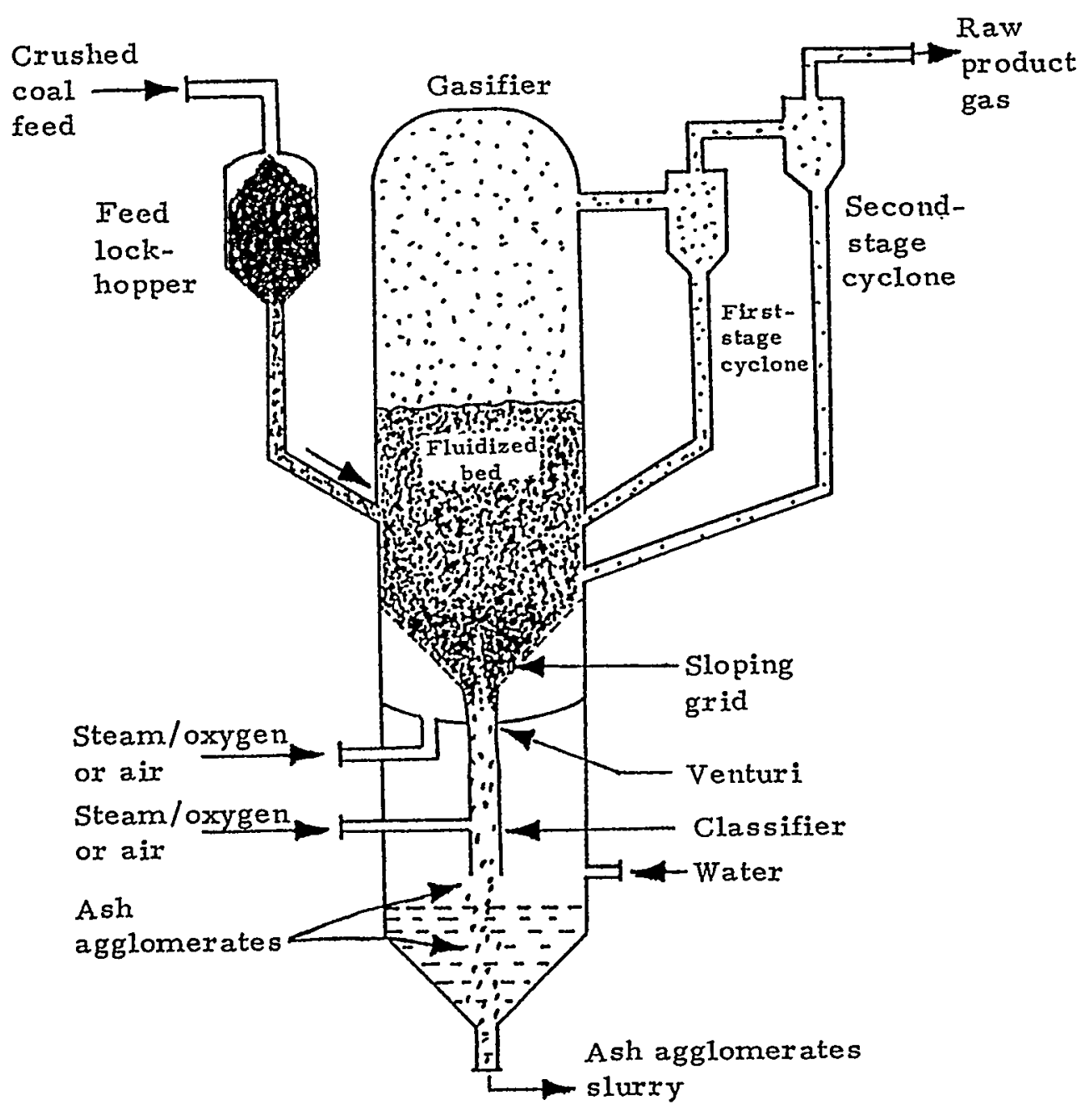

Fig. 3.3-3. Schematic diagram of the U-GAS fluidized-bed gasifler. 
Table 3.3-6. U-GAS process characteristics.

High conversion of coal to gas using an ash-agglomerating technique; capability to gasify all ranks of coal; ability to accept fines in the coal feed; simple design, safe and reliable operation; easy to control, ability to withstand upsets; product gas virtually free of tar and oils; no environmental problems; operation at lower temperature than are used with slagging gasifiers; large turndown capability; large unit capacity.

particular system; for production of an industrial fuel, a minimum pressure of 80 to $100 \mathrm{psi}$ is desirable. At the specified conditions, coal is gasified rapidly, producing a mixture of $\mathrm{H}_{2}, \mathrm{CO}$ and $\mathrm{CO}_{2}$, and small amounts of $\mathrm{CH}_{4}$. Because reducing conditions are always maintained in the bed, nearly all of the sulfur present in coal is converted to $\mathrm{H}_{2} \mathrm{~S}$. Simultaneously with coal gasification, the ash is agglomerated into spherical particles and separated from the bed. A portion of the fluidizing gas enters the gasifier through a sloping grid. The remaining gas flows upward at high velocity through the ash-agglomerating device and forms a relatively hot zone within the fluidized bed. High-ash-content particles agglomerate under these conditions and grow into larger and heavier particles. Agglomerates grow in size until they can be selectively separated and discharged from the bed into water-filled ash hoppers, from which they are withdrawn as a slurry. In this manner, the fluidized bed achieves the same low level of carbon losses in the discharge ash that is generally associated with ash-slagging gasifiers.

Coal fines elutriated from the fluidized bed are collected in two external cyclones. Fines from the first cyclone are returned to the bed, and fines from the second cyclone are returned to the ash-agglomerating zone, where they are gasified and the ash is agglomerated with bed ash. The raw product gas is virtually free of tar and oils, thus simplifying the ensuing heat recovery and purification steps. 


\section{3-3C. Pilot-Plant Description}

Most of the U-GAS process development work has been accomplished on a pilot plant put into operation in 1974. A chronological listing of pilot-plant development is given in Table 3.3-7. The development program has been funded by the US DoE and the American Gas Association. The pilot plant is located at IGT's test facilities in southwest Chicago. It consists of a gasifier and all required peripheral equipment with utilities and other support services. Most of the equipment is contained in an enclosed structure that is about $100 \mathrm{ft}$. high.

The pilot plant consists of a drying and screening system, feedstorage silos, a lockhopper system for feeding coal at rates up to $3000.1 \mathrm{~b} / \mathrm{hr}$., a refractory-lined fluidized-bed reactor with a special agglomerate with-

Table 3.3-7. Test history of the U-GAS pilot plant.

\begin{tabular}{|c|c|c|}
\hline $\operatorname{Date}(s)$ & $\begin{array}{l}\text { Number } \\
\text { of Tests }\end{array}$ & Function \\
\hline 1974 & 9 & Equipment shakedown \\
\hline $1974-1975$ & 53 & Process-feasibility studies \\
\hline 1975 & 13 & Testing of highly-reactive small-size feed \\
\hline 1977 & 4 & Shakedown of the modified pilot plant \\
\hline 1977 & 7 & Testing of highly-reactive feedstock \\
\hline 1977 & 6 & First bituminous coal tests \\
\hline 1978 & 8 & Testing of unwashed high-ash feedstock \\
\hline $1978-1982$ & 25 & $\begin{array}{l}\text { Demonstration/commercial plant } \\
\text { design data }\end{array}$ \\
\hline 1980 & 3 & Testing of highly-caking feedstock \\
\hline 1981 & 3 & $\begin{array}{l}\text { Coal-verification test with different } \\
\text { feedstocks for different clients }\end{array}$ \\
\hline 1983 & 2 & $\begin{array}{l}\text { Coal-verification tests with ROM French } \\
\text { coal }\end{array}$ \\
\hline 1984 & 1 & $\begin{array}{l}\text { Coal-verification tests with ROM Utah Coal } \\
\text { (air and enriched-air gasification) }\end{array}$ \\
\hline
\end{tabular}


drawal system in its base, a product gas quench system, a cyclone system for removal and recycle of elutriated fines, a product-gas scrubber, a productgas incinerator, and a lockhopper ash-removal system. The pilot plant flow diagram is shown in Fig 3.3-4. The gasifier is a mild-steel, refractoryline vessel with an inside diameter of $3 \mathrm{ft}$ and a height of about $30 \mathrm{ft}$. The pilot plant is thoroughly instrumented to provide necessary operating information and data for the calculation of accurate mass and energy balances. A computer system for automatic data acquisition provides on-line process flows, balances, critical variable trend plots, and operating data summaries at regular intervals. The pilot plant contains special sampling systems for complete characterization of the raw product gas, water effluents, and coal fines necessary for gas-purification and wastewater systems.

\section{3-3D. Process Development}

Over the last 7 years, IGT has conducted an extensive, multidisciplinary program to develop important aspects of the U-GAS technology and to obtain information for the design of a commercial plant. The program has included the following steps:

(i). Operations of the U-GAS pilot plant to demonstrate process feasibility, including ash agglomeration and fines recycle. The pilot plant has also yielded data on the process, mechanical and operational design of a commercial plant. A detailed mechanical design of the gasifier has been on-going while the pilot plant has been operational. This procedure has been of great benefit in identifying design data gaps that could be obtained from the operating pilot plant.

(ii). Scale-up studies on large, cold-flow model. The basic concerns in scaling up from a pilot plant to commercial scale are centered around the grid and venturi region of the gasifier. A semi-circular cold-flow model and a pressurized cold-flow model have been operated to understand the hydrodynamics of the grid/venturi region, determine the mechanical configuration of the scaled-up grid-venturi, and select the dimensions of the venturi to discharge the necessary quantity of ash agglomerates. An $X$-ray cinestudy has been conducted to examine visually 


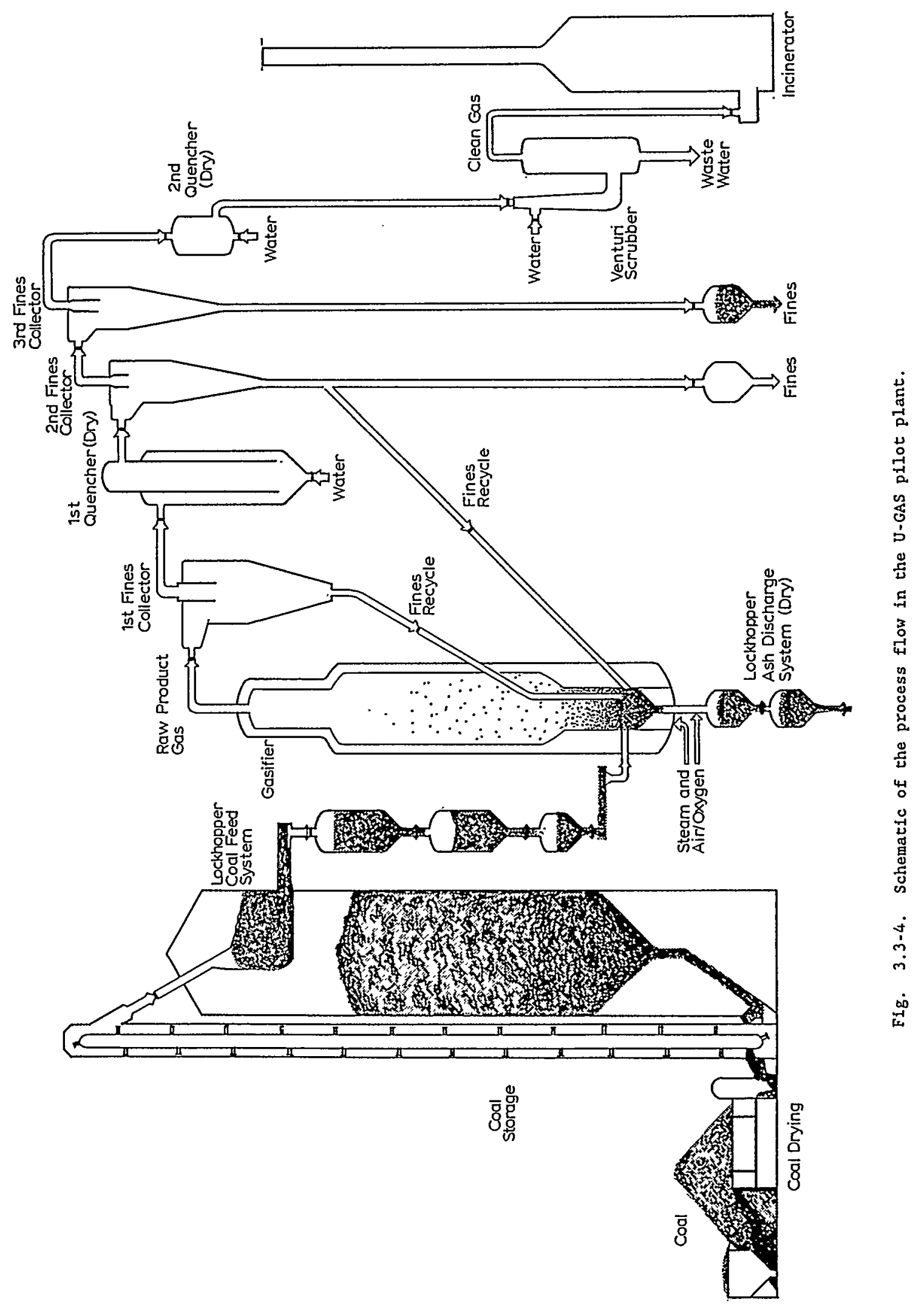


solids circulation, jet penetration, and bubble dynamics in the grid/venturi zones of different mechanical configurations. Numerical simulation and engineering calculations have been carried out to compare the thermal and hydrodynamic similarities between the pilot and commercial plants and to select appropriate design parameters.

(iii). Ash chemistry studies and bench-scale experiments. Extensive ash-chemistry studies have been conducted to understand and develop mechanistic models of ash agglomeration and ash adhesion. Bench-scale experiments have been carried out to determine the main operating variables affecting the formation of ash agglomerates. Steam-oxygen gasification and high-pressure fluidization knowledge and skills have been developed in various other coal-gasification projects at IGT dating back to 1950. A computer model of the U-GAS gasification system has also been developed to predict the performance of the gasifier at different operating conditions and with different coals.

(iv). Environmental characterization of the process. During the pilot-plant operation, extensive sampling and analysis have been conducted to obtain information for complete environmental characterization of the process. The raw product-gas samples have been collected in a specially developed sampling train to trap al1 impurities present in the gas. These analyses have yielded the needed data for design of the downstream gas-purification equipment. The water-discharge stream for the verituriscrubber system has been analyzed for information on design of wastewatertreatment facilities. All solid streams entering and leaving the gasifier have been analyzed for trace metals to obtain a material balance and determine the fate of trace metals present in the coal feed. Ash agglomerates and other solid discharges have undergone leaching tests to assess compliance with regulations. No environmental problem has been encountered in the design of the commercial plant, as evidenced by approval of the Environmental Impact Statement by all US, state, and local regulatory agencies.

Based on successful development of all aspects of the U-GiAS technology, the process is ready for commercialization. Independent evaluations by several large engineering and petroleum companies support this conclusion. 


\section{3-3E. Pilot-Plant Operations}

The U-GAS pilot plant has been the primary unit in which the process development has been conducted. A total of 10,000 hrs of operating time has been logged in the pilot plant, during which period over 120 tests have been conducted with about 3500 tons of various coais. Several test runs have lasted over 2 weeks, thereby providing long, steady-state operating periods with excellent mass and energy-balance closures.

The pilot-plant development has been carried out in a multiphased program starting in 1974. As is typical in pilot-plant developments, both mechanical and process problems were encountered. One by one, solutions were found for each of these. By the end of the development program, all important aspects of the process (raw coal feed, stable ash agglomeration, and fines recycle) were both routinely and repeatedly achieved in several tests. A detailed description of the pilot-plant development is given in IGT reports. In phase I, process feasibility was demonstrated using metallurgical coke and char as feed. For phase II, the pilot plant was modified to feed coals, and trial tests were made with subbituminous and bituminous coals. During phase III, process feasibility was proved using high-sulfur-content, caking bituminous coal as feed and data were developed for scale-up and design of a commercial plant. In phase IV, environmental data were collected and the reactor dynamic response was investigated.

The major achievements in the pilot plant have been as follows: (i) Process feasibility has been verified in a series of tests of extended duration. (ii) The application of the technique of ash agglomeration and fines recycle has been perfected, and an overall coal-utilization efficiency of over $98 \%$ has been achieved. (iii) The process has been shown to have a wide operating window, thus providing flexibility to gasify a wide variety of feedstocks. (iv) The tests have produced a strong data base for scale-up and design of the first commercial plant. ( $v$ ) Data related to environmental aspects of the process, particularly raw gas and wastewater characteristics, have been obtained. These data show that there are virtually no tars or oils produced in the process. (vi) Commercially available refractories and metallurgical products have performed quite satisfactorily in the gasifier. Mechanical information has been obtained for designing gasifier internals, critical hardware, valves, cyclones, etc., which are important for reliable operation. 


\section{3-3F. Feedstocks}

A wide variety of feedstocks have been used in the pilot plant to determine process sensitivity to variables such as ash content, ash properties, particle size, reactivity, free swelling index, and volatile matter. Eight types of different coals and three types of chars have been tested in the pilot plant (cf. Table 3.3-8). The feedstocks for testing have been selected to cover a wide range of important coal properties that could have significant effects on gasification and ash agglomeration. The range of feedstock properties is shown in Table 3.3-9.

Al1 feedstocks except chars are $1 / 4$ inch $\times 0$ in size and are fed to the gasifier without any removal of fines. The coals are also directly fed into the gasifier fluidized bed without any pretreatment, regardless of their caking tendencies (free swelling index). A7so, for western Kentucky coals, both washed and unwashed coals have been successfuliy tested to determine the effects of the large quantity of clay and shale that is present in unwashed underground-mined coals.

Lignites have not been. tested in the pilot plant because of funding limitations, but the Wyoming subbituminous coal has reactivity, moisture, and volatile matter content very similar to lignites. Therefore, lignites should not pose any problems in the U-GAS process. Specifically, ash properties are more significant in the U-GAS process than coal reactivity, and the range of coals tested in the pilot plant covers almost all lignite-ash compositions.

\section{3-3G. Utah Bituminous Coal Test}

A test was carried out with Utah bituminous coal in the U-GAS pilot plant. ANR was interested in evaluating the performance of the U-GAS process to produce low-Btu gas and to provide data for the design of a commercial plant. The test called for 7 days of operation at 5 different set-points.

The test was successful in achieving all of ANR's predetermined test objectives. These objectives were (i) to prove the feasibility of producing low-Btu gas by gasifying the coal with air and steam, (ii) to maximize coal-conversion efficiency, (iii) to gasify coal with enriched air, 
Table 3.3-8. U-GAS gasifier feedstocks.

Western Kentucky No. 9 bituminous coal

(both washed and unwashed)

Western Kentucky No. 11 bituminous coal

Illinois No. 6 bituminous coal

Pittsburgh No. 8 bituminous coal

Australian bituminous coal

Polish bituminous coal

French bituminous (unwashed) coal

Utah bituminous (unwashed) coal

Montana subbituminous coal

Wyoming subbituminous coal

Metallurgical coke

Western Kentucky coal char

Illinois No. 6 coal char

Table 3.3-9. Range of U-GAS gasifier feedstock properties.

\begin{tabular}{l|l}
\hline \multicolumn{1}{c|}{ Property } & \multicolumn{1}{c}{ Value } \\
\hline Moisture, \& & 1 to $32^{\dagger}$ \\
Volatile Matter, \& & 3 to $43 \ddagger$ \\
Ash, \& & 6 to $35 \dagger$ \\
Sulfur, \& & 0.5 to $4.6 \nmid$ \\
Free Swelling Index & 0 to 8 \\
Ash-Softening Temperature, ${ }^{\circ} \mathrm{F}$ & 1980 to 2490 \\
& 1080 to 1370 \\
Gross Heating Value, Btu/lb & 7,580 to $12,650{ }^{\circ} \mathrm{C}$ \\
& 17,631 to 29,424 \\
\hline
\end{tabular}


(iv) to investigate gasifier turndown, (v) to test gas desulfurization using limestone, ( $v i$ ) to evaluate a high-temperature coal-dust filter, (vii) to test combustion characteristics of the low-Btu product gas, and (viii) to obtain data for the design of a commercial plant.

The pilot plant was operated for 6 days during which time 58 tons of Utah coal were gasified. Steady-state, ash-balanced operations were maintained for 6 different set-point operating conditions. The coal-conversion efficiency was 93 to $99 \%$ during the various set-points of operating conditions. The test was voluntarily terminated when all of the test objectives were completed. A summary of the pilot plant test results from one of the set-points is shown in Fig. 3.3-5.

Gasification was carried out with air and steam and enriched air (34\% oxygen) and steam. The heating value of the low-Btu gas was varied from 75 to $171 \mathrm{Btu} / \mathrm{SCF}$. The heating value of the low-Btu gas was lower than is expected in a commercial plant because of ( $i$ ) high heat losses relative to the reactor coal feed capacity and ( $i i)$ excessive cooling of recycled fines in the primary water-jacketed cyclone.

During one of the set points, the capability of the gasifier for turndown was demonstrated by reducing the gas-production rate by half. The ability of banking the gasifier was demonstrated also during some mechanical failures encountered during the test. For example, the coal-feed system was shut down for almost 10 hours to repair the variable speed feed mechanism. During this period, the gasifier was maintained in a hot, standby position and restarted without any problems after repairs were completed. During typical plant upsets, the gasifier was made to respond in a controlled and logical fashion, without major interruptions in gas production.

The test demonstrated total fines recycle, which is necessary to achieve high coal-conversion efficiency. The fines from the primary cyclone were recycled during all six set-points and the fines from the secondary cyclone were recycled during five of the six set-points. Secondary fines recycle was achieved under smooth and controlled conditions and was shown to be easily initiated and controlled. Any intermittent interruptions in the recycle of the secondary fines did not cause operating upsets or reduction in gas production. 
As part of the overall program, three special tests were conducted that were aimed at improving the performance and economics of commercial low-Btu gas plants. In one of these, limestone was injected into the fluidized bed along with coal to test the capture of sulfur compounds generated during coal gasification. The addition of limestone did not have adverse effects in the gasifier, ash discharge, or fines recycle. Data indicated that a large portion of the spent limestone exited the gasifier as $\mathrm{CaSO}_{4}$ rather than $\mathrm{CaS}$. The former is the preferred by-product because of its stability in an atmospheric environment. The degree of sulfur reduction in the product gas could not be precisely determined because of the difficulty in measuring relatively low concentrations of sulfur compounds (the coal contained only 0.6 wt\% of sulfur).

Coal $1343 \mathrm{Ib}$ $\mathrm{C}^{*} 1141 \mathrm{bb}$ Ash $141 \mathrm{lb}$ Moisture $61 \mathrm{lb}$

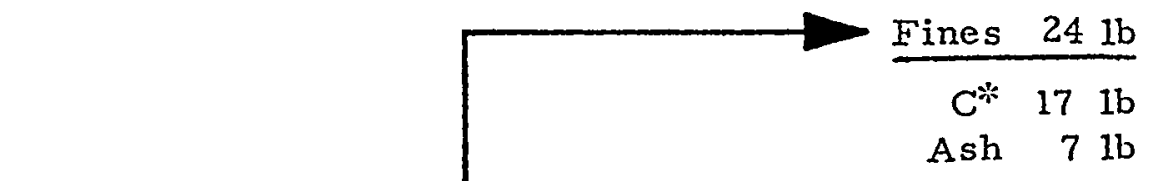

\begin{tabular}{rr} 
Coal $1343 \mathrm{lb}$ \\
\hline $\mathrm{C}^{*}$ & $1141 \mathrm{lb}$ \\
Ash & $141 \mathrm{lb}$ \\
Moisture & $61 \mathrm{lb}$
\end{tabular}

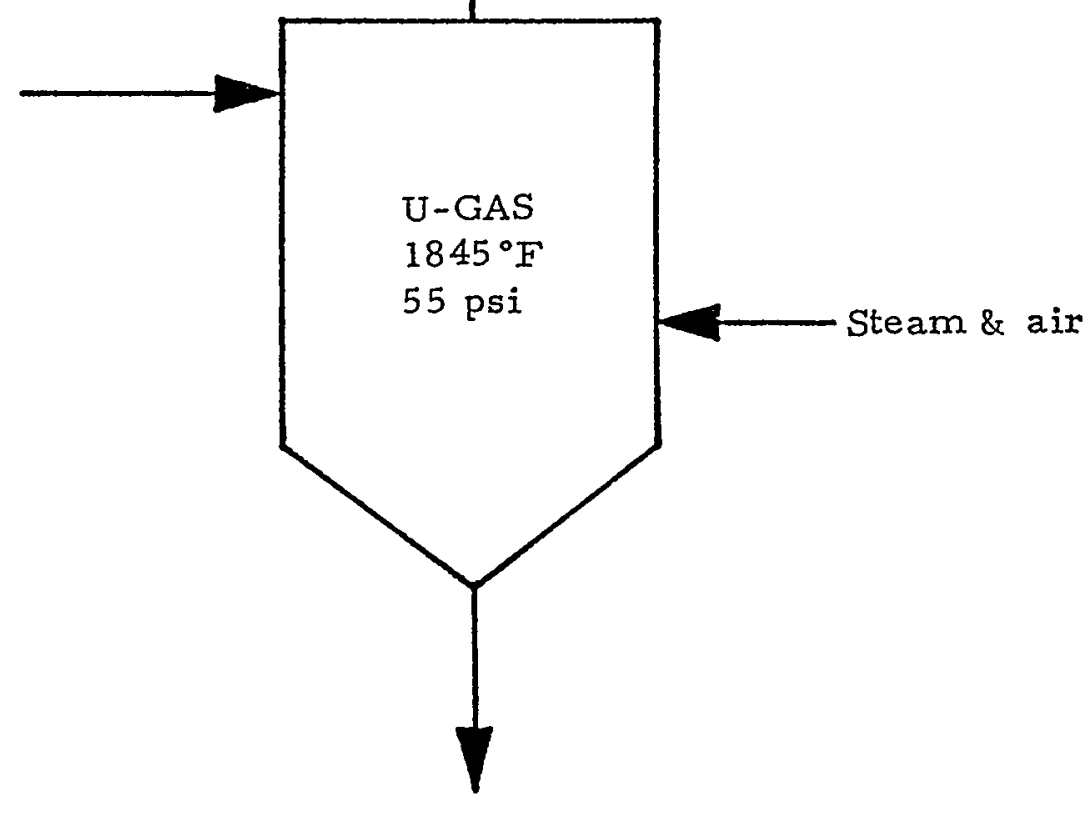

Ash $175 \mathrm{lb}$

$C^{*} 29 \mathrm{lb}$

Ash $146 \mathrm{lb}$

Fig. 3.3-5. Results of the test conducted with Utah coal in the U-GAS pilot plant; coal conversion $=96.08$; $\mathrm{C} *$ represents MAF-coal. 
In another special test, we evaluated the high-temperature coal-fines filter. If coal fines could be removed from the low-Btu product gas at high temperatures $\left(1000^{\circ}\right.$ to $\left.1500^{\circ} \mathrm{F}\right)$, then product gas could be utilized directly, thus simplifying the commercial plant design and improving efficiency and economics. A hot ceramic candle filter was installed in the pilot plant on a slipstream after the primary cyclone. The filter, operated during the test in a completely automatic mode throughout the six-day test and removed all of the dust from the hot product gas. There was no blinding of the filter medium or any continuous increase in pressure drop or cycle time of the filter system. The measurement of dust in the filtered gas was conducted using a photometric particle counter. The results of the measure at one of the set points is shown in Fig. 3.3-6.

The combustion characteristics of the low-Btu product gas resulting from operations at three of the set-points were evaluated in a specially-installed burner and furnace. Stable combustion was achieved with gases from all set-points. The $\mathrm{SO}_{2}$ and $\mathrm{NO}_{x}$ emissions were measured during the combustion tests; in addition, both thermal and fuel $\mathrm{NO}_{x}$ formations were determined.

A complete environmental characterization of the low-Btu product gas was made by using a specially designed sampling loop. These results indicate that the gas does not contain any significant quantity of tar and oils and both the gas-purification and waste-water treatments in a U-GAS plant could be handled by conventional technologies.

\section{3-3H. Pilot-Plant Tests with a French Coal}

A French Merlebach coal was successfully gasified in the U-GAS pilot plant during tests conducted for CdF. Two tests were conducted: The first test provided useful information on operational characteristics of the coal. The second test yielded a long steady-state operating period in which a11 of CdF's test objectives were achieved. These objectives were: demonstration of the operability of the U-GAS process with high-ash French coal, (ii) maximization of coal-conversion efficiency, (iji) production of good-quality product gas, and (iv) data for the design of a demonstration plant. 
In the second test, the plant was operated continuously for 92 hrs, when 48 tons of coal were gasified during $60 \mathrm{hrs}$ of steady-state operation. Ash-agglomerating and ash-balance operations were maintained during three different operating conditions. These involved (i) testing without recycle of fines from the secondary cyclone, (ii) testing with total recycle of fines, and ( $i i j)$ testirig with a lower steam-to-coal ratio. A coal-conversion efficiency higher than $95 \%$ was continuously maintained during the last two tests.

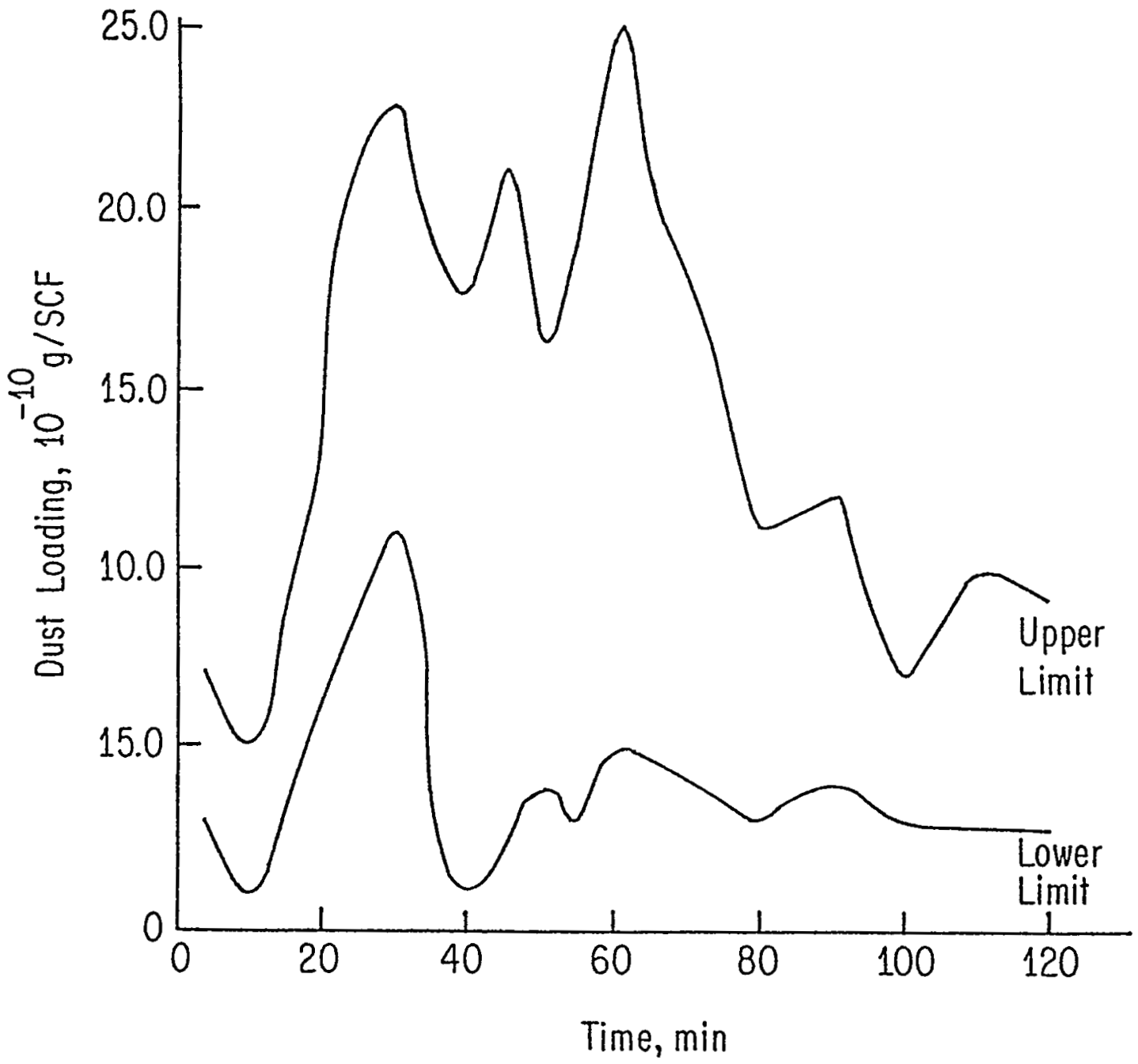

Fig. 3.3-6. Dust loading in the filter exit gas for one of the set points. 
The gasifier was used to handle coals with ash contents from 20 to $35 \mathrm{wt} \%$. In addition, because the coal was unwashed, it contained a large quantity of shale, which was also handled by the gasifier without any detrimental operational effects. Once steady-state operation was achieved and ash agglomeration established, $96 \%$ of the ash discharged was withdrawn through the bottom venturi; the remaining $4 \%$ of ash was withdrawn through the overhead along with the fines. No ash buildup occurred in the fluidized bed, despite the uneven ash-feed rate to the gasifier.

The quality of the product gas in the U-GAS process is strongly influenced by the characteristics of the feed coal. Despite the combination of a high ash and a low volatile matter content with the Merlebach coal, the U-GAS pilot plant yielded a good-quality product gas with an HHV of about 215 Btu/SCF $\left(8600 \mathrm{kj} / \mathrm{m}^{3}\right)$. The pilot plant has relatively high heat losses compared to its coal-feed capacity. In addition, excessive cooling of the recycled fines occurs both in the primary water-jacketed cyclone and the first-stage quench. Our estimate is that a commercial gasifier with appropriately designed cyclones and experiencing lower heat loss per unit volume of product gas will produce a gas with a heating value from 250 to $270 \mathrm{Btu} / \mathrm{SCF}\left(10,000\right.$ to $\left.10,800 \mathrm{kj} / \mathrm{m}^{3}\right)$. During the last set-point in the Merlebach coal test, it was demonstrated that the heating value of the product gas could be significantly improved by appropriate optimization of operating parameters. When generating synthesis gas from coal to produce chemicals, a more critical number than gas-heating value is the combined yield of $\mathrm{H}_{2}$ and $\mathrm{CO}$; any $\mathrm{CH}_{4}$ in the product gas is considered to be by-product. In the U-GAS pilot-plant test, the yield of $\mathrm{H}_{2}+\mathrm{CO}$ was up to 20 SCF/lb $\left(1.25 \mathrm{~m}^{3} / \mathrm{kg}\right)$ of MAF coal.

During the test (see Fig. 3.3-7), we demonstrated with the U-GAS process the ability for a total recycle of fines that is necessary to achieve high coal-conversion efficiency. The fines from the primary cyclone were recycled during the latter two set points only. Secondary fines recycle was shown to be easily initiated and controlled. The testing also demonstrated that occasional minor interruptions in the recycle of the secondary fines did not reduce gas production or cause operating upsets. In fact, the automatic oxygen/temperature controller employed by the U-GAS process promptiy responded to these interruptions and maintained the gasifier under stable operating conditions. Recycle of fines was maintained 
for more than 34 hrs and conclusively demonstrated that the fines could be gasified to extinction while the resultant fine ash was agglomerated and discharged along with the bed ash through the venturi, without buildup of fines or ash in the gasifier system.

The pilot-plant test showed that the ash from the Merlebach coal could be readily agglomerated in the U-GAS process. This was demonstrated by classification and withdrawal of only high ash-content material through the venturi.

\section{3-4. Other Gasifiers}

A comprehensive review of selected gasification systems and associated coals has been prepared for EPRI by Synthetic Fuels Associates. 6 We refer to this study and references cited therein for descriptions of the Lurgi Dry Ash, BGC/Lurgi, KilnGas, and other gasifiers. Descriptions of a number of currently active gasification technologies will be found in Chapter 4.

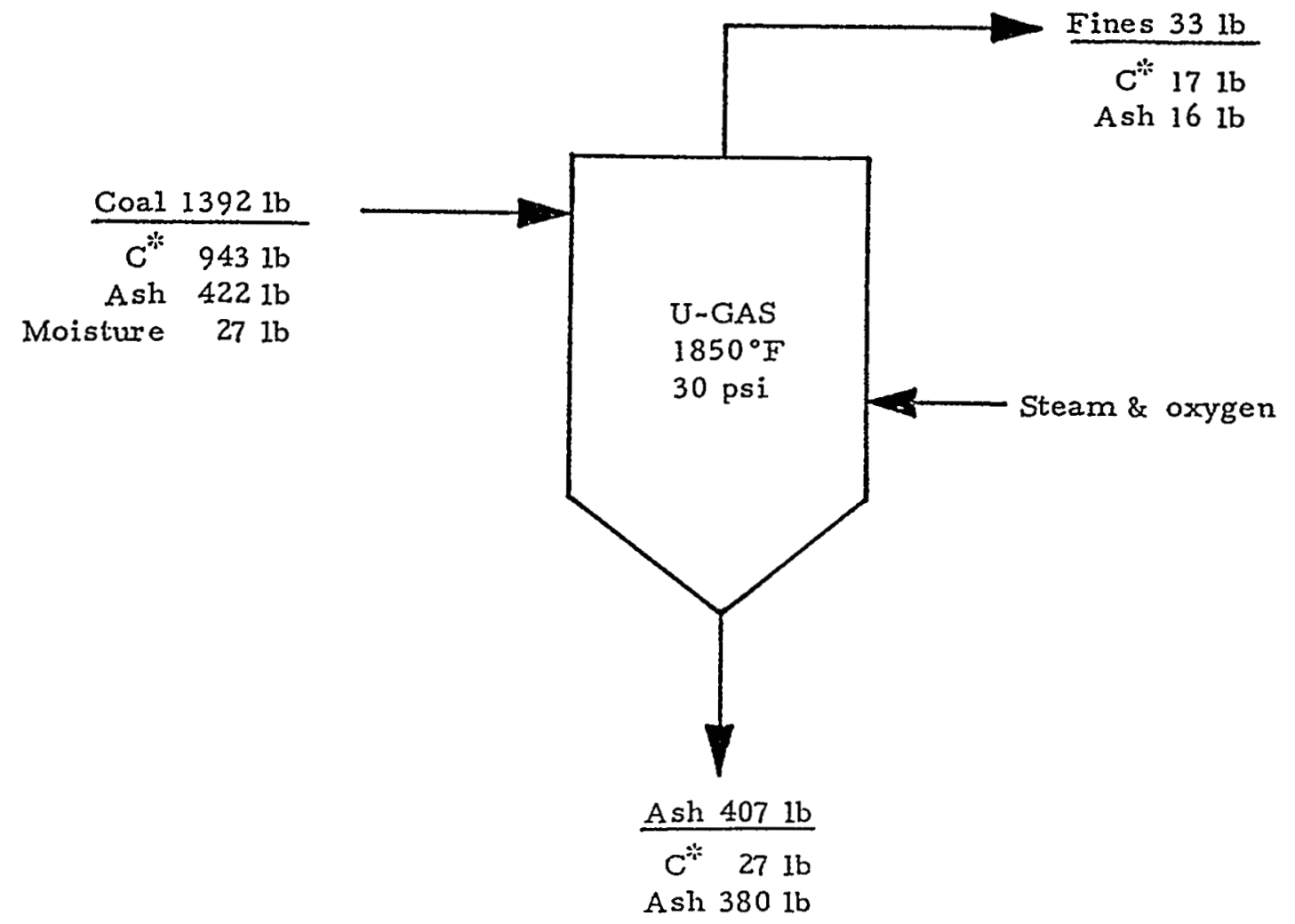

Fig. 3.3-7. Results of the test conducted with French coal in the U-GAS pilot plant; coal conversion $=95.38$; C* represents MAF-coal. 


\section{References for Section 3.3}

1. "Texaco Coal Gasification Process," Texaco Development Corporation, Montebe110, CA (1986).

2. W.G. Schlinger and G.N. Richter, Hydrocarbon Processing 59, 66 (1980).

3. W.G. Schlinger, J.H. Kolaian, M.E. Quintana, and T.G. Dorawala, Energy Progress $\underline{5}, 234$ (1985).

4. W.L. Heitz and M. Nager, "Status of the She77 Coal Gasification Process (SCGP)," Fifth Annual EPRI Contractors' Conference, Palo Alto, CA (October 30-31, 1985).

5. Electric Power Research Institute, "Evaluation of US Coal Performance in the She 11 Coal Gasification Process (SCGP), Report No. EPRI AP-2844, Palo Alto, CA (1984).

6. Electric Power Research Institute, "Coal Gasification Systems: A Guide to Status, Applications, and Economics," Report No. EPRI AP-3109, Palo Alto, CA (1983).

3.4

Research Recommendations for Improving Gasifiers

Primary motivations for supporting research are the needs for cost reduction and operating-life extensions of gasifiers.

There are two important identified research areas, the pursuit of which may lead to improved performance in the SCGP and TCGP. These are reduction or elimination of fouling ${ }^{1}$ and elimination of failure caused by high-temperature corrosion fatigue. ${ }^{2}$

\section{4-1. Fouling and Slagging}

According to the authors of Ref. 1, research on slagging is expected to lead to improved methods for predicting fouling in practical systems. At

* We are indepted for helpful comments to M. Nager and W. Schlinger in the preparation of this section. 
present, the methods used are largely empirical and based on static models, which do not correspond to actually existing conditions in combustors or gasifiers where many different sizes of pulverized coals are utilized. An improved ASME procedure is required to define slagging conditions for coals since the ash-fusion temperature has been shown to be an inadequate measure for slagging. The authors of Ref. 1 suggest the use of bench-scale experiments, with special emphasis on innovative approaches.

Research should include the following types of studies.

Predictions of the slag viscosity, especially under gasifier conditions. Slag viscosity is of critical importance in assuring that the slag is removed continuousiy from the gasification chamber. This problem is complicated by the fact that slags appear in homogeneous and multi-phase

systems. (ii) Phase diagrams incorporating new and existing empirical data, especially for binary, ternary and higher-order mixtures. To use the results properly, the equilibrium behavior of ash must be determined. This approach will also lead to improved understanding of wall-and tube-deposit formations. (iii) Many modern dynamic experiments are performed with large variations in conditions. Data from different experiments may be difficult to compare. Applications to practical systems present even greater challenges. Since experiments may be performed that represent reasonable simulations of actual combustion conditions, standardization of experimental test procedures would be desirable. (iv) The use of improved diagnostic techniques is recommended to verify or improve fundamental understanding of gasification rates and mechanisms and the best available modeling procedures. (v) Static experiments on bulk samples are attractive because of their relatively low costs and simplicity. If possible, static experiments should be devised that provide useful information on fouling and slagging.

\section{4-2. Corrosion and Fatigue}

Three research areas are suggested in Ref. 2: (i) Measurements of high-temperature, corrosion-fatigue data for alloys of commercial interest under accurately controlled and well-defined conditions. (ii) Information on the kinetics and mechanisms of corrosion-fatigue damage formation. (iii) An augmented model incorporating the results obtained under (i) and ( $i$ ) into design calculations. There has been special emphasis on the reducing 
conditions found in coal gasifiers, but other environments could be usefully employed to obtain data over wider ranges of conditions. Interesting temperature ranges $1 i e^{2}$ between 350 and $700^{\circ} \mathrm{C}$, while pressures fall in the 20-60 atm range.

New studies should be performed on the effects of cyclic loadings (50 to 5000 cycles) to identify the influence of cycling on failure rates.

\section{4-3. High-Temperature Sulfur Removal}

Application of a high-temperature sulfur-removal process will significantly improve the efficiency of an IGCC system and a DoE-supported program in this area is therefore recommended.

\section{4-4. Gasifiers for Low-Rank Coals}

Gasifiers for IGCC (cf. Sec. 3.3) have been extended to low-rank coals. EPRI has made a preliminary evaluation of this proposal for the Texaco gasifier using $\mathrm{CO}_{2}-1$ ignite slurries as gasifier feed. The Shell, Dow and other gasifiers have also been demonstrated as applicable to low rank coals.

\section{4-5. Low-Cost Gas Separation and Air Enrichment}

The Shell and Texaco gasifiers, as well as other gasifications systems, will benefit from lower costs if improved gas-separations with air-enrichment systems are developed. This important topic is addressed in Chapter 13.

\section{References for Section 3.4}

1. "Recommendations for Research Leading to New Bench-Scale Experiments for the Prediction of Slagging and Fouling Behavior," ASME Research Committee on Corrosion and Deposits from Combustion Gases (March 18, 1985).

2. W.T. Bakker, "Suggestions for Direction - Low Cycle Fatigue Program," Report of the Second Meeting of COGARN, pp. 212-215 (February 25, 1986), unpublished. 
CHAPTER 4:

COAL GASIFICATION FOR SNG PRODUCTION*

\subsection{Introduction}

\section{1-1. The Great Plains Coal Gasification Plant (GPCGP)}

In the early 1970s, when "Project Independence" was being defined by the Federal Government and serious concerns were being raised about the natural gas (NG) reserves and long-term supply of $N G$, there were more than 100 major projects under consideration that involved the production of substitute natural gas (SNG) from coal. These projects generally involved plants that would produce the equivalent of 250 million standard cubic feet of gas per day (SCF/d) with a heating value of 950-1000 Btu/SCF. Some of these plants were on a schedule that would have placed them on-stream in the mid- to late-1980s. However, the world energy picture changed dramatically and the requirement for producing pipeline-quality gas from coal moved further into the future. Now, SNG from coal is being considered as a potential pipeline-quality gas suppiy option for the post-2000 time frame.

As a result of changes in the energy market, only the GPCGP was constructed. This plant is located in Beulah, North Dakota, and was developed through the combined efforts of a consortium of natural gas companies and the Federal Government. Start-up operations began in 1984, with a nominal output of $125 \mathrm{million}$ SCF/d (at a $90 \%$ stream factor) of pipeline-quality gas. This plant uses North Dakota lignite as the feedstock and its operation is based on dry-bottom Lurgi gasification technology together with commercially available methanation, gas conditioning and clean-up technology.

*This chapter has been written by Kermit E. Woodcock and Vernon L. Hill of GRI. 
To date, the GPCGP is clearly a technical success. ${ }^{1}$ It was constructed within cost, completed on schedule and has involved only minimal problems during its initial period of operation. The plant was designed to produce $137.5 \times 10^{6} \mathrm{SCF} / \mathrm{d}$, but has operated consistently at levels exceeding the original design capacity. In March 1986, the plant production was as follows: highest daily rate $=154.7 \times 10^{6} \mathrm{SCF}(112.5 \%$ of design), highest weekly rate $=1.046310^{9}$ SCF ( $109 \%$ of design), highest monthly rate $=4.536$ $\times 10^{9} \mathrm{SCF}$ ( $106.4 \%$ of design).

In the current economic climate resulting from low world oil prices, the GPCGP is not economically competitive with other gas-supply options. However, the experience gained through the construction and operation of this plant is providing the gasification community with a bench mark of the real costs of SNG based on commercially available technology. In addition, it is helping to identify where process improvements can be effected through engineering changes or process selection and where supporting research and development efforts could have an impact.

\section{1-2. General Thermodynamic Considerations}

The atomic ratio of $H$ to $C$ in coals is less than one. As a result, in order to convert coal to pipeline-quality gas efficiently at an $\mathrm{H} / \mathrm{C}$ ratio of 4 , it is necessary to provide a source of $\mathrm{H}_{2}$. This is usually accomplished by the addition of steam. The overall reaction scheme for producing pipeline-quality gas from coal, with water as source of the: necessary hydrogen, represented by

$$
\mathrm{COal}+\mathrm{H}_{2} \mathrm{O} \longrightarrow \mathrm{CH}_{4}+\mathrm{CO}_{2} \text {. }
$$

In most gasification processes, however, this overall reaction is not, realized in a single step but is accomplished through a series of steps to provide reaction environments for which conversions proceed at acceptable rates. These steps are the unit operations of coal-gasification plarits. As reaction temperatures are raised to higher values (where gasification reactions proceed at adequate rates), the stability of $\mathrm{CH}_{4}$ (methane) is reduced and, at the higher temperatures such as those associated with entrained-flow 
gasifiers (i.e., $1250-1370^{\circ} \mathrm{C}$ ), there is no methane production in the gasifier. Typical off-gas compositions from fixed-bed, fluidized-bed and entrained-flow gasifiers are presented in Table 4.1-1, which show the ranges of methane production that can be expected. These data also provide an indication of the additional conversion to methane that must be accomplished in order to approach the overall reaction scheme represented by Eq. (4.1-1).

As the reaction temperature is raised, the reactions that dominate the gasification process include

$$
\begin{aligned}
& \mathrm{coal} \longrightarrow \mathrm{CH}_{4}+\text { char }+ \text { tars, oils, } \\
& \text { char }+\mathrm{H}_{2} \mathrm{O} \longrightarrow \mathrm{CO}+\mathrm{H}_{2}, \\
& \mathrm{char}+\mathrm{O}_{2} \longrightarrow \mathrm{CO}+\mathrm{H}_{2}, \\
& \mathrm{CO}+\mathrm{H}_{2} \mathrm{O} \leftrightharpoons \mathrm{CO}_{2}+\mathrm{H}_{2} \\
& \mathrm{CH}_{4}+\mathrm{H}_{2} \mathrm{O} \leftrightharpoons \mathrm{CO}+3 \mathrm{H}_{2} \\
& 2 \mathrm{CH}_{4}+\mathrm{O}_{2} \leftrightharpoons \mathrm{CO}+4 \mathrm{H}_{2} \\
& 2 \mathrm{CO} \leftrightharpoons \mathrm{CO}_{2}+\mathrm{C} .
\end{aligned}
$$

In addition to the principal reactions, which control the concentration of the major products of gasification, there occur also a series of reactions involving trace constituents in the coals, such as the nitrogen, sulfur and mineral matter, which result in the formation of additional gaseous species $\left(\mathrm{H}_{2} \mathrm{~S}, \mathrm{NH}_{3}\right.$, COS, mercaptans, sulfides, etc. $)$. The nature of these additional gaseous species depends on the gasifier conditions and coal type and must also be dealt with as part of a coal-to-SNG process.

When the gasification process is controlled by the types of reactions represented by Eqs. (4.1-2) through (4.1-8) and when SNG is the desired end product, additional processing steps are required to convert the $\mathrm{CO}$ and $\mathrm{H}_{2}$ produced in the gasifier to methane. The principal reactions to accomplish this conversion are (a) the water gas shift reaction (WGSR) of 
Eq. (4.1-5), which provides the desired initial $\mathrm{H}_{2} / \mathrm{CO}$ ratio and (b) a methanation reaction which may proceed according to the following steps:

Table 4.1-1. Commercial and developmental gasification processes, oxygenblown reactant consumption and gas production.

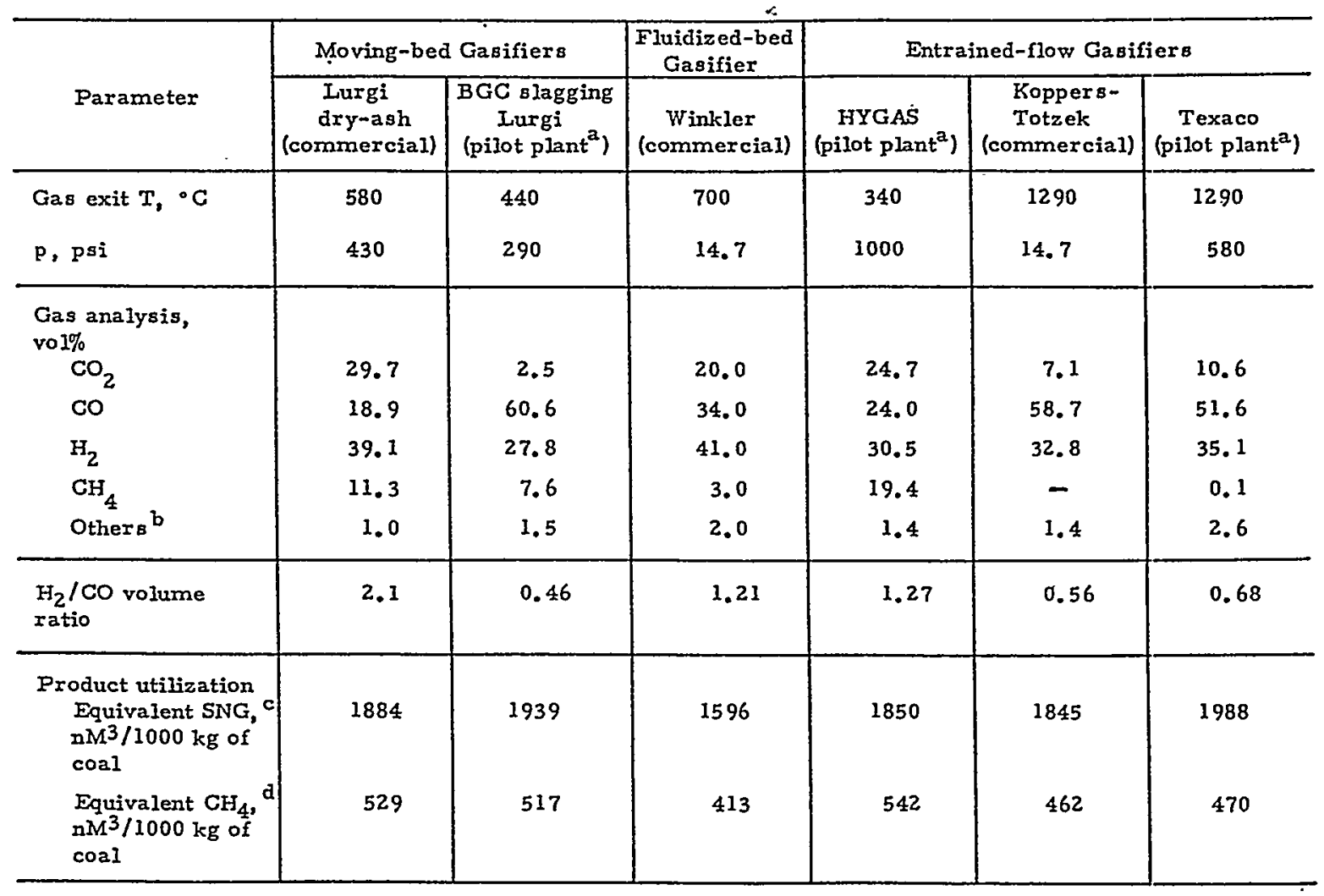

${ }^{a}$ Pilot plants are of various sizes: BGC/Lurgi, $1200 \mathrm{~kg} / \mathrm{h} ;$ HYGAS, $2500 \mathrm{~kg} / \mathrm{h}$; Texaco, $6500 \mathrm{~kg} / \mathrm{h}$.

${ }^{b}$ This value includes nitrogen and various impurities $\left(\mathrm{H}_{2} \mathrm{~S}, \mathrm{COS}, \mathrm{NH}_{3}\right.$, etc.).

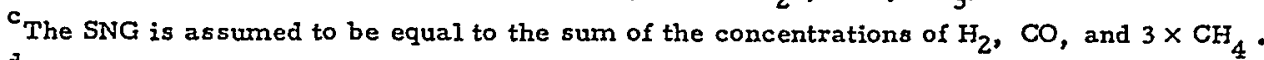

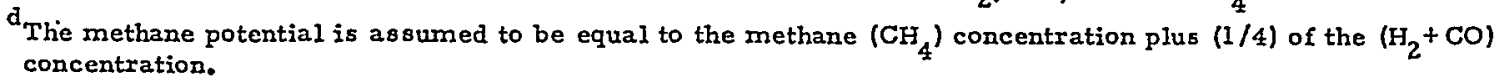

$$
\begin{aligned}
& \mathrm{CO}+3 \mathrm{H}_{2} \longrightarrow \mathrm{CH}_{4}+\mathrm{H}_{2} \mathrm{O}, \\
& 2 \mathrm{CO}+2 \mathrm{H}_{2} \longrightarrow \mathrm{CH}_{4}+\mathrm{CO}_{2}, \\
& \mathrm{CO}_{2}+4 \mathrm{H}_{2} \longrightarrow \mathrm{CH}_{4}+2 \mathrm{H}_{2} \mathrm{O},
\end{aligned}
$$

These reactions depend on the overall initial gas composition and the methanation catalyst used. 
Workers at Exxon, through the use of alkali metal or alkalineearth salts as gasification catalysts and an innovative concept, were able to provide a reaction environment in the gasifier such that all of the methane was formed in the gasifier itself and additional methanation steps were not required (compare Sec. 7.2). However, the methane was still oniy one constituent of a multi-component gas mixture, and separation and gas clean-up steps were required to develop a final product stream of pipeline-quality gas.

\section{1-3. General Flow Sheets}

Because of the heterogeneity of coal, the presence of heteroatoms and interactions of chemical kinetics and thermodynamics, the production of pipeline-quality gas from coal requires integration of many process steps, regardless of the type of gasifier employed. Typical block diagrams showing the number and sequence of major process steps needed for processes in which

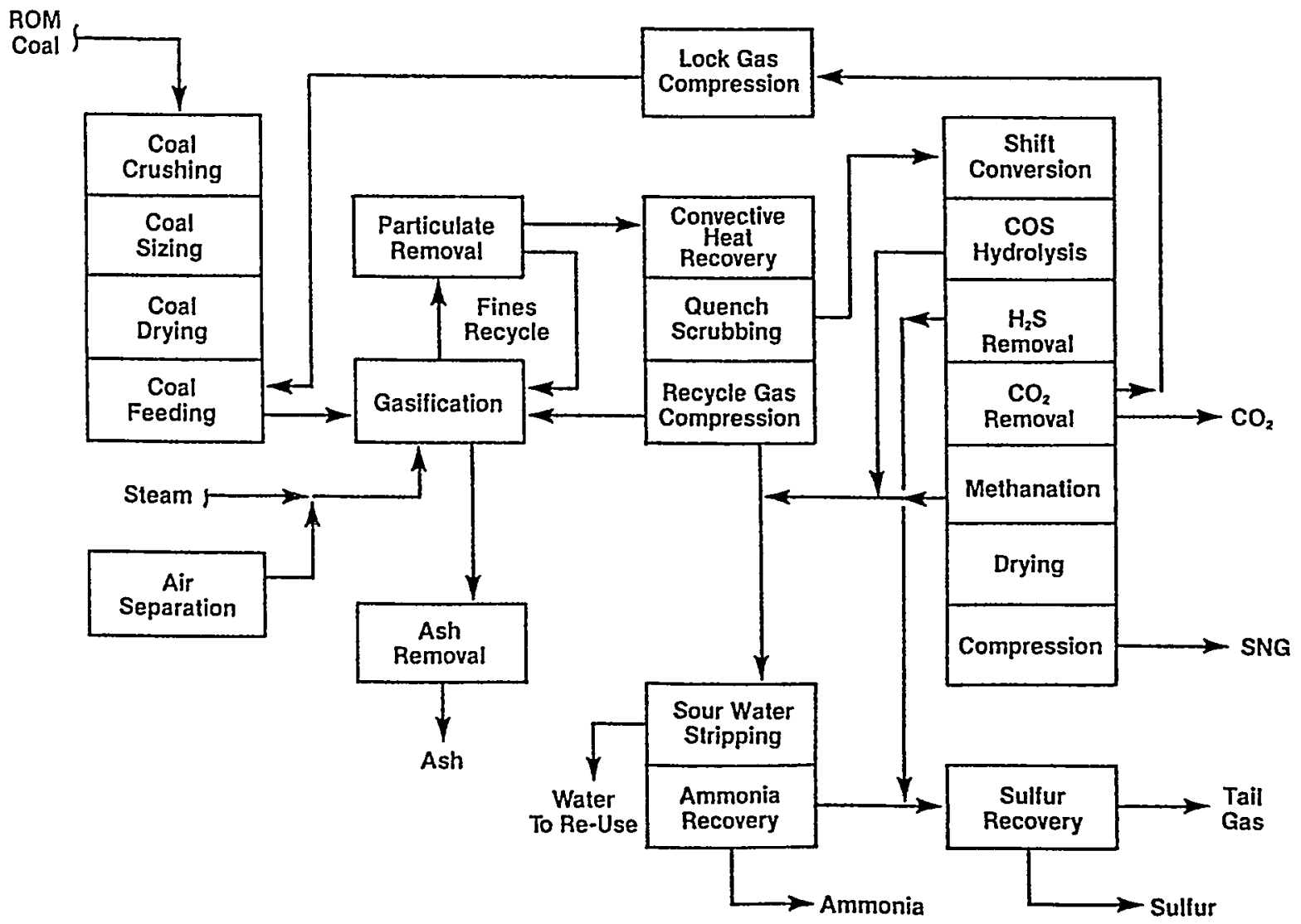

Fig. 4.1-1. Coal-to-SNG in the Kellogg-Rust-Westinghouse (KRW) gasification process. 


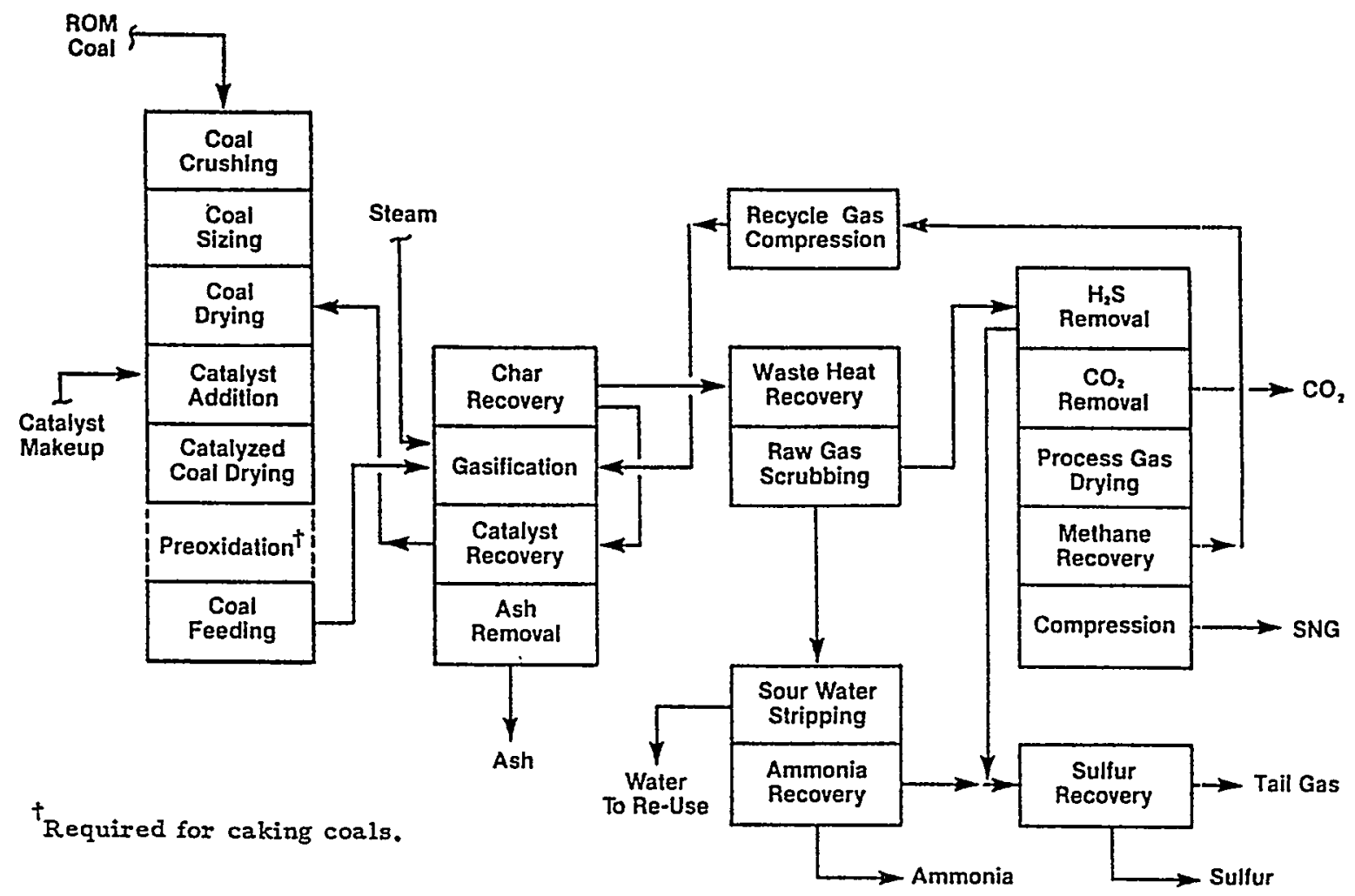

Fig. 4.1-2. Coal-to-SNG in the Exxon gasification process.

methanation is required downstream of the gasifier and where all methane formation is achieved in the gasifier, as in the KRW and Exxon catilytic processes, are shown in Figs. 4.1-1 and 4.1-2; the Exxon process is described in detail in Sec. 7.2.

These diagrams emphasize the importance of effective process integration and indicate that there are many opportunities where process improvements, achieved through continued research and development, can have a positive impact on process configurations, capital costs, operating costs and, ultimately, the end-product cost of pipeline-quality gas. While all process elements contribute to the final end-product cost of SNG from coal, the gasifier, methanation process and clean-up systems represent major determinants in other process requirements and overall process integration. 


\subsection{Advanced Gasification Technology for SNG}

The development of gasification technology to convert coal to SNG has been the subject for extensive research, developments and demonstration programs for at least three decades. In the US in the mid-1970s, over 20 conversion progresses were in various stages of development, and other approaches were being evaluated in Europe. These efforts encompassed exploratory projects, bench-scale studies, evaluations at the engineering-test unit (ETU) and process-development unit (PDU) scales, pilot-plant studies, and detailed design studies for demonstration plants and possible commerical operations. Process concepts that have been or are being evaluated include the following: Lurgi dry-botton (Lurgi GmbH), Bi-Gas (Bituminous Coal Research, Inc.) $\mathrm{CO}_{2}$-Acceptor (Conoco Coal Development Co.) Synthane (U.S. Bureau of Mines), HYGAS (Institute of Gas Technology), COGAS (FMC Corporation), High Mass Flux (Be1l Aerospace), Flash Hydropyrolysis (Rockwell International), Exxon Catalytic (Exxon Research and Engineering), Winkler (Rheinsiche Braunkohlenwerke AGR), U-GAS (Institute of Gas Technology), KRW Ash-Agglomerating (Westinghouse/KRW Energy), Hydrane (U.S. Bureau of Mines), Slagging-Fixed-Bed (British Gas Corporation/Lurgi GmbH), Fluid-bed Hydrogasification (Rheinische Braunkohlenwerke AGR), Ruhr-100 (Ruhrgas/Lurgi GmbH).

Each of these processes was conceived in an effort to improve the commercially available technology with respect to process efficiency, feedstock utilization and flexibility or to reduce the potential for unfavorable environmental interactions with the recognition that improved technology would translate into lower end-product gas costs. As the R\&D program progressed and data became available for use in comparative economic evaluations, work was discontinued on most of these approaches when it was shown that sufficient economic incentives could not be identified to justify continued R\&D expenditures. Today, as a result of the available data bases and the supporting economic studies, development work is still proceeding on the ash-agglomerating, fluid-bed technology (U-GAS, KRW Ash Agglomerating-process), the British Gas/Lurgi slagging gasifier, and the Rheinbraun direct, fluid-bed hydrogasification process for SNG production because of the unique characteristics of the available cost resource base and the advanced stage of the R\&D program. 
Other than the fluid-bed hydrogasification technology, continued gasifer development work is being justified primarily because of process flexibility and the potential for applications in areas other than SNG production (e.g., IGCC for electric power generation).

A brief summary of the technologies still under development, which can be applied to coal-to-SNG processes, is given in the following subsections, except for the U-GAS process which is described in detail in Section 3.3-3.

\section{2-1. BGC/Lurgi Slagging Gasifier}

The BGC/Lurgi slagging gasifier is a fixed-bed gasifier (Fig. 4.2-1) and consists of a vertical cylindrical reactor into which coal is injected through a lockhopper and a rotating coal distributor. The coal moves slowly down the reactor in contact with gases passing countercurrently through the bed. A mixture of steam and oxygen is injected at the bottom of the bed through nozzles (tuyeres). The base of the coal bed is called the raceway and is the location where high temperatures cause the ash to melt, yielding a fluid slag which drains from the hearth through a centrally-placed slag tap. The slag is quenched in a chamber filled with water to form a glass frit and is subsequently removed via a slag lockhopper.

The predominant reaction in the raceway is combustion of devolatilized coal, yielding a product stream of hot gases that contain steam and carbon oxides. As this gas moves up through the fixed bed, carbon is rapidly gasified by steam and carbon dioxide. Since these reactions are highly endothermic, the temperature drops rapidiy, effectively limiting the very high temperature slag liberation zone to a small area. The small slag liberation zone is beneficial in reducing the heat transfer to the coal resulting in progressively lower temperatures, eventually reducing reaction rates to the point where gasification reactions effectively stop. Above this zone, rapid heating of the fresh coal results only in drying and devolatilization reactions. These reactions yield tars and oils, significant amounts of methane, sulfur compounds, steam, and other minor products, which are carried out of the gasifier by the product gas. The $\mathrm{BGC/Lurgi}$ slagging gasifier offers potential advantages over the dry-bottom 
Lurgi technology since it can accommodate caking coals more effectively, utilizes coal fines, and has lower oxygen and steam requirements.

4.2-2. KRW (Kellogg-Rust-Westinghouse) Ash-Agglomerating, Fluidized Bed Gasifier

The KRW (Kellogg-Rust-Westinghouse) process is a fluid-gasifier (Fig. 4.2-2) in which coal and recycled fines are reacted with steam and oxygen to form a synthesis gas consisting mainly of $\mathrm{CO}, \mathrm{CO}_{2}, \mathrm{H}_{2}, \mathrm{CH}_{4}$, and steam. The process development unit (PDU) gasifier is a vertical, refractory-lined vessel operable up to $230 \mathrm{psig}$ and $1000^{\circ} \mathrm{C}$ and consisting of four sections: the freeboard, gasifier bed, combustion zone, and char-ash separator.

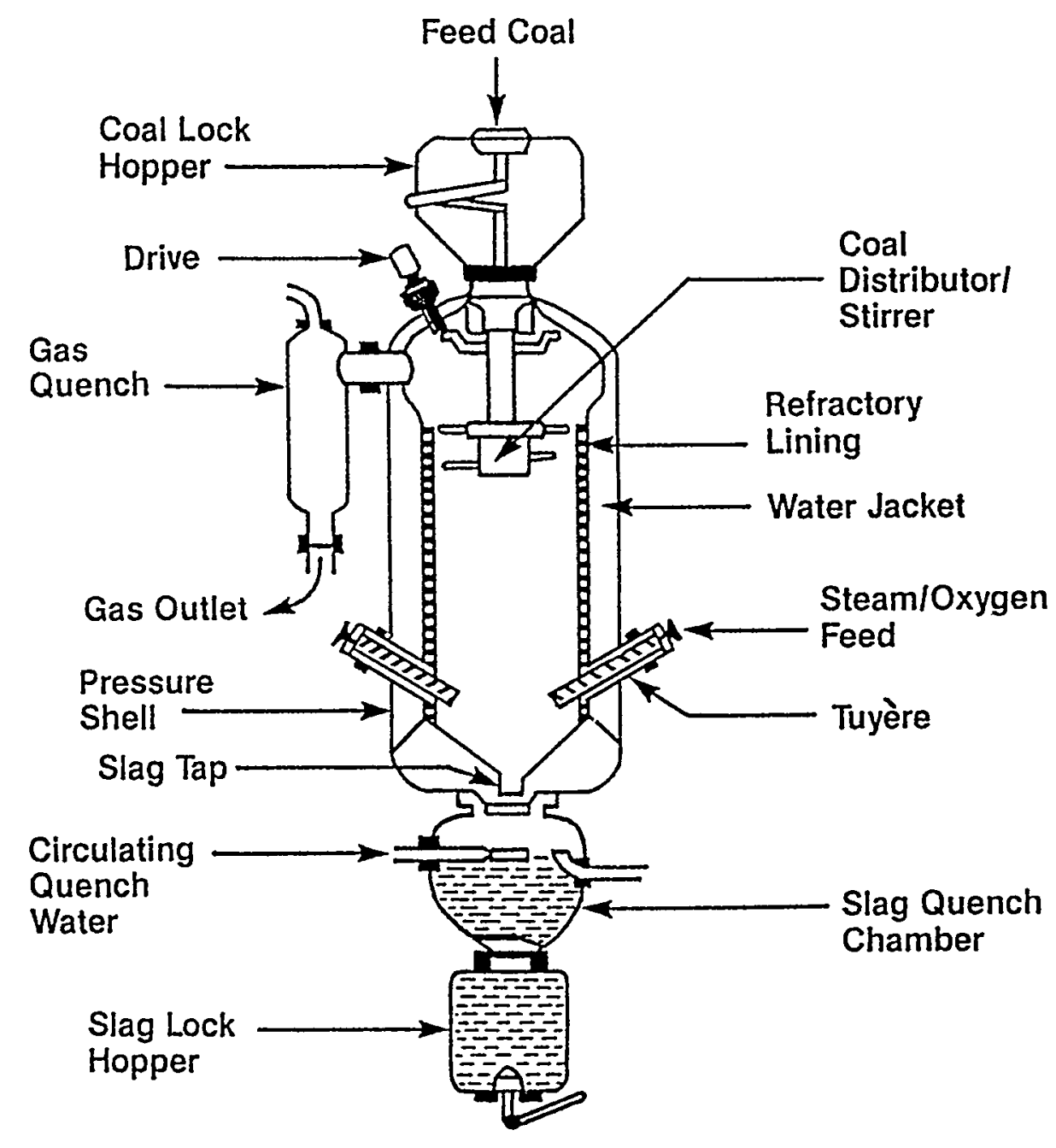

Fig. 4.2-1. The BGC/Lurgi slagging gasifier. 
Raw coal, ground to $3 / 16^{\prime \prime} \times 0^{\prime \prime}$ (and dried to $5 \%$ surface moisture when necessary), is fed pneumatically to the gasifier through a lackhopper system, along with the char fines from cyclones downstream of the gasifier. Feeding is accomplished by means of star wheel feeders and recycle gas. The coal and char are fed to the gasifier along its center line and combusted in a stream of oxidant (oxygen or air) fed through a coaxial feed tube. When oxygen is employed, steam is used together with the oxidant as the gasifying medium.

There are several other key flows into the gasifier, as shown in Fig. 4.2-2. A flow of steam is provided by annular flow around the nozzle tip to prevent carbon deposition at the base of the jet. Additional recycle gas or steam is injected radially at a location near the middle section of the injection nozzle. This flow mildly fluidizes and cools the ash for withdrawal; the sharp temperature gradient at the char/ash interface is utilized to control withdrawal rate. Recycle gas is also injected through a sparger ring at the base of the ash bed to aid in ash withdrawal.

The coal, char and steam reactions in the gasifier form hydrogen, carbon oxides and residual steam as the product gas. The carbon in the char is consumed by combustion and gasification as the bed of char circulates through the jet. The temperature near the bottom of the bed is maintained high enough to ensure that the ash-rich particles resulting from reactions soften, agglomerate and defluidize. The agglomerates migrate to the annulus around the feed tube and are continuously removed by a rotary feeder to lockhoppers. The major portion of the gasifier operates in an essentially isothermal condition up to $1,000^{\circ} \mathrm{C}$. The lower portion of the annulus operates at about $260^{\circ} \mathrm{C}$. Carbon conversion is typicaliy $90-95 \%$ on an overall basis, while the ash is concentrated to $85 \%$ in the agglomerates.

The raw product gas containing no tars or oils passes from the gasifier to two refractory-lined cyclones in series, where the char particles are removed. The fines collected in the cyclones are cooled, inserted into a recycle gas stream and reinjected into the gasifier, either with the coal feed or separately into the lower section of the bed. The product gas is then quenched, cooled and scrubbed of any remaining fines (usually 1\%) before further processing and recycling. Experiments at the PDU scale have demonstrated that high conversion efficiencies can be achieved 
with a wide variety of feedstocks, including both caking and non-caking coals, and that coal fines can be effectively consumed in the gasifier.

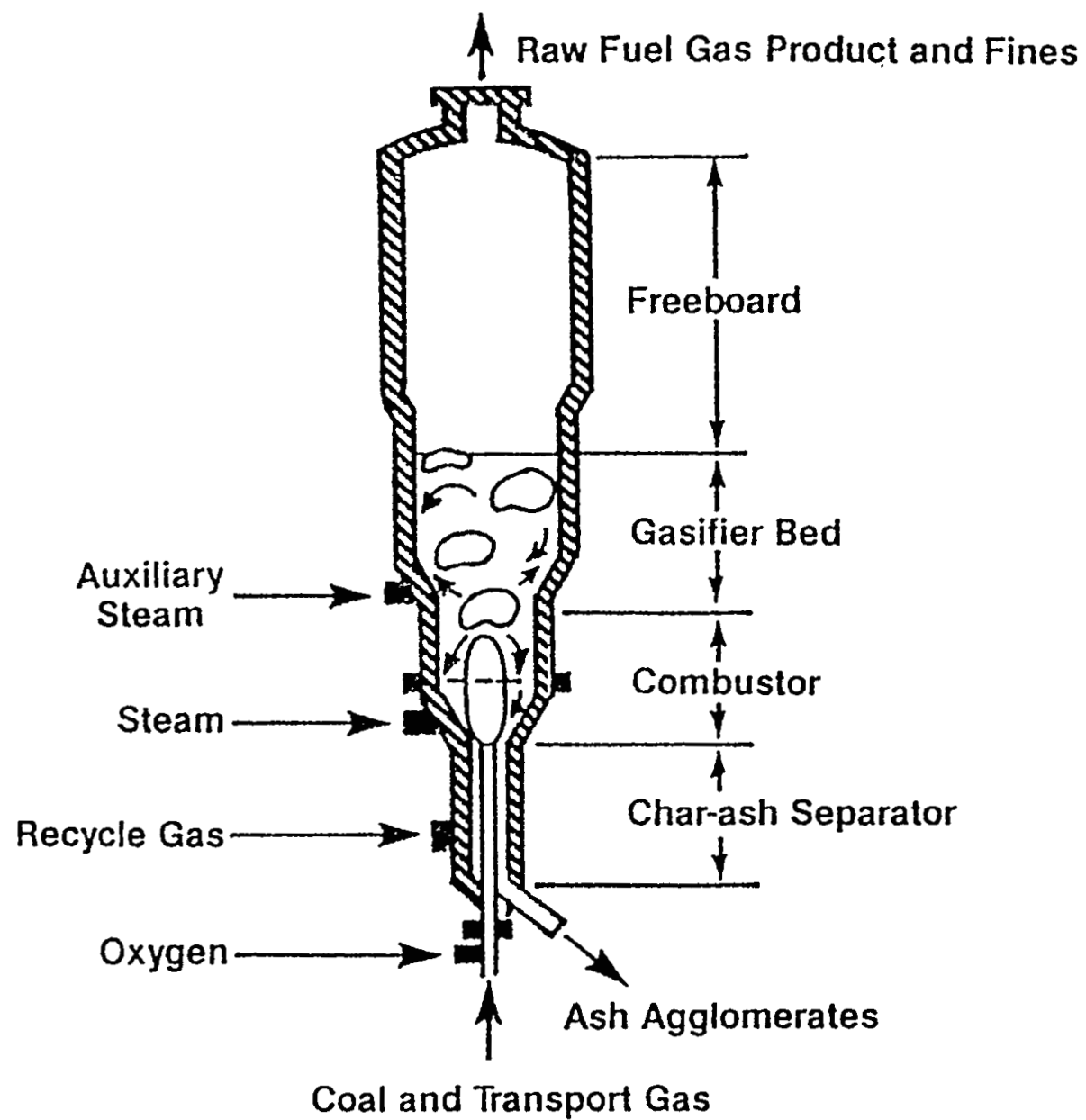

Fig. 4.2-2. Functional schematic of the Westinghouse gasifier.

\section{2-3. Rheinbraun $A G$, Hydrogasification}

Rheinbraun $A G$ has been proceeding ${ }^{2}$ with the development and evaluation of a process to produce SNG through the direct reaction of hydrogen and coal via the overall reaction

$$
\operatorname{coal}+\mathrm{H}_{2} \longrightarrow \mathrm{CH}_{4}+\text { char. }
$$


The overall process under consideration will utilize two fluid-bed reactors. In the upper bed, hydrogen is used as the fluidizing agent for the primary coal feedstock. The resulting product gas is a mixture of $\mathrm{CH}_{4}, \mathrm{H}_{2}, \mathrm{CO}$, and $\mathrm{CO}_{2}$, along with $\mathrm{H}_{2} \mathrm{~S}$ and $\mathrm{NH}_{3}$, that must subsequently undergo clean-up, separation and upgrading steps to achieve the final SNG product stream. The residual hydrogen fraction of the stream is separated cryogenically and recycled to the reactor.

A schematic diagram of the pilot plant used to develop data for the hydrogasification reactor is shown in Fig. 4.2-3. Table 4.2-1 presents operating data from the hydrogasification pilot plant for the relatively reactive Rhenish brown coal and also for West German anthracite.

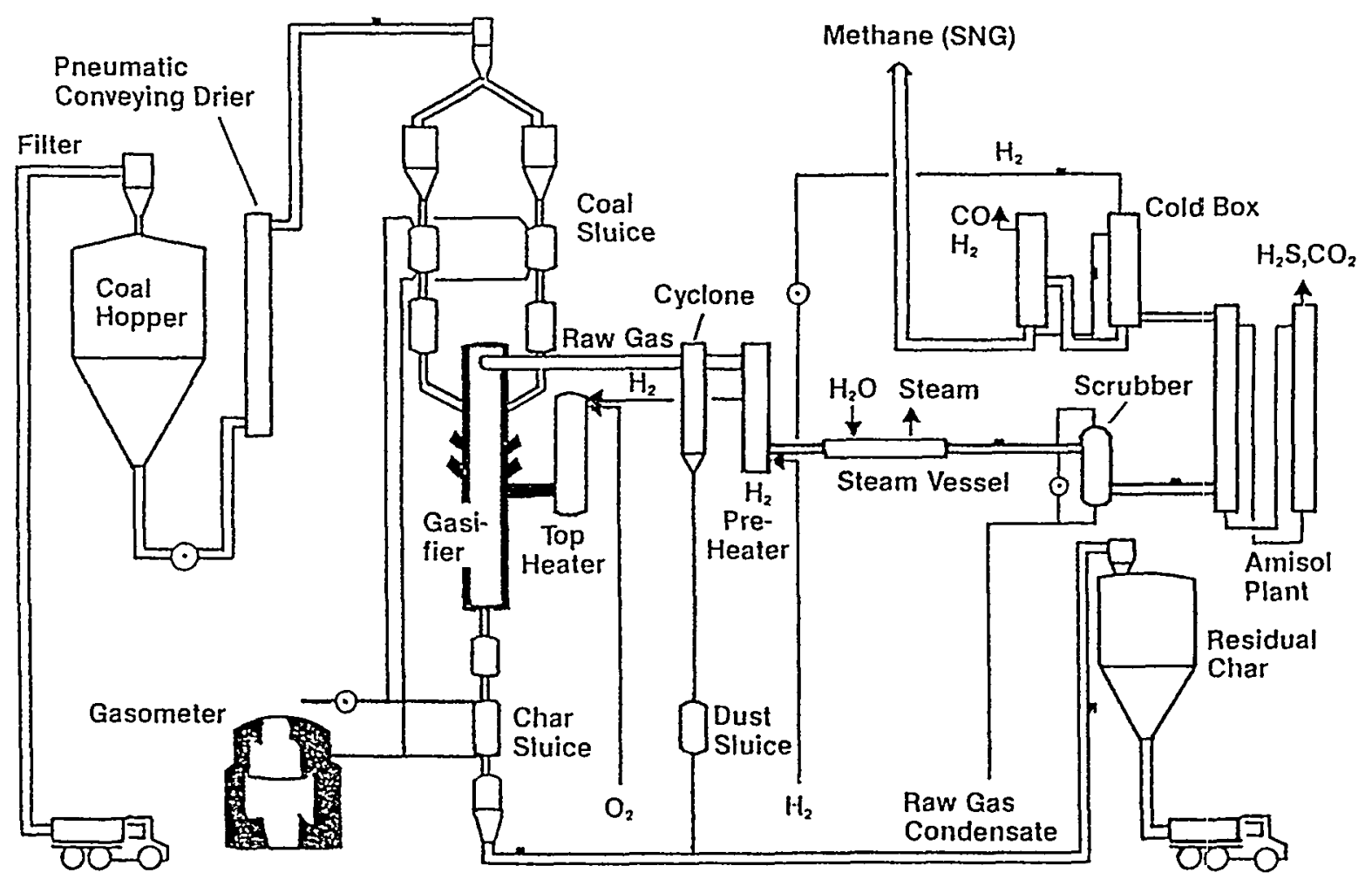

Fig. 4.2-3. Pilot plant for hydrogasification of coal (Rheinbraun AG); gasification pressure: up to 1750 psi; coal throughput: up to $9.6 \mathrm{dried}$ tons $/ \mathrm{hr}$; gasification temperature: up to $950^{\circ} \mathrm{C}$; gas production: up to $7800 \mathrm{~m}^{3}$ (i. N.) $\mathrm{CH}_{4} / \mathrm{hr}$. 
Table 4.2-1. Operating data of the semi-technical pilot plant for hydrogasification of coal at Rheinbraun AG.

\begin{tabular}{l|c|c}
\hline \multirow{2}{*}{ Parameter } & \multicolumn{2}{c}{$1976-1982$} \\
\cline { 2 - 3 } & Rhenish Brown Coal & Anthracite \\
\hline Coal throughput, maf & 1782 tons & 13.6 tons \\
Special coal throughput, maf & max. $700 \mathrm{lb} / \mathrm{hr}$ & max. $350 \mathrm{lb} / \mathrm{hr}$ \\
Methane content of crude gas & up to $48 \mathrm{vol} \%$ & up to $25 \mathrm{vol} \%$ \\
Degree of C-gasification & up to $82 \%$ & up to $47 \%$ \\
Operating temperature & $800-1000^{\circ} \mathrm{C}$ & $940-960^{\circ} \mathrm{C}$ \\
Operating pressure & $800-1375 \mathrm{psi}$ & $1150-1250 \mathrm{psi}$ \\
Solids residence time & $9-80 \mathrm{~min}$ & $28-38 \mathrm{~min}$ \\
\hline Plant in operation \\
with coal throughput
\end{tabular}

The hydrogen required for hydrogasification is produced in the lower fluid-bed. Residual char from the hydrogasification stage is reacted with steam and oxygen to generate SNG that can be shifted to provide the necessary concentrations of hydrogen. The basis for the char gasifier is the high-temperature Winkler process, a pressurized, fluid-bed gasifier that is also being developed by Rheinbraun. The high-temperature Winkler is an extension of earlier, atmospheric pressure, fluid-bed gasifier technology and is designed to provide for higher temperature and higher pressure operation. The higher temperature lowers the make of liquid byproduct and increase carbon utilization. Higher pressures increase the gasifier throughput.

The high-temperature Winkler technology has been demonstrated in a nominal 45 TPD pilot plant at pressures to approximately $130 \mathrm{psi}$ and temperatures to approximately $1100^{\circ} \mathrm{C}$. All types of coal have been processed and it has been demonstrated that the addition of limestone to the fluid-bed can significantly reduce the $\mathrm{H}_{2} \mathrm{~S}$ content of the raw gas. 


\section{2-4. Catalytic Coal Gasification}

Exxon Research and Development has conducted an engineering development program through the PDU stage (1-ton/day) to evaluate the potential for using coal gasification catalysts and a unique process flow sheet to produce SNG from coal in a fluid-bed reactor, without the use of an oxygen plant or a separate methanation step. The catalyst, together with the process concept, led to the direct formation of methane in the gasifier according to the overall reaction

$$
\operatorname{coal}+\mathrm{H}_{2} \mathrm{O} \longrightarrow \mathrm{CH}_{4}+\mathrm{CO}_{2} \text {. }
$$

This technology, which is specifically focused on the production of SNG from coal is discussed in Sec. 7.2.

\subsection{Catalytic Methanation}

Catalytic methanation has been studied extensively since 1902, when Sabatier and Senderens published their classical paper on $\mathrm{Ni}$ catalysts. $^{3}$ Many catalysts were subsequently tried. By 1925, many effective metal catalysts had been identified. ${ }^{4}$ An excellent description of commercial processes is given in Ref. 5 . Although this subject is considered in Chapter 7 , we shall discuss it here from a somewhat different perspective because of its potential importance for SNG production.

\section{3-1. Chemistry and Thermodynamics}

Catalytic methanation involves the exothermic formation of $\mathrm{CH}_{4}$, usually starting with a mixture of $\mathrm{H}_{2}$ and $\mathrm{CO}$, although methanation can also be achieved with mixtures of $\mathrm{H}_{2}$ and $\mathrm{CO}_{2}$. Methane is formed in many coal gasifiers, with the lower temperature gasifiers producing relatively more $\mathrm{CH}_{4}$. Thus, some amount of $\mathrm{CH}_{4}$ may be present in the feed gas to the catalytic reactor. Steam is usually present or is added to the feed to avoid carbon deposition. The heat release depends on the amount of $c 0$ present in the feed gas: for each $1 \%$ of $\mathrm{CO}$, an adiabatic reaction will experience a $60^{\circ} \mathrm{C}$ temperature rise. 
The pertinent reactions are 4,5 :

$$
\begin{aligned}
& 3 \mathrm{H}_{2}+\mathrm{CO} \rightleftharpoons \mathrm{CH}_{4}+\mathrm{H}_{2} \mathrm{O} \text {, } \\
& 2 \mathrm{H}_{2}+2 \mathrm{CO} \rightleftharpoons \mathrm{CH}_{4}+\mathrm{CO}_{2} \text {, } \\
& 4 \mathrm{H}_{2}+\mathrm{CO}_{2} \rightleftharpoons \mathrm{CH}_{4}+2 \mathrm{H}_{2} \mathrm{O} \text {, } \\
& \mathrm{2} \mathrm{CO} \quad \rightleftharpoons \quad \mathrm{C}+\mathrm{CO}_{2}, \\
& \mathrm{CO}+\mathrm{H}_{2} \mathrm{O} \quad \rightleftharpoons \quad \mathrm{CO}_{2}+\mathrm{H}_{2} \text {. }
\end{aligned}
$$

If methanation begins with a mixture of $\mathrm{H}_{2}$ and $\mathrm{CO}$ and nickel-based catalysts are used, the desired $\mathrm{H}_{2} / \mathrm{CO}$ ratio of the feed gas is $3: 1$ [reaction $(4.3-1)]$. When catalysts such as GRI's sulfur-tolerant, direct methanation catalyst are used, the desired initial $\mathrm{H}_{2} / \mathrm{CO}$ ratio is 1 and $\mathrm{Eq} .(4.3-2)$ forms the basis for the methanation reaction.

Other methane-producing processes include the hydrocracking of higher hydrocarbons, typified by

$$
\mathrm{C}_{2} \mathrm{H}_{6}+\mathrm{H}_{2} \longrightarrow 2 \mathrm{CH}_{4} \text {. }
$$

Vaiues of $\Delta H_{R}^{\circ}$ and $\Delta G_{R}^{\circ}$ for reactions (4.3-1) through (4.3-5) are given in Table 4.3-1 for temperatures between 27 and $727^{\circ} \mathrm{C}$. These data show that all reactions are exothermic, with all but the shift reaction (4.3-5) being strongly exothermic. Furthermore, the free-energy values in Table 4.3-1 show that lower temperatures favor methane production; thus, there must be effective heat-removal methods. At temperatures below $\sim 425^{\circ} \mathrm{C}$, the methane yield is not notably affected by pressure.

Carbon deposition, which leads to catalyst fouling, can be encountered under certain operation conditions. These conditions are highly dependent on initial gas composition, catalyst properties, temperature, and pressure. Experience with sulfur-tolerant, direct methanation catalysts has shown that $\mathrm{H}_{2} / \mathrm{CO}$ ratios as 1 ow as 0.1 can be processed without carbon deposition. With catalysts that accomplish methanation through the overall 
reaction represented by $\mathrm{Eq} .(4.3-1)$ and for which feed gas $\mathrm{H}_{2} / \mathrm{CO}$ ratios of 3 are desired, carbon deposition occurs more readily and much larger regions of temperature and $\mathrm{H}_{2} / \mathrm{CO}$ ratios must be avoided, as is shown in Fig. $4.3-1$.

\section{3-2. Catalysts}

In order of activity, the most important metal catalysts are $\mathrm{Ru}>\mathrm{Ni}>\mathrm{Co}>\mathrm{Fe}>\mathrm{Mo}^{4}{ }^{4} \mathrm{Nickel}$ is the most commonly used catalyst in commercial processes because of its relatively low cost. Despite the excellent catalytic performance of Ru, its high cost has precluded its widespread use. The activity of $\mathrm{Ni}$ is generally second to that of $\mathrm{Ru}$, but it is far cheaper and has therefore become the most-used catalyst in commercial methanation processes. ${ }^{4,5}$ Nearly all commercially available methanation catalysts are rapidly poisoned by S-containing compounds and it is necessary to reduce the concentration of sulfur species in the inlet gas to less than $0.5 \mathrm{ppm}$ in order to maintain adequate catalyst activity for long periods of time. The sulfur-tolerant methanation catalysts currently under development do not have a similar requirement for low concentrations of sulfur species in the feed streams and thus afford the opportunity to make major changes in the process elements and their integration in downstream processing trains.

The catalyst base used and the composition of the $\mathrm{Ni}$-based alloy are important. Investigators developing $\mathrm{Ni}$-based catalysts have tried to find materials that yield optimum performance in terms of high Co-conversion, low $C$ deposition, high methane selectively, and yield. Other desirable properties are long, stable catalyst life, ability to accept feeds with low $\mathrm{H}_{2} / \mathrm{CO}$ ratios, and high space velocities over a range of temperatures and/or pressures. A summary of the many different $\mathrm{Ni}$-based catalysts is given in Table 5 of Ref. 4.

Cobalt has also been found to be quite active as a metharlation catalyst. 6,7 However, compared to $\mathrm{Ni}$, Co suffers more severe carbon deposition, 6 requires higher temperatures for similar co conversions, 7 and is less methane-selective. 6,7

Iron-catalyzed methanation has been described in two papers. ${ }^{8,9}$ The long-term effectiveness of this catalyst was 1 imited by $C$ deposition. Because $\mathrm{Fe}$ has very poor methane selectivity, even at high $\mathrm{H}_{2} / \mathrm{CO}$ ratios, ${ }^{8}{ }^{\text {it }}$ is considered to be more suitable for Fischer-Tropsch syntheses than for 
Table 4.3-1. Heats of reaction and free energies of reaction for reactions $(4.3-1)$ through (4.3-5); reproduced from Ref. 4.

\begin{tabular}{|c|c|c|c|c|c|}
\hline \multirow{2}{*}{$\begin{array}{c}\text { Temperature, } \\
{ }^{\circ} \mathrm{C}\end{array}$} & \multicolumn{5}{|c|}{ Reaction } \\
\hline & $(4.3-1)$ & $(4.3-2)$ & $(4.3-3)$ & $(4.3-4)$ & $(4,3-5)$ \\
\hline & \multicolumn{5}{|c|}{ Heat of Reaction, $\Delta \mathrm{H}_{\mathrm{R}}^{\circ}$, kcal/mole } \\
\hline 27 & -49.298 & -59.136 & -39.460 & -41.227 & -9.838 \\
\hline 127 & -50.360 & -60.070 & -40.650 & -41.434 & -9.710 \\
\hline 227 & $-51,297$ & -60.815 & -41.779 & -41.499 & -9.518 \\
\hline 327 & -52.084 & -61.376 & -42.792 & $-41,460$ & -9.292 \\
\hline 427 & -52.730 & -61.780 & -43.680 & -41.350 & -9.050 \\
\hline 527 & -53.248 & -62.047 & -44.449 & -41.190 & -8.799 \\
\hline 627 & -53.654 & -62.203 & -45.105 & -40.996 & -8.549 \\
\hline \multirow[t]{2}{*}{727} & -53.957 & -62.261 & -45.653 & -40.729 & -8.304 \\
\hline & \multicolumn{5}{|c|}{ Free Energy of Reaction, $\Delta G_{R}^{0}$, kcal/mole } \\
\hline 27 & -33.904 & -40.731 & -27.077 & -28.621 & -6.827 \\
\hline 127 & -28.610 & -34.451 & -22.769 & -24.385 & -5.841 \\
\hline 227 & -23.062 & -27.956 & -18.168 & -20.111 & -4.894 \\
\hline 327 & -17.338 & -21.329 & -13.347 & -15.836 & -3.991 \\
\hline 427 & -11.493 & -14.620 & -8.366 & -11.574 & -3.127 \\
\hline 527 & -5.567 & -7.865 & -3.269 & -7.332 & -2.298 \\
\hline 627 & +0.594 & -1.079 & +1.921 & -3.108 & -1.500 \\
\hline 727 & +6.444 & +5.715 & +7.173 & +1.090 & -0.729 \\
\hline
\end{tabular}

Fig. 4.3-1. The effects of synthesis gas ratio and pressure on carbon deposition. Carbon deposition may occur for conditions below the curves.

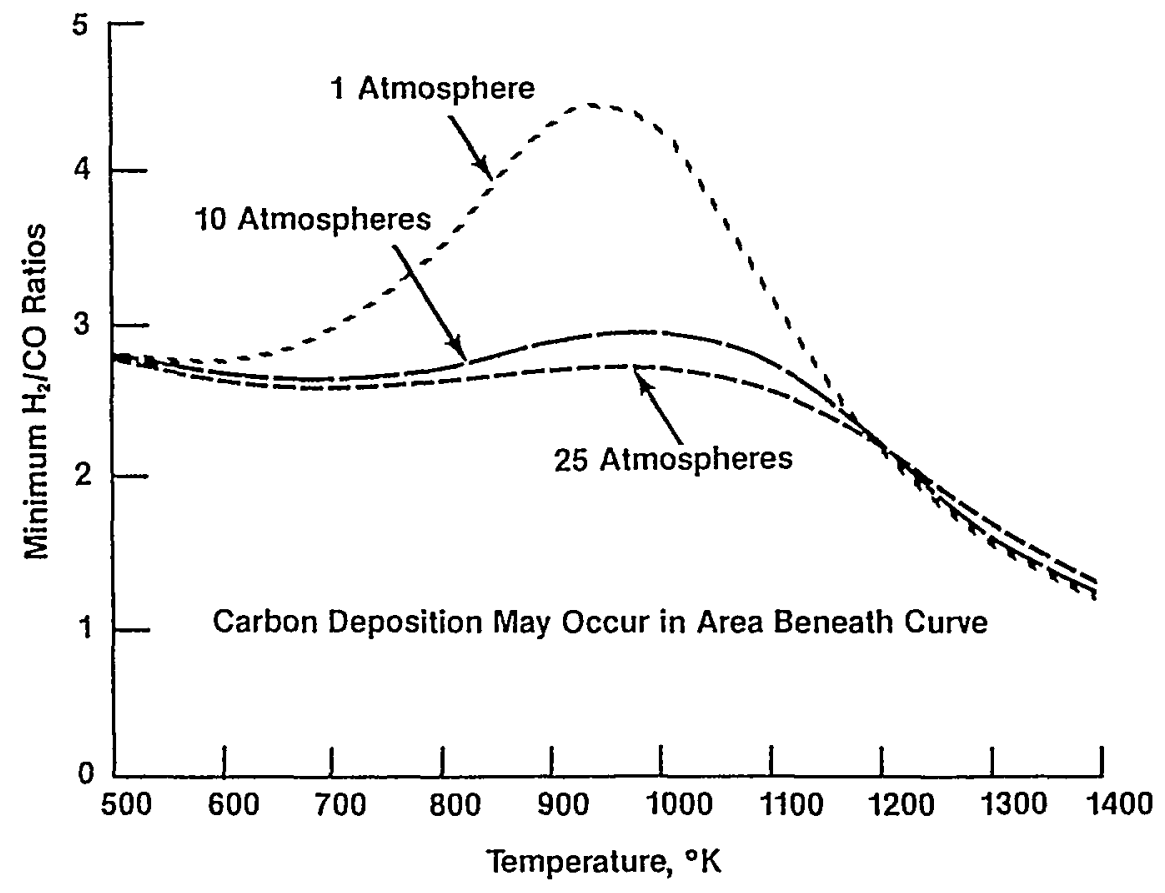


methanation catalysis. Typical yields consisted of $20 \%$ methane and $80 \%$ Fischer-Tropsch products when 1:1 synthesis gas was used. ${ }^{8}$

Molybdenum and $W$ have only moderate activity and require high temperatures for methanation. ${ }^{10,11}$ The motivation for examining these catalysts is their high resistance to sulfur poisoning. 10,12

Noble metals have also been studied for applications in catalytic methanation. ${ }^{10}$ Their activities are generally quite low, but Pd, Rh, Os, and Re have the advantage of being highly methane-selective.

\section{3-3. Commercial Processes}

Methanation systems are used commercially to remove small amounts of $\mathrm{CO}$ and $\mathrm{CO}_{2}$ because these oxides are catalyst-poisons for many chemical manufacturing systems. An example of a commercial system for which this removal is necessary is found in ammonia $\hat{p} l$ ants where the methanation systems serve as gas purifiers. As a result, input $\mathrm{CO}$ and $\mathrm{CO}_{2}$ concentrations to the ammonia synthesis reactors are usually less than $1 \% .^{5}$

When scaling up this technology to the methanation systems required in a coal-gasification plant producing SNG, consideration must be given to a number of potential problem areas. The SNG systems will be much larger and will be required to handle input gases with much higher $\mathrm{CO}$ concentrations. Because of the high heat release associated with high $\mathrm{co}$ input-gas concentrations, adequate heat removal must be incorporated into the reactor design. Sulfur poisoning, catalyst deactivation by high temperature sintering of $\mathrm{Ni}$ catalysts or by $\mathrm{C}$ deposition must also be addressed.

Nickel-based catalysts are currently used in the fixed-bed methanators at the GPCGP. The feed gases are preprocessed by acid-gas removal-systems to reduce the sulfur content to acceptable levels (less than $1 \mathrm{ppm}$ ) before they enter the methanation units.

The status of recent advanced methanation technology development activities is summarized in the following sections.

\section{3-4. Direct Methanation}


Since 1978, GRI has funded the development of the direct methanation process because of the potential for improving the coal-to-SNG economics. ${ }^{13}$ Process development has included catalyst development, catalyst evaluation, evaluation of materials of construction, and preliminary assessment of process economics. Direct methanation is a process based on a catalyst that methanates equi-molar concentrations of $\mathrm{H}_{2}$ and $\mathrm{CO}$, producing $\mathrm{CO}_{2}$ rather than steam as a product via the reaction

$$
2 \mathrm{H}_{2}+2 \mathrm{CO} \quad \rightleftharpoons \quad \mathrm{CH}_{4}+\mathrm{CO}_{2} \text {. }
$$

Accordingly, the process has no requirement for steam, either to shift the gas to an $\mathrm{H}_{2} / \mathrm{CO}$ ratio of 3 or to prevent caking, as is required for $\mathrm{Ni}$-based catalysts. Sulfur removal is not required prior to methanation since the catalyst is not poisoned by any sulfur compounds present in coai-derived gas. As a result, the process can be used to treat the raw, quenched gas from a coal gasifier with little or no pretreatment. This procedure allows use of the acid-gas removal-system to treat a reduced volume of the acid-gas stream to remove $\mathrm{H}_{2} \mathrm{~S}$ and $\mathrm{CO}_{2}$. Polishing methanation may be required to bring the gas to US pipeline standards.

To date, more than 800 catalyst formulations have been tested, resulting in several compositions that have promise for application in the direct methanation process. Carbon formations have not been observed, even with $\mathrm{H}_{2}$ /CO ratios as low as 0.1 in a dry gas stream.

GRI catalysts promote the methanation reaction at temperatures from 260 to $650^{\circ} \mathrm{C}$, pressures from atmospheric to $1000 \mathrm{psig}$, feed gas $\mathrm{H}_{2} / \mathrm{CO}$ molar ratios from 3 to less than 0.4 , steam concentrations from 0 to $15 \mathrm{mo} 1 \%$, and in the presence of up to $1 \mathrm{mo} 1 \%$ of sulfur. Carbon formation was not detected under any of these conditions. HC additions of up to 2 mol\% $\mathrm{C}_{6} \mathrm{H}_{6}, 0.05 \mathrm{mo} \% \mathrm{C}_{6} \mathrm{H}_{5} \mathrm{OH}$, and $0.3 \mathrm{mo} 1 \% \mathrm{HN}_{3}$ also did not poison or foul the catalyst. Limited reforming tests have indicated that the catalysts can yield a single-pass conversion of almost $25 \%$ of $22 \mathrm{ppm} \mathrm{H}_{2} \mathrm{~S}$-containing $\mathrm{NG}$ at $870^{\circ} \mathrm{C}$.

Catalyst samples have been exposed to a Lurgi-type raw gas for $2300 \mathrm{hr}$ (Fig. 4.3-2) under controlled conditions with maintenance of activity, as well as for $10,000 \mathrm{hr}$ under a variety of test conditions. Based on these tests, a minimum of a 1-yr catalyst life has been projected for commercial application. 
Table 4.3-2 lists the ranges of operating conditions over which the catalyst has been tested. The pressure range is typical of anticipated operating conditions downstream of a coal-gasification plant. The catalyst can be operated up to $660^{\circ} \mathrm{C}$, which is indicated by the upper limit of the temperature range studied. The experiments were conducted using gases which reflect (a) anticipated raw gas compositions and $\mathrm{H}_{2} / \mathrm{CO}$ ratios for a variety of coal-gasification processes and (b) gas compositions anticipated at the outlet of a number of direct-methanation reactors operating in series. The catalyst has been tested for heavy HC and sulfur concentrations in the range of 50 to $1350 \mathrm{ppm}$. The catalyst has al so been operated over a wide range of space velocities and feed-gas water concentrations to obtain a range of $\mathrm{CO}$ conversions and $\mathrm{CH}_{4}$ selectivities.

The results of laboratory experiments to determine the canversion characteristics of a GRI direct-methanation catalyst, under conditions simulating the first stage of a methanation process, are presented in Fig. 4.3-3. These data show the effect of temperature and space velocity on CO conversion and provide a basis for developing process-flow sheets that can be integrated into conceptual designs of coal-to-SNG plants.

Workers at Haldor Topsoe, Inc., have been evaluating S-tolerant catalysts for converting $\mathrm{CO} / \mathrm{H}_{2}$ mixtures to methane. 14 They have demonstrated that the catalyst can also be an effective shift catalyst and,

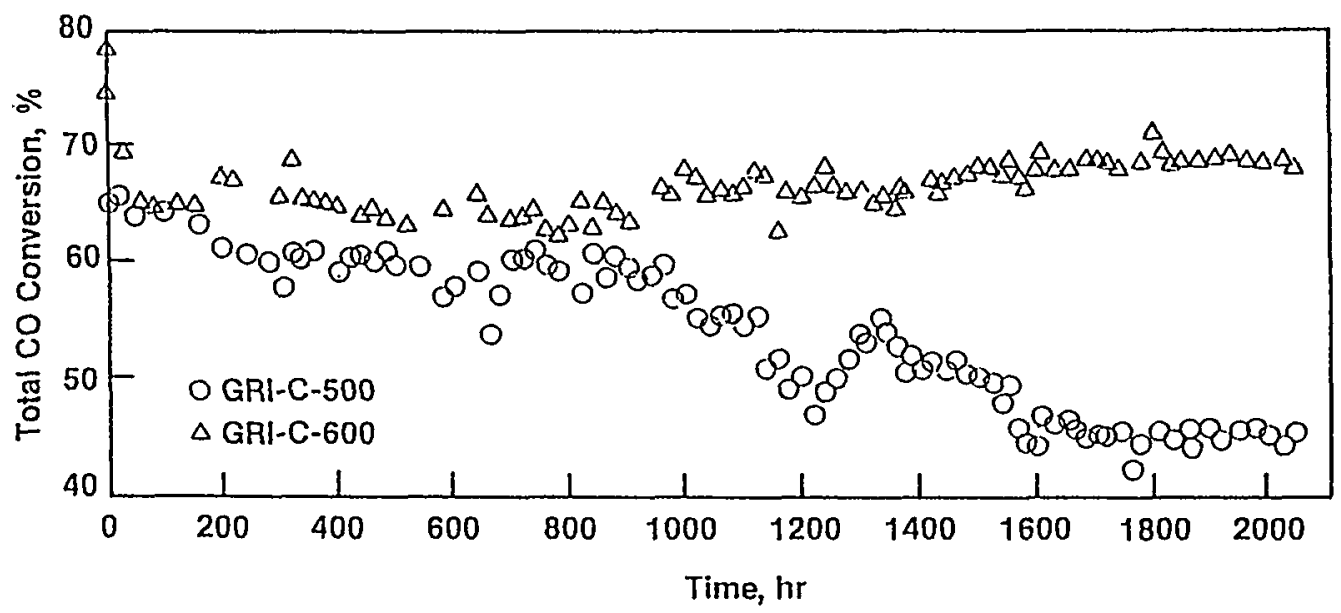

\begin{tabular}{l|r}
\multicolumn{2}{c}{ Lurgi Feed } \\
\hline Species & mol\% \\
\hline $\mathrm{CO}$ & 16.75 \\
$\mathrm{CO}_{2}$ & 28.35 \\
$\mathrm{H}_{2}$ & 39.70 \\
$\mathrm{CH}_{4}$ & 12.20 \\
$\mathrm{C}_{2} \mathrm{H}_{6}$ & 0.47 \\
$\mathrm{C}_{2} \mathrm{H}_{4}$ & 0.28 \\
$\mathrm{C}_{3} \mathrm{H}_{6}$ & $29 \mathrm{ppm}$ \\
$\mathrm{C}_{4} \mathrm{H}_{10}$ & $4 \mathrm{ppm}$ \\
$\mathrm{H}_{2} \mathrm{~S}$ & 0.51 \\
$\mathrm{COS}^{\mathrm{S}}$ & $249 \mathrm{ppm}$ \\
$\mathrm{CS}_{2}$ & $1 \mathrm{ppm}$ \\
$\mathrm{CH}_{3} \mathrm{SH}$ & $1 \mathrm{ppm}$ \\
$\mathrm{C}_{4} \mathrm{H}{ }_{4} \mathrm{~S}$ & $2 \mathrm{ppm}$ \\
$\mathrm{N}_{2}$ & 1.49 \\
$\mathrm{H}_{2} \mathrm{O}$ & 0.22 \\
\hline Total & 100.00 \\
\hline
\end{tabular}

. Fig. 4.3-2. Life-test data of the GRI-C-500 and GRI-C-600 catalysts using a dry-bottom Lurgi-type raw gas (450 psig, $6000 \mathrm{SCF} / \mathrm{hr}-\mathrm{ft}^{3}$, 930 to $980^{\circ} \mathrm{F}, 10 \mathrm{~g}$ of -12 to +20 mesh catalyst). 
Table 4.3-2. GRI tests on direct methanation-catalysts.

\begin{tabular}{|c|c|}
\hline \multicolumn{2}{|c|}{$\begin{array}{l}\text { Reactor conditions: } \mathrm{p}=50-1000 \text { psig, outlet } \mathrm{T}=400-680^{\circ} \mathrm{C} \text {. } \\
\text { Types of feed gases simulated (gasification process/coal type): } \\
\text { BGC/II No. 6, KRW/Pittsburgh No. 8, KRW/Wyodak, Lurgi/ } \\
\text { North Dakota Lignite, Lurgi/Rosebud, Shell/Wyodak, UCG/Rosebud. }\end{array}$} \\
\hline \multicolumn{2}{|c|}{ Feed-gas compositions } \\
\hline Species & Vol\% \\
\hline $\mathrm{CO}$ & $4-42$ \\
\hline $\mathrm{CO}_{2}$ & $0-42$ \\
\hline $\mathrm{H}_{2}$ & $8-44$ \\
\hline $\mathrm{CH}_{4}$ & $6-30$ \\
\hline $\mathrm{C}_{2} \mathrm{H}_{6}$ & $0-0.7$ \\
\hline $\mathrm{C}_{2} \mathrm{H}_{4}$ & $0-0.7$ \\
\hline $\mathrm{C}_{3} \mathrm{H}_{8}$ & $0-0.2$ \\
\hline $\mathrm{C}_{4} \mathrm{H}_{10}$ & $0-90 \mathrm{ppm}$ \\
\hline $\mathrm{H}_{2} \mathrm{~S}$ & $0.05-3$ \\
\hline $\cos$ & $0-0.14$ \\
\hline $\mathrm{N}_{2}$ & $0.3-1.5$ \\
\hline $\mathrm{H}_{2} \mathrm{O}$ & $0-38$ \\
\hline $\mathrm{C}_{6} \mathrm{H}_{6}$ & $0-2.5$ \\
\hline $\mathrm{C}_{6} \mathrm{H}_{5} \mathrm{OH}$ & $0-0.06$ \\
\hline $\mathrm{NH}_{3}$ & $0-1$ \\
\hline Total S & $100 \mathrm{ppm}-3$ \\
\hline $\mathrm{H}_{2} / \mathrm{CO}$ ratio & 0.6 to 3 \\
\hline \multicolumn{2}{|c|}{ Space velocity $=500-25000 \mathrm{SCF} / \mathrm{ft}^{3}-\mathrm{hr}$} \\
\hline \multicolumn{2}{|c|}{$\begin{array}{l}\text { Results: } 18-86 \% \mathrm{CO} \text { conversion (defined as percentage of } \mathrm{CO} \text { in the } \\
\text { feed converted), } 21 \text { to } 100 \% \mathrm{CH}_{4} \text { selectivity (defined as the amount } \\
\text { of } \mathrm{CH}_{4} \text { produced as a percentage of the amount of } \mathrm{CO} \text { converted). }\end{array}$} \\
\hline
\end{tabular}

under some conditions, leads to the formation of other low molecular weight, saturated, $\mathrm{HCs}$ in addition to methane. The general physical characteristics of the catalysts are shown in Table 4.3-3 and the range of test conditions investigated using simulated raw gas is shown in Table 4.3-4.

In addition to laboratory experiments, a methanation PDU was constructed and operated on a slip-stream from an entrained-flow coal gasification PDU being evaluated by Mountain Fuel Resources. The entrained-flow gasification experiments involved five different coal feedstocks and provided different raw gas feed streams to the methanator. The results of these experiments are shown in Fig. 4.3-4 as relative 
catalyst activity vs time. The activity was calculated as the space velocity for $90 \%$ conversion based on the rate-limiting component (i.e., the minor component which is $\mathrm{H}_{2}$ for $\mathrm{CO} / \mathrm{H}_{2}>1$ and $\mathrm{CO}$ for $\mathrm{CO} / \mathrm{H}_{2}<1$ ). Data are also included from the laboratory experiments carried out with the catalyst prior to performing the integrated PDU tests.

A total of $1080 \mathrm{hr}$ of testing was completed with catalyst activity levels remaining high throughout the test. The type of coal appeared to have no effect the activity of the catalyst and the effects of variations in $\mathrm{H}_{2} \mathrm{~S}$ concentration were also sma11. There appeared to be no effect of $\mathrm{H}_{2} \mathrm{~S}$ on activity below a 0.07 vol\% concentration. The catalyst activity remained constant during a $100-h r$ test with the $\mathrm{H}_{2} \mathrm{~S}$ partial pressure as low as $1 \mathrm{ppm}$.

\section{3-5. Comflux Process (Fluid-Bed Methanation)}

The Comflux process is an Ni-catalysed, pressurized, fluid-bed process to convert CO-rich gasification gases into SNG in a single step. 15 This process performs both shift and methanation reactions simultaneously in a single reactor with complete CO conversion. The water formed in the methanation reaction is available for water-gas shift reaction. Thus, a gas with $\mathrm{H}_{2} / \mathrm{CO}<3$ can be methanated without adding steam.

A simplified process flow diagram for the Comflux process is shown in Fig. 4.3-5. The desulfurized feed gas is preheated by heat exchange with the product gas to the reaction-initiation temperature and then fed into the reactor. The gas fluidizes the catalyst, and both methanation and water-gas shift reactions take place simultaneously in the fluidized bed. The axial temperature gradient in the fluidized bed is extremely smal1, and the reactor is operated under high loads almost isothermally. Heated catalyst particles are cooled sufficiently fast by mixing with colder particles and by contact with integrated heat exchangers so that the high heat of the methanation reaction does not cause superheating of the bed. The product gas with less than 0.1 vol\% of $\mathrm{CO}$ is cooled and process water condensed. If the feed gas has $\mathrm{H}_{2} / \mathrm{CO}<3.0$, the $\mathrm{CO}_{2}$ formed with the reaction must be removed to meet pipeline-quality gas specifications. The resulting product gas is SNG with a heating value of 926-1016 BTU/SCF and chemical properties identical to $N G$. 
The Comflux process was evaluated initially in a $1.3 \mathrm{ft}$. diameter ETU and later at the pilot plant scale with a $3.3 \mathrm{ft}$. diameter reactor and SNG production up to $112,000 \mathrm{SCF} / \mathrm{hr}$. Performance data from these development programs are summarized in Table 4.3-5.

\section{3-6. $\quad$ HICOM}

HICOM methanation is a fixed-bed process and is being developed by the British Gas Corporation to accommodate the relatively low $\mathrm{H}_{2} / \mathrm{CO}$-ratio product-gases produced by gasifiers such as the BGC/Lurgi slagging gasifier, KRW (Fluidized bed), U-GAS (Fluidized bed), Shell (entrained-flow), and Texaco (entrained-flow). ${ }^{16}$ Typical off-gas compositions for these gasifiers and the dry-bottom Lurgi gasifier are shown in Table 4.3-6. The gases will also contain compounds of sulfur $\left(\mathrm{H}_{2} \mathrm{~S}, \mathrm{COS}\right.$, etc.) at levels dependent on the sulfur contents of the coals.

The HICOM process employs a series of methanation stages, each of which involves a fixed bed of catalyst; each is connected as shown in the simplified process flow diagram of Fig. 4.3-6. The principal method used to control the temperature rise in each stage is recycle of cooled, equilibrated product gas to dilute the feed gas. The amount of recycle gas is minimized by passing it through at least two stages, with fresh gas added to each stage (split-stream operation). Product gas from upstream stages (split-stream operation) also helps control the temperature rise in each subsequent reactor and high-grade heat is recovered immediately downstream of each reactor. The effect of using split-stream operation in order to

Table 4.3-3. Physical characteristics of the catalyst tested by Haldor Topsol, Inc.

\begin{tabular}{l|l}
\hline Name & SMC 324 \\
Size, I $\times \mathrm{D}$ & $4.5 \mathrm{~mm} \times 4.5 \mathrm{~mm}\left(0.18^{\prime \prime} \times 0.18^{\prime \prime}\right)$ \\
Density & $1.75 \mathrm{gm} / \mathrm{cm}^{3}(109 \mathrm{lb} / \mathrm{CF})$ \\
Bulk density & $1.275 \mathrm{~kg} / \ell(80 \mathrm{lb} / \mathrm{CF})$ \\
Surface area & $100 \mathrm{~m}^{2} / \mathrm{gr}$ \\
Crushing strength & $600 \mathrm{~kg} / \mathrm{cm}^{2}\left(8700 \mathrm{lb} / \mathrm{in}^{2}\right)$ \\
\hline
\end{tabular}



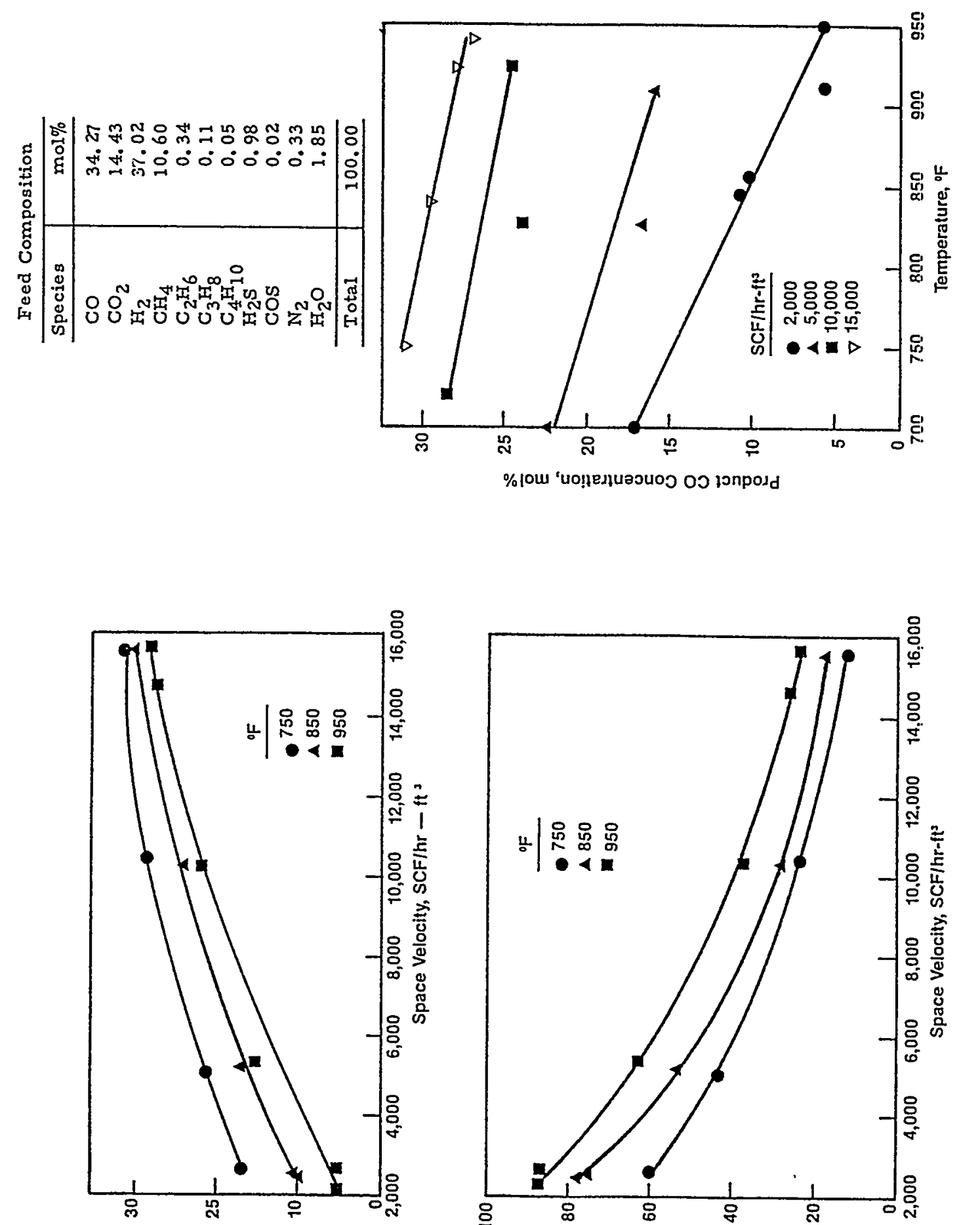

$\%$ lou 'uo!̣edjuəouos os jonposd

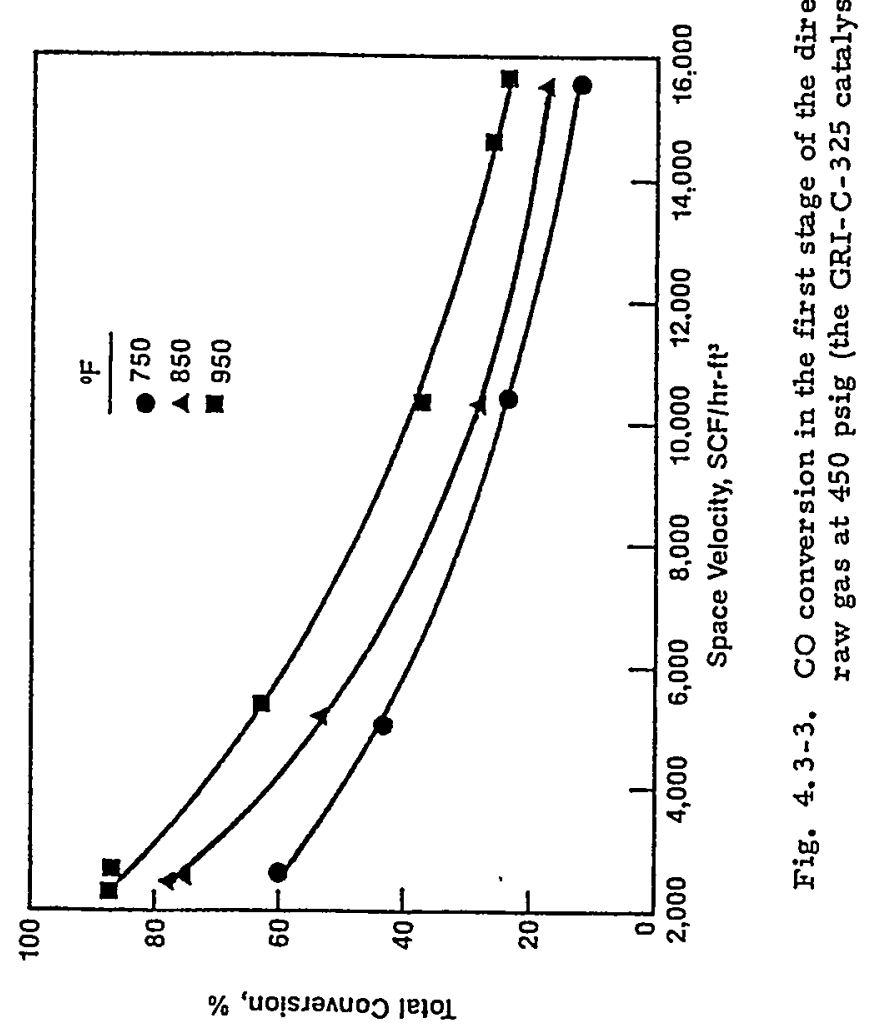


Table 4.3-4. Summary of direct methanation test conditions and resuits; concentrations are given in mol\%.

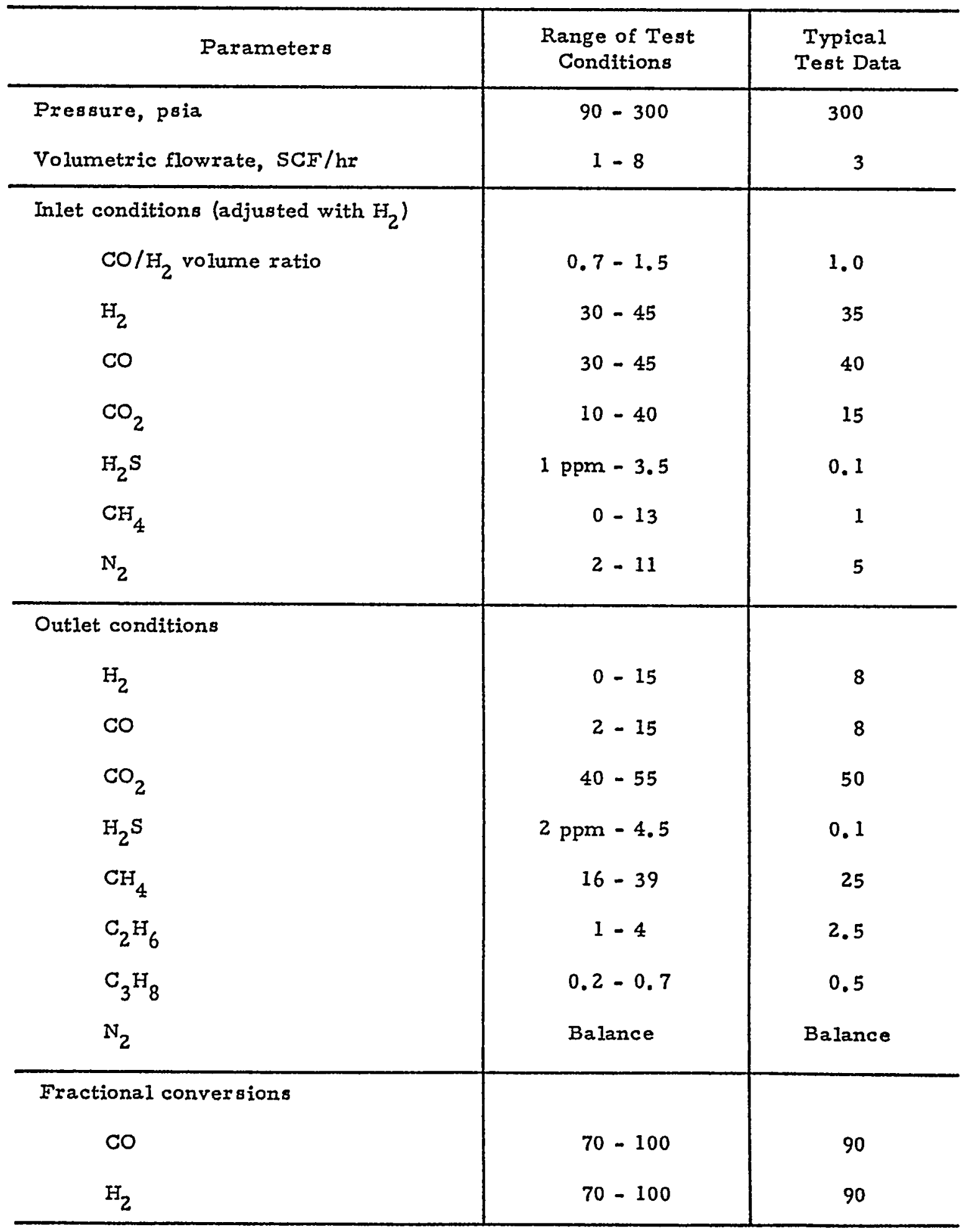




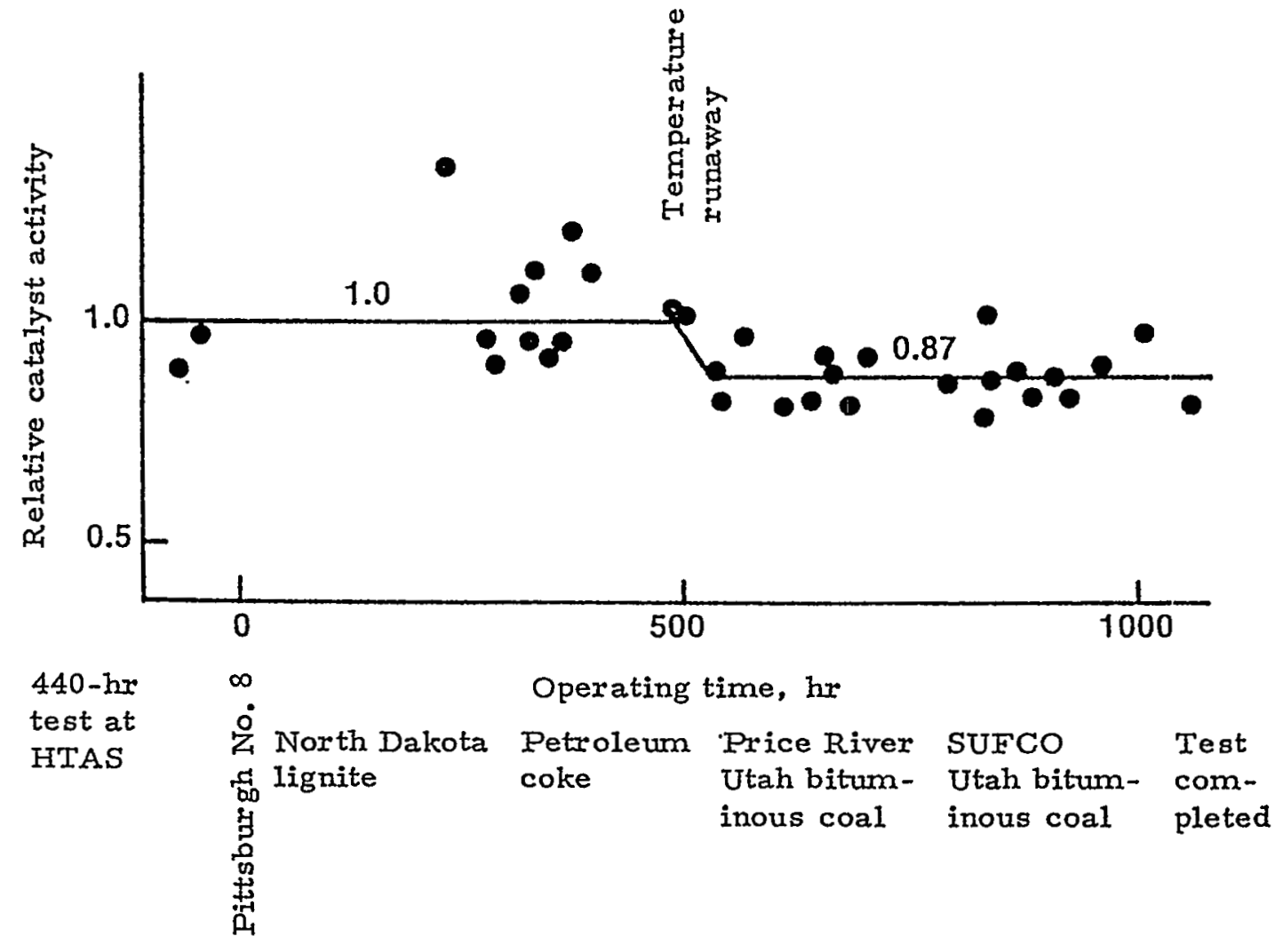

Fig. 4.3-4. Relative catalyst activity vs time in the methanation PDU at Mountain Fuel Resources.

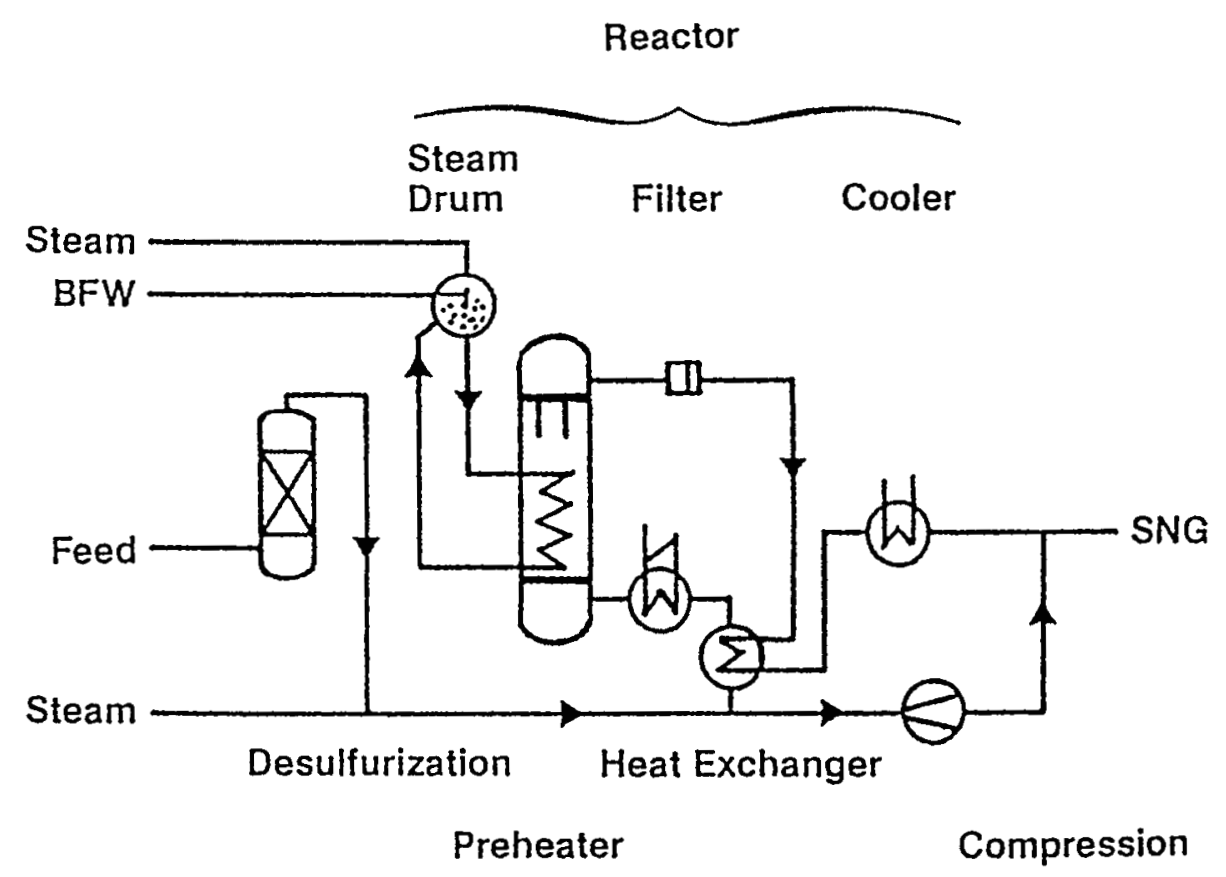

Fig. 4.3-5. Simplified process-flow diagram for the Comflux process. 
Table 4.3-5. Comflux methanation performance data for a semi-technical test plant.

A. Operating Conditions: output capacity $=3500-12300 \mathrm{ft}^{3} / \mathrm{hr}, \mathrm{p}=290-870 \mathrm{psi}$, $\mathrm{T}=400-500^{\circ} \mathrm{C}, \mathrm{H}_{2} / \mathrm{CO}$ volume ratio $=1.8-3$, recycle volumefeed ratio $=0-0.5$, gas velocity $=0.16-0.82 \mathrm{ft} / \mathrm{sec}$.

B. SNG production in vol\%: methane $=86-96, \mathrm{H}_{2}=2-8, \mathrm{CO}=2-6$; gros s heating value $=926-1016 \mathrm{BTU} / \mathrm{SCF}$.

C. Operational Data for the Pilot Plant: reactor diameter $=3.28 \mathrm{ft}$ (internal), reactor height $=36.0 \mathrm{ft}, \mathrm{p}=190-870 \mathrm{psi}$, fluidized bed temperature $=$ $450-550^{\circ} \mathrm{C}$, feed gas $=112,000-400,000 \mathrm{SCF} / \mathrm{hr}, \mathrm{H}_{2} / \mathrm{CO}$ volume ratio $=$ $2.0-3.0$, recycle-gas volume ratio $=0-0.3$, gas velocity $=0.16-$ $1.0 \mathrm{ft} / \mathrm{sec}$, SNG production $=45,000-112,000 \mathrm{SCF} / \mathrm{hr}$, steam production $=1.0-5.2 \mathrm{t} / \mathrm{hr}$, steam temperature $=370-480^{\circ} \mathrm{C}$, fluidized-bed height $=6.4-12.9 \mathrm{ft}$, catalyst charge $=0.8-1.6$, catalyst-particle size distribution $=10-400 \mu \mathrm{m}$.

Table 4.3-6. Typical gasifiex-product gases (in mol\%) for a number of gasifiers and corresponding steam to dry-gas ratios.

\begin{tabular}{c|c|c|c|c|c}
\hline Species & $\begin{array}{c}\text { Lurgi } \\
\text { Dry-Ash }\end{array}$ & $\begin{array}{c}\text { BGC/Lurgi } \\
\text { Slagging }\end{array}$ & Shell & Texaco & $\begin{array}{c}\text { KRW } \\
\text { (Westinghouse) }\end{array}$ \\
\hline $\mathrm{H}_{2}$ & 40 & 29 & 29 & 35 & 27 \\
$\mathrm{CO}$ & 17 & 60 & 65 & 43 & 55 \\
$\mathrm{CO}_{2}$ & 32 & 3 & 2 & 20 & 6 \\
$\mathrm{CH}_{4}$ & 10 & 6 & 0.1 & 0.3 & 9 \\
$\mathrm{~N}_{2}$ & 1 & 1 & 4 & 2 & 3 \\
\hline $\begin{array}{l}\text { Steam/dry } \\
\text { gas ratio }\end{array}$ & 1.4 & 0.13 & 0.03 & 0.23 & 1.0 \\
\hline
\end{tabular}

reduce the amount of recycle gas needed for control of the temperature rise in the reactor beds is shown in Fig. 4.3-7.

The HICOM process employs nickel-based catalysts and uses excess steam in the feed gas to prevent carbon deposition. The process was 
initially evaluated in smali-scale laboratory experiments and subsequently tested at the semi-commercial scale on a slip stream from the BGC/Lurgi slagging gasifier at Westfield, Scotland. In the integrated tests at Westfield, purified gases from the gasifier were successfully processed at a nominal rate of approximately $4.5 \times 10^{6} \mathrm{SCF} /$ day.

\section{3-7. Liquid Phase Methanation}

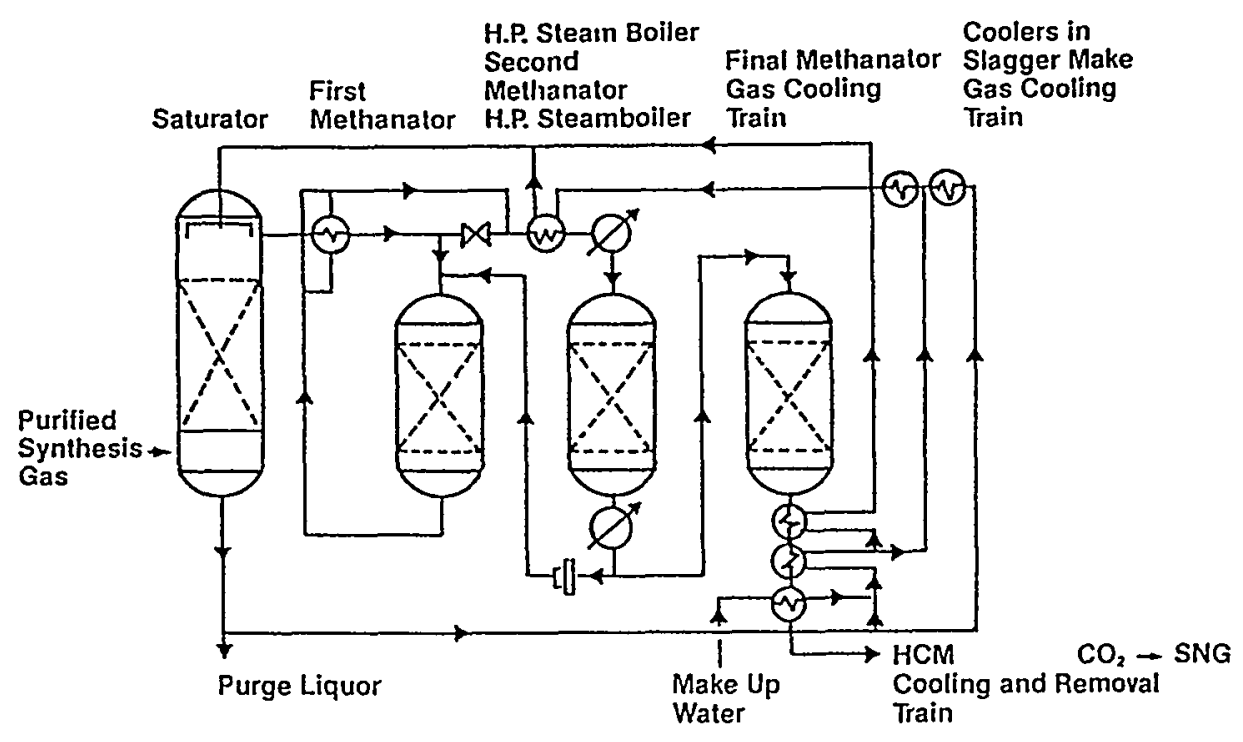

(a) Typical gas compositions from a HICOM pilot test

\begin{tabular}{c|c|c}
\hline Component & $\begin{array}{c}\text { Feed to the HICOM } \\
\text { Reactor, mol\% }\end{array}$ & $\begin{array}{c}\text { Product from the } \\
\text { HICOM Reactor, mol\% }\end{array}$ \\
\hline $\mathrm{CO}$ & 12.6 & 1.1 \\
$\mathrm{CO}_{2}$ & 43.0 & 53.1 \\
$\mathrm{H}_{2}$ & 11.7 & 5.5 \\
$\mathrm{CH}_{4}$ & 31.7 & 39.3 \\
$\mathrm{~N}_{2}$ & 1.0 & 1.1 \\
\hline
\end{tabular}

(b) Range of operating conditions

\begin{tabular}{l|r}
\hline Inlet $\mathrm{T}$ & $230-320^{\circ} \mathrm{C}$ \\
$\mathrm{P}$ & $25-70 \mathrm{bar}$ \\
Maximum $\mathrm{T}$ & $460-640^{\circ} \mathrm{C}$ \\
Total test time & $15,000 \mathrm{hr}$ \\
\hline
\end{tabular}

Fig. 4.3-6. The HICOM process diagram; gas compositions (a) and range of operating conditions (b). 


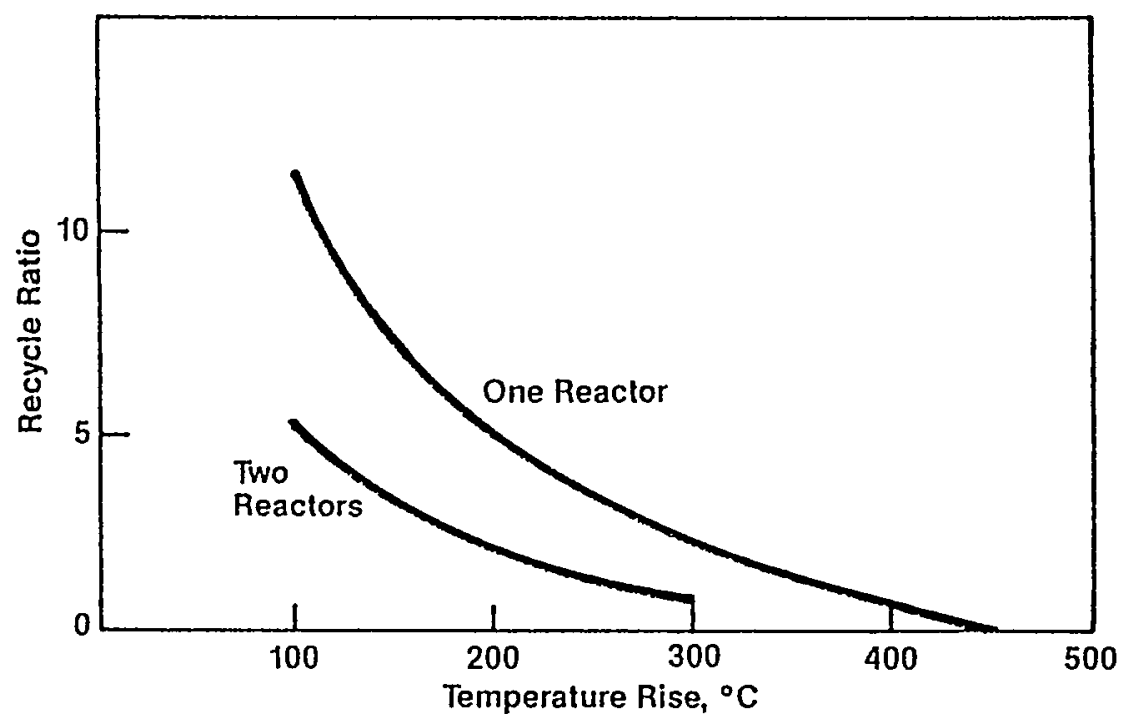

Fig. 4.3-7. Effect of the temperature rise on the required recycle ratio ( = recycle flow/product flow).

Workers at Chem System, Inc., have developed a liquid-phase methanation system in which a granular Ni-catalyst is immersed in a mineral-oil coolant bath, which serves to control the reactor temperature. ${ }^{17,18}$ Fluidization of the catalyst occurs by circulating the oil and fresh SG upward through the reactor. In a large-scale process, heat is recovered from the oil and from the hot product gases. Feed streams with $\mathrm{H}_{2} / \mathrm{CO}<3$ are accommodated by adding steam to the feed, thus forcing the shift reaction. Multiple reactors are required to obtain a co-concentration below $0.1 \%$. Operating temperatures are between 300 and $380^{\circ} \mathrm{C}$ and pressures between 300 and 1000 psi. Very good Co conversions have been demonstrated, but carbon deposition and catalyst disintegration have been problems for some operating regimes.

\subsection{Acid Gas Removal}

\section{4-1. Commercial Processes}

An essential element of a coal-to-SNG process is the removal of gases such as $\mathrm{CO}_{2}, \mathrm{H}_{2} \mathrm{~S}$, COS, mercaptans, and organic sulfides from the product stream in order to satisfy process constraints (such as catalyst poisoning), environmental constraints or product requirements (such as heating value and trace-constituent levels). Because requirements have existed for the removal of these types of gases from a wide variety of 
process streams that are encountered in the chemical industry, in petroleum refining and NG production, a large number of unit processes have been developed and can be used in the downstream processing trains of coal-gasification plants.

Table 4.4-1 contains a list of technologies that have been examined and/or developed for specific applications. Currently, there are more than 90 Rectisol units in operation or under construction in various parts of the world. The Rectisol technology, which uses methanol as the physical solvent, is in use at the SASOL plants and is also employed in the downstream processing train the GPCGP. The Benfield Process, which uses a hot $\mathrm{K}_{2} \mathrm{CO}_{3}$ solution for the chemical absorption of $\mathrm{CO}_{2}, \mathrm{H}_{2} \mathrm{~S}$ and $\mathrm{COS}$, is in use or being considered in over 520 applications throughout the world.

The Selexol process, a physical absorption process which uses the dimethyl ether of polyethylene glycol as the solvent, has been installed at approximately 30 commercial and/or pilot-plant facilities. This technology is currently being used at the Cool Water IGCC project.

\section{4-2. Advanced Technologies}

Because of the extensive catalog of commercially available technologies for acid-gas removal and the large data base that exists on the properties of potential sorbents for the gases of interest, there is only a limited effort devoted to the development of new processes that could improve the economics of producing SNG from coal.

GRI, together with DoE and Consolidated Natural Gas (CNG), has been evaluating an advanced acid-gas removal process specifically for coal conversion. This process relies on the unique gas-solid-liquid equilibrium phase relationships that exist for $\mathrm{CO}_{2}-\mathrm{H}_{2} \mathrm{~S}$ mixtures. Hydrogen sulfide and carbonyl sulfide are soluble in liquid $\mathrm{CO}_{2}$. However, when the temperature of a $\mathrm{CO}_{2} / \mathrm{H}_{2} \mathrm{~S}$ solution is reduced to the point where crystallization occurs, the solid phase that results is almost $100 \% \mathrm{CO}_{2}$ and contains essentially no sulfides. This phase behavior provides an effective means for removing acid gases such as $\mathrm{CO}_{2}, \mathrm{H}_{2} \mathrm{~S}$ and $\mathrm{COS}$ from a coal-gasification process stream and subsequently increasing the concentration of $\mathrm{H}_{2} \mathrm{~S}$ in a stream where it can be effectively converted to elemental sulfur. 
Table 4.4-1. Summary of commercial and developmental acid-gas removal processes; abbreviations: for the process type, $A D=$ adsorption, $A B=$ absor ption, $C D=$ cryogenic distillation; for the solvent, $C=$ chemical solvent, $P=$ physical solvent; for the clean-up mode, $S=$ selective, NS = non-selective.

\begin{tabular}{|c|c|c|c|c|}
\hline Name of Process & Type & Solvent & Mode & $\begin{array}{l}\text { Major Contaminants } \\
\text { Removed }\end{array}$ \\
\hline Activated carbon & $\mathrm{AD}$ & C & NS & $\mathrm{H}_{2} \mathrm{~S}$, oil \\
\hline ADIP & $A B$ & $\mathbf{C}$ & NS & $\mathrm{H}_{2} \mathrm{~S}, \mathrm{CO}_{2}$ \\
\hline Alkazid & $A B$ & C & $\mathrm{S}, \mathrm{NS}$ & $\mathrm{H}_{2} \mathrm{~S}, \mathrm{CO}_{2}$ \\
\hline Amisol & $A B$ & $C / P$ & $\mathrm{~S}, \mathrm{NS}$ & $\mathrm{H}_{2} \mathrm{~S}, \mathrm{CO}_{2}$ \\
\hline Benfield & $\mathrm{AB}$ & C & NS & $\mathrm{H}_{2} \mathrm{~S}, \mathrm{CO}_{2}$ \\
\hline Catacarb & $\mathrm{AB}$ & C & NS & $\mathrm{H}_{2} \mathrm{~S}, \mathrm{CO}_{2}$ \\
\hline Chemsweet & $\mathrm{AD}$ & C & 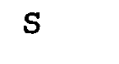 & $\mathrm{H}_{2} \mathrm{~S}$ \\
\hline CNG & $\mathrm{AB}$ & $\mathbf{P}$ & $s$ & $\mathrm{H}_{2} \mathrm{~S}, \mathrm{CO}_{2}$ \\
\hline Estasolvan & $A B$ & $\mathbf{P}$ & S, NS & $\mathrm{H}_{2} \mathrm{~S}, \mathrm{CO}_{2}$, oil \\
\hline Flexsorb SE & $A B$ & C & $s$ & $\mathrm{H}_{2} \mathrm{~S}, \mathrm{CO}_{2}$ \\
\hline Fluor Econamine & $A B$ & C & NS & $\mathrm{H}_{2} \mathrm{~S}, \mathrm{CO}_{2}$ \\
\hline Fluor Solvent & $\mathrm{AB}$ & $P$ & NS & $\mathrm{H}_{2} \mathrm{~S}, \mathrm{CO}_{2}$, oil \\
\hline Giammarco-Vetrocoke & $\mathrm{AB}$ & C & $\mathbf{S}$ & $\mathrm{H}_{2} \mathrm{~S}, \mathrm{CO}_{2}$ \\
\hline MEA & $A B$ & $\mathbf{C}$ & NS & $\mathrm{H}_{2} \mathrm{~S}, \mathrm{CO}_{2}$ \\
\hline MDEA & $A B$ & C & $S, N S$ & $\mathrm{H}_{2} \mathrm{~S}, \mathrm{CO}_{2}$ \\
\hline Molecular sieves & $\mathrm{AD}$ & $\mathbf{P}$ & $\mathbf{s}$ & $\mathrm{H}_{2} \mathrm{~S}$ \\
\hline Purisol & $A B$ & $\mathbf{P}$ & $\mathrm{S}, \mathrm{NS}$ & $\mathrm{H}_{2} \mathrm{~S}, \mathrm{CO}_{2}$ \\
\hline Rectisol & $A B$ & $P$ & $S, N S$ & $\mathrm{H}_{2} \mathrm{~S}, \mathrm{CO}_{2}$ \\
\hline Ryan Holmes & $C D$ & $\mathrm{CD}$ & $\mathbf{s}$ & $\mathrm{H}_{2} \mathrm{~S}, \mathrm{CO}_{2}, \mathrm{C}_{2}^{+}$ \\
\hline Seaboard & $A B$ & C & $s$ & $\mathrm{H}_{2} \mathrm{~S}$ \\
\hline Selexol & $A B$ & $\mathbf{P}$ & $\mathrm{S}, \mathrm{NS}$ & $\mathrm{H}_{2} \mathrm{~S}, \mathrm{CO}_{2}, \mathrm{oil}$ \\
\hline Sepasolv MPE & $A B$ & $\mathbf{P}$ & $\mathrm{S}, \mathrm{NS}$ & $\mathrm{H}_{2} \mathrm{~S}, \mathrm{CO}_{2}, \mathrm{oiI}$ \\
\hline SNPA - DEA & $A B$ & C & NS & $\mathrm{H}_{2} \mathrm{~S}, \mathrm{CO}_{2}$ \\
\hline Stretford & $\mathrm{AB}$ & C & $S$ & $\mathrm{H}_{2} \mathrm{~S}$ \\
\hline Sulfiban & $\mathrm{AB}$ & C & NS & $\mathrm{H}_{2} \mathrm{~S}, \mathrm{CO}_{2}$ \\
\hline SulfinoI & $\mathrm{AB}$ & $\mathrm{C} / \mathrm{P}$ & NS & $\mathrm{H}_{2} \mathrm{~S}_{3} \mathrm{CO}_{2}$ \\
\hline Tripotassium phosphate & $\mathrm{AB}$ & C & $\mathbf{s}$ & $\mathrm{H}_{2} \mathrm{~S}$ \\
\hline Vacuum caxbonate & $A B$ & $\mathbf{C}$ & $\mathbf{s}$ & $\mathrm{H}_{2} \mathrm{~S}$ \\
\hline Zinc oxide & $\mathrm{AD}$ & C & $\mathbf{s}$ & $\mathrm{H}_{2} \mathrm{~S}$ \\
\hline
\end{tabular}


A conceptual flow diagram for the CNG acid-gas removal process is shown in Fig. 4.4-1. The raw feed gas is cooled and residual water vapor is removed in a dehydration system to prevent subsequent icing. The water-free crude gas is further cooled to its $\mathrm{CO}_{2}$ dew point $\left(-56^{\circ} \mathrm{C}\right)$ by countercurrent heat exchange with return clean gas and $\mathrm{CO}_{2}$. Depending on the $\mathrm{CO}_{2}$ dew point, a fraction of the $\mathrm{CO}_{2}$ in the crude gas stream is condensed together with the sulfur compounds. The gas at $-55^{\circ} \mathrm{C}$ is then scrubbed by 1 iquid $\mathrm{CO}_{2}$ to remove $\mathrm{H}_{2} \mathrm{~S}$, COS and other trace impurities. This absorption is essentially isothermal since the heat of absorption is dissipated as heat of vaporization of a small portion of the liquid $\mathrm{CO}_{2}$.

The liquid $\mathrm{CO}_{2}$, together with all of the sulfur compounds, other trace contaminants and some co-absorbed light HCs is combined with the contaminated liquid $\mathrm{CO}_{2}$ that was condensed in precooling the raw gas. The light $\mathrm{HCs}$ are stripped from this combined liquid $\mathrm{CO}_{2}$ stream and recycled and mixed with the feed gas. Any higher $\mathrm{HCs}\left(\mathrm{C}_{4}-\mathrm{C}_{6}\right)$ in the feed gas will remain with the condensed $\mathrm{CO}_{2}$.

The contaminated liquid $\mathrm{CO}_{2}$ stream leaving the light ends stripping tower is processed in a direct-contact, triple-point crystallizer with vapor compression. Solid $\mathrm{CO}_{2}$ is formed by adiabatic flashing of the liquid $\mathrm{CO}_{2}$ stream near the top of the crystallizer. An $\mathrm{H}_{2} \mathrm{~S}$-rich gas stream is produced and is continuously withdrawn from the top. $A 17 \mathrm{C}_{2}-\mathrm{C}_{6} \mathrm{HCs}$ entering the crystallizer are removed with the $\mathrm{H}_{2} \mathrm{~S}$-rich stream. The solid $\mathrm{CO}_{2}$ crystals fall to the bottom of the crystallizer, where they are melted by direct contact with condensing $\mathrm{CO}_{2}$ vapor. Pure $\mathrm{CO}_{2}$ liquid thus produced is split into two streams: one is recycled to the $\mathrm{H}_{2} \mathrm{~S}$ absorber and the other is sent back through the process for refrigeration and power recovery and is subsequently delivered as a product stream or vented to the atmosphere.

Carbon dioxide remaining in the gas after removal of sulfur compounds is absorbed at temperatures below the $\mathrm{CO}_{2}$ triple point with a slurry absorbent. The slurry absorbent is a saturated solution of an organic solvent and $\mathrm{CO}_{2}$ containing suspended particles of solid $\mathrm{CO}_{2}$. As $\mathrm{CO}_{2}$ is absorbed (condensed), the latent heat released melts the solid $\mathrm{CO}_{2}$ contained in the slurry absorbent. The direct refrigeration provided by the melting of solid $\mathrm{CO}_{2}$ enables a small absorbent flow to accommodate the considerable heat of condensation and absorption of the $\mathrm{CO}_{2}$ vapor. The 


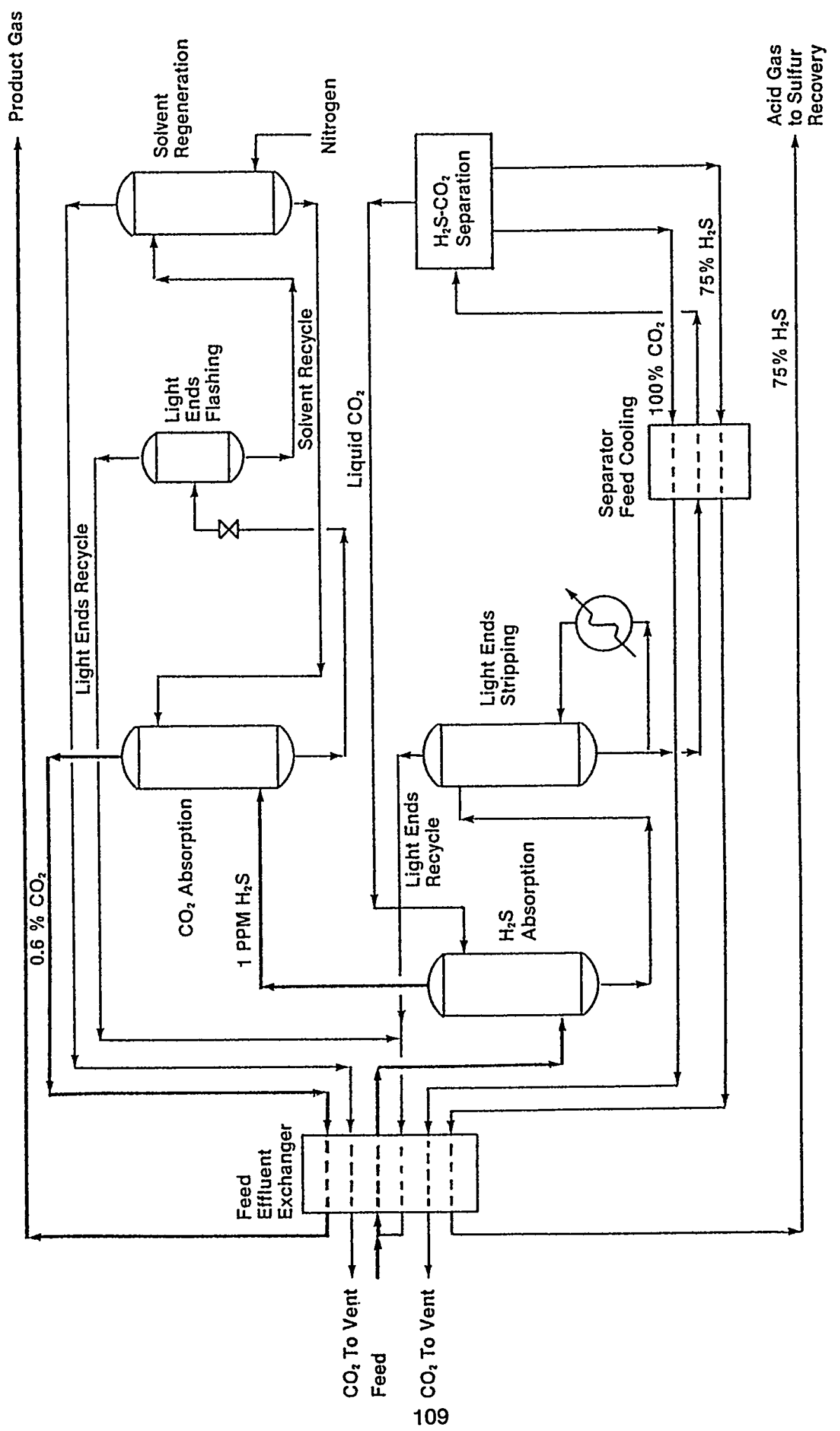

OD 
cold, purified gas stream then leaves the acid-gas removal process after heat exchange with the raw gas stream.

The $\mathrm{CO}_{2}$-rich solvent leaving the $\mathrm{CO}_{2}$ absorber near the triple-point temperature contains no solid $\mathrm{CO}_{2}$. This stream is flashed in a drum to vaporize methane or other light components. The $\mathrm{CO}_{2}$-rich absorbent is next cooled by external refrigeration and then flashed to lower the pressure in a number of stages in order to generate a cold slurry of liquid solvent and solid $\mathrm{CO}_{2}$. Nitrogen stripping of the solvent may sometimes be required to produce a very lean solvent. The regenerated slurry absorbent is recirculated to the $\mathrm{CO}_{2}$ absorber while the $\mathrm{CO}_{2}$-flashed gas is vented to the atmosphere after recovery of refrigeration and power.

\subsection{SNG Economics}

The economics associated with producing natural gas from coal are a function of coal type and cost, the technologies used in the overall conversion processes, as well as site-specific considerations. Figure 4.5-1 shows a comparison of calculated end-product gas costs (in 1982 dollars) for an ash-agglomerating, fluidized bed gasification technology and also for dry-bottom Lurgi technology with both US Western and Eastern coals as the feedstock. These results are presented as a levelized constant dollar (LCD) cost, where the levelized price represents the average gas selling price required over the life of the plant in dollars for a given year to realize a rate of return on equity of $14.5 \%$. The LCD price also requires that a11 costs, except that of coal, escalate at the average rate of inflation.

Figure 4.5-1 shows the relative distribution of the major cost elements (i.e., feedstock, operation and maintenance, and capital investment) for each of the four cases considered. A Western coal was used as the feedstock. The contributions of the major elements to the overall end-product gas costs are: feedstock, 25 to 29\%; operation and maintenance, 45 to $49 \%$; capital, 25 to 26\%). With an Eastern coal, the relative contributions are as follows: feedstock, 42 to 50\%; operation and maintenance, 31 to $39 \%$; capital, 19 to $20 \%$. 


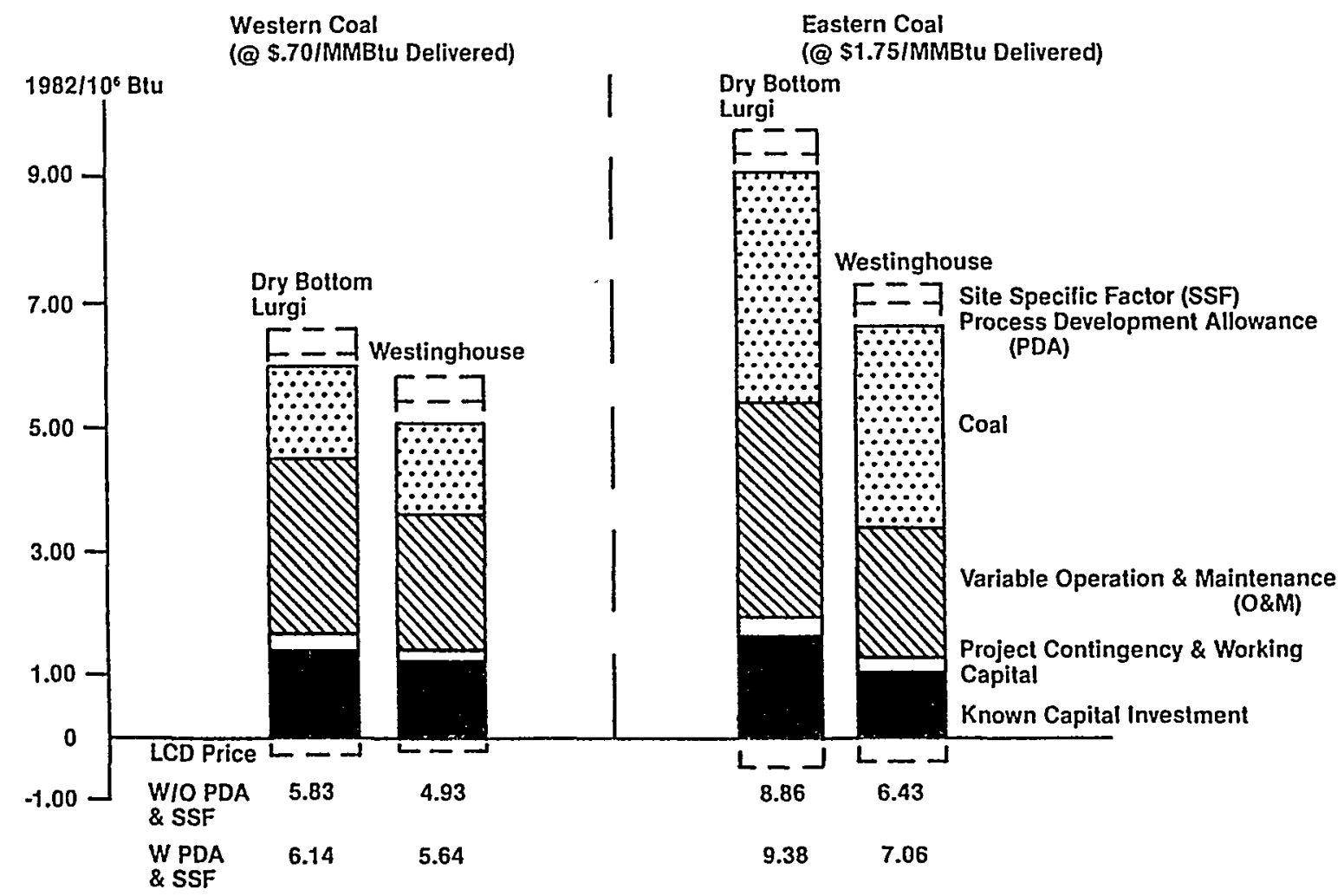

Fig. 4.5-1. Comparison of LCD costs of SNG for selected gasifiers. All estimates are based on a 30-yr plant life, $85 \%$ debt financing, beginning operation in 1990. Delivered coal prices are assumed to escalate at $2 \%$ per year in real terms. Additional primary capital costs were estimated for unknown factors related to potential site requirements (SSF) and state of technology development (PDA).

Figure 4.5-2 shows a comparison of both the levelized constant dollar end-product gas costs and the annual cost of service for coal-to-SNG conversion for a process based on dry-bottom Lurgi gasification and commercially available downstream processes, when using a system based on advanced gasification (ash-agglomerating, fluidized bed) and downstream processing (direct methanation and an advanced acid-gas clean-up system) technologies. Both plants were sized to produce $250 \times 10^{6} \mathrm{SCF} /$ day of pipeline-quality gas using lignite as the feedstock.

The availability of advanced technologies would reduce the average gas cost from approximately $\$ 6.20 / 10^{6}$ BTU to approximately $\$ 4.80 / 10^{6}$ BTU on a cost-of-service basis. The advanced technology would also lead to a first year gas cost that is approximately $\$ 2.00 / 10^{6}$ BTU less than that estimated for the process based on dry-bottom Lurgi technology. This reduction in 
average and first year gas costs will permit coal-to-SNG processes to become economically competitive with other energy- and gas-supply options in an earlier time frame than would otherwise be the case.

\subsection{Research and Development Needs}

The research and development needs associated with the long-range objective of producing SNG from coal cover a spectrum of activities, ranging from engineering studies to basic research. These needs include:

(i) operational/economic data on large, integrated coal gasification plants, (ii) expanded engineering data bases, and ( $i$ ii) the development of more fundamentally-oriented information on the rate-controlling steps of the various process elements. While these needs are focused on coal gasification as related to the production of high-BTU SNG, many of the needs are generic in nature and will be useful in a variety of coal-gasification applications. Specific research needs are listed here for three categories of $R \& D$.

4.6-1. Engineering Development and Testing

(i) Large-scale operational and performance data are needed on IGCC plants such as Cool Water and also for the GPCGP converting coal-to-SNG.

(ii) Expanded engineering data bases should be developed for oxygen-blown, ash-agglomerating, fluidized bed gasifiers to optimize designs for specific applications (pressure, fines collection and recycle, coal types, in-bed desulfurization).

(iij) Scale-up data for emerging technologies are required for such processes as the direct methanation concept and the CNG advanced acid-gas removal concept.

(iv) Integrated performance evaluations of advanced gasification technologies are needed for technologies such as the BGC/Lurgi slagging gasifier and the ash-agglomerating, fluidized bed process with advanced downstream processing, as well as for concepts such as the direct-methanation process and the CNG acid-gas removal system. 


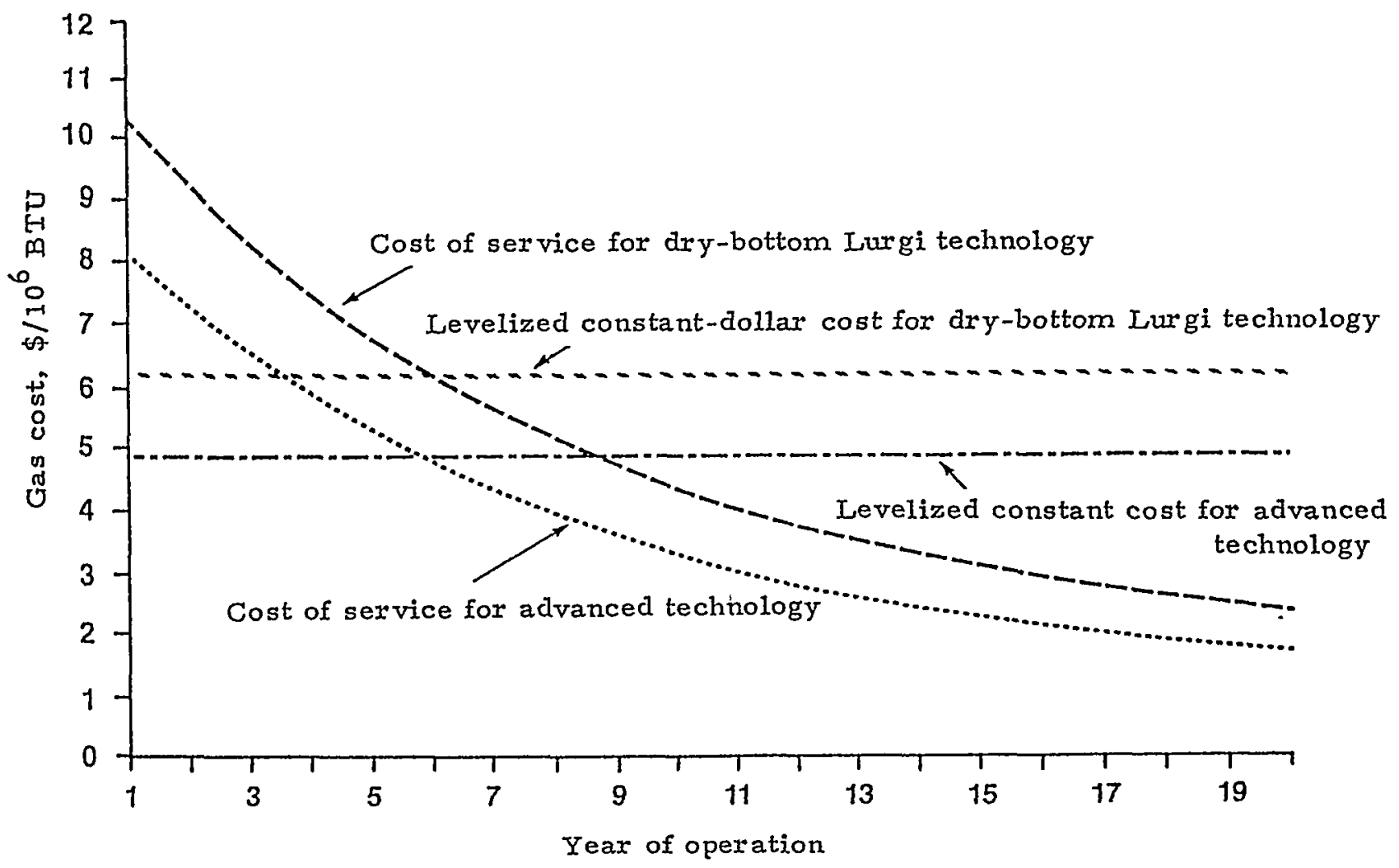

Fig. 4.5-2. Estimated cost of SNG for dry-bottom Lurgi technology and advanced gasification and downstream-processing technologies (250 mm SCF/ day, lignite); constant 1985 dollars are used.

(v) Development and validation are required of scale-up models, with particular emphasis on coal gasifiers.

(vi) Exploratory studies should be carried out to develop initial data bases for new, advanced process concepts for gasification and downstream processing.

(vii) Improved, high-temperature heat recovery systems are needed.

(viii) Expanded environmental data bases should be established for advanced technologies in the areas of production, fate, control, and disposal or treatment of trace constituents.

\section{6-2. Technology Base Data for Design}

(i) The development of metal alloys for high-temperature, heat recovery applications should be supported.

(ii) The development of improved ceramics for high-temperature applications (i.e., particulate filters, valves) should be encouraged. 
(iii) Expanded data bases are needed on the erosion-corrosion behavior and resistance of metals and ceramics in coal-gasification environments.

(iv) Long-term corrosion data (for more than 10,000 hr) should be obtained in coal-gasification environments, with proper consideration of alkali metals, sulfidation, and chlorides.

(v) Vapor-liquid equilibrium data are needed at elevated pressures and temperatures for selected multicomponent systems involving synthesis gas, steam, heavy oils (tars), light aromatics, phenolics, fatty acids, $\mathrm{CH}_{4}, \mathrm{H}_{2} \mathrm{~S}$, $\mathrm{CS}_{2}, \mathrm{COS}$, mercaptans, $\mathrm{NH}_{3}, \mathrm{HCL}, \mathrm{HCN}, \mathrm{AsH}_{3}, \mathrm{SeH}_{2}, \mathrm{Hg}$.

(vi) Transport data (thermal conductivity, viscosity, diffusivity) should be measured for tars and slurries (oil/solids, tar/solids, water/solids).

(vii) Thermodynamic data are required, including improved estimates for free energy of formation, heats of formation, entropies, specific heats.

(viji) Sour-water stripper vapor-liquid equilibria should be measured for $\mathrm{H}_{2} \mathrm{O} / \mathrm{NH}_{3} / \mathrm{CO}_{2} / \mathrm{H}_{2} \mathrm{~S}$ systems at 0 to $100 \mathrm{psig}$ and 20 to $200^{\circ} \mathrm{F}$.

(ix) Improved correlations are needed for predictions of mass-transfer coefficients and other engineering design parameters whenever mulitcomponent systems are involved.

\section{6-3. Basic Research Needs for Advanced Systems}

(i) Improved understanding is needed of the chemical processes associated with and controlling the fragmentation/gasification of coal.

(ii) Improved models are required for predictions of vapor-liquid equilibria in multi-component systems.

\section{References}

1. V. P. Sabin, "Great Plains - Alive and We1l," Council on Synthetic Fuels Alternate Energy ' 86 Conference, Captiva Island, Florida (1986).

2. J. Lambertz, N. Brunge1, W. Ruddeck, and L. Schrader, Rheinische Braunkohlenwerke $A G$, "Recent Operational Results of the High-Temperature Winkler and Hydrogasification Process," Proceedings: Conference on Coal Gasification Systems and Synthetic Fuels for Power 
Generation, Electric Power Research Institute, EPRI AP-4257-SR, Palo A7to, CA (December 1985).

3. P. Sabatier and J. B. Senderens, C.R. Acad. Sci. (Paris) 134, 514 (1902).

4. G. A. Mills and F. W. Steffgen, Catal. Rev. 8,159 (1973).

5. Chemistry of Coal Utilization, Second Supplementary Volume, pp. 1786-1800, M.A. Elliot, ed., John Wiley \& Sons, NY (1981).

6. M. D. Schlesinger, J. J. Demeter and M. Greyson, Ind. Eng. Chem. 48, 68 (1956).

7. H. Kurita and Y. Tsutsumi, Nippon Kagaku Zasshi 82, 1461 (1961).

8. J. F. Schultz, F. S. Karn, R. B. Anderson, and L. J. E. Hofer, Fuel 40, 181 (1961).

9. A. J. Forney, F. J. Demski, D. Bienstock, and J. H. Field, U.S. Bur. Mines Rept. Invest. No. 6609, Pittsburgh, PA (1965).

10. J. F. Schultz, F.S. Karn, and R. B. Anderson, U.S. Bur. Mines Rept. Invest. No. 6974, Pittsburgh, PA (1967).

11. S. Friedman and R. W. Hiteshue, U.S. Patent No. 3,429,679 (1969).

12. K. Wencke, Freiberger Forschungsheft A151, 11 (1960).

13. H. S. Meyer, V. L. HI11, A. Flowers, J. Happe1, and M. A. Hnatow, "Direct Methanation - A New Method of Converting Synthesis Gas to Substitute Natural Gas," ACS Div. Fuel Chem., Preprint 27, No. 1, 109-115 (1982).

14. A. Skov, K. Pedersen, C. L. Chen, and R. L. Coates, "Testing of a Sulfur Tolerant Direct Methanation Process," Proceedings: ACS Div. Fuel Chem. 31, No. 3, Anaheim, CA (September 1986).

15. W. Lommerzheim, "The Pilot Development Stage of the Comflux Process for Methanization of Coal Gas," Proceedings: Conference on Coal Gasification Systems and Synthetic Fuels for Power Generation, AP-4257-SR, EPRI, Palo Alto, CA (December 1985).

16. R. L. Ensel1 and H. J. F. Stroud, "The British Gas HICOM Methanation Process for SNG Production," Proceedings: 1983 International Gas Research Conference, London, UK (June 13-16, 1983). 
17. M. B. Sherwin, M. E. Frank, and D. G. Blum, "Recent Developments in Liquid Phase Methanation," paper presented at the 5 th Synthetic. Pipeline Gas Symposium, Chicago, IL (October 29-31, 1973).

18. M. E. Frank, M. B. Sherwin, D. B. Blum, and R. L. Mednick, "Liquid Phase Methanation/Shift," paper presented at the 8th Synthetic Pipeline Gas Symposium, Chicago, IL (October 18-20, 1976). 
CHAPTER 5:

GASIFICATION FOR THE SYNTHESES OF FUELS AND CHEMICALS*

5.1. Catalytic Conversion of Synthesis Gas to Fuels and Chemicals

\section{1-1. Introduction}

The competition among the various organic-based fuels (chiefly, natural gas, petroleum, and coal, with shale oil and biomass representing more recent entries) has been waged over the years with strange and intriguing use patterns. All but biomass are fossil fuels, omitting the possibility of the existence of abiotic methane in the earth's interior. A11 of these fuels may be converted to synthesis gas (SG, syngas), and this resource availability is a potent reason for the use of $S G$ in the production of fuels or chemicals. SG can be and, in several important applications is, a viable source of clean fuels and large-scale chemical manufacture. Molecular hydrogen has a myriad of uses and it is very extensively made from $S G$.

Natural gas (NG) is now the largest source of $S G$. By far the chief constituent of $N G$ is methane $\left(\mathrm{CH}_{4}\right)$, an unreactive molecule that is a clean fuel but requires conversion to $S G$ to yield reactive species. Petroleum fractions are the next largest source of $S G$, and significant quantities are being made from coal.

It is ironic that coal was the first fossil fuel to be converted to $S G$ for commercial use. The manufacture of methanol ( $\mathrm{MeOH}$ ) from coal-derived SG was started in Germany in 1923. ${ }^{1}$ In the same year and also in in German, the Fischer-Tropsch (FT) process ${ }^{2}$ was first put into commercial operation. The FT process for the manufacture of fuels and

* This chapter has been written by W.O. Haag and J.C. Kuo (both of Mobi1 Research and Development Corporation) and I. Wender (University of Pittsburgh). 
chemicals is now being carried out on a large scale in South Africa and is still based on coal-derived SG.

The route to $\mathrm{MeOH}$, which is now made commercially in large plants throughout the world, is through $S G$ in a 11 cases, with $N G$ as the chief source of the SG. Since NG has been in short supply in Europe, petroleum fractions have been used as a source of $S G$. The near-panic programs pursued following the 1973-1974 oil embargo involved coal as the source of fuels and chemicals, including increased gasification of coal to SG. Coal utilization in the US and worldwide increased and this increase has been sustained, but coal research and development have decreased with the decline in oil and gas prices. The instability of $0 i 1$ and gas markets is actualiy one the the best reasons for sustaining $R \& D$ and technology for the use of $S G$ (often referred to as C-1 chemistry). There are a few salient points, most well-known, that apply to the the supply of fuels and chemicals in general and to SG in particular: (i) The most precarious situation involves the availability of petroleum since the largest oil resource exist in politically unstable areas far from the US. In terms of availability, NG and coal constitute large resources and are ubiquitous. (ii) Petroleum, NG and coal will continue to compete for world markets for several decades. Flexibility will be a. key so that a particular application will not depend on the availability of one kind of fuel. As for coal, use should not be tied to a particular mine or rank. Since $a 11$ of these resources are convertible to SG, applications based on SG use will grow. (iii) It is not possible to separate the fuels and chemicals businesses as many traditionalists are prone to do. Fuels use will govern chemicals use, as they have in the petroleum industry. Fuels are sold by the barrel or by the ton; chemicals are of higher value and are sold by the pound. (iv) With regard to coal use, gasification processes are more forgiving than direct liquefaction. Variability in coal source, rank, mineral matter, etc. is more easily accommodated by gasification processes. Indirect liquefaction ( $v i a S G$ ) products are relatively easily converted to clean gaseous and liquid fuels and chemicals. (v) In indirect liquefaction, all of the coal is converted to crude SG. The conversion of coal to clean SG generally account to $70-80 \%$ of the capital cost of the plant. In direct coal liquefaction, the necessary $\mathrm{H}_{2}$ is obtained by gasification of coal or of some heavy coal-1iquefaction product. In this case, gasification costs amount to about $40 \%$ of the capital cost of the liquefaction plant. 
(vi) $\mathrm{SG}$ will continue to be the source of $\mathrm{MeOH}$, although there is significant ongoing research on the direct oxidation of $\mathrm{CH}_{4}$ to $\mathrm{MeOH}$ and products derived from $\mathrm{MeOH}$, such as formaldehyde. (vii) SG will continue to be the world's principal source of $\mathrm{H}_{2}$. Hydrogen has a great many uses, including primary application for the manufacture of ammonia $\left(\mathrm{HN}_{3}\right)$. (viii) Environmental factors are the eventual determinants in fossil-fuel use. Even a large amount of an available resource, if environmentally harmful, will lose out sooner or later. For coal gasification, environmental constraints are found in gas clean-up and in the nature of gasification residues. The latter should be characterized, be non-leachable and, if possible, be useful in some way (for roads, driveways, construction, etc.). (ix) It is almost inevitable that future power plants will allow the use of any clean fluid fuel: $N G$, oil, SG, MeOH, or even an FT-derived liquid. Coal will first be converted to $S G$, as at Cool Water, and will then be used in a type of integrated gasification combined-cycle (IGCC) mode (see Sec. 3.1 for details). This procedure will result in the proliferation (often nearby) of plants that convert the SG to high-quality transportation fuels or to chemicals or use the gas as a clean industrial fuel. ( $x$ ) The modern petrochemical industry is based on NG and the by-products of petroleum refining. The so-called petrochemical feedstocks are comprised of ethylene, propylene, the butenes, benzene, toluene, and the zylenes. All of these and liquid fuels can be made from $S G$ and it is therefore possible to envision a petroleum-less refinery. ( $x i$ ) As tetraethyllead disappears from automobile gasoline tanks, the demand will grow for oxygenated chemicals with high octane ratings. An economical synthesis of such fuel-blending agents or additives is needed. An economical synthesis of ethanol from SG would help solve this problem. ( $x i i$ ) Sulfur and nitrogen compounds are removed from crude $S G$ and can be sold as solid sulfur or an $\mathrm{NH}_{3}$, respectively. Gasification processes produce $\mathrm{CO}_{2}$ in considerable amounts. This gas is in short supply and has growing uses. It is considerably easier to isolate $\mathrm{CO}_{2}$ from gasification processes than from flue-gas streams. Efforts should be made to remove $\mathrm{CO}_{2}$ in a fairly pure state from gasification processes to satisfy the growing demand for this chemical. Original plans for the Northern Great Plains coal-to- $\mathrm{CH}_{4}$ plant included a pipeline to transport $\mathrm{CO}_{2}$ to oil fields for enhanced oil recovery; this would have produced revenues of $\$ 17$ million per year. Other uses for $\mathrm{CO}_{2}$ are in syntheses of urea, 
supercritical extraction, refrigeration, carbonation of beverages, synthesis of polymers, etc.

It is of considerable interest, before discussing $S G$ as a source of fuels and chemicals, to gain some idea of the amount of SG used in the world today. About 7.5 trillion standard cubic feet (SCF) of SG are consumed each year for the following uses (in SCG): synthesis of $\mathrm{NH}_{3}, \sim 5$ trillion; MeOH manufacture, $\sim 1$ trillion; FT products, $\sim 800$ billion; miscellaneous uses $\left(\mathrm{H}_{2}\right.$ used in processes other than $\mathrm{NH}_{3}$ synthesis, i.e., in petroleum refining, hydrogenations, for the production of various chemicals, carbonylation reactions, etc.), 500 billion; the hydroformylation (0X0) reaction (conversion of olefins to aldehydes and alcohols), 150 billion. Present, emerging and possible future uses of SG will now be discussed.

$S G$ or medium-BTU gas is itself an excellent fuel. It may be transported economically by pipeline over 100 miles for industrial use or it may be used directly as a fuel for the generation of electricity in IGCCs.

Other ways for utilizing SG may be summarized as follows: (i) direct conversion of $S G$ to fuels and chemicals (Table 2.5-1), (ii) indirect conversion to fuels and chemicals via MeOH or MeOH plus SG, $\mathrm{CO}$ or $\mathrm{H}_{2}$ (Table 2.5-2), and ( $i i j)$ products obtainable from synthesis gas plus a chemical not derived from SG (Table 2.5-3).

Commercial or near-commercial processes for the production of fuels form SG are outlined in Fig. 5.1-1. Commercial, near-commercial and potential chemicals from $S G$ are given in Fig. 5.1-2. The first integrated US process to produce chemicals for coal-derived SG is shown in Fig. 5.1-3.

\section{1-2. Synthesis of Methanol and Higher Oxygenated Compounds}

Over ten million tons per year of $\mathrm{MeOH}$ are currently produced. There are several reasons why $\mathrm{MeOH}$ is an important key to an SG-based fuels and chemicals industry. First, $\mathrm{MeOH}$ is synthesized with over $99.9 \%$ selectivity, in sharp contrast to the melange of products, for $\mathrm{CH}_{4}$ to waxes, obtained in the FT reaction. Second, the weight retention of $S G\left(2 \mathrm{H}_{2} / 1 \mathrm{CO}\right)$ as a feedstock for $\mathrm{MeOH}$ approaches $100 \%$. Third, MeOH furnishes selective pathways to a number of important chemicals, including formaldehyde and the widely used two-carbon oxygenated chemicals. This route to fuels and to the two-carbon chemicals from $\mathrm{MeOH}$ is presently more attractive than their 
direct synthesis from SG. In addition, although many more uses of this versatile compound, chiefly as a fuel, will be discussed,
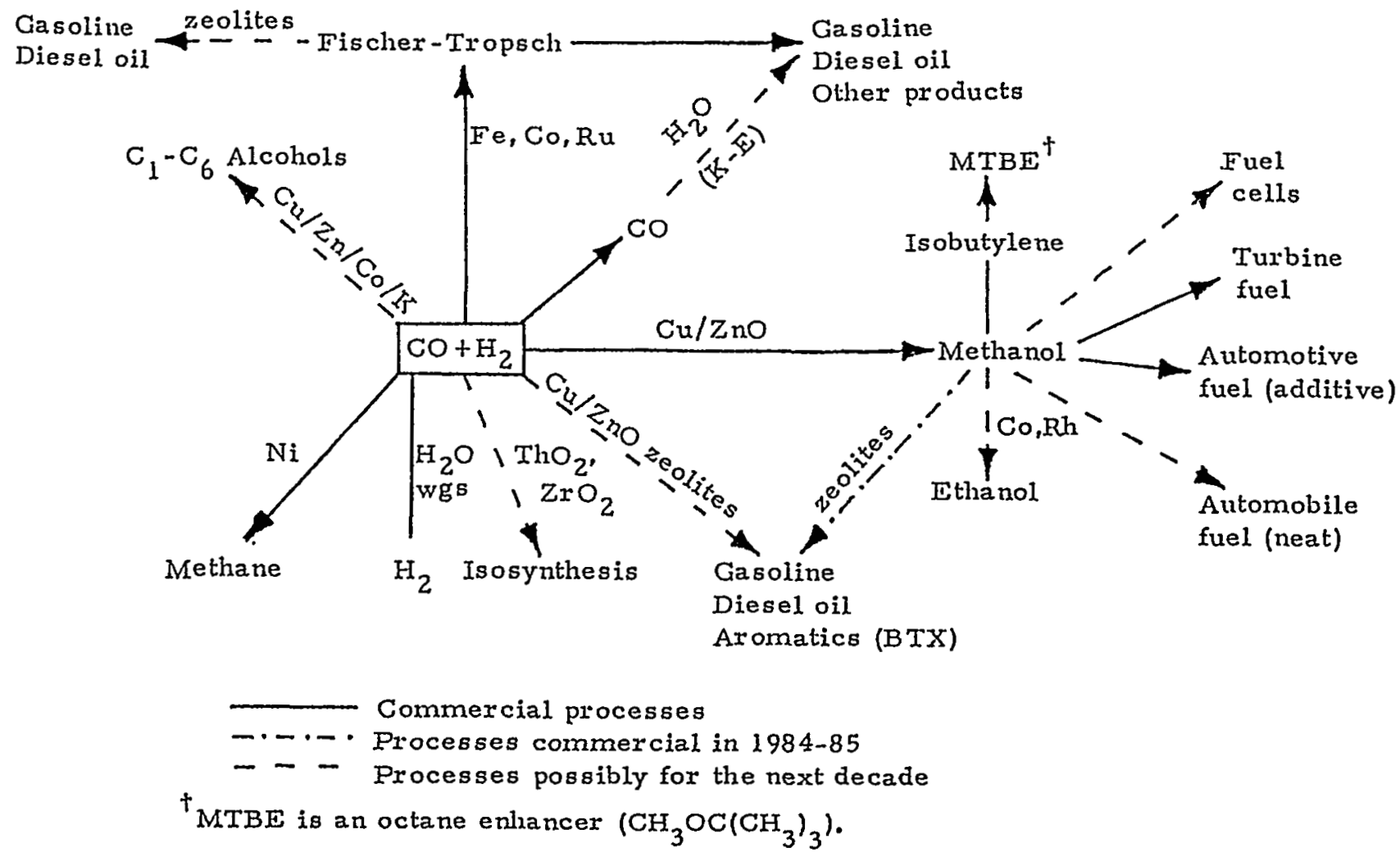

Fig. 5.1-1. Commercial, near-commercial, and potential processes for the production of fluid fuels from synthesis gas.

there is the exciting discovery that $\mathrm{MeOH}$ can be converted to high-octane gasoline by Mobil's MeOH-to-gasoline (MTG) process using a shape-selective zeolite catalyst (HZSM-5). A plant producing about 14,000 BPD of high-octane gasoline form MeOH went on-stream in New Zealand in late 1985. There are presently two primary processes for the manufacture of $\mathrm{MeOH}$ from SG, namely, high-pressure and low-pressure processes. The high-pressure process is

$$
\mathrm{CO}+2 \mathrm{H}_{2} \underset{25-35 \mathrm{MPa},}{\stackrel{\mathrm{ZnO} / \mathrm{Cr}_{2} \mathrm{O}_{3}}{\longrightarrow}} \mathrm{CH}_{3} \mathrm{OH}, \Delta \mathrm{H}_{298 \mathrm{~K}}=-21.68 \mathrm{kcal} / \mathrm{mol} ;
$$




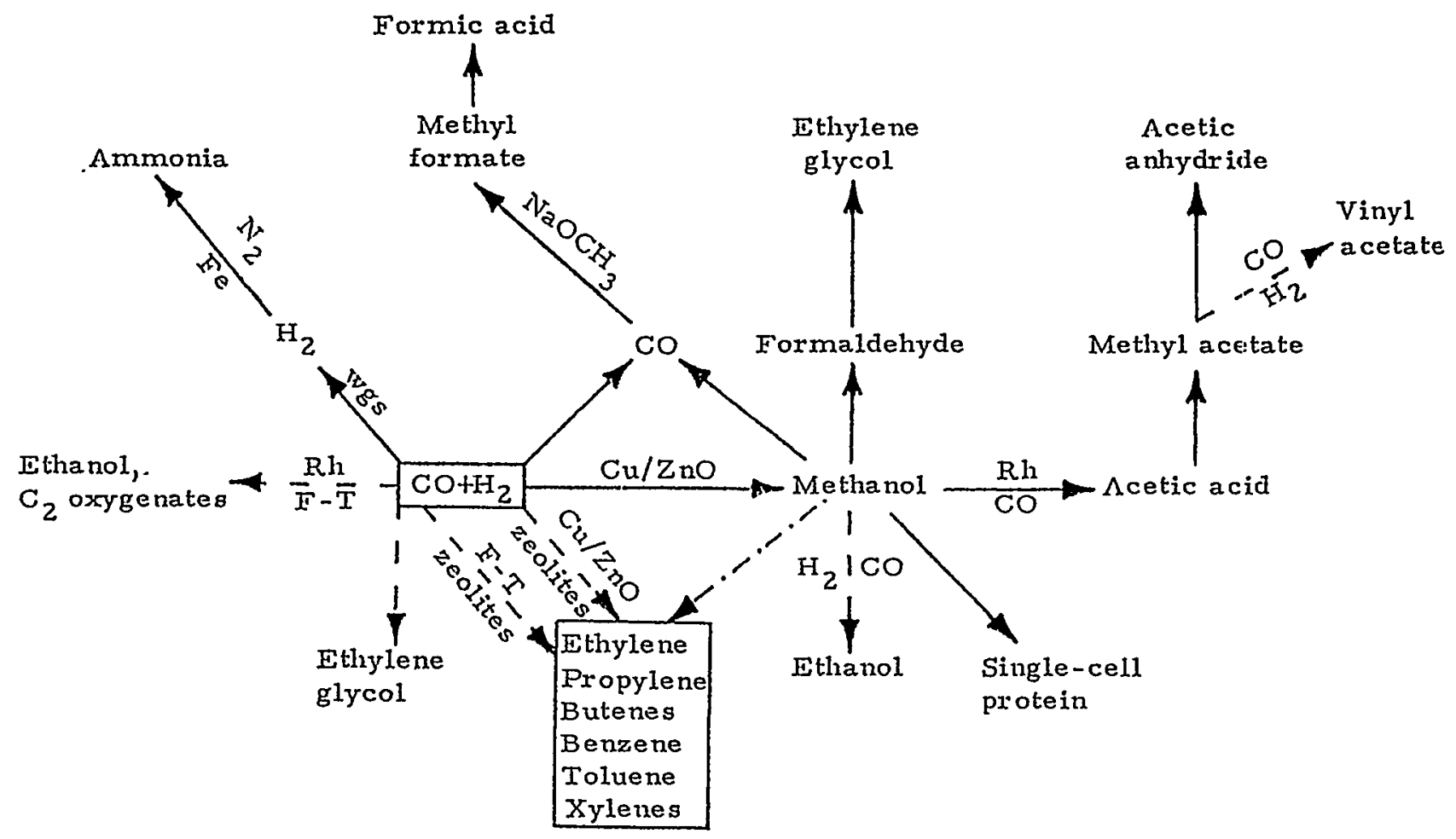

Commercial
$-\cdot-$ - Near commercial
-- - Potential (next decade)

Fig. 5.1-2. Commerclal, near-comnercial, and potential chemicals from synthesis gas.

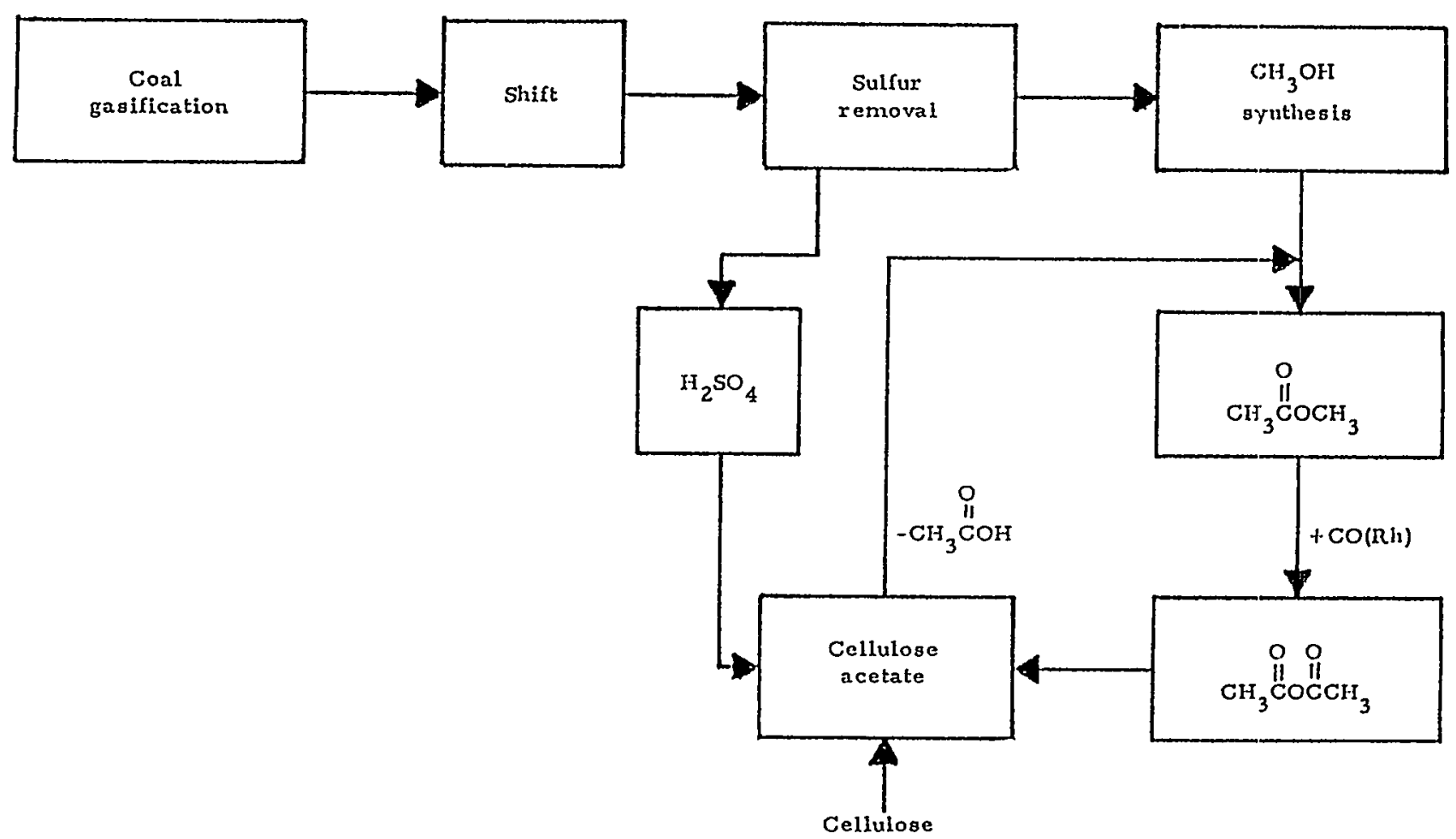

Fig.5.1-3. First Integrated process In the US to produce chemicals from coal-derf.ved syngas (Tennessee Eastman). 
the low-pressure process is based on the reaction

$$
\mathrm{CO}+2 \mathrm{H}_{2} \underset{5 \mathrm{MPa}, 523 \mathrm{~K}}{\stackrel{\mathrm{Cu} / \mathrm{ZnO} / \mathrm{Al}_{2} \mathrm{O}_{3}}{\longrightarrow}} \mathrm{CH}_{3} \mathrm{OH}
$$

$\mathrm{MeOH}$ can be and has been synthesized by the hydrogenation of $\mathrm{CO}_{2}$ with the same catalysts:

$$
\mathrm{CO}_{2}+3 \mathrm{H}_{2} \rightarrow \mathrm{CH}_{3} \mathrm{OH}+\mathrm{H}_{2} \mathrm{O}, \Delta \mathrm{H}_{298 \mathrm{~K}}=-11.83 \mathrm{kcal} / \mathrm{mol} .
$$

All of these reactions are exothermic and involve a contraction in volume. Highest yields and conversions to $\mathrm{MeOH}$ are obtained at elevated pressures and low temperatures.

\section{1-2A: History of Methanol Production}

The commercial source of $\mathrm{MeOH}$, prior to introduction of synthetic processes, was the destructive distillation of wood. In 1905, Sabatier and Senderens ${ }^{3}$ suggested that $\mathrm{MeOH}$ could be synthesized from $\mathrm{CO}$ and $\mathrm{H}_{2}$. In the following years, particularly after the successful high-pressure synthes is of $\mathrm{NH}_{3}$, there were a number of patent applications by BASF in Germany and Patart in France covering the hydrogenation of $\mathrm{CO}$ to oxygenated compounds at elevated temperatures and pressures, with catalysts made up of $\mathrm{Cr}, \mathrm{Co}$, and $\mathrm{Mn}$ in the metallic form, as oxides, or as other compounds. In 1923, BASF built the first commercial MeOH synthesis plant and, a few years later, started exporting synthetic $\mathrm{MeOH}$ to the US at a much lower cost and greater purity than that of wood-derived $\mathrm{MeOH}$. The process used a zinc oxide/chromium oxide catalyst operating at 673K and $20 \mathrm{MPa}$.

At this stage, realizing the $\mathrm{MeOH}$ could be manufactured more economically by the catalytic process, Commercial Solvents Corp. and DuPont started experimenting with $\mathrm{MeOH}$ synthesis and, in 1927, the commercial production by the high-pressure process was inaugurated in the US. In the Commercial Solvents process, $\mathrm{CO}_{2}$ produced at the company's butanol fermentation plant was hydrogenated to $\mathrm{MeOH}$ at $30.6 \mathrm{MPa}$ with metal oxide catalysts. 
In 1927, DuPont operated a plant at Belle, WV, that used coal as the source of the gaseous feedstock. Ammonia and $\mathrm{MeOH}$ were manufactured in tandem in the same plant. The raw gas, a mixture of $\mathrm{CO}, \mathrm{CO}_{2}, \mathrm{H}_{2}$ and $\mathrm{N}_{2}$, was produced from coal or coke by the water-gas reaction, purified and passed over a MeOH-synthesis catalyst and subsequently over a methanation catalyst to remove $\mathrm{CO}$. The remaining gases, $\mathrm{N}_{2}$ and $\mathrm{H}_{2}$, were used in the synthesis of $\mathrm{NH}_{3}$. The DuPont process used $\mathrm{SG}$ and catalysts made of zinc-chromium or chromium-copper. Co-production of $\mathrm{MeOH}$ and $\mathrm{NH}_{3}$ continued at the plant until the late 1940s. At that time a plentiful supply of NG became available and coal was abandoned as a feedstock. However, in the long run, coal promises to be the preferred feedstock for the production of $\mathrm{MeOH}$; this belief persists in spite of current low oil prices.

At present, a commercial plant using coal is in operation in South Africa. Here, the $S G$ is produced by the Koppers-Totzek entrained-flow, atmospheric-pressure gasification of coal and the synthesis involves use of the ICI MeOH process. BASF may be credited with the discovery of zinc-chromium catalysts in Germany in 1913. This was a high-temperature catalyst operating at $623-673 \mathrm{~K}$ because of its low catalytic activity. These catalysts must operate at high pressures (25-35 MPa) because of low SG conversion resulting from less favorable thermodynamic equilibrium limitations at high temperatures. The catalysts are less active than the copper-zinc-based catalysts but are more tolerant towards poisoning by compounds containing sulfur.

ICI introduced the more active copper-zinc based catalysis in 1966. These low-temperature catalysts operate at 523-573K and 5-25 MPa. The use of these catalysts was made possible because more efficient: SG purification processes had become available. The copper-zinc catalysts are much more susceptible to poisoning by sulfur compounds and are easily and permanently deactivated at high temperatures. Hence, proper control of reactor temperature is necessary. But, even with the most carefully prepared catalysts, sma 11 amounts of $\mathrm{CH}_{4}$, dimethyl ether and traces of higher alcohols appear among the products.

\section{1-2B. Chemistry of Methanol Synthesis}

An early excellent review of the synthesis of $\mathrm{MeOH}$ has been 
published by Natta. 4 In this section, we briefly outline the thermodynamics, kinetics and catalysis of the high-temperature synthesis of $\mathrm{MeOH}$ and the use of the copper catalysts now employed in most new $\mathrm{MeOH}$ plants (the low-pressure process).

The catalysts used in the synthesis of $\mathrm{MeOH}$ from SG, which usually contains some $\mathrm{CO}_{2}$, are highly active and, most importantly, very selective. Among the many products obtainable from the catalytic reactions of $\mathrm{SG}, \mathrm{CH}_{4}$ is thermodynamically the most favored. Longer chain HCs are the next most favored. Even longer chain alcohols are thermodynamically more favored than $\mathrm{MeOH}$. $\mathrm{MeOH}$ synthesis reactors must operate with narrow temperature ranges that are set by too low activity at lower temperatures and a thermodynamic limitation at higher temperatures. The effects of temperature and pressure have been studied in detail and reviewed by Strelzoff. 5

It is particularly important to avoid contamination of the $\mathrm{MeOH}-$ synthesis catalyst by metals that are FT catalysts. Care is required in catalyst preparation so as to obtain pure MeOH. Nickel and especially iron, both of which form volatile metal carbonyls $\left[\mathrm{Ni}(\mathrm{CO})_{4}\right.$ and $\mathrm{Fe}(\mathrm{CO})_{5}$ respectively], must not be allowed to come in contact with the SG under reaction conditions. The carbonyls form at lower temperatures and decompose to the metal and $\mathrm{CO}$ at higher temperatures, possibly in upstream heat exchangers, etc. The presence of FT metals in the catalyst or on the reactor walls will result in the formation of $\mathrm{CH}_{4}$, as well as of higher $\mathrm{HCs}$ and higher molecular weight oxygenated products. MeOH-synthes is reactor shells are typically lined with copper, although internals may be constructed of 18-8 stainless steel.

The formation of higher alcohols (ethanol, propanol, etc.) can be suppressed by careful exclusion of alkalis from the catalyst. Dimethyl ether is formed by a the dehydration of $\mathrm{MeOH}$ or by the hydrogenation of $\mathrm{CO}$ and may form in the presence of $\mathrm{Al}_{2} \mathrm{O}_{3}$. However, if a CuZnO low-pressure catalyst is employed with about $7.5 \% \mathrm{AT}_{2} \mathrm{O}_{3}$ as stabilizer and promoter, ether formation is negligible. The copper-zinc catalysts vary in zinc-copper composition and contain different amounts of other metals such as $\mathrm{Cr}, \mathrm{Al}$, $M N, V, A g$, etc.

The Boudouard reaction, $2 \mathrm{CO} \rightleftharpoons \mathrm{C}+\mathrm{CO}_{2}$, which results in carbon laydown, is not significant if the temperature is carefully controlled, despite a highly favorable thermodynamic tendency. 
In the high-pressure process, the reaction rate decreases with conversion because the synthesis of $\mathrm{MeOH}$ is strongly inhibited, both by approach to equilibrium and by the adsorption of $\mathrm{MeOH}$ on the catalyst. the gas leaving the last reaction vessel will typically contain only about $3 \%$ of $\mathrm{MEOH}$. The unreacted gases are recycled. In the low-pressure $\mathrm{MeOH}$ synthesis, the gas leaving the reactor contains 4 to 6.5 vol\% of $\mathrm{MeOH}$.

In practice, $S G$ made from any source contains some $\mathrm{CO}_{2} \cdot \mathrm{SG}$ made by $\mathrm{CH}_{4}$ reforming has a stoichiometric ratio of $\mathrm{H}_{2}$ to $\mathrm{CO}$ that approaches 3 . It contains some $\mathrm{CO}_{2}$, which may also be hydrogenated to $\mathrm{MeOH} . \mathrm{Co}_{2}$ may be added to the $S G$ in order to convert some of the excess $\mathrm{H}_{2}$ to $\mathrm{CO} v \mathrm{v}$ al the reverse water-gas shift (WGS), which is favored at higher temperature $\left[\mathrm{CO}_{2}\right.$ and $\left.\mathrm{H}_{2} \rightarrow \mathrm{CO}+\mathrm{H}_{2} \mathrm{O}\right]$. The presence of $6 \%$ by volume of $\mathrm{CO}_{2}$ in the $\mathrm{SG}$ increases $\mathrm{MeOH}$ yields by about $23 \%$ in the Lurgi $\mathrm{MeOH}$ synthesis. ${ }^{6}$ In various operations, $\mathrm{CO}_{2}$ levels vary from 2 to $6 \%$ and are usually specified by the various producers.

As stated, $\mathrm{MeOH}$ is made in numerous plants with over $99 \%$ selectivity when a mixture of $\mathrm{CO}, \mathrm{CO}_{2}$, and $\mathrm{H}_{2}$ is passed over a $\mathrm{Cu}-\mathrm{ZnO}-\mathrm{Al}_{2} \mathrm{O}_{3}$ catalyst at elevated pressures and temperatures between 493 and $573 \mathrm{~K}$. Surprisingly for such a widely practice process, however, there are few known facts, other than that the reaction is exothermic. 7-9

A major question bedeviling the mechanistic interpretation of $\mathrm{MeOH}$ synthesis is whether the alcohol is synthesized from $\mathrm{CO}$ or from $\mathrm{CO}_{2}$. Rozovskii et al., ${ }^{10}$ using ${ }^{14} \mathrm{CO}_{2}$, showed that the $\mathrm{MeOH}$ synthesis proceeds through $\mathrm{CO}_{2}$ rather than through $\mathrm{CO}$ as follows:

$$
\mathrm{CO}+\mathrm{H}_{2} \mathrm{O} \rightarrow \mathrm{CO}_{2}+\mathrm{H}_{2} \stackrel{2 \mathrm{H}_{2}}{\longrightarrow} \mathrm{CH}_{3} \mathrm{OH}+\mathrm{H}_{2} \mathrm{O} .
$$

Chinchen et al. 7 at ICI have confirmed these findings. MeOH appears to be formed from $\mathrm{CO}_{2}$ and $\mathrm{H}_{2}$, possibly through a surface formate intermecliate.

In any event, the hydrogenation of $\mathrm{CO}$ to $\mathrm{MeOH}$ can be guicled by catalysts that, unlike FT catalysts, do not dissociate the co molecule. It is known that Pd, Pt, Ir, and Cu catalysts chemisorb CO associatively and all are candidates for use in the synthesis of MeOH from SG. Copper-zinc catalysts are presently the catalysts of choice but there is active research on the synthesis of $\mathrm{MeOH}$ using $\mathrm{Pd}$ (and $\mathrm{Pt}$ ) catalysts. 11 
It appears Tikely that the active components in the copper-based catalysts are $\mathrm{Cu}^{\circ}-\mathrm{Cu}^{+}$species in a solid solution of $\mathrm{ZnO} .^{12}$ The catalyst loses its activity if the $S G$ is completely devoid of $\mathrm{CO}_{2}$. The $\mathrm{CO}_{2}$ and perhaps $\mathrm{H}_{2} \mathrm{O}$ or $\mathrm{O}_{2}$ may preserve copper in the $\mathrm{Cu}^{+}$state. In their absence, $\mathrm{Cu}^{+}$is gradually reduced to metallic copper. The copper-based catalysts, since they are more sensitive to poisoning and sinter more easily, have shorter life spans than the zinc oxide/chromium oxide base catalysts.

\section{1-2C. Kinetics}

The kinetics of the $\mathrm{MeOH}$ syntheses are complex and are affected by a number of variables, such as the nature of the catalyst, the physical changes of the catalyst as the reaction progresses, the composition of the gas (which is also constantly changing in the reactor), temperature, and pressure. Modern $\mathrm{MeOH}$ syntheses use copper-zinc low-pressure catalysts and, since the synthesis reaction proceeds to thermodynamic equilibrium very rapidly, the kinetic behavior of the catalyst is not so important. It should be noted that all commercial catalysts and hence their kinetic behavior are proprietary.

\section{1-2D. Feedstocks}

The primary raw material as the source of SG for producing $\mathrm{MeOH}$ at present is NG, which in 1980, accounted for $70 \%$ of worldwide production. Residual fuel oil, naphtha and coal are the other feedstocks. In 1980, they accounted for about 15,5 and under $2 \%$ of worldwide production, respectively. Steam reforming of $N G$ gives $S G$ with a one mole excess of $\mathrm{H}_{2}$ above the stoichiometric requirement for $\mathrm{MeOH}$ synthesis. The excess $\mathrm{H}_{2}$ can be purged and used as a fuel to generate steam. As mentioned earlier, by adding $\mathrm{CO}_{2}$ to $S G$, the excess $\mathrm{H}_{2}$ can be converted to MeOH. Steam reforming of naphtha gives the required ratio of $\mathrm{H}_{2} / \mathrm{CO}$. Partial oxidation of residual oil produces $S G$ with an $\mathrm{H}_{2} / \mathrm{CO}$ ratio of $1: 1$; this ratio must be shifted to achieve the required gas ratio. Nevertheless, this raw material is attractive, since the bottom of the crude oil barrel is profitably utilized. In the long run, more SG for $\mathrm{MeOH}$ manufacture will be made from coal. 


\section{1-2E. Process Technology and Reactors}

The production of $\mathrm{MeOH}$ is an established commercial technology. Nevertheless, constant improvements are being made in process technology and reactor design for better recovery, in lower compression costs, and in processing of the raw $\mathrm{MeOH}$. Marschner ${ }^{13}$ and Satterfield ${ }^{14}$ have summarized these subjects.

\section{1-2F. Liquid-Phase Methanol Synthesis}

An $\mathrm{MeOH}$ synthesis utilizing a liquid-phase slurry reactor is under development. This concept is being tested in a process-development unit at LaPorte, Texas, by Air Products and Chemicals, Inc., with the technical assistance of Chem. Systems. The project is jointly funded by the US DoE, Air Products, Fluor Corp., and EPRI. The construction of a pilot plant based on this technology using SG derived from coal is under consideration. The SG will probably be made in a Texaco gasifier so that the $\mathrm{H}_{2}$ :CO ratio will be low.

The liquid-phase reactor for $\mathrm{MeOH}$ synthesis, in design as well as in operating procedures, is basically similar to that originally proposed by Kolbel for FT synthesis. In laboratory-scale experiments, commercial and experimental $\mathrm{MeOH}-$ synythesis catalysts have been tested at $3.5-7.0 \mathrm{MPa}$ in the temperature range 488-523K. Because equilibrium conversion is favored by low temperature and the temperature is well-controlled in the slurry reactor, high single-pass conversion is possible. About $20 \%$ conversion of $\mathrm{CO}$ to $\mathrm{MeOH}$ with a feed gas of balanced composition can be expected. ${ }^{15}$

The SG used at LaPorte is a synthetic mixture of $\mathrm{H}_{2}, \mathrm{CO}, \mathrm{CO}_{2}$, and $\mathrm{CH}_{4}$, representing gas from conventional or high-temperature coal-gasifiers. In the tests conducted so far, the tail gases are not recycled; instead, they are used to generate power in gas turbines. But it is possible to enrich the exit gases from the reactor with $\mathrm{H}_{2}$ (by adding steam to the feed gas) so that part of the tail gas can be recycled.

\section{1-2G. Other Routes for Methanol Synthesis}

The production of $\mathrm{MeOH}$ from SG using low-pressure $\mathrm{Cu}-\mathrm{ZnO}$-based catalysts will remain dominant in the $\mathrm{MeOH}$ industry whether $\mathrm{NG}$ or coal is 
the feedstock. However, there are other reactions that produce $\mathrm{MeOH}$. One route is through the synthesis of methyl formate and its subsequent hydrogenation to $\mathrm{MeOH}$. The equations for this two-step synthesis are:

$$
\begin{gathered}
\mathrm{CH}_{3} \mathrm{OH}+\mathrm{CO} \stackrel{\mathrm{NaOCH}_{3}}{\longrightarrow} \mathrm{HCOOCH}_{3}, \\
\mathrm{HCOOCH}_{3}+2 \mathrm{H}_{2} \stackrel{\mathrm{Cu} \text { catalysts }}{\longrightarrow} 2 \mathrm{CH}_{3} \mathrm{OH},
\end{gathered}
$$

$$
\mathrm{CO}+2 \mathrm{H}_{2} \longrightarrow \mathrm{CH}_{3} \mathrm{OH} \text {. }
$$

Methyl formate $\left(\mathrm{HCOOCH}_{3}\right)$ is prepared by reacting $\mathrm{MeOH}$ and $\mathrm{CO}$ in the presence of a homogeneous sodium methoxide catalyst at $353 \mathrm{~K}$ and $3.0 \mathrm{MPa}$; this step is followed by the catalytic hydrogenation of methyl formate to $\mathrm{MeOH}$ at $453 \mathrm{~K}$ and 3.OMPa. Work by Trimm et a $1{ }^{16}$ has shown that the temperature and pressure required for hydrogenation of the formate to $\mathrm{MeOH}$ can be lowered significantly. The net result is the synthesis of two moles of $\mathrm{MeOH}$ per mole of starting $\mathrm{MeOH}$.

patent, ${ }^{17}$ in which the catalyst, operating temperature and pressure for the hydrogenation reaction are copper chromite, 373-443K and 2-6 $\mathrm{MPa}$, respectively. A pilot plant was built in Germany in 1945.18 The method may be attractive, since lower temperatures and pressures are used than even in the present low-pressure commercial processes. This route to $\mathrm{MeOH}$ from SG has high yields in both steps, thus avoiding the equilibrium constraints in the presently practiced $\mathrm{MeOH}$ synthesis.

Another route to $\mathrm{MeOH}$ involves the partial oxidation of $\mathrm{CH}_{4}$ and $\mathrm{C}_{2}-\mathrm{C}_{5} \mathrm{HCs}$. These compounds may be catalytically air-oxidated at $3.0 \mathrm{MPa}$ and around $723 \mathrm{~K}$ to 1 iquid and gaseous oxygenated products. Suitable catalysts for the process are iron, nickel and copper as metals, as oxides, or as mixtures of metals and oxides. Selectivity to $\mathrm{MeOH}$ is very poor; acetone and $C_{1}$ and $C_{2}$ aldehydes are produced in significant amounts. There is increasing research in this area.

Methanol has been synthesized using copper-thorium catalysts. ICI has developed a synthesis of $\mathrm{MeOH}$ using an alloy which contains copper with a metal other than radioactive thorium. This alloy catalyst operates at low temperatures $\left(\sim 100^{\circ} \mathrm{C}\right)$ and therefore gives high conversions to $\mathrm{MeOH}$. Unfortunately, the system is sensitive to $\mathrm{CO}_{2}$ and the cost of completely 
removing $\mathrm{CO}_{2}$ from the feed gas stream makes this process presently unattractive.

Workers at Brookhaven National Laboratory have discovered a low-temperature, low-pressure system, based on the use of a homogeneous transition metal complex, that yields a selectivity of over $99 \%$ of $\mathrm{MeOH}$ per pass. Further developments of this and similar systems will be of great interest.

\section{1-2H. Methanol from Coal}

Coal-based $\mathrm{MeOH}$ plants will be more costly and complex than NG plants because of the additional facilities needed to handle coal and solid residues and the required cleanup of resultant gases. The cost and complexity will also be influenced by the type of coal selected and the gasifier used. Some of the features of coal-to-MeOH technology, in which SG is derived from a second-generation slagging gasifier while the $\mathrm{MeOH}$ synthesis, at east for the near future, is accomplished by one of the low-pressure processes, are: (i) the gas is mainly $\mathrm{H}_{2}$ and $\mathrm{CO}$, with smaller amounts of $\mathrm{CO}_{2}$, and is virtually free of $\mathrm{CH}_{4}$; (ii) it is at a much higher temperature than the MeOH-synthesis temperature; (iii) the SG is compressed to 3 to $8 \mathrm{MPa}$, thereby eliminating the cost of compression to the $\mathrm{MeOH}-$ synthesis pressure; and (iv) it has a low value for the $\mathrm{H}_{2} / \mathrm{CO}$ ratio.

The low level of $\mathrm{CO}_{2}$ and $\mathrm{CH}_{4}$ minimizes the buildup of inerts in the MeOH-synthesis loop, thus reducing the amount of purge gas. Excess heat can be recovered in high-pressure steam generators and the steam produced may be used to run compressors and to generate electricity. But the SG is deficient in $\mathrm{H}_{2}$ and additional units may have to be added to the plant. The $\mathrm{H}_{2} / \mathrm{CO}$ ratio must be adjusted to $2: 1$ or slightly higher by the WGS reaction. Since the shift reaction is exothermic, the heat may be recovered to generate additional high-pressure steam. It is probably not economical to have more than $15 \%$ of $\mathrm{CO}_{2}$ in the feed gas.

The gasifier is a vitally important part of a coal-to-MeOH plant. It influences the synthesis pressure and thus the selection of the commercial synthesis process. It also determines the extent to which the SG must be shifted and the specific plant design to optimize waste heat recovery at different stages. In spite of this complexity, a large coal-to-MeOH industry may well be a reality one day. Several conceptual 
plant designs with economic evaluations are available. ${ }^{19,20}$ Moreover, three units of a coal-to-MeOH plant (the shift converter, acid-gas removal unit and $\mathrm{MeOH}$ converter) are fairly well-proven processes. Among the second-generation gasifiers, the Texaco gasif:er is commercially proven and is in operation in several plants. Shell is building a 200-400 TPD of coal unit using a dry feed system to the gasifier. Other coal-gasification systems of interest have been reviewed. 21

\section{1-2I. Methanol and Higher Oxygenated Compounds as Fuels}

Chemicals from $\mathrm{MeOH}$, though now important, will probably be made from excess $\mathrm{MeOH}$ or SG manufactured primarily for fuel use. Methanol is used as a gasoline extender, as a neat fuel for automobiles, in the synthesis of methyl tert-butyl ether (MTBE) which is an octane extender, as a turbine fuel, and as a source of $\mathrm{CO}$ and $\mathrm{H}_{2}$ for the synthesis of transportation fuel. Alcohols were used as transportation.fuels in the early part of the 20th century until cheap gasoline made its appearance. BY 1937, some 70,000 tons of synthetic $\mathrm{MeOH}$ were used in vehicles in Germany. Methanol has been and still is used in racing cars because of increased power obtainable compared to gasoline. Blends of ethanol in gasoline have been in commercial use in Cuba, South Africa and South America for some years.' A number of surveys and reviews have been published on the use of alcohols as automotive fuels. $22-25$

Europe's dependence on imported petroleum, coupled with the 1973 embargo, led Germany to sponsor a comprehensive study on the use of $\mathrm{MeOH}$ and $\mathrm{H}_{2}$ as fuels. Studies on $\mathrm{MeOH}$ as an additive to gasoline have continued since 1975, often with US government support. ${ }^{26}$ In 1976, the Swedish Methanol Development Co. sponsored the first international meeting on $\mathrm{MeOH}$ at the Royal Swedish Academy. 27 Methanol may ultimately be made from remote sources of NG, from coal, and eventually from renewable resources.

Electric utilities have been interested in $\mathrm{MeOH}$ as a fuel on a large scale for peak loads in turbines. Methanol and ethanol are already in use as gasoline additives. The use of neat MeOH will probably be 1 imited initially to fleets in selected regions; hundreds of cars are being tested on neat $\mathrm{MeOH}$ in $\mathrm{Ca}$ lifornia. Gasohol, a blend of $10 \%$ ethanol and $90 \%$ gasoline, has been used in Nebraska for many years and has been sold 
throughout the US. Over a million cars are fueled by neat ethanol or 10 to $20 \%$ ethanol-gasoline mixtures in Brazil.

Methanol differs from a typical gasoline component such as isooctane in that it is a polar molecule with oxygen constituting half of its weight; it thus picks up water easily. It is an attractive gasoline additive. It has a higher octane rating than isooctane and is manufactured all over the world from SG that is obtainable from almost any organic resource. Phase separation (caused by water pick-up), possible corrosion of some engine parts and volatility considerations rule out the use of straight $\mathrm{MeOH}$ or gasoline mixed with large amounts of $\mathrm{MeOH}(>5 \%)$, except for cars that are specially built for use of these fuels. Arco received EPA approval for a MeOH plus cosolvent mixture with gasoline and sold the product in parts of New York State and in Pennsylvania until about 1985. Arco's additive consisted of $4.75 \% \mathrm{MeOH}$ and $4.75 \%$ TBA (tert-butyl alcohol) in $90.5 \%$ unleaded gasoline. Blending $5 \% \mathrm{MeOH}$ and $5 \%$ cosolvent into all gasoline used in the US could reduce crude oil imports by over $200 \mathrm{millij}$. BPY. However, no suitable distribution system exists for such a blend.

Two other points are pertinent. Emissions from the MEOHcosolvent-gasoline blends are lower than from straight gasoline. Also, the cosolvent is not limited to TBA; other alcohols and ethers may be used as cosolvents.

It is possible that MeOH-gasoline blends will serve as a bridge between straight gasoline and straight $\mathrm{MeOH}$. EPA has lowered the allowable addition of tetraethyllead to gasoline to 0.1 gram per gallon; octane enhancement by added alcohols and ethers may therefore become necessary to retain octane ratings.

But the MeOH-gasoline blending picture is complex. It has been stated $^{28}$ that coal-based processes for the synthesis of MeOH will eventually win out but $N G$ will have the edge for a long time to come.

A rapidly growing use of $\mathrm{MeOH}$ as a fuel is in the synthes is of methyl tert-butyl ether (MTBE). This ether was approved by EPA in 1979 as an octane enhancer for unleaded gasoline at concentrations of $7 \%$ or less by volume. MTBE capacity in the US grew from zero in 1970 to 2.18 million metric tons in 1985 and its projected growth seems to be limited only by the availability of isobutene.

The MTBE-gasoline blend provides a number of advantages over 
$\mathrm{MeOH}-\mathrm{gasoline}$ blends. It has a lower oxygen content, less severe water separation problems, fewer front-end volatility effects, and also has a high octane quality. In addition, MTBE is useable in all proportions with gasoline. it is, however, more expensive than $\mathrm{MeOH}$ as a gasoline extender. Methanol as a fuel in stationary combustion turbines for peak loads of electric utilities has often been mentioned. Large amounts of a reliable source of the alcohol would be needed to avoid the possibility of brownouts. Crude oil prices must eventually rise and, when they do, $\mathrm{MeOH}$ potential as a fuel may be realized.

Methanol is an excellent gas-turbine fuel, although it may be necessary to modify turbines somewhat. The sodium content of the fuel in a gas turbine should be kept below $1 \mathrm{ppm}$. MeOH readily picks up water and the water could be contaminated with alkali slats. On the other hand, MeOH as a gas-turbine fuel has low pollutant emissions, good performance and good handling and storage properties. In any case, supply and cost are the main factors which will influence the introduction of $\mathrm{MeOH}$ as a turbine fuel.

\section{1-2J. Dissociated Methanol as a Fuel For Automobiles and Gas Turbines}

It is well known that $\mathrm{MeOH}$ dissociates into $\mathrm{CO}$ and $\mathrm{H}_{2}$ as the temperature is raised and the pressure is lowered according to the process

$$
\mathrm{CH}_{3} \mathrm{OH} \underset{\text { high } \mathrm{p}, \text { low } \mathrm{T}}{\stackrel{\text { low } \mathrm{p} \text {, high T }}{\rightleftharpoons}} 2 \mathrm{H}_{2}+\mathrm{CO} \text {. }
$$

At equilibrium, over $80 \%$ of the $\mathrm{MeOH}$ is dissociated at $1 \mathrm{MPa}$ and $473 \mathrm{~K}$. For this reason, the $\mathrm{MeOH}$-combustion characteristics are similar to those of SG. The major difference in properties is caused by the heat of dissociation of $\mathrm{MeOH}$, which is $90.56 \mathrm{~kJ} / \mathrm{mol}$ at $298 \mathrm{~K}$ and $1 \mathrm{~atm}$ for the gas (13.4\% of the LHV) and $128.5 \mathrm{~kJ} / \mathrm{mol}$ at $298 \mathrm{~K}$ for liquid $\mathrm{MeOH}$ (20.1\% of the LHV). It is possible, however, that a significant amount of exhaust heat used to evaporate and dissociate $\mathrm{MeOH}$ may be recovered and this is what is generally counted on in automotive use.

Dissociated $\mathrm{MeOH}$ may offer higher efficiencies than conventional liquid fuels for three reasons: (i) the just noted waste heat recovery, (ii) extended lean misfire limits, and ( $i i i)$ higher allowable compression ratios. Also, exhaust emissions are lower. At 573K, a temperature which matches the available heat in an engine exhaust, equilibrium favors $99.9 \%$ conversion of $\mathrm{MeOH}$ to $\mathrm{CO}$ and $\mathrm{H}_{2}$, although side reactions can occur. A 
number of catalysts, including $\mathrm{Pt}, \mathrm{Pd}, \mathrm{Cu}, \mathrm{Zn}$, etc. are known to be active in the dissociation of $\mathrm{MeOH}$.

The application of $\mathrm{MeOH}$ dissociation in combustion turbines has been discussed by Finegold et al. 29 Woodley et al. ${ }^{30}$ have compared some advantages of burning liquid $\mathrm{MeOH}$, dissociated $\mathrm{MeOH}$, and steam-reformed $\mathrm{MeOH}$.

\section{1-2K. Ethanol as a Transportation Fuel}

Methanol is toxic to humans. Ethanol $\left(\mathrm{CH}_{3} \mathrm{CH}_{2} \mathrm{OH}\right)$ is somewhat less polar than $\mathrm{MeOH}$ but the additional $\mathrm{CH}_{2}$ group converts it into a beverage made and consumed in a great variety of forms all over the world. The $\mathrm{CH}_{2}$ group also greatly influences the properties of ethanol as a transportation fuel. Ethanol is more $\mathrm{HC}-1$ like than $\mathrm{MeOH}$ and is therefore more soluble in gasoline. Ethanol has a higher boiling point than $\mathrm{MeOH}$ (351.3 vs 337.7K), while their specific gravities are essentially the same. The oxygen atom in $\mathrm{MeOH}$ comprises half of its molecular weight, whereas, in ethanol, only $34.7 \%$ of the molecular weight of the molecule is due to oxygen; ethanol is thus less hygroscopic. The LHV of $\mathrm{MeOH}$ is $56,560 \mathrm{BTU} / \mathrm{ga} 1$ lon $(8,600 \mathrm{BTU} / \mathrm{lb})$; that for ethanol is considerably higher, 75,670 BTU/gallon (11,500 BTU/1b). Both have excellent research octane ratings (106-108). The chemical and physical properties of ethanol make it a better gasoline extender.

The manufacture of ethanol has an interesting history, one that is presently changing rapidly. Ethanol for human consumption has been made by the fermentation of naturally occurring carbohydrates since prehistoric times. Such ethanol is still made by fermentation.

The first synthetic ethanol for industrial use was produced about 1930 in the US. It involved the hydration of ethylene with water in the presence of an acid catalyst. From almost complete dependence on fermentation processes until the late 1920s, over $95 \%$ of ethanol for industrial consumption was made synthetically from ethylene in the $1970 \mathrm{~s}$. But, with the growing use of ethanol in transportation fuels initiated as a result of the 1973 oil embargo, the production ration of fermentation ethanol to synthetic ethanol grew rapidiy.

The use of alcohol fuels has been studied for many years in a number of countries. In 1907, for instance, the US Department of 
Agriculture published a report on the use of alcohol-gasoline mixtures in farm engines. 31 Interest in grain alcohol was given impetus by the oil embargo in 1974. Since then, a great deal of work has been focused on the use of ethanol as a gasoline extender, octane enhancer or as an alternative fuel. There are many studies dealing with engine performance, emission characteristics and the advantages and problems associated with ethanol use in conventional spark-ignition engines. 32 US production of fermentation alcohol for fuel use was about 80 million gallons in 1979. A year later, production of ethanol by fermentation neared 300 million gallons, with production by fermentation continuing to grow. Gasohol and neat ethanol are now used in many countries, especially Brazil.

Ethanol from the fermentation of grain has been made competitive as a transportation fuel in the US largely because of federal and state subsidies aimed at reducing US dependence on imported oil. It is possible that US. production of fermentation alcohol may rise to about a billion gallons by 1990 and may then invade the industrial market of more than 200 million gallons.

Since this study deals with the use of $S G$, we shal1 not further explore the production of fermentation alcohol. We note, however, the important question as to the economic viability of using arable land for the production of fuel rather than food.

\section{1-2L. Ethanol from SG}

What are the possibilities of obtaining ethanol and higher alcohols directly from SG? This conversion would seem to be highly desirable because it would eliminate the need for subsidies and return some land for other uses. In the long run, ethanol from SG may be cheaper than fermentation alcohol and be independent of ethylene made from (imported) petroleum. Ethanol and higher alcohols are better energy-storage chemicals and are less toxic and corrosive than $\mathrm{MeOH}$.

Ethanol and other $\mathrm{C}_{2}$-oxygenated compounds have been synthesized directly from SG using modified FT catalysts. Ichikawa ${ }^{33}$ studied rhodium catalysts on several moderately acidic oxides such as $\mathrm{La}_{2} \mathrm{O}_{3}, \mathrm{TiO}_{2}, \mathrm{CeO}_{2}$, and $\mathrm{ZrO}_{2}$ as supports. He obtained large yields of ethanol and other $\mathrm{C}_{2}$ 
oxygenated compounds such as acetaidehyde and some acetates. A heterogeneous catalyst prepared from $\mathrm{Rh}_{4}(\mathrm{CO})_{12}{ }^{-\mathrm{La}_{2} \mathrm{O}_{3}}$ catalysts yielded, using $1 \mathrm{~atm}$ of $S G$ at $473 \mathrm{~K}$, the following product distribution based on carbon efficiency (\%): $\mathrm{CH}_{3} \mathrm{OH}, 10 ; \mathrm{CH}_{3} \mathrm{CH}_{2} \mathrm{OH}, 49 ; \mathrm{CH}_{3} \mathrm{CHO}+\mathrm{CH}_{3} \mathrm{Coor}, 2 ; \mathrm{CH}_{4}$, $14 ; \mathrm{C}_{2}-\mathrm{C}_{4}, 6 ; \mathrm{CO}_{2}$ + other products, 8 .

This is a lucrative field for further investigation. A synthesis of ethanol directly for SG with over $90 \%$ selectivity would be a great step forward in the manufacture of transportation fuels and chemicals directiy from $S G$.

\section{1-2M. The Homologation of Methanol to Ethanol}

The homologation or reductive carbonylation of $\mathrm{MeOH}$ to yield ethanol plus acetaldehyde and acetates has been extensively studied but has not yet been commercialized. Homogeneous transition metals have been used as catalysts 34,35 in the process

$$
\mathrm{CH}_{3} \mathrm{OH}+2 \mathrm{H}_{2}+\mathrm{CO} \underset{\mathrm{RuCl}_{3}, \mathrm{I}_{2}}{\stackrel{\mathrm{CO}_{2}(\mathrm{CO})_{8}}{\longrightarrow}} \mathrm{CH}_{3} \mathrm{CH}_{2} \mathrm{OH}+\mathrm{H}_{2} \mathrm{O} .
$$

While the methanation of $\mathrm{MeOH}$ is the most thermodynamically favored reaction at $298 \mathrm{~K}$ and $0.1 \mathrm{MPa}$, the formation of ethanol is almost as favorable. At higher temperatures, ethanol and $\mathrm{CH}_{3} \mathrm{CHO}$ become less favored at the expense of dimenthyl ether and $\mathrm{CO}_{2}$. The synthesis of ethanol is thermodynamically more strongly favored as the pressure is raised to $10 \mathrm{MPa}$. The principal problem is kinetic control over the number of possible reaction products $\left(\mathrm{CH}_{4}\right.$, acetates, acetic acid, dimethyl ether, acetals, and $\left.\mathrm{CO}_{2}\right)$.

Cobalt complexes were used first and are good catalysts in their activity and selectivity for the conversion of $\mathrm{MeOH}$ and $\mathrm{SG}$ to ethanol and $\mathrm{CH}_{3} \mathrm{CHO}$. Rhodium, usually more active than cobalt in homogeneously catalyzed reactions involving $\mathrm{MeOH}$ and $\mathrm{SG}$, produces acids and esters, with ethanol a significant product at high $\mathrm{H}_{2}$ partial pressures $\left(\mathrm{H}_{2} / \mathrm{CO}=40: 1\right)$.

Operating temperatures in the 450-485K range are usually used with cobalt. As the temperature rises, selectivity to ethanol increases at the expense of acetaldehyde. A rise in pressure increases conversion of $\mathrm{MeOH}$ while product selectivity also remains constant. At high Co partial 
pressures, the competing alcohol carbonylation dominates and over $70 \%$ selectivity to methyl acetate is observed. At high $\mathrm{H}_{2}$ partial pressures, the catalyst tends to decompose to metal with an accompanying loss of $\mathrm{MeOH}$ to $\mathrm{CH}_{4}$ and dimethyl ether. The highest ethanol selectivity is obtained at. $\mathrm{H}_{2} / \mathrm{CO}$ ratios of $1: 1$.

The most significant discovery in $\mathrm{MeOH}$ homologation has been the rate of enhancement associated with addition of iodine or iodide. This enhancement arises mostly from the in situ formation of $\mathrm{CH}_{3} \mathrm{I}$, which reacts with SG much faster than does $\mathrm{MeOH}$. By the use of cocatalysts, a selectivity to acetaldehyde above $60 \%$ can be obtained at $68 \%$ conversion. For the production of ethanol, ruthenium has been found to be the best cocatalyst since all of the aldehyde is hydrogenated to ethanol. As an example, the use of cobalt acetate, $\mathrm{I}_{2}, \mathrm{RuCl}_{3}$, and $\mathrm{PPh}_{3}$ at $450 \mathrm{~K}$ and $27.2 \mathrm{MPa}$ converts $43 \%$ of $\mathrm{MeOH}$ to ethanol with a selectivity of $80 \% .^{36,37}$ The addition of tertiary phosphine ligands to the catalyst has two desirable effects: greater catalyst stability and enhanced ethanol selectivity.

In conclusion, the cobalt-carbonyl-catalyzed reductive carbonylation of $\mathrm{MeOH}$ with SG to produce acetaldehyde, ethanol and acetates is a complicated system which allows a remarkable high degree of kinetic control over the thermodynamically favored product mixture; however, selectivities to ethanol of $80 \%$ are rare. While the chemical reactions and promoter effects are fairly well understood, it is difficult to see how the system can be perturbed to furnish higher activities or selectivities approaching the carbonylation of $\mathrm{MeOH}$, for which over $99 \%$ selectivity to acetic acid is achieved. The diverse mixture of products coupled with low activity make $\mathrm{MeOH}$ reductive carbonylation an unlikely source of ethanol. A possible use of the product mixture is as a fuel blend.

Chen et al. ${ }^{38}$ have shown that iron or ruthenium, promoted by a tertiary amine, catalyze the homologation of $\mathrm{MeOH}$ to ethanol at SG pressures near $30 \mathrm{MPa}$ and temperatures of about $475 \mathrm{~K}$. Carbon dioxide rather than water is the by-product and no alcohols higher than ethanol are formed, nor are acetates or acetals produced $\left(\mathrm{CH}_{3} \mathrm{OH}+\mathrm{H}_{2}+2 \mathrm{CO} \longrightarrow 2 \mathrm{CH}_{3} \mathrm{CH}_{2} \mathrm{OH}+\mathrm{CO}_{2}\right)$. This reaction calls for further study, although reaction rates appear to be somewhat low. 


\section{1-2N. The Synthesis of Higher Alcohols}

In 1923, Fischer and Tropsch ${ }^{2,39}$ used alkalized iron catalysts to obtain mostly oxygenated products from SG; they called this the Synthol process. It was carried out at 460 to $500 \mathrm{~K}$ and $2 \mathrm{MPa}$ and the product contained up to 70 wt\% of alcohols with carbon numbers up to $C_{20}$. The aim at the time, however, was to obtain $\mathrm{HCs}$ by the hydrogenation of CO. In 1953, Anderson $^{39}$ found that iron nitrides were durable, unique catalysts for the FT synthesis, yielding about $40 \mathrm{wt} \%$ of alcohols.

It has long been known that MeOH-synthesis catalysts promoted with alkali and containing up to three metal oxides yielded higher alcohols [1-propanol and 2-methyl-1-propanol (isobutano 1)] together with the expected $\mathrm{MeOH}$. The catalysts for this synthesis generally operated at about 675 and $20 \mathrm{MPa}$ and lower space velocities than are employed for the usual $\mathrm{MeOH}$ synthesis. Cesium, rubidium and potassium were the most active promoters, with potassium obviously the most practical promoter.

Although the higher alcohols $\left(C_{1}-C_{6}\right.$ especially) are desirable products for fuel use, there has been a paucity of studies dealing with the quantitative aspects of the kinetics and selectivity for these promoted $\mathrm{MeOH}$ catalysts which did not contain copper. The effect of promoting the more active, low-pressure, $\mathrm{Cu} / \mathrm{ZnO} \mathrm{MeOH}$-synthesis catalysts has been reported mostly in the patent literature.

Work has lately begun to center on the use of MeOH-synthesis catalysts combined with FT catalysts, often in the presence of alkali. Courty et al. ${ }^{40}$ at the Institut Francais du Petrole (IFP) have been studying the synthesis of higher alcohols. IFP and Japan's Idemitsu Kosan, both members of RAPAD (Research Association for Petroleum Alternative Development), have been working on syntheses of higher alcohols. Mixed alcohols of up to 30 wt\% of $\mathrm{C}_{2}$ and higher alcohols have been produced using alkalinized zinc and chromium oxides. Using copper-cobalt catalysts, up to 70wt\% of heavier alcohols were obtained at moderate conditions. Copper, cobalt, zinc, aluminum, and sodium oxides have been used, as well as copper, cobalt, chromium, and mixed alkali oxides.

The Idemitsu Kosan Company has built a 7000 BPD demonstration plant in Japan based on IFP's design. 41 First runs confirmed bench-scale 
tests, with $\mathrm{C}_{1}-\mathrm{C}_{6}$ alcohols forming more than $99 \%$ of the product. The alcohol mixture appears to resemble tert-butyl alcohol as far as compatibility with gasoline is concerned.

The reduced cobalt probably acts às an FT catalyst, dissociating CO to furnish the alkyl part of the alcohols, while the action of the copper resembles its role in $\mathrm{MeOH}$ synthesis. Work is proceeding on understanding the mechanisms involved in these complex catalytic reactions. The procedures used in their preparation are critical, especially to avoid FT active catalysts which would yield HCs.

\section{1-3. SG as a Source of Chemicals}

Of the thirty top organic chemicals (in terms of weight) manufactured in the US in 1985, al1 but seven are or can be produced from SG. ${ }^{42}$ Several of these are also used as fuels. SG is composed of various ratios of $\mathrm{H}_{2}$ and $\mathrm{CO}$.

The largest use of SG in the world is in the manufacture of molecular hydrogen, and most of the $\mathrm{H}_{2}$ used worldwide is made from $S G$.

\section{1-3A. $\underline{H}_{2}$ Manufacture}

Hydrogen can be separated cryoscopically or chemically from SG. The $\mathrm{CO}$ is SG is usually converted to an equivalent amount of $\mathrm{H}_{2}$ via the water gas shift (WGS) reaction

$$
\mathrm{CO}+\mathrm{H}_{2} \mathrm{O} \longrightarrow \mathrm{H}_{2}+\mathrm{CO}_{2} \text {. }
$$

Hydrogen is used above all for the manufacture of ammonia:

$$
\begin{aligned}
& \mathrm{Fe}_{2} \mathrm{O}_{3} \\
& \mathrm{~N}_{2}+3 \mathrm{H}_{2} \underset{200 \quad 350 \mathrm{~atm}}{\longrightarrow} 2 \mathrm{NH}_{3} .
\end{aligned}
$$

As was stated earlier, about 5 trillion SCF of SG are used worldwide in $\mathrm{NH}_{3}$ synthesis. 
Hydrogen has many other uses and there is no doubt that the demand for this chemical will grow. It is employed in numerous hydrogenation reactions to saturate aromatics or other molecules cortaining doubile bonds. It is used in hydrocracking heavy oils, in hydrodealkylation reactions, hydrorefining, hydrodesulphurization reactions, etc. Hydrogen is used to upgrade petroleum residua, which constitute a growing part of the petroleum barrel. Synthetic fuels, when and if they are produced, will consume enormous amount of $\mathrm{H}_{2}$, essentially all of which well be derived from SG.

\section{1-3B CO Manufacture}

CO is isolated from SG by cryogenic liquefaction or by selective absorption in cuprous ammonium salt solutions. Reactions involving the addition of $\mathrm{CO}$ to another molecule are called carbonylation reactions; those involving the reaction of both $\mathrm{CO}$ and $\mathrm{H}_{2}$ (SG) with another chemical are called reductive carbonylations; those involving oxygen and $\mathrm{CO}$ are called oxidative carbonylations. These terms are helpful in describing the many reactions of $S G$, especially the conversion of $\mathrm{MeOH}$ to various chemicals.

\section{1-3C. Methanol as a Chemical, Chemical Precursor and Fuel}

In 1980, of the trillion SCF of SG used in the synthesis of MeOH, NG feedstock accounted for $75 \%$ of US and $70 \%$ of worldwide MeOH capacity. Methanol made from residual fuel oil accounted for about $15 \%$ of domestic and worldwide $\mathrm{MeOH}$, naphtha was used to produce $5 \%$, and coal was the raw material for under $2 \%$ of worldwide production. Methanol promises to continue to be not only one of many feedstock chemicals in the future but also an extensively used clean fuel. It is the precursor to a large and growing number of important organic chemicals that have significant uses. Historically, almost half of $211 \mathrm{MeOH}$ produced has been converted to formaldehyde ( $\mathrm{HCHO}$ ), which is a precursor to a number of chemicals. In the future, formaldehyde will lose this position because of $\mathrm{MeOH}$ use in the production of faster growing chemicals (acetic acid, acetic anhydride, methyl-t-butyl ether, etc.). Methanol conversion to gasoline, olefins and 
aromatics via Mobil's MTG process will account for increasing use of this compound.

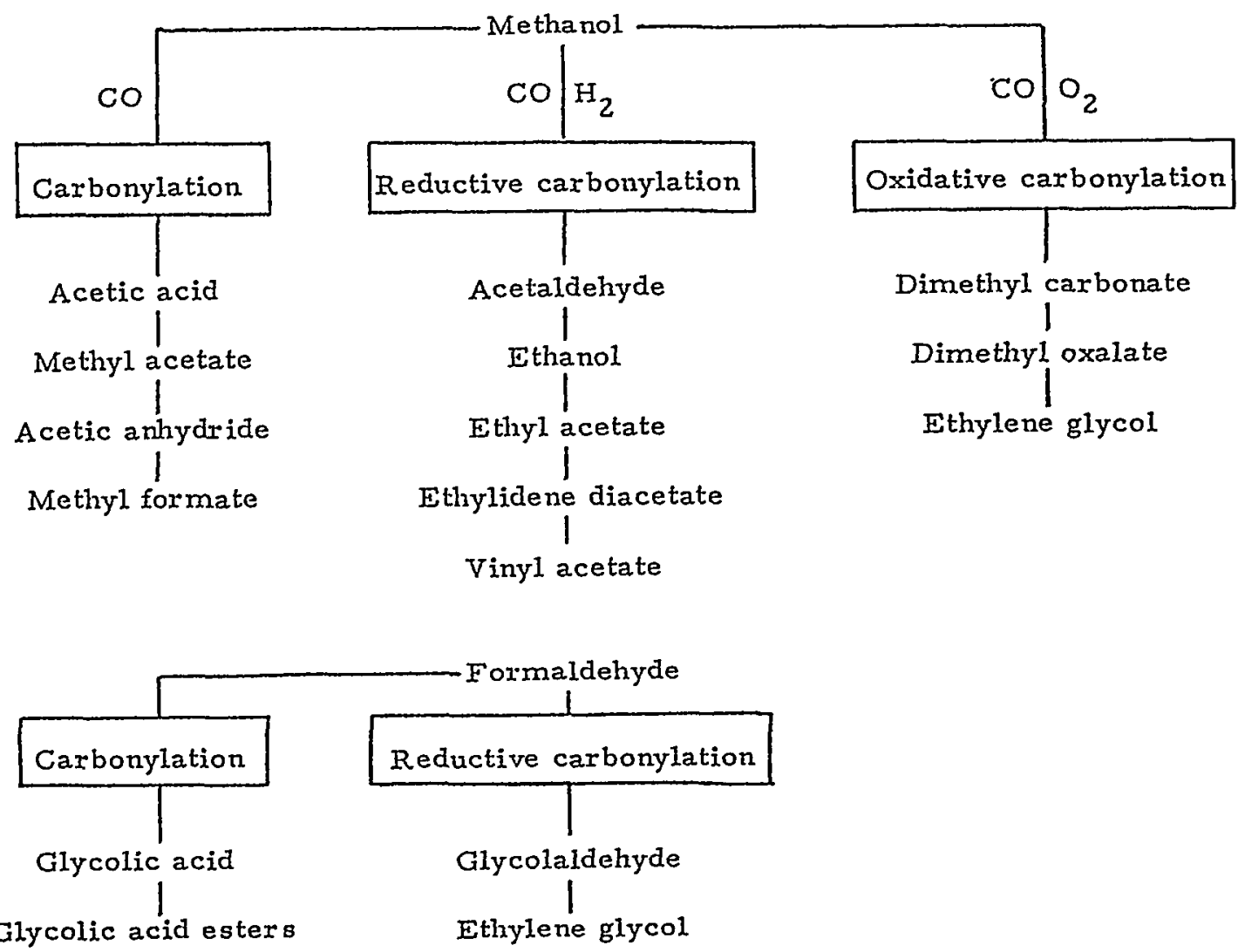

FIg. 5.1-4. Scope of methanol-syngas chemistry.

Chemicals made from $\mathrm{MeOH}$ can be divided into two classes: those now made commercially and those that are emerging commercial processes. The former include formaldehyde, methyl formate, formic acid, acetic acid, methy 1 acetate, chlorinated methanes, methylamines, dimethyl acetate, vinyl acetate, ethylene glycol, styrene, and dimethyl terephthalate. The scope of $\mathrm{MeOH}-\mathrm{SG}$ chemistry is indicated in Fig. 5.1-4.

5.1-3D Forma 1dehyde ( $\mathrm{HCHO})$

Formaldehyde is made from $\mathrm{MeOH}$ by dehydrogenation in the presence of $\mathrm{Ag}$ or $\mathrm{Cu}$ catalysts or by oxidation of $\mathrm{MeOH}$ in the presence of 
iron-containing $\mathrm{MOO}_{3}$ catalysts. Apart from direct applications of aqueous HCHO solutions (formalin), e.g., as a disinfectant and preservative and in the textile, leather, fur, and paper and wood industries, most HCHO is used for the manufacture of resins with phenols, urea and melamine. A number of other chemicals are made commercially from $\mathrm{HCHO}$, including polyhydric alcohols, butynediol, isoprene, and $\beta$-propiolactone.

\section{1-3.E. Acetic Acid $\left(\mathrm{CH}_{3} \mathrm{COOH}\right)$}

About 3 billion pounds of this important chemical were produced in the US in 1985. As late as 1973, about $40 \%$ of the acetic acid capacity was made by oxidation of the acetaldehyde produced via the Wacker process, which was based on the oxidation of ethylene. All processes for the production of acetic acid have been or are being steadily replaced by processes based on the carbonylation of $\mathrm{MeOH}$, so that SG rather than ethylene or other $\mathrm{HCS}$ is now the raw material of choice for acetic acid manufacture.

In 1960 , BASF introduced the carbonylation of $\mathrm{MeOH}$ to acetic acid using a cobalt catalyst in $180^{\circ} \mathrm{C}$ and 3,000 to 10,000 psig: $\mathrm{CH}_{3} \mathrm{OH}+\mathrm{CO} \longrightarrow$ $\mathrm{CH}_{3} \mathrm{COOH}$. In 1976, two plants based on this technology were built in the FRG (35,000 TPY) and in the US (52,000 TPY), but then a new process took over. In the mid-sixties, the Monsanto Co. discovered that rhodium plus iodine was a considerably more active catalytic system for MeOH carbonylation than cobalt. In this process, $\mathrm{MeOH}$ and $\mathrm{CO}$ react in the liquid phase at $150-200^{\circ} \mathrm{C}$ at pressures below 500psi to form acetic acid with selectivities of over $99 \%$ (based on $\mathrm{CH}_{3} \mathrm{OH}$ ) and over $90 \%$ (based on $\mathrm{CO}$ ). In 1970, the first industrial plant went on-stream in Texas City; its capacity was 150,000 TPY of acetic acid. The rhodium-catalyzed carbonylation of $\mathrm{MeOH}$ to acetic acid is the process of choice and all new plants will use this process with SG as the only raw material used.

Vinyl acetate is the principal outlet for acetic acid in the US (40wt\%). Half as much goes into making cellulose acetate (22\%). Another $10 \%$ is used in the production of butyl and isopropyl acetates, acetyl chloride and acetamide. There are many other growing uses for the cheap acetic acid produce by the carbonylation of $\mathrm{MeOH}$.

In 1984, the Tennessee Eastman Co. started up the first integrated facility for the production of chemicals from coal at Kingsport, TN (Fig. 5.1-3). About 900 TPD of the high-sulfur bituminous coal are ground in 
water to form a slurry of 55 to $65 \mathrm{wt} \%$ by weight of the coal in water. The coal contains from 12 to $15 \mathrm{wt} \%$ of mineral matter. The slurry is fed to two Texaco gasifiers, each gasifying 200 gallons per minute of slurry. Each gasifier can provide all of the SG needed for the plant. The plant will produce about 500 million pounds per year of acetic anhydride.

The complex contains eleven separate units, four involved in the gasification of coal, four for SG preparation or by-product recover, and three of the synthesis of $\mathrm{MeOH}$, methyl acetate and acetic anhydride. The reactions involved are:

$$
\begin{aligned}
& \mathrm{Cu}-\mathrm{ZnO} \\
& 2 \mathrm{H}_{2}+\mathrm{CO} \longrightarrow \mathrm{CH}_{3} \mathrm{OH} \text {, } \\
& \mathrm{Rh} \\
& \mathrm{CH}_{3} \mathrm{OH}+\mathrm{CO} \longrightarrow \mathrm{CH}_{3} \mathrm{COOH} \text { (acetic acid) } \\
& \mathrm{CH}_{3} \mathrm{OH}+\mathrm{CH}_{3} \mathrm{COOH} \stackrel{\mathrm{H}^{+}}{\longrightarrow} \underset{\substack{\mathrm{CH}_{3} \mathrm{COCH}_{3}+\mathrm{H}_{2} \mathrm{O} \\
\text { (methyl acetate) }}}{\mathrm{O}} \text {, }
\end{aligned}
$$

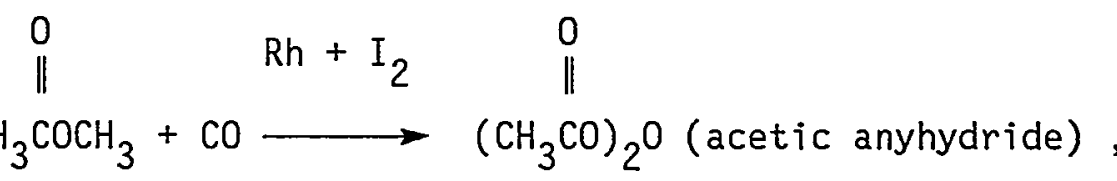

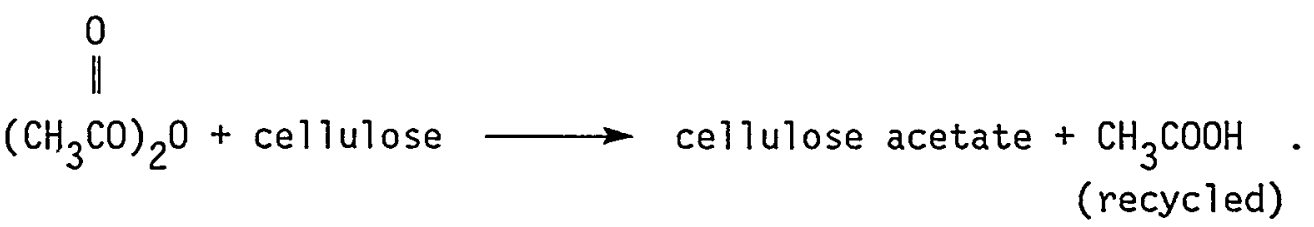

A11 of these reactions, except for reaction (5.1-15), are known commercial reactions. A number of new catalytic systems for the conversion of methy 1 acetate to acetic anhydride have been developed by Tennessee Eastman and some were developed by Hancon International. Patents for this conversion have been obtained by Halcon, Hoechst, Ajinomoto, and Showa Denkon using rhodium as the catalyst. Halcon and Mitsubishi Gas Chemical Co. have also been granted patents for the use of a less expensive nickel catalyst for this conversion. It is probably that acetic anhydride is similar to MeOH carbonylation to acetic acid.

Eastman views this project as currently economically viable. Eastman's location near substantial reserves of high-grade coal is a 
positive factor. It is possible that Eastman stands to be the first company to develop a whole series of important oxygenated chemicals from coaT-derived SG.

5.1-3F. Methyl Formate, Formamide, and Formic Acid ( $\mathrm{HCOOH})$

These chemicals are also made from $\mathrm{MeOH}$ and $\mathrm{CO}$ but in the presence of a base catalyst rather than a transition-metal catalyst. The reactions are

$$
\begin{aligned}
& \mathrm{NaOCH}_{3} \\
& \mathrm{CH}_{3} \mathrm{OH}+\mathrm{CO} \longrightarrow \mathrm{HCOOCH}_{3} \text { (methyl formate), } \\
& 343^{\circ} \mathrm{C} \\
& \text { 2-20MPa } \\
& \mathrm{NH}_{3} \\
& \mathrm{HCOOCH}_{3} \longrightarrow \underset{\text { (formamide) }}{\mathrm{HCONH}}+\mathrm{CH}_{3} \mathrm{OH}, \\
& \mathrm{H}_{2} \mathrm{SO}_{4} \\
& \mathrm{HCONH}_{2} \longrightarrow\left(\mathrm{NH}_{4}\right)_{2} \mathrm{SO}_{4}+\mathrm{HCOOH} \text { (formic acid) }
\end{aligned}
$$

World production of formic acid is about 100,000 TPY.

\section{1-4. Fischer-Tropsch Synthesis}

\section{1-4A. Catalysts and Chemistry of FT Syntheses}

The Fischer-Tropsch (FT) synthesis was first put into commercial operation by Viktor-Rauxel in 1935.43 Numerous FT catalysts have been discovered since then. Of these, $\mathrm{Fe}, \mathrm{Co}, \mathrm{Ru}$, and $\mathrm{ThO}_{2}$ are of special interest. Both Fe and $\mathrm{Co}_{0}$ were used in commercial applications, but only $\mathrm{Fe}$ is employed at the SASOL plant in South Africa since it is inexpensive and allows versatile applications.

The catalysts $\mathrm{Fe}$ and $\mathrm{Co}$ are used at moderate pressure (up to about 450 psig) to produce paraffins and olefins. Iron catalysts generally produce large amounts of olefins and some oxygenates. Ruthenium and $\mathrm{ThO}_{2}$ catalysts are used at high pressure (up to 14,000 psig). The Ru catalysts 
are applied in paraffin wax production, while $\mathrm{ThO}_{2}$ catalysts are used to make isoparaffins. During the early period of FT process development, $\mathrm{Ni}$ catalysts were also employed. They are predominantly utilized for methanation and are not suitable for liquid-fuel synthesis. The enhanced water gas shift (WGS) activity is also an important function of FT catalysts. Iron is well-known for its WGS activity, while neither Co nor Ru has WGS activity. 44

The performance of FT catalysts depends strongly on other factors such as the promoters and supports, preparation and activation method, and reactor design. With few exceptions, all catalysts are sensitive to sulfur poisoning. A major exception is the sulfur-tolerant Mo-based catalyst developed by Dow, ${ }^{45}$ which is mainly used to produce light paraffins. The following discussions are limited to Co and Fe catalysts.

Cobalt catalysts were first used for commercial FT operation but were later replaced by Fe because of the low cast and utility of the latter. A $100 \mathrm{Co} / 18 \mathrm{ThO}_{2} / 100 \mathrm{kieselguhr}$ catalyst was first used in an atmospheric-pressure direct heat-exchange reactor at Oberhausen-Holten, Germany, in 1936. A $100 \mathrm{Co} / 5 \mathrm{ThO}_{2} / 7.5 \mathrm{MgO} / 200$ kieselguhr was used later in a medium-pressure (100-150 psig), direct heat-exchange reactor.

The first commercial Fe catalyst was used in a medium-pressure, fixed, fluidized-bed reactor in the Hydrocol Process at Brownsville, TX, in 1950. Today, $\mathrm{Fe}$ is the only catalyst used in large-scale operation at SASOL. The catalysts can be made into various forms that match the different reactor types and different process conditions needed to make various product distributions. The following Fe catalysts are of special interest: (i) supported precipitated Fe promoted with $\mathrm{Cu}$ and $\mathrm{K}$ (direct heat-exchange reactor, Arge Process at SASOL I), (ii) fused Fe promoted with alkali and other proprietary promoters (entrained fluidized-bed reactor, Synthol process at SASOL I, II, and III), (iii) fused Fe promoted with 1wt\% $\mathrm{K}_{2} \mathrm{CO}_{3}$ (fixed fluidized-bed reactor, Hydrocol process), (iv) unsupported, precipitated Fe promoted with $\mathrm{Cu}$ and $\mathrm{K}$ (slurry reactor), and ( $v$ ) nitrided Fe catalyst developed by the US Bureau of Mines. Alkali components, usually $\mathrm{K}_{2} \mathrm{CO}_{3}$, are the most important promoters for the $\mathrm{Fe}$ compounds. Another common promoter is $\mathrm{Cu}$, which supposedly promotes the reduction of $\mathrm{Fe}_{2} \mathrm{O}_{3}$ to active Fe and iron carbides. 46 Many other promoters have been proposed. 
The products from FT reactions are HCs (mainly n-paraffins, terminal 2-methyl-branched-isoparaffins, and $\alpha$-olefins) and oxygenates (mainly primary alcohols). The chemical reactions may be represented as follows:

$$
\begin{aligned}
& (2 n+1) \mathrm{H}_{2}+\mathrm{nCO} \longrightarrow \mathrm{C}_{n} \mathrm{H}_{2 n+2}+\mathrm{nH}_{2} \mathrm{O}, \\
& 2 \mathrm{nH}_{2}+\mathrm{nCO} \longrightarrow \mathrm{C}_{n} \mathrm{H}_{2 n}+\mathrm{nH}_{2} \mathrm{O}, \\
& 2 \mathrm{nH}_{2}+\mathrm{nCO} \longrightarrow \mathrm{C}_{n} \mathrm{H}_{2 n+1} \mathrm{OH}+(n-1) \mathrm{H}_{2} \mathrm{O} .
\end{aligned}
$$

These reactions imply a minimum $\mathrm{H}_{2} / \mathrm{CO}$ use ratio of 2 and an average use ratio slightly larger than 2, depending on the product distribution. For catalysts that promote the WGS reaction, the $\mathrm{H}_{2} \mathrm{O}$ formed during $\mathrm{FT}$ reactions can react further with the $\mathrm{CO}$ to form $\mathrm{H}_{2}$ according to reaction (5.1-10). At FT reaction temperatures $\left(200-350^{\circ} \mathrm{C}\right)$, chemical equilibrium strongly favors $\mathrm{H}_{2}$ formation. Consequently, as long as the catalyst has sufficient WGS activity, the apparent $\mathrm{H}_{2} / \mathrm{CO}$ use ratio becomes much smaller, except for $\mathrm{MeOH}$-synthesis. The minimum $\mathrm{H}_{2} / \mathrm{CO}$ usage ratio is 0.5 for olefin formation and the maximum is 1.0 for $\mathrm{CH}_{4}$ and ethanol formation.

The $\mathrm{HCS}$ and alcohols produced by FT reactions have a very wide carbon number distribution. This distribution is generally determined by the chain-growth probability mechanism, which is frequently used in describing polymerization. 47 The distribution is

$$
\log \left(M_{i} / I\right)=\log \left(\ell n^{2} \alpha\right)+I(\log \alpha)
$$

where $M_{i}$ is the weight fraction of the $I$ carbon number $H C$ and $\alpha$ the probability of chain growth. A plot of $\log \left(M_{i} / I\right)$ vs carbon number yields $\log (\alpha)$ as the slope and $\log \left(\ell n^{2} \alpha\right)$ as the intersection. With a higher value of $\alpha$, heavier components are produced. A Schulz-Flory distribution also implies that the heavier compounds are produced in reduced molar quantity.

A limited treatment on the thermodynamics of FT reactions has been given by Kuo, ${ }^{1}$ while a thorough treatment may be found in Storch et al. ${ }^{43}$ All FT reactions are highly exothermic. The heats of reaction range from 8 
to $12 \mathrm{~kJ} / \mathrm{g}-\mathrm{HC}$, excluding $\mathrm{CH}_{4}$ and $\mathrm{MeOH}$ formation. Equilibrium $\mathrm{H}_{2}+\mathrm{CO}$ conversion calculations show that high single-pass conversion may be achieved if the $\mathrm{H}_{2} / \mathrm{CO}$ ratio in the feed gas matches the usage ratio. The equilibrium conversion at $250^{\circ} \mathrm{C}$ and 145 psig ranges from 94 to $99 \mathrm{mo} \%$, excluding $\mathrm{CH}_{4}$, ethane and $\mathrm{MeOH}$ formation. The conversion decreases with increasing temperature and paraffin carbon number and also with decreasing olefin and oxygenate carbon numbers.

Low $\mathrm{CH}_{4}$ and ethane formation are very often emphasized in FT syntheses when liquid fuels are made. Since $\mathrm{CH}_{4}$ and ethane are thermodynamically more stable than other FT compounds, low $\mathrm{CH}_{4}$ and ethane yields can only be achieved by careful selection of cataiysts and process conditions. Iron catalysts yield less $\mathrm{CH}_{4}$ and ethane than other FT catalysts. Proper use of alkali promoters will further reduce this yield. In terms of process conditions, low $\mathrm{CH}_{4}$ and ethane yields may be achieved by low temperatures and $\mathrm{H}_{2} / \mathrm{CO}$ ratios and by high pressures.

Carbon formation is an important factor that affects FT catalyst performance. It is described by the following two reactions:

$$
\begin{array}{r}
2 \mathrm{CO} \rightarrow \mathrm{C}+\mathrm{CO}_{2}, \Delta \mathrm{H}\left(250^{\circ} \mathrm{C}\right)=-174 \mathrm{~kJ} ; \\
\mathrm{CO}+\mathrm{H}_{2} \rightarrow \mathrm{C}+\mathrm{H}_{2} \mathrm{O}, \Delta \mathrm{H}\left(250^{\circ} \mathrm{C}\right)=-134 \mathrm{~kJ} .
\end{array}
$$

The first process is the Boudouard reaction and may be more important than the second reaction in carbon formation. Generally speaking, carbon formation is expected to increase drasticaliy with temperature and $\mathrm{CO}$ partial pressure. Dry ${ }^{48}$ has given an excellent review of carbon deposition on Fe catalysts. Extensive experimental work at SASOL led to the conclusion that there was a strong relation between the carbon formation rate and the value of $\mathrm{P}_{\mathrm{CO}} / \mathrm{p}_{2}$ at the reactor entrance on a fused $\mathrm{Fe}$ catalyst. ${ }^{49}$ In an earlier study, ${ }^{50}$ the activation energy of the Boudouard reaction for a fused Fe catalyst was found to be $113 \mathrm{~kJ} / \mathrm{mol}$, which is much greater than that for the FT reaction.

Mechanisms for FT reactions have attracted substantial scientific interest. Many mechanisms have been proposed including: (i) carbide by Fischer and Tropsch; ${ }^{51}$ (ii) hydroxycarbene by Storch et al.; ${ }^{43}$ (iii) 
carbonium by Roginsky; 52 (iv) carbonyl by Pichier and Schulz. ${ }^{53}$ The details of these mechanisms are not discussed here. However, they all contain the concept of chain growth and termination as in polymerization. Among these mechanisms, the carbide and hydroxycarbene mechanisms seem to give the best descriptions of experimental data. However, none of the other mechanism is firmly excluded.

FT kinetics is another area of great interest, although it is not well understood. Complications arise because of the many catalyst variables, such as composition, support, preparation activation, and aging. An excellent review of this work has been given by Storch et al, ${ }^{43}$ while Kuo ${ }^{1}$ provides a bried summary of the various forms of proposed kinetic expressions for catalysts, including Co, fused-Fe, and precipitated-Fe.

\section{1-4B. Commercial Fischer-Tropsch Processes}

For FT reactions, removal of the large exothermic heat is a major problem in commercial reactor designs. Heat removal is essential in order to maintain good temperature control and, hence, catalyst stability and product selectivity. Three types of reactors have been used in commercial application: fixed fluidized-beds, direct heat-exchange reactors and entrained fluidized-beds. The fixed fluidized-bed reactor was used in the Hydrocol process (Hydrocarbon Research Inc.). ${ }^{54,55}$ The plant used NG feed and was erected at Brownsville, TX, in 1950. The reactor was $5 \mathrm{~m}$ in diameter and had about a $100 \mathrm{~m}^{3}$ volume holding $150-180 \mathrm{Mg}$ of catalyst (with $80 \%$ in the size range $43-165 \mu \mathrm{m})$. It also contained bundles of vertical watercooling tubes to remove reaction heat. The reactor had the operating parameters listed in Table 5.1-1. The plant was shut down in 1957 because of the abundance of low-priced crude and never reached design capacity.

Three different designs of direct heat-exchange reactors have been used. All use the principle of keeping the catalyst close to a cooling surface in order to control catalyst temperature. Only one is still in operation today (at SASOL I). It is called the Arge Reactor and was developed by Lurgi and Ruhrchemie. The reactor is $2.9 \mathrm{~m}$ in diameter and contains 2,052 tubes with $4.6 \mathrm{~cm}$ id and a $12 \mathrm{~m}$ catalyst-bed height. Reaction heat is removed by steam generation on the shell side. The average 
performance of this reactor is summarized in Table 5.1-2. It has an HC capacity of about $18,000 \mathrm{Mg} /$ year.

The other two designs of direct heat-exchange reactors are only of historical value. They were used in atmospheric and medium-pressure syntheses with Co catalysts during the $1930 \mathrm{~s} .{ }^{54}$ The atmospheric pressure unit was $4.6 \mathrm{~m}$ long, $2.4 \mathrm{~m}$ high, and $1.8 \mathrm{~m}$ wide and consisted of 555 laminated plates with cooling tubes penetrating the bundle perpendicular to the plates. The distance between the plates was about $7.4 \mathrm{~mm}$ and the catalysts were loaded between the plates. The capacity of the reactor was small (nominally, $1 \mathrm{~km} / \mathrm{hr}$ of synthesis gas). The medium-pressure unit consisted of 2,040 double tubes ( 2.5 and $4.8 \mathrm{~cm}$ diameter), $4.6 \mathrm{~m}$ in length. The catalysts were loaded in the annulus and the cooling water was circulated inside the inner tube and outside the outer tube for heat removal. Reactor capacity was comparable to that of the normal pressure unit.

Gasification for the Syntheses of Fuels and Chemicals

Table 5.1-1. Operating parameters of the fixed fluidized-bed reactor used in the Hydrocol process.

\begin{tabular}{l|c}
\hline \multicolumn{1}{c|}{ Parameters } & Numerical values \\
\hline $\mathrm{T},{ }^{\circ} \mathrm{C}$ & $300-350$ \\
$\mathrm{p}$, psia & $375-450$ \\
Molar $\mathrm{H}_{2} / \mathrm{CO}$ ratio & $1.8-2.1$ \\
Molar recycle ratio & 2 \\
$\mathrm{C}_{3}{ }^{+}$yield, $\mathrm{g} / \mathrm{m}^{3}\left(\mathrm{H}_{2}+\mathrm{CO}\right)$ & 165 \\
$\mathrm{H}_{2}+\mathrm{CO}$ conversion, 8 & $90-95$ \\
\hline
\end{tabular}


The entrained fludized-bed reactor is the most important FT reactor used today (in SASOL I, II, and III) and is now identified as the SASOL Synthol Reactor. Figure 5.1-5 illustrates the major features of the reactor while Table 5.1-2 summarizes typical operating conditions and product selectivities for SASOL I and II. SASOL III is a duplicate of SASOL II. The difference in the product selectivities between the Synthol and Arge reactors is clearly shown. Then Synthol reactor generally produces more light HCs, gasoline, and oxygenates. The HCs are also more olefinic and contain fewer n-paraffins. The combined fresh feed and recycle gas is heated immediately to the reaction temperature $\left(315^{\circ} \mathrm{C}\right)$ by the returning hot catalyst. The reaction heat is removed in the intercoolers located in the reactor section. There are two versions of the intercooler. The older version uses tube bundles with cooling oil on the shell-side. This method causes occasional catalyst plugging on the tube-side. The newer version uses serpentine coils placed vertically up and down in the reactor section as intercoolers. The entrained catalyst exits from the reactor section at about $340^{\circ} \mathrm{C}$. SASOL II reactors use the new intercooler and have about two and a half times the capacity of the SASOL I reactor. 
Table 5.1-2. The SASOL Fischer-Tropsch reactors. 56-59

\begin{tabular}{|c|c|c|c|}
\hline \multirow{2}{*}{$\begin{array}{l}\text { Operating conditions and } \\
\text { product selectivity (wt })\end{array}$} & \multicolumn{2}{|c|}{ SASOL I } & \multirow{2}{*}{$\frac{\text { SASOL II }}{\text { Synthol }}$} \\
\hline & Arge & Synthol & \\
\hline $\begin{array}{l}\text { Catalyst, alkali promoted } \mathrm{Fe} \\
\text { Catalyst circulation rate, } \mathrm{Mg} / \mathrm{hr} \\
\mathrm{T},{ }^{\circ} \mathrm{C} \\
\mathrm{P}, \mathrm{MPa} \\
\text { Fresh feed } \mathrm{H}_{2} / \mathrm{CO} \text {, molar } \\
\text { Recycle ratio, molar } \\
\mathrm{H}_{2}+\mathrm{CO} \text { conversion, mols } \\
\text { Fresh feed, Nkm } / \mathrm{hr} \\
\text { Diameter } \times \text { height, m }\end{array}$ & $\begin{array}{c}\text { Precipitated } \\
0 \\
220-255 \\
2.5-2.6 \\
1.7-2.5 \\
1.5-2.5 \\
60-68 \\
20-28 \\
3 \times 17\end{array}$ & $\begin{array}{l}\text { Fused } \\
8000 \\
315 \\
2.3-2.4 \\
2.4-2.8 \\
2.0-3.0 \\
79-85 \\
70-125 \\
2.2 \times 36\end{array}$ & $\begin{array}{l}\text { Fused } \\
\text { N.A. } \\
320 \\
2.2 \\
\text { N.A. } \\
\text { N.A. } \\
\text { N.A. } \\
300-350 \\
3 \times 75\end{array}$ \\
\hline $\begin{array}{l}C_{1}= \\
c_{2}= \\
C_{2}= \\
c_{3}= \\
C_{3}= \\
C_{4}= \\
C_{4} \\
C_{5}-c_{12} \\
C_{13}-c_{18} \\
C_{19}-C_{21} \\
C_{22}-c_{30} \\
C_{30}\end{array}$ & $\begin{array}{r}5.0 \\
0.2 \\
2.4 \\
2.0 \\
2.8 \\
3.0 \\
2.2 \\
22.5 \\
15.0 \\
\\
6.0 \\
17.0 \\
18.0\end{array}$ & $\begin{array}{r}10.0 \\
4.0 \\
6.0 \\
12.0 \\
2.0 \\
8.0 \\
1.0 \\
39.0 \\
\\
5.0 \\
\\
1.0 \\
3.0 \\
12.0\end{array}$ & $\begin{array}{c}11.0 \\
7.5 \\
13.0 \\
11.0 \\
37.0 \\
\left(\mathrm{C}_{5}-191^{\circ} \mathrm{C}\right) \\
11.0 \\
\left(191-399^{\circ} \mathrm{C}\right) \\
3.0 \\
\left(399-521^{\circ} \mathrm{C}\right) \\
0.05 \\
\left(>521^{\circ} \mathrm{C}\right)\end{array}$ \\
\hline $\begin{array}{l}\text { Nonacid chemicals } \\
\text { Acids }\end{array}$ & $\begin{array}{l}3.5 \\
0.4\end{array}$ & $\begin{array}{l}6.0 \\
1.0\end{array}$ & $\begin{array}{l}6.0 \\
\text { N.A. }\end{array}$ \\
\hline
\end{tabular}




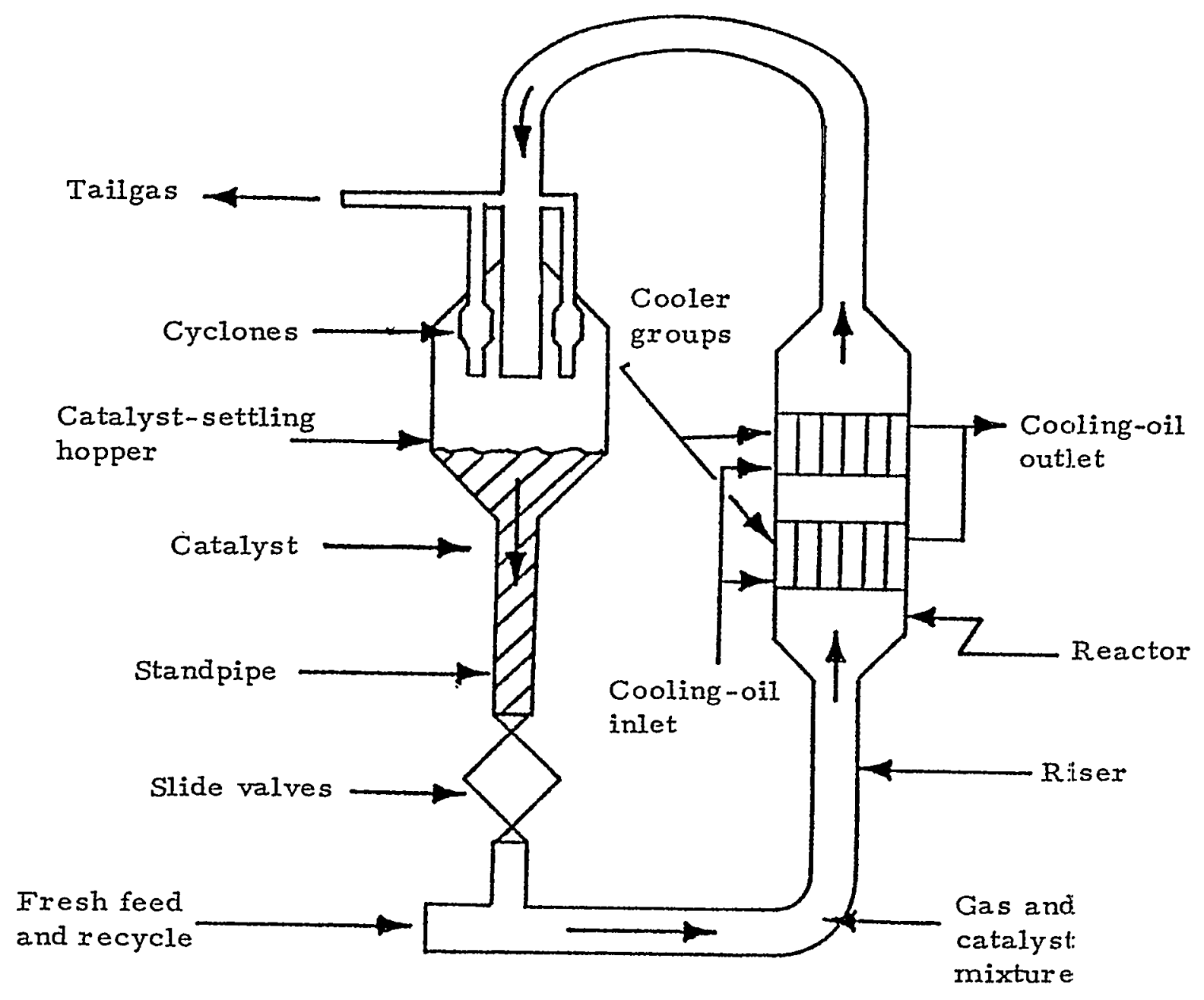

Fig. 5.1-5. Schematic diagram of an entrained fluidized-bed FT reactor. ${ }^{60}$ 
5.1-4C. Fischer-Tropsch Processes Not Yet in Commercial Operation

FT development work was and is being carried out in and outside of the US. The following discussions include the hot-gas recycle reactor, the oil-recycle reactor, the slurry reactor, SASOL development, the She11 SMDS process, and Dow's FT process.

The hot-gas recycle reactor recycles a large volume (about 100 times that of the fresh feed) of hot gas in a fixed-bed reactor for temperature control. 61 During the 1960 s, work at what is now PETC was directed to use high-voidage catalysts in order to minimize the reactor pressure drop caused by high gas-flow rates. ${ }^{62}$

The oil-recycle reactor used recycle cooling oil over a fixed- or expanded-bed reactor to control the catalyst temperature. A fixed-bed reactor concept was investigated by Duftschmid and others in $1934 .{ }^{63}$ Later, workers at PETC extended the concept to expanded-bed reactors. ${ }^{62}$ Various FE catalysts were investigated. A 100-150 BPD demonstration plant was built at Louisiana, MO, ${ }^{64}$ with a reactor diameter of $91 \mathrm{~cm}$ and a height of 9.4m. Table 5.1-3 summarizes the operational data for the plant at half its design capacity. A low $\mathrm{H}_{2} / \mathrm{CO}$ ratio synthesis gas was used because of good temperature control with an Fe catalyst.

A slurry FT reactor has been under development during the last few years. Using a precipitated Fe catalyst, the slurry reactor is the only FT reactor that was demonstrated to yield high single-pass $\mathrm{H}_{2}+\mathrm{CO}$ conversion with low (0.6-0.7) $\mathrm{H}_{2} / \mathrm{CO}$ ratio gases. It has the additional advantages of high $\mathrm{C}_{3}{ }^{+}$product yields and a simple reactor design. By coupling it with a low-cost advanced gasifier and an improved FT product-upgrading scheme, this reactor could become the backbone for a potentially economical indirect coal-1iquefaction process.

The slurry reactor was first used by Fischer and coworkers, ${ }^{65}$ with a finely divided catalyst suspended in an oil reactor medium. Since then, substantial research and development work have been conducted by various workers, including $\mathrm{Ha} 11,{ }^{66}$ Schlesinger et al., ${ }^{67}$ Koelbel, ${ }^{68}$ Mitra and Roy, ${ }^{69}$ and Sakai and Kunugi. ${ }^{70}$ An excellent review of the development of the slurry FT work up to the 1970 s was given by Koelbel and Ralek. ${ }^{46}$ A high point of the development was the construction and operation of the 
Rheinpreussen-Koppers demonstration plant in 1953. The reactor had a diameter of $1.55 \mathrm{~m}$, was $8.6 \mathrm{~m}$ in height, and had a capacity to produce $11.5 \mathrm{Mg} /$ day of $\mathrm{HCs}$. Vertical cooling tubes with steam generation were placed inside the reactor for temperature control. Precipitated, unsupported FE catalysts (promoted with potassium and copper) were used. Table 5.1-4 summarized typical operational data from the $\mathrm{plant;} \mathrm{H}_{2} / \mathrm{CO}$ ratios as low as 0.67 were used.

Table 5.1-3. Operational data from the Louisiana oilrecycle FT demonstration plant. 64

\begin{tabular}{l|c}
\multicolumn{1}{c|}{ Parameter } & Numerical Value \\
\hline Fresh feed gas flow, & $1,750 \mathrm{Nm}^{3} / \mathrm{h}$ \\
Feed-gas H2/Co ratio & $0.76 \mathrm{~mole} / \mathrm{mole}$ \\
Recycle ratio & $1.63 \mathrm{~mole} / \mathrm{mole}$ \\
Maximum T & $273^{\circ} \mathrm{C}$ \\
Rise in T & $8^{\circ} \mathrm{C}$ \\
Maximum p & $2.4 \mathrm{MPa}$ \\
Pressure drop & $0.2 \mathrm{MPa}$ \\
Space velocity & $531 \mathrm{vol} / \mathrm{vol}-\mathrm{hr}$ \\
Oil-recycle rate & $114 \mathrm{~m}^{3} / \mathrm{hr}$ \\
$\mathrm{H}_{2}+$ Co conversion & $85.9 \mathrm{~mol} 8$ \\
$\mathrm{C}_{1}+\mathrm{C}_{2}$ yield & $13.8 \mathrm{wt}$ \\
\hline
\end{tabular}


Table 5.1-4. Typical operational data from RheinpreussenKoppers slurry FT demonstration plant. 68

\begin{tabular}{|c|c|}
\hline Parameter & Numerical Value \\
\hline Expanded slurry volume & $10 \mathrm{~m}^{3}$ \\
\hline Precipitated Fe catalyst & $880 \mathrm{~kg}$ of $\mathrm{Fe}$ \\
\hline Pressure & $1.2 \mathrm{MPa}$ \\
\hline Temperature & $268^{\circ} \mathrm{C}$ \\
\hline $\mathrm{H}_{2} / \mathrm{Co}$ molar ratio & 0.67 \\
\hline Feed gas rate & $2,700 \mathrm{Nm}^{3} / \mathrm{hr}$ \\
\hline $\mathrm{H}_{2}+\mathrm{CO}$ feed rate & $2,300 \mathrm{Nm}^{3} / \mathrm{hr}$ \\
\hline Superficial feed-gas velocity & $9.5 \mathrm{~cm} / \mathrm{sec}$ \\
\hline CO conversion & $91 \operatorname{mol} 8$ \\
\hline $\mathrm{H}_{2}+\mathrm{CO}$ conversion & $89 \operatorname{mol} 8$ \\
\hline Hydrocarbon products & \\
\hline $\mathrm{C}_{1}+\mathrm{C}_{2}$ & $12\left[\mathrm{~g} / \mathrm{Nm}^{3}\left(\mathrm{H}_{2}+\mathrm{CO}\right)\right]$ \\
\hline $\mathrm{C}_{3}^{+}$ & $166\left[\mathrm{~g} / \mathrm{Nm}^{3}\left(\mathrm{H}_{2}+\mathrm{CO}\right)\right]$ \\
\hline Water-soluble oxygenates & $3\left[\mathrm{~g} / \mathrm{Nm}^{3}\left(\mathrm{H}_{2}+\mathrm{CO}\right)\right]$ \\
\hline
\end{tabular}

The major development on slurry FT processes since 1980 have been carried out at the Mobil Research and Development Corp., with partial funding from DoE. ${ }^{71,72}$ The development was done in association with the concept of upgrading a total vaporous FT reactor effluent over a ZSM-5 catalyst. Two modes of operation were established: (i) a gasoline (G) or low-wax mode of operation and $(i i)$ a gasoline and diesel $(G+D)$ or high-wax mode of operation.

The major difference between these two modes is the $\mathrm{HC}$ distribution. In the G-mode of operation, the reactor wax yield is defined 
as the liquid product for the FT reactor conditions and is $5-20$ wt\% of the total $\mathrm{HCs}$ produced, while the $\mathrm{CH}_{4}+$ ethane yields are 8-15\%. Typical $\mathrm{HC}$ selectivities are given in Table 5.1-5. In the (G+D)-mode of operation, the reactor wax yield increases substantially to $40-60$ wt\% with a decrease in $\mathrm{CH}_{4}$ and ethane yield to 2-6wt\%. As will be discussed later, the reactor wax can be further upgraded to make G+D. Table 5.1-6 shows typical HC selectivities for this mode. The intrinsic relation between the reactor wax yield and $\mathrm{CH}_{4}$ yield found is one of the most interesting phenomena established (see Fig. 5.1-6). The high-wax mode of operation is excellent in maximizing the G+D yield. These different modes of operation were achieved by varying the catalyst preparation and process conditions. The ranges of normal operating conditions of the two-stage (slurry FT/ZSM-5) pilot plant are listed in Table 5.1-7. A method for using an on-line catalyst settling device was al so successfully developed to withdraw continuously reactor wax containing less than 0.03 wt\% of solid catalyst. In both operations, single-pass $\mathrm{H}_{2}+\mathrm{CO}$

Table 5.1-5. Gasoline mode hydrocarbon selectivities obtained in the two-stage slurry FT/ZSM-5 pilot plant. 71

\begin{tabular}{|c|c|c|c|}
\hline \multirow[b]{2}{*}{ Product Type } & \multicolumn{2}{|r|}{ Yield, wts } & \multirow[b]{2}{*}{$\begin{array}{l}\text { After } \\
\text { Alkylation }\end{array}$} \\
\hline & $\begin{array}{l}\text { After FT } \\
\text { synthesis }\end{array}$ & $\begin{array}{l}\text { After the } \\
\text { ZSM-5 catalyst }\end{array}$ & \\
\hline $\mathrm{c}_{1}$ & 7.5 & 7.7 & 7.7 \\
\hline $\mathrm{C}_{2}=/ \mathrm{C}_{2}$ & $1.6 / 3.0$ & $1.1 / 3.1$ & $1.1 / 3.1$ \\
\hline $\mathrm{C}_{3}=/ \mathrm{C}_{3}$ & $8.0 / 2.0$ & $4.0 / 5.1$ & $0.0 / 5.1$ \\
\hline $\mathrm{C}_{4}=$ & 6.6 & 4.4 & 0 \\
\hline$i-C_{4} / n-C_{4}$ & $0 / 2.0$ & $7.8 / 4.3$ & $(2.2) / 4.3$ \\
\hline$c_{5}-c_{11}$ & 33.5 & 52.8 & 71.2 \\
\hline $\mathrm{C}_{12}+$ (1iquid) & 27.8 & 1.7 & 1.7 \\
\hline Reactor wax & 8.0 & 8.0 & 8.0 \\
\hline $\begin{array}{l}\text { Gasoline Properties } \\
\text { RVP, psi } \\
\text { PONA, vol\& } \\
\text { R+O } \\
\text { M+0 }\end{array}$ & & $\begin{array}{c}- \\
48 / 18 / 6 / 28 \\
- \\
-\end{array}$ & $\begin{array}{c}10 \\
66 / 13 / 4 / 17 \\
90 \\
83\end{array}$ \\
\hline
\end{tabular}


conversions of $80-85$ mol\% were reached. In the G-mode of operation, an 86 -day run was completed with a total HC production of $815 \mathrm{~g} / \mathrm{gFe}$. In the high-wax mode of operation, a 34 -day run with $350 \mathrm{gHC} / \mathrm{gFe}$ was terminated when catalyst segregation occurred in the bubble-column reactor. This catalyst segregation is a new phenomenon and probably resulted from catalyst agglomeration or some unknown phenomenon, which requires further studies.

Table 5.1-6. High reactor-wax mode hydrocarbon selectivities for the two-stage slurry FT/ZSM-5 pilot plant. 72

\begin{tabular}{|c|c|c|}
\hline \multirow[b]{2}{*}{ Product Type } & \multicolumn{2}{|c|}{ Yield, wto } \\
\hline & $\begin{array}{l}\text { After } \\
\text { FT }\end{array}$ & $\begin{array}{c}\text { After ZSM-5 } \\
\text { (after alkylation) }\end{array}$ \\
\hline $\mathrm{c}_{1}$ & 3.3 & 3.4 \\
\hline$c_{2}=/ c_{2}$ & $1.8 / 0.7$ & $1.1 / 0.7$ \\
\hline$c_{3}=/ c_{3}$ & $2.8 / 0.8$ & $0 / 3.2$ \\
\hline $\mathrm{C}_{4}=$ & 2.5 & 0 \\
\hline$i-C_{4} / n-C_{4}$ & $0 / 0.9$ & $(1.0) / 0.7$ \\
\hline $\mathrm{C}_{5}-\mathrm{C}_{11}$ & 22.4 & 39.6 \\
\hline $\mathrm{C}_{12^{+}}+($(1iquid) & 9.7 & 1.0 \\
\hline Reactor wax & 50 & 51.3 \\
\hline Oxygenates & 5.1 & - \\
\hline $\begin{array}{l}\text { Gasoline Properties } \\
\text { RVP, psi } \\
\text { PONA, volf } \\
\text { R+O }\end{array}$ & & $\begin{array}{c}10 \\
60 / 14 / 7 / 19 \\
92\end{array}$ \\
\hline
\end{tabular}


Fig. 5.1-6. Reactor-wax vs methane ylelds for slurry FT operation. 72

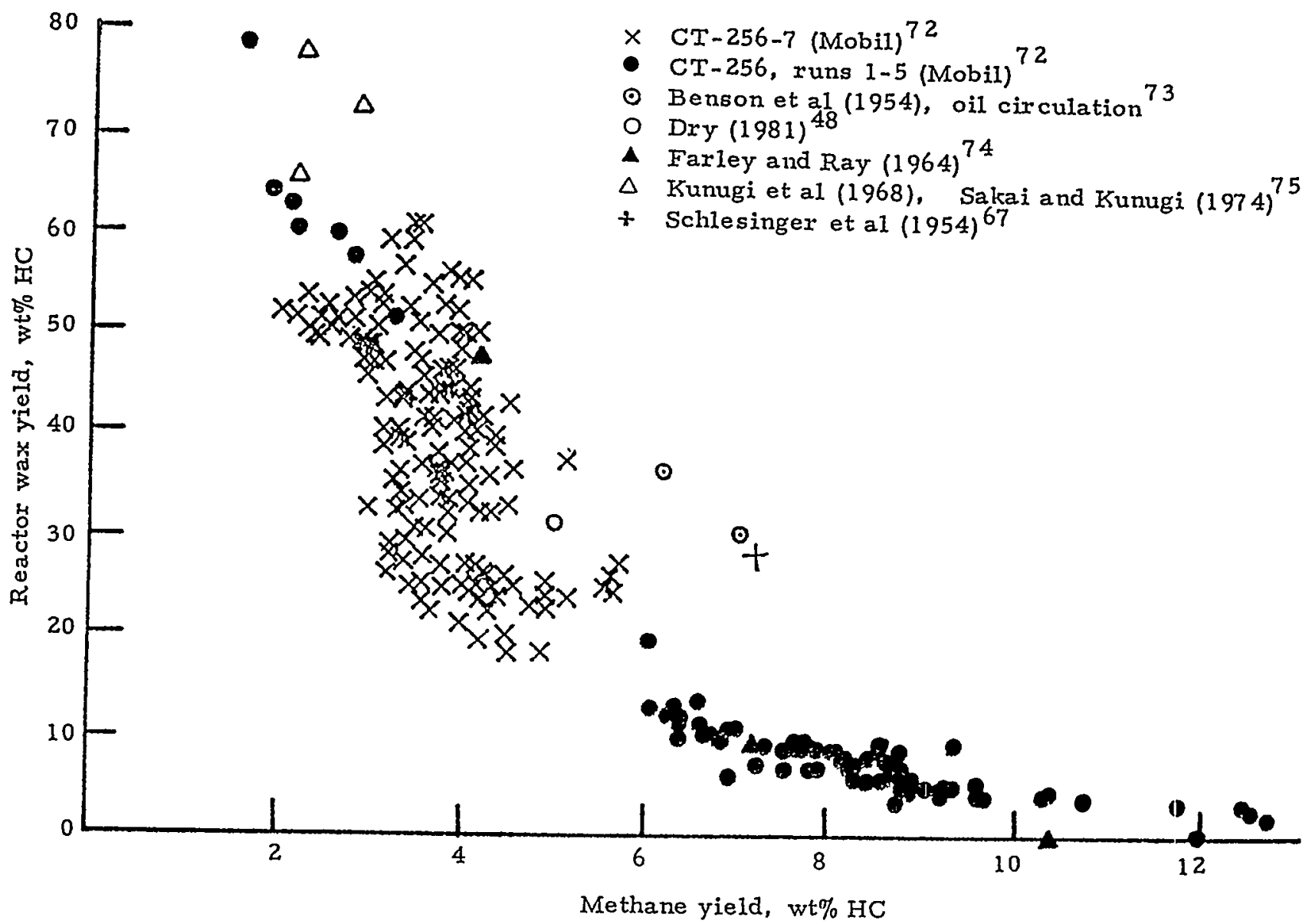

Table 5.1-7. Range of normal operating conditions for the two-stage slurry FT/ZSM-5 pilot plant. 71,72

\begin{tabular}{l|l}
\hline First-Stage FT Reactor & \\
$\mathrm{T}$ & $240-280^{\circ} \mathrm{C}$ \\
$\mathrm{P}$ & $150-350 \mathrm{psig}$ \\
Superficial gas velocity & $2-6 \mathrm{~cm} / \mathrm{sec}$ \\
Molar ratio $\mathrm{H}_{2} / \mathrm{CO}$ & $0.6-0.7$ \\
Space velocity & $1.5-5.0 \mathrm{~N} 1 / \mathrm{gFe}-\mathrm{hr}$ \\
Catalyst loading & $10-20 \mathrm{wt}$ \\
Slurry inventory & $8-12 \mathrm{~kg}$ \\
\hline Second-Stage ZSM-5 Reactor & \\
Inlet T & $288-454^{\circ} \mathrm{C}$ \\
P & $150-350 \mathrm{psig}$ \\
Space velocity & $0.5-1.5 \mathrm{gHC} / \mathrm{g}-\mathrm{hr}$ \\
Catalyst loading & $200-300 \mathrm{~g}$ \\
Severity index, molar ratio $\mathrm{i}-\mathrm{C}_{4} /\left(\mathrm{C}_{3}{ }^{2}+\mathrm{C}_{4}{ }^{\circ}\right)$ & $0.2-0.2$ \\
\hline
\end{tabular}


Workers at SASOL have conducted a pilot plant study with a $5 \mathrm{~cm}$ id and $3.8 \mathrm{~m}$ long slurry bubble-column, utilizing a commercially precipitated FE catalyst. 48 This study differed form the other slurry FT work in two aspects: the use of synthesis gas with an $\mathrm{H}_{2} / \mathrm{CO}$ ratio equal to 2 or higher and the use of a supported, precipitated Fe catalyst. Because of the use of gas with high $\mathrm{H}_{2} / \mathrm{CO}$ ratio, the study is related to the dry-ash Lurgi gasifiers used at SASOL but not to advanced gasifiers which generate gases with low $\mathrm{H}_{2} / \mathrm{CO}$ ratios.

Workers of SASOL have also investigatèd improvements to the existing Arge and Synthol reactors. 76 The potential improvements of the Arge unit involve either increasing the reactor diameter or else raising its operating pressure. The potential improvement of the Synthol unit is to replace it with fixed fluidized-bed reactor. Few details concerning these improvements have been reported.

In 1985, Shell announced its SMDS (Shell middle-distillate synthesis) process for producing middle distillates (kerosine and gas oil) from NG. 77 The synthesis gas is produced by a conventional partial-oxidation process and is then converted to highly paraffinic HCs over a proprietary FT catalyst in an Arge-type reactor. This paraffin synthesis reactor is highly selective in producing heavy paraffin wax; no light paraffin yield was reported. Since the synthesis gas is obtained from $N G$, it is expected to have little or no WGS activity because otherwise a large portion of $\mathrm{CO}$ will be converted to $\mathrm{CO}_{2}$.

Gulf announced in 1983 the Gulf-Badger process for converting NG to $\mathrm{HC}$ liquid via $\mathrm{CH}_{4}$ steam reforming followed by $\mathrm{FT}$ synthesis. 78 The proposed synthesis reactor is also an Arge-type reactor. The catalyst used is not disclosed but it has little or no WGS activity. Table 5.1-8 lists typical process conditions and HC product selectivities. The diesel fraction of the product has good properties. In order to maintain the $\mathrm{H}_{2} / \mathrm{CO}$ feed ratio between 1.5 and $2, \mathrm{CO}_{2}$ recycle to the steam reformer and $\mathrm{H}_{2}$ removal from the synthesis gas are required. The integrated system appears to be complicated and expensive.

Workers at Dow have developed new Mo-based catalysts for the synthesis of $\mathrm{C}_{2}-\mathrm{C}_{4}$ paraffins and olefins. 45 The process was demonstrated in a single-tube, direct heat-exchange reactor containing 26-28 liters of catalyst. The catalyst is Mo on a carbon support (6-20wt\% loading) promoted with $0.5-4$ wt\% $K$. The Mo is a known methanation catalyst. The addition of 
$K$ maximizes the $C_{2}-C_{5}$ yield. The $C_{2}-C_{5}$ is the main product and can be used as a feedstock in making ethylene in conventional thermal crackers. The major process disadvantage is the high $\mathrm{CH}_{4}$ yield of $30-40 \mathrm{wt} \%$. The process used $0.8 \mathrm{H}_{2} / \mathrm{CO}$ feed gas, $350-400^{\circ} \mathrm{C}$, 500psig and up, and yielded $57-80 \mathrm{mo} \%$ $\mathrm{H}_{2}+\mathrm{CO}$ conversion. The Mo catalysts have the advantage of $\mathrm{S}$-tolerance up to $20 \mathrm{ppm}$.

5.1-5. Syntheses of Chemicals Using SG, CO or Methanol Plus Other

\section{Chemicals}

The hydroformulation (OXO) reaction is represented by the conversion

$$
\mathrm{CH}_{3} \mathrm{CH}=\mathrm{CH}_{2}+\mathrm{CO}+\mathrm{H}_{2} \rightarrow \underbrace{\mathrm{CH}_{3} \mathrm{CH}_{2} \mathrm{CH}_{2} \mathrm{CHO}+\mathrm{CH}_{3} \mathrm{CH}\left(\mathrm{CH}_{3}\right) \mathrm{CHO} \text { (5.1-22) }}_{\substack{\mathrm{H} 2 \\ \text { alcohols }}}
$$

Almost every olefin undergoes this reaction at $110-160^{\circ} \mathrm{C}$ and $20-250$ atm of SG. The reaction was discovered by Roelen in 1937 while studying the mechanism of the cobalt-catalyzed FT reaction. World production of OXO alcohols is now about 10 billion pounds per year.

First-generation hydroformylation plants, most of which are still in operation, used cobalt salts or the simple transition-metal carbonyl, $\mathrm{Co}_{2}$ $(\mathrm{CO})_{8}$, as the catalyst. New plants use rhodium-tertiary phosphine complexes as catalysts; these operate at lower temperatures and pressures. Easily polymerized olefins such as styrene and methyl methacrylate react cleanly with rhodium catalysts to yield aldehydes having the one carbon atom more than the original olefin.

Products from the hydroformylation of olefins include solvent alcohols (n-propanol, n-butanol, $C_{5}$ alcohols), plasticizer alcohols $\left(C_{8}\right.$, $C_{9}, C_{10}$ alcohols) and detergent alcohols $\left(C_{11}-C_{16}\right.$ primary alcohols). 
Table 5.1-8. Typical process conditions and $\mathrm{HC}$ selectivities of the Gulf-Badger process. 78

\begin{tabular}{|c|c|}
\hline Parameter & Values \\
\hline Process Conditions & \\
\hline $\mathrm{T}$ & $210^{\circ} \mathrm{C}$ \\
\hline $\mathbf{p}$ & 250psig \\
\hline $\mathrm{H}_{2} / \mathrm{CO}$ feed ratio & $1.5-2$ \\
\hline Space velocity & $500-1,000 \mathrm{~L} / \mathrm{hr}$ \\
\hline CO conversion & 40-60molz \\
\hline $\mathrm{C}_{5}+$ selectivity, \& of carbon converted & $>708$ \\
\hline Parameter & Values \\
\hline HC Selectivities & \\
\hline $\mathrm{CH}_{4}$ & 13.7 \\
\hline $\mathrm{C}_{2} \mathrm{H}_{4}$ to $\mathrm{C}_{4} \mathrm{H}_{10}$ & 11.6 \\
\hline$C_{5}-C_{8} \cdot($ naphtha $)$ & 25.4 \\
\hline $\mathrm{C}_{9}-\mathrm{C}_{20}$ (distillate) & 33.4 \\
\hline$c_{21}+($ wax $)$ & 14.2 \\
\hline Oxygenates & 1.7 \\
\hline
\end{tabular}

The important plasticizer 2-ethylhexanol is made in large quantities from propylene. This olefin is hydorformylated to n-butyraldehyde, which then undergoes a base-catalyzed aldolization to 2-ethylhexenal that is hydrogenated to 2-ethylhexanol. The conditions used for preparation of this alcohol from propylene with commercial cobalt and rhodium catalysts are shown in Table 5.1-9.

Table 5.1-9. Preparation of 2-ethylhexanol.

\begin{tabular}{l|cc}
\hline \multirow{2}{*}{ Property } & \multicolumn{2}{|c}{ Catalyst } \\
\cline { 2 - 3 } & Cobalt & Rhodium \\
\hline P, atm & 250 & 20 \\
T, ${ }^{\circ} \mathrm{C}$ & 145 & 120 \\
Selectivity to & & \\
n-butyraldehyde, 8 & 66 & 85 \\
\hline
\end{tabular}


The hydroformylation of olefins with SG has been used with a great variety of compounds such as steroids, terpenes, and many other unsaturated compounds to synthsize various aldehydes and alcohols, solvents, and specialty chemicals.

\section{1-5A. Methyl t-Butyl Ether (MTBE)}

A steadily growing use for $\mathrm{MeOH}$ as a fuel is in the synthesis of MTBE, an effective octane booster, by the process reaction:

$$
\begin{aligned}
& \text { acid resin } \\
& \underset{\mathrm{CH}_{3}}{\mathrm{CH}_{3} \mathrm{OH}}+\underset{80^{\circ} \mathrm{C}}{\mathrm{CH}_{3}-\mathrm{C}}=\mathrm{CH}_{3} \mathrm{OC}\left(\mathrm{CH}_{3}\right)_{3}(\text { MTBE) } \cdot(5.1-27)
\end{aligned}
$$

\section{1-5B. Methyl ChToride from Methanol and $\mathrm{HCl}$}

Methanol can be esterified with $\mathrm{HCl}$, either in the liquid phase at $100-150^{\circ}$ in the presence of e.g., $\mathrm{ZnCl}_{2}$ or, preferably, in the gas phase at $300-380^{\circ} \mathrm{C}$ and 3-6 atm with $\mathrm{Al}_{2} \mathrm{O}_{3}$ as the catalyst: $\mathrm{CH}_{3} \mathrm{OH}+\mathrm{HCl} \rightarrow \mathrm{CH}_{3} \mathrm{Cl}+\mathrm{H}_{2} \mathrm{O}$. The selectivity to methy $\mathrm{l}$.chloride is almost $98 \%$ relative to $\mathrm{MeOH}$. Stauffer Chemical developed a process of the latter type and produced 27,000 tons of $\mathrm{CH}_{3} \mathrm{Cl}$ in 1973. Hoechst. and Huls in the FRG, using a modified Stauffer process, produced about 40,000 tons of $\mathrm{MeOH}$ and 28,000 tons of $\mathrm{CH}_{3} \mathrm{Cl}$, respectively, in 1973. In 1976, Japanese production of this chemical exceeded 22,000 tons. Methyl chloride is also used instead of $\mathrm{CH}_{4}$ for the synthesis of the higher chloromethanes $\left(\mathrm{CHCl}_{3}, \mathrm{CCl}_{4}\right)$ by thermal chlorination.

5.1-5C. The Koch Reaction: Carbonylation of Olefins to Branched Acids

Several companies operate industrial processes based on the Koch reaction. This reaction involves the acid-catalyzed reaction of olefins with $C O$ and water to give highly-branched acids which are thermally, oxidatively, and hydrolytically stable: 


$$
\mathrm{RCH}_{2} \mathrm{CH}=\mathrm{CH}_{2}+\mathrm{CO}+\mathrm{H}_{2} \mathrm{O} \stackrel{\mathrm{H}_{2} \mathrm{SO}_{4}}{{ }_{\mathrm{CH}_{3}}^{\mathrm{R}}-\mathrm{C}-\mathrm{COOH}} .
$$

5.1-5D. Styrene From Methanol and Toluene

About 7 billion pounds of styrene are produced each year in the US. Traditionally, styrene is made by a two-step process: benzene is alkylated to ethylbenzene, which is then dehydrogenated to styrene. But toluene is cheaper than benzene and $\mathrm{MeOH}$ is or will be cheaper than ethylene. A one-step route to styrene via alkylation of toluene with $\mathrm{MeOH}$ would offer advantages of both lower raw material costs and smalier energy costs. This reaction can be accomplished, using a zeolite-containing boron, as follows:

$$
\mathrm{C}_{6} \mathrm{H}_{5} \mathrm{CH}_{3}+\mathrm{CH}_{3} \mathrm{OH} \underset{4}{\stackrel{\text { CsBX zeolite }}{\underset{400^{\circ} \mathrm{C}}{\longrightarrow}} \mathrm{C}_{6} \mathrm{H}_{5} \mathrm{CH}=\mathrm{CH}_{2}+\mathrm{H}_{2} \mathrm{O}+\left(\mathrm{H}_{2}\right) .} \text { (styrene). }
$$

The geometry and acidity of the cesium-boron type- $X$ zeolite both activate the toluene molecule and protect,it from attack at an undesirable location, i.e., at the para position of toluene. In a most unusual type of reaction, only the methyl group in toluene is exposed for alkylation. This process falls in the category of emerging processes.

5.1-5E. Terephthalic Acid From Toluene and Methanol and From Toluene and $\underline{\mathrm{CO}}$

Terephthalic acid is usually made by the oxidation of p-xylene obtained from petroleum reformate. But toluene can be used in two relatively new ways to synthesize the important chemical, terephthalic acid. The production of terephthalic acid is illustrated by the process 


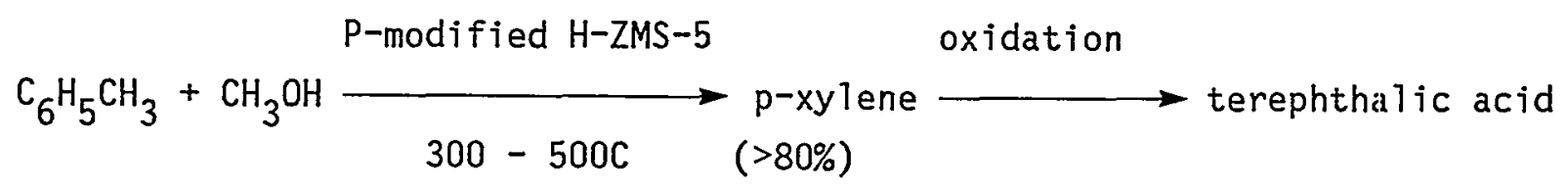

The great concentration of $p-x y l e n e$, because of the restricted pore size of the ZSM-5 shape-selective catalyst, could lower the costs of the separation process that is ordinarily used for its recovery from reformate.

An alternate route is to eliminate $p$-xylene completely by carbonylating toluene to p-tolualdehyde; the aldehyde is then oxidized to terephthalic acid.

A significant amount of $\mathrm{MeOH}$ is used to esterify terephthalic acid to dimethyl terephthalate. In $1985,7.2$ billion pounds of terephthalic acid were produced in the US.

\section{1-5F. Some Miscellaneous Uses of Methanol}

About $4 \%$ of $\mathrm{MeOH}$ is consumed in the manufacture of methy methacrylate, a chemical used to produce acrylic sheet, surface coating resins, and molding and extrusion powders.

Methylamines are produced by catalytically reacting $\mathrm{MeOH}$ with $\mathrm{NH}_{3}$.

Solvents account for about $8 \%$ of $\mathrm{MeOH}$ demand. It is also used as an antifreeze, gasoline de-icer, windshield washer fluid, and hydrate inhibitor in NG.

\section{1-6. Other Chemicals from SG, Methanol and CO; Emerging Processes}

As already indicated, $S G, M e O H$ and $\mathrm{CO}$ are the raw materials for the syntheses of a number of fuels and chemicals of commercial and near-commercial use. It is well to summarize, at this point, the scope of $\mathrm{MeOH}-\mathrm{SG}$ chemistry as it applies to the synthesis of important oxygenated chemicals. Some are already commercial, some are coming on stream, and some are of potential interest.

5.1-6A. Vinyl Acetate (VA) 
The present commercial process for VA is based on SG for $70 \%$ of its weight and the process has high yields and moderate processing costs. It consists of the vapor-phase acetoxylation of ethylene:

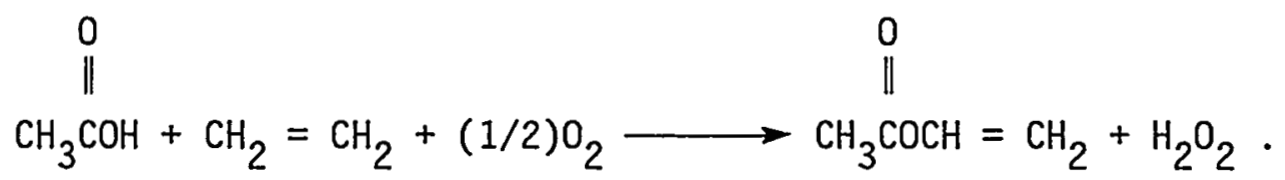

Halcon has developed the reductive carbonylation of methyl acetate (made from SG) to ethylidene diacetate:

$$
\mathrm{CH}_{3} \mathrm{COOCH}_{3}+3 \mathrm{CO}+3 \mathrm{H}_{2} \longrightarrow \underset{\text { ethylidene diacetate }}{\mathrm{CH}_{3} \mathrm{CH}\left(\mathrm{OCOCH}_{3}\right)_{2}+\mathrm{H}_{2} \mathrm{O} .}
$$

The ethylidene diacetate may then be pyrolyzed to VA. The chemistry of the reductive carbonylation of methyl acetate strongly resembles that of its carbonylation to acetic anhydide, but the mechanism is not so well defined. Both palladium and rhodium have been claimed to be good catalysts for the reaction. This technology, while promising, is not competitive in the US at the present stage of development.

\section{1-6B. Ethylene Glycol $\left(\mathrm{HOCH}_{2} \mathrm{CH}_{2} \mathrm{OH}\right)$}

About 4.7 billion pounds of ethylene glycol (EG) were produced in the US in 1985 . The present commercial process for its synthesis proceeds from ethylene to ethylene oxide to $E G$.

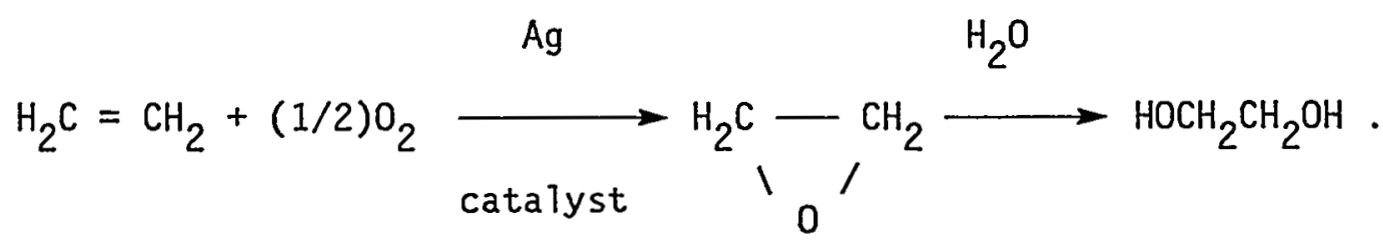

The synthesis is vulnerable to replacement by processes based on SG or raw materials derived from $S G$. The reaction for the direct production of $E G$ from $\mathrm{SG}$ is $3 \mathrm{H}_{2}+2 \mathrm{CO} \longrightarrow \mathrm{HOCH}_{2} \mathrm{CH}_{2} \mathrm{OH}$ and has been realized previously, although at pressures too high to be of commercial use. But the raw-material consumption in $1 \mathrm{lb}$ of feed per $1 \mathrm{~b}$ of product is unity and the 
$\mathrm{H}_{2} / \mathrm{CO}$ ratio in the $\mathrm{SG}$ is 1.5 , making this route to $E G$ very attractive. The synthesis of $\dot{E}$ from $S G$ would present a case of high added value in the final product.

The driving force for the development of a route from $S G$ to $E G$ is high and there are a number of new processes under development to achieve this end. At the current stage of development, the route from $\mathrm{MeOH}$ and $\mathrm{HCHO}$ appears to have the edge. A large research and development program is underway to synthesize EG from $S G$ or from $C O$.

\section{EG from Methanol and Formaldehyde}

Celanese and Redox Technologies ${ }^{79}$ have developed an economically attractive process to $\mathrm{EG}$ from $\mathrm{MeOH}$ and $\mathrm{HCHO}$. It has significant raw material advantages over the ethylene oxide process. Methanol and HCHO react in the 1 iquid phase at $125-200^{\circ} \mathrm{C}$ and $300-600$ psig using a free radical initiator. Both starting materials are made from $S G$ and the selectivity to $E G$ is high. The process is:

$$
\mathrm{CH}_{3} \mathrm{OH}+\mathrm{HCHO} \underset{125-250^{\circ} \mathrm{C}}{\stackrel{\text { peroxide }}{\longrightarrow}} \mathrm{HOCH}_{2} \mathrm{CH}_{2} \mathrm{OH} \text { (EG). }
$$

\section{EG by Carbonylation of $\mathrm{HCHO}$}

DuPont operated a commercial process catalyzed by $\mathrm{H}_{2} \mathrm{SO}_{4}$ until 1968 but it required high pressure and temperature and neutralization of the $\mathrm{H}_{2} \mathrm{SO}_{4}$ to recover the product. Chevron 79 has improved this route to EG by using HF as both catalyst and solvent, which results in much lower pressure ( $100 \mathrm{psig})$ and ease of catalyst separation and recycle:

$$
\mathrm{HCHO}+\mathrm{CO}+\mathrm{H}_{2} \mathrm{O} \underset{10 \mathrm{Psi}}{\stackrel{\mathrm{HF}}{\longrightarrow}} \mathrm{HOCH}_{2} \mathrm{COOH} \text { (hydroxyacetic acid). }
$$

The acid is esterified and then hydrogenated to $E G$. 


\section{EG from Oxalate Esters (Oxidative Carbonylation)}

In this route to $E G$, oxidative coupling of $\mathrm{MeOH}$ and $\mathrm{CO}$ (Pd-based) is separated from a water-generation reaction ( $\mathrm{Cu}$-bàsed) by using nitrous esters, which represents a preoxidation of. the alcohol. The overall equation may be written as $2 \mathrm{CH}_{3} \mathrm{OH}+(1 / 2) \mathrm{O}_{2}+2 \mathrm{CO} \longrightarrow$ dimethyl oxalate + $\mathrm{H}_{2} \mathrm{O}$. The dimethyl oxalate is hydrogenated to $\mathrm{EG}$ and $\mathrm{MeOH}$.

\section{EG Directly from SG}

Although the direct synthesis of $E G$ from $S G$ is the most attractive route from a raw material point of view, the following synthesis has thus far been an elusive goal: $3 \mathrm{H}_{2}+2 \mathrm{CO} \stackrel{\mathrm{Rh} \text { or } \mathrm{Ru}}{\rightarrow} \mathrm{HOCH}_{2} \mathrm{CH}_{2} \mathrm{OH}$. The reaction rate is too low, pressures (up to $20,000 \mathrm{psig}$ ) too high, and the production of $\mathrm{MeOH}$ as a significant (20-40\% carbon efficiency with rhodium) by-product have combined to make this route uneconomical at present. But the very significant potential rewards justify continuing efforts to improve this" process.

EG by Reaction of $\mathrm{HCHO}$ with $S G$

A number of companies have obtained patents using the route 79

$$
\mathrm{HCHO}+\mathrm{CO}+2 \mathrm{H}_{2} \longrightarrow \mathrm{HOCH}_{2} \mathrm{CH}_{2} \mathrm{OH} \text {. }
$$

This reaction proceeds under mild conditions but potentially serious problems may arise by side reaction of $\mathrm{HCHO}$, i.e., reduction to $\mathrm{MeOH}$ and the formation of formose (sugar-like) products.

\section{Newer Routes to EG Starting with Formaldehyde}

One route, studied at Monsanto, is shown by the following equation:

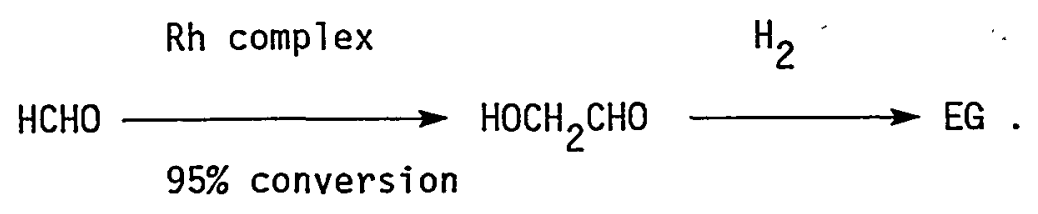


Another approach is followed at Exxon:

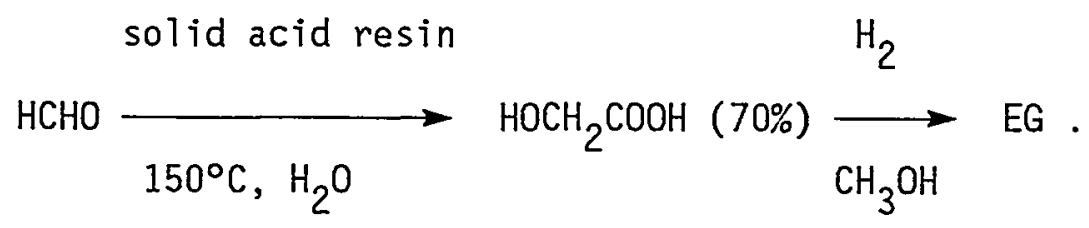

\section{1-6C. Big Acids From Little Ones: Homologation of Acids}

Texaco has discovered a potentially useful reaction for increasing the chain length of a carboxylic acid by one carbon, i.e., converting acetic acid to propionic acid 80 in the presence of a RuO ${ }_{2}$-HI cataiyst at 100 atm and about $220^{\circ} \mathrm{C}$. Since acetic acid is itself made entirely from SG, all of these acids can, if need be, be built exclusively from $S G$ and no petroleum feedstock would be needed.

\section{1-D. Single-Cell Protein From Methanol}

A protein-rich animal feed ingredient has been made by the continuous fermentation of $\mathrm{MeOH}$ or ethanol. The product may eventually be processed into an ingredient suitable for human food. The Phillips Petroleum Company has a product called Provesteen which is $60 \%$ protein, $5 \%$ lipid and $18 \%$ carbohydrate with essential vitamins and minerals.

\subsection{Catalytic Processing of Synthsis-Gas-Derived Products}

\section{2-1. Introduction}

The discussions in this section deal mainly with further processing of two major synthesis gas derived products, namely, MeOH and FT products. In particular, they are targeted at making the following end products: light olefins $\left(\mathrm{C}_{4}^{-}\right)$and liquid fuels (gasoline and diesel).

Since $\mathrm{MeOH}$ is a chemically reactive compound, it is an excellent building block in making chemicals and liquid fuels. The MeOH-to-gasoline (MTG) process developed by the Mobil Research and Development Corp. is one 
of the very few synthetic fuel technologies being put into commercial application since the 1973 oil embargo. Conversions of $\mathrm{MeOH}$ first to olefins and then to diesel are also being developed.

Established practices of upgrading FT products at SASOL will now be reviewed. The effort of producing more selective product slates directly from FT processes has been a failure after many years of intense studies. It is relatively easy to make light paraffins and high molecular-weight waxes. Further processing is necessary to produce desirable products such as gasoline, diesel, or olefins. The light paraffins are poor feedstocks for further processing because they are thermodynamically very stable. In contrast, the FT waxes have the unique characteristic that they are excellent feedstocks for catalytic cracking. Consequently, the high-wax mode of operation in FT synthesis is a prudent approach. Various approaches for upgrading the FT reactor wax will be summarized. The high-wax mode of operation also results in 1 ow $\mathrm{CH}_{4}$ and ethane yield, which is highly desirable in making liquid fuels. Another prudent approach is the direct upgrading of the total vaporous FT reactor effluent. This procedure has the potential of saving a large number of upgrading units that are currently used in the SASOL plants.

The use of zeolites is essential in processing of the SG-derived products because of the unique shape-selective characteristics of these catalysts. A discussion of this aspect will also be given here.

\section{2-2. Methanol to Gasoline (MTG)}

\section{2-2A. Catalysts and Chemistry of the MTG Process}

The work on the MTG Process has been dominated by Mobil. The technology is based on the zeolites of the ZSM-5 class. 81 A review by Chang $^{82}$ on $\mathrm{MeOH}$ conversion to $\mathrm{HCs}$ included a detailed description of other zeolite and non-zeolitic catalysts for $\mathrm{MeOH}$ conversion. None of these catalysts give the following unique results that are obtained by using ZSM-5 catalysts: high gasoline yield, excellent gasoline quality, very low $\mathrm{CH}_{4}+$ ethane yield, high activity, high stability, and very low coke yield. 
Symbolically, MTG reactions may be represented by the following dehydration reaction.

$$
\mathrm{nCH}_{3} \mathrm{OH} \longrightarrow\left(\mathrm{CH}_{2}\right)_{\mathrm{n}}+\mathrm{nH}_{2} \mathrm{O}
$$

The actual reaction path is quite complex ${ }^{83}$ and will not be discussed here. The following steps describe the essence of the reaction path:

$$
\begin{aligned}
2 \mathrm{CH}_{3} \mathrm{OH} & \longrightarrow\left(\mathrm{CH}_{3}\right)_{2} \mathrm{O}+\mathrm{H}_{2} \mathrm{O}, \\
\mathrm{CH}_{3} \mathrm{OH}\left(\mathrm{CH}_{3}\right)_{2} \mathrm{O} & \rightarrow \text { light olefins }+\mathrm{H}_{2} \mathrm{O}, \\
\text { light olefins } & \longrightarrow \text { heavy olefins, } \\
\text { heavy olefins } & \rightarrow \text { aromatics, paraffins, naphthenes }(5.2-4)
\end{aligned}
$$

Because of the shape-selective pore structure of the ZSM-5 class catalysts, the HCs fall predominantiy in the gasoline boiling range. A large yield of aromatics is obtained and the paraffins are dominated by isoparaffins. Consequently, the majority of the compounds in the $\mathrm{C}_{5}+$ range are high-octane compounds. The aromatics are highly methyl-substituted as the result of the alkylation of the aromatics by methanol and dimethyl ether. $C_{9}+$ aromatics are dominated by symmetrically methylated isomers, reflecting the shape-selective structure of the catalysts.

The $\mathrm{C}_{10}$ aromatics are dominated by durene $(1,2,4,5$-tetramethy $7-$ benzene), which has an excellent octane number but a freezing point of $79^{\circ} \mathrm{C}$. Too high a durene content in the gasoline may impair automobile driving characteristics because of the crystallization of durene at low temperatures. Workers at Mobil have conducted a fleet test and found no drivability loss at $-18^{\circ} \mathrm{C}$ when using a gasoline containing $4 \mathrm{wt} \%$ of durene. ${ }^{84}$ Nevertheless, in order to remove process contraints on MTG operation and to retain a lower target of durene, Mobile has also developed a heavy gasoline treating (HGT) process to convert durene into other high-quality gasoline components by isomerization and dealkylation. 85

The MTG reactions are highly exothermic. The heat of reaction ranges from 1.5 to $1.75 \mathrm{~kJ} / \mathrm{g}$ of $\mathrm{MeOH}$ and varies with product distributions. The product distribution varies with process conditions and reactor types. 
MTG reactors are designed to remove the large amount of reaction heat in a manner that is similar to the procedure used in FT reactors.

\section{2-2B. Various MTG Reactor Designs}

Three types of reactors were developed for the MTG: (i) adiabetic fixed-bed, (ii) fixed fluidized-bed, and ( $i$ ii) direct heat exchange. The first two types were developed by Mobil and the last by Lurgi.

The adiabetic fixed-bed process uses a two-stage concept. In the first-stage DME reactor, which contains a dehydration catalyst, the $\mathrm{MeOH}$ is dehydrated to an equilibrium mixture of $\mathrm{MeOH}$, dimethyl ether, and water. The effluent is then mixed with the light recycle gas and fed into a fixedbed ZSM- 5 reactor. The temperature rise in this reactor is limited by the heat carrying capacity of the recycle gas. The ZSM-5 catalyst requires periodic oxidative regeneration to overcome gradual coke deposition. The typical cycle length is 20 to 40 days, depending on the space velocity and operating conditions. After extensive early development work using microreactors and bench-scale pilot plants, a 4-BPD demonstration plant was developed. It had a $5 \mathrm{~cm}$ id and $4 \mathrm{~m}$ long dehydration reactor. $\mathrm{A} 10 \mathrm{~cm}$ id by $4 \mathrm{~m}$ long MTG reactor was erected. Table 5.2-1 shows typical process conditions and product yields (averaged over one cycle) for this plant. The first commercial plant of 14,500 BPD gasoline capacity was constructed in New Zealand. The plant has been running successfully since 1985 start-up. The synthesis gas used is generated via steam reforming from the NG obtained from the off-shore Maui field. An HGT plant is also operating successfully in New Zealand and reduces the durene in the gasoline to 2 wt\%.

A fluidized-bed MTG reactor concept was developed concurrently with the fixed-bed reactor at Mobi1. The heat of reaction can be removed either" directly from the reactor using a cooling coil or indirectly by using an external catalyst cooler. The reactor can be made to maintain a constant catalytic activity by continous catalyst regeneration and makeup. This concept has gone through many stages of pilot-plant development, including bench-scale fixed fluidized-bed, 4BPD, and 100BPD cold-flow models, and finally a 100BPD semi-work plant. Typical process conditions and product yields from the 4BPD pilot plant are also given in Table 5.2-1. The product yields are 
Table 5.2-1. Typical process conditions and product yields for MTG processes. 85

\begin{tabular}{|c|c|c|}
\hline Conditions & Fixed-bed reactor & Fluid-bed reactor \\
\hline $\begin{array}{l}\text { MeOH/water charge, } \mathrm{w} / \mathrm{w} \\
\text { Dehydration reactor inlet } \mathrm{T},{ }^{\circ} \mathrm{C} \\
\text { Dehydration reactor outlet } \mathrm{T},{ }^{\circ} \mathrm{C} \\
\text { Conversion reactor inlet } \mathrm{T},{ }^{\circ} \mathrm{C} \\
\text { Conversion reactor outlet } \mathrm{T},{ }^{\circ} \mathrm{C} \\
\mathrm{p}, \mathrm{kPa} \\
\text { Recycle ratio, mol } / \mathrm{mol} \text { charge } \\
\text { Space velocity, wHSV }\end{array}$ & $\begin{array}{c}83 / 17 \\
316 \\
404 \\
360 \\
415 \\
2,170 \\
9.0 \\
2.0\end{array}$ & $\begin{array}{c}83 / 17 \\
\cdots \\
-- \\
413 \\
413 \\
275 \\
\cdots \\
1.0\end{array}$ \\
\hline $\begin{array}{l}\text { Yields (wt8 of } \mathrm{MeOH} \text { charged) } \\
\mathrm{MeOH}+\text { dimethyl ether } \\
\mathrm{HCs} \\
\text { Water } \\
\mathrm{CO}, \mathrm{CO}_{2} \\
\text { Coke, other }\end{array}$ & $\begin{array}{r}0.0 \\
43.4 \\
56.0 \\
0.4 \\
0.2 \\
100.0\end{array}$ & $\begin{array}{r}0.2 \\
43.5 \\
56.0 \\
0.1 \\
0.2 \\
100.0\end{array}$ \\
\hline $\begin{array}{l}\text { Hydrocarbon product (wt }) \\
\text { Light gas } \\
\text { Propane } \\
\text { Propylene } \\
\text { Isobutane } \\
\text { n-Butane } \\
\text { Butenes } \\
\text { C }_{5} \text { gasoline }\end{array}$ & $\begin{array}{r}1.4 \\
5.5 \\
0.2 \\
8.6 \\
3.3 \\
1.1 \\
79.9 \\
100.0\end{array}$ & $\begin{array}{r}5.6 \\
5.9 \\
5.0 \\
14.5 \\
1.7 \\
7.3 \\
60.0 \\
100.00\end{array}$ \\
\hline $\begin{array}{l}\text { Gasoline (including alkylate), } \\
\text { RVP- } 62 \mathrm{kPa} \text { ( } 9 \mathrm{psi}) \\
\text { LPG } \\
\text { Fuel gas }\end{array}$ & $\begin{array}{r}85.0 \\
13.6 \\
1.4 \\
100.0\end{array}$ & $\begin{array}{r}88.0 \\
6.4 \\
5.6 \\
100.0\end{array}$ \\
\hline Gasoline octane $(\mathrm{R}+0)$ & 93 & 97 \\
\hline
\end{tabular}


quite different from those of the fixed-bed reactor, mainly because of non-recycle operation. Without recycle, large amounts of light olefins are preserved. By properly balancing the $C_{3}$ and $C_{4}$ olefin yields with those of isobutane, a maximum yield of high-quality alkylate can be produced when using conventional alkylation processes. This procedure results in a high gasoline yield. The fuel gas contains substantial amounts of ethylene, which may be recycled to make more gasoline.

The 100BPD semi-work program was jointiy conducted by Union Rheinische Braunkohlen Kraftstoff AG (URBK), Uhde GmbH, and Mobile, with additional funding from the FRG Bundesministerium fur Forschung and Technologie (BMFT) and the US DoE. The program was successfuily concluded in late 1984. The MTG reactor has a $60 \mathrm{~cm}$ id and a maximum bed height of $15 \mathrm{~m} .86$ The tests demonstrated better than $99.9 \% \mathrm{MeOH}$ conversion, a gasoline yield of over $92 w t \%$ (including alkylate and recycle of the excess light olefins), and a low catalyst makeup rate.

A direct heat-exchange MTG reactor concept was developed by Lurgi. 87 Some light gas recycle, in addition to the primary heat removal accomplished by circulating a brine in the shell side, is also used to control the reactor temperature. The conversion, gasoline yield and quality are similar to those of the fixed-bed reactor. The cycle length is longer than that of the fixed-bed but the reactor is more costly.

\section{2-3. Methanol Conversion to Olefins and Diesel}

\section{2-3A. Methanol Conversion to Olefins (MTO)}

During the MTG development work at Mobil, it was discovered ${ }^{88}$ that the HC-product distribution can be shifted to light olefins by increasing the space velocity, decreasing the MeOH partial pressure, and/or increasing the reaction temperature. Since then, major pilot-plant development work was conducted at Mobil, including the use of microreactors, a bench-scale fluidized-bed pilot plant, and a 4BPD fluidized-bed reactor. These tests finally led to demonstration runs in the 100BPD semi-work plant previously used for fluidized-bed MTG process development (see Sec. 5.2-2B). The runs were conducted under the sponsorship of the same partners as those of the 
100BPD MTG program. The ranges of operating conditions are: ${ }^{89} \mathrm{~T}, 470-515^{\circ} \mathrm{C}$; $\mathrm{p}, 1.2-2.5$ bar gauge; space velocity, $0.8-1.15 \ell / \mathrm{hr}$; reaction index $\left(\mathrm{C}_{3} / \mathrm{C}_{3}=\right.$ ), $0.5-0.1$; superficial gas velocity, $0.35-0.55 \mathrm{~m} / \mathrm{s}$. The catalyst makeup rate was less than $0.5 \%$ of the total catalyst inventory per day. The yield data agreed well with those from the $4 B P D$ pilot plant. For the 4BPD pilot plant operation, the following typical yields were reported: ${ }^{90} C_{1}-C_{3}$ paraffins, $4 w t \% ; C_{4}$ paraffins, $4 w t \% ; C_{2}-C_{4}$ olefins, $56 w t \% ; C_{5}+$ gasolines, $36 w t \%$.

Hoelderich et al ${ }^{91}$ of BASF investigated the use of zeolites for the conversion of $\mathrm{MeOH}$ to olefins for MTO. The nominal conditions investigated were atmospheric pressure, $300-600^{\circ} \mathrm{C}, 2.7-7.8 \mathrm{~h} / \mathrm{hr}$ WHSV and 25-80wt\% MeOH. $\quad \mathrm{C}_{2}-\mathrm{C}_{4}$ olefin selectivities as high as 80 wt\% were reported.

Lurgi has also reported MTO pilot-plant results using comnercial catalysts. ${ }^{87}$ The following product yields were obtained based on an average over $1,000 h r$ of operation: $C_{1}-C_{4}$ paraffins, 4wt\%; $C_{2}-C_{4}$ olefins, 8.1wt\%; $C_{5}+$ hydrocarbons, $13 w t \%$. Catalyst and process conditions were not reported.

\section{2-3B. Olefin Conversion to Diesel and Gasoline}

Using olefins from the MTO and FT processes, diesel and gasoline may be made from $\mathrm{MeOH}$ via a process that converts olefins to $D+G$. Catalytic polymerization is a standard refinery process using acid catalysts and is currently being used at SASOL to convert $C_{3}-C_{4}$ olefins into G+D. 92 Detailed operational information is not available.

Recently, Mobil has developed an MOGD (Mobil olefins to gasoline and diesel) process using a Mobil commercial zeolite catalyst. 90,93,94 The $G+D$ selectivity is better than $95 w t \%$ and is highly flexible with respect to G-to-D distribution (from $100 \% \mathrm{G}$ to $90 \% \mathrm{D}$ ). Because of the catalyst shape-selectivity, the majority of the products are methyl-branched isoolefins. These compounds have good octane rating in the gasoline range. The diesel-range olefins may be hydrogenated to give isoparaffins, which 
have excellent diesel properties. The qualities of the proper diesel and jet fuel fractions exceed the required product specification. A commercial-scale testing of the MOGD process was made in a Mobil refinery in late 1981. The feedstock was a mixture of $\epsilon_{3}-C_{4}$ olefins and paraffins from an FCC unit. The test was carried out successfully for 70 days.

\section{2-4. Processing of Fischer-Tropsch Products}

\section{2-4A. Special Feature of Fischer-Tropsch Products}

The FT products generally exhibit the following special features: (i) very wide carbon-number distribution for both HCs and oxygenates, nominally following the Schulz-Flory distribution [Eq. (5.1-23)]; (ii) no or minimal ring compounds; ( $i i i)$ highly olefinic (mainly a-olefins) character; (iv) production of mostly n-paraffins; and (v) n-alcohols as oxygenates. These features are reflected in the following deficiencies of the FT raw products: (i) low gasoline and diesel yields; (ii) low octane number in the gasoline fraction; ( $i i i$ ) waxy diesel fraction; and (iv) large amount of oxygenates in the product water. Further processing of these products is necessary to overcome these deficiencies. Upgrading schemes will now be discussed briefly.

\section{2-4B. SASOL Practices}

Because the product selectivities from the Arge and Synthol reactors are very different, the upgrading schemes are also drastically different. Hoogendoorn and Salomon 59,95 have given an excellent review of SASOL I (containing both Arge and Synthol reactor) upgrading schemes. The SASOL II and. III (containing only Synthol reactors) upgrading schemes were reported by Dry ${ }^{96}$ and Brink. ${ }^{92}$ Upgrading schemes for both cases are complex.

Following the Arge reactor, the $\mathrm{C}_{3}-\mathrm{C}_{4}$ fraction is sent to a catalytic polymerization unit to upgrade the $C_{3}-C_{4}$ olefins into $G+D$. The gasoline fraction is sent to a hot refining unit. (a fixed-bed catalytic 
reactor) to convert oxygenates into $\mathrm{HCs}$ and $\alpha$-olefins into the higher octane-number internal olefins. A moderate pressure hydrogenation unit (a fixed-bed catalytic reactor) is used to upgrade the $370^{\circ} \mathrm{C}+$ wax by converting olefins and oxygenates into paraffins. A de-oiling unit (solvent extraction) is used to remove oil from the hydrogenated $370-460^{\circ} \mathrm{C}$ wax. The $460^{\circ} \mathrm{C}+$ wax is thermally cracked in a paraformer unit to make medium and soft wax. The same unit is also used to crack the $320-370^{\circ} \mathrm{C}$ wax into $D+G$. The oxygenates in the aqueous stream are first separated by distillation and then subjected to hydrogenation to convert aldehydes into alcohols.

The upgrading schemes for the Synthol products as SASOL II and III are different from those at SASOL I. Since the practices at SASOL I are probably out of date, we concentrate our discussions on SASOL II and III. At SASOL II and III, the $\mathrm{C}_{2}$-fraction is cryogenically separated into $\mathrm{CH}_{4}$, ethane, and ethylene. The $\mathrm{CH}_{4}$ is converted into $S G$ using a partial oxidation reformer and the ethane is converted to ethylene in conventional ethane crackers. A heavy catalytic polymerization unit is used to upgrade the olefins in the $C_{3}-C_{4}$ fraction to $G+D$. The $C_{5}-C_{6}$ fraction is subjected to catalytic isomerization in a fixed-bed catalytic reactor using a catalyst similar to cracking catalysts in order to convert $\alpha$-olefins to higher octane-number isomers and to remove impurities. The $C_{7}-190^{\circ} \mathrm{C}$ fraction is first hydrogenated to eliminate olefins and oxygenates and then sent to a UOP continuous regeneration platformer to make high-octane gasoline. An 82 vol\% gasoline yield is obtained at 88 RON. The $190^{\circ}+$ fraction is first hydrogenated and the heavier fraction is sent to a selective cracking unit (a fixed-bed reactor using ZSM-5 zeolite) to lower its pour point. The water-soluble oxygenates are treated as in SASOL I to produce various alcohols and ketones.

\section{2-4C. Direct Upgrading of Total Vaporous F-T Reactor Effluent}

Use of this novel concept greatly simplifies the processing of FT products. The concept is to take the whole vaporous FT reactor effluent directly to a zeolite reactor without cooling and separation. 97 In a single step, a large portion of olefins is converted into aromatics and isoparaffins while cracking the heavy paraffins and olefins into 
gasoline-range paraffins and olefins. Isomerization activity of the zeolites ensures that the product will contain larger quantities of high octane number isocompounds. Large amounts of isobutane can be alkylated with the remaining $C_{3}$ and $C_{4}$ olefins to make alkylate, a high quality gasoline blending stock. The process also converts all of the oxygenates into gasoline-range HCs.

This concept has the important potential of improving the process economics of the FT technologies. In connection with a slurry bubble-column FT reactor, operation of a pilot-plant of this concept has been conducted at Mobil since 1981. 71,72 A set of typical operational data from G-mode (low-wax mode) operation is given in Table 5.1-5. Comparison of the HC distribution of the FT effluents with those from the ZSM-5 reactor clearly demonstrates the function of the ZSM-5 catalyst. Similar conclusions may be drawn from the high-wax mode operational data given in Table 5.1-6.

\section{2-4D. Processing of Fischer-Tropsch Reactor Wax}

The FT reactor waxes are produced from slurry or Arge-type reactors that operate at relatively low temperature and moderate pressure. These waxes generally have the following special properties: (i) highly paraffinic; ( $i i)$ mainly straight-chain $H C s$ and oxygenates with no or few ring compounds; ( $i i i$ ) some olefins and oxygenates; and ( $i v$ ) no sulfur, nitrogen, or heavy metal compounds. These properties make FT reactor wax very different from conventional pertroleum waxes. High-carbon-number straight-chain compounds are easily cracked and are excellent feedstocks in making high-quality diesel. Considerable caution must be exercised to prevent production of undesirable products (such as light paraffins and coke) because of overcracking.

Commercial applications to upgrade FT reactor wax are practiced at SASOL I with operation of the Arge reactor. A description of the practice is given in Sec. 5.2-4B. It is used primarily to make high quality waxes.

Development work on the processing of FT reactor waxes was carried out at Mobil, SASOL and She11. Mobil's work was partially supported by $\mathrm{DoE}^{72}$ and included the following scoping experiments to convert FT reactor wax from the high-wax mode of operation of the slurry FT reactor: thermal 
cracking, hydrodewaxing, hydrocracking, and fluidized-bed catalytic cracking (FCC). Thermal cracking does not produce the final products but provides instead a practical way to separate catalyst fines from the wax when coupled with vacuum distillation. The overhead solid-free wax can then be further upgraded. The other three studies use commercial catalysts. To compare these processes, the useful targets are high conversion and low $\mathrm{C}_{3}$-paraffin yield. Using these targets, the hydrodewaxing route is inferior to the other two.

Scoping hydrocracking resulted in a single-pass conversion of $72 w t \%\left(343^{\circ} \mathrm{C}\right.$ - as products) and $93 \mathrm{wt} \% \mathrm{G}+\mathrm{D}$ selectivity was achieved using a Ketjen 742 catalyst (CoMo on alumina). The unconverted fraction may be recycled to extinction. The diesel obtained had excellent quality, while the small amount of gasoline produced is low in octane number and needs further processing.

Some very interesting results were reported in scoping FCC processing of the same reactor-wax. Better than 90 wt\% single-pass conversion was easily achieved using Engelhard HEZ-53 catalysts (fresh, commercial equilibrium, and coked). Very high olefin yield (70wt\%) was obtained. Contrary to conventional petroleum-based FCC operation, the coke yield was very small. The small unconverted fraction may again be recycled to extinction. The highly olefinic product from the FCC is an ideal feedstock for MOGD processing (see Sec. 5.2-3B) in making G+D. It was estimated that, by combining an FCC with a MOGD and an alkylation unit, a total $G+D$ yield as high as $95 w t \%$ can be achieved. Both $G$ and $D$ are expected to have excellent qualities after conventional hydrofinishing of the $D$. A11 of these results were derived from scoping experiments. Improved results may be expected if optimizations on both catalysts and process conditions are carried out.

Dry has reported SASOL development work on mild hydrocracking of FT wax from its Arge reactor. 98 A yield structure of $5 \mathrm{wt} \% \mathrm{C}_{4}-115 \mathrm{G} / 80 \mathrm{D}$ was given. No process conditions or conversions were reported.

The work at Shell of FT wax upgrading is associated with its SMDS process (see Sec. 5.1-4C). The FT wax is produced from a direct heat-exchange reactor using a proprietary catalyst. The heavy, waxy HCs (mainly paraffins) are separated after passing through a separator and are 
fed to a heavy paraffin conversion (HPC) reactor. 77 The HPC reactor uses a commercial Shell catalyst performing hydroisomerization and hydrocracking. The process may be operated in a gas oil or kerosene mode. No.light paraffin yield and conversion were reported. The unconverted fraction (heavier than gas $0 i 1$ ) is recycled to the HPC reactor to extinction.

\subsection{Interaction of Coal Gasifiers with Synthesis Gas Conversion Processes}

\section{3-1. Introduction}

Matching a coal gasifier with a synthesis gas conversion process is an important factor in determining the technical and economic viability of coal conversion processes. In commercial applications, the ultimate factor that determines the viability of the process is economics. Unfortunately, good and consistent economic comparisons of various processes are essentially non-existent because economic process calculations use information and assumptions that are generated without consistent guidelines. Fortunately, large economic differences obtained under consistent guidelines are almost always caused by technical features and vice versa. Consequently, searching for sensible technical differences constitutes good reasoning when judging one process combination against another. The objective of this section is to define sensible, technical reasons for properly matching a coal gasifier with a downstream SG conversion process.

Coal-conversion processes are simply energy-conversion processes, and high thermal efficiency is an essential factor in maintaining good process economics. High thermal efficiency reflects not only high recovery of raw material but also means that less equipment is needed to transfer mass and reject additional waste energy. Consequently, thermal efficiency comparisons are useful technical tools for process-economics comparisons.

The issues associated with integration of coal gasifiers with SG conversion processes are many. The downstream conversion process dictates a minimum partial pressure of the active compounds $\left(\mathrm{H}_{2}\right.$ and $\left.\mathrm{CO}\right)$ in the SG. This minimum partial pressure is affected by three factors in the gasifiers: gasifier pressure, oxygen purity used, and the amount of light paraffins 
(mainly $\mathrm{CH}_{4}$ ) generated in the gasifiers. In addition, the SG pressure is changed by using either a gas compressor or an expander.

The $\mathrm{H}_{2} / \mathrm{CO}$ ratio of the $\mathrm{SG}$ is another important issue. It is costly to decrease the $\mathrm{H}_{2} / \mathrm{CO}$ ratio because of thermodynamic constraints. However, the use of a WGS unit to increase the $\mathrm{H}_{2} / \mathrm{CO}$ ratio is a proven technology that adds substantially to the process cost. Furthermore, the SG conversion processes use catalysts that usually require SG with less than a defined minimum threshold level of impurities (ususally of $\mathrm{H}_{2} \mathrm{~S}$ and (OS). Expensive SG purification units are needed to remove excess impurities. Another important integration issue is the co-production of energies in various forms. There are actually two sub-issues involved here. One is the co-production of fuel gas and SNG with liquid fuels to achieve high thermal efficiency. In a coal-based synfuel plan, it is almost always more costly to have a process set up to produce only liquid fuels. By recycling the light $\mathrm{HCs}$ to make additional $\mathrm{SG}, 30-40 \%$ of the energy in the iight HCs is easily lost. The other sub-issue is the co-production of steam and electricity, as in cogeneration. With proper integration and optimization of a coal gasifier with an SG-conversion process, the resulting high thermal efficiency results in a large surplus of steam or electricity. The steam may be exported to nearby factories as process steam or to nearby communites as utility steam, while the electricity is exported to the local utility network. Cogeneration is more often practiced outside than inside the US and is a desirable practice.

\section{3-2. $\underline{H}_{2}+\mathrm{CO}$ Partial Pressure Requirements}

The degree of importance attached to high $\mathrm{H}_{2}+\mathrm{CO}$ partial pressures in the SG depends strongly on the SG-conversion process. Molar contraction almost always occurs with SG conversion; consequently, the conversion is thermodynamically more favorable at higher $\mathrm{H}_{2}+\mathrm{CO}$ partial presssures. However, the importance of this requirement varies with the conversion process. Generally speaking, conversion reactions that are limited by chemical equilibrium, such as $\mathrm{MeOH}$ syntheses, will require higher partial pressures. The FT reactions are less strongly constrained by equilibrium 
considerations and may tolerate low $\mathrm{H}_{2}+\mathrm{CO}$ partial pressures. This contrast is clearly illustrated in Fig. 5.3-1, which shows thermodynamic equilibrium

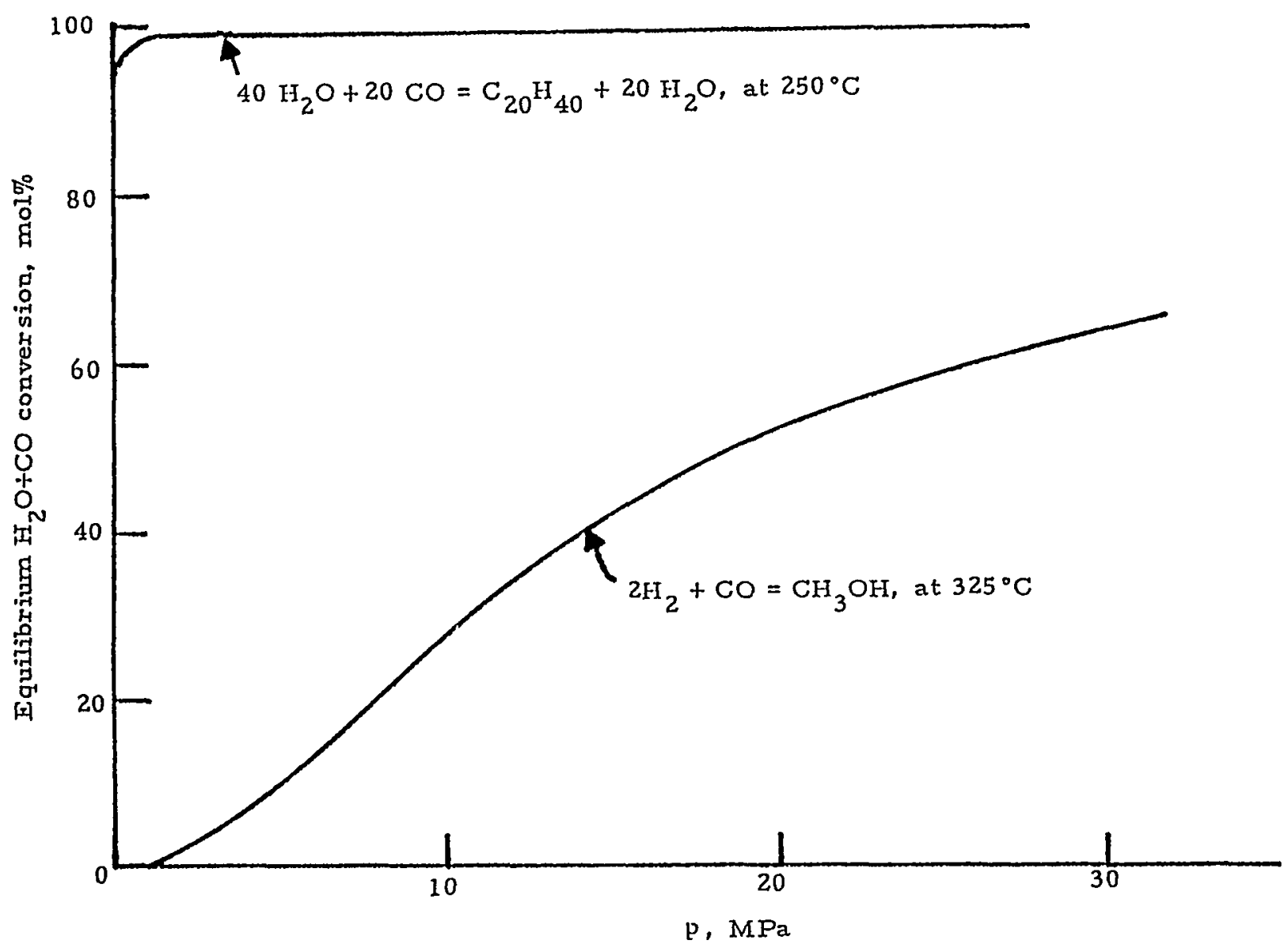

FIg. 5.3-1. $\mathrm{II}_{2}+\mathrm{CO}$ conversion at thermodynamic equilibrium.

conversion for both reactions. For simplicity, a single reaction for $C_{20}$ olefin formation is used to represent the FT reactions. In actual application, $\mathrm{MeOH}$ syntheses generally requires a minimum $\mathrm{H}_{2}+\mathrm{CO}$ partial pressure of 600-700psia. A7though the FT reactions may proceed to high $\mathrm{H}_{2}+\mathrm{CO}$ conversion at low pressure, moderate to high partial pressures (200-1,000 psia) are usually used to improve process economics.

The easiest way to obtain the required $\mathrm{H}_{2}+\mathrm{CO}$ partial pressure is to choose gasifiers operating at the proper pressure. If a low-pressure gasifier is used, the SG is simply compressed to the required value. The energy consumed for this compression may be very large if a coal-derived SG 
at atmospheric pressure is compressed to 500-1,000psia; energy equivalent to 16-20\% of the coal LHV will be needed to generate the compression work. 99 This reference also shows that the net thermal efficiencies of l.ow-pressure gasifiers, such as the Kopper-Totzek and Winkler, are 15-20\% 1ower than those of the moderate-pressure gasifiers used to produce clean, 400psia SG. This result implies that it is more efficient to compress the gasifier $\mathrm{O}_{2}$ and use high-pressure steam for gasification than to compress the output SG and follows because the coal-gasification reactions are molar-expansion reactions and compression work increases linearly with the number of moles. However, the fuel penalty for gas compression is relatively smaller at high pressures (e.g., above 300 psia) because the compression ratio is reduced. Thus, the best operating gasifier pressure ranges are 300-500 psia.

The other practical procedure for changing the $\mathrm{H}_{2}+\mathrm{CO}$ partial pressure is to vary the purity of $\mathrm{O}_{2}$ used for gasification. The thermodynamic constraint of the SG-conversion reactions again plays an important role in determining purity requirements for $0_{2}$. The requirement of high $\mathrm{H}_{2}+\mathrm{CO}$ partial pressure in the conventional $\mathrm{MeOH}$ synthesis clearly demands $S G$ from $\mathrm{O}_{2}$-blown gasifiers. The equilibrium $\mathrm{H}_{2}+\mathrm{CO}$ conversion for $\mathrm{MeOH}$ synthesis at low temperature becomes so high that use of SG from air-blown gasifiers may become practical. FT synthesis may also tolerate SG from the air-blown gasifiers. This combination may, however, not be economical because it is costly to move large quantities of the inert gas $\left(\mathrm{N}_{2}\right)$ through the entire system. The procedure demands substantialiy larger facilities to handle all of the streams and results in larger energy degradation assaciated with heating and cooling $\mathrm{N}_{2}$. The separation of $\mathrm{HC}$ products from the $\mathrm{N}_{2}$ is also very costly. Furthermore, low $\mathrm{H}_{2}+\mathrm{CO}$ partial pressure in the FT synthesis reactor may also induce undesirable effects such as high light $H C$ yields and high catalyst-aging rates. It is preferable to use $\mathrm{O}_{2}$-blown gasifiers. In theory, there is an optimal $\mathrm{O}_{2}$ purity for any combination of gasifier and synthesis process. Unfortunately, these optimal oxygen purities are not generally known.

The last item that affects the $\mathrm{H}_{2}+\mathrm{CO}$ partial pressure in the $S G$ is the light paraffin content of the gas. The amount of $\mathrm{CH}_{4}$ and ethane in the clean SG varies greatly with types of gasifiers and, to a lesser degree, with types of coals. Table 5.3-1 summarizes SG compositions of typical selected gasifiers. The $\mathrm{H}_{2}+\mathrm{CO}$ compositions range from 82.6 to $99.3 \mathrm{mo} 1 \%$. 
Table 5.3-1. Properties of clean synthesis gas from typical coal gasifiers.

\begin{tabular}{|c|c|c|c|c|c|c|c|}
\hline \multirow{2}{*}{$\begin{array}{l}\text { Operational } \\
\text { parameters }\end{array}$} & \multicolumn{7}{|c|}{ Gasifter } \\
\hline & $\begin{array}{l}\text { Dry-ash } \\
\text { Lurgi }\end{array}$ & Winkler & $\begin{array}{l}\text { Koppers- } \\
\text { Totzek }\end{array}$ & $\begin{array}{c}\text { BGC- } \\
\text { Lurgi } \\
\text { slagger }\end{array}$ & Texaco & $\begin{array}{l}\text { Shel1- } \\
\text { Koppers }\end{array}$ & KRIV \\
\hline Coal & Wyoming & $\begin{array}{c}\text { German } \\
\text { brown } \\
\text { coal }\end{array}$ & TVA & Frances & $\begin{array}{l}\text { Illinois } \\
\text { No. } 6\end{array}$ & $\begin{array}{l}\text { I1].inois } \\
\text { No. } 6\end{array}$ & Nyoming \\
\hline $\begin{array}{l}\text { Exit gasifier p, } \\
\text { psia }\end{array}$ & 430 & 30 & 20 & 365 & 600 & 435 & 415 \\
\hline \multicolumn{8}{|l|}{$\begin{array}{l}\text { Clean gas } \\
\text { composition, mol\% }\end{array}$} \\
\hline $\mathrm{H}_{2}$ & 55.7 & 50.2 & 38.6 & 29.4 & 40.0 & 32.8 & 40.1 \\
\hline co & 26.9 & 46.1 & 60.1 & 58.4 & 58.8 & 66.5 & 52.4 \\
\hline $\mathrm{Cli}_{4}$ & 16.1 & 2.3 & -- & 7.0 & 0.1 & $\therefore-$ & 6.8 \\
\hline $\mathrm{c}_{2}$ & 0.9 & - & -- & $0 . \dot{5}$ & - & -- & - \\
\hline $\mathrm{N}_{2}$ & 0.4 & 1.4 & 1.3 & 4.7 & 1.1 & 0.7 & 0.7 \\
\hline $\mathrm{H}_{2} / \mathrm{CO}$ ratio & 2.07 & 1.09 & 0.638 & 0.504 & 0.679 & 0.494 & 0.763 \\
\hline Clean gas LHV, $\%$ & & & & & & 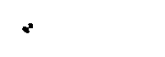 & \\
\hline$n_{2}+C O$ & 59.7 & 93.0 & 100.0 & 79.5 & 99.6 & 100.0 & 81.8 \\
\hline$c_{1}+c_{2}$ & 40.3 & 7.0 & -- & 20.5 & 0.4 & -- & 18.2 \\
\hline Ref. & 100 & 101 & 102 & 103 & 104 & 105 & 106 \\
\hline
\end{tabular}

Generally, the gasifiers that allow long residence time for coal devolatiliztion (such as the dry-ash Lurgi) and the coals containing large amounts of volatiles (such as the Wyoming coals) produce the largest $\mathrm{CH}_{4}$ and ethane yields. However, even the $\mathrm{CH}_{4}$ and ethane content in the $\mathrm{SG}$ from the dry-ash Lurgi using Wyoming coal is tolerable for MeOH synthesis. The net effect is a somewhat higher total pressure requirement or as slightly lower $\mathrm{H}_{2}+\mathrm{CO}$ conversion than is required for $S G$ that contains little or no light paraffins.

The light paraffins in the SG affect the amount of chemical energy available for synthesis. For example, in the case of the dry-ash Lurgi with Wyoming coal, $40 \%$ of the chemical energy in the clean $\mathrm{SG}$ is in $\mathrm{CH}_{4}$ and ethane (see Table 5.3-1). This yield is definitely inferior to the gases obtained from the Texaco and She11-Koppers gasifiers. Of course, the $\mathrm{CH}_{4}$ and ethane may be separated and then reformed to make $\mathrm{H}_{2}$ and $\mathrm{CO}$ for use in the SG conversion process, but this recycle imposes a large (30-40\%) thermal penalty. 


\section{3-3. $\underline{H}_{2}$ /CO Ratio Requirement}

\section{3-3A. Methanol Synthesis}

Synthesis of $\mathrm{MeOH}$ from $\mathrm{H}_{2}$ and $\mathrm{CO}$ requires a stoichiometric $\mathrm{H}_{2} / \mathrm{CO}$ ratio of 2. In practice, the feed gas also contains some $\mathrm{CO}_{2}$, which reacts with $\mathrm{H}_{2}$ to make $\mathrm{MeOH}$. The result is a stoichiometric $\mathrm{H}_{2} /\left(2 \mathrm{CO}+3 \mathrm{CO}_{2}\right)$ ratio of 1. In commercial applications, this ratio in the fresh feed gas is slightly larger than 1 to provide a kinetic driving force; consequently, this synthesis requires an $\mathrm{H}_{2}$-rich gas.

\section{3-3B. Fischer-Tropsch Synthesis}

Depending on the $\mathrm{H}_{2} / \mathrm{CO}$ use ratio, $\mathrm{FT}$ processes may be classified into two goups according to catalyst types. One uses catalysts of little or no WGS activity while the other has significant WGS activity. A typical catalyst used in the first group is Co and in the second Fe.

For catalysts without WGS activity, the oxygen in the $\mathrm{CO}$ is rejected as water, which results in an $\mathrm{H}_{2} / \mathrm{CO}$ use ratio of 2 in making olefins and alcohols and an $\mathrm{H}_{2} / \mathrm{CO}$ use ratio slighly larger than 2 in making paraffins (see reactions $(5.1-20$ to $5.1-22)$. These catalysts thus always require high $\mathrm{H}_{2} / \mathrm{CO}$ ratio gases.

For catalysts that promote the WGS reaction, the oxygen in $C 0$ will be mainly rejected as $\mathrm{CO}_{2}$, i.e., the $\mathrm{H}_{2} \mathrm{O}$ formed in the $\mathrm{FT}$ reaction reacts with the $\mathrm{CO}$ to form additional $\mathrm{H}_{2}$ resulting in an apparent $\mathrm{H}_{2} / \mathrm{CO}$ use ratio of 0.5 for olefin formation. However, because of formation of paraffins and oxygenates and the incompleteness of the WGS reaction, the actual mimimum $\mathrm{H}_{2} / \mathrm{CO}$ use ratio is about 0.6 . Consequently, low $\mathrm{H}_{2} / \mathrm{CO}$ ratio gases can be used with these catalysts.

There are potential process limitations that result from the use of low $\mathrm{H}_{2} / \mathrm{CO}$-ratio gases in $\mathrm{FT}$ reactor, including excessive carbon formation, carbide formation, reaction heat generation, and reactor-'wax formation. Based on the thermodynamics of the Boudouard reaction, the potential for carbon formation is proportional to the square of the co partial pressure. The trend of carbide formation also depends strongly on $C O$ 
partial pressure. Excessive reaction-heat generation results directly from the possibility of high single-pass conversion when $S G$ with an $\mathrm{H}_{2} / \mathrm{CO}$ ratio close to the use ratio is employed. The FT HC product distribution is expected to shift to heavier compounds when the $\mathrm{H}_{2} / \mathrm{CO}$ ratio of the feed is reduced. Consequently, low $\mathrm{H}_{2} / \mathrm{CO}$ ratio gases promote reactor-wax formation.

In a fluidized-bed reactor such as the Synthol reactor, the carbon, carbide, and reactor-wax formation may strongly affect catalyst fluidization. In a direct heat-exchange reactor such as the Arge reactor, the carbon and carbide formation may cause reactor plugging. The excessive reaction heat generation may cause catalyst overheating. Consequently, higher $\mathrm{H}_{2} / \mathrm{CO}$ ratio gases may be required, even with catalysts that have WGS activities for these two types of reactors.

Applications of SASOL technology are further complicated by use of the dry-ash Lurgi gasifier, which gives $\mathrm{H}_{2} / \mathrm{CO}$ ratios ranging from 1.7-2.4. 59 The discussions in the proceding paragraphs are then irrelevant. However, the indicated constraints are important when low $\mathrm{H}_{2} / \mathrm{CO}$ ratio gasifiers are employed.

Recycle operations are used in both the Synthol and Arge reactors at SASOL to achieve two goals: increase overall $\mathrm{H}_{2}+\mathrm{CO}$ conversion and decrease overal1 WGS conversion. The second goal is achieved by the accumulation of $\mathrm{CO}_{2}$ in the recycle gas to retard the WGS reaction. The recycle operation causes large increased in the $\mathrm{H}_{2} / \mathrm{CO}$ use ratio to match the high $\mathrm{H}_{2} / \mathrm{CO}$ ratios in the fresh feed. $\mathrm{H}_{2} / \mathrm{CO}$ ratios for both Arge and Synthol reactors at SASOL I are summarized in Table 5.3-2

Slurry reactors using unsupported, precipitated Fe catalysts were demonstrated to give high single-pass $\mathrm{H}_{2}+\mathrm{CO}$ conversion over a long period of time when using $S G$ with $0.6-0.7 \mathrm{H}_{2} / \mathrm{CO}$ ratios. $68,71,72$ This result is attributed to the following system properties: (i) micron-size, very active precipitated Fe catalyst with high WGS activity; (ii) a feed $\mathrm{H}_{2} / \mathrm{CO}$ ratio close to the single-pass usage ratio; (iii) excellent temperature control in the slurry reactor; (iv) a slurry reactor that sustains catalyst disintegration; and (v) a slurry reactor that sustains reactor-wax formation. Consequently, low $\mathrm{H}_{2} / \mathrm{CO}$ ratio $S G$ may be used directly. The $\mathrm{H}_{2} / \mathrm{CO}$ ratios for slurry FT reactors are also included in Table 5.3-2. 


\section{3-3C. Synthesis Gas $\mathrm{H}_{2}$ /CO ratios from Coal Gasifiers}

Table 5.3-1 summarizes the $\mathrm{H}_{2} / \mathrm{CO}$ ratios of the synthesis gases from typical gasifiers. The ratios range from 0.5 to 2.1 . Shinnar and Kuo ${ }^{99}$ evaluated the thermal efficiencies of various gasifiers and concluded that advanced, high-efficiency gasifiers use little steam (or water), thus producing low $\mathrm{H}_{2}$ /CO-ratio gases. Of course, it is easy to convert some $\mathrm{CO}$ in the gas to $\mathrm{H}_{2}$ by adding steam in a separate WGS unit to obtain a higher $\mathrm{H}_{2} / \mathrm{CO}$ ratio. However, a part of the efficiency gained by using the advanced gasifiers will then be negated because a WGS unit will require large amounts of steam and the construction of an a new unit and will also suffer thermal degradation because of additional cooling and heating. Furthermore, any $S G$ conversion processes using high $\mathrm{H}_{2} / \mathrm{CO}$ ratio gases must reject the oxygen in $\mathrm{CO}$ as $\mathrm{H}_{2} \mathrm{O}$ and, therefore, has the inherent deficiency of pushing large amounts of additional water (or steam) through the downstream synthesis system. Since water has a very high latent heat, moving large amounts of water also implies a large movement of energy. This large movement of mass and energy strongly affects process economics, as was pointed out by EI Sawy ${ }^{107}$ and Jones. 108 It is therefore always prudent to adopt an SG-conversion using directly a low $\mathrm{H}_{2} / \mathrm{CO}$-ratio gas from an advanced gasifier.

\section{3-3D. Use of Water-Gas Shift Units}

A separate WGS unit may be employed to increase the $\mathrm{H}_{2} / \mathrm{CO}$ ratio of any SG stream. WGS technologies are wel1-developed and commercially proven. Kuo $^{1}$ has given a concise review of WGS catalysts and chemistry. Chemical equilibrium in the WGS reaction leads to increasing $\mathrm{H}_{2}$ formation with decreasing temperature. The equilibrium constant $K_{p}$ is defined as $\mathrm{P}_{\mathrm{H}_{2}} \mathrm{P}_{\mathrm{CO}_{2}} / \mathrm{P}_{\mathrm{CO}} \mathrm{P}_{2} \mathrm{O}$ and is greater than 20 when $\mathrm{T}$ is less than $350^{\circ} \mathrm{C}$. Although the WGS reaction attains equilibrium rapidly, the required exothermic reaction heat implies considerable effort in reactor design, especially for low $\mathrm{H}_{2} / \mathrm{CO}$ ratio SG.

There are basically three types of WGS catalysts: high-temperature shift catalysts (HTS) operating at $440-700^{\circ} \mathrm{C}(\mathrm{Cr}-\mathrm{Fe}$ oxide 
or $\mathrm{Zn}-\mathrm{Cr}$ oxide); low-temperature shift catalysts (LTS), $230-350^{\circ} \mathrm{C}$ (Cu-Cr oxide); raw-gas shift catalysts (RGS), $180-550^{\circ} \mathrm{C}$ (Co-Mo sulfide). The

Table 5.3-2. $\mathrm{H}_{2} / \mathrm{CO}$ ratios of FT reactors.

\begin{tabular}{l|c|c|c|c}
\hline \multicolumn{1}{c}{ Parameter } & \multicolumn{2}{c}{ SASOL I (from Ref.54) } & Slurry reactor 71,72 \\
\cline { 2 - 5 } & $\begin{array}{c}\text { Arge } \\
\text { reactor }\end{array}$ & $\begin{array}{c}\text { Synthol } \\
\text { reactor }\end{array}$ & $\begin{array}{c}\text { Low-wax } \\
\text { mode }\end{array}$ & $\begin{array}{c}\text { High-wax } \\
\text { mode }\end{array}$ \\
\hline Fresh feed & 1.70 & 2.77 & 0.67 & 0.67 \\
Tail gas & 1.71 & 15.6 & -- & -- \\
Combined feed & 1.72 & 4.65 & -- & -- \\
Usage & 1.69 & 2.45 & 0.585 & 0.560 \\
\hline
\end{tabular}

LTS catalysts are used mainly to achieve high CO conversion, which is important for $\mathrm{H}_{2}$ and $\mathrm{NH}_{3}$ syntheses but not for $\mathrm{MeOH}$ and $\mathrm{FT}$ syntheses. The HTS catalysts are relatively more stable and yield partial CO conversion which is sufficiently high to prepare the SG for $\mathrm{MeOH}$ and FT syntheses. Both LTS and HTS catalysts require a low sulfur level in the synthesis gas. On the other hand, the RGS catalysts require some suifur in the gas to maintain activity. This feature adds the advantages of directly processing the raw gasifier gas without extensive cooling and cleaning. Part of the waste sensible heat in the raw gas may also be used to generate steam for the WGS reaction. Furthermore, a single SG purification unit may now be used to remove both the sulfur compounds and $\mathrm{CO}_{2}$.

Further optimization of WGS operation may be possible by minimizing the amount of the excess steam in the feed gas and utilizing a low-temperature heat source to raise steam required for the WGS unit.

\section{3-4. Purity Requirements for Synthesis Gas}

Most of the impurities in the gasifier SG can easily be removed, except for sulfur compounds. Coal dust, ash, tar, and $0 i 1$ are removed by water washing or by mechanical means. Ammonia and phenol are removed by water washing. 
Removal of sulfur compounds is essential since these may poison many catalysts in the downstream processes. There are many commercially established purification processes for removal of sulfur compounds. A

concise review has been given by Kuo. ${ }^{1}$ The maximum allowable sulfur levels depend on the catalyst used downstream; rough guidelines are provided in Table 5.3-3.

\subsection{Zeolites as Shape-Selective Catalysts}

\section{4-1. Introduction}

Zeolites may be viewed as solid analogs of such classical acids as sulfuric acid or aluminum chloride and have with them in common the ability to promote a large number of acid-catalyzed reactions, including polymerization, cracking, isomerization of olefins, paraffins and aromatics, alkylation of aromatics and of paraffins, transalkylation, and many others: Some, such as gas oil cracking, belong to the largest catalytic processes.

The first solid acid catalysts were activated natural clajs and synthetic binary oxides, such as silica-alumina. Their acidic properties have been well described. 109 They have remained a very important class of catalysts, both as acidic catalysts and as acidic components in dual functional catalysts, by the addition of a second function of hydrogenation and oxidation, etc. The evolution and optimization of these catalysts has remained a highly empirical art, partly because these amorphous catalysts are difficult to characterize. By contrast, zeolites are crystalline porous solids that have a well defined pore system and large intracrystalline surface area. 110,111 It was discovered in the late fifties at the Mobil laboratories that catalytic reactions can take place inside these structures. This discovery marked the real beginning of zeolite catalysis.

Two aspects make zeolites unique. The intracrystalline surface is an inherent part of the crystal structure and hence topologicaily well defined, in sharp distinction to amorphous and even most crystalline solids for which the outer surface may be considered to be a crystal defect: with atoms whose coordination number differs from atoms in the crystal. The second distinctive feature of zeolites is that the diameter of their pores 
is uniform and of similar magnitude as that of many organic molecules of interest. Molecular sieving and shape selectivity, previously unknown with man-made catalysts, became possible.

Each zeolite has a unique pore system and crystal structure. Nature has provided us with 34 different zeolites. 111-114 However, among those of interest to catalysis, only a few are found in abundance. The ability to synthesize zeolites of known and new structures in the laboratory made new discoveries in zeolite catalysis possible. To date, nearly 100 synthetic zeolites have been identified covering a large variety of different framework structures, with pore openings ranging from less than $5 \AA$ to larger than $10 \AA$.

In heterogeneous catalytic processes, one usually considers three major performance characteristics: activity, selectivity towards one or several products, and stability of operation, i.e., low catalyst aging. These performance features are complex, interacting functions of

Table 5.3-3. Approximate minimum allowable sulfur levels for selected catalysts.

\begin{tabular}{l|c}
\hline \multicolumn{1}{c|}{ Catalysts } & $\begin{array}{c}\text { Minimum sulfur } \\
\text { level (ppmv) }\end{array}$ \\
\hline Low-p methanol & 1 \\
High-p methanol & Higher than 1 \\
FT, except Mo-based & $1-2$ \\
Mo-based FT & 20 \\
LTS and HTS WGS & 1 \\
RGS WGS & Very high \\
\hline
\end{tabular}

several basic catalyst properties: sorption energies for feeds and products; rates of transport of molecules to and from the active sites (mostly by diffusion); and intrinsic activities for various reactions. With zeolites, it has now become possible to vary these properties in a systematic way and one at a time.

\section{4-2. Classification of Zeolites}

Zeolites are porous tectosilicates, ${ }^{110}$ i.e., three-dimensional 
networks built up of $\mathrm{TO}_{4}$-tetrahedra ( $\mathrm{T}=\mathrm{Si}$ or heteroatom) such that each of the four oxygen atoms is shared with another tetrahedron. The most common forms are alumino-silicates, although structures containing boron, gallium or iron in place of aluminum and germanium in place of silicon have been reported. 110 The tetrahedron can link up to form a variety of secondary building units from which zeolites of various framework topologies are derived. Meier and 01 son $^{113}$ have summarized the structures of 38 zeolites; in addition, the framework topologies of ZSM-12, ${ }^{115}$ ZSM-22, ${ }^{116,117}$ ZSM-23, 118 and of $Z S M-48^{119}$ and others have been described. Altogether, the crystal structure of about 50 zeolites is now known. 120

The structure characteristics of greatest interest for catalysis is the channel system, which is described for some of the more important zeolites in Table 5.4-1. Depending on the largest channel, zeolites are characterized as small, medium or large pore zeolites if they contain apertures made by rings of 8, 10 or 12 linked tetrahedra. Framework structures and pore openings of representative zeolites of each group are depicted in Fig. 5.4-1. Within each group, there is considerable variation in the aperture, both in size and ellipticity. For example, the opening in Linde $A$ is circular $(4.1 \AA)$, but in erionite it is elliptical $(3.6 \times 5.2 \AA)$.

The projections of a series of similar zeolites (Fig. 5.4-2) show the subtle variations of channel dimensions and shapes available. The channel system may be one-dimensional, e.g., ZSM-22, ZSM-48, two-dimensional as in ferrierite, or three-dimensional as in ZSM-5 (Fig. 5.4-3). Multi-dimensional channels often intersect each other, but this is not always the case. The interconnecting channels can be of the same size (e.g., faujasite) or smaller (ferrierite); they may be straight (ZSM-11) or tortuous $(Z S M-5)$. The connectivity of the channel system has major consequences for diffusion and aging characteristics. For example, zeolites with one-dimensional channels are more subject to deactivation than those with a three-dimensional pore system because of their susceptibility to pore mouth plugging.

The pores in some zeolites are relatively uniform tubes, e.g., in ZSM-48 (Fig. 5.1-3); in other zeolites, they contain larger cavities (e.g., erionite, Linde A) or supercages (e.g., zeolite Y, Fig. 5.4-1) which are connected by windows. Zeolites containing large cavities are more prone 
to deactivation since molecules such as condensed aromatics can form but cannot escape through the smaller port holes and are trapped. ${ }^{121,122}$ Most medium pore zeolites have pores of uniform dimensions. This particular feature is believed to account for their unusually low coke-forming propensity in acid-catalyzed reactions. Their non-aging character is one of the major contributing factors to the successful industrial applications of these zeolites.

Table 5.4-1. Channel system of representative zeolites.

\begin{tabular}{l|c|c}
\hline Structure Type & $\begin{array}{c}\text { Ring Size } \\
\text { of Channels }\end{array}$ & Largest Channel, ${ }^{(b)}$ \\
\hline Linde Type A & $8-8-8$ & 4.1 \\
Chabazite & $8-8-8$ & $3.6 \times 3.7$ \\
Erionite & $8-8$ & $3.6 \times 5.2$ \\
ZSM-22 & 10 & $4.5 \times 5.5$ \\
ZSM-23 & 10 & $4.5 \times 5.6$ \\
ZSM-48 & 10 & $5.3 \times 5.6$ \\
Ferrierite & $10-8$ & $4.3 \times 5.5$ \\
ZSM-5 & $10-10$ & $5.4 \times 5.6$ \\
ZSM-11 & $10-10$ & 5.5 \\
& 12 & $5.7 \times 6.1$ \\
ZSM-12 & 12 & 7.1 \\
Linde Type I & 12 & 7.4 \\
Mazzite & $12-8$ & $6.7 \times 7.0$ \\
Mordenite & $12-8-8$ & 6.4 \\
Offretite & $12-12-12$ & 7.4 \\
Faujasite & & \\
\hline
\end{tabular}

(a) Number of either $T$ - or 0 -atoms forming the smallest rings of the channels.

(b) Crystallographic free diameter, based on an oxygen radius of $1.35 \AA$, of the smallest ring or window in the channel. 

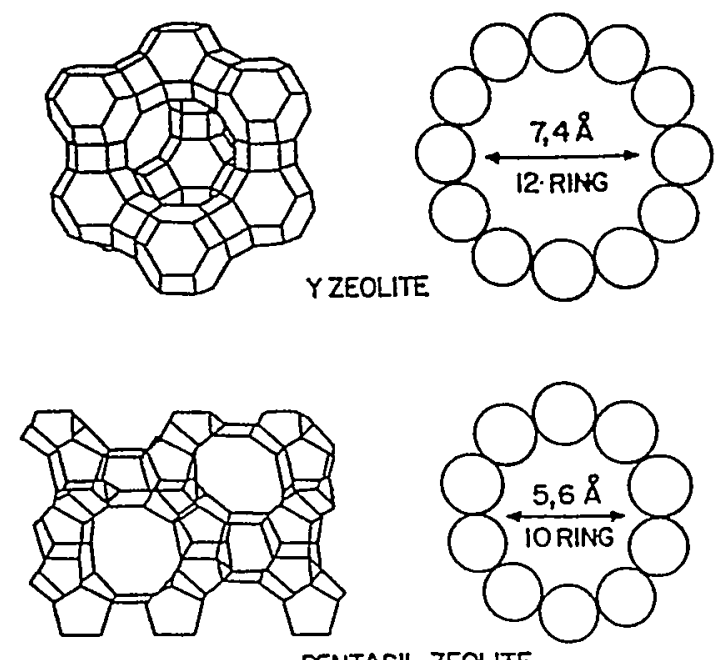

PENTASIL ZEOUTE
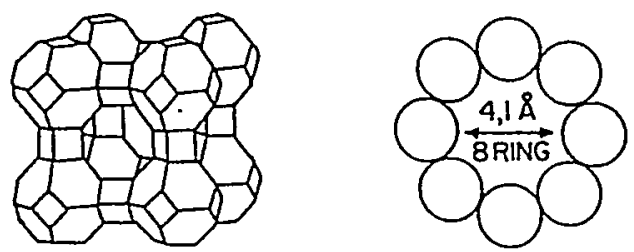

A ZEOLITE

Fig. 5.4-1. Framework structures and projections of representative large, medium, and small pore zeolites.

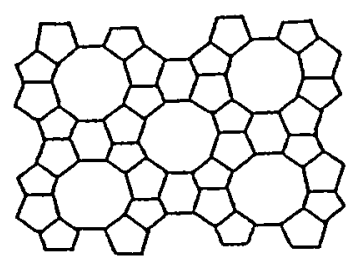

ZSM-5 $0.54 \times 0.56$

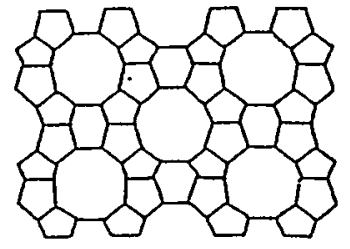

ZSM-11 $0.51 \times 0.55$

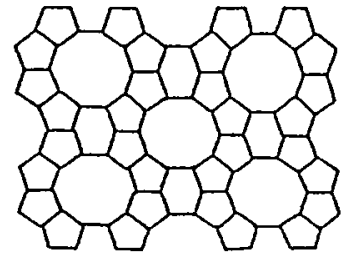

ZSM-48 $0.53 \times 0.56$

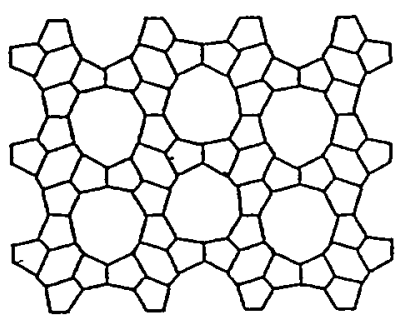

ZSM-23 $0.45 \times 0.56$

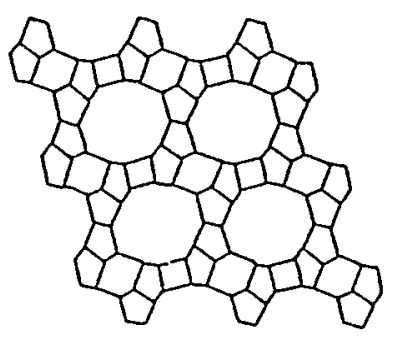

ZSN-12 $0.57 \times 0.61$

Fig. 5.4-2. Profections of $\mathrm{ZSM}-5,-11,-12,-23$, and -48 structures. The axes of the channels (in $\mathrm{nm}$ ) are indicated. 


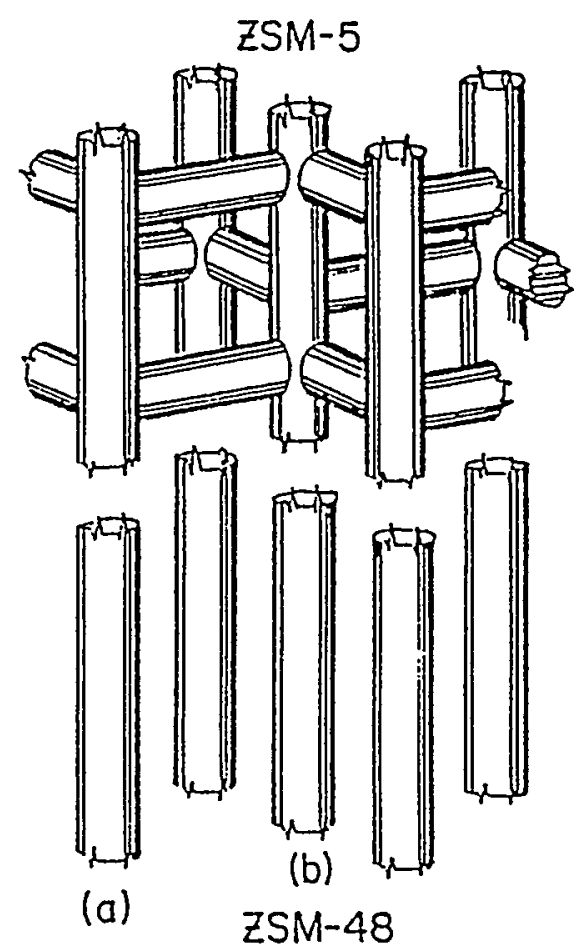

FIg. 5.4-3. Schematic channel system of ZSM-5 (three-dimensional) and ZSM-48 (one-dimensional).

Zeolites with 8-membered rings sorb only straight chain molecules such as n-paraffins, n-olefins and primary alcohols. Some larger pore zeolites also behave like small pore zeolites, when their structure contains many stacking faults which reduce the effective pore diameter. Examples are gmelinite, stilbite, dachiardite, Linde T, ZSM-34, epistilbite, heulandite/clinoptilolite, ferrierite, etc.

Medium pore zeolites with 10 membered ring systems are of most interest as shape selective catalysts. Not only do they sorb straight, chain molecules, they also can discriminate, either by size exclusion or by rate of diffusion, among a variety of branched and cyclic molecules. Included in this group are ZSM-5, ZSM-11, ZSM-22 (Theta-1), ZSM-23, ZSM-48, and ferrierite.

The 12-membered ring zeolites include all the large pore zeolites. The synthetic faujasites, zeolite $X$ and $Y$, and mordenite are the best known and most studied zeolites in this group.

The silica to alumina ratios of different zeolites structures are 
another distinguishing feature. Within each group, the ratio can be varied, especially with medium pore silica-rich zeolites. Figure 5.4-4 shows the compositional ranges for selected zeolites structures.

\section{4-3. Intrinsic Catalytic Properties of Zeolites}

The acid activity of zeolites depends on the presence of three-valent ions such as $\mathrm{Al}^{3+}$ in the zeolite framework of share $\mathrm{SiO}_{4}$-tetrahedra. Without their presence, crystalline or amorphous silicas have no acid activity. These Al-ions give rise to Bronsted acid sites whose structure is depicted in Fig. 5.4-5.

The catalytic activity in HZSM-5 preparation with an Si/Al from about 17 to 180,000 has been found to be strictly proportional to their aluminum concentration and hence to their contents of active sites, which range from $5.6 \times 10^{16}$ to $5.6 \times 10^{20}$ sites per gram. The correlation 1 ine goes through the origin (Fig. 5.4-6). The proportionality between activity and number of $A 1$ atoms indicates that every acid site contributes equally to the observed activity, independently of the total site concentration.

\section{4-4. Shape Selectivity}

Molecular shape-selective catalysis in zeolites can be obtained when the dimensions of reactant or product molecules approach those of the intercrystalline pores. Several reviews describe the phenomenological aspects of shape selectivity. 123,124

Two different mechanisms operate to cause shape selectivity. In one, selectivity results from a large difference in the diffusivity of the participating molecules in the zeolite channels (mass transport selectivity). In the other, selectivity is caused by steric constraints in the transition state of the catalytic transformation step (transition state selectivity).

The unique properties of zeolites as acid catalysts has led to their rapid commercial utilization. A summary of processes in which zeolite catalysts have been used is shown in Table 5.4-2. 


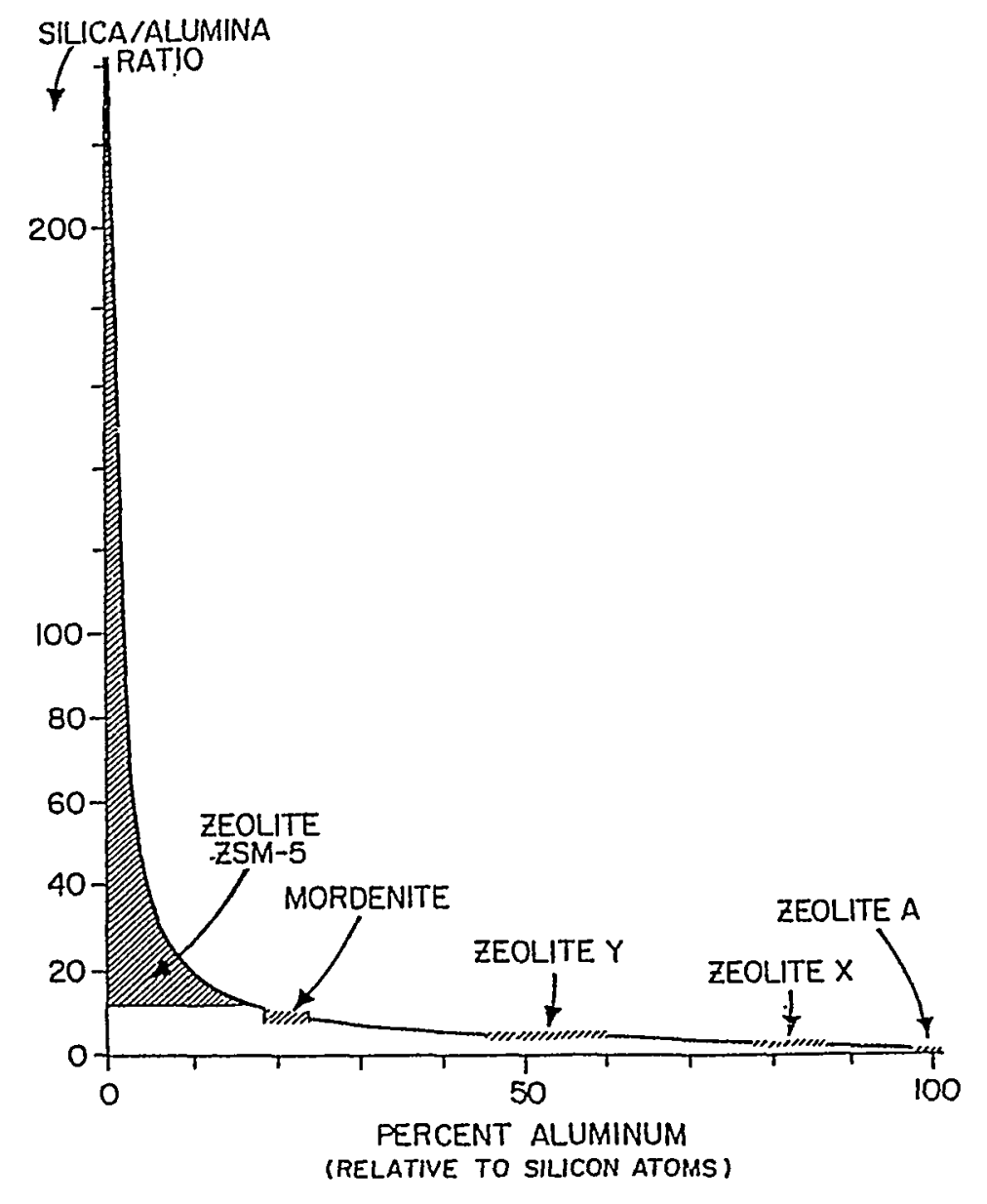

Fig, 5.4-4. Aluminum concentration and silica/alumina ratio for various zeolites.

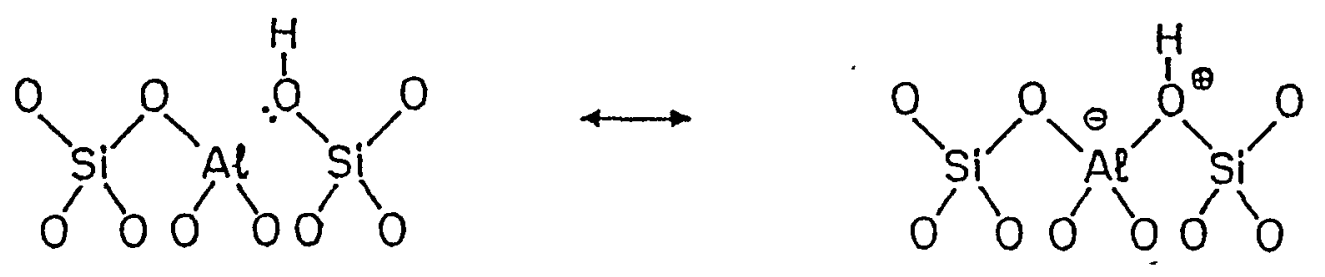

Fig. 5.4-5. The structure of the Bronsted actd site in zeolites. 
Table 5.4-2. Processes utilizing zeollte catalysts.

\begin{tabular}{|c|c|c|}
\hline Process & Application & Catalyst \\
\hline Cracking & $\begin{array}{l}\text { Gas oil to gasoline } \\
\text { and Distillates }\end{array}$ & $\begin{array}{l}\text { REY, US - Y } \\
\text { ZSM-5 }\end{array}$ \\
\hline Hydrocracking & $\begin{array}{l}\text { Heavy fractions to } \\
\text { naphtha and distillates }\end{array}$ & $\begin{array}{l}M E+R E X \\
R E Y, U S-Y\end{array}$ \\
\hline Hysomer & $\begin{array}{l}\text { Isomerization of } \\
\text { pentane and hexane }\end{array}$ & Pt/mordenite \\
\hline Selectoforming & Post reforming process & Erionite \\
\hline M-Forming & Upgrading of reformate & ZSM-5 \\
\hline MDDW , MLDW & $\begin{array}{l}\text { Dewaxing of distillates } \\
\text { and lube oil }\end{array}$ & $"$ \\
\hline MLPI, MVPI, MHTI & Xylene isomerization & $"$ \\
\hline MTDP & Toluene disproportionation & $"$ \\
\hline MEB & Ethylbenzene synthesis & $n$ \\
\hline MOGD & $\begin{array}{l}\text { Conversion of olefins to } \\
\text { gasoline and distillate }\end{array}$ & $"$ \\
\hline MTG & $\begin{array}{l}\text { Methanol conversion to } \\
\text { gasoline }\end{array}$ & $"$ \\
\hline MTO & $\begin{array}{l}\text { Methanol conversion } \\
\text { to olefins }\end{array}$ & $"$ \\
\hline M2-Forming & $\begin{array}{l}\text { Formation of axomatics } \\
\text { from paraffins and olefins }\end{array}$ & $"$ \\
\hline Para Selective & $\begin{array}{l}\text { Synthesis of p-ethyltoluene, } \\
\text { synthesis of p-xylene from } \\
\text { toulene }\end{array}$ & $"$ \\
\hline
\end{tabular}




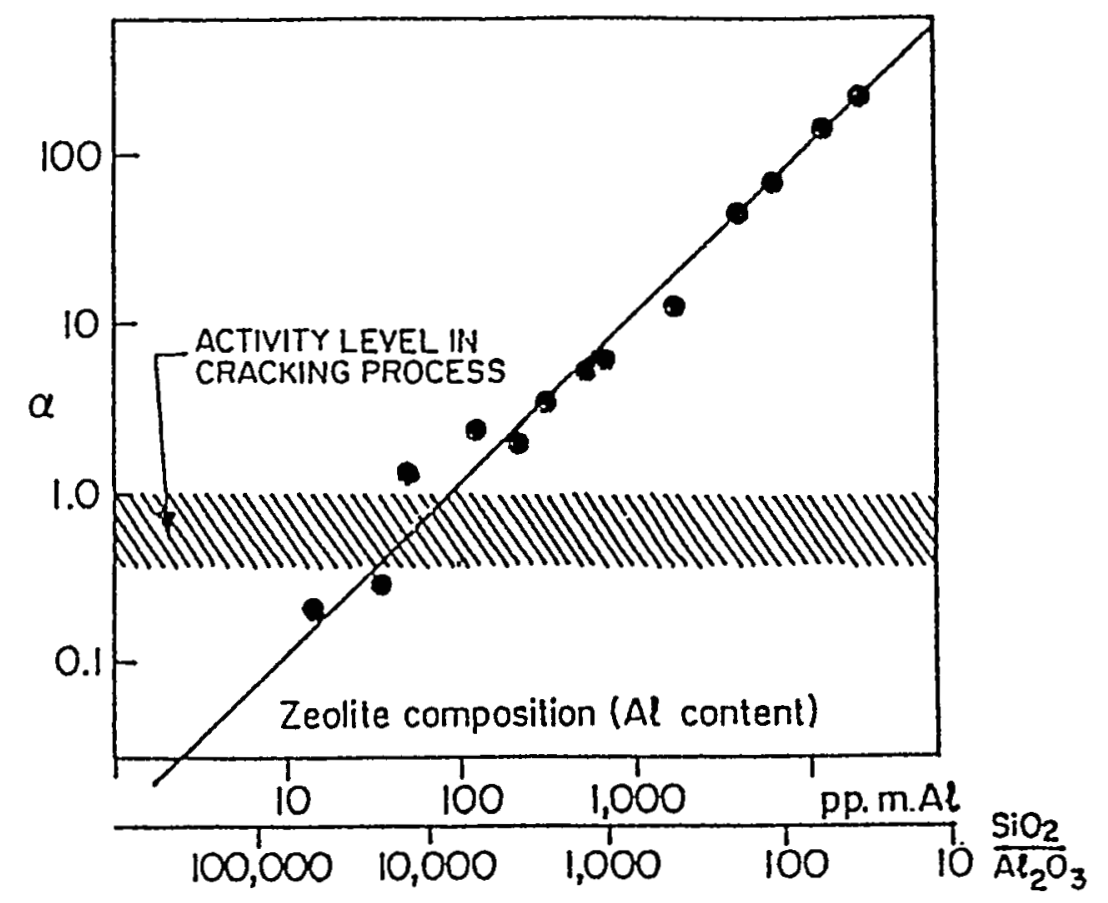

Fig. 5.4-6. The hexane cracking activity ${ }^{83} \alpha$ plotted agains the aluminum content in IIZSM-5. The shaded band indicates activities near $\alpha \approx 1$.

\section{$\underline{\text { References }}$}

1. J. C. W. Kuo, "Gasification and Indirect Liquefaction" in The Science and Technology of Coal and Coal Utilization, B. R. Cooper and W.A. Ellingson, eds., Plenum Publ. Corp. NY (1984).

2. F. Fischer and H. Tropsch, Brennst. Chem. 4, 276 (1923).

3. P. Sabatier and J. B. Senderens, Ann. Chim. Phys. 4, 418 (1905).

4. G. Natta, "Methanol," in Catalysis, Vol. 3, P. H. Emmett ed., Reinhold Publ. Corp. NY (1955).

5. S. Strelzoff, "Methanol: Its Technology and Economics," pp. 54-68 in Methanol Technology and Economics, G. A. Donner ed., AIChE Symposium Series 66, No. 98 (1970). 
6. A. Stratton, D. F. Hemning and M. Teper, "Methanol Production from Natural Gas or Coa1," IEA Coal Research, EAS Report No. E4/82, London, England (Dec. 1982).

7. G. C. Chinchen, P. J. Denny, D. G. Parker, G.D. Short, M.S. Spencer, K.C. Waugh, and D.A. Whan, ACS Preprints (Div. of Fuel Chem.) 29, 178 (1984).

8. H. H. Kung, CataT. Rev. -Sci. Eng. 22, 235 (1980).

9. K. Klier, Adv. Catal. 31, 243 (1982).

10. A. Ya Rozovski, G. Lim, L. B. Liberov, E. V. Slivinskii, S. M. Loktev, Yu. B. Kagan, and A.N. Bashkirov, Kinetics and Catalysts (English translation) 18, 691 (1977).

11. M. L. Poutsma, L.F. Clek, P.A. Ibarabia, A. P. Risch, and A. J. Rabo, J. Catal. 52, 157 (1978).

12. R. G. Herman, K. Klier, G. W. Simmons, B. P. Finn, J. B. Bulko, and T. P. Kobylinsky, J. Catal. $\underline{56}, 407$ (1979).

13. F. Marschner F. W. Moller and R. Schulze-Bentrop, "Methanol from Synthesis Gas," Chap. 9 in Chemical Feedstocks from Coal, J. Falbe ed., John Wiley \& Sons, NY (1982).

14. C. N. Satterfield, Heterogeneous Catalysts in Practice, pp. 295-301, McGraw-Hi11, NY (1980).

15. J. Klosek and R. J. Mednik, "Progress in Liquid-Phase Methanol Snythesis," in Ninth Annual EPRI Contractor's Conference on Coal Liquefaction, Palo Alto, CA (May 8-10, 1984).

16. J. W. Evans, P. W. Casey, M. S. Wainwright, D. L. Trimm, and N. W. Cant, Appl. Catal. 7, 31 (1983).

17. H. Brendlein, German Patent No. 809, 803 (Aug. 2, 1951).

18. H. F. Woodward, Jr., "Methanol," pp. 370-398 in Kirk-Othmer Encycl Chem. Technol., 2nd ed., Vol. 13, John Wiley \& Sons, NY (1967).

19. P. A. Buckingham, D. D. Cobb, A. A. Leavitt, and W. G. Synder, "Coal-to-Methanol. An Engineering Evaluation of Texaco Gasification and ICI Methonal Synthesis Route," EPRI Report No. AP-1962, Project No. 832-4, Palo Aito, CA (1981).

20. J. P. Leonard and M. E. Frank, Chem. Eng. Progr. 75, 68 (1979).

21. D. R. Simbeck, R. L. Dickensen and E. D. 0liver, EPRI Report No. AP-3109, Project No. 2207, Palo Alto, CA (June 1983). 
22. F. H. Kant, R. P. Cahn, A. R. Cunningham, M. H. Farmer and W. Herbst, "Feasbility Study of Alternative Fuels for Automotic Transportation," EPA-4603-74-009A, Band C, Exxon Res. and Engrg. Co., Linden NJ (June 1974).

23. J. Pangorn and J. Gillis, "Alternative Fuels for Automotive Transportation - A Feasibility Study," EPA-460/3-74-012-a,b, f, Institute of Gas Technology, Chicago, IL (July 1974).

24. G. J. Anderson, B. Berger, J. Carlson, W. Crothers, D. Gregg, and A. Pasternack, "LLL Contribution to the AEC Methanol Report: Fuel Utilization and Environmental Impact," UCB/LBL, CA, UCID-1642 Lawrence. Livermore Labs., Livermore, CA (January 18, 1974).

25. P. E. Cassady, "The Use of Methanol as a Motor Vehicle Fuel," paper presented at the 169th ACS National Meeting, Philadelphia, PA (April 6-11, 1975).

26. D. L. Hagen, Ph.D. Thesis, University of Minnesota, Minneapolis, MI (December 1976).

27. Royal Swedish Academy of Sciences and the Swedish Methonal Development Co., "Methanol as a Fue1," Proc. Symp., Stockholm, Sweden (March 23, 1976).

28. Chem. Eng. News. pp. 9-15 and pp. 31-35 (July 16, 1984).

29. J. H. Finegold, J. T. McKinnon and M. E. Karpuk, "Dissociated Methanol as a Combustion Hydride for Automobile and Gas Turbines," paper presented at the World Hydrogen Energy Conference IV, Pasadena, CA (June 1984).

30. N. M. Woodley, D. A. Nordman, J. R. Legro, and D. G. Davies, "Reformed Alcohol Fuels for Combustion Turbines: Technical and Economic Feasbility Assessment," Report No. AST-82-1683, Westinghouse Electric Corp., Pittsburgh, PA (1982).

31. C. E. Lucke and S. M. Woodward, "Use of Alcohol and Gasoline in Farm Engines," USDA Farmers Bulletin, Washington, D.C. (1907).

32. T. Tarr and J. R. Jones, "Ethanol in Motor Gasoline," pp. 55-70 in Monohydric Alcohols, Manufacture, Applications and Chemistry) E: J. Wickson ed., ACS Symposium Series 159 (1981).

33. M. Ichikawa, ChemTech. 12, 674 (1982).

34. I. Wender, R. Levine and M. Orchin, J. Am. Chem. Soc. 71, 4160 (1949).

35. M. E. Fakley and R. A. Head, Appl. Catal. $\underline{5}, 3$ (1983). 
36. R. A. Fiato, US Patent No. 4,233,460 (1980).

37. R. A. Fiato, US Patent No. 4,253,987 (1981).

38. M. J. Chen, H. M. Feder and J. W. Ruthke, J. Am. Chem. Soc. 104, 7346 (1982).

39. R. B. Anderson, The Fischer-Tropsch Synthesis, Academic Press, NY (1984).

40. P. Courty, D. Durand, E. Freund, and A. Sugier, J. Mol. Cata1. 17, 241 (1982).

41. J. Haggin, Chem. Eng. News. pp. 7-13 (May 19, 1986).

42. Chem. Eng. News, p. 35 (June 9, 1986).

43. H. H. Storch, N. Golumbic and R. B. Anderson, The Fischer-Tropsch and Related Syntheses, John Wiley \& Sons, NY (1951).

44. T. J. Huang and W. O. Haag, "Aromatic Gasoline from Hydrogen/Carbon Monoxide Over Ruthenium/Zeolite Catalysts," in Catalyst Activation of Carbon Monoxide, P. C. Ford ed., ACS Symposium Series 152 (1981).

45. C. B. Murchison, "Synthesis Gas to Hydrocarbon Feedstocks," paper presented at the 182nd ACS National Meeting (Div. of Ind. \& Eng. Chem.), NY (August 23-28, 1981).

46. H. Koelbel and M. Ralek, Catal. Rev.-Sci. Eng. 21, 225 (1980).

47. P. L. Flory, Principles of Polymer Chemistry, Cornell University Press, Ithaca, NY (1967).

48. M. E. Dry, "The Fischer-Tropsch Synthesis," Chap. 4 in Catalysis Science and Technology, J. R. Anderson and M. Boudart ed., Springer Verlag, NY (1981).

49. M. E. Dry, Hydrocarbon Processing 59, 92 (February 1980).

50. M. E. Dry. T. Shingles, L. J. Boshoff, C. S. van H. Botha, J. Catal. 17, 347 (1970).

51. F. Fischer and H. Tropsch, Brennst, Chem. 7, 97 (1926).

52. S. Z. Roginsky, "Molecular Mechanism of Some Catalytical Reactions as Revealed by Means of Isotopic Kinetic Effects and Experiments with Tracer Molecules," pp. 939-956 in Proceedings of the Third International Congress on Catalysis, W. M. H. Sachtler, G. C. A. Schuit and P. Zwietering eds., Amsterdam, Netherlands (July 20-25, 1964).

53. H. von Pichler and H. Schulz, Chem. -Ing. -Tech. 42, 162 (1970).

54. "Carbon Monoxide-Hydrogren Reactions," pp. 446-489 in Kirk-Othmer Encycl. of Chem. Technol. Vo1. 4, John Wiley \& Sons, NY (1964). 
55. H. von Pichler, Brennst. Chem. 30, 105 (1949).

56. J. C. Hoogendoorn, "Experience with Fischer-Trpsch Synthesis at SASOL," in Clean Fuels from Coal Symposium Papers, IGT, Chicago, IL (September 10-14, 1973).

57. J. C. Hoogendoorn, "New Applications of the Fishcer-Tropsch Process", in Clean Fuels from Coal Symposium Papers, IGT, Chicago, IL (June 23-27, 1975).

58. T. D. Pay, "Foreign Coal Liquefaction Technology Survey and Assessment, SASOL-The Commercial Experience," Gilbert Associates, Inc., ORNL/Sub-79/13827/4 (1980).

59. J. C. Hoogendoorn and J. H. Salomon, Brit. Chem. Eng. 2, 308 (1957). 60. D. Gray, M. Lytton, M. B. Neuworth, and G. Tomlinson, "THe Impact of Developing Technologies on Indirect Liquefaction, "Final Report (MTR-80W326), DoE Contract No. EF-77-C-01-2783, Mitre Corp., McLean VA (November 1980).

61. W. Faragher and J. Foucher, "The $\mathrm{CO}+\mathrm{H}_{2}$ Synthesis at I. G. Farben," p. 123 in F.I.A.T. Final Report 1267, PB 97368, Vo1. 1, Part C, (1947).

62. M. J. Baird, R. R. Scheh1, W. P. Haynes, and J. T. Cobb, Jr., IE\&C Prod. Res. Dev. 19, 175 (1980).

63. F. Duftschmid, E. Linckh and F. Winkler, US Patent No. 2,159,077 (May 23, 1939).

64. M. L. Kastens, L. L. Hirst and R. G. Dressler, Ind. Eng. Chem. 44, 450 (1952).

65. F. Fishcher, 0. Roeien and W. Feist, Brennst. Chem. 13, 461 (1932).

66. C. C. Hal1, D. Gall and S. L. Smith, J. Inst. Petr. Technolog. 38, 845 (1952).

67. M. D. Schlesinger, H. Benson, E. Murphy, and H. H. Storch, Ind. Eng. Chem. 46, 322 (1954).

68. H. Koelbe1, P. Ackerman and F. Engelhardt, p. 227 in Proceedings of Fourth World Petroleum Congress, Section IV/C, Carlo Colombo Publishers, Rome (1955).

69. A. K. Mitra and A. N. Roy, Indian Chem. Eng. ㅁ, 127 (1963).

70. T. Sakai and T. Kunugi, Sekiyu Gakkai Shi 17, 863 (1974).

71. J. C. W. Kuo, "Slurry Fischer-Tropsch/Mobit Two-Stage Process of Converting SG to High Octane Gasoline," Final Report (DoE/PC/30022-10) DoE Contract No. DE-AC22-80PC30022, Mobil Res. and Dev. Copr., Paulsboro, NJ (June 1983). 
72. J. C. W. Kuo, "Two-Stage Process for Conversion of Synthesis Gas to High Quality Transportation Fuels," Final Reports (DoE/PC/60019-9 and -9A) DoE Contract No. DE-AC22-83PC60019, Mobi1 Fes. and Dev. Corp., Paulsboro, NJ (October 1985).

73. H. E. Benson, J. H. Field, D. Bienstock, and H. H. Storch, Ind. Eng. Chem. 46, 278 (1954).

74. R. Farley and D. J. Ray, J. Inst. Pet. Technology $\underline{50}, 27$ (1964).

75. T. Kunugi, T. Sakai and N. Negishi, Sekiya Gakkai Shi 11, 636 (1968).

76. M. E. Dry, "Recent Developments in SASOL Fischer-Tropsch Technology," paper presented at 191st ACS National Meeting (Div. of Fuel Chemistry), NY (Apri 13-18, 1986).

77. M. J. van der Burgt, J. van Kliken and S. T. Sie, "The Shell Middle Distillate Synthesis Process," paper presented at the 5 th Synfuels Worldwide Symposium, Washington, D.C. (November 11-13, 1985).

78. A. H. Singleton and S. Regier, Hydrocarbon Proc. 62, 71 (1983).

79. A. Aquilo, J. S. Alder, D. N. Freeman, and R. J. H. Voorhoeve, Hydrocarbon Processing, pp. 57-65 (March 1983).

80. J. F. Knifton, ChemTech 609 (1981).

81. S. L. Meisel, J. P. McCullough, C. H. Lechthaler, and P. B. Weisz, Chem Tech $\underline{6}, 86$ (1976).

82. C. D. Chang, Catal. Rev. -Sci. Eng. 25, 1 (1983).

83. C. D. Chang and A. J. Silvertri, J. Cata7. 47, 249 (1977).

84. J. E. Penick, W. Lee, and J. Maziuk, ACS Symposium Series 226, 19 (1983).

85. C. D. Chang and A. J. Silvertri, "The MTG Process: Origin and Evolution," paper presented at the 21st State-of-the-Art ACS Symposium on Methanol as a Raw Material for Fuels and Chemicals, Marco Island, FL (June 15-18, 1986).

86. A. A. Avidan, M. Edwards, W. Loeffler, H. -H. Gierlich, N. Thiagarajan, and E. Nitschke, "The Fluid-Bed MTG PRocess," in Ref. 85.

87. E. Supp, Energy Progr. 5,127 (1985).

88. R. F. Socha, C. T. W. Chu and A. A. Avidan, "An Overview of Methanol-to-01efins Research at Mobi1: From Inception to Demonstration Plant," in Ref. 85. 
89. J. L. Soto and A. A. Avidan, "Status of the 100 BPD Fluid-Bed Methanol-to-0lefins Demonstration Plant," in Proceedings of the 5 th DoE Contractors Conference on Indirect Liquefaction, Houston, TX (December 2-5, 1985).

90. S. A. Tabak, A. A. Avidan and F. J. Krambeck, "MTO-MOGD Process," in Ref. 85.

91. W. Hoelderich, H. Eichhorn, R. Lehnert, L. Marosi, W. Mross, R. Reinke, W. Rappel, and H Schlimper, pp. 545-555 in Proceedings of the 6th Int. Zeolite Conference (1983).

92. A. Brink, "New Developments in the Field of Fischer-Tropsch Synthesis," paper presented at the 50th API Refining Department Mid-Year Meeting, Kansas City, MO (May 13-16, 1985).

93. S. A. Tabak and F. J. Krambeck, Hydrocarbon Proc. 64, 72 (September 1985).

94. S. A. Tabak, A. A. Avidan and F. J. Krambeck, "Production of Synthetic Gasoline and Diesel Fuel from Non-Petroleum Resources, "presented at the 191st ACS National Meeting (Div. of Fuel Chemistry), NY (Apri 1 13-18, 1986).

95. J. C. Hoogendoorn and J. H. Salomon, Brit. Chem. Eng. 2, 368 (1957).

96. M. E. Dry, ChemTech 12, 744 (1982).

97. J. C. W. Kuo, U.S. Patent No. 4,046,830 (September 6, 1977).

98. M. E. Dry, Proceedings of the 10th Annual COGLAC International Conference, Pittsburgh, PA (August 1983).

99. R. Shinnar and J. C. W. Kuo, "Gasifier Study for Mobil Coal to Gasoline Processes," Final Report No. FE-2766-13, DoE Contract No. EF-77-C-01-2766, Mobil Res. and Dev. Corp., Paulsboro, NJ (October 1978).

100. M. Schreiner, "Research Guidance Studies to Assess Gasoline from Coal by Methanol-to-Gasoline and SASOL-Type Fischer-Tropsch Technologies," FE-2447-13, Mobil Res. and Dev. Corp., Paulsboro, NJ (August 1978).

101. C. E. Jahnig, "Evaluation of Pollution Control in Fossil Fuel Conversion Processes, Gasification, Section 8: Winkler Process, "Exxon Res. and Eng. Corp., PB-249-846 September 1975).

102. D. A. Waitzman H. L. Faucett, D. E. Nichols, S. V. Tomlinson, and W. J. Broadfoot, "Evaluation of Intermediate-Btu Coal Gasification Systems for Retrofitting Power Plants," TVA, EPRI AF-531, Palo Alto, CA (August 1977). 
103. British Gas Corporation, "Reports on Runs TSP 001-001-002-003 (Westfield Slagger)," Westfield, Scotland (October-November 1977).

104. K. Chandra, B. McElmurry, E. W. Neben, and G. E. Pauk, "Economic Studies of Coal Gasification for Combined Cycle System for Electric Power Generation," Fluor Engineers and Constructors, Inc., EPRI AF-642, Palo A7to, CA (January 1978).

105. E. V. Vogt and M. H. van der Burgt, CEP 76, 65 (1980).

106. D. Gray, M. B. Neuworth and G. Tomlinson, "Further Studies on Developing Technology for Indirect Liquifaction," DoE Report DE-AC01-77ET10280, MITRE Corp., McLean VA (March 1982).

107. A. El Sawy, D. Gray, M. B. Neuworth, and G. Tomlinson, "A Techno-Economic Assessment of the Mobil Two-Stage Slurry Fischer-Tropsch/ZSM-5 Process," Final Report No. MTR-84W173, DoE Contract No. 58-0336, MITRE Corp., McLean, VA (November 1984).

108. W. S. Jones J. Shen and E. Schmetz, "Liquid Fuels from Coal Derived Synthesis Gas," in Reg. 94.

109. K. Tanabe, Solid Acids and Bases, Academic Press, NY (1970).

110. R. M. Barrer, Hydrothermal Chemistry of Zeolites, Academic Press, London (1982).

111. D. W. Breck, Zeolite Molecular Sieves, Wiley-Interscience, NY (1974).

112. R. M. Barrer, Chem. Ind. (London) 1203 (1968).

113. W. M. Meier and D. H. 0lson, "Atlas of Zeolite Structure Types", Intern. Zeolite Assocn., Polycrystal Book Service, Pittsburgh, PA (1978).

114. W. M. Meier, Z. Kristallogr 115, 439 (1979).

115. R. B. La Pierre, A. C. Rohrman, Jr., J. L. Schlenker, J. D. Wood, M. K. Rubin, and W. J. Rohrbaugh, Zeolites 5, 346 (1985).

116. G. K. Kokotai10, J. L. Schlenker, F. G. Dwyer, and E. W. Valyocsik, Zeolites 5, 349 (1985).

117. S. A. I. Barri, G.W. Smith, D. White, and D. Young, Nature $\underline{312}, 533$ (1984).

118. A. C. Rohrman, Jr., R. B. La Pierre, J. L. Schlenker, J. D. Wood, E. W. Valyocsik, M. K. Rubin, J. B. Higgins and W. J. Rohrbaugh, Zeolites 5, $382(1985)$.

119. J. L. Schlenker, W. J. Rohrbaugh, P. Chu, E. W. Valyocsik and G. T. Kokotai1o, Zeolites $\underline{5}, 355$ (1985). 
120. R. von Ballmoos, Collection of Simulated XRD Powder Patterns for Zeolites, Butterworth Scientific Pub1., Guildford, UK (1984).

121. P. B. Venuto, L.A. Hamilton and P.S. Laudis, J. Catal, 5 , 484 (1966).

122. P. B. Venuto and P. S. Laudis, Avd. Cata1. 18, 259 (1968).

123. S. M. Csicsery, Zeolites 4 , 202 (1984).

124. S. M. Csicsery, "Shape Selective Catalysis" in Zeolite Chemistry and Catalysis, J. A. Rabo ed., Am. Chem. Soc. Monograph 171, 680 (1976). 

CHAPTER 6:

COAL GASIFICATION IN FUEL-CELL APPLICATIONS

A potentially important application of coal gasifiers (CGs)

involves gas processing for use in fuel cells (FCs). In this chapter, we present first an overview of FC development status and then discuss design features of CGs for these uses.

\subsection{Overview of FCs*}

In order to appreciate gasifier requirements properly, it is desirable to begin with a description of salient features of fuel-cell operation.

\section{1-1. Introduction}

Hydrogen-containing fuels have two heating values (molar heats of combustion), corresponding to the formation of water in the gaseous state (low-heating value, LHV) or in the liquid state (high-heating value, HHV). The free energy of reaction of the fuel, i.e., the maximum energy theoretically available as work, also has two values. While the heat of reaction shows only a small change with temperature, the free energy of reaction varies nearly linearly according to the relation

$$
\Delta G=\Delta H-T \Delta S
$$

* This section has been written by A. J. Appleby, Electric Power Research Institute (EPRI), 3412 Hillview Ave., Palo A7to, CA 94303. Figures, illustrations and design diagrams have been deleted but may be found in the publication of the DoE Advanced Fuel Cell Working Group. Energy 11 , $1-229$ (1986). 
where $\Delta H$ is the heat (enthalpy) of reaction, $\Delta G$ the free energy or chemical potential, $\Delta S$ the entropy of reaction, and $T$ the absolute temperature. When the combustion reaction has been completed, the free energy of reaction is close to zero, no remaining chemical potential exists which can be converted directly into work, and the heat of reaction is transformed into ambient heat equal to $T \Delta S$ at temperature $T$. If this heat is to be converted into useful work, a heat engine is required with a thermodynamic cycle between a heat source at $T_{1}$ and a heat sink at $T_{2}$. The heat engine usually uses the expansion and contraction of a fluid to provide work; however, thermoelectric devices and thermochemical cycles to split water into $\mathrm{H}_{2}$ and $\mathrm{O}_{2}$ are also in practice heat engines. ${ }^{1}$ Carnot $^{2}$ in 1824 showed that the maximum efficiency, $E$, of an ideal (reversible or quasi-stationary) thermodynamic cycle is given by

$$
\varepsilon=\left(T_{1}-T_{2}\right) / T_{1}
$$

Real cycles invoive motion, and their efficiencies will always be less than the theoretical value. In a typical cycle using steam as the working fluid, a practical efficiency equal to $2 / 3$ of the limiting Carnot value may be obtained. In such a cycle, $T_{1}$ is limited by materials considerations to about $900 \mathrm{~K}$, and $T_{2}$, by the minimum turbine water condensation temperature (about $310 \mathrm{k}$ ). The non-ideality of the cycle therefore limits the best large coal-fired utility power plants to a practical heat-to-work efficiency (high-heating-value of coal to AC electricity) of $40 \%$. Recent implementation of effluent controls has lowered efficiencies to about. $35 \%$ or $9860 \mathrm{Btu} / \mathrm{kWh}$. Small coal plants ( $200 \mathrm{MW}$ ) are less efficient. Coals are unlike liquid and gaseous fuels in that they contain more $\mathrm{H}_{2}$ as moisture. In general, the HHV for coals is $1.5-2 \%$ higher than the LHV for anthracites, $5-7 \%$ higher for bituminous and subbituminous coals, and about $9-10 \%$ higher for lignites. Since fuels are always burned to give gaseous products in which the heat of evaporation of the product water is not recovered, LHVs should be used when efficiencies with different fuels or systems are compared. For high-quality coals, the difference is not important. For fuel oi1, the HHV is about $6 \%$ higher than the LHV, whereas for natural gas, the corresponding value is $10 \%$ because of its high $\mathrm{H} / \mathrm{C}$ ratio. For $\mathrm{H}_{2}$, it is 
$15 \%$ and, therefore, efficiencies based on HHV and LHV differ considerably. As we will see, this difference is important in considering fuel-cell efficiencies. Steam plants using natural gas or other clean fuels have $40 \%$ LHV efficiencies, but high fuel costs. The use of more than one thermodynamic cycle in the same plant (e.g., a gas-turbine Brayton cycle with exhaust-heat recovery via a Rankine steam cycle) may yield up to $45-47 \%$ LHV efficiency in smaller units $\left(\simeq 200 \mathrm{MW}_{e}\right)$, at a relatively low capital cost $\left(\$ 500 / \mathrm{kW}_{e}\right.$, compared with $\$ 1100 / \mathrm{kW}_{e}$ for a modern coal plant). In contrast the cheapest generating units, combustion turbines without steam cycle $\left(\$ 270 / \mathrm{kW}_{\mathrm{e}}\right)$, have poor LHV efficiencies $(10,000-13,800 \mathrm{Btu} / \mathrm{kWh}$ or $25-34 \%$ efficiency, depending on size and characteristics).

\section{1-2. The FC as a Direct Energy-Conversion Device}

FCs are not limited by the Carnot efficiency for heat-to-work conversion. They are used to convert the thermodynamically available free energy in fuels at a relatively low temperature directly into useful work in the form of direct-current electricity: $\Delta G$ is numerically equal to $-n F E$, where $n$ is the number of equivalents per mole (number of electrons per mole transferred in complete oxidation), and $E$ is the theoretical potential that would be developed between two thermodynamically reversible electrodes in contact with the fuel and $\mathrm{O}_{2}$.

The $\mathrm{FC}$ is essentially a primary battery. In a $\mathrm{Zn}-\mathrm{MnO}_{2}$ cell with saline $\left(\mathrm{ZnCl}_{2}-\mathrm{NH}_{4} \mathrm{Cl}\right)$ electrolyte, $\mathrm{Zn}$ is oxidized at the negative electrode by anodic dissolution, whereas the $\mathrm{MnO}_{2}$ is reduced in a stoichiometric process. Electrons flow in the outer circuit because of the potential difference ( $E$ for reversible conditions) between about 1.0 to $1.5 \mathrm{~V}$, depending on the total current and state of discharge of the cel1. The electronic current, under the potential difference, is capable of doing work as in an electric motor. The circuit is completed by ions moving in the electrolyte.

In the battery, the fuel $(\mathrm{Zn})$ and oxidant $\left(\mathrm{MnO}_{2}\right)$ are solids and are themselves the electrode structure through which electrons are conducted. On the other hand, the electrode structures in an FC are not consumed and are continuously supplied with a fuel (normally gaseous $\mathrm{H}_{2}$ ) at 
the anode and with an oxidant (normally atmospheric $\mathrm{O}_{2}$ ) at the cathode. Anodic oxidation of the $\mathrm{H}_{2}$ and cathodic reduction of $\mathrm{O}_{2}$ produce electrons in the outer circuit and ions in the electrolyte. For an FC with an acid electrolyte, electrons and $\mathrm{H}^{+}$ions are produced at the anode, and both combine with $\mathrm{O}_{2}$ at the cathode to form water, thus completing the reaction and the electrical circuit.

For $\mathrm{H}_{2}$ and $\mathrm{O}_{2}$ at $25^{\circ} \mathrm{C}, \Delta \mathrm{G}$ to form $\mathrm{H}_{2} \mathrm{O}(\mathrm{l})$ is a substantial fraction of the HHV. The quantities $\Delta G$ and $\Delta H$ are 56.69 and $68.39 \mathrm{kcal} / \mathrm{mole}$ for $\mathrm{H}_{2} \mathrm{O}(\ell)$, respectively. Since the formation of one mole of water involves two electrons $(n=2)$ via the process

$$
\mathrm{H}_{2} \rightarrow 2 \mathrm{H}^{+}+2 \mathrm{e}^{-}, \quad(1 / 2) \mathrm{O}_{2}+2 \mathrm{H}^{+}+2 \mathrm{e}^{-} \rightarrow \mathrm{H}_{2} \mathrm{O}
$$

we can convert these quantities into electron-volts ( $1 \mathrm{eV}=23.06 \mathrm{kca}$ ), obtaining 1.23 and $1.48 \mathrm{~V}$, respectively, for $\Delta G$ and $\Delta H$ for the formation of $\mathrm{H}_{2} \mathrm{O}(\mathrm{l})$. If we could make a theoretically perfect, thermodynamically reversible FC operating under these conditions in an aqueous electrolyte, it would develop $1.23 \mathrm{~V}$ across the electrodes and would produce work in the form of electricity at an efficiency of $\Delta G / \Delta H$ or $83 \%$ of the $H H V$ of $H_{2}$. For comparison with thermal machinery, this represents $96 \%$ LHV efficiency for $\mathrm{H}_{2}$, which is more than twice the efficiency obtained for the best heat engine and the primary motivation for FC development.

However, in practice, FCs do not operate under ideal conditions, just as heat engines never show the theoretical Carnot efficiency. The most obvious loss in an FC results from its internal ohmic resistance, although this loss can be minimized by careful design. Of greater importance in most FCs are losses due to the irreversibility or time increments required for the electrode reactions and to concentrate gradients of the reactants and products of reaction (ions, water) in a cell operating at a useful net rate. These losses are also minimized by careful electrode design.

At temperatures between ambient and $\sim 200^{\circ} \mathrm{C}$ in acid electrolyte, the $\mathrm{H}_{2}$ electrode is sufficiently rapid for practical use if wel1-designed electrodes allowing effective gas supply and suitable catalysts are used. Unfortunately, the $\mathrm{O}_{2}$ electrode is much less ideal, even with the most active catalysts; the low rate of molecular $\mathrm{O}_{2}$ reduction, as compared for 
example with that of the halogens, makes biochemical evolution possible. The rate of $\mathrm{O}_{2}$ reduction is typically about $10^{-6}$ times slower than that of $\mathrm{H}_{2}$ under similar conditions. Electrochemical reactions proceeding at a net forward rate normally obey Tafel's 1 aw, ${ }^{3}$ which may be regarded as a generalization of the thermodynamics of irreversible processes or processes occurring sufficiently far from equilibrium to neglect the back reaction. ${ }^{4}$ Tafel's law may be expressed in the form

$$
\log i=A+B \eta
$$

where $A$ and $B$ are constants for a given process, and $\eta$ is the overpotential (i.e., the displacement in electrical potential of the electrode from the equilibrium value $E$ at a net current density $i$, in $\left.A / \mathrm{cm}^{2}\right)$. A is the logarithm of the rate of the process at equilibrium (the exchange current), which varies in a rather complex manner with concentration of reactants raised to a normally fractional power, the electrochemical reaction order. At a constant potential on some independent or reference scale, electrochemical reactions obey the usual laws of chemical kinetics. For example, the rate of the $0_{2}$-reduction reaction is proportional to the first power of the $\mathrm{O}_{2}$ partial pressure (i.e., the reaction is first order), which is useful in assessing the effect of pressurization on FC performance. The electrochemical reaction order arises from the fact that the equilibrium potential varies with reactant partial pressure $(P)$, corresponding to concentration, according to the expression (RT/nF) in $P$, where $R$ is the molar gas constant and $F$ the Faraday unit. A similar (negative) expression applies to reaction products. When the change in equilibrium potential with pressure or concentration is combined with the change in equilibrium rate from the Tafel equation, the resulting electrochemical reaction order becomes a fraction of the normal chemical reaction order. According to this simplified theory, the value of $B$ in the Tafel equation is given by the expression $\alpha F / R T$, where $\alpha$ normally lies between 0.5 and 1.5 , depending on the reaction mechanism followed. The theory is given in greater detail in Refs. 5 and 6.

According to this theory, $\alpha$ should be temperature-independent but, for $\mathrm{O}_{2}$ in acid electrolyte, it seems to be proportional to the absolute 
temperature. $^{7}$ As a result, the Tafel slope (B) appears to be temperature-independent and is typically equal to about $100 \mathrm{mV} /$ decade on Pt-catalyzed acid $\mathrm{FC}$ electrodes. For $\mathrm{O}_{2}$ reduction in basic media, $\alpha$ lies between 1.0 and 1.5, depending on the catalyst used. In alkaline solution, the cathodic Tafel slope is therefore lower, and thus $n$ is also generally reduced, since $A$ in the Tafel equation is about the same for both media. ${ }^{8} \mathrm{~A}$ more detailed overview of electrochemical kinetics is given in Ref. 5 . For the purposes of this overview, it suffices to say that, with the exception of alkaline fuel cells (AFCs) operating at high temperature $\left(\sim 200-250^{\circ} \mathrm{C}\right)$, the slow kinetics of the $\mathrm{O}_{2}$ electrode in aqueous solution means that an $\mathrm{H}_{2}$ FC never operates close to its theoretical standard potential of about $1.23 \mathrm{~V}$ $\left[\sim 1.14 \mathrm{~V}\right.$ at $200^{\circ} \mathrm{C}$, cf. Eq. (6.1-1)], even under open-circuit (zero current) conditions. The $\mathrm{O}_{2}$ electrode rest potential for these aqueous electrolyte cells is typically $0.9-1.0 \mathrm{~V}$, which is a potential at which $0_{2}$ reduction and a parasitic anode process (corrosion of the electrode) have equal rates. ${ }^{9}$ According to the Arrhenius equation, an increase in cell-operating temperature increases the net rate and hence the value of $A$. Thus, $n$ will decrease with temperature. At the same time, however, $\Delta G$ and $E$ decrease somewhat with temperature [compare Eq. (6.1-1)], although this thermodynamic effect is smali compared with the kinetic effect on $\eta$. As a consequence of the reduced cathodic $\eta$ value, the usual operating voltage of acid cells is 0.65-0.75 $\mathrm{V}$ at practical current densities, whereas AFCs may operate at about $0.8 \mathrm{~V}$. In both cases, correctly designed cathodes are not affected by diffusion $\left(\mathrm{O}_{2}\right.$ concentration gradients), and Tafel's law is obeyed.

As already discussed, $\mathrm{H}_{2}$ electrodes operate close to their reversible potential with properly chosen catalysts. Catalytic poisons reduce actually achieved potentials. The maximum efficiency of AFCs operating on pure $\mathrm{H}_{2}$ will be about $0.8 / 1.28$ or $62.5 \%$ based on the LHV of $\mathrm{H}_{2}$ consumed in the cell. For acid cells, the efficiency will be less because of their lower voltage. The operating potential given for acid cells corresponds to operation on an $\mathrm{H}_{2} / \mathrm{CO}_{2}$ mixture produced by steam-reforming a practical fuel such as natural gas $(N G)$, followed by water-gas shifting to reduce $\mathrm{CO}$ to low levels. While the acid cell will run advantageously on pure $\mathrm{H}_{2}$ (with a performance gain of about $20 \mathrm{mV}$ ), in practical terms use of 
the unseparated $\mathrm{H}_{2} / \mathrm{CO}_{2}$ mixture is more effective, since the system is simplified.

Since the AFC is not $\mathrm{CO}_{2}$-rejecting and carbonate formation in its electrolyte reduces performance, it must be fed with pure $\mathrm{H}_{2}$ separated from the $\mathrm{H}_{2} / \mathrm{CO}_{2}$ fuel gas. This separation requires work and reduces overall electrical efficiency with methane. This loss is compensated, to some extent, by the fact that all of the pure $\mathrm{H}_{2}$ supplied can be consumed in the AFC, whereas the $\mathrm{H}_{2} / \mathrm{CO}_{2}$ fuel for acid cells becomes progressively more dilute as $\mathrm{H}_{2}$ is consumed. This fact limits practical utilization to about $85 \%$ of total $\mathrm{H}_{2}$, but the tail gas can be used (instead of $N G$ ) to provide heat for endothermic reforming. Finally, practical AFCs are limited to operation at $80^{\circ} \mathrm{C}$ by materials constraints, whereas acid cells with phosphoric acid electrolyte (PAFCs) can operate at $200^{\circ} \mathrm{C}$. The waste heat of PAFCs can then be used to provide steam for reforming, which leads to an overall system efficiency advantage with practical fuels such as NG. High temperature cells are even more advantageous, since their waste heat can also be used to provide enthalpy for reforming.

DC power from the $F C$ is converted to grid-quality $A C$ at an efficiency of about $98.5 \%$ using a solid-state inverter. The overall NG-AC LHV efficiency for the PAFC system is $46.5 \%$ and thus equal to the best large combined cycles. In the future, molten carbonate fuel celis (MCFCs) may yield LHV efficiencies of $60 \%$ or more on NG.

A useful way to classify $\mathrm{FC}$ s is by electrolyte type.

Historically, the first gaseous voltaic battery demonstrating the principle of the FC was described by Sir William Grove in 1839-42. ${ }^{10}$ It used sulfuric acid electrolyte. The first cell of practical importance was an AFC. Acid electrolyte cells, molten salt electrolyte cells, and solid oxide cells will be briefly reviewed, with emphasis on current developments. For historical developments of FC types, readers are referred to Ref. 11 .

\section{1-3. Alkaline Fuel Cells (AFCs)}

It was soon realized that it might be easier to make an effective aqueous FC using a caustic electrolyte rather than acid. The reason for this is the much broader choice of materials available for the less 
aggressive alkaline solutions, even at the high positive potential of the $\mathrm{O}_{2}$ electrode. This advantage is shown by Pourbaix's compilation of thermodynamic data for elements in the presence of water as a function of potential and $\mathrm{pH} .^{12}$ The Pourbaix diagrams represent the thermodynamic stability of materials but do not show what is theoretically unstable or quasi-stable in practice because of very slow corrosion kinetics. In acid, only the noble metals and the oxides of $\mathrm{Ta}$ and $\mathrm{Nb}$ are stable at the $\mathrm{O}_{2}$ cathode. In alkaline solution, many metal oxides are stable, and many metals can be used as construction materials, since they form protective passive oxide films. According to thermodynamics, carbon or graphite should be oxidized in both acid and alkaline solutions at the $\mathrm{O}_{2}$ cathode. This process is, however, extremely slow, and graphite was used as the basis of the first effective AFC electrodes in a small non-optimized cell by Tobler in 1933. ${ }^{13}$ His electrodes operated at low temperature and at low current density $\left(7.5 \mathrm{~mA} / \mathrm{cm}^{2}\right)$ and used graphite impregnated with catalysts arid the concept of controlled wetting to make the catalytic electrolyte-gas interface as large as possible, so that the highest current density at a given over potential could be achieved. He did this by impregnating the electrode with water-repellent paraffin, so that it consisted of a partially-wetted electrolyte side and a dry gas side, with a very large area containing microscopic wetted and unwetted pores inside. Maximization of the gas-electrolyte-catalyst interface in the three-phase boundary electrode has since proved to be the key to effective FC performance.

Bacon's contribution to AFC technology started at about the same time as Tobler's 1933 work. His approach was that of an engineer: first, use commonly available construction materials and avoid costly catalysts; second, increase reaction rates at constant cell potential by employing high pressures and temperatures. Bacon, whose work ${ }^{14}$ extended into the early $1960 \mathrm{~s}$, used nickel components, $40 \mathrm{wt} \% \mathrm{KOH}$ electrolyte at $200^{\circ} \mathrm{C}$, and pure $\mathrm{H}_{2}$ and $\mathrm{O}_{2}$ at pressures up to 40-45 atm. Since no wet-proofing agent wa.s available for use at $200^{\circ} \mathrm{C}$, Bacon depended on sintered nickel powder electrodes for capillarity to maintain the correct three-phase bounclary. His electrodes consisted of two layers, one of sintered fine-pore nickel (4-5 $\mu$ particle size, $16 \mu$ pore diameter) in contact with the electrolyte and totally wetted by $i t$, with a layer of similar particle diameter but $32 \mu$ 
average pore diameter facing the gaseous reactants. The coarse-pore layer was kept open by control of the gas and electrolyte pressures to give maximum active area. The electrolyte was circulated for temperature control. The results obtained were very good, about $800 \mathrm{~mA} / \mathrm{cm}^{2}$ at $0.8 \mathrm{~V}$, and may be attributed to the use of high temperature and pressures.

The Bacon cell was modified at the Pratt \& Whitney Division of United Technologies Corporation (UTC) for use aboard the Apollo service module to provide electric power and potable water (PC3A-2 units). To reduce weight, they lowered the cell pressure but maintained a high performance by increasing the system temperature to $260^{\circ} \mathrm{C}$, which required the use of $75 \mathrm{wt} \% \mathrm{KOH}$ to avoid boiling of the electrolyte. The three-phase boundary was maintained by the use of a gas pressure of $0.7 \mathrm{~kg} / \mathrm{cm}^{2}$ above the electrolyte pressure $\left(3.5 \mathrm{~kg} / \mathrm{cm}^{2}\right)$. Heat removal and water-vapor control were maintained using a closed-loop $\mathrm{H}_{2}$ recirculation system. ${ }^{15}$ The Apollo system used three $110 \mathrm{~kg}$ modules, designated $\mathrm{PC} 3 \mathrm{~A}-2$, each $57 \mathrm{~cm}$ in diameter and $112 \mathrm{~cm}$ high. Each delivered $1.42 \mathrm{~kW}$ at $27-31 \mathrm{~V}$, with an average mission power requirement of $0.6 \mathrm{~kW}$. Module life was limited by corrosion of the sintered cathode structure, which consisted of chemically lithiated NiO under the conditions of cell operation, and design life was only about $500 \mathrm{hr}$. No further PC3A-2 units were made after termination of the Apollo program.

A lighter and much higher performance AFC system (the PC-17C) was developed by UTC for the Space-Shuttle. Each of the three Space-Shuttle units is $35 \mathrm{~cm}$ high, $38 \mathrm{~cm}$ wide and $101 \mathrm{~cm}$ long. Original units had a peak power of $12 \mathrm{~kW}$ at a weight of $91 \mathrm{~kg}$, so that the power density is ten times that of the Apollo unit. The system operates at lower temperature $\left(82-89^{\circ} \mathrm{C}\right)$ than the PC3A-2 unit, which allows a service life of $2000 \mathrm{hr}$. The high performance is obtained by use of electrodes of the same general type as those developed for varjous acid applications. They are descendents of Tobler's using a wet-proofing agent to maintain the three-phase boundary. However, like all modern wet-proofed electrodes, the most stable and hydrophobic of organic waxes, polytetrafluorethylene (Teflon ${ }^{3}$ ), are employed. For high performance, the catalysts are pure noble metals. The anode consists of $10 \mathrm{mg} / \mathrm{cm}^{2}$ of metal black ( $80 \% \mathrm{Pt}, 20 \% \mathrm{Pd}$ ); the cathode has $20 \mathrm{mg} / \mathrm{cm}^{2}(90 \% \mathrm{Au}, 10 \% \mathrm{Pt})$. The cell yields $0.5 \mathrm{~A} / \mathrm{cm}^{2}$ at $0.9 \mathrm{~V}$ for a 
reactant gas pressure of only $4-4.4 \mathrm{~atm}$. The pure $\mathrm{H}_{2}$ and $\mathrm{O}_{2}$ reactants are supplied from the cryogenic fuel supply of the Space-Shuttle. The system uses electrolyte immobilized in a asbestos matrix and is of bipolar (filter-press) construction to give very low intercell IR drop and uniform current density. Gold-plated magnesium bipolar conduction plates are used between cells. Cooling is by a dielectric liquid, and water removal is by evaporation, with condensation in the $\mathrm{H}_{2}$ feedback loop. The system operates like other $F C$ s on the free energy of conversion of $\mathrm{H}_{2}$ to water vapor, and its efficiency should therefore be expressed in LHV terms. The system is described in Ref. 16.

During the 1960 s and 1970 s, a number of small AFC units were developed, often using exotic fuels such as hydrazine for specialized applications. 11,15 At that time, research was conducted on AFCs in Europe and elsewhere because of the ability to utilize inexpensive materials. 11 Another practical attraction is the cathode reaction, which often occurs via a rapid two-electron $\mathrm{O}_{2}$ reduction process to peroxide ion, followed by chemical disproportional of peroxide to $\mathrm{H}_{2} \mathrm{O}$ and $\mathrm{O}_{2}$, which is further reduced to peroxide in a cyclic process as follows:

$$
\begin{aligned}
\mathrm{O}_{2}+\mathrm{H}_{2} \mathrm{O}+2 \mathrm{e}^{-} & \longrightarrow \mathrm{O}_{2} \mathrm{H}^{-}+\mathrm{OH}^{-}, \\
\mathrm{O}_{2} \mathrm{H}^{-} & \longrightarrow(1 / 2) \mathrm{O}_{2}+\mathrm{OH}^{-} .
\end{aligned}
$$

This cycle sequence allows the use of a wide range of inexpensive catalysts, including active carbons, at relatively low temperatures. It was often felt that only AFCs would find wide application, since acid cells appeared to require costly construction materials and noble-metal catalysts. As already noted, however, AFCs have the great disadvantage that the electrolytes do not reject $\mathrm{CO}_{2}$, and hence all common fuels must be converted to pure $\mathrm{H}_{2}$ before introduction into the cell anode. Furthermore, air would normally have to be scrubbed to remove $\mathrm{CO}_{2}$ before use at the cell cathode. Removal of $\mathrm{CO}_{2}$ from steam-reformed hydrocarbons requires significant amounts of energy, and fuel is required to raise steam for reforming and for the endothermic reforming process itself if no waste heat is available. Since AFCs using inexpensive materials will not operate satisfactorily at 
temperatures higher than $80^{\circ} \mathrm{C}$, fuel must be burnt to provide the $50 \%$ excess of steam required for efficient reforming. This energy represents about $15 \%$ of the LHV of methane or light distillate fuel. PAFCs now operate at temperatures up to $200^{\circ} \mathrm{C}$ using cheap materials (graphite), their waste heat may be used to raise steam, and they do not require $\mathrm{CO}_{2}$ removal from the fuel stream. In consequence, interest in the AFC using reformed hydrocarbon fuels has waned in recent years. They are now used in specialized applications using pure $\mathrm{H}_{2}^{\prime}$ (aerospace, deep-sea, emergency power requiring instant start-up) and may in the future find large-scale use when $\mathrm{H}_{2}$ will be available in quantity (e.g., in chlorine plants today and in the future $\mathrm{H}_{2}$ economy). In the $\mathrm{H}_{2}$ economy, $\mathrm{H}_{2}$ will be produced by water electrolysis using hydroelectric or off-peak nuclear power and eventually solar energy. 18 Very simple, cheap AFCs with about $\$ 50 / \mathrm{kW}$ of active area not including catalysts should have about the same cost and are being examined for industrial chlorine-plant application; ${ }^{19}$ they may find future use for transportation using fossil or non-fossil $\mathrm{H}_{2}$ or cracked ammonia 20 as fuel. Their wide application is not limited by the availability of noble-metal catalysts, as is the PAFC.

\section{1-4. Acid Fuel Cells}

There are presently two types of acid fuel cells: those with liquid electrolytes and those with an acid solid polymer ion-exchange membrane as the electrolyte (solid polymer electrolyte or SPE cells). By far the most important are the liquid electrolyte cells using phosphoric acid (PAFCs), since they are likely to find wide application for the dispersed generation of electricity. SPE cells are described in Refs. 15 and 16. The first SPE system was developed by the General Electric Co. for the Gemini capsule. It used high Pt loadings, operated at ambient temperature, and used polystyrene sulfonic acid as electrolyte. ${ }^{11}$ Typical current densities were about $37 \mathrm{~mA} / \mathrm{cm}^{2}$. A new polymer, Nafion ${ }^{\circledR}$ (a sulfonated polyfluoroolefin) then became available, allowing operation at temperatures up to about $90^{\circ} \mathrm{C}$ and giving a system which could be used at very high current density (up to $1 \mathrm{~A} / \mathrm{cm}^{2}$ ) under pressure conditions, even at high differential pressures. The SPE has the advantage of a totally 
immobilized semi-solid electrolyte, thereby reducing system materials problems. Its main disadvantages are the need for high Pt loadings, since the catalyst-membrane interface is linear rather than three-deminsional as in a conventional three-phase-boundry electrode, and the high cost of the membrane $\left(\$ 400 / \mathrm{m}^{2}\right)$. In addition, the membrane dries out and becomes non-conductive at temperatures above $100^{\circ} \mathrm{C}$ (this is apparently true of all fluorinated sulfonic acids). Thus, like the AFC, it cannot be used to raise steam for reforming.

Since acid cells are $\mathrm{CO}_{2}$-rejecting, they can theoretically be employed to oxidize carbonaceous compounds directly. The liquid electrolyte cell grew out of attempts to make a direct hydrocarbon fuel cell in the late 1950s. Most of this work took place at the General Electric Research and Development Center. ${ }^{11}$ Since the hydrocarbon oxidation reaction is very slow, even compared to $\mathrm{O}_{2}$ reduction, very high catalyst loadings (20-40 $\mathrm{mg} / \mathrm{cm}^{2}$ of $\mathrm{Pt}$ or its alloys) were required to obtain rates of a few $\mathrm{mA} / \mathrm{cm}^{2}$ in $5 \mathrm{~N}$ sulfuric acid at the maximum operating temperature of about $80^{\circ} \mathrm{C}$; the acid is reduced by $\mathrm{H}_{2}$ at higher temperatures. The only common inorganic acid stable at high temperatures is phosphoric acid and was therefore tried as an electrolyte. Even at $150^{\circ} \mathrm{C}$, rates of reaction were poor, and the concept was abandoned as not cost-effective. The Pt catalyst cost alone was $\$(1984) 15,000 / \mathrm{kW}$.

In 1967, the American Gas Association started the TARGET program to develop small 12.5-kW FC generators intended to supply both electricity and domestic heat-from NG in a co-generation mode to individual households. It occurred to workers at UTC (the prime contractor) that a PAFC operating at temperatures of $150^{\circ} \mathrm{C}$ or above would be capable of using the dirtiy (i.e., CO-containing) $\mathrm{H}_{2} / \mathrm{CO}_{2}$ mixture produced by steam-reforming of $\mathrm{NG}$, sirice poisoning of the $\mathrm{H}_{2}$ electrode by $\mathrm{CO}$ is minimal above this temperature. In addition, the high PAFC operating temperature would allow steam to be raised for reforming, thus yielding and integrated high efficiency system. The principal problems were economic: catalyst requirements, stack-construction materials, and whether the chemical engineering system in a 12.5-kW unit would prove to be practical.

The major breakthrough occurred in 1968-69, when graphite was shown to be a satisfactory cell-construction material, with an exceptionally 
low corrosion rate even at the $0_{2}$ cathode at $200^{\circ} \mathrm{C} .21$ Work conducted since about 1970 showed how it was possible to increase the effective surface area of pure Pt (compared with that of the pure Pt black previously used) by more than a factor of 5 by depositing it on a conductive support (high-surface-area carbon black). Improvements in teflon-bonded electrode structures a.llowed higher catalyst utilization: $0.5 \mathrm{mg} / \mathrm{cm}^{2}$ of Pt at $10 \mathrm{wt} \%$ on a high-surface-area carbon carrier was shown to be as active as the $20 \mathrm{mg} / \mathrm{cm}^{2}$ pure Pt of older electrodes. Cell performance in the early 1970s was less than $0.6 \mathrm{~V}$ at $150 \mathrm{~mA} / \mathrm{cm}^{2}$ in atmospheric-pressure cells. The scope of the program was later changed to include larger units for which operation under pressure would prove to be economical. In the late 1970s, the resulting PAFC system existed in two versions: a 40-kW, atmospheric-pressure design fueled by reformed $N G$ and intended for gas-utility on-site use (the PC-18, an up-dated version of the original TARGET PC-11) and a 4.5-MW (AC), 3.4-atm unit intended as an electric utility prototype. Experimental 4.5-MW units were constructed in New York and at Goi on Tokyo Bay. The latter ran successfully for the first time in April 1983. About fifty 40-kW on-site co-generation units were ordered by various gas utilities for testing and are presently (1985) operating successfully.

All UTC PAFC stacks now use the ribbed-substrate stack technology, 22 in which a fibrous, graphite-ribbed electrode substrate allows for the distribution of gaseous reactants and can also serve as an electrolyte reservoir. In this way, sufficient phosphoric acid can be stored in the cell to allow for gradual evaporation over a 40,000-hr lifetime. Each of the ribbed substrates is about $2 \mathrm{~mm}$ thick. They are arranged in a crossflow configuration in contact with a solid graphite bipolar plate $1.2 \mathrm{~mm}$ thick. The teflon-bonded catalyst layers are applied to the inner flat faces of each ribbed substrate, and these in turn contact the silicon carbide matrix (about $0.5 \mathrm{~mm}$ thick) containing the electrolyte. The matrix is bonded with about $10 \mathrm{wt} \%$ teflon and is still satisfactorily wetted by electrolyte. On the other hand, the hydrophobic electrodes contain about $40 \mathrm{wt} \%$ of teflon. The stacks are cooled by pressurized water in cooler plates for every five cells, and the produced steam is fed to the reformer. The on-site unit was designed to develop $0.65 \mathrm{~V} / \mathrm{ce} 11$ at end-of-life at 
$140 \mathrm{~mA} / \mathrm{cm}^{2}$ (for the later $200 \mathrm{~kW}$-units, this will be about $200 \mathrm{~mA} / \mathrm{cm}^{2}$ ). The 4.8-MW (3.4-atm) unit ran at the same voltage but at $270 \mathrm{~mA} / \mathrm{cm}^{2}$. The LHV heat-rate of the latter was about $8,650 \mathrm{Btu} / \mathrm{kWh}$ LHB on naphtha or NG (39.5\% LHV efficiency). Cells in the former system were $0.20 \mathrm{~m}^{2}$ in area; those of the latter, $0.34 \mathrm{~m}^{2}$.

In 1985, UTC began to develop a $200 \mathrm{~kW}$ version of the on-site unit, using $0.34 \mathrm{~m}^{2}$ components, for GRI. International Fuel Cells (IFC), a UTC-Toshiba joint venture, will produce an electric utility unit rated at $11 \mathrm{MW}^{23}$ and using $0.98 \mathrm{~m}^{2}$ stack components. This unit will operate at $8.2 \mathrm{~atm}$, allowing $0.73 \mathrm{~V} / \mathrm{ce} 11$ at $216 \mathrm{~mA} / \mathrm{cm}^{2}$. This large PAFC uses 0.25 $\mathrm{mg} / \mathrm{cm}^{2}$ of Pt at the anode and a proprietary Pt alloy with about $0.5 \mathrm{mg} / \mathrm{cm}^{2}$ loading at the cathode on a corrosion-resistant, treated carbon black support. The fuel-processing system will be a simplified version of that used in the 4.8-MW demonstrator; the higher pressure and higher cell voltage increase power to $11 \mathrm{MW}$. LHV system efficiency will be $46 \%$ or better. This unit will be offered to utilities starting in 1986.

Other U.S. corporations involved in acid FC development are Engelhard Industries and Energy Research Corporation (ERC). Both are concentrating on small acid units for special applications. ERC uses an air-cooled stack technology, which has been licensed to Westinghouse in the U.S. and to Sanyo in Japan. Westinghouse plans to offer a 7.5-MW, air-cooled PAFC to electric utilities, which will use small rectangular cel1s, each about $0.14 \mathrm{~m}^{2}$ in area, in a cruci-form arrangement cooled by air passing through cooling plates in the stacks to a central plenum. Steam will be raised for reforming using a heat exchanger. The system will operate at $190^{\circ} \mathrm{C}$ and $4.8 \mathrm{~atm}$, giving $0.68 \mathrm{~V} / \mathrm{ce} 11$ at $250 \mathrm{~mA} / \mathrm{cm}^{2}$. The cell voltage is $50 \mathrm{mV}$ lower than that of the IFC unit, but the system heat-rate will be the same as the result of an improved heat-recovery cycle in the turbocompressor. The Westinghouse system uses stacks of ribbed bipolar plate construction, which do not have an electrolyte reservoir and require an acid-replenishment system. Further details of the design are given in Ref. 24. Finally, a series of electric utility PAFCs, inspired by UTC's pressurized stack technology, are under development at Toshiba, Hitachi, Fuji Electric, and Mitsubishi Electric in Japan, with partial funding from 
the Japanese government. Their present aim is to construct two 1-MW demonstrators for operation in 1986.

While PAFC-system LHV efficiency is currently $46-47 \%$, it may be slightly improved by future modifications to turbocompressors and other system components, but any major increase can only be brought about by increasing cell potential. Presently-used catalysts are close to the theoretical limit of small particle size, and it is unlikely that a further increase in performance will be obtained unless more active stable catalysts can be developed. Another possible approach is to improve electrode structure, so that higher catalyst loadings can be used effectively. The use of higher temperatures and pressures will also yield higher cathode potentials, but this combination of physical factors will result in increased cathode-support corrosion and shorter cell 1 ife, which may be improved by the use of new support materials. The upper limits of temperature and pressure will finally be dictated by the rate of surface-area loss of the catalyst by disolution/recrystallization. An upper limit for cathode potential of $0.8 \mathrm{~V}$ may possibly be achieved and will result in a maximum PAFC (LHV) system efficiency of about $52 \%$ $(6,600 \mathrm{Btu} / \mathrm{kWh})$. Finally, the PAFC can also be used with a low-sulfur medium- or low- Btu gas from a coal gasifier.

\section{1-5. Molten Carbonate Fuel Cel1s (MCFCs).}

Molten carbonate fuel cells in their present form have been examined since the $1950 \mathrm{~s} .11$ The electrolyte (usually between $70 \mathrm{wt} \% \mathrm{Li}_{2} \mathrm{CO}_{3}$, $30 \mathrm{wt} \% \mathrm{~K}_{2} \mathrm{CO}_{3}$ and $50 \mathrm{wt} \% \mathrm{Li}_{2} \mathrm{CO}_{3}, 50 \mathrm{wt} \% \mathrm{~K}_{2} \mathrm{CO}_{3}$ ) is intrinsically $\mathrm{CO}_{2}$-rejecting. At the high operating temperature of the cell $\left(600-650^{\circ} \mathrm{C}\right)$, the $\mathrm{O}_{2}$ electrode process is much more nearly reversible than in acid electrolytes at $200^{\circ} \mathrm{C}$. Even at atmospheric pressure, the cell will function well at reactant concentrations which would cause large losses as the result of diffusional gradients at $200^{\circ} \mathrm{C}$, despite the relatively low active area of MCFC electrodes, which results from sintering and other materials constraints at the high cell operating temperatures. While the kinetic and parasitic losses in the cell are low, this advantage is partially offsite by the thermodynamic change of open-circuit potential with temperature [see Eq. 
$(6.1-1)]$, which amounts to about $215 \mathrm{mb}$ between 25 and $650^{\circ} \mathrm{C}$. However, the gain in overall system efficiency justifies the high operating temperature. While HC fuels have measurable oxidation rates in the cell, their direct use leads to cracking, which can be prevented by steam injection. This fact suggests the possibility of reforming fuels such as NG internally by using cell waste heat.

The MCFC anode consists of an $\mathrm{Ni}$ sinter containing sintering inhibitors. The structure is often ribbed to provide gas passages. The anode generally incorporates a fine pore layer or bubble barrier to prevent gas crossover under differential pressure conditions. The inner side of the anode contacts a relatively fine pore matrix consisting of lithium aluminate containing the molten electrolyte. The cell has a porous cathode (currently Li-doped NiO) and a metal bipolar plate; a current collector is located between cells. The bipolar plate consists of 316 stainless steel on the cathode side and clad with $\mathrm{Ni}$ on the anode side. No wet-proofing agents are used: the electrolyte three-phase-boundaries are maintained by surface tension resulting from matched pore-size distributions.

MCFCs are being developed at UTC, ERC and IGT, under DoE and EPRI sponsorship. The system is expected to have two utility applications: as modular dispersed internal-reforming NG units (IR MCFCs) with 5,800 Btu/kWh or better LHV heat-rate (59\% or more LHV efficiency) using clean fossil fuels $\mathrm{s}^{25}$ and as units integrated with coal gasifiers with bottoming cycles for central stations with $6,500 \mathrm{Btu} / \mathrm{kWh}$ coal-AC heat rate. ${ }^{26}$ In both cases, emissions will be very low, even less than for the PAFC, with about

1 ppmv $\mathrm{NO}_{x}$ and 0 ppmv $S$ (PAFC emmissions are 0 ppmv $S, 3-17$ ppmv $\mathrm{NO}_{x}$ ). NSPS standards for combustion turbines are currently 75 ppmv.

The MCFC has a sufficiently high operating temperature to supply not only the steam for NG reforming but also the reaction heat. Thus, a separate reformer is not needed, and all fuel-processing operations (except desulfurization) can be carried out in the anode compartment if a suitable steam-reforming catalyst is present. From the systems viewpoint, the cell behaves as if it used NG directly as fuel, and it is therefore much more efficient and simpler than a PAFC unit fueled by NG. Since NG has an LHV of $1.04 \mathrm{~V}, 100 \%$ utilization at a cell voltage of $0.73 \mathrm{~V}$ would yield an overall LHV efficiency of $0.73 / 1.04$ or $70 \%$. In a practical system, the major energy 
loss is that for transferring $\mathrm{CO}_{2}$ from the depleted anode stream to the cathode as required by the stoichiometry of the reactions in the MCFC:

$$
\begin{aligned}
& \mathrm{H}_{2}+\mathrm{CO}_{3}=\longrightarrow \mathrm{H}_{2} \mathrm{O}+\mathrm{CO}_{2}+2 \mathrm{e}^{-} \quad \text { (anode) }, \\
& (1 / 2)_{2}+\mathrm{CO}_{2}+2 \mathrm{e}^{-} \longrightarrow \mathrm{CO}_{3}=\text { (cathode) }
\end{aligned}
$$

These chemical mechanisms require a $\mathrm{CO}_{2}$-transfer device.

An energy-efficient process to deplete $\mathrm{CO}_{2}$ from one gas stream and enrich it in another in a sufficiently energy-efficient manner does not exist at present, and the transfer is therefore accomplished by burning the depleted cell anode stream and condensing the water to obtain a mixture of $\mathrm{N}_{2}$ and $\mathrm{CO}_{2}$. This mixture is then added to air in the correct amount to provide the cathode reactant. The presence of excess $\mathrm{N}_{2}$ inevitably leads to a dilute reactant gas mixture (typically about $7.5 \% \mathrm{O}_{2}, 15 \% \mathrm{CO}_{2}$ ), and recycle will be used on both the anode and cathode sides to keep reactant concentrations at as high effective values as possible to minimize polarization losses. The anode-gas utilization in the cell can probably be kept at $85 \%$ or better, with a minimum total LHV efficiency of $60 \%$ on NG fuel. Parasitic losses for energy used in pumping and in the DC-AC inverter will reduce this value by about $3 \%$. The overall IR MCFC efficiency is much higher than that of a PAFC unit, which is 1 imited to $47 \%$ LHV efficiency at the same cell potential $(0.73 \mathrm{~V})$ because it requires external fuel processing. The IR MCFC is also much simpler from a systems viewpoint than a PAFC and it should therefore be less costly.

Efficiency, cost and systems aspects of an IR MCFC in the 2-MW class have been studied. ${ }^{25}$ The baseline system used hot recycle of the fuel and oxidant gas streams, operated at atmospheric pressure, and required only one heat exchanger with a total area of $3.5 \mathrm{~m}^{2}$. Other systems were more complex variants of the baseline unit; some incorporated pressurization. To the extent possible, off-the-shelf components were used in the evaluation; the only exception was the high-temperature blower for the baseline system.

An inverter efficiency of $97 \%$ was assumed, and parasitic power losses were estimated to be $5 \%$ of rated output; more reasonable values are $98.5 \%$ and $4 \%$, respectively. The cell potentials were estimated by using a 
simple model for the dependence of polarization on reactant pressures. When HHV efficiencies were calculated, the more complex systems showed little improvement over the baseline system, which had an estimated $0.705 \mathrm{~V} / \mathrm{ce} 11$ at $200 \mathrm{~mA} / \mathrm{cm}^{2}$ with $80 \%$ fuel utilization at $659^{\circ} \mathrm{C}$ average temperature, giving $46 \%$ HHV efficiency ( $51 \%$ LHV). At $90 \%$ fuel utilization and $160 \mathrm{~mA} / \mathrm{cm}^{2}$ average current density, the same system should give $0.73 \mathrm{~V} / \mathrm{ce} 11$, corresponding to $52 \%$ HHV efficiency ( $58 \%$ LHV). This figure has been confirmed using an extensive computer analysis of internal-reforming cells, provided that thin, low-resistance electrolyte layers and high-performance off-eutectic electrolytes are used. 27

This study shows that improved, simple, dispersed MCFCs with $60 \%$ (LHV) system efficiencies are possible if development problems can be solved. The units should have simpler, smaller and more efficient chemical engineering systems than PAFCs. Assuming stack costs of $\$ 200 / \mathrm{kW}$ of active area $(\$ 20 / \mathrm{kg}$, compared with average material costs of $\$ 7 / \mathrm{kg})$, plant costs of $\$ 800 / \mathrm{kW}$ uninstalled, with non-automated assembly, were estimated for breadboard units based on 40-kW stacks. The use of larger, better optimized stacks should reduce the cost of mature units by more than a factor of 2.25

Higher efficiencies (to $65 \%$ LHV) may be obtained if higher capital costs can be justified (more complex systems with bottoming cycles and $\mathrm{CO}_{2}$-transfer devices when developed). Dispersed NG-fueled units will prove the value of the MCFC to electric utilities. Eventualiy, MCFCs can be anticipated in pressurized coal-fired central stations, using $0_{2}$-blown gasifiers and bottoming cycles. Such stations will have a coal-AC heat-rate of about $6,800 \mathrm{Btu} / \mathrm{kWh}^{26}$ or $50 \%$ efficiency. As remarked earlier, they will have essentially zero emissions. 26

Though IRMC single cells have been run successfully, they do not show the effect of the electrolyte-management problems on performance that are characteristic of stacks. Recent (1984-85), non-internal-reforming, pressurized 20-cel1,9.3- $\mathrm{cm}^{2}$ stacks developed at UTC have shown excellent performance with very little dispersion between cells over 1000-2000 hr, when end cells started to flood at the negative end of the stack, and electrolyte loss occurred at the positive end. This transfer is caused by osmotic pumping up the manifold gaskets, particularly at the cathode. The electrolyte migration results from transfer of carbonate from the anode of 
each cell to the outside of the wet-seal by reduction of depleted cathode gas (surrounding the stack) on the outside of the anode hardware. Parasitic reduction of anode gas takes place in the cell to complete the ionic circuit. This electrolyte transfer can be reduced by careful design of cell-edge and manifold seals and stack design but cannot be totally eliminated. Only the electrolyte content of the final five cells at each end of the stack appears to be affected. Hence, transfer will be less important in large stacks that have greater electrolyte inventories per unit of edge-seal length. Practical stacks may have to be designed with suitable reservoirs at each end, so that controlled osmotic pumping can be used to maintain correct inventory and electrolyte composition throughout.

Materials problems presently include slow cathode dissolution, anode creep, corrosion of the cathode-current collector and contamination of the reforming catalyst. With the possible exception of cathode dissolution, they can $a 11$ be handled with materials that are now available.

Dispersion-hardened $\mathrm{Ni}$ anodes largely eliminate creep. Formation of lithium ferrite on the 316 stainless steel cathode current collector will lead to films of about $4 \mathrm{mils}(0.1 \mathrm{~mm})$ thickness after $40,000 \mathrm{hr}$ and will not be life-limiting. The metal edge-seal areas in contact with anode and cathode gases are effectively protected from corrosion by aluminizing. Finally, any electrolyte loss (e.g., by evaporation) can be made up using electroosmotic transfer up the cell stack.

The slow dissolution and reprecipitation of the Li-doped NiO cathode material was first discovered by UTC in cells with then new, thin tape-cast electrolyte layers under high pressure (high partial pressures of $\left.\mathrm{CO}_{2}, \mathrm{P}_{\mathrm{CO}_{2}}\right)$. Investigations have shown that the $\mathrm{Ni}^{2+}$ solubility depends inversely on melt oxide-ion concentration, which accounts for the $\mathrm{P}_{\mathrm{CO}_{2}}$ dependence. The $\mathrm{Ni}$ diffuses down its concentration gradient to the anode, where it precipitates and can eventually short-circuit the cell. The effects of dissolution are seen earlier in life with thin, low-resistance electrolytes, especially under high-pressure operation, and resulting lifetimes may not be acceptable unless improvements become possible. These include slowing NiO dissolution by chemical modification of the electrode and/or electrolyte or by the use of cells at low $\mathrm{P}_{\mathrm{CO}_{2}}$ and reduced operating temperature (average $625^{\circ} \mathrm{C}$ ). 
Other conducting oxides are being examined as substitutes for $\mathrm{NiO}$. Many materials, for example, p-type perovskites, have been shown to be unstable. Ideally, any substitute should not have a component which can precipitate as metal under anode conditions. The best candidates would be cel1-corrosion products, e.g., lithium ferrite. Workers at ANL have examined this compound using $\mathrm{Mn}^{2+}$ as dopant, together with $\mathrm{Mg}^{2+}$-doped lithium manganite. Results have not been reproducible.

Many practical problems are involved in the design of a cost-effective IRMC fuel cell stack. This must take into account materials and electrolyte-management problems, plus pressure requirements for electrical contact, cell-edge resiliance, sealing, creep, and the location of the anode-reforming catalyst. The latter is on a carbonate-resistant support but must be protected from excessive wetting by carbonate. For this purpose, a non-wetting anode of the cermet type developed at GE may be a possible direction, since pure $\mathrm{Ni}$ is not wetted by molten carbonate.

Another approach is the use of a fine-pore $\mathrm{Ni}$ protective layer to retain carbonate by surface tension, which could also serve as the bubble-barrier to prevent gas cross-over if micro-cracking of the electrolyte layer occurs after a thermal cycle. Destructive cracking of the cell is now prevented by the use of coarse-particle crack-arresters in the electrolyte.

The rapid development of cell stack technology is indicative of the progress made over the last 5 years. The component design and assembly requirements for a cost-effective IRMC stack are being actively pursued by ERC and IGT. A prototype stack is planned for about 1988 and an internal reforming FC may be available by 1995 .

\section{1-6. Solid Oxide Fuel Cells (SOFCs)}

Some doped inorganic oxides show oxide $\left(0^{F}\right)$ ion conductivity at high temperature $\left(\sim 1000^{\circ} \mathrm{C}\right)$. Yttria-stabilized zirconia is one of the best of these materials. Their use for FCs and other applications goes back to the Nernst glower 28 of 1900 and is reviewed in Ref. 11 . This class of materials as FC electrolytes is attractive because of their thermal stability and the absence of problems of electrolyte management, with no composition-buffering requirement by transfer of a neutralizing agent from 
one electrode to another. The latter procedure is needed in the MCFC, where $\mathrm{CO}_{2}$ must be transferred by an external circuit from anode to cathode to preserve neutrality, as in the automatic internal $\mathrm{H}^{+}$transfer from and to the cathode via the electrolyte in the PAFC. Materials similar to those used in carbonates may be employed for the electrodes, but the all-solid-state system reduces the possibility of chemical interaction and consequent lack of stability.

The low conductivity of the solid oxide materials (at $1000^{\circ} \mathrm{C}$, about $10 \%$ of that of carbonate at $650^{\circ} \mathrm{C}$ ) requires very high operating temperatures and very thin, gas-tight electrolyte layers ( $50 \mu \mathrm{m}$ or less) to give good performance. Thermal expansions require that electrodes, electrolyte layers and other components are accurately matched to prevent cracking or delamination, thereby reducing the overall choice of suitable materials. Finally, means must be found to construct individual cells by building up layers of components and to transfer current from cell to cell with connections that are electrically in series. A satisfactory filter-press system with geometrically parallel bipolar cells proved difficult to fabricate. Early cells were therefore constructed on a porous support tube in the form of short cylindrical units, arranged linearly in series along the tube. Current was collected along the length of each cell. A typical cylindrical length was a few $\mathrm{mm}$ to avoid excessive IR drop. The anode of each cell was in contact with the porous tube, which was supplied with fuel gas on the inside. The cathode-was outside, over the concentric electrolyte layer, and a masked ceramic was used to connect the anode of one cell to the cathode of the next to provide a series arrangement. A ceramic interconnect material was required which had chemical stability and electronic conductivity in both the cathode and the anode environments. Lifetests on these cell arrangements have shown stability for more than $34,000 \mathrm{hr}$ with suitable materials. ${ }^{29}$ At that time, problems which require solution in practical systems were not addressed. These include sealing of the tube ends and thermal cycling.

In 1980, workers at the Westinghouse $R \& D$ Center developed a new arrangement of the basic components, which simplified construction, allowed the use of larger cells, could be cycled thermally, and avoided the end-seal problem. The cell is turned inside out by putting the cathode directly onto 
the porous support tube (non-conducting calcia-stabilized zirconia) and is closed at one end. A narrow arc of the tube, along its length on top of the cathode layer, is now occupied by a strip of interconnect material, with the remainder of the cathode covered by electrolyte. Finally, the anode layer is placed on top of the electrolyte, thus avoiding contact with the interconnect by masking during manufacture. The interconnect is then attached to the next cell by a linear $\mathrm{Ni}$ felt in the fuel-gas atmosphere along the length of each tubular cell. The cell is provided with air via a narrow central alumina tube reaching the closed end; fuel is supplied to the outside in a co-flow arrangement. Reformate fuel, coal gas or possibly NG with steam, can be used; depleted fuel (after 85-90\% utilization in the ce11) is burned with depleted air after passing through a leaky ceramic header into a plenum chamber. The heat produced preheats the reactants and can be used in a bottoming cycle. The whole ingenious arrangement has been tested in thermally-cycled three-cell and larger stacks.

The only suitable materials, in view of thermal expansion and physicochemical requirements, are lanthanum chromite for the interconnect, Sr (or another alkaline or rare earth) doped with lanthanum manganite for the air electrode, and an Ni-stablized zirconia cermet for the anode. The layers are applied successively to the cathode by filtration onto the support tube. This step is followed by cathode sintering, which requires a lower temperature than the sintering of stabilized zirconia. After masking, the interconnect is applied, and then the electrolyte is deposited by EVD. The cathode is applied in the form of a slurry, followed by EVD zironcia-cermet formation. The EVD involves reaction of a mixture of vapor-phase chlorides on one side of the tube, with water vapor on the other. A film of yttria-stabilized zirconia is formed and conducts 0 ions; thus, $\mathrm{H}_{2}$ is formed by reduction of water vapor on one side and chlorine on the other. Because of ionic conduction in the film, the latter forins and continues to grow at $100 \%$ density, even at $25-\mu m$ thickness. However, many steps are involved in tube preparation, and costs are presently undetermined. Materiais costs are about $\$ 150 / \mathrm{kW}$.

At $1000^{\circ} \mathrm{C}$, activation polarization is not apparent in the cell, but the change in $\Delta G$ with temperature $[\mathrm{Eq} .(6.1-1)]$ results in low open-circuit potentials. In addition, the IR drop around the circumference 
of the air electrode is high. Typical tubes of $1.7-\mathrm{cm}$ diameter yield $0.65 \mathrm{~V}$

under the same conditions $\left(160 \mathrm{~mA} / \mathrm{cm}^{2}\right)$ as an MCFC at $0.73 \mathrm{~V}$. Unless air-electrode resistance and/or tube diameter can be reduced, individual cell efficiencies will always be about $10 \%$ less than those of the MCFC system. On the other hand, the higher-quality waste heat can be used in an efficient bottoming cycle in a sufficiently large system. The costs for the numerous small tubes, headers and manifolds are as yet unknown.

Recently, workers at ANL have focused on a tape-cast filter-press variant (the monolithic cel1) with shorter current pathways and therefore lower IR drop. 30 Manifolding, thermal cycling and cost problems for this concept are not presently known.

\section{1-7. Conclusions}

FCs have very high efficiencies, even at part load and in small units (200 kW to several MW), are silent, and have virtually zero emissions. They can therefore be placed anywhere (e.g., in inner cities or on-site for cogeneration). In addition to these advantages over combustion turbines, their main attraction to U.S. electric utilities is rapid availability in sma11, very efficient units which allow rapid capital pay-back. FCs can therefore be introduced as new capacity is required, as an alternative to installing coal or nuclear central stations several years earlier, in anticipation of future demands. A $46 \%$ efficient (LHV) unit can be expected to achieve a $6.6 \%$ penetration of total installed capacity in the early years of the 21 st century, provided that reasonable cost goals (about $\$ 800 / \mathrm{kW}$ ) are met. $^{31}$ For a $51 \%$ efficient (LHV) unit, the corresponding figure is $18.2 \%$. We believe that the PAFC, which will be commercialized first, will gain the initial market share, with the higher-performance MCFC system later taking a further share. Both types of cell have a bright future for utilities. The SOFC may also have some place in the utility generation mix if it is used with a bottoming cycle and if its final cost is acceptable. Finally low-cost alkaline systems using inexpensive catalysts may find wide application in mobile systems for transportation when storable $\mathrm{H}_{2}$ is available as a fuel. 


\subsection{Coal Gasifiers for $\mathrm{FC}_{\mathrm{s}}$ *}

The development of coal gasifiers for FCs has tended to concentrate initially on gasifiers for the earliest commercial system, namely, phosphoric acid fuel cells (PAFCs). Design criteria and gasifier requirements are summarized in Table 6.2-1 for two gasification plants, namely, a 20-30 MW $\mathrm{e}$ plant for United Power Association (IPA) and a 150-MW unit for Southern California Edison (SCE).

A schematic of the coal-gasification-FC system is shown in

Fig. 6.2-1. The initially chosen gasifier is an air-blown, fixed-bed design, which involves commercially-tested technology and statisfies the requirements of modular construction with high conversion efficiency. These gasifiers are, however, small units that produce coal fines, heavy oils, and tars. A schematic of the single-stage, fixed-bed gasifier is shown in Fig. 6.2-2. A more detailed flow diagram of system functions is reproduced in Fig. 6.2-3.

\section{2-1. The Site-Specific UPA Design}

The procedure followed in designing the UPA unit is described in Table 6.2-2, where both plant requirements and study objectives are listed. Table 6.2-3 shows performance comparisons of the gasifier-FC system with a coal-fired boller, a fluidized-bed unit, and a gasifier-combined-cycle system. Reference to Table 6.2-3 indicates that the gasifier-FC system has by far the highest expected overall plant-conversion efficiency. Furthermore, costing studies summarized in Table 6.2-4 show that the anticipated bus-bar cost of electricity is relatively low for the gasifier-FC system, roughly comparable with that of a direct coal-fired boiler. However, compared with this system, it has significantly less emission of $\mathrm{NO}_{x}$ and $\mathrm{SO}_{x}$ (compare Table 6.2-5).

* This section has been abstaced (by S. S. Penner and D. Wiesenhahn) from viewgraphs presented by D.Rastler of EPRI at the Second Technical Meeting of COGARN (Lawrence Berkeley Laboratory, February 25, 1985). 
Table 6.2-1. Design criteria for coal gasifiers for PAFCs.

\begin{tabular}{l|c|c}
\hline \multicolumn{1}{c|}{ Design Criteria } & SCE & UPA $^{\dagger}$ \\
\hline Plant size & $150 \mathrm{MW}$ e & $20-30 \mathrm{MW}$ e \\
Coal type & Western low-S & North Dakota lignite \\
Operational requirements & $4-1$ turn down & base load \\
Emission requirements that must be met & California & Minnesota \\
Atmospheric, air-blown, fixed-bed gasification & $\mathrm{X}$ & $\mathrm{X}$ \\
UTC I1.6-MW FC power section and inverter & $\mathrm{X}$ & $\mathrm{X}$ \\
$\begin{array}{l}\text { Commercially-proven equipment } \\
\text { Truck-transportable, factory-fabricated } \\
\text { equipment }\end{array}$ & $\mathrm{X}$ & $\mathrm{X}$ \\
\hline
\end{tabular}

$t_{\mathrm{SCE}}=$ Souther $\mathrm{n}$ California Edison; ${ }^{\ddagger} \mathrm{UP \Lambda}=$ United Power Association

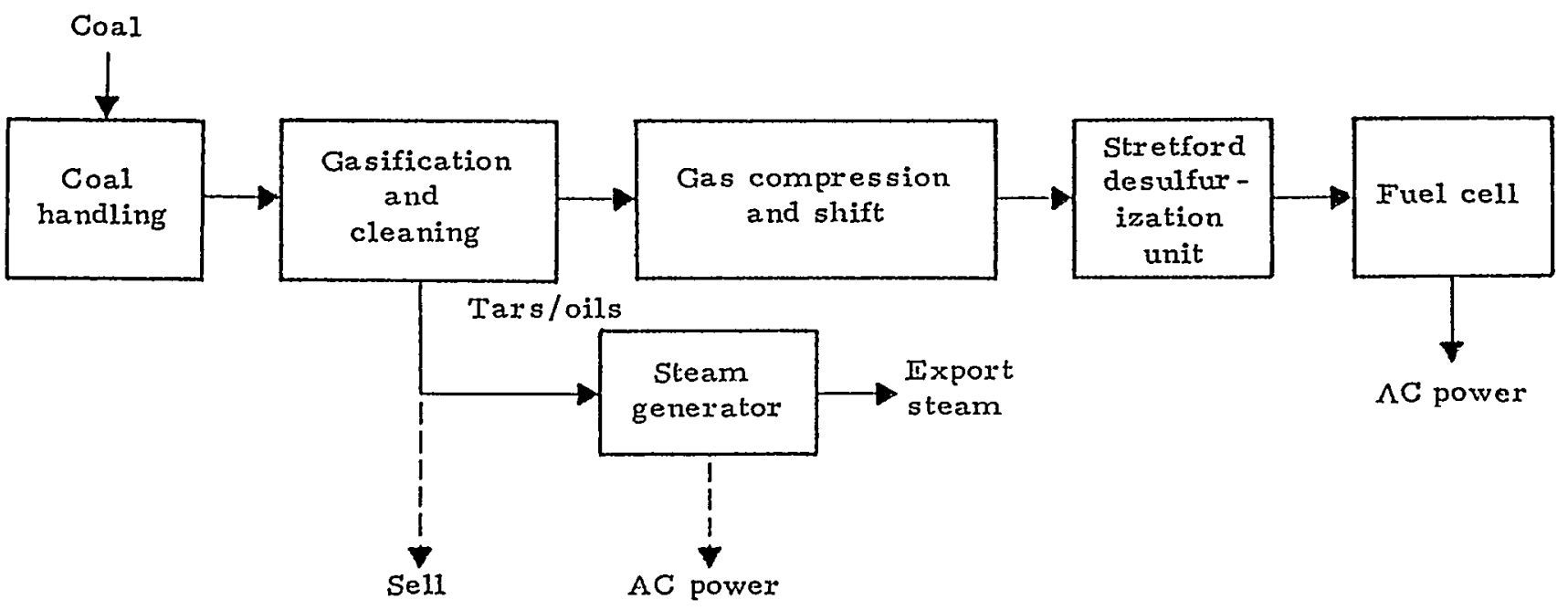

Fig. 6,2-1. Schematic of the coal-gasification-PAFC process. 


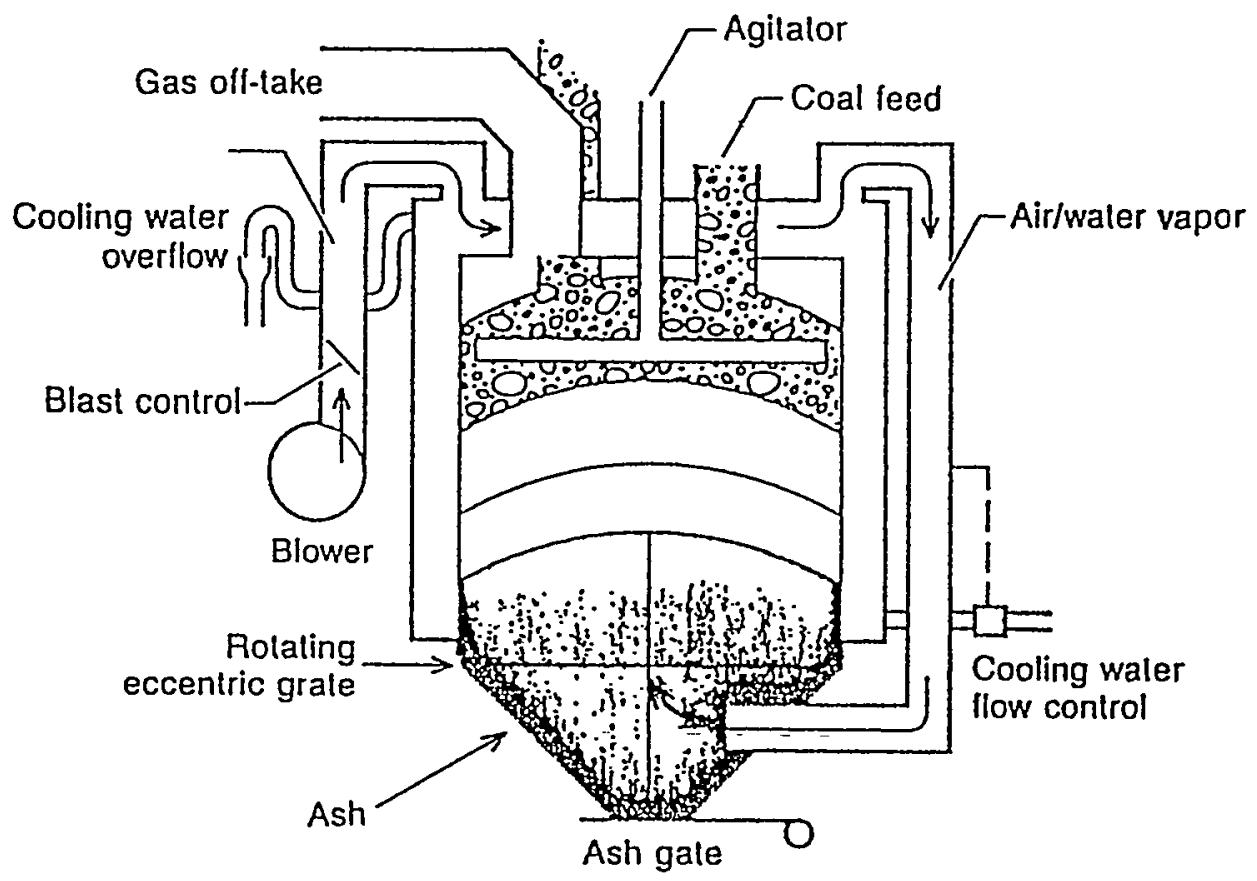

Fig. 6.2-2. Schematic of a single-stage, atmospheric pressure, fixed-bed coal gasifier.

Table 6.2-2. Background on site-Bpecific studies for the UPA unit.

Host utility: United Power Association (UPA).

Contractor: Ralph M. Parsons.

Sponsors: EPRI/NRECA.

Study site: Willmar, Minn.

Plant requirements: N.D. lignite, $20-50 \mathrm{MW}_{\mathrm{e}}$ cogeneration, UTC fuel-cell modules.

Study objectives: cost/economics of small coal plant, optimal configuration, verification of cost estimates, as sessments of alternative technologies, detailed environmental assessments. 


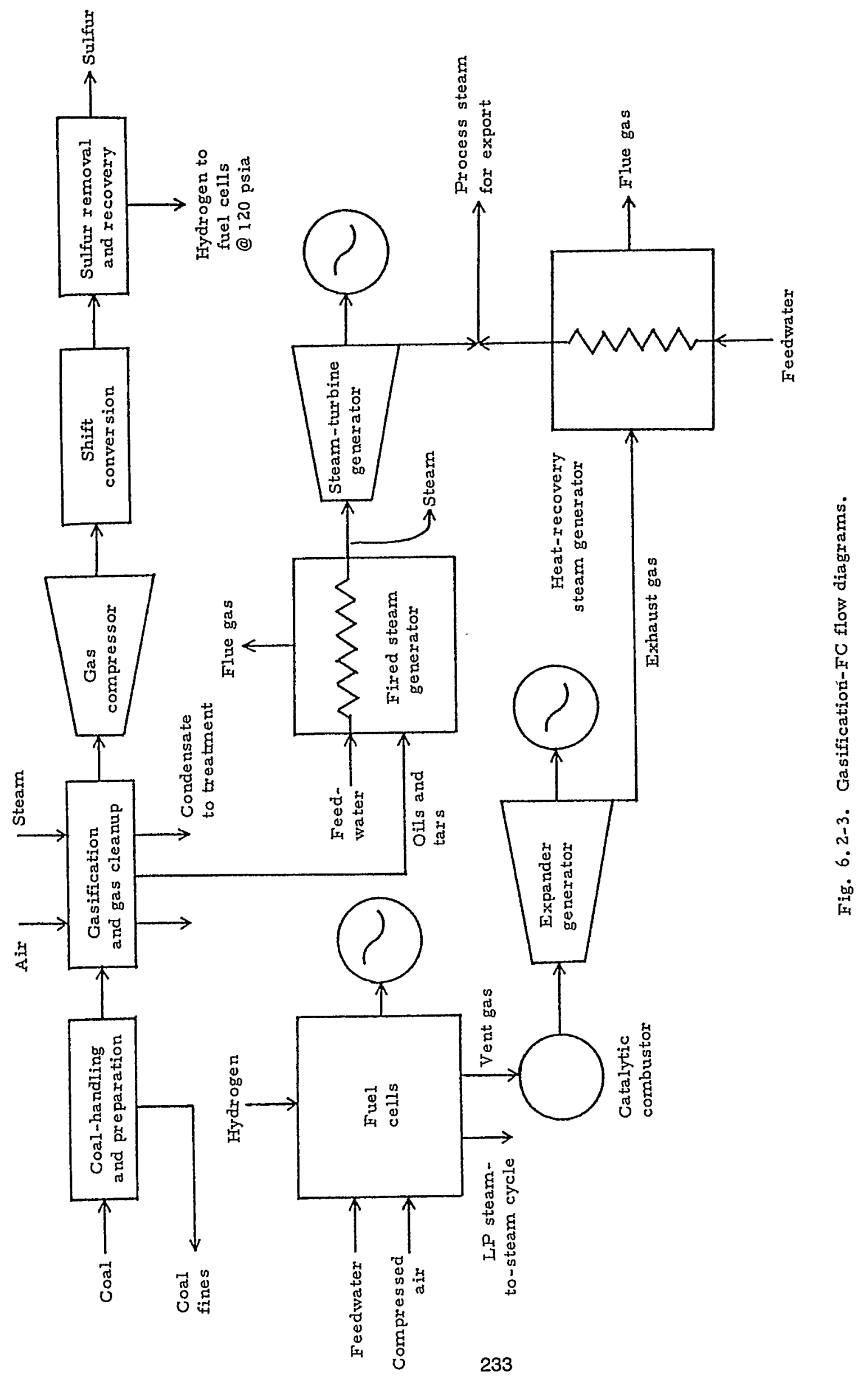


Table 6.2-3. Performance comparison of four design options studied for the UPA site.

\begin{tabular}{l|c|c|c|c}
\hline \multicolumn{1}{|c|}{ Plant Feed and Output } & $\begin{array}{c}\text { Gasifiex- } \\
\text { FAFC }\end{array}$ & $\begin{array}{c}\text { Gasifier- } \\
\text { Combined-Cycle } \\
\text { System }\end{array}$ & $\begin{array}{c}\text { Fluidized- } \\
\text { Bed Unit }\end{array}$ & $\begin{array}{c}\text { Direct } \\
\text { Coal-Fired } \\
\text { Boiler }\end{array}$ \\
\hline Net lignite feed rate, TPD & 740 & 740 & 740 & 740 \\
Plant output, MW export & 32.5 & 20.1 & 20.6 & 21.5 \\
Steam (150 psig), Jb/hr & 107,000 & 100,400 & 100,000 & 100,000 \\
Overall plant efficiency & 56.1 & 44.1 & 43.1 & 43.6 \\
\hline
\end{tabular}

Table 6.2-4. Economic comparison of options for the UPA site-specific study.

\begin{tabular}{|c|c|c|c|c|}
\hline Capital and Other Costs ${ }^{\dagger}$ & $\begin{array}{l}\text { Gasifier- } \\
\text { PAFC }\end{array}$ & $\begin{array}{c}\text { Gasifier- } \\
\text { Combined-Cycle } \\
\text { System }\end{array}$ & $\begin{array}{l}\text { Fluidized- } \\
\text { Bed Unit }\end{array}$ & $\begin{array}{c}\text { Direct } \\
\text { Coil-Fixed } \\
\text { Boiler }\end{array}$ \\
\hline $\begin{array}{l}\text { Capitalization charges, } \\
\text { mills/kWh }\end{array}$ & 35 & 45 & 36 & 32 \\
\hline Fuel cost & 24 & 40 & 36 & 35 \\
\hline$O \& M$ & 29 & 30 & 29 & 25 \\
\hline Steam and by-products credits & $(20)$ & (34) & (27) & (26) \\
\hline Busbar costs, mills / $\mathrm{kWh}$ & 68 & 81 & 74 & 66 \\
\hline
\end{tabular}

Table 6.2-5. Environmental comparison of options for the UPA site-specific study.

\begin{tabular}{|c|c|c|c|c|}
\hline Emissions (1b/10 6 BTU) & $\begin{array}{l}\text { Gasifier- } \\
\text { PAFC }\end{array}$ & $\begin{array}{c}\text { Gasifier-Combined- } \\
\text { Cycle Systcm }\end{array}$ & $\begin{array}{l}\text { Fluidized- } \\
\text { Bed Unit }\end{array}$ & $\begin{array}{l}\text { Direct Coal- } \\
\text { Fired Boiler }\end{array}$ \\
\hline $\mathrm{NO}_{\mathrm{x}}$ & 0.004 & 0.05 & 0.11 & 0.35 \\
\hline $\mathrm{SO}_{\mathrm{x}}$ & 0.06 & 0.06 & 0.06 & 0.11 \\
\hline Particulate matter & 0.02 & 0.02 & 0.02 & 0.02 \\
\hline
\end{tabular}

\section{2-2. The Site-Specific SCE Design}

The procedure followed in designing the SCE unit is described in Table 6.2-6. Figure 6.2-4 shows a cost breakdown for the SCE facility. The estimated total cost of electricity is $69 \mathrm{mills} / \mathrm{kWh}$ and is divided in the manner illustrated in Fig. 6.2-5. 
Table 6.2-6. Site-specific studies for the SCE unit.

Host utility: Southern California Edison Company

Contractor: Kinetics Technology International Corporation

Sponsors: EPRI/SCE

Study site: Barstow, CA

Plant requirements: Colorado subbituminous coal, $150 \mathrm{MW}$ all electric plant, UTC fuel-cell modules

Study objectives: Assess scale-up issues, determine environmental impacts, provide a detailed cost and economic analysis

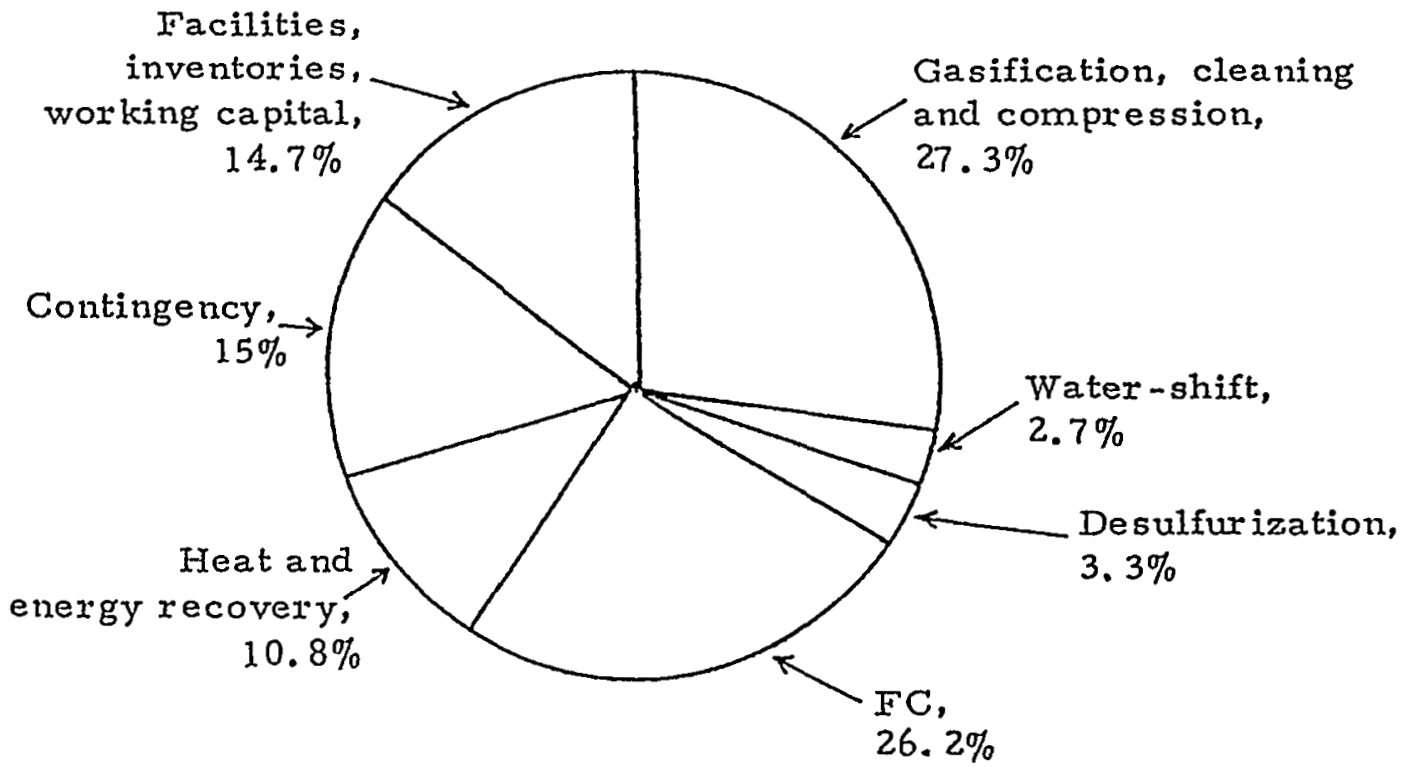

Fig. 6,2-4. 150-MW plant cost summary $(\$ 1630 / \mathrm{kW})$. 


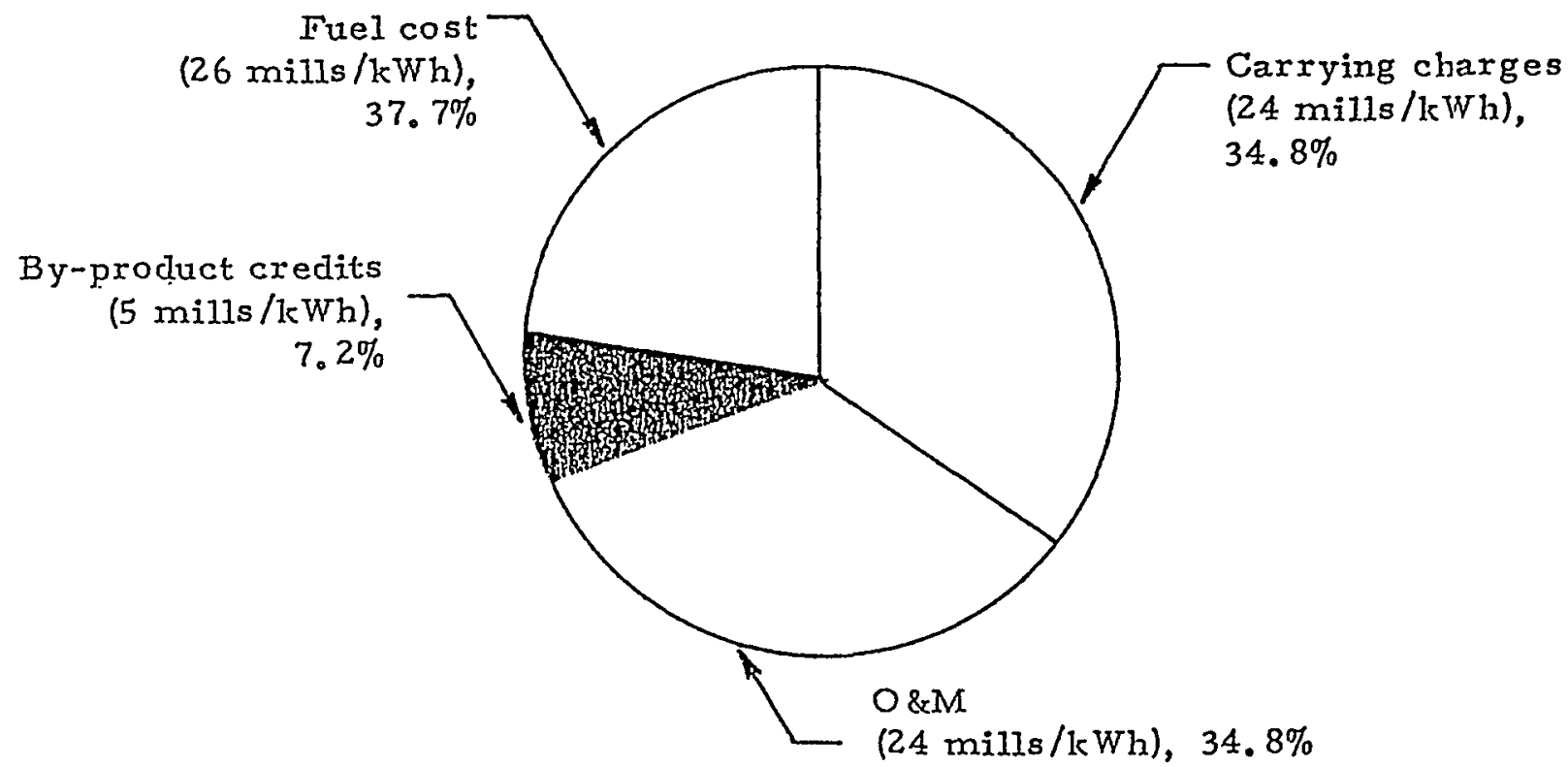

Fig. 6.2-5. The total cost of electricity is $69 \mathrm{mills} / \mathrm{kWh}$ and is broken down as shown in this diagram. A 25 -yr book life, $65 \%$ cumulative load factor, ancl a constant January 1983 dollar were used.

\section{2-3. Conclusions}

The following are the principal conclusions reached from these evaluations: (i) No technical barriers appear to exist to successfu1 operation of the conceptual design. (ii) Except for the FC-inverter, all process equipment and systems are commercially available.

(iii) Site-specific emission requirements can be easily met. The use and disposition of plant by-product must be evaluated on a case-by-case basis. (iv) The plant configuration is modular and can be erected and on-stream within a 3-4 year period. (v) The coal gasifier FC plant is expected to compete well with other coal-based power generation options in the plant range of $100-150 \mathrm{MW}_{\mathrm{e}}$. 


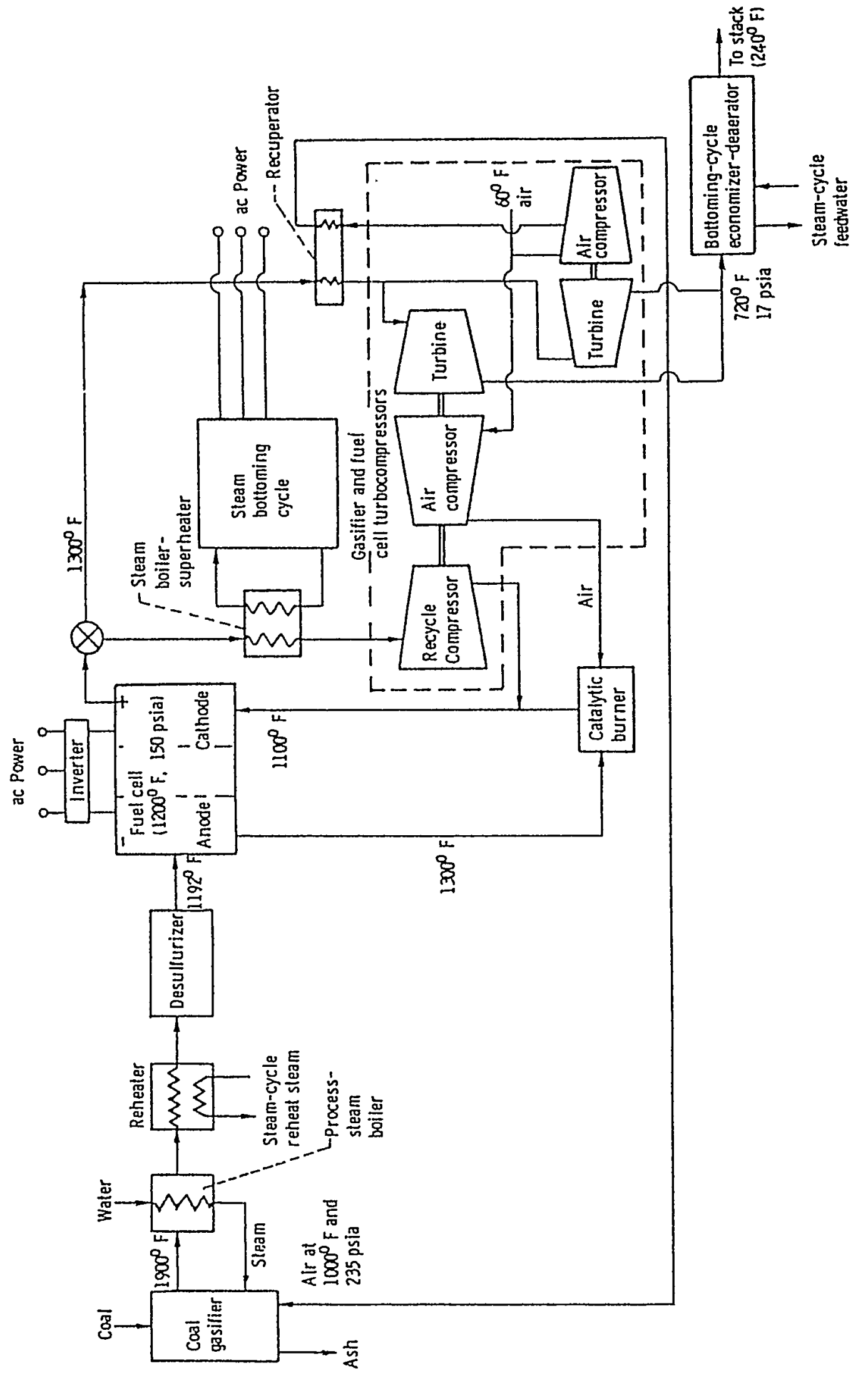

di 


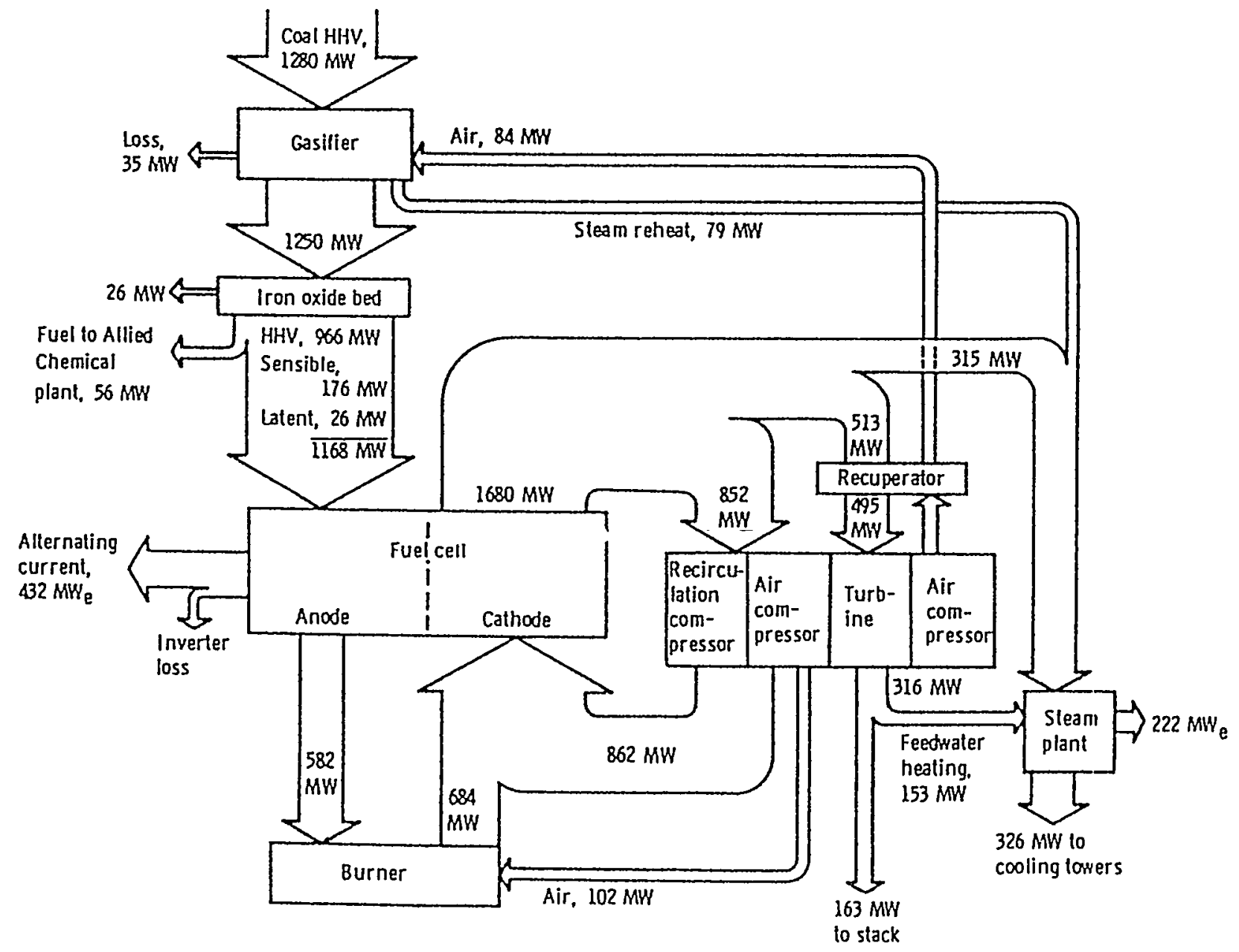

Fig. 6.2-7. Energy flow diagram for a low Btu gasifier/molten-carbonate fuel cell-MCSC-steam system. The net power output is $635 \mathrm{MW}_{\mathrm{e}}$ auxiliary power plus transformer losses are $19 \mathrm{MW}_{\mathrm{e}}$. 


\section{2-4. Research Needs on Gasifier-PAFC Systems}

The coal gasifier should be a modular 20-50 $\mathrm{MW}_{\mathrm{e}}$ unit producing $\mathrm{H}_{2}$ + co. An atmospheric-pressure air-blown unit is acceptable but a pressurized gasifier would be preferable. The gasifier must have high reliability and be easy to operate for a wide range of coals. It should produce $\mathrm{H}_{2}$-CO mixtures with high efficiency, yield minimal amounts of tar and oils in the raw-gas condensate, and become commercially available between the early and mid-1990s.

Candidate gasification systems include those of She11, Texaco, Lurgi, KRW (Westinghouse), KGN, MHI, and U-GAS.

Research and development to provide one or more of these gasifiers at acceptable costs in the specified size range is recommended.

\section{2-5. Other Gasifier-FC Systems}

A conceptual design of a gasifier-MCFC-steam system, in which low-BTU gas is produced in the gasifier, is shown in Fig. 6.2-6. The energy-flow diagram for this unit is sketched in Fig. 6.2-7. Gasifier optimization for this system is not expected to be the pacing technology since commercial MCFC units are not likely to become available before the mid-nineties.

\section{References}

1. A. J. Appleby in Electrochemistry, p. 373, H. Bloom and F. Gutmann eds., Plenum, NY (1977).

2. S. Carnot, Reflexions sur 1a Puissance Motrice du Feu (1824).

3. J. Tafe1, Z. Phys. Chem. 50, 641 (1905).

4. P. Van Rysselberghe in Modern Aspects of Electrochemistry, Vol. 4, p. 1, J. O'M. Bockris and B. E. Conway eds., Plenum, NY (1966).

5. J. O'M. Bockris and A. K. N. Reddy, Modern Electrochemistry, Plenum NY (1972). 
6. A. J. Appleby in Modern Aspects of Electrochemistry, Vol. 9, p. 369, B. E. Conway and J. O'M. Bockris eds., Plenum, NY (1974); see also Comprehensive Treatise of Electrochemistry, Vol. 7, p. 173, B.E. Conway, J. O'M. Bockriis, E. Yeager, S. U. M. Khan, and R. E. White eds., Plenum, NY (1983).

7. A. J. Appleby, J. Electrochem, Soc. 117, 641 (1970); E. Yeager, D. Scherson and B. Simic-Glavaski, Ext. Abstr. Spring Meeting Electrochem. Soc., p. 1043 (May 1983).

8. J. P. Hoare, The Electrochemistry of Oxygen, Interscience, NY (1968).

9. P. Stonehart and J. P. MacDonald, Final Report, EM-1664, Electric Power Research Institute, Palo Alto, CA (1981).

10. W. R. Grove Phil. Mag. S. 3 21, 417 (Dec. 1942).

11. H. A. Liebhafsky and E. J. Cairns, Fuel Cells and Fuel Batteries, Wiley, NY (1968).

12. M. Pourbaix, Atlas d'Equilibres Electrochimiques, Gautier-Villars, Paris (1963).

13. J. Tobler, Z. Electrochem. 39, 148 (1933).

14. F. T. Bacon in Trends in Electrochemistry, J. O'M. Bockris, D. J. Rand, and B. J. Welch eds., Plenum, NY (1977); J. Electrochem. Soc. $126,7 C$ (1979).

15. B. J. Crowe, "Fuel Cel1s, A Survey," NASA SP-5115, National Aeronautics and Space Administration, Washington, D.C. (1973).

16. D. Linden in Handbook of Batteries and Fuel Cells, p. 42-1, D. Linden ed., McGraw-Hill, NY (1984).

17. A. P. Fickett, p. 43-1 in Ref. 16.

18. J. O'M. Bockris, Energy Options, Australia and New Zealand Book Co., Sydney, Australia (1980).

19. A. T. Emergy, Ext. Abstr. National Fuel Cell Seminar, p. 98 (1983).

20. D. Bloomfield, E. Behrin, and P. N. Ross, Report LBL-14500, Lawrence Berkeiey Laboratory, Berkeley, CA (1982). 
21. A. J. Appleby in The ELectrochemistry of Carbon, p. 251, S. Sarangapani, J. R. Akridge and B. Schumm eds., The Electrochemical Society, Pennington, NJ (1984).

22. L. M. Handley, W. E. Houghtby, W. H. Johnson, T. G. Schiller, and H. Y. Stryker, EPRI EM-1134, Electric Power Research Institute, Palo Alto, CA (1979).

23. L. M. Handley, EPRI EM-3161, Electric Power Research Institute, Palo Alto, CA (1983).

24. M. K. Wright and L. E. VanBibber, Ext. Abstr. National Fuel Cel1 Seminar, P. 69 (1982).

25. P. S. Pate1, EPRI EM-3307, Electric Power Research Institute, Palo Alto, CA (1983).

26. T. L. Bonds, M. H. Dawes, A. W. Schnacke, and L. W. Spradin, EPRI EM-1670, Electric Power Research Institute, Palo Alto, CA (1981).

27. E. T. ong, R. A. Donado, C. T. Li, and T. D. Claar, in "Proc. Workshop on Molten Carbonate Fuel Cel1s, Nov. 1978," pp. 4-18, EPRI WS-78-135, Electric Power Research Institute, Palo Alto, CA (1979).

28. W. Nernst and W. Wald, Z. Electrochem. 7, 373 (1900).

29. F. J. Rohr, Ext. Abstr. Workshop High Temp. Solid Oxide Fue1 Cells, Brookhaven National Laboratory, Brookhaven, NY (1977).

30. D. C. Fee, R. K. Steunenberg, T.D. Claar, R. B. Poeppe1, and J. P. Ackerman, Ext. Abstr. National Fuel Cell Seminar, p. 74 (1983).

31. C. K. Pang, S. T. Lee, K. Lee, and D. T. Imamura, EPRI EM-3205, Electric Power Research Institute, Palo Alto, CA (1983). 


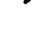




\section{CHAPTER 7:}

USE OF CATALYSTS DURING GASIFICATION

\subsection{Selected Examples of Current Research *}

\section{1-1. Introduction}

Catalysts play an important role in coal gasification. A list of possible uses is given in Table 7.1-1. Catalysts may be added to the feed stream just ahead of the gasifier to enhance gasification rates and improve the quality of the initial decomposition product slate. Catalysts are used for gas clean-up to facilitate efficient pollutant removal and product recovery. Processing of product gases to synthesize fuel and/or chemicals requires the appropriate use of catalysts.

This chapter deals with catalytic activity during gasification. Since in this application the catalyst material is usually added to the feed before it enters the gasifier, these are referred to as pre-gasification catalysts.

Some of the purposes of using pre-gasification catalysts are the following: to reduce gasification temperatures, pressures, and residence times; to minimize overall system sizes and costs; and improve gasifier quality and yields. Properly chosen catalysts will perform all of the specified functions and will also be sufficiently cheap to eliminate the need for complex or costly catalyst-recovery steps.

Despite extensive use and experience with catalysts, relatively little is known about the catalyst reaction mechanisms that occur in coal gasifiers. Fundamental research aimed at elucidating these functions has been an active field for research. The basic parameters governing gasification rates, such as active coal-surface area, active sites, catalyst dispersion, etc. are the proper targets of modern research. Catalytic processes

* This section has been prepared by S. S. Penner and D. F. Wiesenhahn. 
are found in operating commercial plants, but few of these employed as pregasification catalysts. An example of efficient gasification on a nearly commercial scale is provided by the Exxon catalytic-coal-gasification process (see Sec. 7.2 for details).

The following summary is largely derived from (i) papers presented at the 1985 International Conference on Coal Science. ${ }^{1-8}$ and (ii) information communicated to COGARN by $H$. Heinemann.

7.1-2. Results from the 1985 International Coal Science Conference ${ }^{1-8}$

The catalyst most often studied is $\mathrm{K}_{2} \mathrm{CO}_{3}$. Although the performance achieved with this and another commonily used potassium salt, $\mathrm{KOH}$, has been good, they are too expensive for use as throw-away materials. For this reason, other cheaper catalysts are being examined, for exarnple, the alkali salts $\mathrm{CaCO}_{3}, \mathrm{Na}_{2} \mathrm{CO}_{3}, \mathrm{NaOH}$, etc., as well as metals such as $\mathrm{Ni}$. A summary of the catalysts studied in Refs. 1-8 is given in Table 7.1-2.

Basic catalyst parameters include coal-surface area, ${ }^{1-3}$ catalyst dispersion, ${ }^{1,4,7}$ catalyst-loading levels, $2,3,5,6,8$ and coal characteristics. $^{3,7}$ Kinetic parameters were determined for assumed first-order reaction rates and an Arrhenius expression ${ }^{1,5}$ or for rate laws corresponding to Langmuir-Hinshelwood kinetics. ${ }^{6}$ A summary of these papers follows.

In Ref. 1 , the rates and mechanisms of steam gasification of petroleum coke and activated charcoal were studied using the sodium salts listed in Table 7.1-2. For augmentation of gasification rates, the catalysts were ranked as follows: Na-lignosulfate $>$ EDTA-Na-salt $>$ Na-oxalate > Na-salicylate > Na-benzoate, Na-formate, Na-acetate > NaOH, $\mathrm{Na}_{2} \mathrm{CO}_{3}$. These results are valid at temperatures of 650 and $750^{\circ} \mathrm{C}$.

The reaction mechanism for EDTA-salt, Na-oxalate and others involved removal of the hetero-atom from the carbon matrix and using this atom for complexing. This procedure created edges which served as active sites for gasification. Cation exchange is the mechanism used to explain the action of the $\mathrm{Na}-\mathrm{lignosulfate}$ catalyst. Active sites are formed by the exchange of sodium atom with a hetero-atom in the carbon matrix; thus, the high effectiveness of $\mathrm{Na}-\mathrm{lignosulfate}$ is the result of its very high cation exchange. Dispersion effects were briefly discussed. 
Table 7.1-1. Catalyst applications covering all phases of coal gasification are expected to show the listed advantages.

Increased gasification rates and reduced operating temperatures, pressures, residence times, and/or component sizes.

Improved gasifier-output quality, thus facilitating control of initial product-gas compositions and yields; reduced initial product-gas compositions and yields; reduced initial product-gas pollutant concentrations.

Easier gas clean-up for high- and low-temperature pollutant removal, productgas purification.

Improved gas processing for the methanation of mixtures of $\mathrm{CO}, \mathrm{CO}_{2}, \mathrm{H}_{2}$.

Improved methods for the separation of $\mathrm{O}_{2}$ and $\mathrm{N}_{2}$ from air.

Facilitated production of coal-derived liquids.

Table 7.1-2. Summary of catalysts for which studies were reported at the 1985 International Conference on Coal Sciences (see Refs. 1-8).

\begin{tabular}{|c|c|c|c|}
\hline Catalyst & References (s) & Catalyst & References (s) \\
\hline $\mathrm{Na}_{2} \mathrm{CO}_{3}$ & $1,2,5$ & $\mathrm{~K}-\mathrm{Sn}$ & 2 \\
\hline $\mathrm{NaOH}$ & 1 & $\mathrm{Ni}$ & 3,7 \\
\hline Na-acetate & 1 & $\mathrm{Ni}-\mathrm{Ca}$ & 3 \\
\hline $\mathrm{Na}$-formate & 1 & $\mathrm{Fe}-\mathrm{Ca}$ & 3 \\
\hline Na-benzoate & 1 & $\mathrm{KCl}-\mathrm{NaCl}$ & 4 \\
\hline Na-salicylate & 1 & $\mathrm{KCl}-\mathrm{MgCl}_{2}$ & 4 \\
\hline $\mathrm{Na}$-oxalate & 1 & $\mathrm{KCl}-\mathrm{NaCl}-\mathrm{MgCl}_{2}$ & 4 \\
\hline EDTA-Na-salt & 1 & $\begin{array}{l}\mathrm{KCl}-(\mathrm{mg} \text { or } \mathrm{Ca}) \\
-\left(\mathrm{SO}_{4} \text { or } \mathrm{CO}_{3}\right)\end{array}$ & 4 \\
\hline Na-lignosulfate & 1 & $\mathrm{~K}_{2} \mathrm{SO}_{4}-\mathrm{FeSO}_{4}$ & 4 \\
\hline $\mathrm{K}_{2} \mathrm{CO}_{3}$ & $2-7$ & $\mathrm{Ca}_{\mathrm{C}} \mathrm{O}_{3}$ & 5 \\
\hline $\mathrm{KOH}$ & 2 & $\mathrm{Na}-\mathrm{Ca}$ & 5 \\
\hline $\mathrm{ZnCl}_{2}$ & 2 & $\mathrm{Na}-\mathrm{Ca}-1$ & 5 \\
\hline $\mathrm{SnCl}_{2}$ & 2 & Fe-MaII & 5 \\
\hline $\mathrm{AlCl}_{3}$ & 2 & $\mathrm{Na}-\mathrm{RCl}_{3}$ & 5 \\
\hline $\mathrm{FeCl}_{3}$ & 2 & $\mathrm{~K}$ & 8 \\
\hline $\mathrm{NiCl}_{2}$ & 2 & $\mathrm{Na}$ & 8 \\
\hline $\mathrm{K}-\mathrm{Zn}$ & 2 & Cs & 8 \\
\hline $\mathrm{K}-\mathrm{AI}$ & 2 & & \\
\hline
\end{tabular}


Gasification of Greek lignites and lignite chars with $\mathrm{H}_{2}$ or $\mathrm{N}_{2}$ flows was examined in Ref. 2. Catalysts were chosen in order to optimize conversion and methane yield. For methane yields, the catalysts were ranked as follows: $\mathrm{K}-\mathrm{Zn}>\mathrm{K}-\mathrm{Sn}, \mathrm{KOH}>\mathrm{K}-\mathrm{Al}, \mathrm{Na}_{2} \mathrm{CO}_{3}, \mathrm{~K}_{2} \mathrm{CO}_{3}>\mathrm{FeCl}_{3}, \mathrm{ZnCl}_{2}, \mathrm{SnCl}_{2}$, $\mathrm{AlCl}_{3}$. The loading required to achieve effective catalytic activity for $\mathrm{K}-\mathrm{Zn}$ was determined to be $\geq 5 \%$. Increased loading lowered the temperature for peak methane output by approximately $100^{\circ} \mathrm{C}$, with a concurrent increase in methane production. Generally, methane formation began around $\mathrm{T}-200^{\circ} \mathrm{C}$ and reached a plateau at about $\mathrm{T}=600^{\circ} \mathrm{C}$ before increasing again with temperature. Methane yield from chars were higher than from unreacted lignites. The contribution to methane production made by $\mathrm{CH}_{3}$ radicals freed from the surface was small.

The high reactivity (in the presence of catalysts) of Blair Athol (an Australian coal) was investigated in Ref. 3. Catalysts utilized were $\mathrm{Ni}, \mathrm{Fe}-\mathrm{Ca}$, and $\mathrm{K}_{2} \mathrm{CO}_{3}$. Other specimens tested included chars from six different coals. Pressures were 1,10 , or $30 \mathrm{~atm}$ at 750,850 or $900^{\circ} \mathrm{C}$, while typical catalyst loadings were $1-2 w t \%$. Mixtures of $\mathrm{H}_{2} \mathrm{O}, \mathrm{H}_{2}$ and/or He were employed. Because it was demonstrated that the catalytic contribution was roughly proportional to the surface area divided by the crystallinity of the coal, the high reactivity of Blair Athol with $\mathrm{Ni}$ as catalyst was explained in terms of the great surface area of this coal. High gasification rates were obtained for the catalyst systems $\mathrm{Ni}-\mathrm{Ca}$ or $\mathrm{Fe}-\mathrm{Ca}$. Tentative explanations include $\mathrm{Ca}$ mediating the carbon-transition metal interactions or the small amount of mineral matter found in Blair Athol coal. The influence of coal mineral matter, especially silica and alumina, on K-catalysed gasification was verified by showing that the conversion was proportional to catalyst loading only with demineralized coal. The effects of surface area, crystallinity and pore size for K-catalysed and non-catalysed coals are discussed in Ref. 3.

The goals of the authors of Ref. 4 were (i) reduction of catalyst melting points and acceleration of $\mathrm{KCl}$ hydrolysis by using the mixtures $\mathrm{KCl} / \mathrm{NaCl}, \mathrm{KCl} / \mathrm{MgCl}_{2}$, and $\mathrm{KCl} / \mathrm{NaCl} / \mathrm{MgCl}_{2}$; (ii) formation of more active $\mathrm{K}$-salts by using an in situ anion exchange between $\mathrm{KCL}$, alkali earth sulfates, and carbonates for $\mathrm{KCL} /\left(\mathrm{Mg}^{++}\right.$or $\left.\mathrm{Ca}^{++}\right) \mathrm{SO}_{4}{ }^{--}$and $\mathrm{KCL} /\left(\mathrm{Mg}^{++}\right.$or $\left.\mathrm{Ca}^{++}\right) \mathrm{CO}_{3}{ }^{--}$; and (iii) catalytic in situ reduction of $\mathrm{K}_{2} \mathrm{SO}_{4}$ to $\mathrm{K}_{2} \mathrm{~S}$ using an 
iron catalyst, viz., $\mathrm{K}_{2} \mathrm{SO}_{4} /\left(\mathrm{Fe}^{++}\right.$or $\left.\mathrm{Fe}^{+++}\right)\left(\mathrm{SO}_{4}^{--}, \mathrm{Cl}^{-}\right.$, or $\left.0^{--}\right)$. By monitoring $\mathrm{CO}_{2}$ production, it was found that the temperature at which gasification begins increases with the melting temperature of the catalyst system, i.e., the catalytic system with the lowest melting point initiated $\mathrm{CO}_{2}$ production at the lowest temperature. For this reason, the catalyst efficiencies were ranked according to catalyst melting points as follows: $\mathrm{KCl} / \mathrm{NaCl} / \mathrm{MgCl}_{2}\left(397^{\circ} \mathrm{C}\right)>\mathrm{KCl} / \mathrm{MgCl}_{2}\left(488^{\circ} \mathrm{C}\right)>\mathrm{KCl} / \mathrm{NaCl}\left(650^{\circ} \mathrm{C}\right)>\mathrm{KCl}\left(770^{\circ} \mathrm{C}\right)$. All catalyst-containing systems showed significant improvements over uncatalysed systems. The free energy of reaction $\left(\Delta G_{R}{ }^{\circ}\right)$ was used for the four forward and reverse reactions

$$
\begin{array}{ll}
2 \mathrm{KCl}+\left(\mathrm{Mg}^{++} \text {or } \mathrm{Ca}^{++}\right) \mathrm{SO}_{4}^{--} & \rightleftarrows \mathrm{K}_{2} \mathrm{SO}_{4}+\left(\mathrm{Mg}^{++} \text {or } \mathrm{Ca}^{++}\right) \mathrm{Cl}_{2}^{-}, \\
2 \mathrm{KCl}+\left(\mathrm{Mg}^{++} \text {or } \mathrm{Ca}^{++}\right) \mathrm{CO}_{3}^{--} & \rightleftarrows \mathrm{K}_{2} \mathrm{CO}_{3}+\left(\mathrm{Mg}^{++} \text {or } \mathrm{Ca}^{++}\right) \mathrm{Cl}_{2}^{-},
\end{array}
$$

and also for the anion-exchange reactions

$2 \mathrm{KCl}+\left(\mathrm{Mg}^{++}\right.$or $\left.\mathrm{Ca}^{++}\right) \mathrm{SO}_{4}^{--}+\mathrm{H}_{2} \mathrm{O} \rightleftarrows \mathrm{K}_{2} \mathrm{SO}_{4}+\left(\mathrm{Mg}^{++}\right.$or $\left.\mathrm{Ca}^{++}\right) \mathrm{O}^{--}+2 \mathrm{HCl}$,
$2 \mathrm{KCl}+\left(\mathrm{Mg}^{++}\right.$or $\left.\mathrm{Ca}^{++}\right) \mathrm{CO}_{3}^{--}+\mathrm{H}_{2} \mathrm{O} \rightleftarrows \mathrm{K}_{2} \mathrm{CO}_{3}+\left(\mathrm{Mg}^{++}\right.$or $\left.\mathrm{Ca}^{++}\right) \mathrm{O}^{--}+2 \mathrm{HCT}$.

It was found that the sulfate systems react more effectively with $\mathrm{KCl}$ than the carbonate systems. Experiments confirmed the relatively high activity of the $\mathrm{KCl} / \mathrm{MgSO}_{4}$ system, although pure $\mathrm{KCl}$ was more effective. Based on thermodynamic calculations, Fe was predicted to be a good catalyst for the following in situ reduction reactions:

$$
\begin{gathered}
\mathrm{K}_{2} \mathrm{SO}_{4}+4 \mathrm{Fe} \longrightarrow \mathrm{K}_{2} \mathrm{~S}+4 \mathrm{FeO}, \\
4 \mathrm{FeO}+4\left(\mathrm{C}, \mathrm{H}_{2} \text {, or } \mathrm{CO}\right) \longrightarrow 4 \mathrm{Fe}+4\left(\mathrm{CO}, \mathrm{H}_{2} \mathrm{O} \text {, or } \mathrm{CO}_{2}\right) .
\end{gathered}
$$

Improved activation of $\mathrm{K}_{2} \mathrm{SO}_{4}$ by $\mathrm{Fe}$ was demonstrated experimentally.

The variations of conversion, gas composition, and burn-off rate with catalyst type, loading, gasification temperature, and the steam-to-carbon ratio were determined in Ref. 5 . The effectiveness of catalysts, based on gasification rates, was ranked as follows: $\mathrm{Na}-\mathrm{Ca}-\mathrm{I}>$ 
$\mathrm{Na}_{2} \mathrm{CO}_{3}>\mathrm{K}_{2} \mathrm{CO}_{3}>\mathrm{CaCO}_{3}, \mathrm{Na}-\mathrm{Ca}>\mathrm{Fe}-\mathrm{M}-\mathrm{I}>\mathrm{NaRCl}_{3}$. Increased catalyst loadings and gasification temperatures always increased the gasification rates and conversions. Increased steam-to-carbon ratios enhanced conversion and an empirical relation was determined between these parameters. For defined ranges of steam-flow rate, temperature and carbon conversion, the gasification rates are kinetically of the first order. Resultant activation energies were calculated for an Arrhenius rate law and showed that $\mathrm{Na}-\mathrm{Ca}-\mathrm{I}$ catalysed carbon had an activation energy $90 \mathrm{~kJ} / \mathrm{mole}$ lower than uncatalysed carbon. Resultant gas compositions differed as follows: uncatalysed carbon produced predominantly $\mathrm{CO}_{2}$ with very small percentages of $\mathrm{H}_{2}$ for $\mathrm{T} \leq 700^{\circ} \mathrm{C}$, while the carbon catalysed with $\mathrm{Na}-\mathrm{Ca}-\mathrm{I}$ produced substantial amounts ( $>54 \%$ ) of $\mathrm{H}_{2}$ for al1 temperatures studied $\left(600 \leq \mathrm{T},{ }^{\circ} \mathrm{C} \leq 750\right)$. The gas composition of $\mathrm{Na}_{2} \mathrm{CO}_{3}$-catalysed carbon was found to be insensitive to loadings for values between 2 and $5 w t \%$, but the carbon conversion increased dramaticality over this range.

The authors of Ref. 6 studied the effects of temperature, pressure, gasifying agent, and catalyst-loading levels on $\mathrm{K}_{2} \mathrm{CO}_{3}$-catalysed gasification of a low-ash char. Experimental conditions included pressures between 2 and 40 bar, temperatures between 650 and $750^{\circ} \mathrm{C}$, and loadings of either 4 or 10 wt\%. Gasifying agents were either steam or $\mathrm{CO}_{2}$. Gasification rates were always higher with higher catalyst loadings. LangmuirHinshelwood kinetics gave a good gasification and different catalyst loadings. Gasification rates increased with pressure up to about 15 bar; thereafter, the gasification rate was independent of pressure. If a single product gas is added to the gasifying agent, a dramatic decrease in gasification rate is known to occur. This effect was demonstrated by adding $\mathrm{H}_{2}$ to the steam in $\mathrm{K}_{2} \mathrm{CO}_{3}$-catalysed gasification, although the magnitude of the rate decrease was not as large as expected. An appropriate correction was made in the kinetic expressions based on these results. Furthermore, an empirical expression relating gasification and conversion rates is given for uncatalysed gasification in the presence of hydrogen.

Thirty-four coals catalysed with $\mathrm{K}_{2} \mathrm{CO}_{3}$ or $\mathrm{Ni}$ were gasified in the experiments described in Ref. 7. The coals ranged from anthracite to peat and gasification was carried out with steam at $750^{\circ} \mathrm{C}$ and $0.06 \mathrm{MPa}$. The catalyst loading was metal/coal $=10 \mathrm{wt} \%$. The conversion of $\mathrm{K}_{2} \mathrm{CO}_{3}$-catalysed coal was always enhanced and the degree of improvement did not appear to depend 
on coal type. However, low-rank coal catalysed with $\mathrm{Ni}$ showed significant enhancement of conversion. Very little improvement was seen for the higher-rank coal with $\mathrm{Ni}$ catalyst. The critical coal characteristic was determined to be an approximate carbon content of $77 \mathrm{wt} \%$ daf. These results were explained in terms of catalyst dispersion. Nickel has excellent dispersion only on low-rank coals, while good dispersion occurs in a steam environment for $\mathrm{K}_{2} \mathrm{CO}_{3}$ and is independent of coal rank. A proposed explanation is that, when $\mathrm{K}_{2} \mathrm{CO}_{3}$ melts, a liquid film is formed or else the $\mathrm{K}_{2} \mathrm{CO}_{3}$ decomposes to form $\mathrm{KOC}$, which is dispersed on the carbon surface.

The catalytic mechanisms involving the influence of alkali carbonates on coal gasification were determined in Ref. 8 by studying the effects of alkalis on oxygen-transfer mechanisms in the reaction $\mathrm{C}+\mathrm{CO}_{2} \longrightarrow 2 \mathrm{CO}$. For the same metal/carbon ratios, catalyst-gasification activity was ordered as follows: $\mathrm{Cs}>\mathrm{K}>\mathrm{Na}$. This order also applies to catalyst saturation. where saturation is defined as the metal/carbon ratio above which no further improvement in gasification rate occurs. The difference in reactivity between $\mathrm{K}$ and $\mathrm{Na}$ (possibly also $\mathrm{Cs}$ ) was explained by postulating the presence of a different number of active species. Oxygen-exchange mechanisms are believed to involve the following reactions:

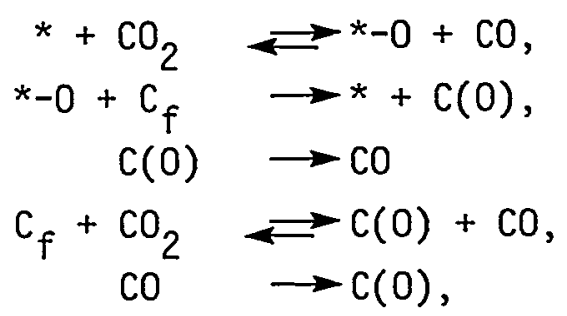

where $C_{f}$ is fuel carbon and the asterisk denotes an active site on the catalyst.

7.1-3. Catalytic Conversions at Reduced Temperatures ${ }^{9}$ *

Most of the catalytic conversions discussed in Refs. 1-8 were performed at temperatures between 800 and $900^{\circ} \mathrm{C}$. It is clearly desirable to

* The authors are greatiy indebted to $H$. Heinemann of the Lawrence Berkeley Laboratory for required information to prepare this section, for helpful advice, and for correcting errors in the final manuscript. 
search for catalysts that are effective at reduced $T$ and $p$ because of the associated cost reductions for capital equipment and operations. It is shown in Ref. 9 that this desirable objective is met when $\mathrm{KOH}$ is combined with mixtures of transition-metal oxides.

Preliminary studies have indicated that small amounts of $\mathrm{CH}_{4}$ could be produced at very low temperatures in the presence of $\mathrm{KOH}$-impregnated graphite subjected to a steam atmosphere. The rate of methane production as a function of time is shown in Fig. 7.1-1; an initially high rate of production followed by a slower rate has been attributed to agglomeration leading to large globules of $\mathrm{KOH}$ crystals. Results similar to those of Fig. 7.1-1 were observed for the alkali hydroxides $\mathrm{CsOH}, \mathrm{NaOH}$, and $\mathrm{LiOH}$.

In similar experiments, graphite impregnated with $\mathrm{KOH}$ was gasified with steam at $T=525^{\circ} \mathrm{C}$. The resultant rate of gas production is shown in Fig. 7.1-2 and shows features similar to those in Fig. 7.1-1. Essentially the only gas produced in the portion of the curve labeled region I was $\mathrm{H}_{2}$, while $\mathrm{H}_{2}$ and small amounts of $\mathrm{CO}$ were produced in region II. The abrupt change in gas-production rate at $\sim 2.5 \mathrm{hr}$ is caused by completion of the stoichiometric reaction:

$$
2 \mathrm{C}+2 \mathrm{KOH} \rightarrow 2 \mathrm{COK}+\mathrm{H}_{2}
$$

After all of the $\mathrm{KOH}$ has been converted, the production of $\mathrm{H}_{2}$ ceases. However, by raising the temperatures to $\sim 1000^{\circ} \mathrm{C}$, it is possible ta decompose the phenolate with water, thus recovering the $\mathrm{KOH}$ according to the process:

$$
2 \mathrm{COK}+\mathrm{H}_{2} \mathrm{O} \rightarrow \mathrm{C}+2 \mathrm{KOH}+\mathrm{CO} \text {. }
$$

This newly formed $\mathrm{KOH}$ is available to produce more $\mathrm{H}_{2}$ according to reaction $(7.1-1)$. It follows, therefore, that an effective conversion catalyst can catalyze reaction (7.1-2). The overall process for reactions (7.1-1) and $(7.1-2)$ is:

$$
\mathrm{C}+\mathrm{H}_{2} \mathrm{O} \rightarrow \mathrm{CO}+\mathrm{H}_{2}
$$

It was found ${ }^{9}$ that incorporation of a transition-metal oxide accelerates completion of reaction (7.1-2) and thus acts as a gasification 
catalyst. The overall process of reaction (7.1-2) has been described by the following two sequential reactions:

$$
\begin{aligned}
2 \mathrm{COK} \stackrel{\mathrm{MeOx}}{\longrightarrow} \mathrm{K}_{2} \mathrm{O}+\mathrm{C}+\mathrm{CO}, \\
\mathrm{K}_{2}+\mathrm{H}_{2} \mathrm{O} \stackrel{\longrightarrow}{\longrightarrow} 2 \mathrm{KOH}
\end{aligned}
$$

Conversions catalyzed by this process are illustrated in Fig. 7.1-3, which shows substantially enhanced gas-production rates at $T \geq 600^{\circ} \mathrm{C}$ for the graphite- $\mathrm{KOH}-\mathrm{Fe}_{2} \mathrm{O}_{3}$ system. Figure 7.1-4 shows a comparison of various transition-metal oxides and indicates that $\mathrm{NiO}$ is the most effective oxide.

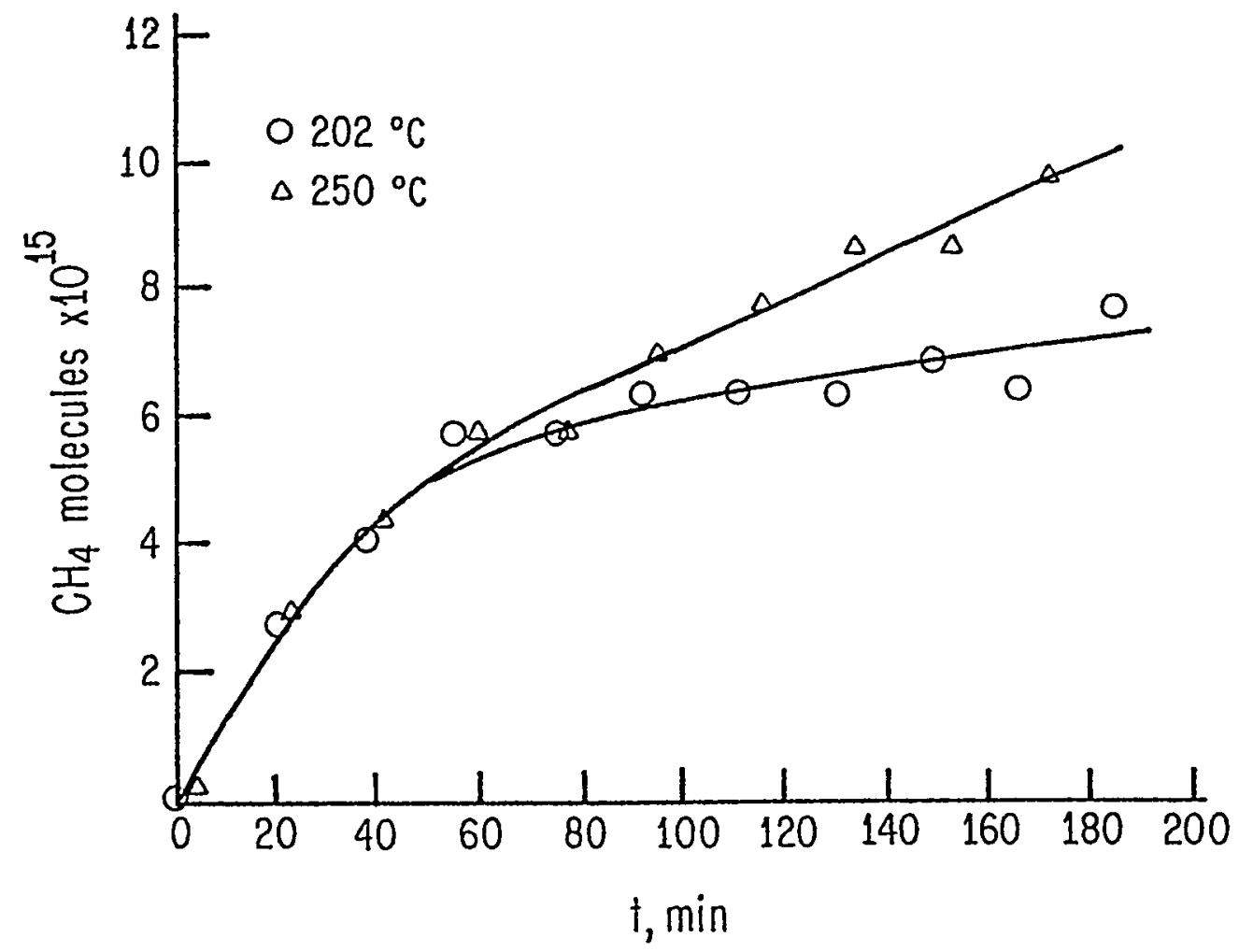

Fig. 7.1-1. Methane production at low temperatures is shown for the $\mathrm{KOH}$-catalyzed steam gasification of graphite; reproduced from Ref. 9. 


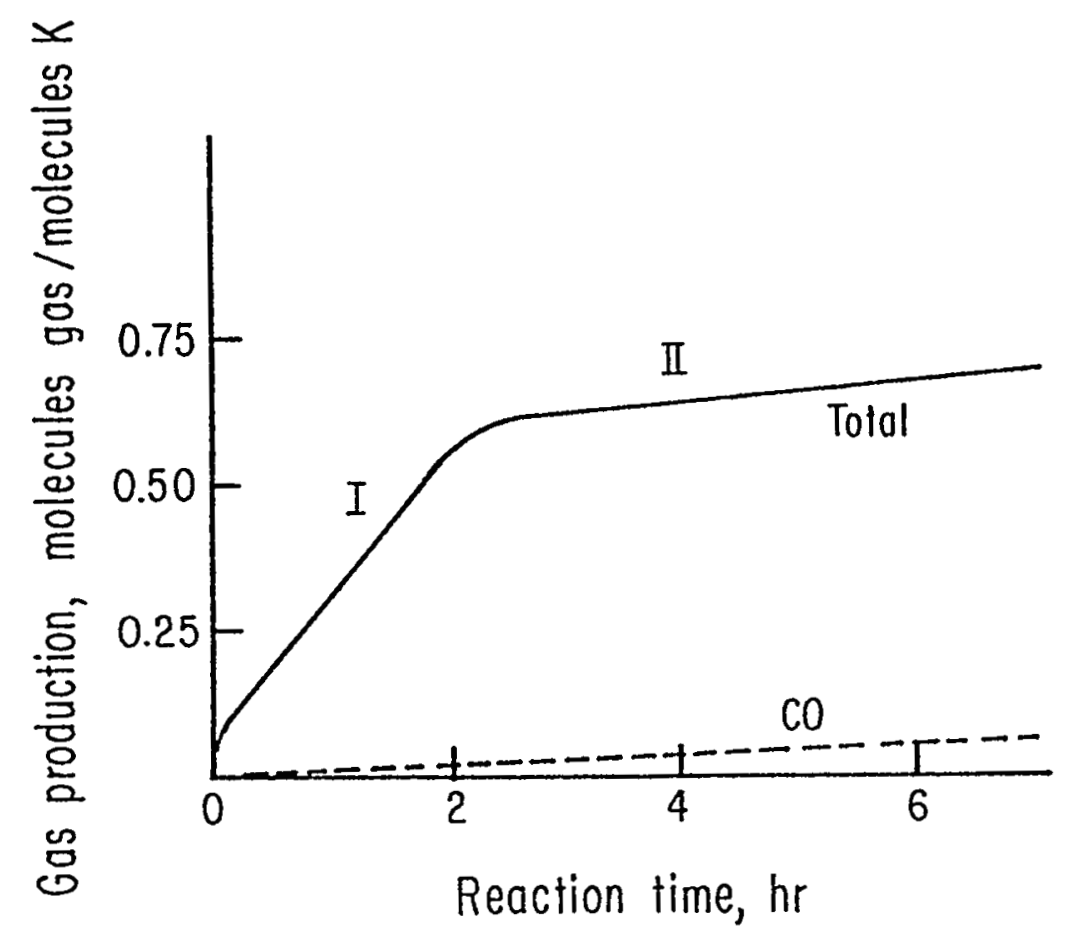

Fig. 7.1-2. The gas-production rate for $\mathrm{KOH}$-catalyzed gasification of graphite; $\mathrm{T}=525^{\circ} \mathrm{C},(\mathrm{KOH}) /(\mathrm{C})=0.043$. Roman numerals $\mathrm{I}$ and II refer to regimes before and after completion of the stoichiometric reaction $2 \mathrm{C}+2 \mathrm{KOH}+2 \mathrm{COK}+\mathrm{H}_{2}$; reproduced from Ref. 9.

Gas-production rates for $\mathrm{NiO}, \mathrm{KOH}$, and $\mathrm{KOH}$ and $\mathrm{NiO}$ used together are shown in Fig. 7.1-5 as a function of time. The characteristic rates for $\mathrm{KOH}$ used alone (compare Fig. 7.1-5 with Figs. 7.1-1 and 7.1-2) are not observed with $\mathrm{KOH}-\mathrm{NiO}$ mixtures, and the $\mathrm{KOH}-\mathrm{NiO}$ system is far more effective than $\mathrm{KOH}$ used alone. The high initial rate observed with $\mathrm{NiO}$ is consistent with the results of previous studies: the almost immediate loss of effectiveness is explained by the coating of $\mathrm{Ni}$ with $\mathrm{C}$. The $\mathrm{KOH}-\mathrm{NiO}$ system is superior to the $\mathrm{K}_{2} \mathrm{CO}_{3}$ system, as is illustrated in Fig. 7.1-6 which applies to Montana subbituminous coal.

Figure 7.1-7 shows XPS diagrams for $\mathrm{Ni}$ spectra and for $\mathrm{Ni}-\mathrm{KOH}$ on graphite. These indicate that $\mathrm{Ni}$ deposited alone on graphite is not stable to at least $700^{\circ} \mathrm{C}$. Similar XPS data, summarized in Fig. 7.1-8, indicate that $\mathrm{KOH}$ alone is not stable in the presence of water above $550^{\circ} \mathrm{C}$, whereas it retains considerable stability in the presence of $\mathrm{NiO}$ for $\mathrm{T} \geq 700^{\circ} \mathrm{C}$. These results suggest the formation of a compound between $\mathrm{K}$ and $\mathrm{Ni}$ oxides, 


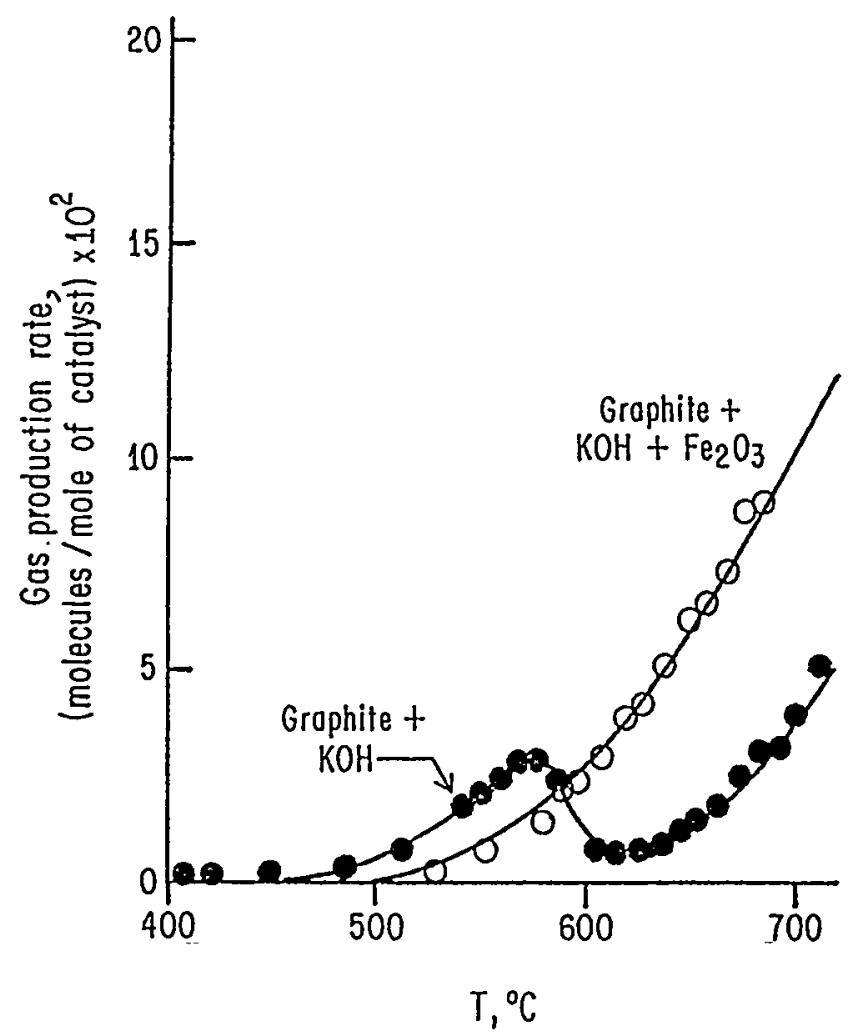

Fig. 7.1-3. Gas-production rates of the $\mathrm{KOH}$ - and $\mathrm{Fe}_{2} \mathrm{O}_{3}$-catalyzed gasification of graphite; reproduced from Ref. 9.

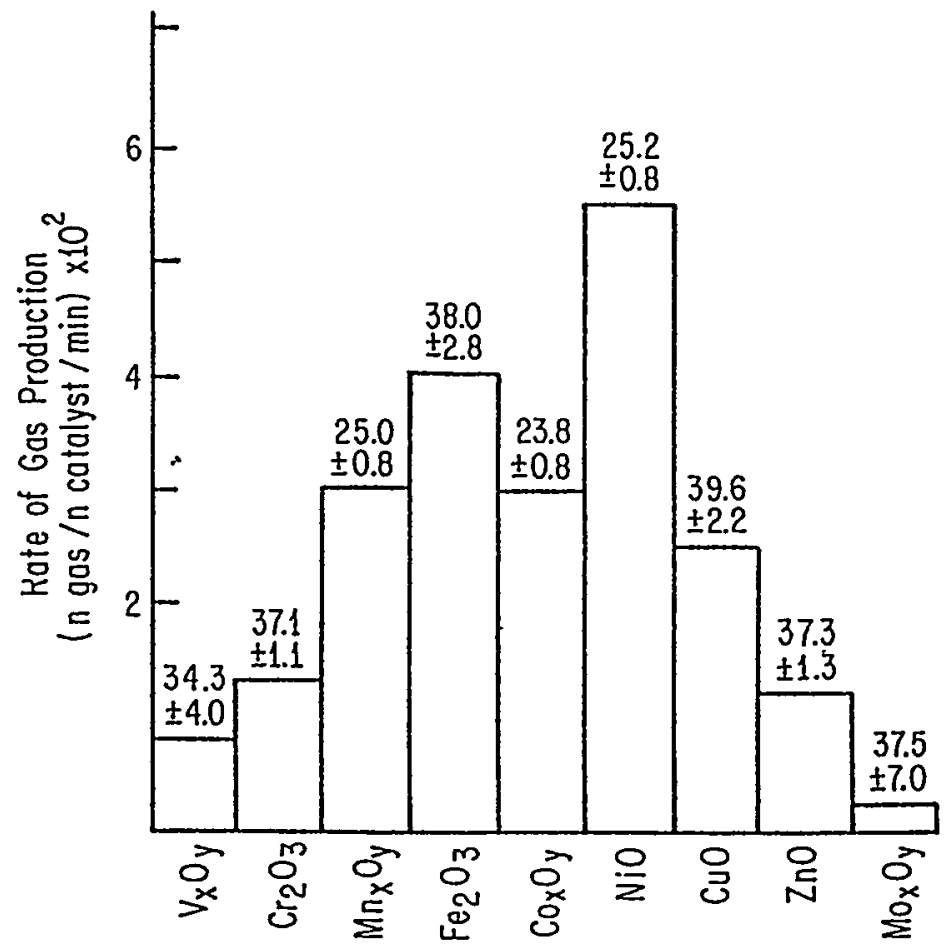

FLg. 7.1-4. Performance of various metal oxides mixed with Koll; (metal oxide $) /(\mathrm{KOH})=1 ;(\mathrm{KOH}) /(\mathrm{C})-0.04 ; \mathrm{T}-625^{\circ} \mathrm{C}$; reproduced from Ref. 9. The numbers refer to the activation energies in kcal/ mole of the indicated metal-oxide-KOH catalyzed system. 


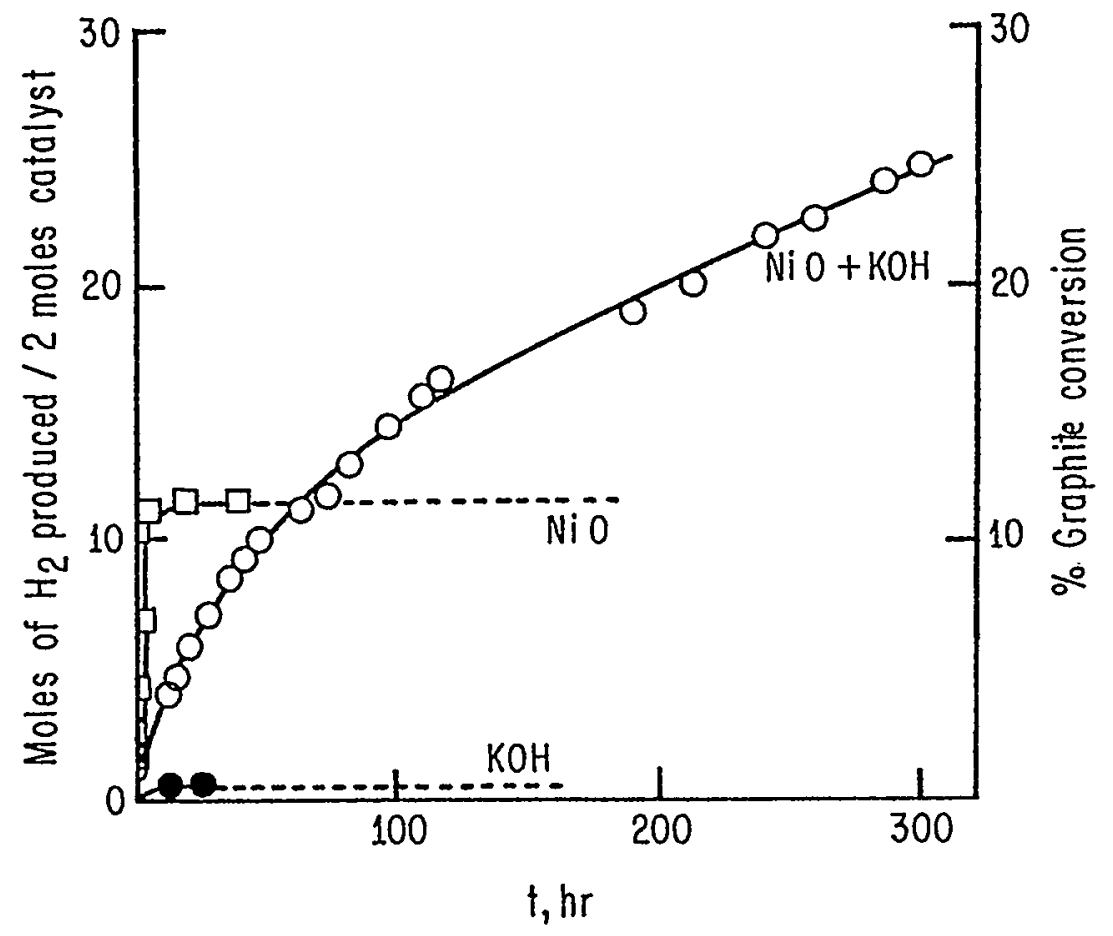

Fig. 7.1-5. Hydrogen production from graphite for the indicated catalysts at $\mathrm{T}=527^{\circ} \mathrm{C}$; reproduced from Ref. 9 .

which is much more stable and is a more effective catalyst than either component alone. Recent work at LBL, performed in collaboration with workers at Exxon, has shown by electron microscopy in an environmentally controlled chamber that the mixed catalyst proceeds during gasification by edge recession at relatively good rates, while either component alone proceeds at lower rates by tunneling. The latter effect is illustrated in Fig. 7.1-9.

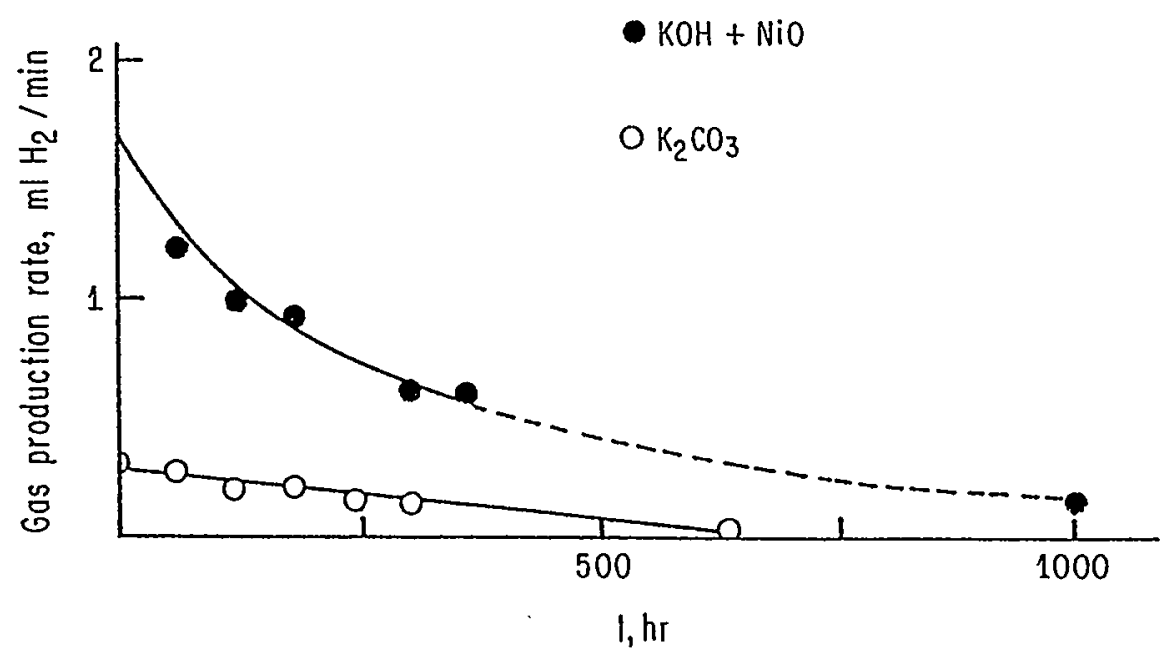

Fig. 7.1-6. Gas-production rates for Montana subbituminous coal using $\mathrm{K}_{2} \mathrm{CO}_{3-}$, $\mathrm{KOH}-$, and $\mathrm{NiO}$-catalyzed gasification; $(\mathrm{K}) /(\mathrm{C})-0.01$; $(\mathrm{K}) /(\mathrm{Ni})=1.0, \mathrm{~T}-620^{\circ} \mathrm{C}$; reproduced from Ref. 9 . 
(a)

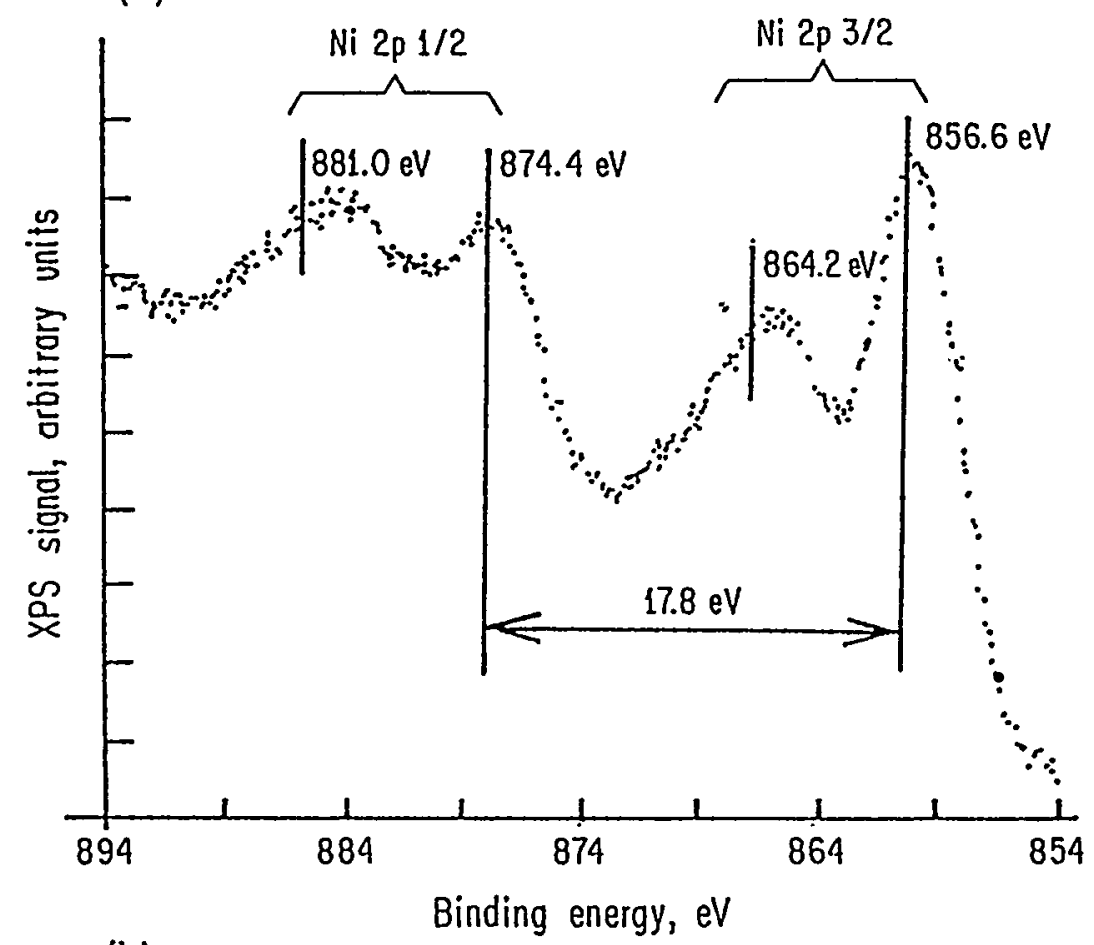

(b)

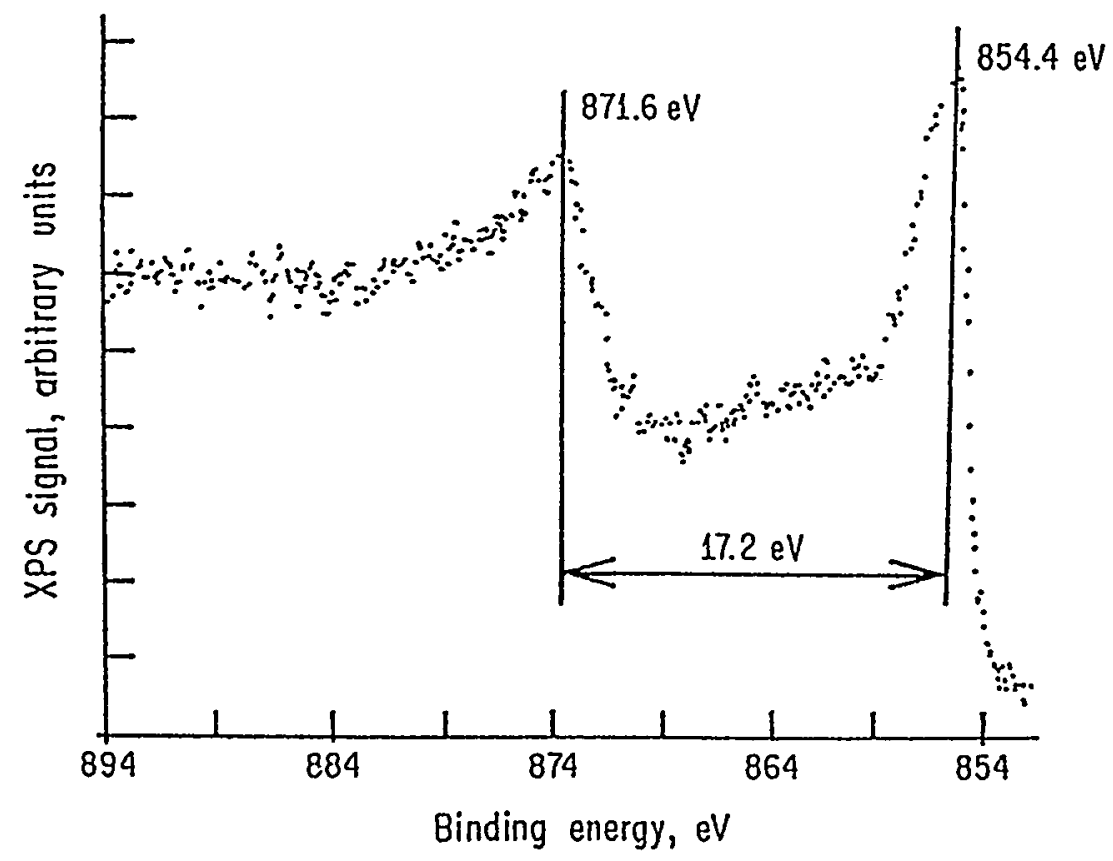

Fig. 7.1-7. The XPS diagrams for (a) $\mathrm{NI}$ and (b) $\mathrm{NI}$ and $\mathrm{KOH}$; reproduced from Ref, 9 . 


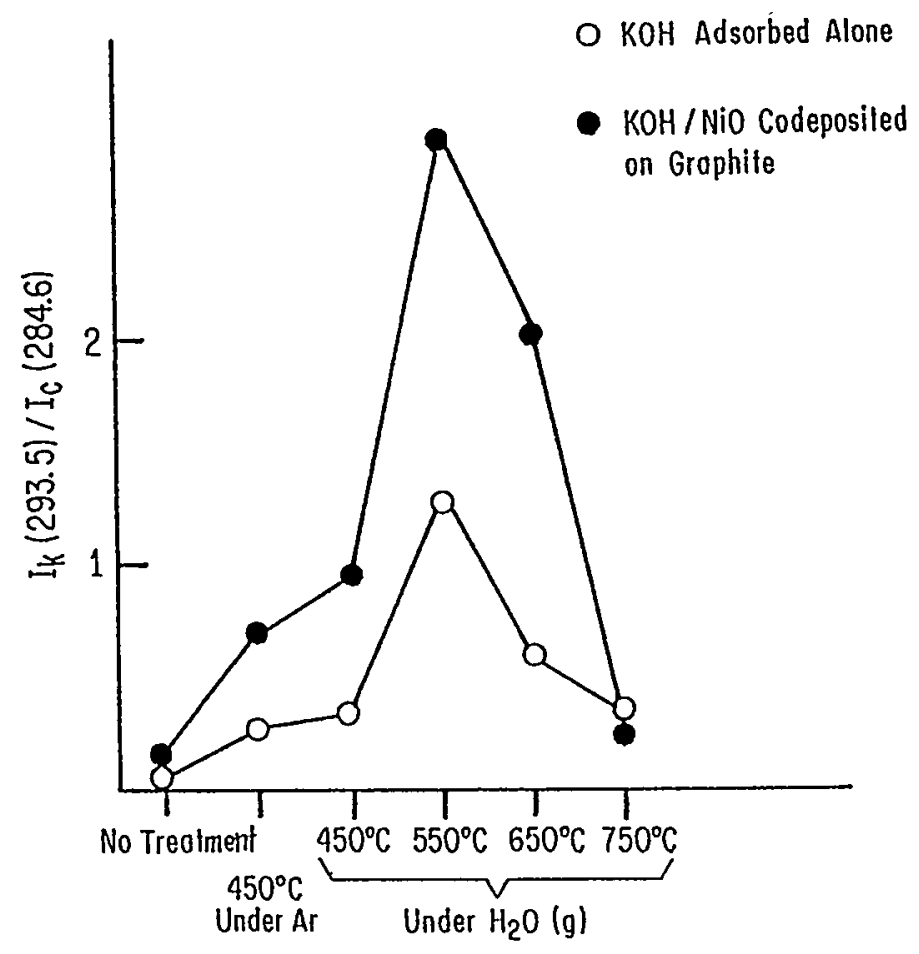

Fig. 7.1-8. The reciprocal binding energy, in terms of the ratio of the intensity at $\lambda=293.5 \mathrm{~nm}$ to the intensity at $\lambda=284.6 \mathrm{~nm}$, is plotted as a function of temperature and in the presence of steam; reproduced from Ref. 9.

(a)

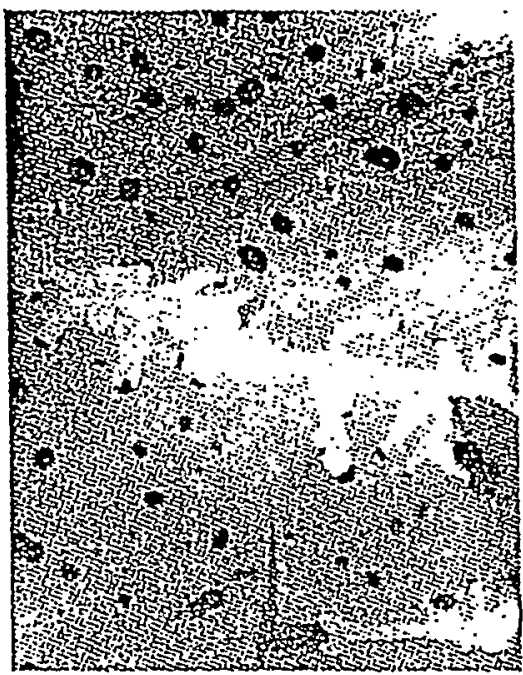

(b)

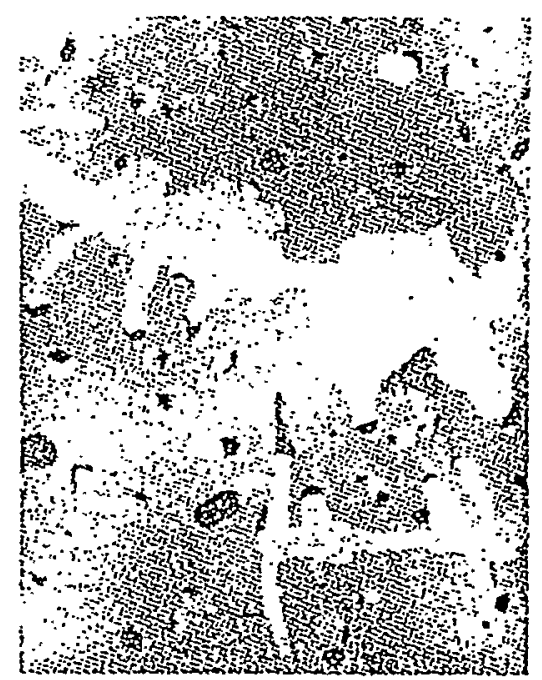

Fig. 7.1-9, Electron inicrographs of KOH-catalyzed graphite; reproduced from Ref. 10; (b) was taken 11 min after (a) and shows tunneling effects induced by the catalyst. 
References for Section 7.1

1. V. V. S. Revankar, A. N. Gokarn and L. K. Doraiswamy, "Catalytic Gasification of Carbon by Steam - Effect of Sodium Salts," Proceedings of the 1985 International Conference on Coal Science, pp. 249-252, Pergamon Press, NY (1985).

2. P. S. Kokorotsikos, G. G. Stavropoulos and G. P. Sakellaropoulos, "Catalytic Gasification of Greek Lignites," pp. 253-256 in Ref. 1.

3. Y. Nishiyama and T. Haga, "Peculiarity in Catalytic Gasification of an Australian Coal," pp. 257-260 in Ref. 1.

4. K. J. Hüttinger and R. Minges, "New Technical Perspectives for Catalytic Coal Gasification by Improving Activation of Low-Cost Catalyst Raw Materia1s," pp. 261-265 in Ref. 1.

5. M. $-Z$. Wei, X. -Q. Bani and K. -Q. Huang, "Effect of Several Compound Catalysts on Steam Gasification of Carbon," pp. 266-268 in Ref. 1.

6. W. Schumacher, H. J. Mühlen, K. H. van Heek, and H.Jüntgen, "Influence of Temperature, Pressure and Gasifying Agent on the $\mathrm{K}_{2} \mathrm{CO}_{3}$-Catalyzed Gasification of Char," pp. 269-272 in Ref. 1.

7. T. Takarada, Y. Tamai, and A. Tomita, "Effectiveness of $\mathrm{K}_{2} \mathrm{CO}_{3}$ and $\mathrm{Ni}$ Catalysts on the Steam Gasification of Thirty-Four Coals," pp. 273-276 in Ref. 1.

8. M. B. Cerfontain, R. Meijer and J. A. Moulijn, "The Difference in Reactivity of the Alkali Carbonates for the Catalyzed Carbon Gasification Interpreted with Transient Kinetic Measurements," pp. 277-280 in Ref. 1.

9. H. Heinemann, "Steam Gasification at Relatively Low Temperatures," unpublished, Lawrence Berkeley Laboratory, CA, and "Fundamental Research at UCB," pp. 309-336, Report of the Second Technical Meeting of COGARN, Feb. 25, 1986.

10. H. Heinemann and G. A. Somorjai, "Mechanism of the Catalytic Gasification and Reactivity of Graphite," pp. 401-410 in Chemical

Reactions in Organic and Inorganic Constrained Systems, R. Setton, ed., D. Reidel Publishing Co., Hingham, MA (1986). 


\subsection{The Exxon Process for Catalytic Coal Gasification *}

The Exxon Process is based on the long-known ${ }^{1}$ discovery that potassium salts promote the gasification of coal. A single reactor process, called the Catalytic Coal Gasification (CCG) reactor, was developed at Exxon to gasify coal at a temperature of $\sim 700^{\circ} \mathrm{C}$.

\section{2-1. Process Features}

In the reaction of $\mathrm{H}_{2}$ with $\mathrm{CO}$, low temperatures strongly favor equilibrium production of $\mathrm{CH}_{4}$ (Fig. 7.2-1). However, the gasification of coal, which must take place earlier than this methanation reaction in order to produce $\mathrm{CO}$ and $\mathrm{H}_{2}$, occurs slowly at these lower temperatures $\left(T \leq 900^{\circ} \mathrm{C}\right)$.

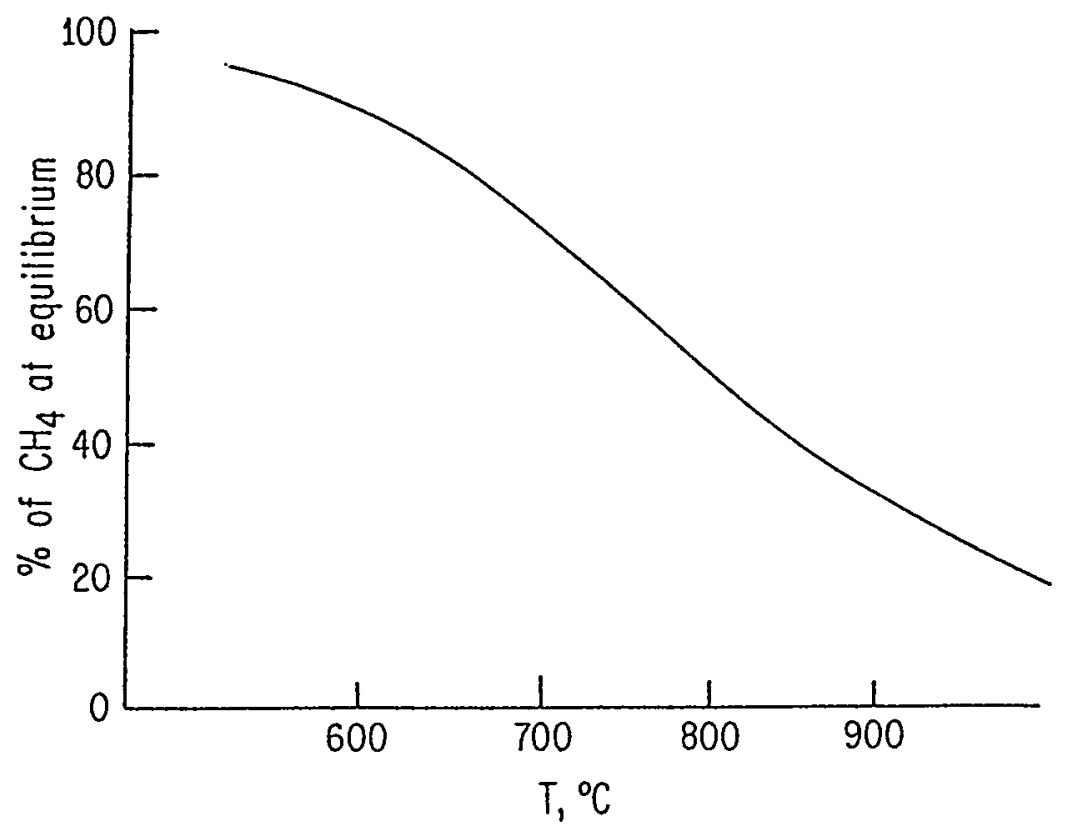

Fig. 7.2-1. Equilibrium conversion to methane according to the reaction $3 \mathrm{H}_{2}+\mathrm{CO} \rightleftarrows \mathrm{CH}_{4}+\mathrm{H}_{2} \mathrm{O}$ at $3.5 \mathrm{MPa}$ as a function of temperature; reproduced from Ref. 2 .

* Prepared by S. S. Penner and D. F. Wiesenhahn. The authors are greatly indebted to A. M. Edelman (Exxon) for supplying published information and for helpful advice. 
The role of $\mathrm{K}$, which is used at a level of 10 to $20 \%$ of the dry coal weight, is to accelerate the gasification of coal at lower temperatures. Workers at Exxon discovered that $K$ on coal is a good methanation catalyst. Thus, addition of $\mathrm{K}$ allows both the gasification and the methanation reactions to occur at the same temperature in a single reaction vessel that is sufficiently small to be commercially acceptable. Since the overall coal-to-methane conversion is almost thermoneutral (Fig. 7.2-2), occurrence of both reactions in a single vessel requires

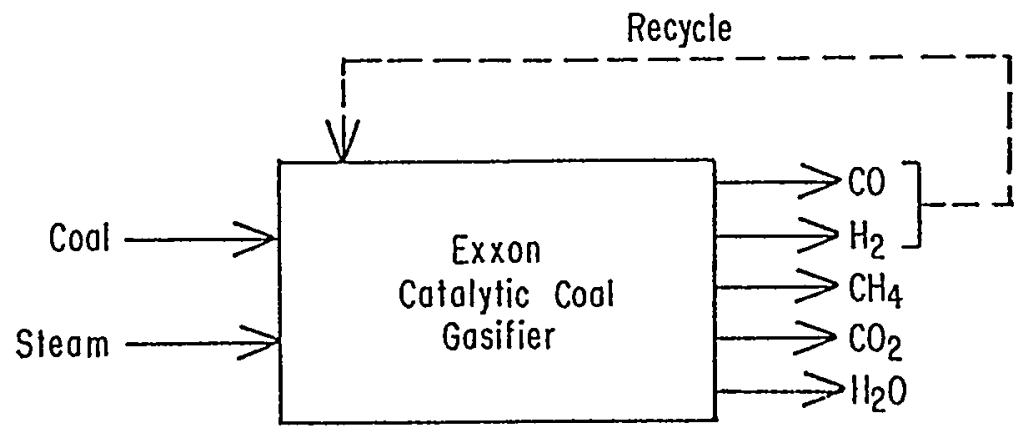

\begin{tabular}{lll} 
Gasification reaction: & $\mathrm{CC}+2 \mathrm{H}_{2} \mathrm{O} \longrightarrow 2 \mathrm{CO}+2 \mathrm{H}_{2}$, & $\Delta \mathrm{H}_{R}=268 \mathrm{~kJ} ;$ \\
Shift conversion: & $\mathrm{CO}+\mathrm{H}_{2} \mathrm{O} \longrightarrow \mathrm{CO}_{2}+\mathrm{H}_{2}$, & $\Delta \mathrm{H}_{\mathrm{R}}=-34 \mathrm{~kJ} ;$ \\
Methanation: & $\mathrm{CO}+3 \mathrm{H}_{2} \longrightarrow \mathrm{CH}_{4}+\mathrm{H}_{2} \mathrm{O}$, & $\Delta \mathrm{H}_{\mathrm{R}}=-226 \mathrm{~kJ} ;$ \\
\hline Overall reaction: & $2 \mathrm{C}+2 \mathrm{H}_{2} \mathrm{O} \longrightarrow \mathrm{CH}_{4}+\mathrm{CO}_{2}$, & $\Delta \mathrm{H}_{R}=8 \mathrm{~kJ}$.
\end{tabular}

Fig. 7.2-2. Diagram showing the overall reactions occurring in the Exxon CCG. ${ }^{2}$

a very small heat input. This small energy deficit is made up by addition of steam and by recycling the $\mathrm{CO}$ and $\mathrm{H}_{2}$ of the product gas.

A schematic diagram of the plant design is shown in Fig. 7.2-3. As received coal is crushed (1) to $<2.4-\mathrm{mm}$ size, partially dried, mixed with aqueous catalyst solution, dried again to about $4 \%$ moisture (2), and fed to the gasifier through a lock hopper (3); for some caking and swelling coals, the last drying step 2 incorporates mild oxidation to reduce swe11- 


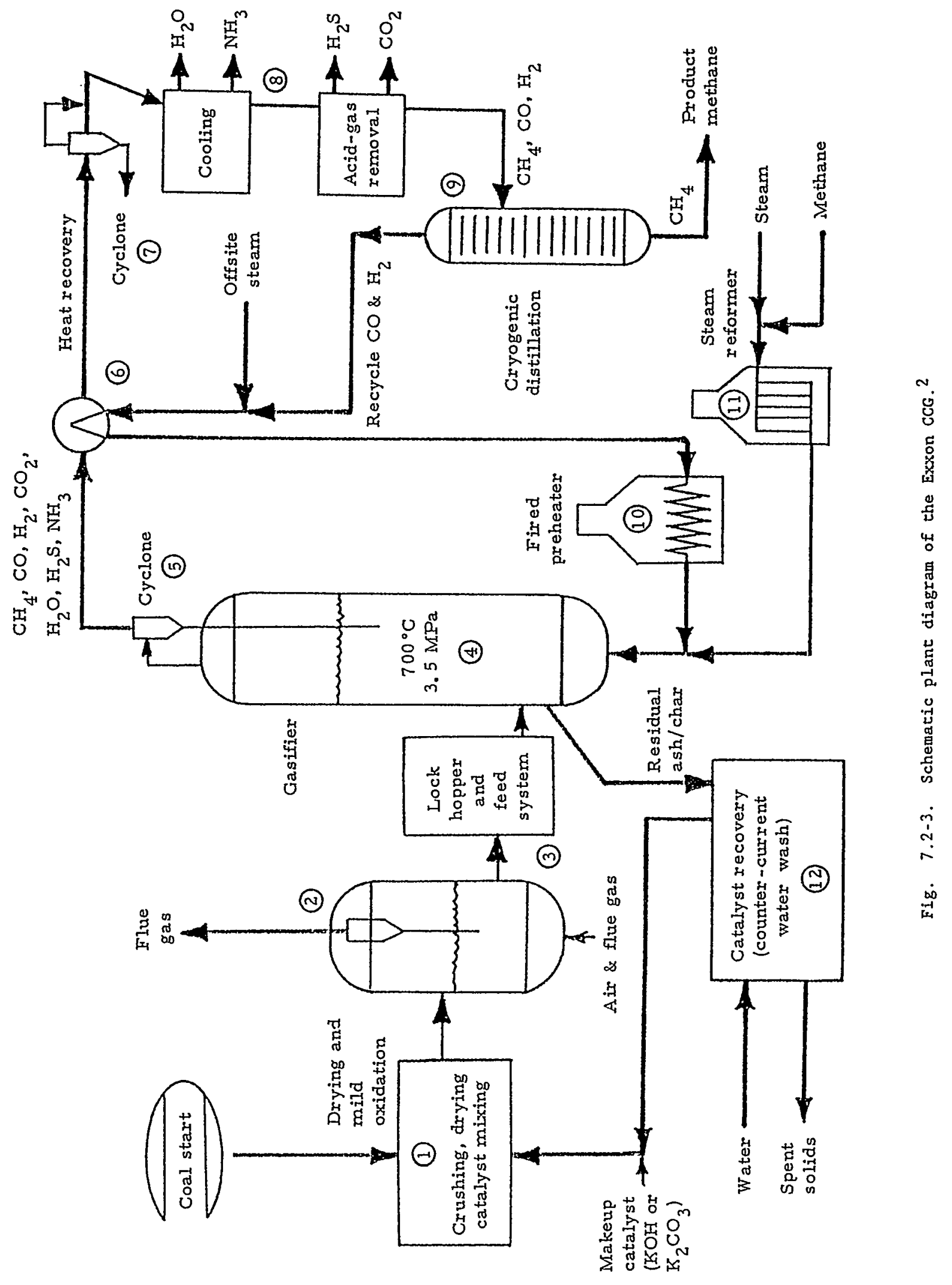


ing in the gasifier. The gasifier (4) operates at $700^{\circ} \mathrm{C}$ and $3.5 \mathrm{MPa}$. A cyclone (5) is used to return entrained fines from the effluent gases to the gasifier. After high-level heat recovery (6), the remaining fines are removed by cyclones and a venturi scrubber (7) before the unconverted steam is separated and cooling and acid-gas removal (with commercially available technology) occurs. The methane is separated from the product stream of $\mathrm{CH}_{4}$, $\mathrm{CO}$, and $\mathrm{H}_{2}$ by cryogenic distillation (9), while $\mathrm{CO}$ and $\mathrm{H}_{2}$ are recycled to the gasifier after heat recovery in (6) and additional preheating in (10). The output gases are thus $\mathrm{CO}_{2}, \mathrm{CH}_{4}, \mathrm{H}_{2} \mathrm{O}$ and small amounts of $\mathrm{NH}_{3}$ and $\mathrm{H}_{2} \mathrm{~S}$. Some of the product methane may be reacted with steam (11) to augment the input of $\mathrm{CO}$ and $\mathrm{H}_{2}$ and to increase the $\mathrm{H}_{2}$-to-CO mole ratio. The catalyst is recovered from the residual ash/char leaving the gasifier by using a counter-current water wash (12) and is then recycled to the catalyst-mixing unit (1).

A portion of the catalyst reacts with the coal ash to form insoluble compounds, primarily potassium aluminum silicates, and cannot be recovered. The extent of catalyst removal depends on coal-ash level and composition. With Illinois No. 6 coal, about $70 \%$ of the catalyst is water-soluble, i.e., about $30 \%$ of the original potassium must be made up (as $\mathrm{KOH}$ or $\mathrm{K}_{2} \mathrm{CO}_{3}$ ).

\section{2-2. Development Work}

Development of CCG technology proceeded with DoE support from bench-scale research ( $<20 \mathrm{~g}$ of coal per test) between July 1976 and January 1978 at a cost of $\$ 2.4 \times 10^{6}$, to pilot-plant testing (25 to $90 \mathrm{~kg} /$ day) between July 1978 and March 1981 with DoE and GRI support at a level of $\$ 6.8 \times 10^{6}$, to a process-development unit (PDU, $1 \mathrm{mt} /$ day) and engineering designs of larger plants. ${ }^{2}$ The automated PDU at Baytown, TX, was complete with all components operational and was sufficiently large for continuous coal feed and product withdrawal. ${ }^{2}$ The gasifier had a $0.25 \mathrm{~m}$ diameter and was $25 \mathrm{~m}$ long. The reactor and feed equipment were contained in a 12-story tower. Following start-up in mid-1979, the PDU was operated intermittently for about 4 years, with a 23-day demonstration run in Apri 1 1981 on Illinois' No. 6 coal. Results are summarized in Table 7.2-1 and 14 material balances (with $5 \%$ closure) were completed for separate $24-\mathrm{hr}$ 
periods. Entrained fines were not recycled in the PDU; recycling would have further improved the carbon conversion. The somewhat low methane yield of $21 \%$ is consistent with the steam/coal ratio used.

In 1982, two bituminous and one subbituminous coal (Wyodak, a U.S. Western coal) were tested, with the bituminous coal simulating the 111 inois No. 6 test results. ${ }^{3-5}$ Coal pretreatment and performance require inprovements. The Wyodak coal performance is summarized in Table 7.2-2. Comparisons of results listed in Tables 7.2-1 and 7.2-2 show that, for comparable test-bed conditions, the Wyodak coal yielded higher bed densities. Furthermore, lower overhead char was obtained presumably because Wyodak coal swells less than Illinois No. 6 coal. The high moisture content of Wyodak is expected to yield good catalyst impregnation. Carbon conversion decreased with increasing coal-feed rate and reduced gasifier-residence time, whereas the overhead entrained char remained essentially constant, i.e., fines production appeared to depend on feed-coal characteristics and not on processing conditions. 2 of particular importance is the strong dependence of methane yield on steam/coal ratio, which was also observed for Illinois No. 6 and is claimed to be predicted from the Exxon gasifier model used for analysis.

In the 25-m long process-development unit for gasification, the bed level during operation reached 15 to $17 \mathrm{~m} .{ }^{5}$ The highly automated PDU had a programmable controller for sequential and cyclic operations, safety interlocks and shutdown, while monitoring $\sim 800$ process variables concurrentIy with off-line data analyses. 5 Following start-up in 1979, the most serious operational problem encountered was agglomerate formation at the bottom of the gasifier at low gasifier fluidized-bed density and low $\mathrm{CH}_{4}$ production. The agglomerates consisted of either (i) black, waterinsoluble, low-conversion coal particles cemented together by hydrocarbons or (ii) light clusters that were disintegrated by water and consisted of ash particles held together by water-soluble $\mathrm{K}_{2} \mathrm{CO}_{3}$. If allowed to persist for several hours, the agglomerates accumulated at the bottom in the presence of steam and formed a plug that interfered with char withdrawal. The agglomerates were ultimately eliminated by increasing the gas velocity in the coal-feed line and thereby prevented fresh coal particles from sticking together. ${ }^{5}$ Successful runs of 20 to 30 days and 5000 operating hours were subsequently accomplished over a period of 2 years. 5 
Table 7.2-1. Results for a 23-day PDU CCG on Illinois No.6 coal at $3.5 \mathrm{MPa}$; reproduced from Ref. 2 .

\begin{tabular}{l|r|c}
\multicolumn{1}{c|}{ Performance Parameter } & Targets & Achieved \\
\hline Coal plus catalyst feed rate, $\mathrm{kg} / \mathrm{hr}$ & 60 & 60 \\
Temperature, ${ }^{\circ} \mathrm{C}$ & 704 & 693 \\
Pressure, $\mathrm{MPa}$ & 3.45 & 3.45 \\
Steam/coal ratio & 1.7 & 1.9 \\
Bed density, kg/m 3 & $>160$ & 256 \\
Carbon conversion, 8 & $>85$ & $85-90$ \\
Steam conversion, 8 & $30-40$ & 35 \\
CH4 in product gas, 8 & $>25$ & 21 \\
Test duration, days & $14-21$ & 23 \\
\hline
\end{tabular}

Table 7.2-2. Results for a 27-day test of CCG for Wyodak coal at $3.5 \mathrm{MPa}$; reproduced from Ref. 2 .

\begin{tabular}{l|r|r|r}
\hline \multirow{2}{*}{ Performance Paramater } & \multicolumn{3}{|c|}{ Coal Plus Catalyst Feed Rate, $\mathrm{kg} / \mathrm{hr}$} \\
\cline { 2 - 4 } & 50 & 59 & 79 \\
\hline & & & \\
Temperature, ${ }^{\circ} \mathrm{C}$ & 692 & 693 & 694 \\
Steam/coal ratio & 2.1 & 1.8 & 1.5 \\
Solids residence time, hrs & 38 & 27 & 14 \\
Bed density, $\mathrm{kg} / \mathrm{m}^{3}$ & 480 & 432 & 320 \\
Entrained char, 8 & 12 & 16 & 13 \\
Carbon conversion, 8 & 92 & 85 & 79 \\
Steam conversion, 8 & 36 & 38 & 33 \\
CH$_{4}$ in product gas, 8 & 16 & 19 & 24 \\
\hline
\end{tabular}


An initially obtained low fluidized-bed density ( 75 to $100 \mathrm{~kg} / \mathrm{m}^{3}$ ) into fine particles leading to excessive fines losses. This problem was ultimately solved by mild oxidative pretreatment in the presence of catalyst in a narrow temperature range (around $200^{\circ} \mathrm{C}$ for some oxygen concentrations), where the coal swelling-index is very low (see Fig. 7.2-4). ${ }^{5}$ During mild oxidation, carboxylic acid groups are added to the coal structure and the number of these added groups is greatest at the optimum temperature. With mild preoxidation, the reduction in fluidized-bed densities from an initial value of $300 \mathrm{~kg} / \mathrm{m}^{3}$ was strongly inhibited. Finally, it was shown ${ }^{5}$ that preoxidation during 4 to 11 hours at 175 to $200^{\circ} \mathrm{C}$ yielded gasifier bed densities of 200 to $450 \mathrm{~kg} / \mathrm{m}^{3}$. At $\sim 5 \%$ incremental cost, a fluidized bed dryer may be used for both drying and preoxidation (cf. Sec. 7.2-3).

Methane production in the PDU is kinetically determined and falls well below the theoretical equilibrium curve as the steam-to-carbon mole ratio is lowered (see Fig. 7.2-5). As is evident from Fig. 7.2-5, about 27\% of $\mathrm{CH}_{4}$ was obtained in the product gas at a steam-to-carbon mole ratio of about 1.7 .

Equilibrium catalyst recycle was not achieved. Instead, a theoretically predicted steady-state recycle catalyst composition was made up and tested. Process results for Illinois No. 6 coal were found to be the same with once-through and simulated recycle catalyst. However, the simulated recycle catalyst was found, in two successive trials, to produce a hole, after 10 days of operation, in the 316 stainless steel (SS) overhead line leading from the gasifier to the cyclones, filters and gas coolers. The cause of pipe failure was hot corrosion caused by molten salt fluxing of protective oxides from the metal surfaces, followed by rapid sulfidation. Bench-scale studies showed that alloys with higher Cr-contents would resist hot corrosion. The test section and results are shown in Fig. 7.2-6. The higher Ni-alloys should provide resistance to caustic stress-corrosion cracking, while 310 SS gave the best results. 


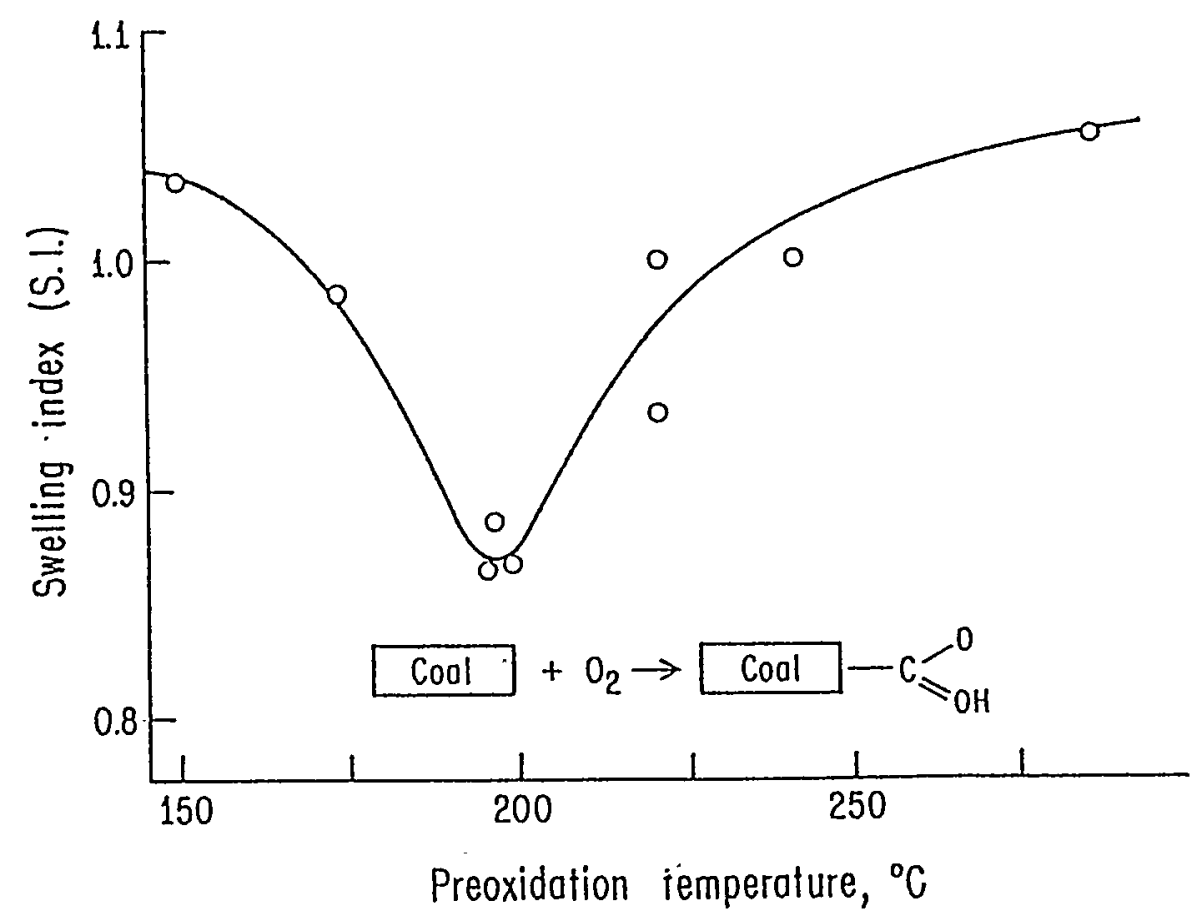

Fig. 7.2-4. The swelling index is shown as a function of coal preoxidation cemperature from a bench-scale experinent with $68 \mathrm{O}_{2}$ in $\mathrm{N}_{2}$ and a $6-\mathrm{hr}$ residence time; the S.I. of unoxidized coal $=1.3$; reproduced from Ref. 5 .

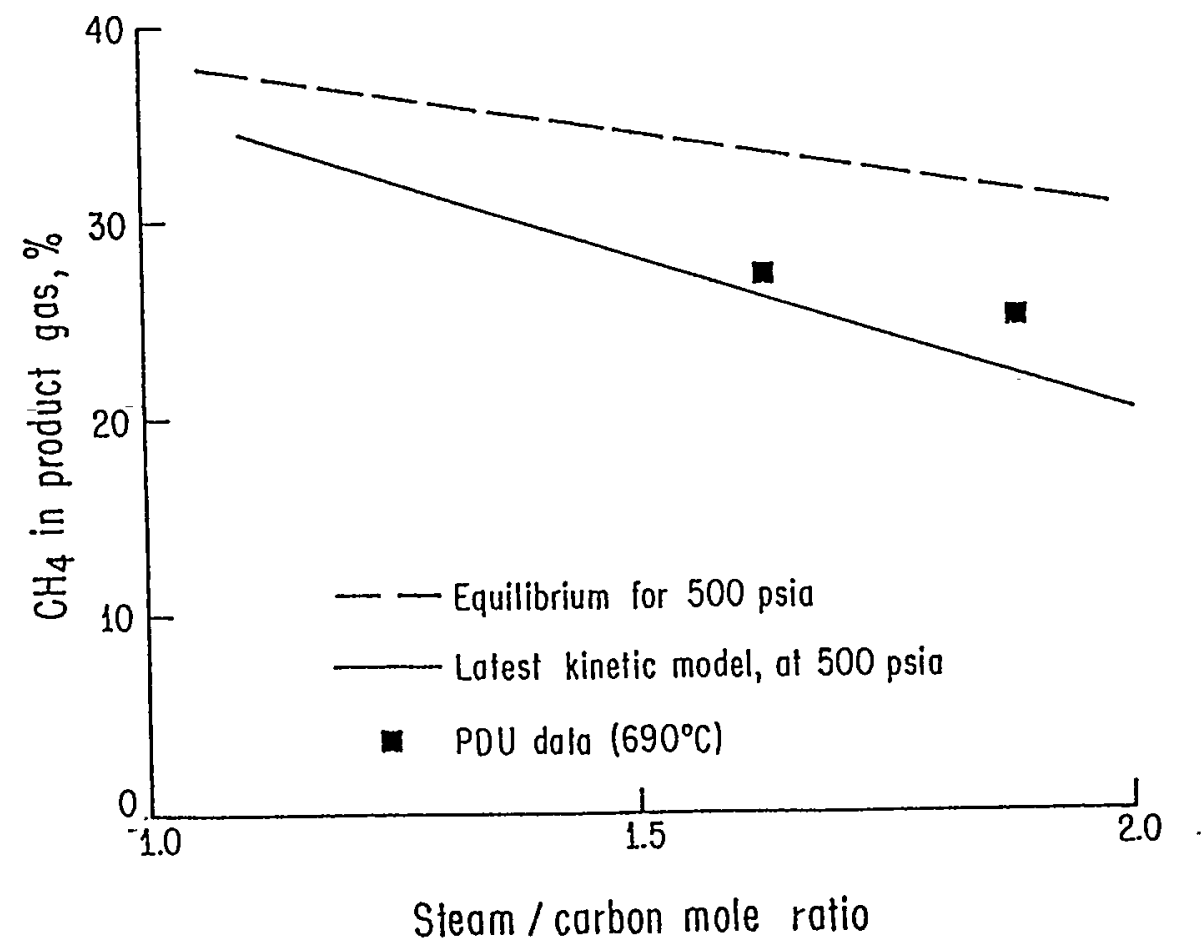

Fig. 7.2-5. The amount of methane in the product gas is shown as a function of the steam/carbon ratio at $3.5 \mathrm{MPa}$ ( $500 \mathrm{psia})$; reproduced from Ref. 5 . 


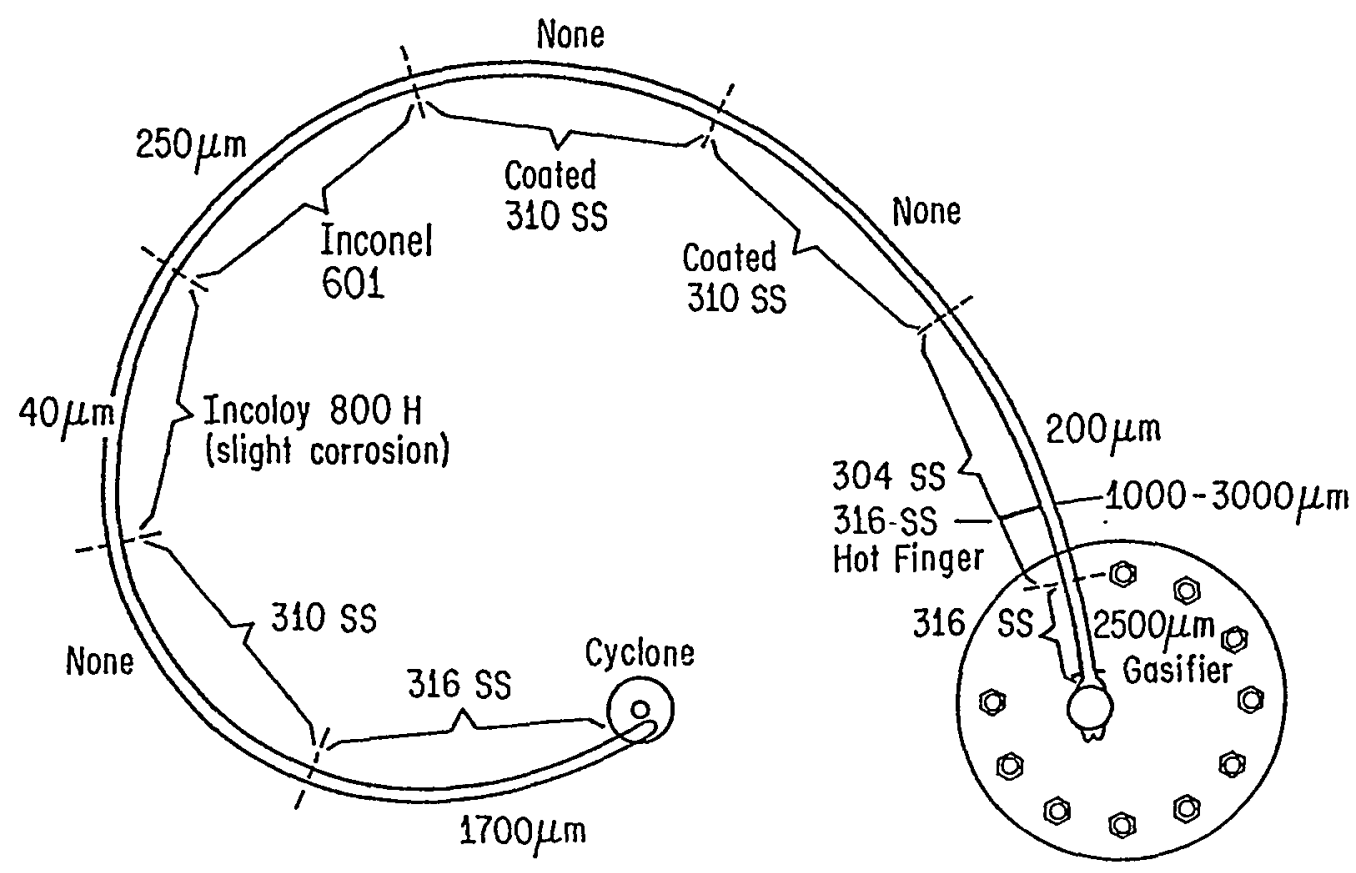

Fig. 7.2-6. Test section used for 9 days in hot-corrosion studies; the 310 SS and the coatings performed well, whereas 316 ss was heavily corroded. The thickness in $\mu \mathrm{m}$ represents approximate corrosion losses; reproduced from Ref. 2.

\section{2-3. Fluid-Bed Slurry Dryer (FBSD)}

The FBSD is used to recapture heat from coal drying (Fig. 7.2-7). Wet catalyzed coal slurry is fed to the unit, which operates at 4MPa and $260-425^{\circ} \mathrm{C}$. Superheated steam is used to fluidize the solids and evaporate water. The steam leaving the dryer is scrubbed to remove entrained coal fines. Some of the steam leaving the scrubbers is compressed, superheated and recycled, while the remainder is fed to the gasifier. The dried coal is transferred to the gasifier in the fluidized state. The FBSD ( $i$ ) recovers energy for coal drying as gasification steam and (ij) produces preheated coal for the gasifier at a higher $T$ than can be fed through the lock-hopper system. A 2-mt/day FBSD was started up in 1983.

\section{2-4. Mechanisms of Catalysis and Selection of Alternative Catalysts}

The rates and reaction mechanisms involving the potassium are not understood. In fact, the label catalyst for $K$ is a misnomer since experimental measurements (see Fig. 7.2-8) of the gasification rate as a function 
of $\mathrm{K} / \mathrm{C}$ mole ratio show the effective rate coefficient to be a linear function of the active $K / C$ ratio, where the rate constant $k$ is defined by the ratio

$$
k=-[\mathrm{d} \ln (\mathrm{C}) / \mathrm{dt}] /\left[\left(\mathrm{H}_{2} \mathrm{O}\right) /\left(\mathrm{H}_{2}\right)\right]
$$

The fact that (compare Fig. 7.2-8)

$$
-d(C) / d t=k(C)\left(H_{2} \mathrm{O}\right) /\left(H_{2}\right) \cong 7.5 \times\left(K_{\text {active }}\right)\left(H_{2} \mathrm{O} /\left(\mathrm{H}_{2}\right)\right.
$$

suggests a complex reaction mechanism with $K$ as an active participant and the possibility of finding alternative chemicals that may be more effective than $K$ in gasification. In Fig. 7.2-8 and in Eq. (7.2-2), (K active) is the total molar $K$ concentration less the molar $K$ concentration bound in ash minerals. The precise form of $C$ is seen to have little effect on gasification activity (compare Fig. 7.2-8). The method of introduction used for $K$ was also found to be unimportant, since substantially equivalent results were obtained for carbon compounds impregnated with aqueous $\mathrm{K}_{2} \mathrm{CO}_{3}$ or $\mathrm{KOH}$ or dry $\mathrm{K}_{2} \mathrm{CO}_{3}$ in powdered form.

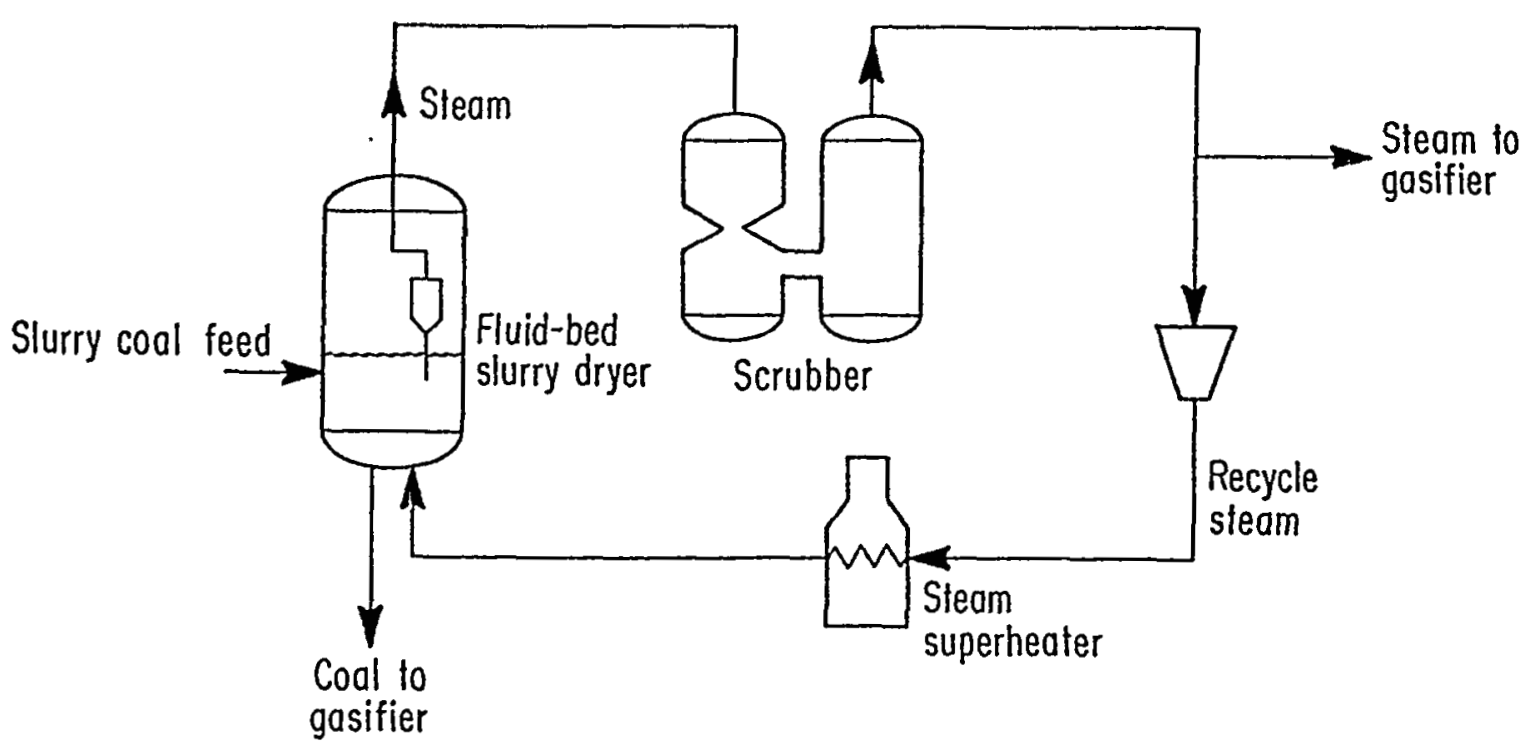

Fig. 7.2-7. Schematic diagram of the FBSD; reproduced from Ref. 2. 


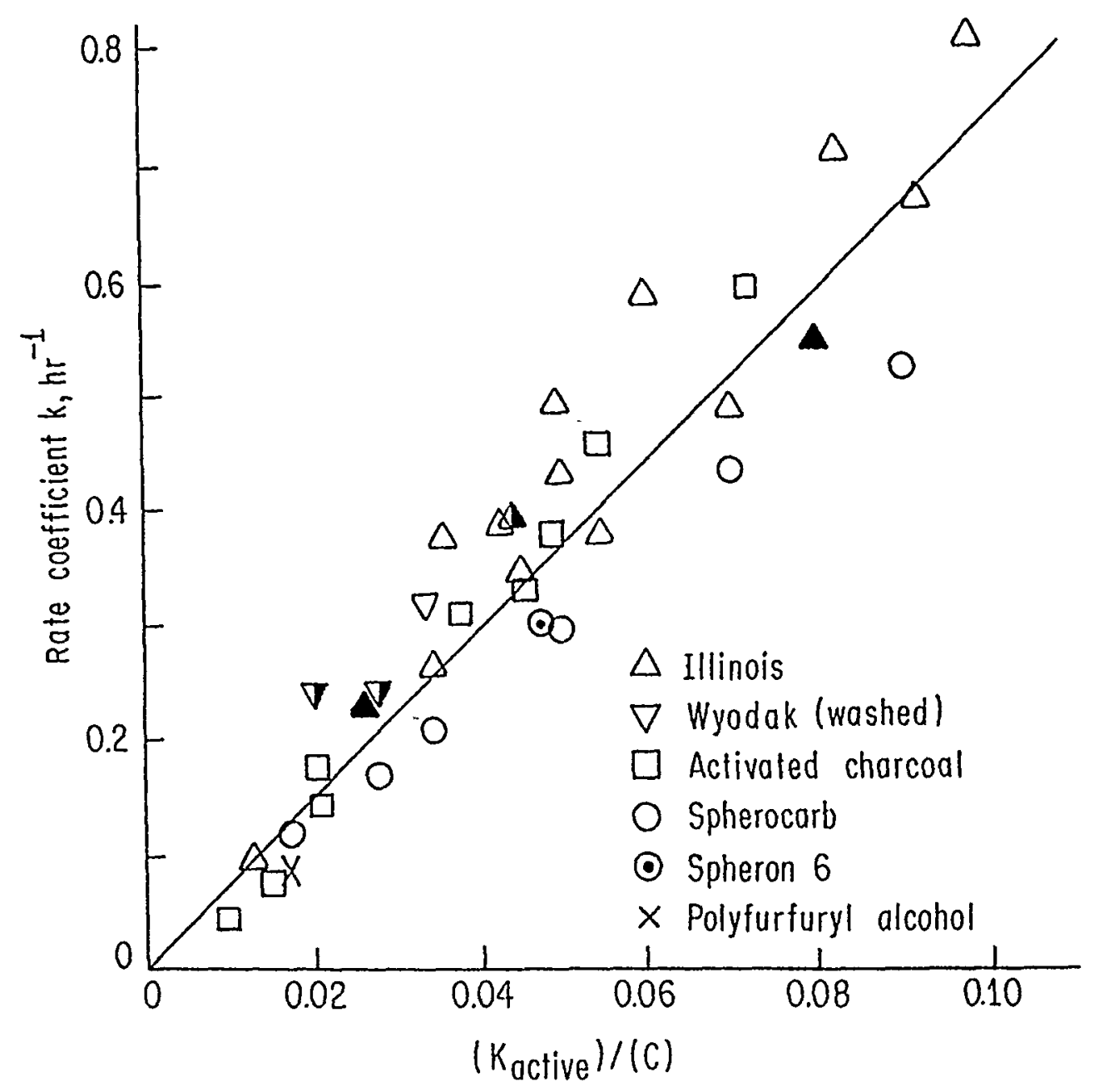

Fig. 7.2-8. The rate coefficient $k$ observed in a small flow reactor as a function of the molar ratio of $k$ to $C$ for a variety of carbonaceous materials at $1 \mathrm{~atm}$; reproduced from Ref. 5. Open symbols refer to $\mathrm{K}$ introduced as aqueous $\mathrm{K}_{2} \mathrm{CO}_{3}$ or $\mathrm{KOH}$, whereas filled-in symbols refer to $\mathrm{K}$ added as dry $\mathrm{K}_{2} \mathrm{CO}_{3}$ powder; the half-open symbols refer to $\mathrm{K}$ introduced by ion-exchange.

The results were interpreted ${ }^{5}$ to show that active sites form on the coal surface by combination of $\mathrm{K}_{2} \mathrm{CO}_{3}$ with char, leading to the release of $\mathrm{CO}_{2}$. This mechanism was verified by $\mathrm{C}-14$ labeling of some of the $\mathrm{C}$ in $\mathrm{K}_{2} \mathrm{CO}_{3}$, which was observed to be released when reacted with coal. Furthermore, X-ray diffraction also showed the disappearance of $\mathrm{K}_{2} \mathrm{CO}_{3}$ as it interacted with the coal. Using isotope tracers, rapid water decomposition and surface oxide formation were observed at the active sites, whereas the rate was inhibited by oxide reduction with $\mathrm{H}_{2}$. The final rate-determining 
step leads to co formation and involves the critical surface oxide. ${ }^{5}$ The following are believed ${ }^{5}$ to be critical reaction steps in the gasification mechanism:

$$
\begin{aligned}
& \text { char }+\mathrm{K}_{2} \mathrm{CO}_{3} \longrightarrow \mathrm{K} \text {-char }+\mathrm{CO}_{2} \quad \text { (complex formation), (7.2-3) } \\
& \mathrm{K} \text {-char }+\mathrm{H}_{2} \mathrm{O} \longrightarrow \mathrm{K}-\text { char }-\mathrm{O}+\mathrm{H}_{2} \quad \text { (water activation), (7.2-4) } \\
& \mathrm{K}-\text { char-O } \longrightarrow \mathrm{K} \text {-char }+\mathrm{CO} \quad \text { (gasification). (7.2-5) }
\end{aligned}
$$

This reaction model was usefully employed in the design of the gasification reactor. 6,4

The observed approach to the equilibrium curve of Fig. 7.2-1, at fixed pressure and catalyst loading, is strongly dependent on T. For $20 w t \%$

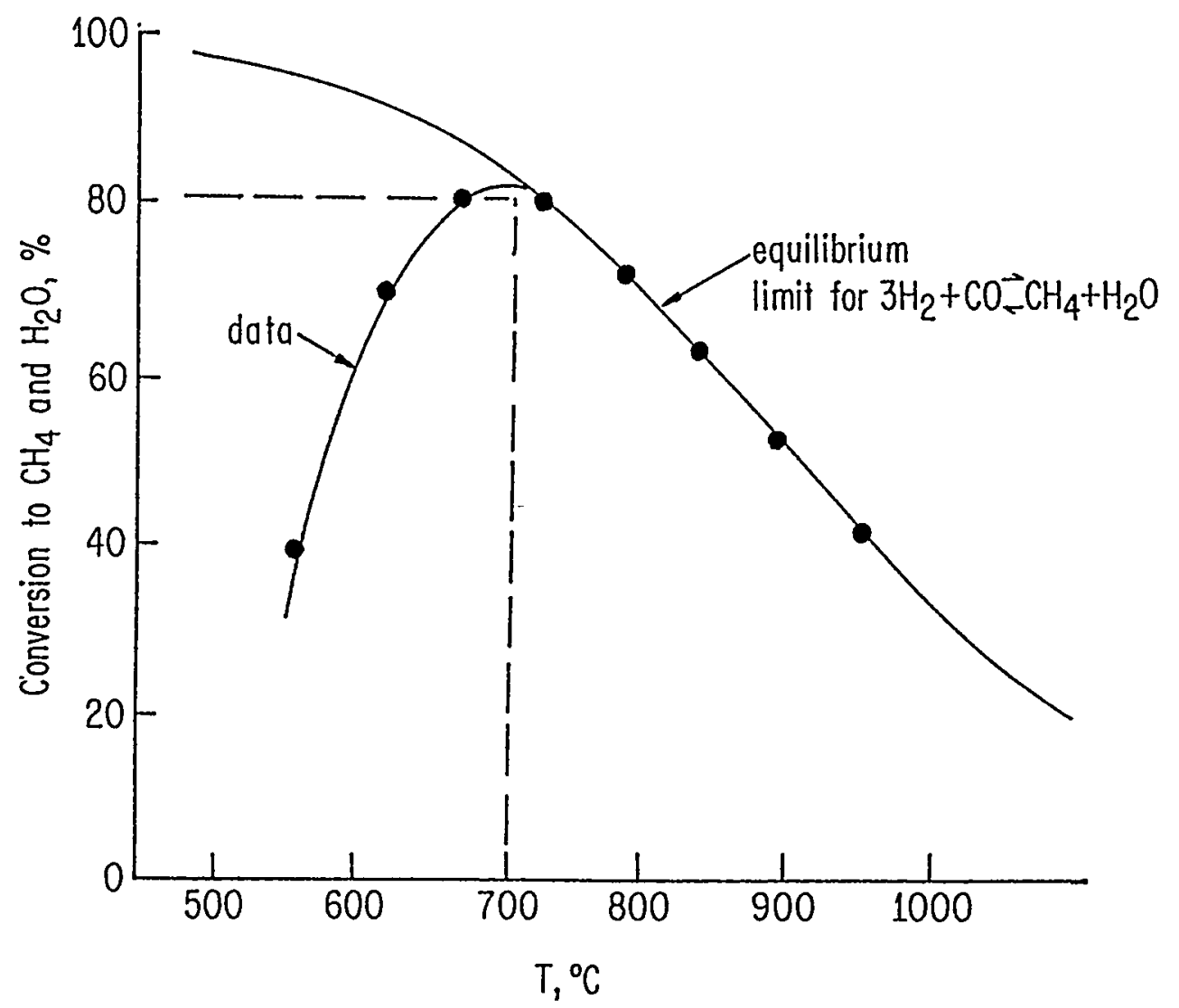

Fig. 7.2-9. Conversion to methane as a function of temperature for 20wts $\mathrm{K}_{2} \mathrm{CO}_{3}, 80 \mathrm{wt}$ char, at $3.5 \mathrm{MPa}$ and a space velocity of 2300 volumes of reactants per hour per volume of gasified bed; reproduced from Ref. 5 . 
$\mathrm{K}_{2} \mathrm{CO}_{3}, 3.5 \mathrm{MPa}$, and a space velocity of 2300 volumes of reactants $/ \mathrm{hr}$ per volume of gasifier bed, the equilibrium composition was observed in experimental studies (see Fig. 7.2-9) down to about $700^{\circ} \mathrm{C}$. Below $T=700^{\circ} \mathrm{C}$, a sharp drop-off in percentage conversion to $\mathrm{CH}_{4}$ occurred from $\sim 82 \%$ at $700^{\circ} \mathrm{C}$ to $\sim 40 \%$ at $540^{\circ} \mathrm{C}$. An ideal catalyst would allow conversion to $\mathrm{CH}_{4}$ to follow the equilibrium curve to substantially lower temperatures $\left(\sim 300=500^{\circ} \mathrm{C}\right)$.

Alternative catalysts should be so inexpensive that catalyst recovery is not necessary and so effective that reduced process temperatures may be used, while the methane content of the product gas is sufficiently high to eliminate the need for cryogenic separation (compare Fig. 7.2-3) and recycle to $\mathrm{CO}$ and $\mathrm{H}_{2}$. A promising candidate for a throw-away catalyst is $\mathrm{Ca}$, which was shown in bench-scale tests on Illinois No. 6 coal to yield nearly the same gasification rates as $\mathrm{K}$ at $700^{\circ} \mathrm{C}$. The requirement of a somewhat higher operating $T$ with $\mathrm{Ca}$ is a detriment. In general, a small reduction in methane yield and the greater difficulty of catalyst impregnation with $\mathrm{Ca}$ must be weighed against elimination of the catalyst-recovery unit and the use of lower cost materials. Hot corrosion and caustic stresses associated with $K$ may also be reduced with $\mathrm{Ca}$.

\section{2-5. Environmental Aspects of CCG}

Applicable environmental standards will be met with CCG, using conventional technology such as a Claus plant to convert $H_{2} S$ to $S_{x}$ and biological oxidation and/or carbon absorption for wastewater treatment. Tar or heavy oil by-products are not produced in normal CCG operation. At 90\% carbon conversion, the wet char, after catalyst recovery, will contain 10-15\% of carbon and 7 to $10 \%$ of $K$ as insoluble salts; for long-term disposal, this material must be processed, e.g., by combustion to remove residual carbon while raising steam and forming stable aggregates.

The char has not shown genetic activity or carcinogenicity in short-term tests; long-term dermal tests remain to be completed. Leaching of toxic material met applicable standards of the US Resources Conservation and Recovery Act for nonhazardous wastes. 
7.2-6. Large Pilot Plant

Long-term process and equipment performance data on a large pilot plant are needed before scale-up to commercial plant sizes. Also needed are results for a variety of coals. Environmentally acceptable performance over a long period of time remains to be demonstrated.

\section{References for Section 7.2}

1. H. S. Taylor and H. A. Neville, JACS $\underline{43}, 2065$ (1921).

2. R. A. Cardello, R. A. Reitz and F. C. R. M. Smits, "Catalytic Coal Gasification Development," Discussion No. 5, 11th World Petroleum Con= gress, London, England (August 1983).

3. R. R. Lessard and R. A. Reitz, "Catalytic Coal Gasification: An Emerging Technology for SNG," presented at the 9th Energy Technology Conference, Washington, D.C. (February 1982).

4. C. A. Euker, Jr., and R. D. Wesselhoft, "Catalytic Coal Gasification-Process Development Unit Operations," presented at the 90th AIChE National Meeting, Houston, TX (Apri1 1981).

5. R. L. Hirsch, J. E. Gallagher, Jr., R. R. Lessard, and R. D. Wesselhoft, Science 215, 121 (1982).

6. J. M. Eakman, R. D. Wesselhoft, J. J. Dunkleman, and D. J. Vadovic, Coal Processing Technology, Vol 6, pp. 146-158, AIChE, New York (1980).

\subsection{Recommended Research for Syngas Production from Coal}

The following items 1 to 6 are viewed as high-priority and item 7 as a possible research area, which would be pursued at Exxon if the project were still active:

1. Definitions of optimal coal-pretreatment conditions for different coals and catalysts.

2. Studies of rates and mechanisms of salts leaching from coal ash during counter-current washing for catalyst recovery; studies to reduce costs of the recycle system. 
3. Long-term, hot-corrosion testing under steady-state operating conditions and laboratory studies to define mechanisms and rates of hot corrosion.

4. Identification of lower-cost, throw-away catalysts.

5. Identification of catalysts for operation at reduced $T$.

6. Research to assure long-term leaching stability of coal ash.

7. Improvement of the quantitative gasifier model.

The $1 \mathrm{mt} /$ day PDU project was terminated in late 1983. Exxon believes that its 1978 cost estimates are generally valid but that the fossil-fuel market conditions changed to such an extent that adequate return on investment could not be assured in the foreseeable future with syngas production.

Laboratory research should focus on development catalysts that hold the promise of improving operating conditions (e.g., lowering required temperatures, residence times, pressures, system sizes) or improving the initial gas composition (lowering pollutant levels, increasing methane yields, etc.). Many different approaches and catalysts are being studied empirically (Sec. 7.1-1). A useful theoretical interpretation and classification of research results in terms of systems promise remains to be worked out and should be supported by DoE. 


\section{CHAPTER 8: \\ GAS-CLEANING PROCESSSES FOR COAL GASIFICATION*}

\subsection{Introduction}

Gas-cleaning systems are incorporated in the process design of coal-gasification facilities for the purpose of converting the raw gas exiting the gasification reactor into a gas which meets end-use specifications. Thus, the design and structure of the gas-cleaning system (Fig. 8.1-1) depend on both the characteristics of the gasification process, which determines raw-gas composition, and on end-use specifications. Potential end uses for the gaseous products from coal gasification include fuel for on-site boilers, turbines or fuel cells and synthesis gas for the production of methane (SNG), ammonia, methanol, or other HC products. The gas composition and purity specifications vary widely for these applications, as is illustrated in Table 8.1-1.

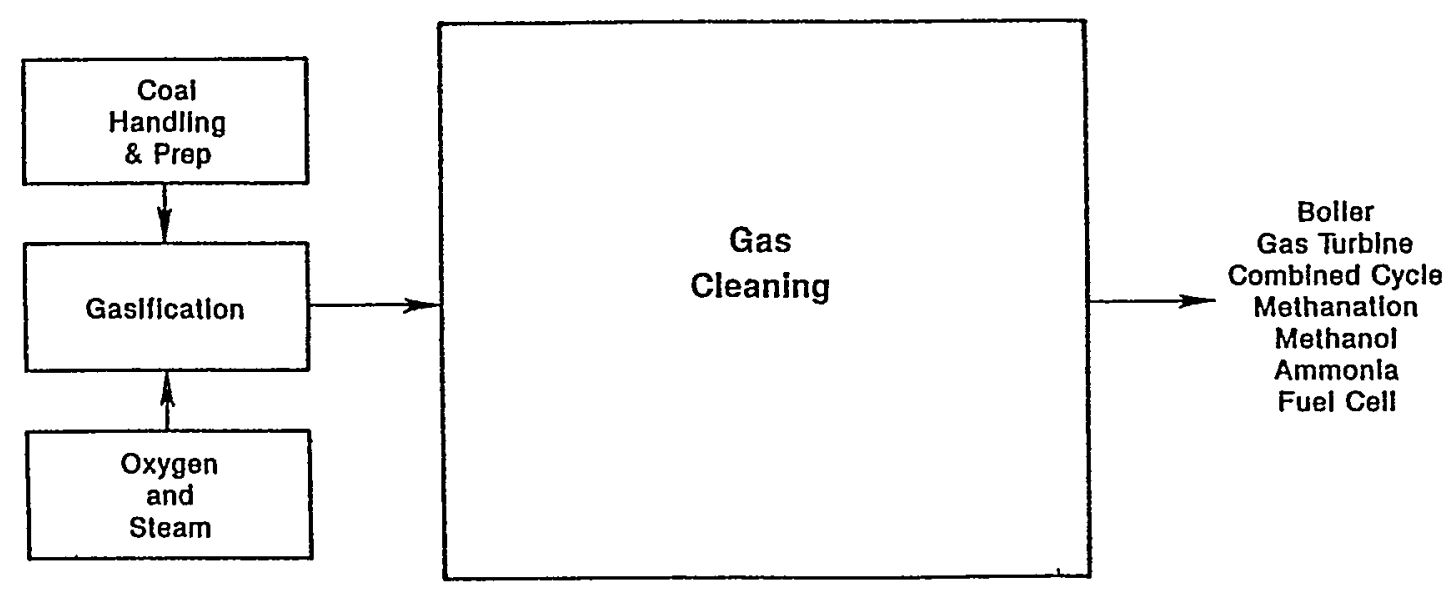

Fig. 8.1-1. Role of gas cleaning in coal gasification.

* This chapter has been written by Robert A. Magee (Radian Corp.). An Appendix to this chapter by J.F. Elliott (M.I.T.) deals with the use of slag for in-bed sulfur removal. 
Table 8.1-1. Example of gas cleanup requirements.

\begin{tabular}{|c|c|c|c|c|}
\hline Parameter & $\begin{array}{c}\text { Boiler } \\
\text { combustion }\end{array}$ & $\begin{array}{c}\text { Gas } \\
\text { turbine }\end{array}$ & $\begin{array}{l}\text { Fuel } \\
\text { cells }\end{array}$ & $\begin{array}{c}\text { Methanation, } \\
\text { methanol }\end{array}$ \\
\hline Particulates & $\begin{array}{l}0.03 \mathrm{lb} / 10^{6} \mathrm{BTU} \\
(0.07 \mathrm{~g} / \mathrm{SCF} \text { at } \\
\text { at } 350 \mathrm{BTU} / \mathrm{SCF})\end{array}$ & $\begin{array}{ll}0.025 & \mathrm{~g} / \mathrm{SCF}(<3 \mu \mathrm{m}) \\
0.03 \mathrm{~g} / \mathrm{SCF}(3-5 \mu \mathrm{m}) \\
0.0036 \mathrm{~g} / \mathrm{SCF}(>5 \mu \mathrm{m})\end{array}$ & & \\
\hline $\mathbf{S}$ & $\begin{array}{l}1.21 \mathrm{~b} / 10^{6} \mathrm{BTU} \\
(2500 \mathrm{ppm})\end{array}$ & $500 \mathrm{ppm}$ & 5 ppm & $0.2 \mathrm{ppm}$ \\
\hline $\begin{array}{l}\mathrm{Cl} \\
\mathrm{NH}_{3} \\
\end{array}$ & & & $\begin{array}{l}1.0 \mathrm{ppm} \\
0.1 \mathrm{ppm}\end{array}$ & \\
\hline $\begin{array}{l}\text { Metals }(\mathrm{ppm}, \mathrm{w} / \mathrm{w}) \\
\mathrm{V} \\
\mathrm{Na}+\mathrm{K} \\
\mathrm{Ca} \\
\mathrm{Pb} \\
\mathrm{Cu}\end{array}$ & & $\begin{array}{c}0.5 \\
0.5 \\
10 \\
2 \\
0.2\end{array}$ & & \\
\hline
\end{tabular}

The parameters listed in Table 8.1-1 represent some of the fuel specifications for boilers, turbines or fuel cells and for methanol production. Some of these specifications, such as those for boiler fuels, reflect environmental limitations that are imposed on the resulting emissions through end-use applications. Other specifications are based on operational requirements relating to the end-use process, for example, the avoidance of catalyst poisoning in methanation or the production of methanol.

\subsection{Gas Cleanup Systems}

Current design approaches for gas cleaning consist of the serial application of a number of gas-cleaning processes, each of which is designed to remove one or more contaminant species, as illustrated in Fig. 8.2-1. The contaminant species of interest for most combinations of gasification and end-use applications are aerosols (both particles and liquid droplets), sulfur compounds, inorganic compounds, alkali and heavy metals, and organic chemicals. The capital cost for these processes is a significant portion of the total cost of the facility. The 1979 data shown in Table 8.2-1 still constitute a relatively accurate presentation of the impact of major elements of a coal-gasification facility on the total capital cost of the facility. ${ }^{2}$ The data apply to two of the primary types of coal-gasification 
systems that are commercialiy available [i.e., pressurized, fixed-bed (Lurgi) and pressurized, entrained-bed (Texaco) systems] when these are applied in combination with two of the most economically viable end uses

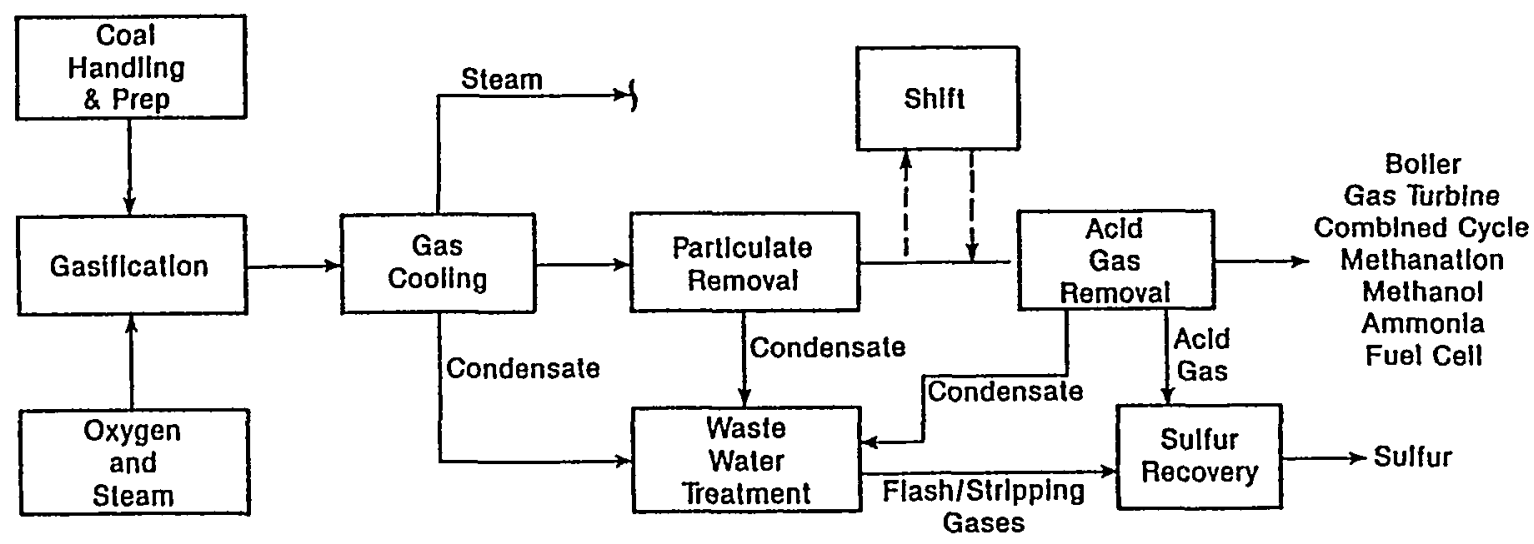

Fig. 8,2-1. Major coal-gasification-process units.

Table 8.2-1. Plant investment breakdown; reproduced from Ref. 2.

\begin{tabular}{|c|c|c|}
\hline \multirow{2}{*}{ Process } & \multicolumn{2}{|c|}{ Percent of Total Plant } \\
\hline & Lurgi SNG & Texaco IGCC \\
\hline Coal handling and preparation & 1.0 & 3.7 \\
\hline Oxygen and steam & 29.3 & 18.7 \\
\hline Gasification and ash handling & 18.3 & 3.8 \\
\hline $\begin{array}{l}\text { Gas cooling and condensate } \\
\text { treatment }\end{array}$ & 10.5 & 13.6 \\
\hline Shift & $2.5\}=31.9$ & $=23.7$ \\
\hline Acid-gas removal & 15.6 & 8.1 \\
\hline Sulfur recovery & 3.3 & 2.0 \\
\hline Methanation and SNG handling & 11.7 & -- \\
\hline Combined-cycle system & -- & 42.8 \\
\hline Support facilities & 7.8 & 7.3 \\
\hline Total & 100.0 & 100.0 \\
\hline$\frac{\Sigma \text { Gas cleaning }}{\text { gas plant }}$ & 36.1 & 41.4 \\
\hline
\end{tabular}

(production of SNG and IGCC for electric power generation). Since 1979, these process configurations have been constructed and operated on a commercial scale and the relative capital costs 1 isted in Table 8.2-1 have been demonstrated to apply to the US. 
Based on the generally accepted design approach for serial applications of species-specific processes, the most probable means for reducing significantly the capital investment required for the gas-cleaning portion of a coal-gasification facility is the drastic simplification of the elimination of one or more process units in the gas-cleaning system. With this objective in mind, the approaches and processes available to remove contaminants from the process gas were reviewed and examined for opportunities to achieve simplification or elimination of units through additional research and development. The process components reviewed were (i) quenching, cooling and heat recovery; ( $i i)$ removal of particles, aerosols, and inorganic compounds; and ( $i i j$ ) acid-gas removal and sulfur recovery.

\subsection{Quenching, Cooling and Heat Recovery}

These processes may be grouped into two broad generic categories: direct and indirect.

Direct processes involve intimate contact between the gas and the cooling or quenching medium (usually water) and are generally accomplished in a scrubber system, which also removes at least a portion of the aerosols and inorganic contaminants. The direct contact processes are distinguished by their mechanical configuration or mode of forced mixing and cortact between the gas and the scrubbing medium. Configurations include spray towers, venturi and packed-bed scrubbers and simple dip-tube quench-chambers. Although these vary widely in contact efficiency, they suffer from common problems and limitations. The liquid-phase build-up of dis-solved or suspended components that are removed from the gas results in deposits or plugging if it is not reduced by blowdown. This blowdown must be treated prior to discharge or recycle to the process. In $a 11$ configura-tions, the contact efficiency between gas and liquid is proportional to the energy expended in the contacting process. Minimization of the slope of this energy-efficiency relation has been the objective of years of research in gas-liquid contractor design.

Indirect processes involve the transfer of heat through an intermediate from the gas to the cooling or quenching medium. Indirect contact configurations include shell-and-tube and water-wall boiler designs, as well as gas-recyciing schemes. The transfer of heat from the gas to the cooling 
medium involves not only the characteristics of the medium and the gas but also those of the transfer medium and the contact configuration. Thus, the efficiency may be enhanced through materials research and refinement and through development of techniques which predict the heat-transfer properties and longevity of the transfer medium. Research on heat transfer, tube fouling and waste-heat boilers and models may be expected to contribute to this predictability and, therefore, to the design efficiency of future systems. For example, the radiant heat boiler at the Cool Water Gasification Project is significantly over-designed in order to provide adequate contingencies for uncertainties in boiler-design parameters and the unpredictability of the impact of ash and metals deposition on tubes and other heat-transfer surfaces.

\subsection{Removal of Particles, Aerosols and Inorganic Compounds}

Processes for the removal of particles and aerosols may be broadly grouped as wet and dry processes. Dry processes rely on filtration, as well as on aerodynamic momentum or electrostatic forces to impact and collect solid or liquid aerosols entrained in the flowing gas streams. High-temperature filtration developments have included applications of ceramic materials to the removal of fine particles from process-gas streams. Confident design and operation of dry aerosol-removal processes requires detailed understanding of solid-gas transport phenomena at gasification temperatures and pressures. Fluid dynamic data for complex mixtures at these conditions increase the design reliabilities and operating efficiencies of cyclones and similar aerodynamic collection devices.

Wet-collection processes are similar to the specified direct cooling and quenching processes. Many of the same design and operation considerations apply. In particular, gas-liquid mass-transfer models and parameters for $\mathrm{NH}_{3}, \mathrm{CO}_{2}, \mathrm{H}_{2} \mathrm{~S}, \mathrm{HCN}, \mathrm{HCl}$, and other inorganic gasification products for the range of mixtures encountered for these components, are required to predict the performance of gas-scrubbing processes. Operation of these systems is often limited by precipitation or scale formation from dissolved components, in particular, carbonates and silicates. In addition, blowdown from these processes must be treated prior to discharge or recycle. 
The construction of treatment processes requires similar gas-liquid mass-transfer data for the design of flash and stripping processes.

\subsection{Acid-Gas Removal and Sulfur Recovery}

Acid-gas removal and sulfur recovery are currentiy the most complex portions of the gas-cleaning train. A wide variety of collection media and contact configurations have been employed to enhance efficiency and reduce the costs of these processes. The commercially available processes may be grouped into five categories, depending on the collection media and chemical or physical processes involved: (i) chemisorption (mildiy alkaline chemicals); (ii) physical absorption (organic solvents with high $\mathrm{CO}_{2}$ and $\mathrm{H}_{2} \mathrm{~S}$ solubilities); (iii) hybrid systems (mixtures of mildly alkaline chemicals and organic solvents); (iv) solid sorbents; and (v) sulfur conversion (solutions or reactors which oxidize sulfide to elemental sulfur or sulfur oxides).

Each of these collections media and process types has distinctive characteristics, which lead to advantages and disadvantages for various applications. A summary description of the commercially available sulfur and acid-gas removal and recovery processes, their operating characteristics, and normal equipment configurations is presented in Ref. 3. Table 8.5-1 is a summary of example processes and characteristics for each major process type.

A great deal of industry-funded and proprietary development has contributed to the availability of a variety of liquid sorbent-based systems for acid-gas removal from process-gas petroleum-refining industries. All of the chemisorption and physical sorption processes require cooling of the gas prior to treatment and an additional process unit to treat the concentrated acid gases in order to recover sulfur components that are removed from the process gas. Significant economic advantages would be gained if cooling could be eliminated or removal and sulfur recovery accomplished in a single step. Solid sorbents offer the potential for elimination of the cooling requirement. Redox sulfur-conversion processes allow collection and conversion of sulfur components in a single process unit. The status of these two process types will now be described in greater detail. 
Table 8.5-1. Examples of acid-gas removal and sulfur-recovery processes.

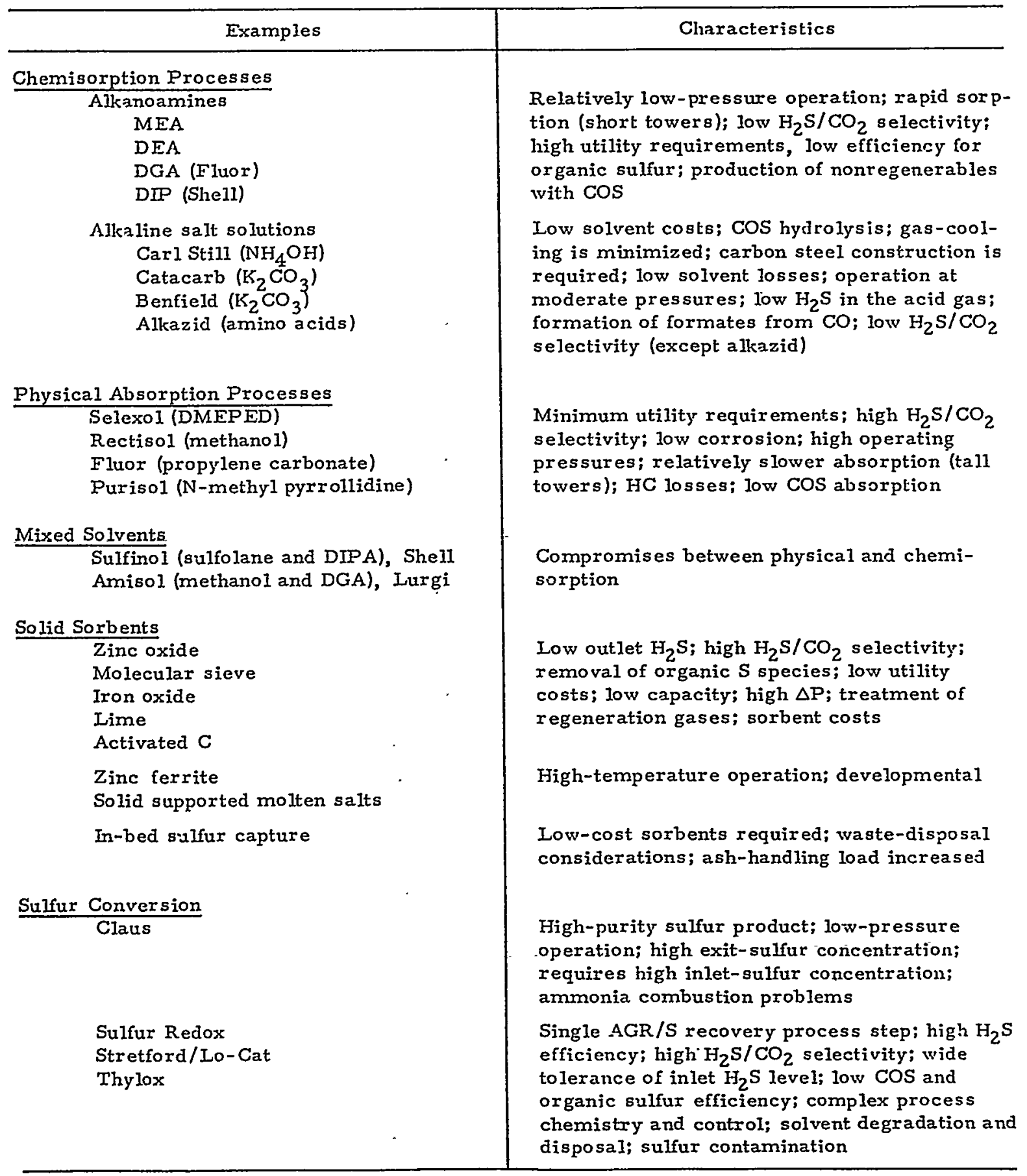

\section{5-1. Solid Sorbents and In-Bed Desulfurization}

The fundamental reactions involved in the removal of gas-phase sulfur with solid-sorbent reactors and the absorption of sulfur from coal by using solid additives in the gasification reactor are essentially the same. 
Although operating conditions in terms of temperature, pressure and gas composition are somewhat different, similarities are nevertheless sufficiently great to allow a combined discussion. The reaction of reduced sulfur compounds, particularly $\mathrm{H}_{2} \mathrm{~S}$, with oxides of metals and alkali metals has been utilized for decades to desulfurize process gases. Common absorbents are oxides of $\mathrm{Fe}, \mathrm{Zn}, \mathrm{Ca}$ and $\mathrm{Mg}$ or carbonates of calcium and/or magnesium (1imestone or dolomite). In most previous applications, the sulfurized solid was disposed of after complete reaction. In some cases, the reactions are reversible, thus allowing reuse of the sorbent until physical degradation requires replacement.

Recent research supported by $D o E^{4}$ has demonstrated that mixed oxides of $\mathrm{Zn}$ and $\mathrm{Fe}$ (zinc ferrites) are effective sorbents of reduced sulfur compounds at temperatures which allow elimination of much of the cooling of gasification-product gas. These sorbents have been regenerated through contact with air and steam to allow reuse of the sorbent materials. Product gas at $800-1200^{\circ} \mathrm{F}$ and $4000-9000 \mathrm{ppm}$ sulfur may be cleaned to levels containing 2-4 ppm sulfur. The sulfurized solid sorbent may then be regenerated with with air and steam at less than $1500^{\circ} \mathrm{F}$, thus producing an exhaust stream of steam, sulfur dioxide and nitrogen. Advantages of the zinc ferrite sorbent process are: (i) extremely high sulfur capture by removing $\mathrm{H}_{2} \mathrm{~S}, \mathrm{COS}$ and $\mathrm{CS}_{2}$; (ii) operating temperatures applicable to gas-turbine systems; (iii) a dry, inexpensive, regenerable sorbent materia1: (iv) sharp reaction profiles, allowing for reactor-design flexibility; ( $v$ ) reasonable operating pressure drops; and $(v i)$ sorbent resistant to sintering because of the high melting points of zinc oxide/sulfide compounds.

The process has been tested on side-streams of product gases from both fixed- and fluidized-bed gasifiers. The results of these tests have shown the capability of reducing the sulfur contents, while demonstrating regenerability through multiple absorption-regeneration cycles. Current plans are to evaluate the process at the pilot scale through operation at a fluidized bed gasification-pilot facility. Remaining uncertainties for the process include: (i)sorbent durability; (ii) solid phase equilibrium boundaries; (iii) solid sulfate formation during regeneration; (iv) zinc evaporation; (v) sorbent structural changes; ( $v i$ ) treatment or disposal of regeneration exhaust gases; ( $v i j$ ) control of product gas ammonia content; and ( $v i i i)$ process economics. 
To compete economically with existing sulfur processes, the sorbent durability must be increased and allow approximately for 100 sorption-regeneration cycies. At the same time, the sulfur loading in the product gas must be lowered through in-bed sulfur capture or gasification of low-sulfur coals. However, the process offers the potential advantages of increasing overa 11 energy-recovery efficiency through the treatment of process gas with minimum prior cooling.

Limestone and dolomite have been used for desulfurization of process gases and the absorption of sulfur in the gasification reactor. In the mid-1970s, extensive fundamental research was conducted on the reaction kinetics and equilibria of these sorbents with reduced sulfur compounds. 5 These data define the absorption and desorption reactions of sulfur compounds, which formed the basis for sulfur control in the $\mathrm{CO}_{2}$ Acceptor Process. The pilot-scale tests for in-bed desulfurization of the KRW fluidized-bed gasification reactor have shown similar behavior. These materials are inexpensive and may be disposed of economically with the ash residues from the gasification process, which is an essential characteristeric for in-bed desulfurization sorbents. Limestone- or dolomite-based solid sorbent processes have the following advantages: (i) readily available, inexpensive sorbent materials; (ii) potential for once-through use of sorbent with disposal in combination with gasification ash-residues; (iii) tolerance of product-gas particulate loadings; (iv) potential for tar and ammonia cracking; (v) reasonable operating pressure drops; and (vi) easily integrated in-bed desulfurization and product-gas desulfurization using the same sorbent material. However, the use of these materials has not been demonstrated for gasification process-gas cleanup at the commercial scale and, therefore, the following uncertainties remain: (i) sorption capacity of the sorbents at various gasification-reactor conditions and for various product-gas compositions, temperatures and pressures: (ii) disposal of solids with high concentrations of sulfides, which may oxidize to soluble or be released as sulfide gases; (iii) impact of sorbent additions on operations of the gasifier reactors; and (iv) removal of adequate product-gas nitrogen (primarily as ammonia) to meet limitations for combustion emissions.

In summary, the principal advantages of applications of solid-sorbent technologies to desulfurization of gasification product-gases are ( $i)$ reductions of gas cooling requirements and ( $i i)$ the potential to 
eliminate the requirement for sulfur recovery. Reduction of gas cooling requirements will not only reduce capital investment but will also enhance significantly the overall process-energy efficiency, provided the end-use process utilizes the thermal energy of higher temperature gases. Elimination of sulfur recovery will reduce capital investment and operating costs and simplify the solids-handling and disposal operation if the sorbent can be disposed of together with the gasification ash residues.

\section{5-2. Sulfur Redox Processes}

Sulfur-redox processes convert sulfides to elemental sulfur through the use of oxidizing agents. ${ }^{6}$ In general, these processes are based on the sequential occurrence of the following three reaction steps: (i) absorption of gaseous sulfur compounds in the process solution (which is usually alkaline); ( $i$ ) oxidation of dissolved HS- to elemental sulfur by an oxidizing agent; and ( $i i_{i}$ ) regeneration of the oxidizing agent.

The multiplicity of potential sulfur-oxidation states is responsible for the occurrence of extremely complex chemistry in the operation of these processes, since a wide variety of side reactions and interactions with contaminant components may occur. The operating history of sulfur-redox processes during commercial applications has been varied, but the difficulties have generally been directly related to the complexity of the gas composition being treated. ${ }^{7}$ Process advantages have led to their continued selection in proposed designs for gasification facilities 8 and, therefore, further development to exploit these advantages is warranted. Advantages of the redox processes include: (i) acid-gas removal and sulfur recovery in a single process unit, thereby eliminating one process unit; ( $i$ i) high $\mathrm{H}_{2} \mathrm{~S}$ collection efficiency, with a high selectivity for $\mathrm{H}_{2} \mathrm{~S}$ over $\mathrm{CO}_{2}$; ( $\mathrm{iii}$ ) wide tolerance for inlet sulfur loading without loss of collection efficiency; and (iv) low operating and capital costs compared to use of the Claus reactor for sulfur recovery. ${ }^{9}$

Sulfur-redox processes depend on the successful control of sulfur-solution chemistry for reliable process design and operation. For commercialty applied processes, both uncertainties of the design basis and 
difficulties with operational control have contributed to application problems. Uncertainties associated with sulfur-redox processes include the following: (i) little detailed information is available on process chemistry and both the equilibrium and kinetic data are insufficient to develop detailed design relationships; ( $i$ i) the complex chemistry and potential for side reactions and reactions with contaminants result in low contaminant tolerance in the inlet gas; ( $i i j$ ) the degradation of reagents due to incomplete regeneration and chemical and biological activity leads to higher than expected reagent use; (iv) contaminants in the inlet gas lead to decreased sulfur purity; and ( $v$ ) many potential applications in the gasification industry would benefit greatly from pressurized operation, which has not yet been demonstrated.

In summary, the primary advantages of the sulfur-redox processes for gas-clean in coal-gasification are etimination of a sulfur-recovery unit, wide tolerance for varying inlet sulfur loadings, and reduced capital and operation costs compared to other sulfur-recovery processes.

\section{References}

1. F. L. Robson and W. A. Blecher, "Assessment of Fuel-Gas-Cleanup Systems, Final Report," DE81025927, DOE/MC/12050-149, United Technologies Research Center, East-Hartford, CT (November 1980).

2. S. S. Penner et a1., "Assessment of Long-Term Research Needs for Coal-Gasificatior Technologies," DOE/ER-78-C-01-6335, MTR-79W00160. The Mitre Corporation, McLean, VA (April 1979).

3. R. D. Parekh, "Handbook of Gasifiers and Gas-Treatment Systems," DE83004846, DOE/ET/10159-T24, UOP/SDC, McLean, VA (September 1982).

4. Science Applications, Inc., "Coal Gas Desulfurization at High Temperatures, Status of METC Investigations," DOE/MC/16545-1666; DE85003382, Morgantown, WV (October 1984).

5. G. P. Curran et al., "High Temperature Desulfurization of Low-Btu Gas," EPA 68-02-1333, 600/7-77-031, Consolidated Coa1 Company, Library, PA (Apri1 1977).

6. C. N. Sawyer and P. L. McCarty, Chemistry for Environmental Engineering, McGraw-Hill Book Company, New York, NY (1978). 
7. "Hydrogen Sulfide Removal," Chem. Eng. News 49(38), 48 September 13, 1971).

8. M. S. Edwards, "H $\mathrm{H}_{2} \mathrm{~S}$ Removal Processes for Low-Btu Coal Gas," ORNL/TM-6077, Oak Ridge National Laboratory, Oak Ridge, TN (January 1979).

9. P. Grancher, Society Nationale Elf Aquitaine, Pau France, "Advances in Claus Technology. Part 2: Improvements in Industrial Units and Operating Methods," Hydrocarbon Processing 57, 247 (1978). 
The following sulfur-dissolution process accurs in ferroussilicate slags near $1300^{\circ} \mathrm{C}$, provided the oxygen partial pressure $\left(\mathrm{p}_{\mathrm{O}_{2}}\right)$ is less than $10^{-5} \mathrm{~atm}$ and $\mathrm{SO}_{2}$ is not produced:

$$
\underline{2}_{2 S_{2}(g)+0}=\quad \frac{1}{2 O_{2}}+S .
$$

The equilibrium constant for this process is

$$
k_{p}=\left(p_{0_{2}} / p_{S_{2}}\right)^{\frac{1}{2}}\left(p_{s}=/ p_{0}=\right) \text {, }
$$

where the ratio $p_{S}=/ p_{0}$ is constant for ionized species as long as they exist. Hence,

$$
K_{p}^{\prime}=K_{p}\left(p_{0}=/ p_{S}\right) \quad\left(p_{0_{2}} / p_{S_{2}}\right)^{\frac{3}{2}}
$$

is a function of temperature only. Multiplying by (\%S) dissolved and defining the sulfide capacity as

$$
c_{S} \equiv K_{p}^{\prime}(\% S)=k_{p}\left(p_{0}=/ p_{S}=\right)(\% S)=\left(p_{0_{2}} / p_{S_{2}}\right)^{\frac{1}{2}}(\% S),
$$

it follows that

$$
(\% S)=c_{S}\left(p_{S_{2}} / p_{0_{2}}\right)^{\frac{1}{2}}
$$

Thermodynamic analyses lead to the conclusion that

$$
a \log C_{S^{\prime}} / 2(1 / T)=8,190 \mathrm{~K} \text {. }
$$

For $10^{-5}<\mathrm{p}_{\mathrm{O}_{2}}$, atm $<10^{-3}$, the sulfate or pyrosuifate may form according to the reactions

$$
\mathrm{SO}_{2}(\mathrm{~g})+\frac{3}{2} \mathrm{O}_{2}(\mathrm{~g})+\mathrm{O}^{=} \longrightarrow \mathrm{SO}_{4}
$$

and

$$
2 \mathrm{SO}_{2}(\mathrm{~g})+\mathrm{O}_{2}(\mathrm{~g})+\mathrm{O}=\mathrm{C} \mathrm{S}_{2} \mathrm{O}_{7}=
$$

* This section has been abstracted from a presentation made by J. F. Elliott (M.I.T.) at the Fourth Technical Meeting of the COGARN Working Group (May 23, 1986). 
The sulfide capacity $C_{S}$ is seen to depend on the equilibrium constant $K_{p}$, the ratio of $O^{=}$to $S=$ activities in the slag, and the $\% S$ dissolved. It is obtained in practice by measuring $\mathrm{PO}_{2} / \mathrm{P}_{\mathrm{S}_{2}}$ and $\% \mathrm{~S}$. Sulfide capacities are reproduced in Fig. 8A-1 for a number basic slags as a function of mole fraction of base or lime.

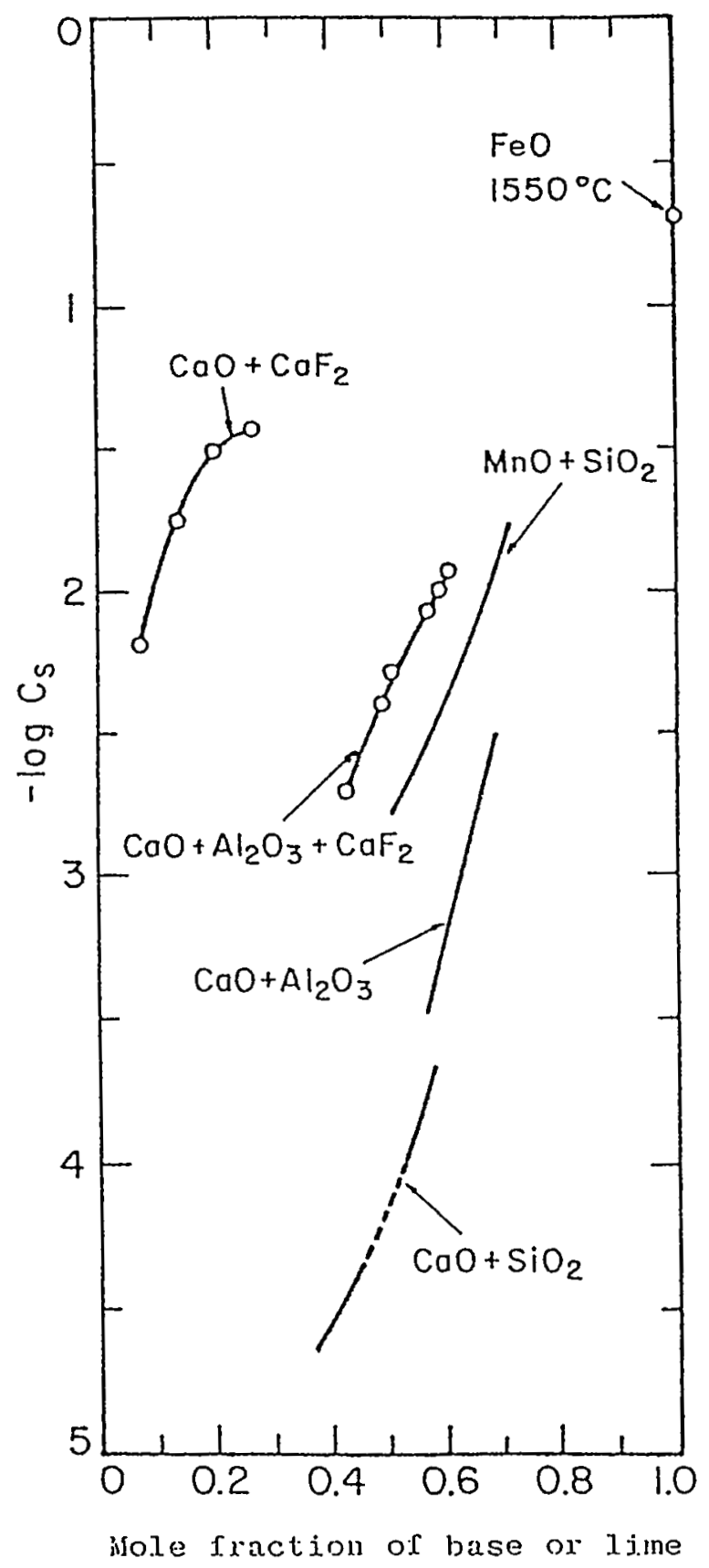

Fig. 8A-1. Sulfide capacities $\mathrm{C}_{\mathrm{S}}$ of some simple slags. 
As a practical matter, under the most favorable conditions of low oxygen and high sulfur pressures, even the most basic slags will contain only a few wt\% of $S$. Sulfur removal from hot gases is most effective when a separate oxysulfide phase forms in addition to the slag. The oxysulfide phase may be the liquid phase in the Fe-0-S system (Fig. 8A-2), or it may be solid calcium sulfide ( $\mathrm{CaS}$ ). The equilibrium oxygen and sulfur pressures at which the liquid phase in the $\mathrm{Fe}-0-\mathrm{S}$ system is stable at $1300^{\circ} \mathrm{C}$ is shown by the stability diagram for the phase in Fig. 8A-3. On the low sulfur-pressure side, the phase may be saturated with respect to metallic iron, $\mathrm{FeO}(\mathrm{s})$ or magnetite $\left(\mathrm{Fe}_{3} \mathrm{O}_{4}\right)$. The oxygen pressures for equilibrium between $\mathrm{FeO}, \mathrm{CO}(\mathrm{g})$ and $\mathrm{CO}_{2}(\mathrm{~g})$ at several temperatures of interest are shown in Table $8 \mathrm{~A}-1$.

It is seen that, for coal-gasification systems, good desulfurization can be achieved with the formation of the oxysulfide or sulfide phase, but not through the action of the slag phase alone. Desulfurization in coal-combustion systems by way of the slag that may be formed may not be practical, particularly if the slag is in equilibrium with the oxygen potential of the combustion gases.

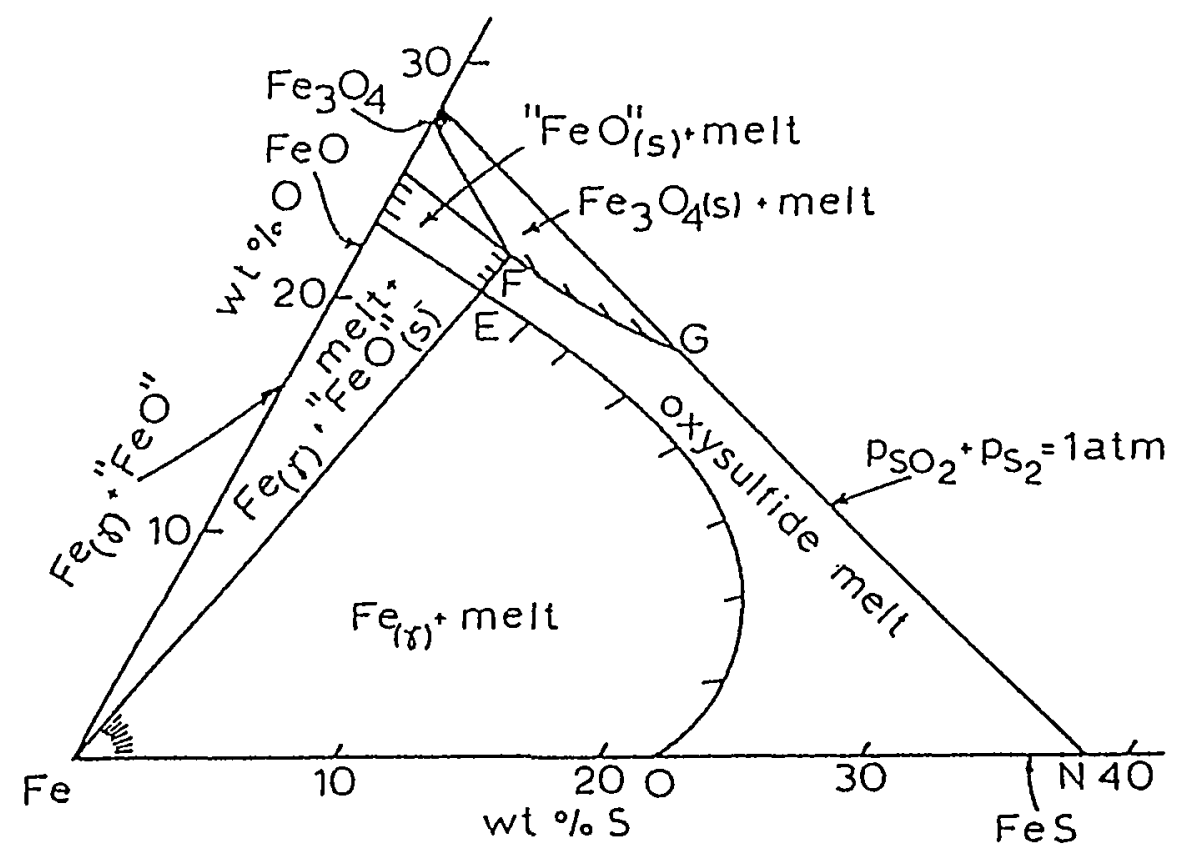

Fig. 8A-2. The $1300^{\circ} \mathrm{C}$ isotherm of the Fe-O-S system; "FeO" denotes the lack of stoichiometry in the phase. 


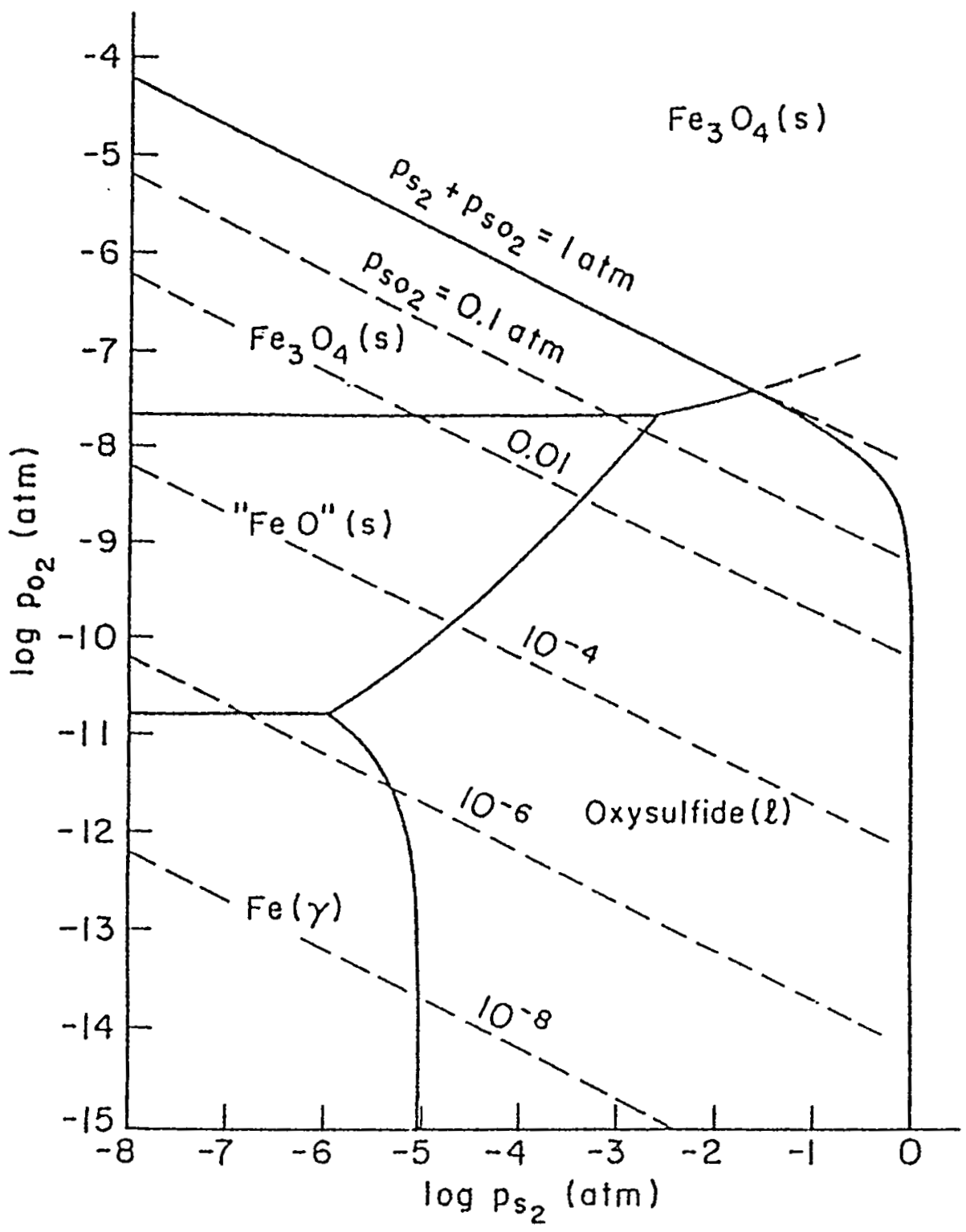

Fig $8 \mathrm{~A}-3$. Stability diagram of the Fe-O-S system at $1300^{\circ} \mathrm{C}$; "FeO" denotes the lack of stoichiometry in the mixture. 
Table 8A-1. Iquilibrium oxygen partial pressures when the reaction $\mathrm{FeO}+\mathrm{CO}=\mathrm{CO}_{2}+\mathrm{Fe}$ occurs, coupled with $\mathrm{CO}+\frac{1}{2} \mathrm{O}_{2}=\mathrm{CO}_{2}$.

\begin{tabular}{c|c|c|c}
\hline${ }^{\circ} \mathrm{C}$ & ${ }^{\circ} \mathrm{F}$ & $\mathrm{P}_{2}, \mathrm{~atm}$ & ${ }^{\mathrm{P}_{\mathrm{CO}}} / \mathrm{P}_{\mathrm{CO}_{2}}$ \\
\hline 800 & 1475 & $10^{-19.5}$ & 1.8 \\
1000 & 1830 & $10^{-15.5}$ & 2.6 \\
1200 & 2160 & $10^{-12.5}$ & 3.0 \\
1400 & 2550 & $10^{-10}$ & 3.3 \\
\hline
\end{tabular}

The preceding comments indicate the importance of studying phase equilibria in coal slags and the need to perform quantitative work in this field in order to make useful predictions or correlations about the extent of sulfur dissolution in coal slags as functions of lime addition under equilibrium conditions. The extent to which equilibrium conditions are limiting practical system performance remains to be evaluated. 



\section{CHAPTER 9:}

ENVIRONMENTAL ISSUES*

\subsection{Introduction}

We present an overview of technical and regulatory issues affecting the environmental control of coal-gasification processes arid discuss future regulatory directions and their implications for coal-gasification research. We review recent data characterizing emissions from various types of gasifiers and the methods presently available for the control of gaseous, liquid and solid contaminants. Key research needs are suggested which relate to meeting current and future environmental requirements at minimum cost.

\subsection{Overview of US Regulatory Policy}

\section{2-1. Trends in Environmental Regulation}

Concern over environmental quality in the US has been at the forefront of national attention since the early 1970s, when Congress enacted sweeping new laws related to air- and water-pollution control. Since that time, environmental regulations have continued to grow more complex and comprehensive, having profound impacts on a wide variety of industrial and energy-conversion processes.

Figure 9.2-1 graphically depicts the long-term trend in US environmental regulation over the last century. ${ }^{1}$ It shows the total number of federal laws related to environmental protection up to the present date. The dramatic increase in the last two decades underscores the now

* This chapter has been written by Edward S. Rubin. 
well-accepted fact that environmental regulations play a critical role in determining the viability of technological systems such as coal gasification. Recent trends suggest that environmental constraints are

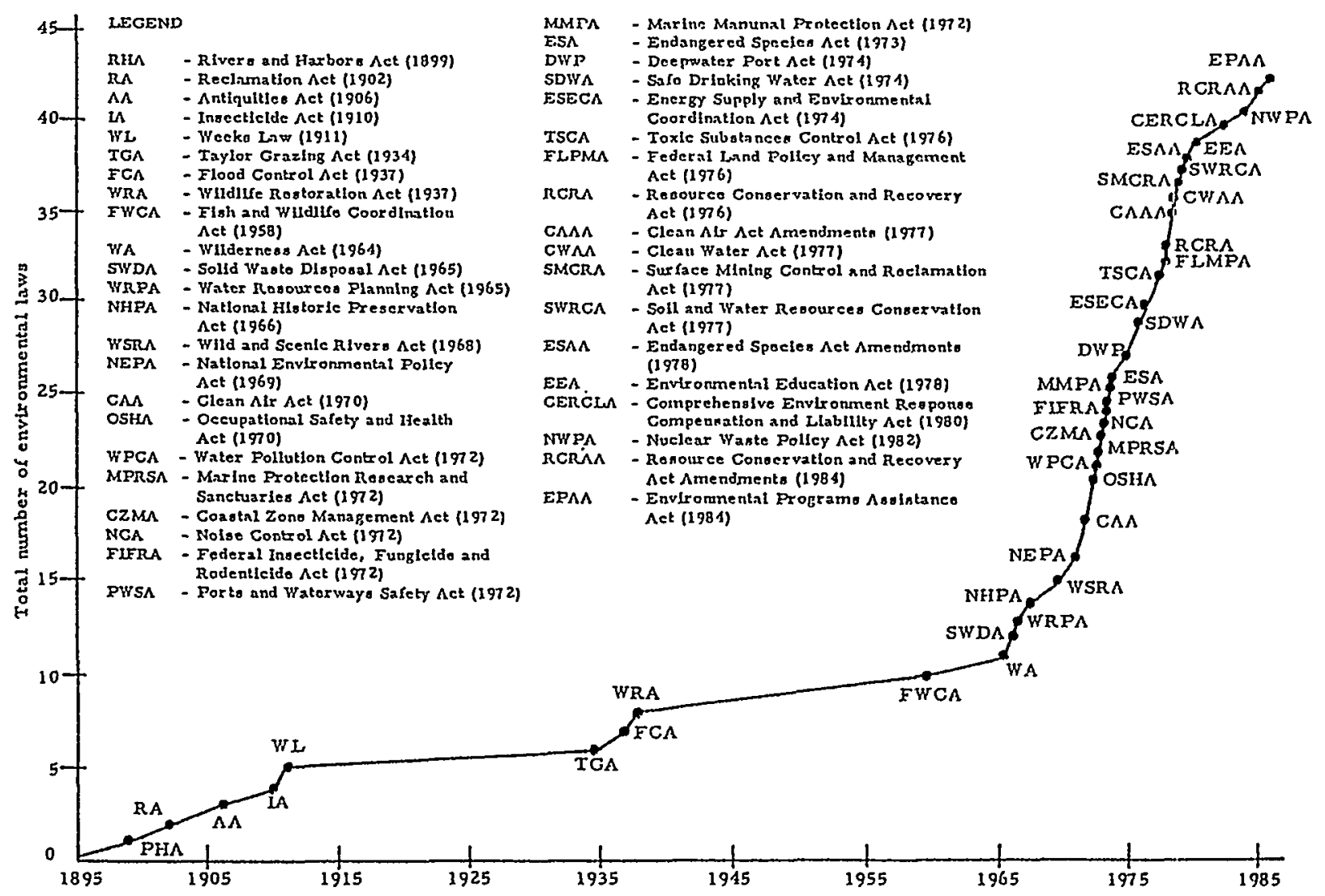

Fig. 9.2-1. US laws on environmental protection (Ref. 1).

likely to grow more important over time and must thus be factored carefilly into research development planning for advanced energy-conversion technologies. The major elements of current regulatory policy affecting coal gasification are briefly reviewed in Sec. 9.2-2, followed by a discussion of future regulatory directions and their implications.

\section{2-2. Elements of Current Policy}

Table 9.2-1 summarizes some of the key elements of envirormental regulatory policy affecting coal-gasification plants. These regulations 
fall into two general categories: (i) standards defining acceptable environmental quality and ( $i j)$ standards limiting the discharge of specific substances to the environment from specified sources. It is the latter type of standards which most directly affect the design and cost of coalgasification systems, though in many cases environmental quality standards also play a major role, particularly in plant siting.

\section{2-2A. Air Pollution Control}

While air-pollution-control requirements have long been part of the regulatory landscape, the Federal Clean Air Act Amendments of 1970 brought air-pollution control to the forefront of national efforts to insure a clean and healthful environment. The newly established US Environmental Protection Agency (EPA) was required by the Act to promulgate primary national ambient air-quality standards (AAQS) to protect human health and secondary standards to protect human welfare. The latter category encompassed the effects of air pollution on materials, vegetation, visibility, animal life, etc. EPA's responsibility also included a mandate to insure the "non-degradation" of air whose quality was better than National standards (including pristine areas such as National parks and forests). The air pollutants initially regulated under the Clean Air Act included $\mathrm{SO}_{2}$, total suspended particulates (TSP), $\mathrm{NO}_{2}, \mathrm{CO}$, and photochemical oxidants. Since oxidants are produced indirectly, guidelines for non-methane HCs were also established. More recently, lead has been added to the list of criteria pollutants. Table 9.2-2 summarizes these standards.

To achieve ambient air-quality standards, state and local authorities were directed to promulgate appropriate emissions standards, subject to approval by EPA. The right was reserved to state and local authorities to implement ambient air-quality standards more stringent than the National standards and to regulate pollutants not covered by Federal standards. State emission limits for individual sources of air pollution typically specify a maximum allowable discharge rate and/or concentration of each regulated poliutant. In some cases, specific control methods for limiting pollutant discharges are specified.

The Federal role in the direct regulation of emissions is limited by the Clean Air Act to specific categories of new sources, including new 
Table 9.2-1. Elements of environmental regulatory policy affecting coal-gasification plants.

\section{Aix Pollution Control}

National Ambient Air Quality Standards (Pximary, Secondary, Nondegradation)

Federal New Source Performance Standards

National Emission Standards for Hazardous Air Pollutants

State and Local Standards (Air Quality, Emission Limits, Control Methods)

\section{Water Pollution Control}

Federal Safe Drinking Water Standards

Federal New Source Performance Standards

National Clean Water Act

Ioxic and Hazardous Waste Regulations

State and Local Standards (Stream Quality, Effluent Limits, Txeatment Methods)

\section{Solid Waste Control}

Federal Toxic and Hazaxdous Waste Regulations

State and Local Standards (Classification, Disposal Methods)

Table 9.2-2. National ambient air-quality standards; codified at 40 CFR Part 50.

\begin{tabular}{|c|c|c|c|}
\hline Pollutant & Primaxy Standards & Averaging Time & Secondar:y Standards \\
\hline CO & $\begin{array}{r}9 \mathrm{ppm} \\
35 \mathrm{ppm}\end{array}$ & $\begin{array}{l}8-h r^{a} \\
1-h r^{a}\end{array}$ & None \\
\hline Lead & $1.5 \mu \mathrm{g} / \mathrm{m}^{3}$ & Quarterly average & $\begin{array}{l}\text { The same as the } \\
\text { primary }\end{array}$ \\
\hline $\mathrm{NO}_{2}$ & $0.053 \mathrm{ppm}$ & Annual (arithmetic mean) & $\begin{array}{l}\text { The same as the } \\
\text { primary }\end{array}$ \\
\hline $\begin{array}{l}\text { Particulate matter }{ }^{b} \\
\text { (ISP) }\end{array}$ & $\begin{array}{r}75 \mu \mathrm{g} / \mathrm{m}^{3} \\
260 \mu \mathrm{g} / \mathrm{m}^{3}\end{array}$ & $\begin{array}{c}\text { Annual (geometric mean) } \\
24-\mathrm{hr}^{\mathrm{a}}\end{array}$ & $\begin{array}{r}60 \mu_{\mathrm{g}} / \mathrm{m}^{3} \mathrm{c} \\
150 \mu_{\mathrm{g}} / \mathrm{m}^{3}\end{array}$ \\
\hline Ozone & $0.12 \mathrm{ppm}$ & $1-h x^{d}$ & $\begin{array}{l}\text { The same as the } \\
\text { primary }\end{array}$ \\
\hline Sulfur oxides & $\begin{array}{l}0.03 \text { ppm } \\
0.14 \text { ppm }\end{array}$ & $\begin{array}{c}\text { Annual (arithmetic mean) } \\
24-h x^{a} \\
3-h r^{a}\end{array}$ & $\frac{-}{-}$ \\
\hline
\end{tabular}

${ }^{a}$ Not to be exceeded more than once per year.

${ }^{b}$ Changes to the TSP standard were proposed in the Federal Register (March 20, 1984). The notice proposed changing the indicator from TSP to particles smaller than $10 \mu \mathrm{m}$. Ranges of 24-hr standards of $150-250 \mu \mathrm{g} / \mathrm{m}^{3}$ and annual standards of $50-65 \mu \mathrm{g} / \mathrm{m}^{3}$ were proposied. An annual secondary TSP standard in the range of $70-90 \mu \mathrm{g} / \mathrm{m}^{3}$ was also proposed.

${ }^{c}$ Guide to achieving the 24-hr standard.

$d$ The standard is attained when the expected number of days per calendar year with maximum hourly average concentrations above $0.12 \mathrm{ppm}$ is equal to or less than 1 . 
automobiles and classes of new stationary sources of emissions. The latter include specified industrial processes judged by EPA to represent major potential sources of air pollution. Currently, they include approximately 60 sources, including fossil-fuel-fired steam generators, petroleum refineries, chemical plants, and coal-carbonization (coking) plants, but not coal-gasification facilities. The 1970 Clean Air Act specified that Federal New Sources Performance Standards (NSPS) for designated processes should require the use of "best adequately demonstrated technology," taking into account cost and other factors. In practice, NSPS requirements have come to represent the nominal design standard for new facilities.

By requiring that NSPS limits reflect the technological ability to reduce emissions, Congress put into place a dynamic constraint that is independent of ambient air-quality considerations, except in cases where the latter require emission controls more stringent than NSPS requirements. Table 9.2-3 illustrates the impact by showing recent changes in pollutant-emissions limits for coal-fired power plants. Standards for $\mathrm{SO}_{2}$, $\mathrm{NO}_{x}$ and TSP all have become more stringent over time in response to technological improvements. As an indication of current trends, standards applicable to the Cool Water coal-gasification plant in California are also shown. The data suggest the potential for further tightening of Federal NSPS requirements, especially for $\mathrm{NO}_{x}$ emissions, which may be reduced by an order of magnitude with currently commercial technology.

The list of air pollutants regulated at the federal level has also been expanded over time to include chemical species designated as hazardous. Pollutants currently regulated or proposed to be regulated by National Emission Standards for Hazardous Pollutants (NESHAP) are shown in

Table 9.2-3. Trend in air-pollution emission standards for new coal-fired power plants (lbs/106 Btu).

\begin{tabular}{c|c|c|c|c}
\hline Pollutant & $\begin{array}{c}\text { Pre- } \\
\text { NSPS }\end{array}$ & $\begin{array}{c}1971 \\
\text { NSPS }\end{array}$ & $\begin{array}{c}1978 \\
\text { NSPS }\end{array}$ & $\begin{array}{c}\text { Cool Water } \\
(1984)\end{array}$ \\
\hline TSP & $\sim 0.2$ & 0.1 & 0.03 & 0.03 \\
\hline $\mathrm{SO}_{2}$ & None & 1.2 & $\begin{array}{c}\sim 0.1-1.2 \\
(70-90 \% \\
\text { removal })\end{array}$ & $\begin{array}{c}0.04-0.4 \\
(95-97 \% \\
\text { removal) }\end{array}$ \\
\hline $\mathrm{NO}_{\mathbf{x}}$ & None & 0.7 & $0.5-0.6$ & 0.065 \\
\hline
\end{tabular}


Table 9.2-4. A much larger number of organic and inorganic chemicals have been identified as being potentially hazardous or toxic, of which about 25 are under study by EPA as part of their current commitment. New approaches involving risk assessment and risk management are being used to guide the development of regulatory priorities and standards at the Federal level.

While the potential for Federal regulation of coal-gasification plants has been extensively studied, no regulations have yet been proposed since the industry has yet to materialize. In the meanwhile, state and local regulations will determine allowable emission limits at coal-gasification facilities. ${ }^{2}$ Many states are now also moving to develop toxic air programs that may have implications for coal-gasification plants in the future.

\subsubsection{B. Water-Pollution Control}

Current regulatory policy for water pollutants bears a number of similarities to air-pollution control in that standards apply both to water quality and effluent discharges, with the federal role in the latter area limited to specified categories of new sources. In contrast to uniform $\mathrm{Na}-$ tional standards of acceptable air quality, water-quality standards are determined by individual states; thus, it is not at a 11 uncommon to find different states setting different limits for a given pollutant on the same river. The Federal Water Pollution Control Act Amendments of 1972 aimed to "restore and maintain the chemical, physical, and biological integrity of the nation's waters," establishing the "national goal that the discharge of pollutants into the navigable waters be eliminated by 1985." Thus, the notion of "zero discharge" is imbedded in current Federal legislation. Furthermore, the 1972 Act established a National goal of having water quality which provides for the protection and propagation of fish, shellfish, and wildlife, while also providing for recreation in and on the water. Toward this end, states individually set their own receiving water-quality standards, subject to EPA approval. There are also general water-quality criteria designed to protect the water uses of streams. These limits typicaliy refer to the elimination of floating solids, films, scums, bottom deposits, and objectionable odors. States also set specific limits for particular pollutants, e.g., all states typically set limits on $\mathrm{pH}$, temperature, and dissolved oxygen (though, as noted earlier, the values of these limits may 
differ from state to state).

Effluent discharge limitations generally reflect technological means of control and often are only loosely related (if at all) to water-quality standards. Thus, concepts such as "best practicable technology currently available" and "best available technology economically achiev$a b l e "$ provide the guidelines for limiting specified water pollutants from new sources subject to Federal regulation and also guide the setting of many state and local standards. Federal NSPS do not currently cover coal-gasification facilities, so that waste-water effluents from such plants are subject only to state and local regulatory requirements which vary across the country.

Other elements of current regulatory policy in the water area are the US Public Health Service Drinking Water Standards. While these do not impact coal-gasification facilities directly, they do have an indirect effect in that some of these standards are used as criteria for determining the toxicity of leachable materials from solid wastes, including coal-gasification wastes. Wastes found to be hazardous require special handling.

Table 9.2-4. Pollutants subject to national emission standards for hazardous air pollutants.

\begin{tabular}{l|l}
\hline \multicolumn{1}{c|}{ Promulgated } & \multicolumn{1}{|c}{ Forthcoming ${ }^{\dagger}$} \\
\hline Asbestos & Butadiene \\
Beryllium & Carbon tetrachloride \\
Mercury & Cadmium \\
Vinyl chloride & Chromium \\
Coke-oven emissions & Chloroform \\
Benzene & Ethylene oxide \\
Inorganic arsenic & Ethylene dichloride \\
Fugitive volatiles & Methylene chloride \\
& Perchloroethylene \\
& Trichloroethylene \\
\hline
\end{tabular}

$\uparrow$ EPA Notice of Intent to propose standards issued in 1985; promulgation is expected in 1988. 


\section{2-2C. Solid Waste Control}

Important Federal legislation regarding the handling and disposal of solid wastes has come along only in the last decade in the form of the 1976 Toxic Substances Control Act (TSCA) and the Resource Conservation and Recovery Act (RCRA). A principal concern of this legislation is the potential for releasing hazardous or toxic chemical substances into surface or ground water systems as a result of runoff or chemical leaching through soils. To a large extent, the focus of this concern has been wastes from various chemical and industrial processes (as opposed to those from coal-conversion processing). Nonetheless, as air and water pollution regulations have prohibited or minimized the release of coal-related pollutants to the water and air, their presence in solid wastes has grown in significance.

The designation of wastes as either hazardous or non-hazardous under RCRA is perhaps the most critical factor affecting coal-gasification processes. At the present time, EPA regulations treat high-volume wastes from coal combustion at electric power plants as a special category exempt from the procedures for determining toxicity on a case-by-case basis. Limited testing of wastes from coal-gasification plants shows characteristics similar to those from conventional coal combustion, though coal-gasification plant wastes are not currently exempt from RCRA. Wastes found to be hazardous according to EPA criteria must be handled and disposed of in special disposal sites, adding considerabley to the complexity and cost of disposal. These regulations are still developing and could affect coal-gasification facilities in the future. In addition, state and local regulations also apply, which may be more stringent than Federal regulations or guidelines for waste disposal.

\section{2-3. Future Regulatory Directions}

The clear trend toward increasingly stringent regulation of emissions to air, water and land has significant implications for the 
development of coal-gasification processes. In particular, the following regulatory directions are likely to be of special importance: (i) New Source Performance Standards for conventional pollutants (e.g., $\mathrm{SO}_{2}$, $\mathrm{NO}_{x}$, TSP) will continue to become more stringent as better technology becomes available to reduce emissions below currently achievable levels. (ii) Concern over hazardous and toxic substances is rapidly expanding the list of pollutants of concern to include many organic species and trace elements not heretofore regulated or measured (or, in some cases, measurable). This is a multi-media problem, affecting air pollutants, water pollutants and solid wastes. (iii) The policy of zero discharge of waste-water contaminants will continue to play an important role in the design and siting of coal-gasification facilities. Indirectly, it will also increase the severity of solid-waste disposal-problems. (iv) Regulations regarding the handling and disposal of solid wastes will continue to grow in importance. For example, regulations recently proposed by EPA include a modification of the procedure used to determine leachate toxicity, adding organics and other e1ements to the test criteria. The current exemption of coal ash and slag as non-hazardous under RCRA would also be removed. These changes would introduce a high degree of uncertainty that coal-gasification wastes could consistently be classsified as non-hazardous.

All of these items have implications for coal-gasification research needs. Recommended research to address current environmental issues and anticipate new ones in the future are discussed at the end of this chapter, following a review of recent characterization studies and current methods of environmental control.

\subsection{Environmental Emissions from Coal Gasification}

Table 9.3-1 summarizes some of the potential pollutants associated with coal-gasification plants. Gasification plants potentially constitute a major source of water pollutants, in addition to air pollutants and solid wastes. Because coal is chemically complex, gasification reactions are capable of directly or indirectly producing a wide range of organic and inorganic compounds whose presence may constitute an environmental problem or hazard. 


\section{3-1. Process Overview}

To highlight the nature and sources of environmental emissions of concern, we show in Fig. 9.3-1 a typical configuration for a plant producing low- or medium-BTU gas (in this case for electric power generation). Coal may first go through a preparation or pre-treatment step, which may give rise to small quantities of particulate matter and (if mild heating is involved) sulfur dioxide emissions. This step is typically well controlled.

Table 9.3-1. Some potential pollutants from coal-gasification plants,

\begin{tabular}{|c|c|c|}
\hline Air & Water & Land \\
\hline $\mathrm{SO}_{2}$ & $\mathrm{NH}_{3}$ & Slags \\
\hline $\mathrm{NO}_{x}$ & $\Phi O H$ & Ash slurries \\
\hline $\operatorname{TSP}$ & $\mathrm{CN}$ & Fines \\
\hline $\mathrm{HCs}$ & SCN & Dry residues \\
\hline $\mathrm{CO}$ & $B O D$ & Waste treatment \\
\hline $\mathrm{H}_{2} \mathrm{~S}$ & COD & Sludges \\
\hline COS & TOC & Spent catalyst \\
\hline $\mathrm{NH}_{3}$ & TSS & \\
\hline $\mathrm{HCl}$ & TDS & \\
\hline $\mathrm{HCN}$ & $\mathrm{pH}$ & \\
\hline Metals & $\mathrm{H}_{2} \mathrm{~S}$ & \\
\hline \multirow[t]{6}{*}{ Organics } & $\mathrm{S}_{2} \mathrm{O}_{3}=$ & \\
\hline & $\mathrm{SO}_{4}=$ & \\
\hline & $\mathrm{CI}^{-}$ & \\
\hline & $F^{-}$ & \\
\hline & Alkalinity & \\
\hline & Oils/grease & \\
\hline
\end{tabular}

* Power generation represents an environmental worst case since the coalgas products are burned, releasing pollutants into the environment. Other applications, such as chemical manufacture or high-BTU gas production, involve converting or upgrading the product into a useful form, which reduces the environmental consequences at the gasification facility. 


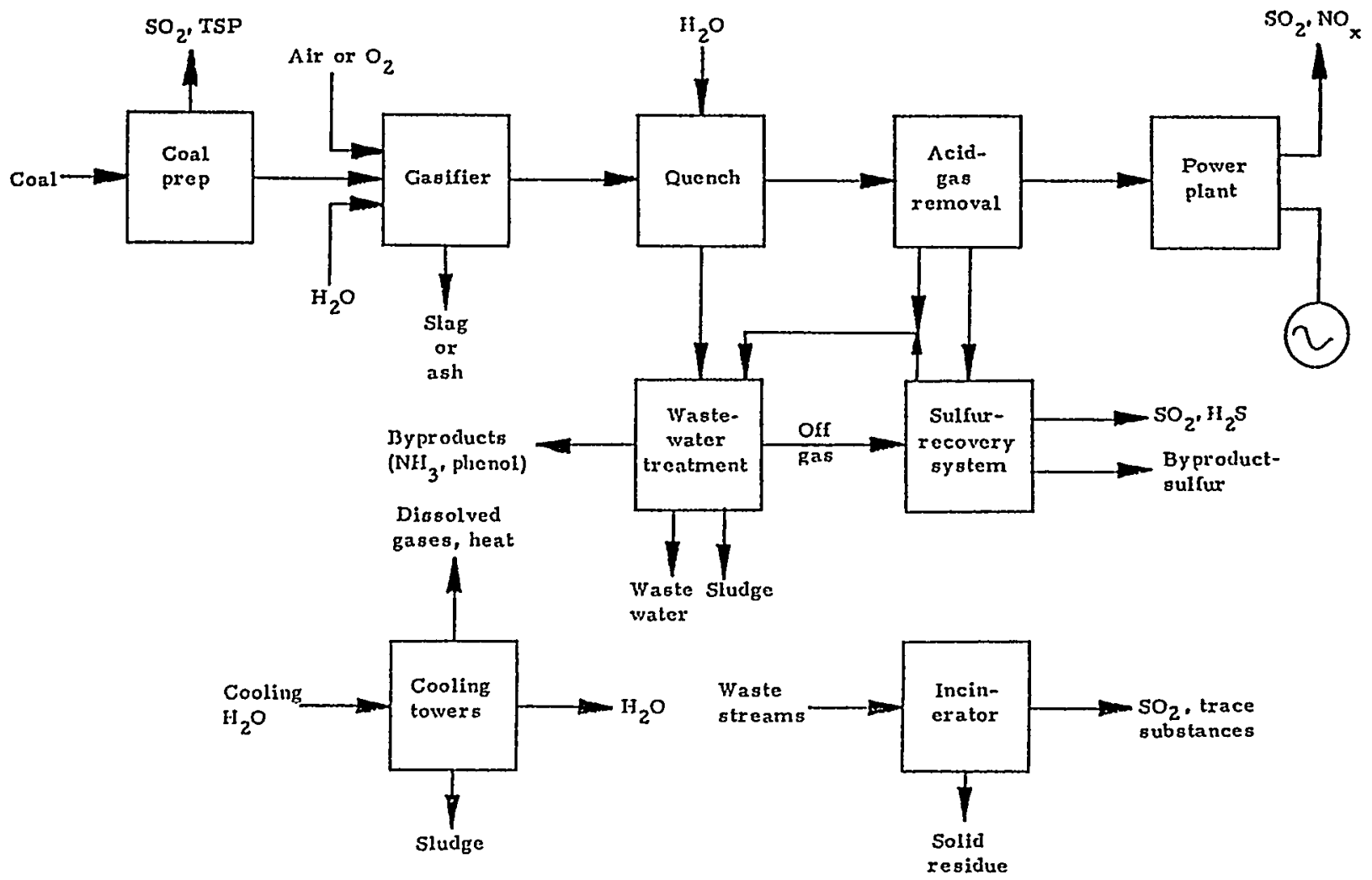

Fig. 9.3-1. Typical environmental control and emissions for coal-gasification processes.

Emissions from the gasifier itself consist primarily of slag or ash, which is quenched or sluiced with water upon removal. After exiting the gasifier, the gas products are typically cooled by water quenching (or other form of cooling) to remove particulate matter and gas-phase condensables. This procedure gives rise to the principal wastewater stream associated with coal-gasification plants. The product gas is next routed to an acid-gas removal-system where sulfur (predominantly in the form of $\mathrm{H}_{2} \mathrm{~S}$ ) is removed. If the product gas is then used for power generation, it is combusted, giving rise to conventional air-pollutant emissions (primarily $\mathrm{SO}_{2}$ and $\mathrm{NO}_{\mathrm{x}}$ ).

Other sources of emissions are the various environmental control technologies used to treat primary waste streams. These include the wastewater-treatment system, sulfur-recovery system, cooling towers, and any flares or incinerators included in the plant design. Figure 9.3-1 shows the types of environmental emissions typically associated with these components. 
Thus, coal-gasification processes represent potentially significant sources of air pollutants, water pollutants and solid wastes.

\section{3-2. Recent Characterization Studies}

Recent characterization studies of emissions from coal-gasification facilities have been conducted by the US DoE and EPA. Most of this work was conducted in the mid-to-late 1970 s and early $1980 \mathrm{~s}$ when the potential for a significant coal-gasification industry in the US appeared real. The DoE work focused primarily on a number of pilot plants

constructed in the 1970 s to test several advanced gasification processes. 3-5 EPA studies focused more intensively on commercial gasification facilities in different parts of the world. A series of recently published reports by EPA summarizes the results of its multi-year testing program ${ }^{6-8}$ and provides a comprehensive overview of environmental data for coal-gasification facilities. These summaries cover a variety of gasifier types and characterize emissions of air pollutants, water pollutants and solid wastes. Environmental characterization studies have also been carried out at the Great Plains gasification facility in North Dakota and at the Cool Water plant in California, and some information from these facilities is now becoming available. These plants are discussed later in this chapter.

\section{3-2A. Air Pollutants}

Tables 9.3-2 and 9.3-3 summarize features of the ten coal-gasification facilities characterized in the EPA studies. These include both air-blown and oxygen-blown gasifiers, encompassing fixed-bed, fluidized-bed, and entrained-bed designs.

The characterization of air-pollutant emissions is focused on sulfur and nitrogen species, which are the key pollutants of concern in coal gasification. Figure 9.3-2 summarizes the partitioning of sulfur among various outlet streams for each of the gasifiers tested. ${ }^{6}$ Most of the total sulfur in coal is converted to gaseous species, with small amounts of sulfur 
exiting the gasifier in process waters and solids. Figure 9.3-3 shows the distribution of sulfur species in the vapor phase. Most of the product gas sulfur is seen to be in the form of $\mathrm{H}_{2} \mathrm{~S}$, which accounts for $82-94 \%$ of the total vapor-phase sulfur in the eight gasification processes for which data were available. Reduced sulfur species, including carbonyl sulfide (COS), methyl mercaptan $\left(\mathrm{CH}_{3} \mathrm{SH}\right)$, ethyl mercaptan $\left(\mathrm{C}_{2} \mathrm{H}_{5} \mathrm{SH}\right)$, and carbon disulfide $\left(\mathrm{CS}_{2}\right)$ generally were present at detectable levels where analyses were conducted. The most prevalent of these species was COS, which averaged about $10 \%$ for the processes tested.

The fate of total nitrogen generally parallels the outlet sulfur distribution, with the majority of nitrogen exiting in the gas stream, as shown in Fig. 9.3-4. In these cases, however, several of the gasifiers have significant quantities of nitrogen in aqueous and by-product tar streams. Most of the vapor-phase nitrogen appears as ammonia, with the balance appearing as cyanide and thiocynate (Fig. 9.3-5). For the four low-BTU gas processes for which data were available, ammonia accounted for $81-87 \%$ of the vapor-phase nitrogen (excluding $\mathrm{N}_{2}$ ). No vapor-phase volatile amines of low molecular weight organo-nitrogen species determinations were reported for these processes. For two of the gasifiers (Lurgi and Koppers-Totzek, ) the low ammonia levels correspond to conditions downstream after an aqueous quench rather than upstream, as in the other cases. A11 of the gasification systems incorporate some type of quenching or cooling step downstream of the gasifier, in which nearly all of the nitrogen compounds are transferred to an aqueous phase.

Other potential air pollutants from coal-gasification facilities involve various fugitive emissions from cooling towers, seals, flanges, etc., and particulate emissions resulting from carryover of gasifier solids. Particulate emissions, however, are not usually significant because of the quenching and downstream processing that removes virtually all solids from the gas. To the extent particulate emissions are significant, they are most likely to be found at auxiliary facilites such as coal-fired steam plants or solid-waste incinerators. Fugitive emissions, on the other hand, have not been well characterized in past studies and represent an area where additional research is needed. 
Table 9.3-2. Coal and coal-gasification facility type (Ref. 6).

\begin{tabular}{|c|c|c|c|c|}
\hline Type of Gasifier & Site & Type of Coal & $\begin{array}{l}\text { Year } \\
\text { of } \\
\text { Study }\end{array}$ & $\begin{array}{l}\text { Product Gas } \\
\text { Feat } \\
\text { Content }\end{array}$ \\
\hline Chapman-Wilputte & Kingsport, TN & Virginia bituminous & 1978 & Low \\
\hline $\begin{array}{l}\text { Foster-Wheeler/ } \\
\text { STOIC }\end{array}$ & $\begin{array}{l}\text { Univ. of } \\
\text { Minnesota } \\
\text { (Duluth) }\end{array}$ & $\begin{array}{l}\text { Bituminous coal from Pinnada } \\
\text { Seam }\end{array}$ & 1981 & Low \\
\hline Koppers-Totzek & $\begin{array}{l}\text { Modderfontein, } \\
\text { So. Africa }\end{array}$ & $\begin{array}{l}\text { Bituminous, ligh volatile coal } \\
\text { from So. Africa }\end{array}$ & 1979 & Medium \\
\hline Lurgi, dry ash & $\begin{array}{l}\text { Westfield, } \\
\text { Scotland }\end{array}$ & $\begin{array}{l}\text { Rosebud, sub-bituminous coal } \\
\text { from Montana; bituminous } \\
\text { coals from Percy, Tllinois; } \\
\text { and Pittsburgh non-caking and } \\
\text { non-swelling coal from the } \\
\text { Federal No. I mine }\end{array}$ & $\begin{array}{l}1973- \\
1974\end{array}$ & Medium \\
\hline $\begin{array}{l}\text { Lurgi-type, dry } \\
\text { ash }\end{array}$ & $\begin{array}{l}\text { Kosovo, } \\
\text { Yugoslavia }\end{array}$ & Lignite from Kosovo mine & 1981 & Medium \\
\hline $\begin{array}{l}\text { Luxgi, tri-state } \\
\text { synfuels test }\end{array}$ & $\begin{array}{l}\text { Sasolburg, } \\
\text { So. Africa }\end{array}$ & Western Kentucky coal & 1981 & Medium \\
\hline $\begin{array}{l}\text { Riley (modifica- } \\
\text { tion of Morgan } \\
\text { Gas Producer) }\end{array}$ & $\begin{array}{l}\text { Worchester, } \\
\text { MA }\end{array}$ & North Dakota lignite & 1979 & Low \\
\hline KRW-PDU & Madison, PA & $\begin{array}{l}\text { Wyoming sub-bituminous coal, } \\
\text { Pittsburgh No. } 8 \text { bituminous coal, } \\
\text { and North Dakota lignite }\end{array}$ & 1983 & Medium \\
\hline Texaco & $\begin{array}{l}\text { Ruhrkohle/ } \\
\text { Ruhrchemie, } \\
\text { FRG }\end{array}$ & Illinois bituminous coal & 1980 & Medium \\
\hline Wellman-Galusha & $\begin{array}{l}\text { Glen-Gery } \\
\text { Brick Co., } \\
\text { York, PA }\end{array}$ & PennsyIvania anthracite & 1978 & Low \\
\hline Wellman-Galusha & Fort Snelling & $\begin{array}{l}\text { North Dakota lignite } \\
\text { (Indianhead) }\end{array}$ & 1978 & Low \\
\hline
\end{tabular}

\section{3-2B. Water Pollutants}

The quantity and quality of wastewaters produced by coal-gasification facilities depend significantly upon the gasifier type, the feed-coal characteristics, and the nature of gas cleanup and ash-removal/handling systems. Wastewaters may be categorized into two gen- 


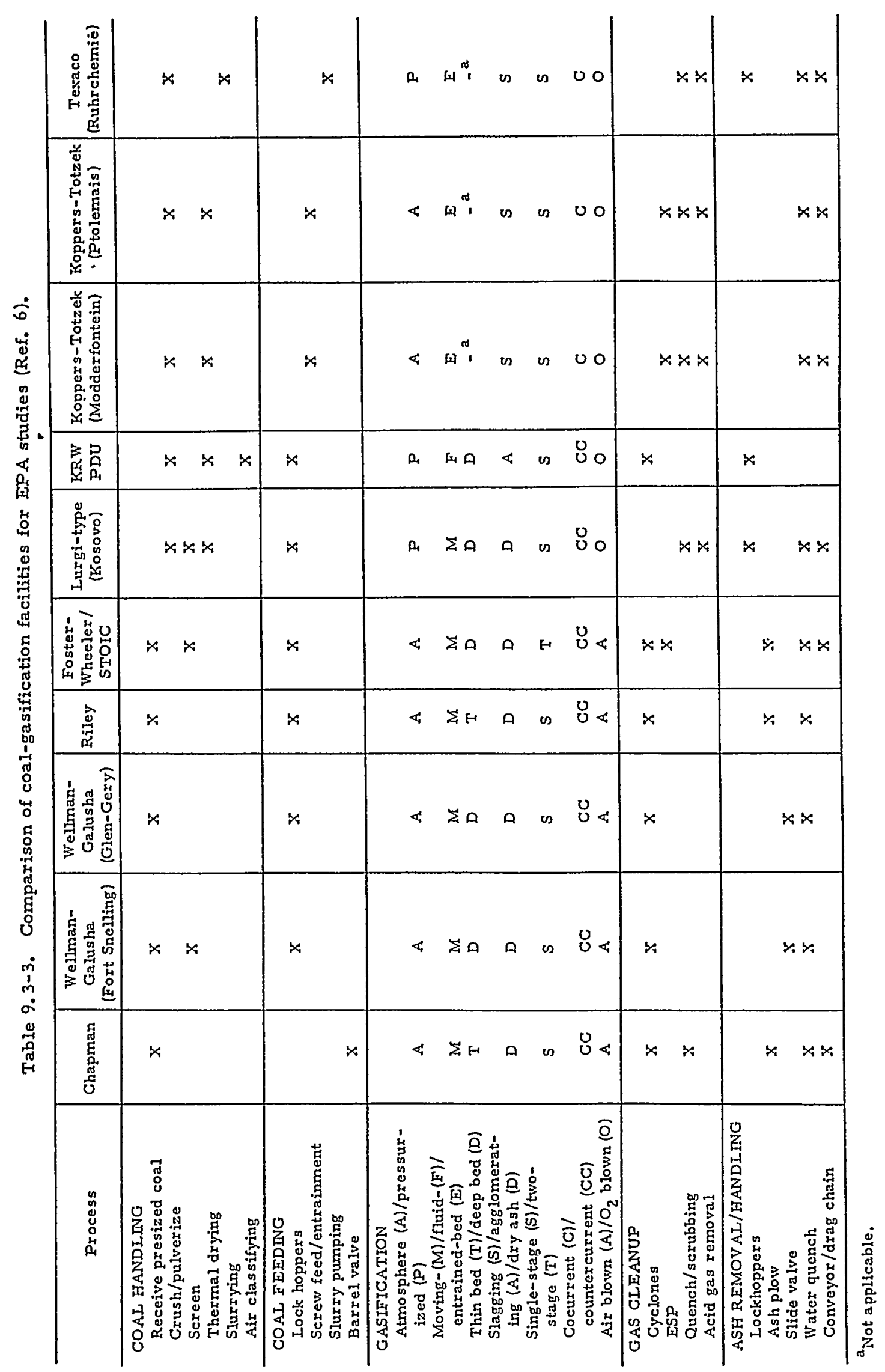



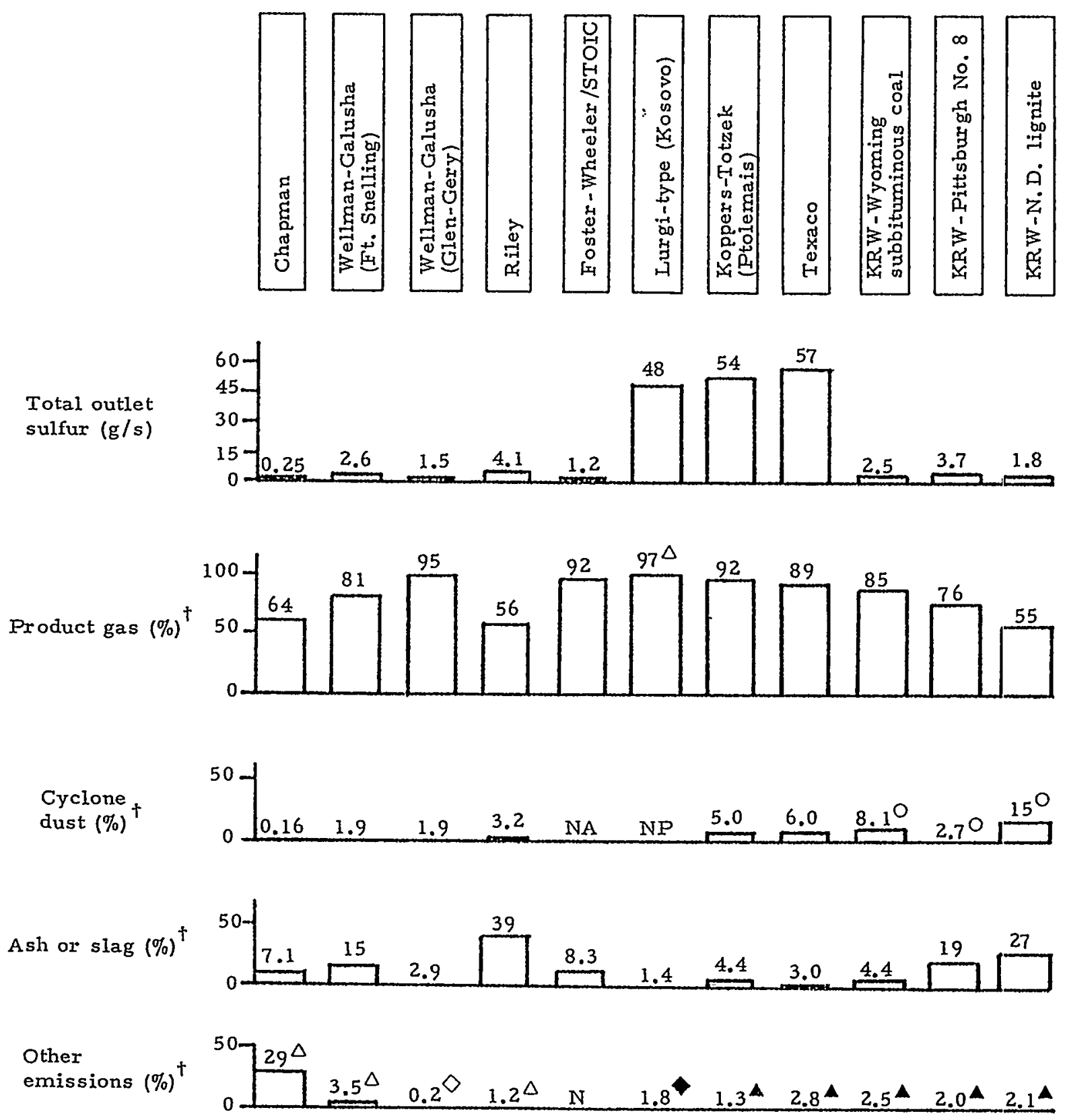

${ }^{\dagger}$ As percent of the total outlet sulfur

OSludge cyclone dust is recycled

$\Delta_{\text {By-product tar }}$ $\mathrm{N}=$ Negligible or nonexistent $\quad \mathrm{NA}=$ Not analyzed $\quad \mathrm{NP}=$ Not present

Vent gases are $1.5 \%$ of total, aqueous discharges are $0.3 \%$

$\diamond_{\text {Vent gases }}$

Aqueous discharges

Fig. 9.3-2. Sulfur distribution among outlet streams (Ref. 6). 

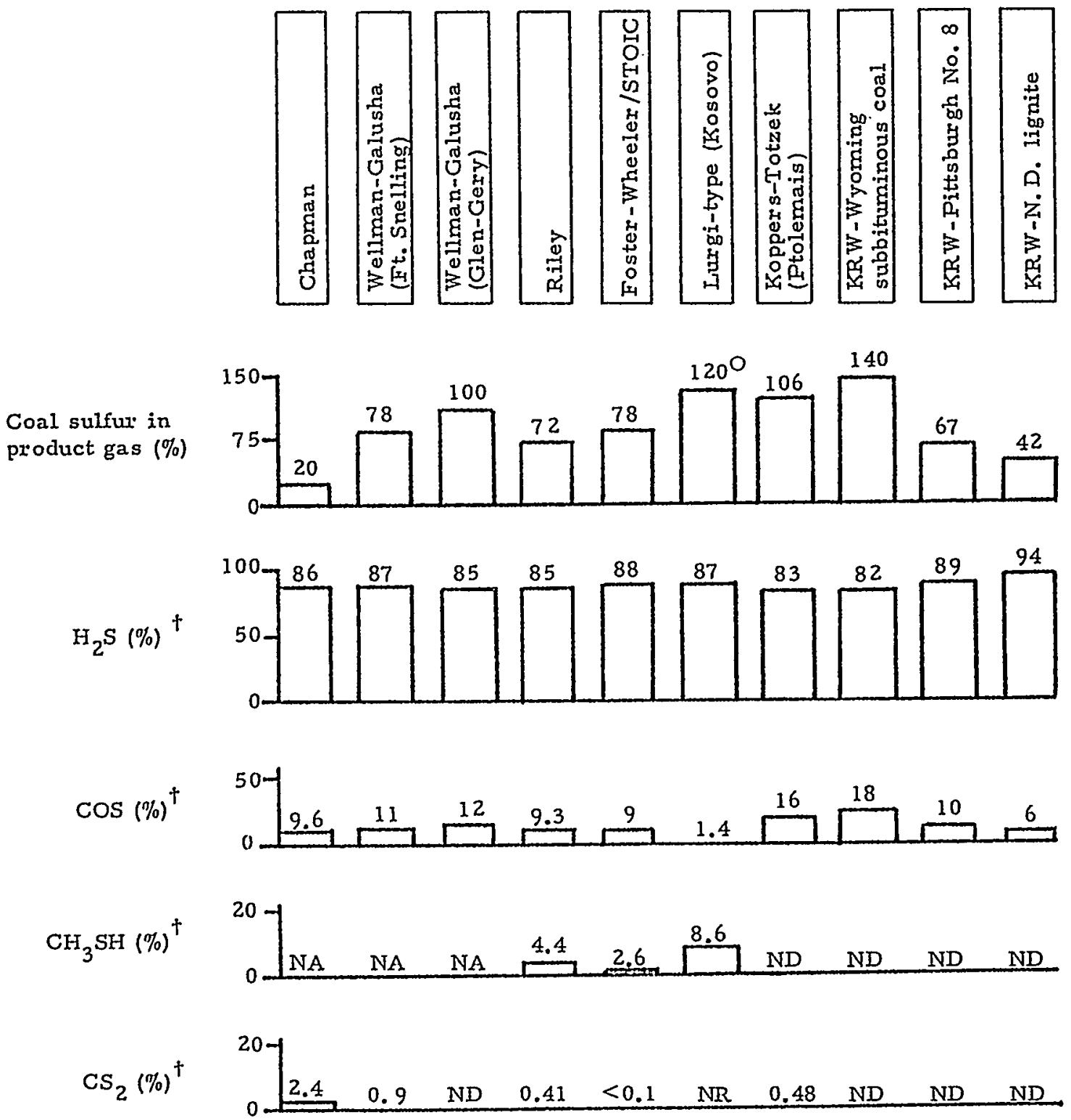

\begin{tabular}{|c|c|}
\hline${ }^{\dagger}$ Percent of product gas sulfur & NA $=$ Not analyzed \\
\hline $\begin{array}{l}{ }^{O} \text { Crude product gas, includes } \\
\text { tar/oil }\end{array}$ & $\begin{aligned} \mathrm{ND}= & \text { Not detected } \\
& (<\sim 3 \text { ppmv })\end{aligned}$ \\
\hline
\end{tabular}

Fig. 9.3-3. Distribution of vapor-phase sulfux species (Ref. 6). 

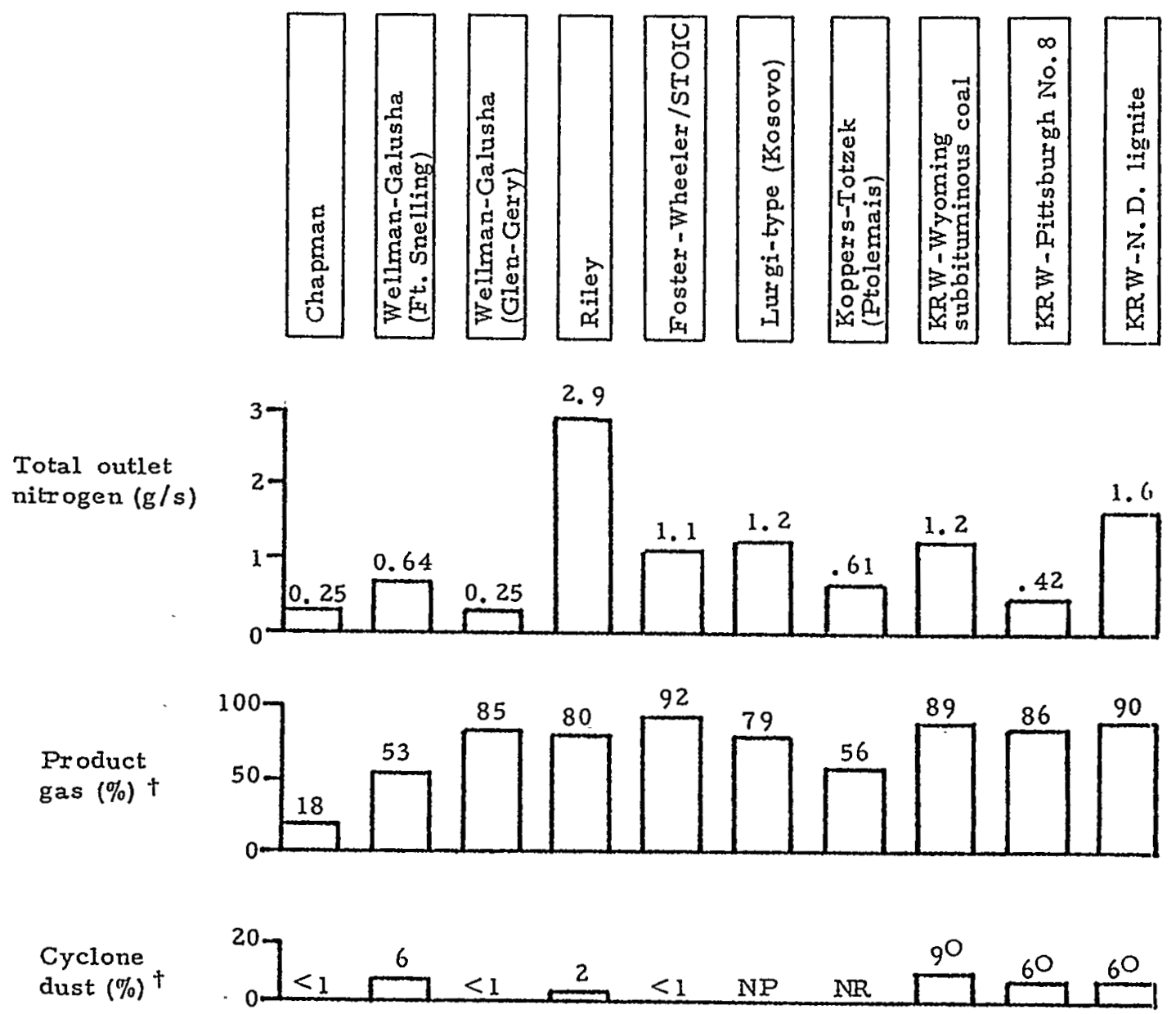

Ash or slag (\%) $\left.{ }_{0}^{+20}\right]_{N D}$

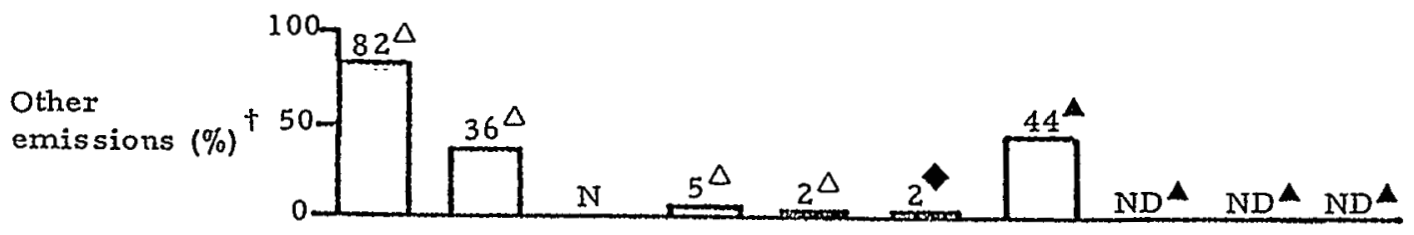

${ }^{\dagger}$ As percent of the total outlet nitrogen

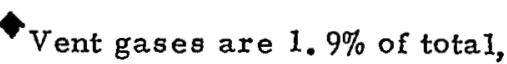
aqueouts discharges are $0.2 \%$

OSludge cyclone dust is recycled

Aqueous discharges

$\Delta_{\text {By-product tar }}$

$$
\begin{array}{ll}
\mathrm{N}=\text { Negligible or nonexistent } & \text { ND }=\text { Not detected } \\
\mathrm{NP}=\text { Not present } & \text { NR }=\text { Not reported }
\end{array}
$$

Fig. 9.3-4. Nitrogen distribution among outlet streams, excluding $\mathrm{N}_{2}$ (Ref. 6). 

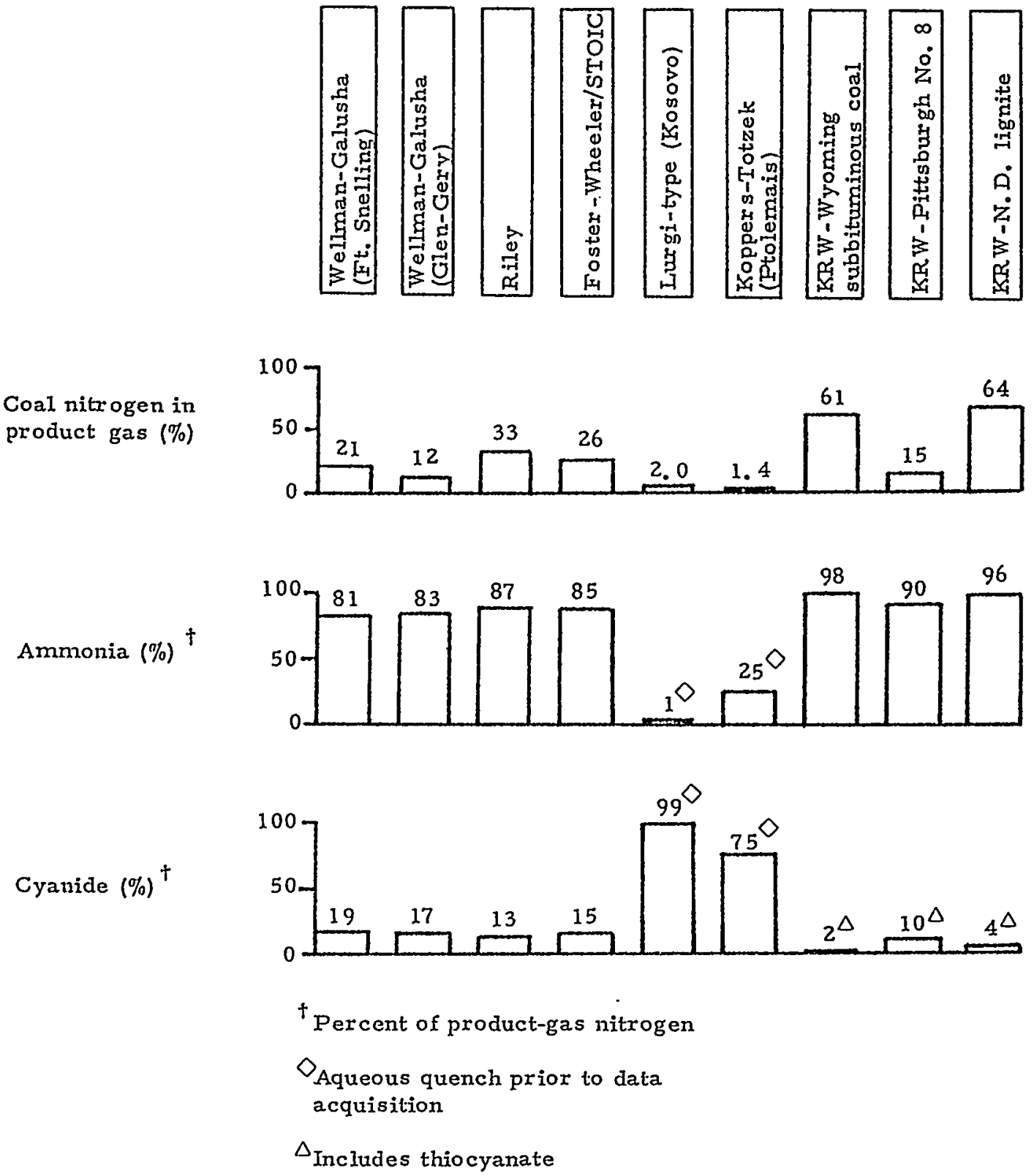

Fig. 9.3-5. Distribution of vapor-phase nitrogen species (Ref. 6).

eral groups: those from tar-producing gasifiers and those from non-tar producing gasifiers. The former refer to fixed-bed systems which produce substantial quantities of phenolics, oils and tars, while the latter category includes ash-agglomerating, fluidized-bed, and entrained-bed gasifiers which produce little or none of these pollutants.

Coal gasification wastewaters include gas-quench condensates, 
cyclone-dust quenchwaters, ash-pan waters, gas-compression and cooling condensates, acid-gas removal waters, and leachates from slag and ash-disposal facilities. Among these, the quench condensates represent the principal wastewater source in terms of pollutant strength and stream volume (Table 9.3-4). The aqueous pollutants of greatest environmental concern are ammonia, cyanide, phenols, and sulfur compounds (primarily suflides).

Characterizations of wastewater contaminants were conducted by EPA for the ten low- and medium-BTU coal gasifiers shown in Table 9.3-2. ${ }^{7}$ Tar producing (fixed-bed) systems are the Chapman, Wellman-Galusha, Riley, Foster Wheeler/STOIC, and Lurgi processes. Entrained-bed gasifiers are represented by the Koppers-Totzek and Texaco processes, while the KRW process development unit (PDU) represents an ash-agglomerating fluidized bed process. Waterwater data were catalogued in terms of conventional pollutants (e.g. BOD, $\mathrm{COD}, \mathrm{NH}_{3}$, TDS, etc.), trace elements, and organics. Wastewater sources were treated in three general categories: (i) process waters from the gasifier, particulate removal, gas cooling, and acid-gas removal operations, ( $i i)$ process waters from ash and slag handling, and ( $i j i$ ) leachates from gasification slag and ash.

Tables 9.3-5 to 9.3-11 summarize the EPA data on conventional pollutants, trace metals, and organics in some of the major process streams of tar- and non-tar producing coal-gasification wastewaters. These data con-

Table 9.3-4. Normalized production of quench liquors/gas-cooling condensates (Ref. 7).

\begin{tabular}{|c|c|c|c|c|c|}
\hline Casifier & Coal & $\begin{array}{c}\text { Wastewater } \\
\text { produced, } \\
\text { kg water } / \mathrm{kg} \text { coal }\end{array}$ & $\begin{array}{c}\text { Stcam } \\
\text { consumed, } \\
\mathrm{kg} \text { steam } / \mathrm{kg} \text { coal }\end{array}$ & $\begin{array}{c}\text { Tar/oil } \\
\text { produced, } \\
\mathrm{kg} \text { T-O/kg coal }\end{array}$ & $\begin{array}{c}\text { Phenols } \\
\text { producod, } \\
\mathrm{kg} \mathrm{C}_{6} \mathrm{~N}_{5} \text { OH1/kg coal } \\
\end{array}$ \\
\hline \multirow[t]{5}{*}{ Lurgi ${ }^{2}$} & Montana Rosebud ${ }^{b}$ & 1.0 & 1.25 & 0.04 & 0.004 \\
\hline & Ulinois No. $6^{b}$ & 2.1 & 2.51 & 0.03 & 0.005 \\
\hline & Illinols No. $5^{b}$ & 1.8 & 2.25 & 0.05 & 0.005 \\
\hline & Pittsburgh No. $8^{b}$ & 2.6 & 3.24 & 0.05 & 0,004 \\
\hline & Montana Rosebud $^{c}$ & 0.9 & 1.01 & 0.04 & 0.005 \\
\hline Texaco $^{d}$ & Illinois No. $6^{\mathrm{e}}$ & $0.7-1.3$ & $0.78^{f}$ & g & g \\
\hline Koppers-Totzek ${ }^{\text {h }}$ & Jllinois No. $6^{\mathrm{c}}$ & 0.9 & $\mathrm{~N} \Lambda^{i}$ & & g \\
\hline $\begin{array}{l}{ }^{a} \text { Lurgi gasifier at } \\
\text { b Coarse graded }(6 \\
c_{\text {Fine graded (2-1 }} \\
d_{\text {Ruhrkolie/Rulurc }} \\
{ }^{\text {e Pulverized }(<2,}\end{array}$ & $\begin{array}{l}\text { Vestrield, Scotland. } \\
32 \mathrm{~mm} \text { ). } \\
\mathrm{mm}) \text {. } \\
\text { lemic in Oberhausen- } \\
\mathrm{m}) \text {. }\end{array}$ & Iolten, FRG. & $\begin{array}{l}\text { fsteam flow rate } \\
\text { slurry water, co } \\
\text { ancl flocculants. } \\
\text { g }_{\text {Negligible. }} \\
\text { h'TVA projectiona. } \\
\text { 'NA - data not ava }\end{array}$ & $\begin{array}{l}\text { taken as the sur } \\
\text { molsture, and }\end{array}$ & $\begin{array}{l}\text { of freslimakeup } \\
\text { vatex in additive }\end{array}$ \\
\hline
\end{tabular}


Table 9.3-5. Conventional pollutants in coal-gasification wastewaters (Ref. 7). ${ }^{2}$

\begin{tabular}{|c|c|c|c|c|c|c|c|c|c|c|}
\hline \multirow{2}{*}{$\begin{array}{c}\begin{array}{c}\text { Gasificntion } \\
\text { system }\end{array} \\
\begin{array}{c}\text { Type of waste- } \\
\text { water }\end{array}\end{array}$} & \multirow{2}{*}{$\frac{\text { Rlley }}{\text { Asli pan }}$} & \multirow{2}{*}{$\begin{array}{c}\text { Chapman } \\
\begin{array}{c}\text { Separator } \\
\text { liquor }\end{array}\end{array}$} & \multirow{2}{*}{$\begin{array}{c}\text { Wollnian- } \\
\text { Galusha } \\
\text { at Fort } \\
\text { Snelling } \\
\text { Gyclone- } \\
\text { dust } \\
\text { quencli- } \\
\text { water }\end{array}$} & \multicolumn{4}{|c|}{ Koppers-Totzek at Modderfontein } & \multicolumn{3}{|c|}{ KRW-PDU } \\
\hline & & & & $\begin{array}{c}\text { Com- } \\
\text { pressor } \\
\text { con- } \\
\text { densate }\end{array}$ & $\begin{array}{l}\text { Com- } \\
\text { pressor } \\
\text { con- } \\
\text { densate }\end{array}$ & Rectisol $1^{\mathrm{b}}$ & Rectisol ${ }^{c}$ & $\begin{array}{l}\text { Sub- } \\
\text { bituminous } \\
\text { coal }\end{array}$ & $\begin{array}{c}\text { Bituminous } \\
\text { coal }\end{array}$ & Lignite \\
\hline $\begin{array}{l}\text { pH, standard } \\
\text { units }\end{array}$ & 11.3 & 7.66 & 20.0 & 8.2 & 8.0 & .9 .1 & 8.1 & 8.4 & 8.4 & 8.7 \\
\hline TDS & 2,160 & 6,300 & 390 & 260 & 170 & 1,390 & 1,640 & 390 & 331 & 2.219 \\
\hline TSS & 32 & 114 & d & $<1$ & 12 & 70 & 20 & 4,600 & 3,100 & 1,000 \\
\hline $\begin{array}{l}\text { Hardness as } \\
\mathrm{CaCO}_{3}\end{array}$ & & & & 60 & 46 & 691 & 554 & & & \\
\hline $\begin{array}{l}\text { Alkalinity as } \\
\mathrm{CaCO}_{3}\end{array}$ & & 2,110 & & 2,990 & 2,690 & 78 & 144 & 6,770 & 2,382 & 12,067 \\
\hline $\begin{array}{r}\text { Conductivity } \\
(\mu \mathrm{m} / \mathrm{s} / \mathrm{cm})\end{array}$ & 2,900 & 32,000 & & 6,000 & 5,500 & 1,800 & 2,000 & 12,300 & 5,200 & 16,700 \\
\hline COD & 87 & 22,200 & 800 & 641 & 569 & 28 & 1,000 & 150 & 237 & 115 \\
\hline TOC & 15 & & 185 & & & & & 48 & 55 & 170 \\
\hline BOD & 41 & 6,530 & 85 & & & & & & & \\
\hline $\mathrm{NH}_{3}$ (total) & & 5,000 & 0.97 & 973 & 900 & 26 & 49 & 2,430 & 965 & 1,125 \\
\hline $\mathrm{CN}^{-}$ & $N^{e}$ & 1,000 & 0.36 & 7.3 & 10.5 & 2.8 & ND & 2.2 & 59 & 62 \\
\hline $\mathrm{SCN}^{-}$ & $<4$ & 70 & & 10.9 & 17.1 & 110 & 137 & 79 & 105 & 62 \\
\hline $\mathrm{H}_{2} \mathrm{~S}$ & & $<10$ & & 43.9 & 53.5 & 1.1 & 4.5 & 18 & 79 & 102 \\
\hline $\begin{array}{l}\mathrm{S}_{2} \mathrm{O}_{3} \\
\mathrm{SO}_{3}=\end{array}$ & & & 12 & $\begin{array}{l}4.8 \\
<1\end{array}$ & $\begin{array}{l}7.8 \\
<1\end{array}$ & $\begin{array}{c}18.5 \\
<1\end{array}$ & $\begin{array}{l}16.4 \\
<1\end{array}$ & 10 & 10 & 12 \\
\hline $\mathrm{SO}_{4}=$ & 1,380 & 1,000 & 55 & 56 & 49 & 461 & 541 & 225 & & 65 \\
\hline $\mathrm{PO}_{4}^{-3}$ & 0.06 & 60 & 0.1 & 2 & 3 & 0.1 & 2.8 & 3.7 & 0.6 & 1.5 \\
\hline Chloride & 110 & 300 & 34 & 23 & 13 & 153 & 158. & 22 & 493 & 61 \\
\hline Metianol & & & & ND & ND & $<0.1$ & $<0.1$ & & & \\
\hline $\mathrm{NO}_{3}^{-}$ & $<0.02$ & & $<0.5$ & & & & & 1.4 & 0.9 & \\
\hline $\mathrm{NO}_{2}^{-}$ & & & $<0.01$ & & & & & & & \\
\hline Fluorido & 0.71 & 200 & 2 & & & & & 1.8 & 25 & 30 \\
\hline Total sulfur & 18 & & & & & & & & & \\
\hline $\mathrm{NHI}_{3}$ fixed & $<30$ & & & & & & & & & \\
\hline Carbonate & $2 \times 10^{\circ}$ & & & & & & & & & \\
\hline \multicolumn{11}{|c|}{ 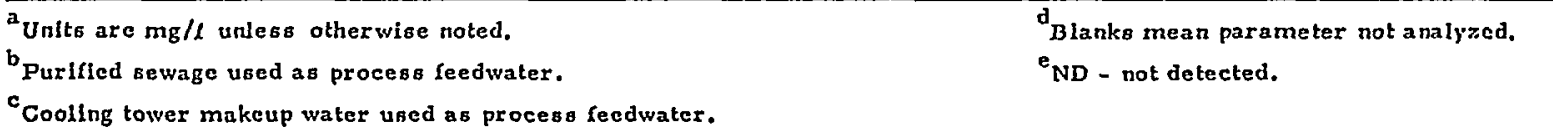 } \\
\hline
\end{tabular}


Table 9.3-6. Conventional pollutants in Iurgi coal-gasification wastewaters (Ref. 7 ). $^{a}$

\begin{tabular}{|c|c|c|c|c|c|c|c|c|c|}
\hline \multirow{2}{*}{$\begin{array}{c}\begin{array}{c}\text { Gasification } \\
\text { system }\end{array} \\
\begin{array}{c}\text { Type of } \\
\text { wastewater }\end{array}\end{array}$} & \multicolumn{4}{|c|}{ Lurgi at Sasolburg } & \multicolumn{2}{|c|}{$\begin{array}{l}\text { Lurgi at } \\
\text { Westfield }\end{array}$} & \multicolumn{3}{|c|}{ Lurgi-type at Kosovo } \\
\hline & $\begin{array}{c}\text { Raw-gas } \\
\text { liquor }\end{array}$ & $\begin{array}{l}\text { Extracted- } \\
\text { gas liquor }\end{array}$ & $\begin{array}{c}\text { Stripped } \\
\text { gas liquor }\end{array}$ & $\begin{array}{c}\text { Coal- } \\
\text { sluxry } \\
\text { water }\end{array}$ & $\begin{array}{c}\text { Gas } \\
\text { liquor } \\
b\end{array}$ & Gas ${ }^{c}$ & $\begin{array}{l}\text { Cyanic } \\
\text { water }\end{array}$ & $\begin{array}{c}\text { Gas } \\
\text { liquor }\end{array}$ & $\begin{array}{l}\text { Quenched- } \\
\text { ash d } \\
\text { water }\end{array}$ \\
\hline $\begin{array}{l}\mathrm{PHI}, \text { standard } \\
\text { units }\end{array}$ & 9.0 & 10.4 & 6.5 & & 7.63 & 8.1 & 11.9 & 9.2 & 8.1 \\
\hline TDS & $1,180^{e}$ & $390^{\mathrm{e}}$ & $420^{\mathrm{e}}$ & & 1,140 & 1,940 & 590 & 2,170 & 2,100 \\
\hline TSS & $<1$ & $<1$ & $<1$ & & $f$ & & 140 & 150 & 8,760 \\
\hline $\begin{array}{l}\text { Conductivity } \\
(\mu \mathrm{mho} / \mathrm{cm})\end{array}$ & 3,100 & 330 & 140 & 120 & & & & & \\
\hline COD & 12,000 & 990 & 1,400 & 170 & 5,900 & 18,600 & 205 & 18,900 & 1,460 \\
\hline TOC & & & & & & & & 4,970 & \\
\hline $\mathrm{BOD}$ & & & & & 4,300 & 12,250 & & 9,030 & 90 \\
\hline $\mathrm{NH}_{3}$ (total) & 6,600 & 5,500 & 390 & 25 & & & & & \\
\hline $\mathrm{CN}^{-}$ & & 0.85 & 0.17 & $<20$ & 16 & 8 & & $<1$ & 0.01 \\
\hline $\mathrm{SCN}^{-}$ & & & & $24 \mathrm{~g}$ & 210 & 60 & & $<75$ & 0.026 \\
\hline $\mathrm{H}_{2} \mathrm{~S}$ & 720 & 170 & $g$ & & 220 & 330 & & & Trace \\
\hline $\mathrm{SO}_{3}=$ & 240 & 55 & 40 & & & & & & Trace \\
\hline $\begin{array}{l}\mathrm{SO}_{4}^{=} \\
\mathrm{PO}_{4}^{-3}\end{array}$ & 8.7 & 5.2 & 16,0 & & & & & & 495 \\
\hline Chloride & 1,690 & 950 & 600 & & 160 & 9 & & & 28 \\
\hline $\mathrm{NO}_{3}^{-}$ & 99 & 12 & $<1$ & & & & & $<1$ & 4.8 \\
\hline $\mathrm{NO}_{2}^{-}$ & 0.15 & 0.03 & 0.04 & & & & & Trace & 0.4 \\
\hline Fluoride & 45 & 40 & 50 & & & & & & 0.91 \\
\hline Calcium & 3.2 & 1.9 & 2.9 & 770 & & & & & \\
\hline Magnesium & 0.51 & 0.46 & 1.0 & 91 & & & & & \\
\hline Sodium & 6.0 & 6.5 & 6.1 & 230 & & & & & \\
\hline $\begin{array}{c}\text { TDS after } \\
\text { ignition }\end{array}$ & & & & & 20 & 30 & & & \\
\hline Total sulfur & & & & & 340 & 450 & 60 & 84 & \\
\hline $\begin{array}{l}\text { Fatty acids } \\
\text { as acetic }\end{array}$ & & & & & 260 & 1,050 & & & \\
\hline $\mathrm{NH}_{3}$ - free & & & & & 4,090 & 8,930 & & 3,510 & Trace \\
\hline - fixed & & & & & 250 & 470 & & 250 & 1.9 \\
\hline Carbonate & & & & & 10,650 & 19,960 & & & \\
\hline Total solids & & & & & & & 730 & 2,230 & 10,900 \\
\hline $\begin{array}{l}\text { Total non- } \\
\text { volatile } \\
\text { solids }\end{array}$ & & & & & & & 560 & & 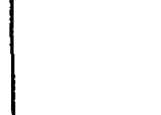 \\
\hline $\begin{array}{l}\text { Permanganate } \\
\text { number }\end{array}$ & & & & & & & 570 & 14,200 & 8,060 \\
\hline Tar \& oils & & & & & & & & $<400$ & \\
\hline $\begin{array}{l}{ }^{\mathrm{a}} \text { Units are mg } \\
\mathrm{b}_{\text {Wastewater a }} \\
\mathrm{c}_{\text {Wastewater a }} \\
\mathrm{d}_{\text {Includes coal }} \\
\text { vent-gas } \mathrm{scr} \text { u }\end{array}$ & $\begin{array}{l}\text { / le unless } \\
\text { associated } \\
\text { associated } \\
\text { bunker ve } \\
\text { abber blow }\end{array}$ & $\begin{array}{l}\text { otherwise } n \\
\text { with Pittsb } \\
\text { with Monta } \\
\text { ent-gas scru } \\
\text { downs. }\end{array}$ & $\begin{array}{l}\text { uoted. } \\
\text { urgh } \# 8 \text { coa } \\
\text { na Rosebud } \\
\text { abber and as }\end{array}$ & $\begin{array}{l}\text { coal. } \\
\text { sh-lock }\end{array}$ & $\begin{array}{l}\mathrm{e}_{\mathrm{T}} \\
\mathrm{f}_{\mathrm{B}} \\
\mathrm{at}_{\mathrm{r}} \\
\mathrm{gP}_{\mathrm{P}}\end{array}$ & $\begin{array}{l}\text { DS meas } \\
\text { lanks me } \\
\text { nalyzed. } \\
\text { ossible }\end{array}$ & $\begin{array}{l}\text { sured at } \\
\text { tean para } \\
\text { analytic: }\end{array}$ & $\begin{array}{l}180^{\circ} \mathrm{C} . \\
\text { ameter } \mathrm{n} \\
\text { al interf }\end{array}$ & $\begin{array}{l}\text { not } \\
\text { ferences. }\end{array}$ \\
\hline
\end{tabular}


Table 9.3-7. Trace elements in fixed-bed coal-gasification wastewaters (Ref. 7$)^{a}$

\begin{tabular}{|c|c|c|c|c|c|c|c|c|c|c|}
\hline $\begin{array}{c}\text { Gasification } \\
\text { system }\end{array}$ & $\begin{array}{l}\text { Foster - } \\
\text { Wheeler/ } \\
\text { STOIC }\end{array}$ & & Lurgi at Sa & solburg & & & $\begin{array}{l}\text { g1-type } \\
\text { Sosovo }\end{array}$ & Rlley & Chapman & $\begin{array}{l}\text { Wellman-Galusha } \\
\text { at Fort Snelling }\end{array}$ \\
\hline $\begin{array}{c}\text { Type of } \\
\text { wastewater }\end{array}$ & $\begin{array}{r}\text { Ash } \\
\text { pan }\end{array}$ & $\begin{array}{c}\text { Raw-gas } \\
\text { liquor } \\
\end{array}$ & $\begin{array}{l}\text { Extracted- } \\
\text { gas liquor }\end{array}$ & $\begin{array}{l}\text { Stripped- } \\
\text { gas liquor }\end{array}$ & $\begin{array}{l}\text { Coal- } \\
\text { slurry } \\
\text { water }\end{array}$ & $\begin{array}{c}\text { Cyanic } \\
\text { water }\end{array}$ & $\begin{array}{c}\text { Phenosolvan } \\
\text { effluent }\end{array}$ & $\begin{array}{l}\text { Ash } \\
\text { pan }\end{array}$ & $\begin{array}{c}\text { Separator } \\
\text { lliquor }\end{array}$ & $\begin{array}{l}\text { Cyclono-dust } \\
\text { quench-watex }\end{array}$ \\
\hline $\begin{array}{c}\text { Method of } \\
\text { analysis }\end{array}$ & $\operatorname{sSMS}^{\mathbf{b}}$ & ICPES $^{c}$ & ICPES & ICPES & ICPES & SSMS & SSMS & $\mathrm{AAS}^{\mathrm{d}}$ & SSMS & SSMS \\
\hline $\begin{array}{l}\text { Aluminum } \\
\text { Antimony } \\
\text { Arscnic } \\
\text { Barium } \\
\text { Berylilum } \\
\text { Boron } \\
\text { Bromine } \\
\text { Cadmium } \\
\text { Calcium } \\
\text { Gerlum } \\
\text { Cesium } \\
\text { Clilorine } \\
\text { Chromlum } \\
\text { Cobalt } \\
\text { Copper } \\
\text { Fluorine } \\
\text { Gallium } \\
\text { Germanium } \\
\text { Iodine } \\
\text { Iron } \\
\text { Lanthanum } \\
\text { Lead } \\
\text { Lithium } \\
\text { Magnesium } \\
\text { Manganese } \\
\text { Mercury } \\
\text { Molybdenum } \\
\text { Nickel } \\
\text { Niobium } \\
\text { Phosphorus } \\
\text { Potas Bium } \\
\text { Rubidium } \\
\text { Scandium } \\
\text { Selenium } \\
\text { Silicon } \\
\text { Silver } \\
\text { Sodlum } \\
\text { Strontium } \\
\text { Sulfur } \\
\text { Tellurium } \\
\text { Thallium } \\
\text { Thorium } \\
\text { Tin } \\
\text { Titanium } \\
\text { Uranium } \\
\text { Vanadium } \\
\text { Ytterbium } \\
\text { Yttrium } \\
\text { Zinc } \\
\text { Zirconium }\end{array}$ & 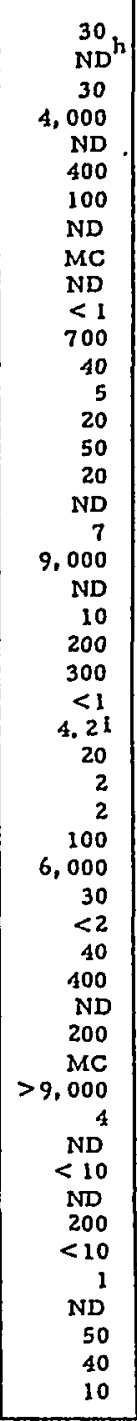 & $\begin{array}{c}430 \\
<2^{1} \\
<1 \\
510 \\
<1 \\
660^{1} \\
<2 \\
<3 \\
<200 \\
<40 \\
\\
600^{1} \\
7,900 \\
<2 \\
6,000 \\
14\end{array}$ & $\begin{array}{r}520 \\
<2^{i} \\
18 \\
460 \\
<1 \\
79^{1} \\
<2 \\
4 \\
<200 \\
<40 \\
\\
300^{1} \\
7,700 \\
<2 \\
6,500 \\
3 \\
<2^{1}\end{array}$ & $\begin{array}{r}5,600 \\
61^{i} \\
28 \\
1,000 \\
<1 \\
6.2^{i} \\
<2 \\
3 \\
<200 \\
2,400 \\
\\
89^{i} \\
7,800 \\
<2 \\
6,100 \\
15 \\
\\
<2^{i} \\
12^{i} \\
13^{i} \\
<2 \\
29\end{array}$ & $\begin{array}{c}M C \\
83^{i} \\
140 \\
M C \\
<1 \\
1.9^{i} \\
<2 \\
<3 \\
3,200 \\
<40 \\
\\
9^{i} \\
M C \\
<2 \\
M C \\
1,900 \\
M C \\
<2^{i}\end{array}$ & $\begin{array}{r}70 \\
\text { ND } \\
90 \\
20 \\
\text { ND } \\
20 \\
100 \\
\text { ND } \\
\text { ND } \\
\text { ND } \\
4 \\
4,000 \\
9 \\
\leq 3 \\
20 \\
300 \\
N D \\
20 \\
400 \\
4.000 \\
8 \\
8 \\
2 \\
M C \\
40 \\
N D \\
N D \\
7 \\
N D \\
N D \\
7,000 \\
<1 \\
52 \\
N D \\
1,000 \\
N D \\
30 \\
50 \\
N D\end{array}$ & $\begin{array}{r}100 \\
N D \\
20 \\
50 \\
N D \\
100 \\
9 \\
N D \\
6,000 \\
N D \\
N D \\
1,000 \\
5 \\
3 \\
30 \\
4,000 \\
N D \\
30 \\
20 \\
500 \\
N D \\
70 \\
3 \\
2,000 \\
10 \\
N D \\
N D \\
80 \\
N D \\
80 \\
1,000 \\
N D \\
55 \\
30 \\
1,000 \\
N D \\
4,000 \\
20 \\
M C \\
\text { ND } \\
\text { ND } \\
70 \\
N D \\
10 \\
20 \\
400 \\
530 \\
10\end{array}$ & $\begin{array}{c}1,900 \\
1.3 \\
58 \\
0.5\end{array}$ & 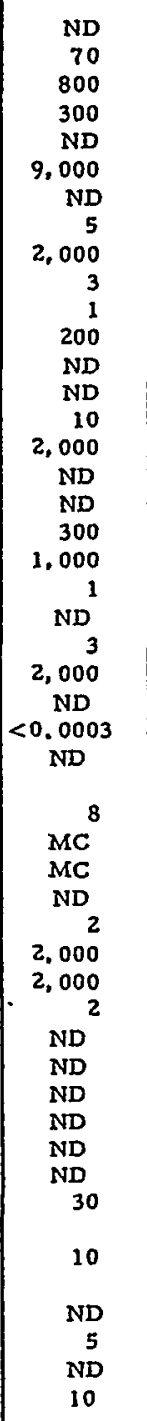 & 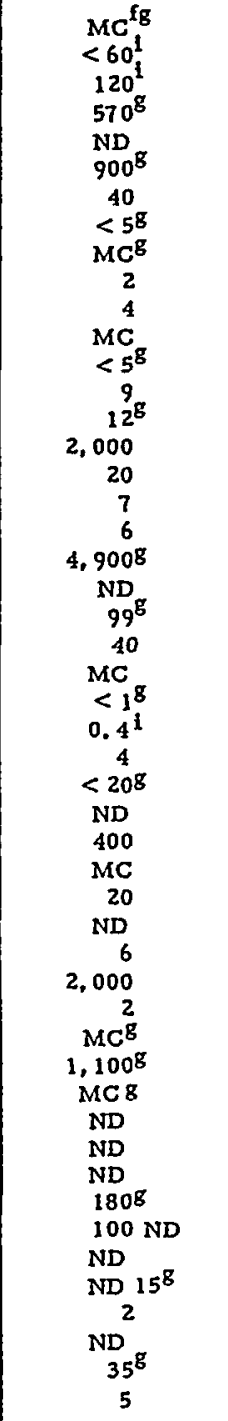 \\
\hline
\end{tabular}

${ }^{a}$ Units are $\mu \mathrm{g} / \mathrm{l}$ unless otherwise noted.

${ }^{b}$ SSMS - spark source mass spectrometry.

ICPES - induced coupled argon plasma-emission spectrometry.

dAAS - atomic absorption spectrophotometry.

eBlanks mean parameter not analyzed.

${ }^{f_{M C}}$ - major component in the wastewater, concentration greater than $10,000 \mu \mathrm{g} / \mathrm{l}$.

g Analyzed by induced coupled argon plasma-emission spectrometry.

hot detected.

${ }^{i}$ Analyzed by atomic absor ption spectrophotometry. 
Table 9.3-8. Trace elements in non-tar producing coal-gasification wastewaters (Ref. 7). ${ }^{a}$

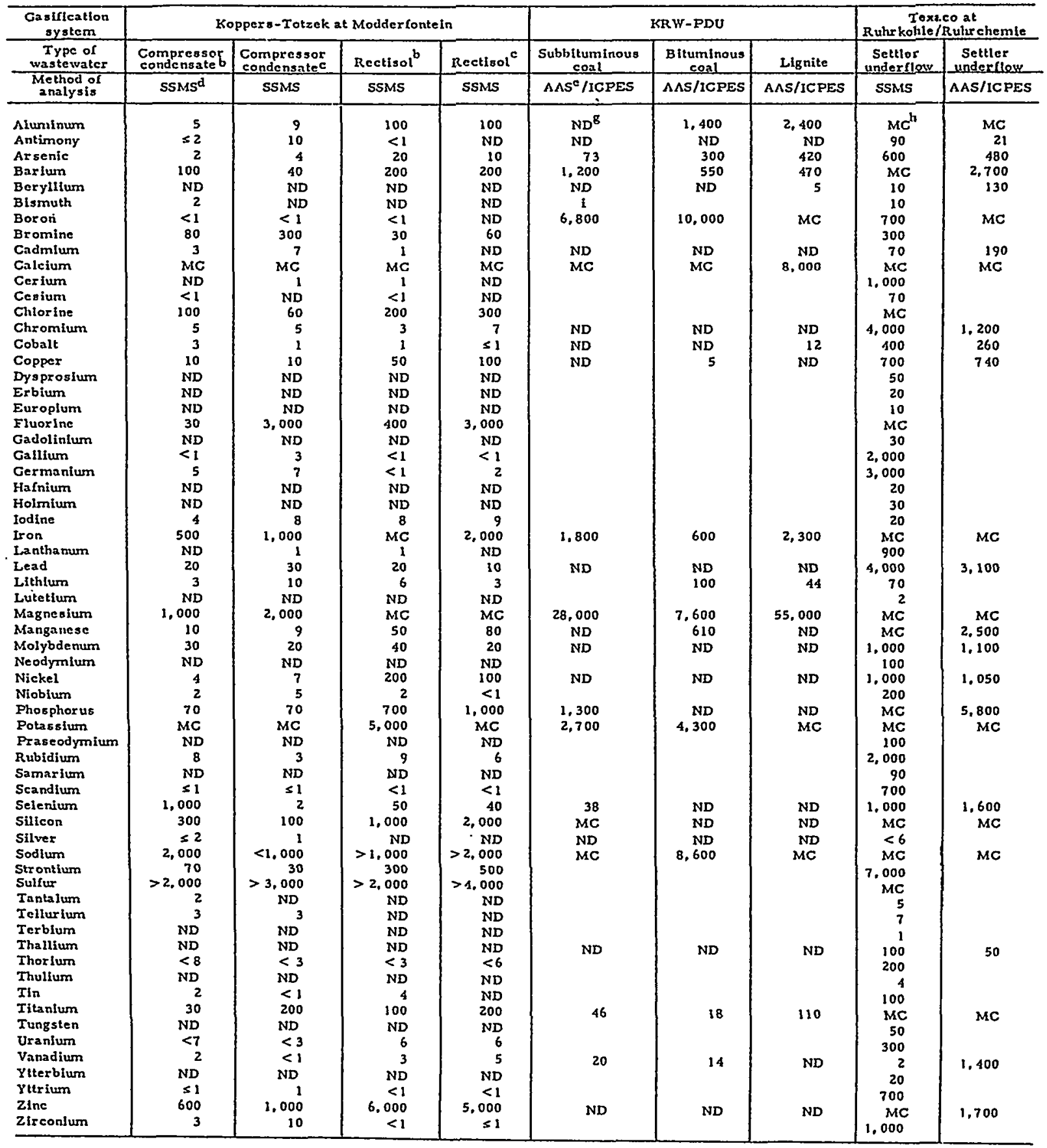

${ }^{a}$ Units as $\mu \mathrm{g} / \mathrm{l}$ unless otherwise noted.

${ }^{b}$ Purified sewage used as process feedwater.

${ }^{c}$ Cooling tower makeup water used as process feedwater.

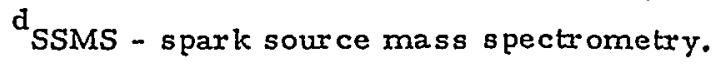

e AAS - atomic absor ption spectrophotometry.

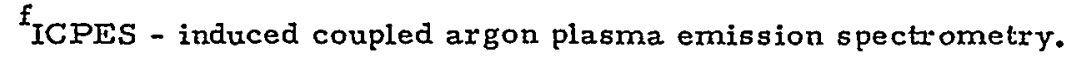

$\mathrm{g}_{\mathrm{ND}}$ - not detected.

${ }^{h} M C$ - major component in the wastewater, concentration greater than $10,000 \mu g / l$.

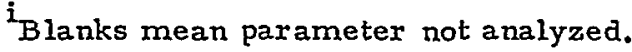


Table 9.3-9. Organics in fixed-bed coal-gasification wastewaters (Ref. 7 ). ${ }^{2}$

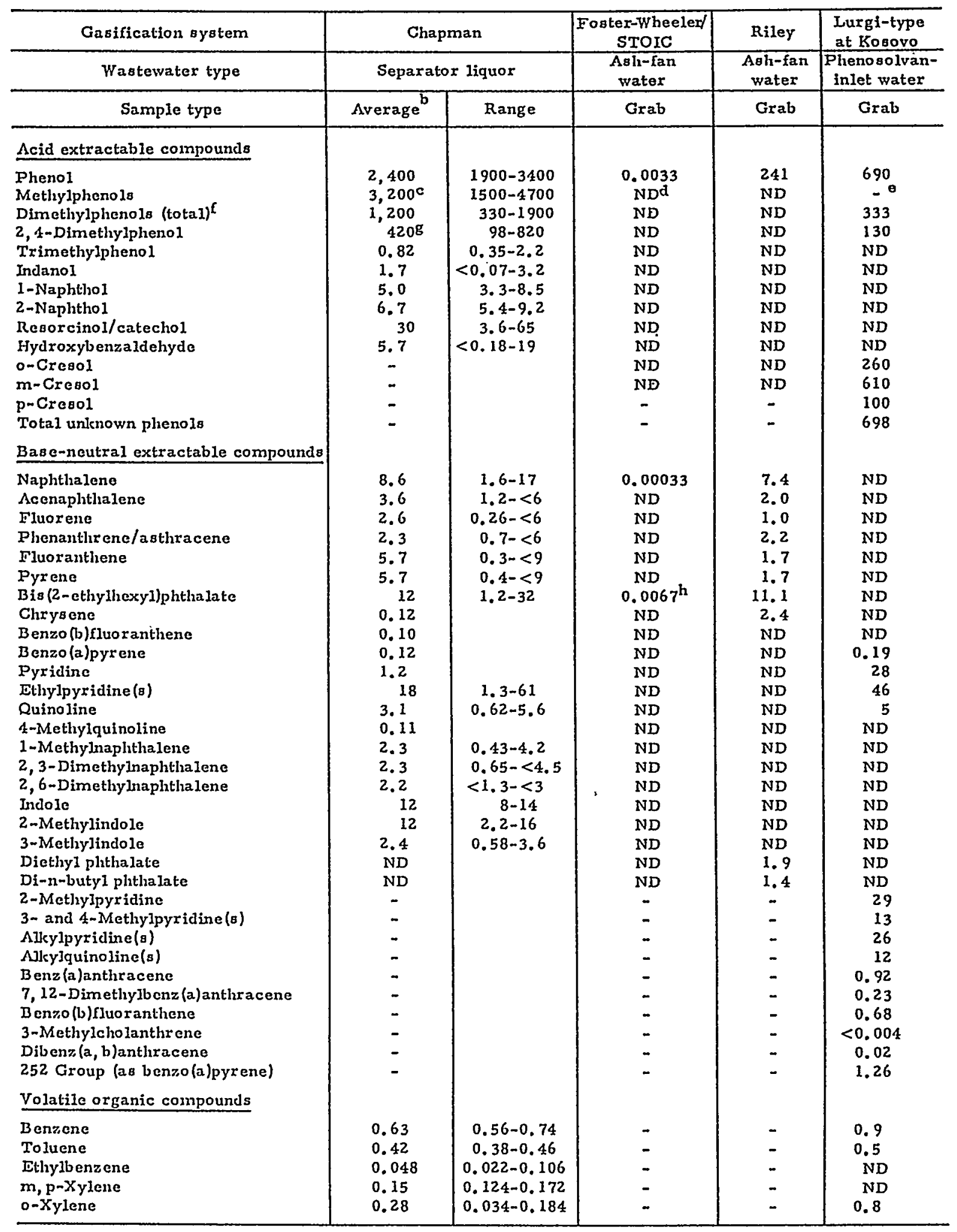

a All clata as $\mathrm{mg} / \mathrm{L}$.

b Average of grab Bamples.

cone extremely high data point is not included in the average but the compound was identified 6 of 6 times.

¿ND means not detected.

cDashea mean parameter not analyzed.

Inclucles 2, 4-DMP.

GThe portion of $2,4-D M P$ from the $B / N$ fraction was estimated from the anount found in the acid fraction.

hprobable artifact of sample handling. 
Table 9.3-10. Organics in non-tar-producing coal-gasification wastewaters (Ref. 7). ${ }^{\text {a }}$

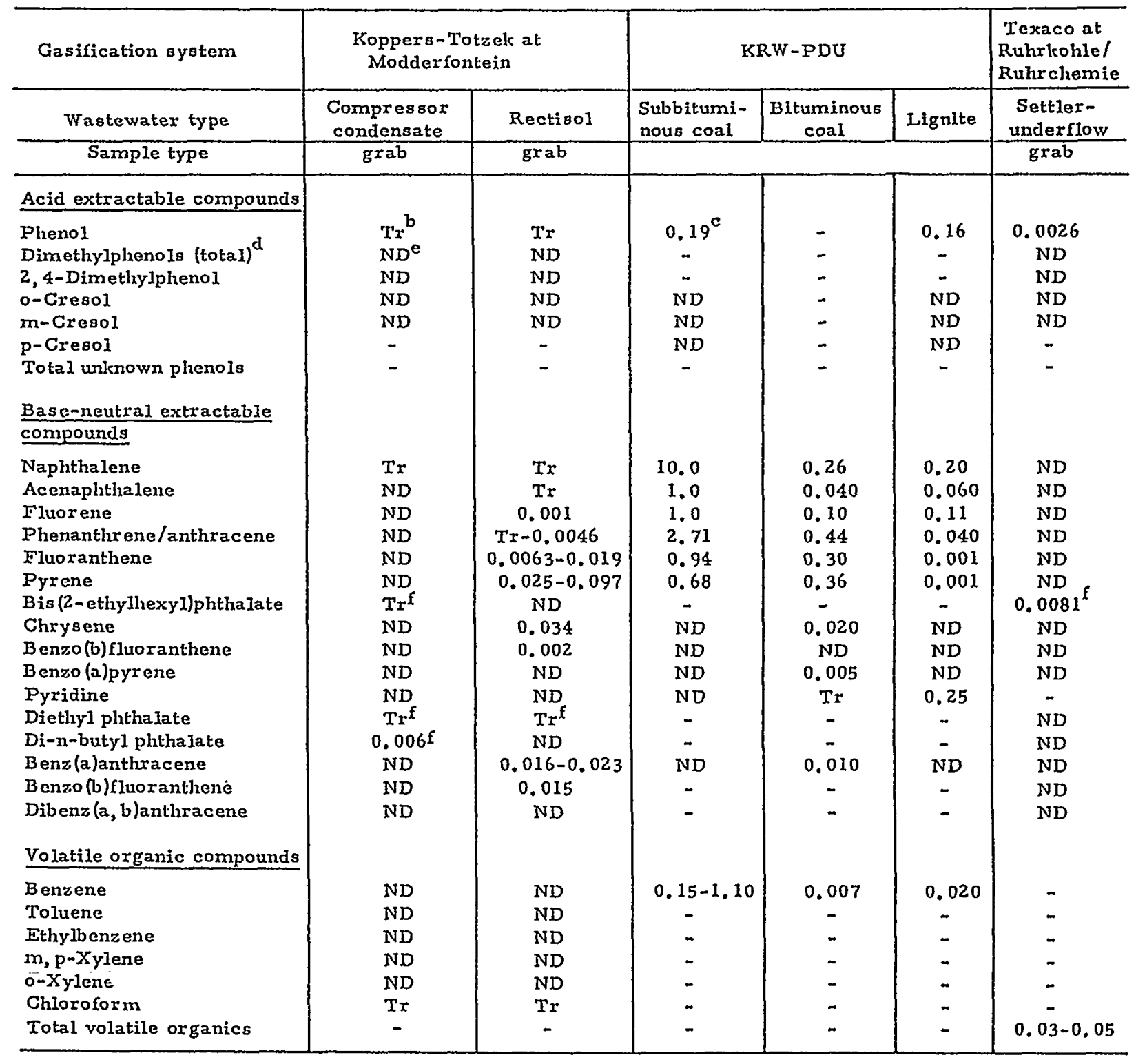

${ }^{\text {a All data as mg/l. }}$.

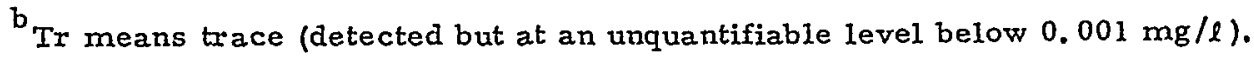

${ }^{c}$ Dashes mean parameter not analyzed.

Includes 2, 4-DMP.

ND means not detected.

${ }^{f}$ Probable artifact of sample handling. 
Table 9.3-11. Summary data for wastewater bioassay tests (Ref. 7).

\begin{tabular}{|c|c|c|c|c|}
\hline \multirow[b]{2}{*}{ Gasifier/wastewater } & \multicolumn{4}{|c|}{ Bioassay Test Results } \\
\hline & $\mathrm{AMES}^{2}$ & $\begin{array}{l}\text { In-vitro } b \\
\text { cytotoxicity }\end{array}$ & $\begin{array}{c}\underset{E_{50}}{\text { Freshwater algae }} \mathrm{c} \\
\end{array}$ & $\begin{array}{l}\text { Fathead minnow } \\
\qquad \mathrm{LC}_{50}\end{array}$ \\
\hline $\begin{array}{l}\text { Lurgi-type Kosovo/gas } \\
\text { liquor }\end{array}$ & positive & $\mathrm{CHO}-\mathrm{M}$ & $-e$ & - \\
\hline $\begin{array}{l}\text { Lurgi-type Kosovo/ } \\
\text { pretreated gaṣ liquor }\end{array}$ & negative & $\mathrm{CHO}-\mathrm{M}$ & - & - \\
\hline $\begin{array}{l}\text { Lurgi-type Kosovo/ } \\
\text { ASTM slag leachate }\end{array}$ & negative & CHO-ND & - & - \\
\hline $\begin{array}{l}\text { Iurgi Sasolburg/ } \\
\text { pretreated gas liquor }\end{array}$ & - & - & - & $4.5-7.5 \%$ \\
\hline $\begin{array}{l}\text { Lurgi Sasolburg/ } \\
\text { bioreactor effluent }\end{array}$ & - & - & - & $38 \%$ \\
\hline Riley/ash leachate & negative & CHO-I & $3 \% \%^{f}$ & - \\
\hline $\begin{array}{l}\text { Riley/cyclone dust } \\
\text { leachate }\end{array}$ & negative & CHO-ND & $4 \%$ & - \\
\hline $\begin{array}{l}\text { Chapman/separator } \\
\text { liquor }\end{array}$ & negative & RAM-ND & 0.1 to $1.0 \%$ & $0.02 \%$ \\
\hline $\begin{array}{l}\text { Wellman-Galusha } \\
\text { (Fort Snelling)/ } \\
\text { asl sluice water }\end{array}$ & negative & WI-38-M & - & - \\
\hline $\begin{array}{l}\text { Wellman-Galusha } \\
\text { (Fort Snelling)/cyclone } \\
\text { dust quench water }\end{array}$ & negative & $W I-38-N D$ & - & - \\
\hline $\begin{array}{l}\text { Wellman-Galusha } \\
\text { (Glen-Gery)/ash } \\
\text { sluice water }\end{array}$ & negative & $W I-38-N D$ & - & - \\
\hline $\begin{array}{l}\text { Wellman-Galusha } \\
\text { (Glen-Gery)/ash } \\
\text { leachate }\end{array}$ & negative & WI-38-ND & - & - \\
\hline $\begin{array}{l}\text { Texaco Ruhrkohle/ } \\
\text { Ruhrchemie/settler } \\
\text { underflow }\end{array}$ & negative & $\mathrm{CHO}-\mathrm{H}$ & $1.4-1.7 \%$ & $1.2-1.3 \%$ \\
\hline $\begin{array}{l}\text { Texaco Ruhrkohle/ } \\
\text { Ruhrchemie/ASTM } \\
\text { slag leachate }\end{array}$ & negative & CHO-ND & $13-19 \%$ & - \\
\hline $\begin{array}{l}\text { Texaco Ruhrkohle/ } \\
\text { Ruhrchemie/ASTM } \\
\text { fines leachate }\end{array}$ & negative & $\mathrm{CHO}-\mathrm{L}$ & $10-11 \%$ & $9.0 \%$ \\
\hline $\begin{array}{l}\text { Texaco Ruhrkohle/ } \\
\text { Ruhrchemie/bior eactor } \\
\text { effIuent }\end{array}$ & negative & CHO-ND & $20 \%$ & $9.3-13 \%$ \\
\hline \multicolumn{5}{|c|}{ 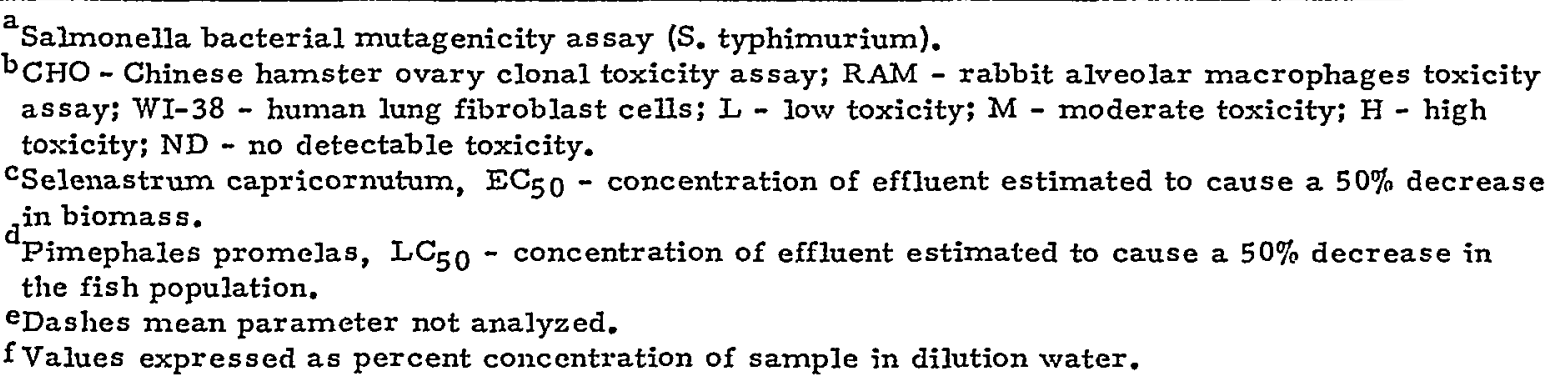 } \\
\hline
\end{tabular}


firm that quench condensates produce the most contaminated waste streams from coal gasification. These streams contain substantial amounts of COD, $\mathrm{BOD}, \mathrm{NH}_{3}, \mathrm{SCN}, \mathrm{CN}$, reduced sulfur compounds, carbonates, and dissolved solids. The fixed-bed gasifiers also contain significant quantities of dissolved organics and volatile inorganics. Trace-element compositions generally reflect the composition of the parent coal, with most of these substances reporting to the liquid or solid effluent streams from the gasifier.

The critical point affecting the research agenda for coal gasification is that wastewater treatment processes add considerable cost to the overal1 system, so that process improvements which reduce or eliminate these steps are highly desirable. Similarly, a better understanding of fundamental process chemistry, particularly in the context of recycle and reuse of contaminated waters, could help minimize the need for downstream treatment. We return to these points in summarizing research recommendations at the end of this chapter.

\section{3-2C. Solid Wastes}

The major solid-waste streams from coal-gasification processes are the ash or slag from the gasifier, plus dust collected in the cyclone separators found in some process designs. Byproduct tar and oil may also be discharged from some types of gasifiers. EPA test data on solid wastes from various gasifiers include characterization of chemical properties, physical characteristics, leaching test, and bioassay tests (Table 9.3-12). Details concerning these data are summarized in Ref. 8.

The most critical aspects of solid-waste handling and disposal concern whether or not the waste is classified as hazardous under RCRA or whether it poses any biological hazard, as indicated by bioassay tests. Results for gasifier ash, slag and cyclone dust, which originate primarily from the inorganic components of coal, have demonstrated that these materials are non-hazardous under current RCRA criteria (Table 9.3-13). This observation is consistent with the results of other testing programs carried out by the US DoE on several coal-gasification pilot plants. Available data for gasifier ashes, slags and dusts suggest similarities to ashes from con- 
ventional coal-combustion systems. ${ }^{8}$ The general conclusion from characterization studies to date is that disposal of gasifier and cyclone solid wastes should not require management practices substantially different from those currently used for coal-combustion solid wastes. As noted earlier, however, EPA has recently proposed modifications to the current RCRA criteria which could make the future status of coal-gasification wastes far less certain. In this context, additional testing of archived samples of gasifier ash and slag could provide an expanded data base to assess the impact of new RCRA test criteria.

EPA characterization studies also included tar- and oil-discharge streams typical of fixed-bed gasifiers. These indicated the presence of polynuclear aromatic compounds (PNAs) including benzo(a)pyrene, one of the most potentially hazardous PNAs identified in gasifier tars. ${ }^{8}$ In addition to toxic or carcinogenic organic compounds, these streams were found to contain many trace elements. Co-disposal of such substances with other solid wastes could affect their RCRA classification. Since these tars and oils have relatively high heating values, however, they are quite suitable (and often used) as a fuel rather than a solid waste. The environmental concerns in this case could include the ultimate fate of trace metals and the emission of trace organics from incomplete combustion.

\section{3-3. Methods of Environmental Control}

We present in this section a very brief overview of current and developing methods for environmental control of major contaminants at coal-gasification facilities.

\section{3-3A. Air Pollutants}

As previously noted, emissions of sulfur species have traditionally constituted the primary air-pollution concern at coal-gasification facilities. Current regulations also focus on emissions of particulates and nitrogen oxides, while future regulations may address hazardous or toxic species such as organics and trace metals. 
One of the virtues of coal gasification has been the ability to reduce atmospheric sulfur emissions to levels far below those achievable in conventional coal-combustion systems. This result is achieved because sulfur occurs primarily in the form of gaseous $\mathrm{H}_{2} \mathrm{~S}$ (rather than $\mathrm{SO}_{2}$ ), thus inaking it amenable to removal by a variety of physico-chemical acid-gas removalprocesses already commercialized in related industries such as petroleum refining. Whether the acid-gas removal-process is viewed as an environmental control technology or simply as a process component depends on the process application. For high-BTU gas production, removal of sulfur is a necessary part of the process to avoid contamination of methanation catalysts. In the production of fuel gases, however, the acid-gas removal-step is needed primarily to comply with environmental regulations on allowable $\mathrm{SO}_{2}$ emissions once the fuel is burned. In this case, it is clearly an environmental control technology.

Conventional acid-gas removal processes operate in conjunction with a sulfur-recovery system, which typically converts $\mathrm{H}_{2} \mathrm{~S}$ and other reduced sulfur species to elemental sulfur, one of the major by-products from coal gasification. A typical sulfur-recovery system might consist of a Claus plant with a tail-gas treatment-system. For properly operating systems, atmospheric emissions would consist of some tail-gas $\mathrm{SO}_{2}$ and/or $\mathrm{H}_{2} \mathrm{~S}$ in very low concentrations (several ppm). The largest source of $\mathrm{SO}_{2}$ from coal gasification arises from the combustion of the low- or medium-BTU coal-gas product, where the $\mathrm{H}_{2} \mathrm{~S}$ not removed by the acid-gas removal-system is oxidized to $\mathrm{SO}_{2}$ on combustion.* This combustion-gas stream is also the principal source of nitrogen oxide emissions, which are derived from fuel-bound nitrogen (principally from ammonia not dissolved in the gasifier quench stream), plus thermal $\mathrm{NO}_{x}$ produced from nitrogen and oxygen present in airblown gasifiers. Nitrogen oxide control measures thus consist of ammonia removal together with combustion controls designed to minimize the formation of thermal $\mathrm{NO}_{\mathrm{x}}$ by methods such as steam injection, burner-design modifications, and other standard methods.

* This statement applies to fuel-gas applications such as electric power generation. For other applications, the largest source of $\mathrm{SO}_{2}$ emissions is likely to be an auxiliary coal-fired boiler producing steam for process use. 


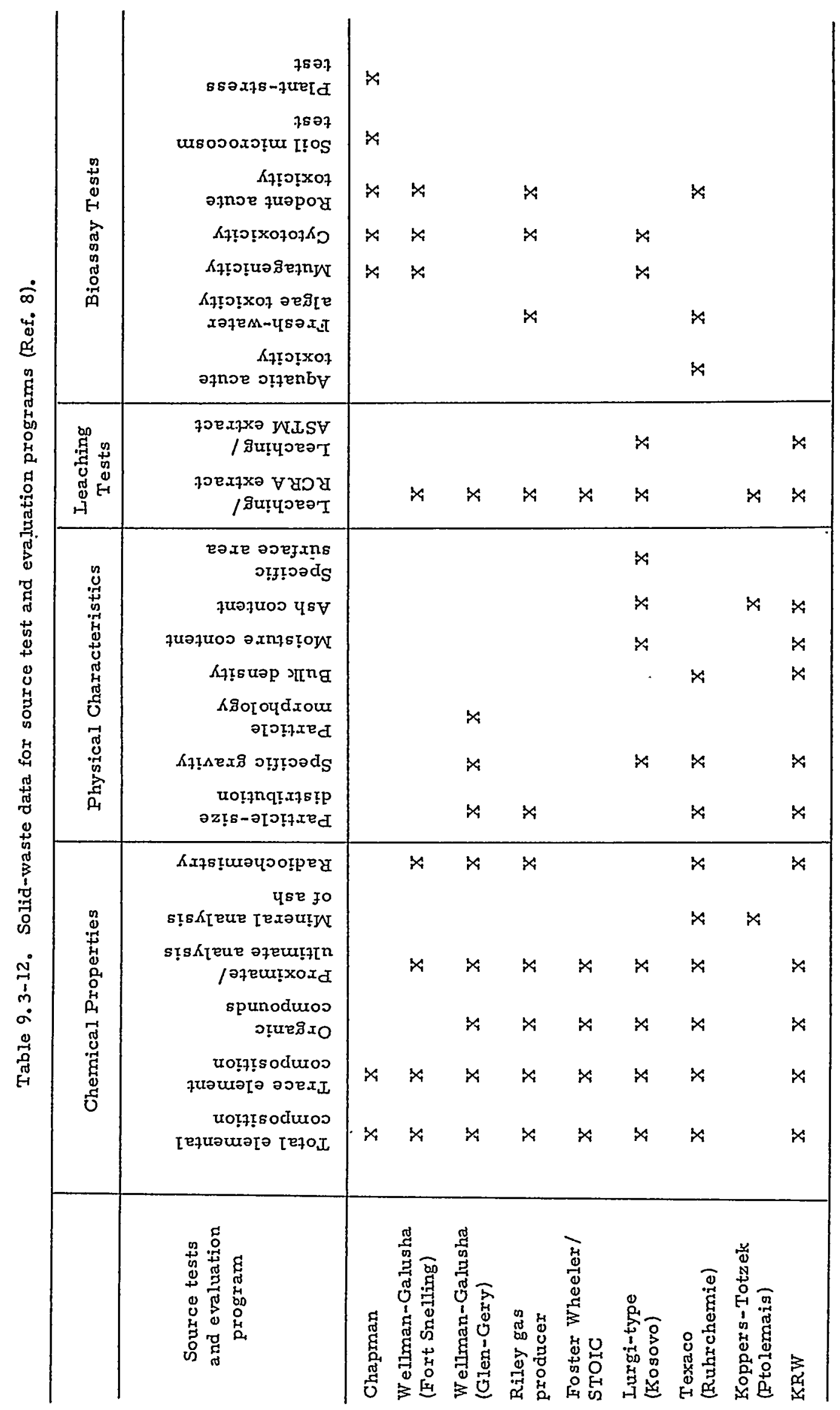


Table 9.3-13. Summaxy ranges of chemical concentrations of elements in RCRA EPA extracts from gasifier ashes, mg/l (Ref. B).

\begin{tabular}{|c|c|c|c|c|}
\hline \multirow{2}{*}{ Elements } & \multicolumn{2}{|c|}{ Facilities ${ }^{a}$} & \multirow{2}{*}{ Range } & \multirow{2}{*}{$\begin{array}{l}\text { RCRA } \\
\text { Limit }\end{array}$} \\
\hline & High & Low & & \\
\hline Aluminum & $F$ & $A$ & $<\mathrm{BC}^{\mathrm{b}}-0.15$ & \\
\hline Antimony & $-c$ & - & $<0.005-<0.050$ & \\
\hline Arsenic & $\mathrm{D}$ & $\mathrm{G}, \mathrm{H}$ & $<0.002-0.033$ & 5 \\
\hline Barium & $K$ & $\mathrm{~F}$ & $0.019-7.2$ & 100 \\
\hline Beryllium & - & - & $<0.0005-<0.002$ & \\
\hline Cadmium & $\mathrm{L}$ & $\mathrm{D}, \mathrm{F}$ & $<0.0005-0.1$ & 1 \\
\hline Calcium & $\mathbf{B}$ & C & $0.099-\mathrm{MC}^{\mathrm{d}}$ & \\
\hline Chromium & $\mathrm{E}$ & $D, G$ & $<0.001-0.3$ & 5 \\
\hline Cobalt & $F$ & $A$ & $<\mathrm{BC}-3.3$ & \\
\hline Coppex & $\mathbf{B}$ & $D, G$ & $<0.001-0.1$ & \\
\hline Iron & $\mathbf{E}$ & $\mathrm{D}$ & $<0.008-10$ & \\
\hline Lead & $\mathbf{H}$ & $D, F, G, L$ & $<0.002-0.025$ & 5 \\
\hline Lithium & G & A & $N D^{e}-0.29$ & \\
\hline Magnesium & $\mathrm{B}$ & $\mathrm{C}$ & $0.036-\mathrm{MC}$ & \\
\hline Manganese & $\mathrm{B}$ & $E$ & $0.001-0.5$ & \\
\hline Mer cury & - & - & $<0.0002-<0.0005$ & 0.2 \\
\hline Molybdenum & $\mathrm{E}$ & A & $<\mathrm{BC}-0.1$ & \\
\hline Nickel & $\mathrm{B}, \mathrm{E}$ & A & $<\mathrm{BC}-0.04$ & \\
\hline Potassium & $\mathrm{B}$ & $I$ & $N D-M C$ & \\
\hline Selenium & A & $\mathrm{C}$ & $<0.001-0.01$ & 1 \\
\hline Silicon & B & C & $0.2-M C$ & \\
\hline Silver & $\mathrm{K}$ & $\mathrm{D}$ & $<0.0005-0.007$ & 5 \\
\hline Sodium & $\mathrm{D}$ & $F$ & $1.6-140$ & \\
\hline Strontium & $\mathrm{B}$ & C & $0.06-6$ & \\
\hline Titanium & $A, B$ & G, I & $<0.005-0.1$ & \\
\hline Vanadium & $E$ & A & ND -0.07 & \\
\hline Zinc & C & A & $<\mathrm{BC}-4$ & \\
\hline
\end{tabular}

${ }^{a}$ The code used in this table to identify source tests is as follows: A, Chapman; B, WellmanGalusha (FortSnelling); C, Wellman-Galusha (Glen Gery); D, Riley; E, Lurgi type (Kosovo); F, Texaco (Ruhrchemie); G, Lurgi (SASOL 1); H, IGT U-GAS; I, KRW-WY subbituminous coal; J, KRW-Pittsburgh \#8; K, KRW-ND lignite; L, Foster-Wheeler/STOIC.

${ }^{b} \angle B C=$ less than or equal to blank concentration.

c All analyses below detection limit.

$\mathrm{d}_{\mathrm{MC}}=$ majox component.

'ND- not detected.

In view of regulatory trends, improved $\mathrm{NO}_{x}$ control methods may be needed in conjunction with hot-gas cleanup systems currently being developed for application to IGCC power generation. High-temperature pollutant control 
offers the significant advantage of eliminating the need to quench and subsequently treat the condensables from gasifier products. While recent DoE research on high-temperature removal of sulfur and particular matter appears to be quite promising, levels of $\mathrm{NO}_{x}$ emissions are similar to those currently required for new coal-fired power plants (i.e., about 0.6 lb/MBTU). Thus, additional efforts are warranted on high-temperature removal systems to achieve the much lower levels of $\mathrm{NO}_{x}$ emissions currently obtainable with low-temperature gas-treatment processes and commercial flue-gas treatment systems.

Other potential air pollutants from coal-gasification processes are largely fugitive in nature. Here, the need for or viability of additional control technology remains speculative and large a matter of future regulatory developments. In these cases, more complete characterizations of fugitive organic and inorganic materials are the first step required to assess the need for additional controls.

\section{3-3B. Water Pollutants}

Wastewater-treatment systems at coal-gasification plants are designed primarily to deal with the quench-condensate stream plus smaller streams such as those from acid-gas removal-processes, ash sluicing, etc. Several steps are common to wastewater-treatment systems. These include the stripping and recovery of the ammonia and phenols, which represent potentially useful by-products. This step is typically followed by a biological oxidation process to remove additional organics. In some instances, there may be added still another polishing operation such as filtration through activated carbon.

As noted, requirements for coal-gasification wastewater-treatment presently depend on state and local regulations. At plants subject to zerodischarge regulations, treated waters and waste sludges typically are sent to an impermeable solar evaporation pond in regions where rainfall levels are relatively low. However, this method is not viable in many parts of the country. In these cases, some allowable discharge may be permitted, depending on local circumstance; otherwise, alternative methods of disposal involving wastewater recycle must be used. No generalizations are possible at this time since US experience is extremely limited. 


\section{3-3C. Solid Waste}

Disposal of gasification-plant solid wastes generally involves a conventional sanitary landfill with an impermeable liner to prevent leaching into groundwater. As noted earlier, waste disposal methods are determined principally by whether or not wastes are classified as hazardous by Federal or state agencies. To the extent that future research leads to innovative means of utilizing coal-gasification wastes in ways that are economically productive, the uncertainties and costs of dealing with solid-waste disposal problems may be greatly ameliorated. Additional discussions of the use and disposal of ash from gasifiers are given in Sec. 13.2.

\subsection{Experience at Commercial Facilities}

In recent years, two commercial facilities have come on-line in the US, which provide the most up-to-date experience in dealing with environmental problems of coal gasification. These facilities are the Great Plains coal-gasification project in North Dakota (producing SNG) and the Cool Water gasification project in California (producing electricity in an IGCC). Here, we briefly highlight some of the environmental control issues and performance data that are available from these plants.

\section{4-1. The Great Plains Gasification Plant}

The Great Plains facility represents the first US plan constructed to demonstrate the production of SNG at a commercial scale. Despite the financial problems surrounding operation of the plant in the current market environment, it remains a technological success insofar as production of pipeline-quality gas is concerned. Environmentally, however, Great Plains also has demonstrated the potential pitfalls of applying off-the-shelf technology to new situations. In this case, the Stretford unit employed for sulfur removal has failed to operate as anticipated, with the result that emissions have not complied with $\mathrm{SO}_{\mathrm{x}}$ regulations. ${ }^{9}$ The problem is generally attributed to the presence of trace compounds in the gas stream which adversely affect Stretford process chemistry and catalyst performance. After many months of study, however, no solution has yet been found and the plant 
continues to operate under a special variance from the North Dakota Pollution Control Agency.

Other environmental control systems at Great Plains appear to be performing adequately, though all details of environmental monitoring have not yet been made public. Since the Great Plains facility employs a tar-producing Lurgi gasifier, special attention has been paid to waste-water treatment and disposal. Cleaned waters from the wastewater-treatment facility are recycled as cooling-tower makeup-water since no discharge are permitted. Dewatered cooling-tower and wastewater treatment sludges are incinerated and disposed of with the solid residue by deep-well injection. Gasifier ash, however, is classified as non-hazardous and is disposed of in a conventional landfill. A detailed environmental monitoring program is being carried out as part of the current plant operation under the auspices of DoE.

\section{4-2. The Cool Water Gasification Facility}

The $100 \mathrm{MW}$ Cool Water coal-gasification project produces condensates from an entrained-bed Texaco gasifier, which are treated in a sourwater stripper. The effluent is then sent to an evaporation pond along with clarified waters from the slag- and ash-handling system. Groundwater monitoring tests to date indicate no leakage around the evaporation pond or slag disposal areas. ${ }^{10}$ The gasifier slag at Cool Water has been designated as non-hazardous according to Federal and state criteria based on standard leaching tests for trace elements and organics. Typical results are shown in Table 9.4-1.

The performance of air pollution control systems at Cool Water has exceeded that needed to comply with applicable emission limits imposed by California. The principal emission sources are the stacks of the heatrecovery steam generator (HRSG) and the plant incinerator. Results of compliance testing and supplemental environmental monitoring for the steam-generator stack gases are shown in Tabies 9.4-2 and 9.4-3, respectively. Emissions of $\mathrm{SO}_{2}, \mathrm{NO}_{x}$, and $\mathrm{CO}$ are significantly below allowable limits, with low to negligible levels of trace metals, organics, and other potentially harmful pollutants. Qualitatively similar findings result from com- 
pliance and supplemental testing of the incinerator stack gases, as is shown in Tables 9.4-4 and 9.4-5.

Table 9.4-1. Results of Cool Water solid-waste tests (Ref, 10).

(a) Gasifier slag: RCRA waste-testing results.

\begin{tabular}{|c|c|c|c|c|}
\hline \multicolumn{2}{|c|}{$\begin{array}{l}\text { Ignitability } \\
\text { Corrosivity } \\
\text { Reactivity }\end{array}$} & \multicolumn{3}{|c|}{$\begin{array}{l}\text { Negative } \\
\text { Negative } \\
\text { Negative }\end{array}$} \\
\hline \multicolumn{2}{|c|}{ RCRA EPA Parameters } & $\begin{array}{c}\text { Leachate } \\
\text { concentration }\end{array}$ & $\begin{array}{l}\text { RCRA } \\
\operatorname{limit}\end{array}$ & $\begin{array}{l}\text { Detection } \\
\text { limit }\end{array}$ \\
\hline Arsenic, & $\mathrm{mg} / \mathrm{l}$ & ND & 5.0 & $(<0.06)$ \\
\hline Barium, & $\mathrm{mg} / \mathrm{s}$ & 0.039 & 100.0 & \\
\hline Cadmium, & $\mathrm{mg} / \mathrm{l}$ & ND & 1.0 & $(<0.002)$ \\
\hline Chromium (total), & $\mathrm{mg} / \mathrm{l}$ & ND & 5.0 & $i<0,005)$ \\
\hline Lead, & $\mathrm{mg} / \mathrm{l}$ & ND & 5.0 & $(<0.08)$ \\
\hline Mercury, & $\mathrm{mg} / \mathrm{l}$ & ND & 0.2 & $(<0.0004)$ \\
\hline Selenium, & $\mathrm{mg} / \mathrm{l}$ & ND & 1.0 & $(<0.08)$ \\
\hline Silver, & $\mathrm{mg} / \mathrm{l}$ & ND & 5.0 & $(<0.002)$ \\
\hline
\end{tabular}

(b) Gasifier slag: State of California waste-leaching testing results.

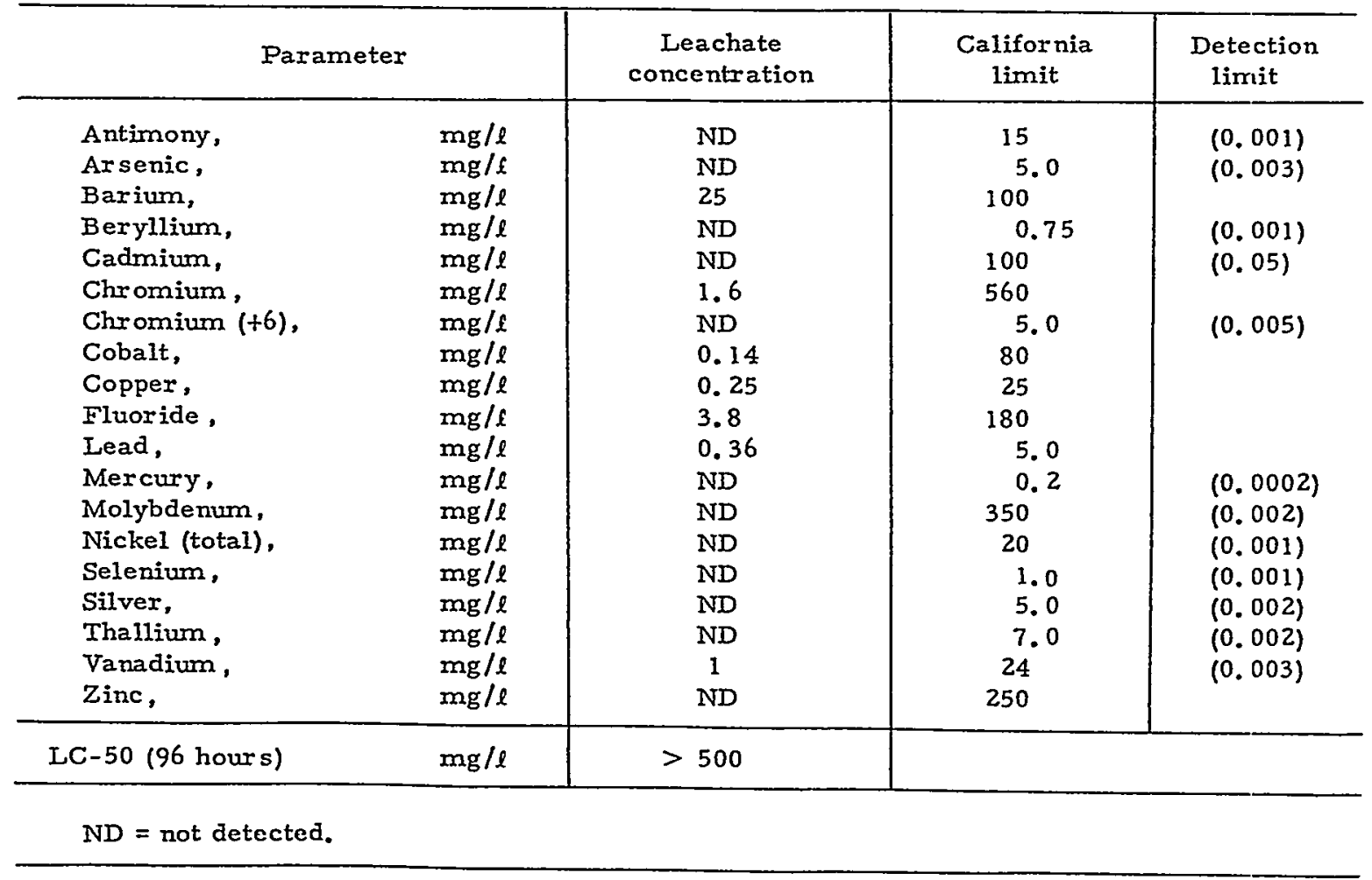


$\mathrm{SO}_{2}$ control at Cool Water is obtained by using the Selexol acid-gas removal-process in conjunction with a $\mathrm{Claus/Scot}$ sulfur-recovery system. Sulfur levels in the gas are reduced by $95-97 \%$. $\mathrm{NO}_{\mathrm{x}}$ emissions are controlled through steam injection in the gas turbine. When normalized on coal-energy input, $\mathrm{NO}_{x}$ emissions are an order of magnitude below current New Source Performance Standards for coal-fired power plants. This level is comparable to emissions achieved by using selective catalytic reduction systems on coal-fired power plants in Japan and the FRG.

While the environmental control equipment at Cool Water has generally performed quite successfully, some aspects of the original design still remain to be demonstrated. For example, problems encountered during start-up required incinerating the off-gas stream from the waste-water treatment process rather than direct treatment in the $\mathrm{Claus} / \mathrm{Scot}$ unit as designed. Similarly, some rerouting of plant wastewater and recycle streams directly to the evaporation pond was required to achieve adequate performance of the water-treatment facility. Understanding and correction of these problems is expected as plant operation continues.

\subsection{Research Needs and Priorities}

We now present a summary of key recommendations related to the environmental control of coal-gasification facilities. These recommendations are framed by several general questions regarding the methods and cost of meeting current and future environmental control requirements: (i) Are adequate control technologies available to meet current environmental control requirements for surface coal-gasification facilites? Can the performance of such technology be predicted reliably to assure compliance with current requirements for air, water and solid waste emissions from commercial gasification processes? ( $i i)$ What are the anticipated trends in future environmental control requirements, and how will these affect future gasification technology in various applications? Is adequate technology and information available to handle potential future situations? (iii) What is the potential for significantly reducing the cost of environmental control through new process development and/or the development of improved control technology? What research is needed to pursue these opportunities? 
Each of these issues provides a context for research recommendations. The scope of these recommendations is tailored to the mission of DoE's Surface Coal Gasification Program. Priorities are designated as either 1 (high) or 2 (lower).

\section{5-1. Current Control Technology}

Environmental research on coal gasification processes conducted over the past decade has been focused, to a large extent, on characterizing the chemical composition of gaseous, liquid and solid waste streams from various types of gasifiers. This procedure has aided the design of technology for air-pollution control, waste-water treatment, and solid-waste disposal, with the result that current environmental control requirements are generaliy met, albeit based often on empirical design criteria rather than fundamental understanding.

Recent experience also underscores the continuing need for more fundamental research on process factors related to environmetal control. Examples from the two most recently commercialized US coal-gasification facilities serve to illustrate the general point that, while control technology is available to meet current environmental regulations, the performance of such systems cannot always be predicted reliably and, in some cases, falls short of the mark. Invariably, this problem reflects a lack of basic understanding of process and chemistry details relevant to environmental control-system design and performance. The two areas where additional research may be especially productive are in gaseous pollutant removal and water treatment/recycle systems. The following research recommendations are thus suggested with priority 2: (i) Basic research is needed to obtain better understanding of the process chemistry related to the control of gaseous pollutants. The chemistry of sulfur removal from complex gas mixtures, including the effects of trace compounds found in coal-gasification plant processes, is a particular area of concern. ( $i i)$ Fundamental research is similarly needed on gasification-process water-chemistry, particularly in the context of waste-water recycle systems (which offer the potential for waste elimination). This research should provide a basic understanding of 
the reactions of species and the fate of contaminants common to coal-gasification process condensates and wastewaters.

\section{5-2. Future Environmental Requirements}

Our earlier discussion showed that, over the past two decades, there has been a clear and continuing trend toward more stringent environmental control requirements for energy-conversion processes of all types. In recent years, environmental requirements have become more comprehensive in scope, covering emissions to all environmental media (air, water and land). At the same time, the level of sophistication with which potential pollutants are identified, measured, and regulated has also increased. While the nature of future environmental requirements inevitably remains speculative, the following-general trends are likely to affect coal gasification processes: (i) Control of criteria air pollutants (those originally

Table 9.4-2. EPA performance-test results for the Cool Water FRSG stack gases (Ref. 10).

\begin{tabular}{|c|c|c|c|c|}
\hline Parameter & Units & $\begin{array}{l}\text { Emission } \\
\text { limit }\end{array}$ & $\begin{array}{l}1984 \\
\text { Test }\end{array}$ & $\begin{array}{l}1985 \\
\text { Test }\end{array}$ \\
\hline Sulfur dioxide & $\mathrm{lb} / \mathrm{hr}$ & 35 & 33.1 & 16.8 \\
\hline Nitrogen oxides & $\begin{array}{l}\text { lb } / h r \\
\text { ppmv @ } 15 \% \text { oxygen }\end{array}$ & $\begin{array}{r}140 \\
50\end{array}$ & $\begin{array}{l}61.2 \\
22.8\end{array}$ & $\begin{array}{l}68.9 \\
25\end{array}$ \\
\hline Carbon monoxide & $\mathrm{lb} / \mathrm{hx}$ & 77 & 2.9 & 3.7 \\
\hline Fluoride & $\mathrm{lb} / \mathrm{hr}$ & None & 0.0053 & NR \\
\hline Mercury & $\mathrm{lb} / \mathrm{hr}$ & None & ND & $\mathrm{NR}$ \\
\hline Beryllium & $\mathrm{lb} / \mathrm{hr}$ & None & ND & NR \\
\hline Sulfuric acid mist & $\mathrm{Ib} / \mathrm{hr}$ & None & 2.7 & $\mathrm{NR}$ \\
\hline Particulate loading & $\mathrm{lb} / \mathrm{hr}$ & None & 1.23 & NR \\
\hline \multicolumn{5}{|c|}{$\begin{array}{l}\text { Approval to construct/modify a stationary source: } \\
\text { Region II. }\end{array}$} \\
\hline \multicolumn{5}{|c|}{$\begin{array}{l}\text { ND }=\text { not detected at the following detection limits: merciury }(<0.000065 \\
\mathrm{lb} / \mathrm{hr}) \text { and beryllium }(<0.00016 \mathrm{lb} / \mathrm{hr}) \text {. }\end{array}$} \\
\hline
\end{tabular}


Table 9.4-3. Cool Water HRSG stack gases: supplemental environmental data (Ref. 10).

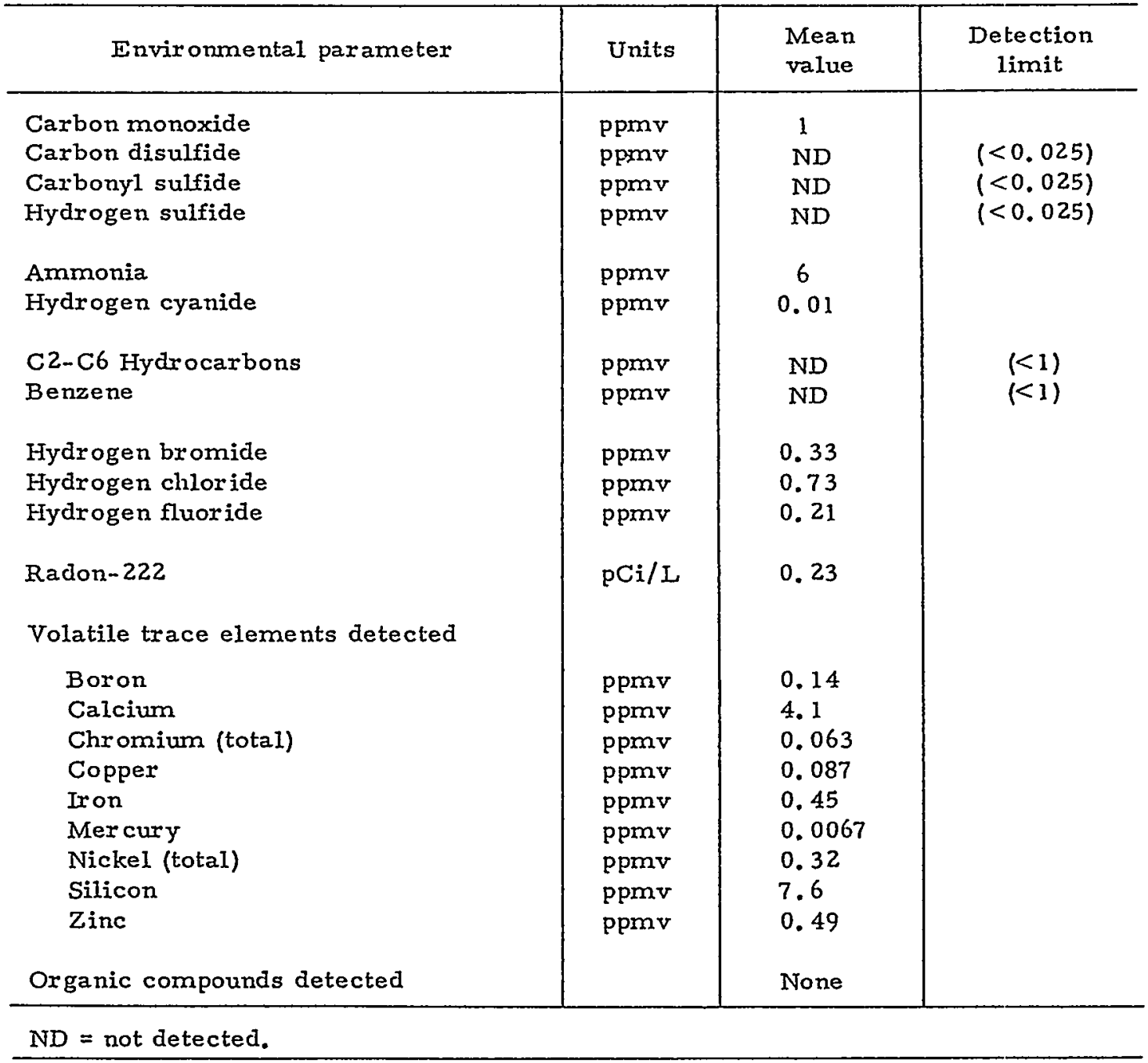

Table 9.4-4. EPA performance-test results for the Cool Water incinerator-stack gases (Ref. 10).

\begin{tabular}{l|c|c|c|c}
\hline \multicolumn{1}{|c|}{ Parameter } & Units & $\begin{array}{c}\text { Emission } \\
\text { limits }\end{array}$ & $\begin{array}{c}1984 \\
\text { Test }\end{array}$ & $\begin{array}{c}1985 \\
\text { Test }\end{array}$ \\
\hline $\begin{array}{l}\text { Sulfur dioxide } \\
\text { Fluoride }\end{array}$ & $\mathrm{lb} / \mathrm{hr}$ & 4.4 & 3.2 & 3.4 \\
Mercury & $\mathrm{lb} / \mathrm{hr}$ & None & 0.06 & $\mathrm{NR}$ \\
Beryllium & $\mathrm{lb} / \mathrm{hr}$ & None & 0.00015 & $\mathrm{NR}$ \\
Sulfuric acid mist & $\mathrm{lb} / \mathrm{hr}$ & None & $\mathrm{ND}$ & $\mathrm{NR}$ \\
\hline
\end{tabular}

$\mathrm{ND}=$ not detected at a beryllium detection limit of $<0.000002 \mathrm{lb} / \mathrm{hr}$. NR = not required for the 1985 performance test. 
Table 9.4-5. Cool Watex incinerator-stack gases: supplemental environmental data (Ref, 10).

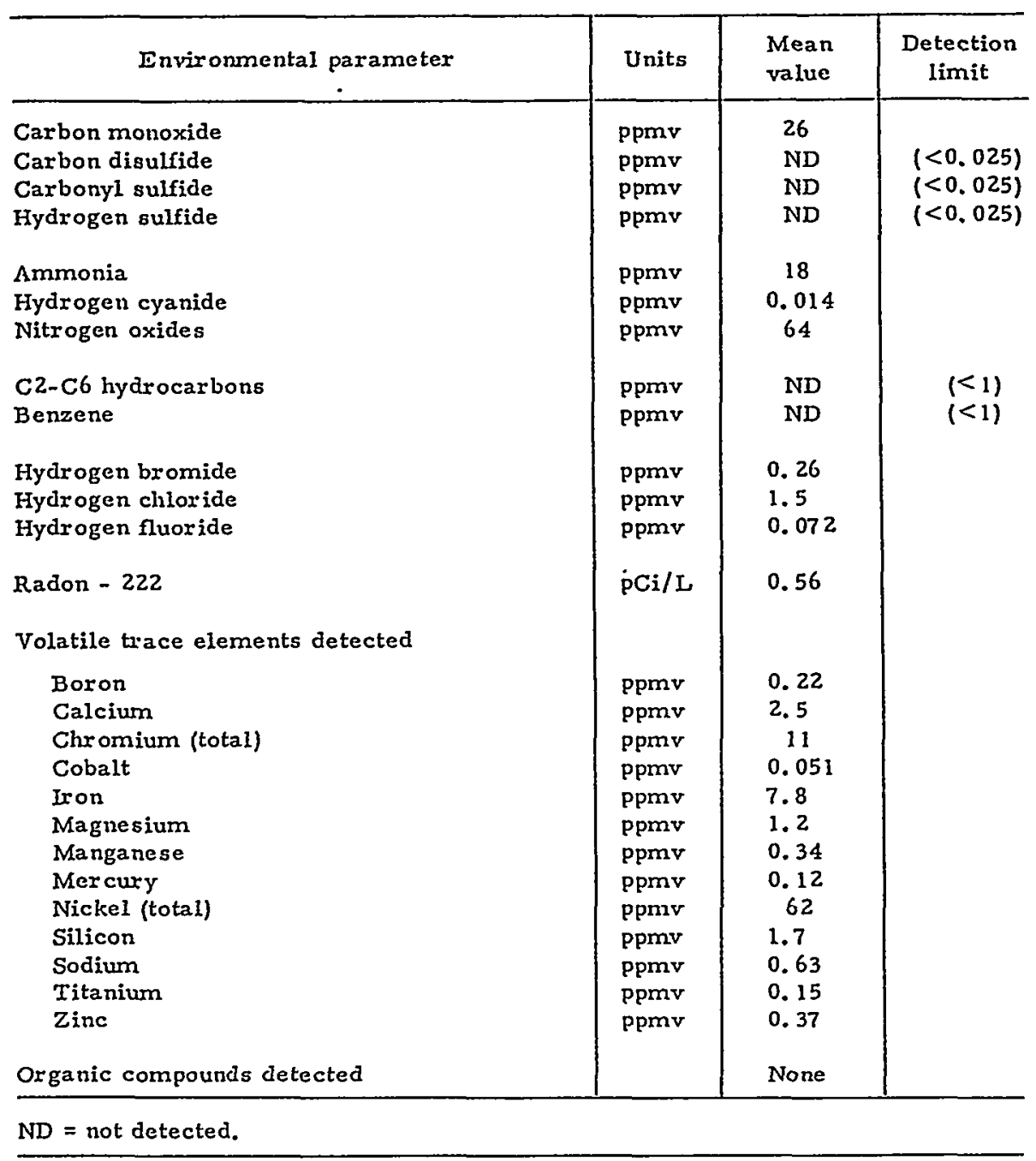

regulated by the 1970 Clean Air Act, e.g., $\mathrm{SO}_{2}$, particulate matter, $\mathrm{NO}_{\mathrm{X}}$, HCs, and photochemical oxidants) will continue to be important. Recently, the NSPS for combustion-related pollutants have tended to become more stringent as control-technology capabilities have improved. In terms of future developments, the commercialization of technology yielding much lower emissions of $\mathrm{NO}_{x}$ at coal-fired power plants than were heretofore required may compel further tightening of current NSPS requirements in the future, particularly if $\mathrm{NO}_{x}$ emissions prove to be implicated in environmental issues such as acid rain. (ii) Hazardous and toxic air pollutants are likely to become more heavily regulated in response to concerns over their health and ecological impacts. In the context of coal-gasification processes, this problem could affect emissions of heavy (trace) metals and organic compounds 
emitted in small quantities. (iij) Zero discharge of waste-water contaminants can be expected to continue to be the prevailing philosophy guiding regulatory requirements at the Federal, state and local levels. This requirement could have significant implications for commercial

coal-gasification facilities in parts of the country where relatively simple methods such as solar evaporation ponds cannot be used. (iv) The disposal of solid as well as liquid wastes will come under increasing scrutiny to ensure that waste materials by-products and potential leachates are envirormentally benign. Criteria defining hazardous and toxic substances are likely to evolve as new measurement techniques and research results become available. Research recommendations flowing from these observations include the following with priority 1: (i) Sustained research is needed to characterize emissions of trace metals, organic compounds and other potentially hazardous or toxic substances to air, water and land emanating from coal-gasification process streams, control technologies, fugitive emission sources, and leachates. (ii) Continued research is similarly needed in the areas of solid and liquid waste management, particularly the characterization of wastes under evolving RCRA criteria, and the utilization of solid residues as by-products rather than wastes. Understanding of the fate of organic and inorganic contaminants in the environment, both near-source reactions and longe-range transport, is needed.

\section{5-3. Advanced Control Technology}

Environmental-control systems currently account for a significant portion of total coal-gasification process-costs, so that high priority must be assigned to novel or advanced methods for reducing these costs while maintaining environmental quality standards.

The ability to eliminate or substantially simplify environmental control processes will depend, in part, on the gasifier design and perhaps, more substantially, on process application. Thus, processes yielding gas for use at room temperature invariably produce condensates requiring some degree of waste-water treatment, in addition to gaseous pollutant removal (although gasifier types such as entrained beds produce inherently cleaner condensates than others, e.g., tar-producing fixed-bed gasifiers). 
On the other hand, gasifier applications for electric power generation offer the potential for significant simplification of environmental control systems by using hot-gas cleanup. Removal of pollutants at high temperatures, followed by combustion of the gaseous products, not only yields improved process efficiency but also eliminates several unit operations required for low-temperature processing (e.g., waste-water treatment). The ongoing DoE research program on hot-gas cleanup offers an excellent opportunity for major improvements of this nature. Our priority 1 research recommendations are: (i) Current DoE research on hot-gas cleanup is important, generally wel1-focused, and deserving of strong continued support. Key research needs have been identified and are being pursued to develop viable means of particulate and sulfur removal at high temperature using gas treatment and/or in-bed removal processes. (ii) Additional research appears to be needed to ensure that $N_{x}$ emissions with hot-gas cleanup systems can be controlled to the same degree that is achievable with current low-temperature coal-gasification systems and combustion-gas treatment devices. Such levels are an order of magnitude lower than current NSPS requirements, but represent reasonable targets for on-going research and development.

\section{References}

1. S.B. Baruch and J.S. Feher, "Toxic Substances: Future Electric Utility Considerations," Proceedings of the American Power Conference, Vo1.47, I17inois Institute of Technology, Chicago, IL. (1985).

2. E.S. Rubin and F.C. McMichae1, Environ. Sci. Technol. 9, 112 (1975).

3. J.P. Fi1lo and M.J. Massey, "Fate of Phenols During the Gasification of Coal," Symposium Proceeedings Environmental Aspects of Fuel Conversion Technology IV, Report No. EPA-600/7-79-217, PB880-134729, NTIS, Arlington, VA (September 1979).

4. R.G. Luthy, J.Water Pollution Contr. Fed. 53 , 325 (1981).

5. R.M. Felder and J.K. Ferrell, "Pollutants from Coal Conversion Processes," Report No. DoE/PC/30232-T8 to US DoE from North Carolina State University, Raleigh, NC (1983). 
6. M. Kilpatrick, "Coal Gasification Environmental Data Summary: Sulfur and Nitrogen Species, "Report No. EPA-600 /7-86-015b, US EPA, Research Triangle Park, NC (April 1986).

7. F.J.Castaldi and F.D. Skinner, "Coal Gasification Environmental Data Summary: Low and Medium-BTU Wastewaters," Report No. EPA-600/7-86-015a, US EPA, Research Triangle Park, NC (April 1986).

8. A.G. Eklung, "Coal Gasification Environmental Data Summary: Solid Wastes and Byproduct Tars," Report No. EPA-600/7-86-015c, US EPA, Research Traingle Park, NC (April 1986).

9. V.P. Sabin, "Progress Report on Great Plains Gasification Project," Alternate Energy ' 86 Conference, Council on Synthetic Fueis, Captiva Island, FL, May 1986; also, private communications with US DoE, Radian Corp., and ERT, Inc. (1986).

10. R.W. Grover et al., "Preliminary Environmental Monitoring Results: Cool Water Coal Gasification Program," National AICHE Meeting, Boston, MA, American Institute of Chemical Engineers, NY (April 1986). 
CHAPTER 10:

COAL BENEFICIATION*

This chapter is an introduction to coal beneficiation. It includes a brief review of current commercial practices and several developmental coal-cleaning methods. Recent advances in coal beneficiation processes have been driven by environmental concerns and the desire to produce superclean or ultraclean coal to make coal-water slurry fuels. Coalwater slurry fuels are being developed as a potential replacement for No. 6 fuel oil in oil-fired power plants. Some of these techniques may also find applications in coal gasification.

Coal beneficiation research should focus on attaining a better understanding of coal morphology and on developing innovative coal-cleaning methods that can yield high ash and sulfur removals from coal in a cost-effective manner.

\subsection{Background}

Coal beneficiation is basic to coal-conversion processes because most of these technologies are designed to handle coals that have specific properties. Mined coal does not conform to these specifications. For example, Lurgi gasifiers require coal that is approximately 2 in to $1 / 4$ in in size, while Koppers-Totzek gasifiers require coal that is $90 \% 1$ ess than 200 mesh in size. It is evident that lower levels of impurities in the coal reduce cleanup required during conversion or post-conversion

* This chapter has been prepared by Suman P.N. Singh, Chemical Technology Division, Oak Ridge National Laboratory (ORNL), Oak Ridge, TN 37831 . ORNL is operated by Martin Marietta Energy Systems, Inc., under contract No. DE-AC05-840R21400 with the U.S. DoE. The author thanks R.E. Hucko (DoE, PETC) for assistance in providing recent information on developmental coal-cleaning technologies funded by PETC. 
processing. Coal beneficiation has received far less attention than other cleanup technologies. As environmental laws become stricter, greater reliance is likely to be placed on coal beneficiation in order to comply with regulations.

Raw coal ranges in size from large rocks to dust. In addition to the organic coal matter, the mine product contains shale from mine partings, stray machine parts, pieces of lumber, water and ash, as well as other mineral impurities such as pyrites. The raw mine product is often referred to as run-of-mine (ROM) or as-mined coal.

Coal beneficiation is a generic term that is used to designate the various operations performed on the as-mined coal to make it more suitable for end-use application without destroying the physical identity of the coal. Coal beneficiation includes coal preparation and washing. In the past, when the primary need was for lump coal, coal beneficiation consisted of manual operations such as hand picking of coal lumps from the mine product. In recent years, the term coal beneficiation has been redefined to include the entire spectrum of operations, ranging from the relatively simple crushing and size classification operations (that are almost routinely performed on a 11 coals used today) to rather elaborate chemical and microbial processes that are being developed to render the ROM coal more suitable for the end-use process.

The extent to which a coal is beneficiated is determined by several factors such as the ROM coal ash, sulfur, and moisture levels; end use; emissions regulations on the end-use facility; and market forces. For example, if the coal is to be burned in an existing utility boiler with soft emissions regulations, the extent of the beneficiation is likely to be minimal and may consist only of size reduction and rock removal. However, at the other extreme, if the coal is a raw material for the manufacture of a high-value product (e.g., activated carbons or carbon electrodes), the level of beneficiation may be quite extensive and a much higher coal cleaning cost is justified because of the higher value obtained for the cleaned-coal product. Beneficiating the coal has the following advantages: (i) The cleaned coal is more uniform in size, composition, calorific value, and moisture content. When the cleaned coal is consumed, it results in more reliable and uniform operation. (ii) By reducing the ash in the coal, beneficiation contributes to reduced slagging and fouling in the furnace, thus increasing boiler on-steam availability, decreasing 
maintenance, and lowering overall operating costs. (iii) Reducing the sulfur level in the coal reduces sulfur oxide emissions after combustion and, thus, decreases flue gas desulfurization (FGD) requirements. This decrease may translate into reduced production costs. Sulfur oxide emissions from power plants have been implicated as one of the major precursors of acid precipitation (acid rain). ${ }^{1}$ (iv) Removal of the associated mineral matter and sulfur from the ROM coal results in lower transportation costs for shipment of the same energy value, higher combustion efficiency, and reduced ash disposal and FGD requirements for the same furnace calorific value. (v) The moisture content of the cleaned coal may be reduced, thereby yielding improved coal handling and burning characteristics. This procedure leads to more efficient fuel use because less energy is wasted in drying the coal. (vi) Beneficiation can be used to tailor the coal to customer specifications, thus creating a higher value for the product. ( $v i i$ ) Beneficiation may allow the use of many high-sulfur and high-ash coals which could not otherwise be used, thereby increasing the usable energy-resource base.

Coal beneficiation also has negative aspects. The major disadvantages are as follows: (i) Beneficiating the coal results in reduced marketable coal output from the mine product because some of the coal is discarded with the refuse. (ii) Beneficiating the coal involves capital and operating costs that must be recovered and result in higher prices for the product coals. ( $i i j)$ The beneficiation-plant operator is confronted with the problems and cost of disposing of the plant refuse in an environmentally acceptable manner. These problems are either absent or significantly reduced when as-mined coal is shipped directly to the consumer.

The advantages of some coal beneficiation generally outweigh the disadvantages. A study by Hoffman et al. ${ }^{2}$ indicated that coal beneficiation, combined with FGD, appeared to offer the most economical means of achieving sulfur oxides emission control for coal-burning facilities at an $\mathrm{SO}_{2}$ emissions limit of $1.2 \mathrm{lb} / 10^{6}$ BTU. As emissions regulations become more stringent, coal beneficiation will become more attractive. For some coals, beneficiation may eliminate the need for FGD systems. 2 
Coal is expected to provide an increasing share of National energy needs. According to the U.S. Bureau of Mines, ${ }^{3}$ coal use for power generation alone in the US is expected to rise from $52 \%$ in 1986 to $63 \%$ by the year 2000. Future coal-utilization plants will be required to meet increasingly stringent environmental regulations that are motivated by acid precipitation and solid-waste disposal concerns. The supply of compliancequality coal may be limited; if so, coal beneficiation will play an increasingly important role in meeting the Nation's energy needs in an environmentally acceptable manner.

Summaries of current coal beneficiation methods and recent advances in coal cleaning are given in the following sections and will provide a perspective of the technology. References 4-7 may be consulted for further details.

\section{2. Current Commercial Practice}

Current commercial coal preparation relies primarily on physical (mechanical) processes to beneficiate the coal. The chemical, microbial, and other novel coal beneficiation technologies of recent origin are at various levels of process development. None of the novel methods have found commercial application because their use is not yet cost-effective.

Physical beneficiation processes involve gravity separation, centrifugal action, the use of surface tension, and magnetic separation to separate lower-density coal matter (specific gravity 1.2) from higherdensity impurities (specific gravity $>2.5$ ). Physical beneficiation processes generally consist of combinations of some or all of the following unit operations:

Size reduction - This operation consists of reducing the size of the coal received from the mine (often 24 in $\times 0$ ) to more manageable dimensions. Size reduction is usually accomplished by using equipment such as rotary breakers, impact mills, and single- and double-roll crushers. Sketches of some typical size-reduction equipment are shown in Fig. 10.1. Size Classification - This operation consists of segregating the coal into various size fractions to facilitate downstream processing. Both the ROM coal and the crushed product may be classified into different 
size fractions. Equipment for size classification includes stationary, vibrating, and cross-flow screens and classifying cyclones. Figure 10.2 presents some sketches of typical size-classification equipment.

Cleaning - This operation, which is at the heart of many coal-beneficiation plants, primarily involves separation of the physically attached sulfur compounds and/or mineral impurities (of higher specific gravities) from the coal (of lower specific gravity). It is often accomplished by using jigs, cyclones, and concentration tables, which utilize a combination of frictional, gravitational, and centrifugal forces to effect an apparent density-differential separation between the coal and its sulfur and mineral impurities. Schematics of typical equipment used in coal-preparation plants are given in Fig. 10.3.

Another commonly used cleaning method is heavy-medium separation, in which we employ an intermediate specific-gravity suspension of fine, dense minerals (e.g., magnetite or sand) in water to effect the desired separation. In general, heavy-medium separation results in a fairly high recovery of the clean coal, although the clean coal must be separated from the dense medium before it can be either used or processed further. Because of this additional processing step, heavy-medium separation incurs higher operating costs than similar beneficiation processes using only clear water.

Froth flotation processes are also generally used to beneficiate very fine-size ( 28 mesh $\times 0$ ) fractions. In froth flotation, the coal is beneficiated in a liquid medium (water) by finely dispersed air bubbles which are injected into the coal bath and float the very fine, clean-coal particles to the liquid surface, where they are mechanically skimmed. A surfactant is generally added to the coal bath in order to render the coal more hydrophobic and thereby facilitate coal flotation. Impurities associated with the coal sink to the bottom of the vessel, from which they are then removed for eventual disposal.

Drying - This unit operation involves reduction of the coal moisture-content to the desired value. Various types of equipment such as screens, filters, centrifuges, and thermal dryers are used to dry the coal, depending on the moisture content desired in the product coal. Figure 10.4 is a sketch of a fluidized-bed coal-dryer installation. 

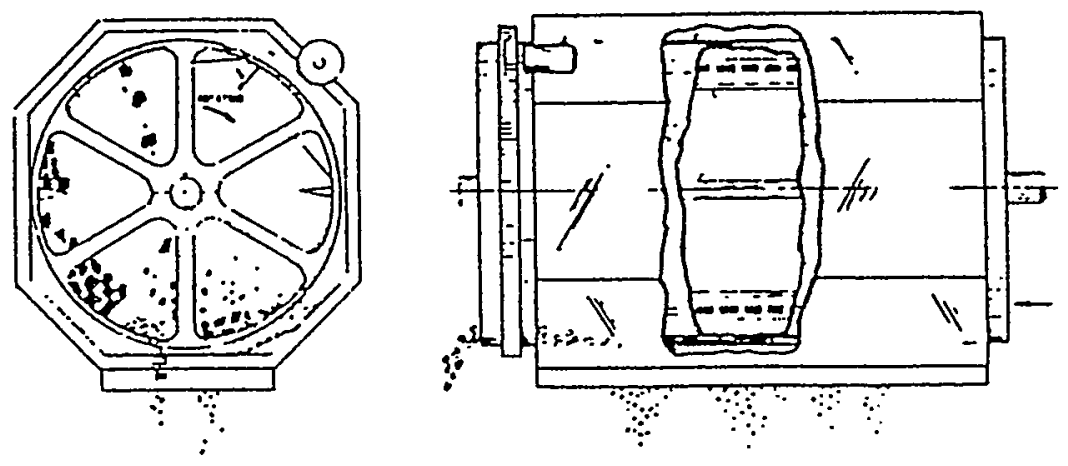

(a) Rotary breaker

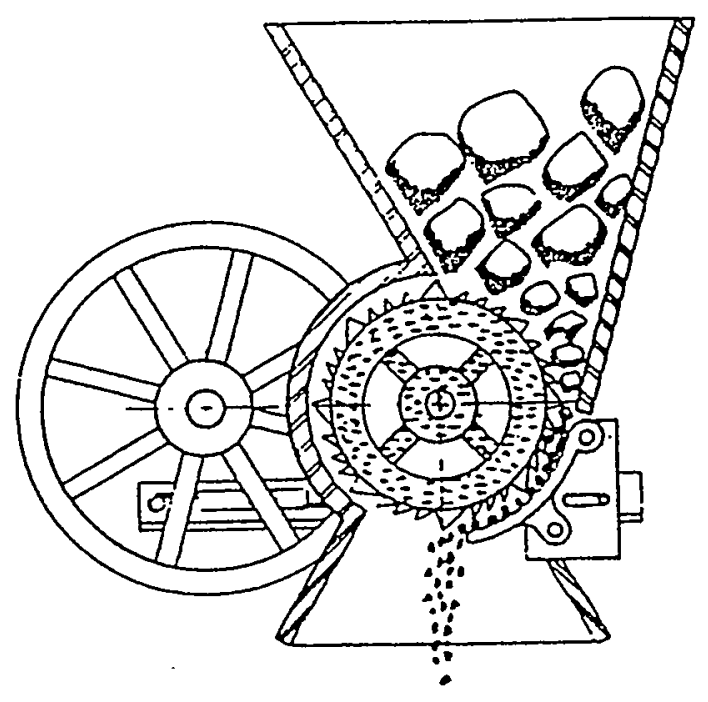

(b) Single-roll crusher

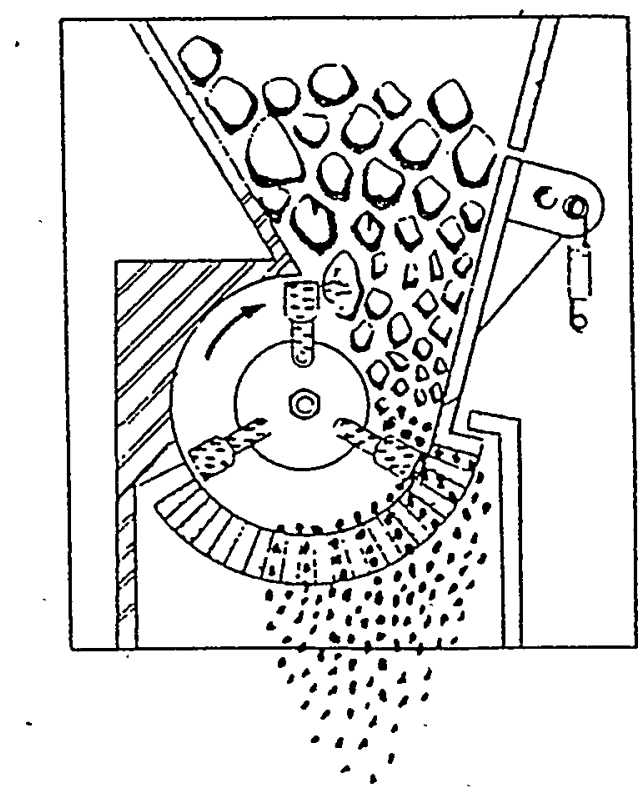

(c) Hammer impact mill

Fig. 10.1. Sketches of typical size-reduction equipment used in coal preparation plants. 


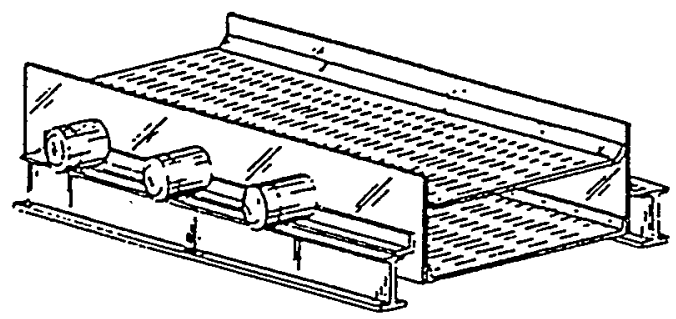

(a) Double-deck, mechanically vibrated screen

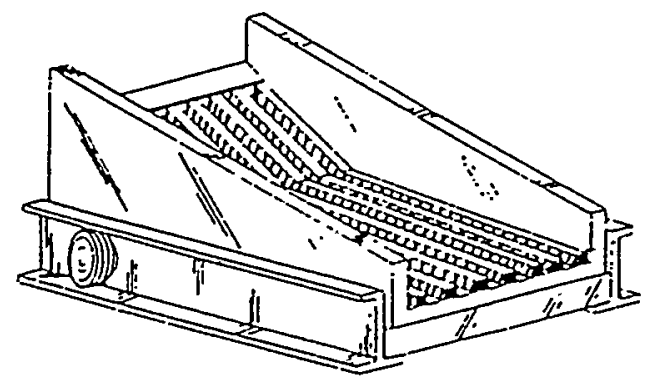

(b) Mechanically vibrated bar grizzly

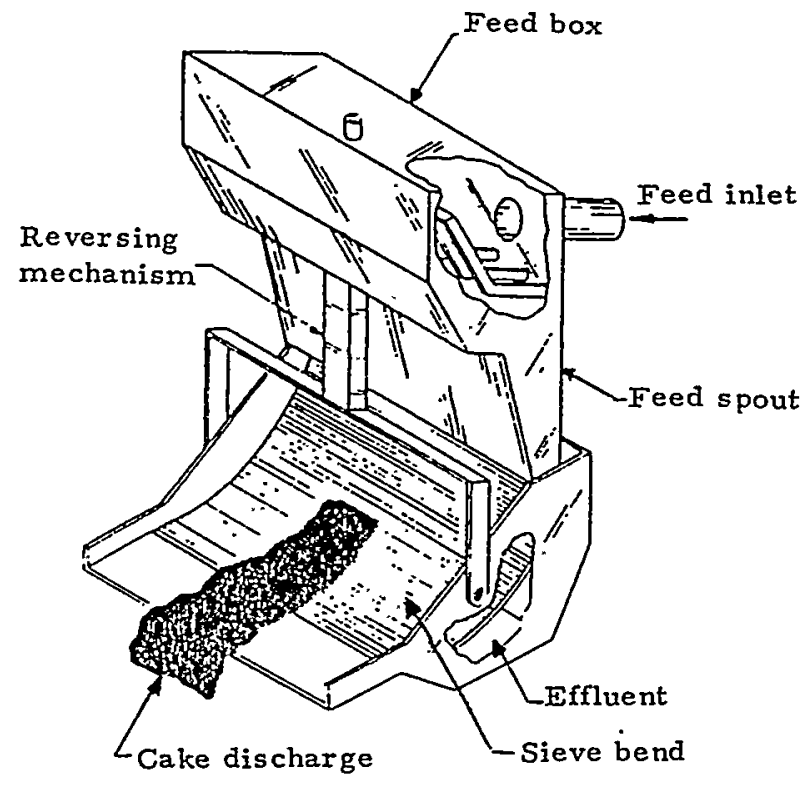

(c) Sieve bend

Fig. 10.2. Sketches of typical size-classification equipment used in coal-preparation plants. 


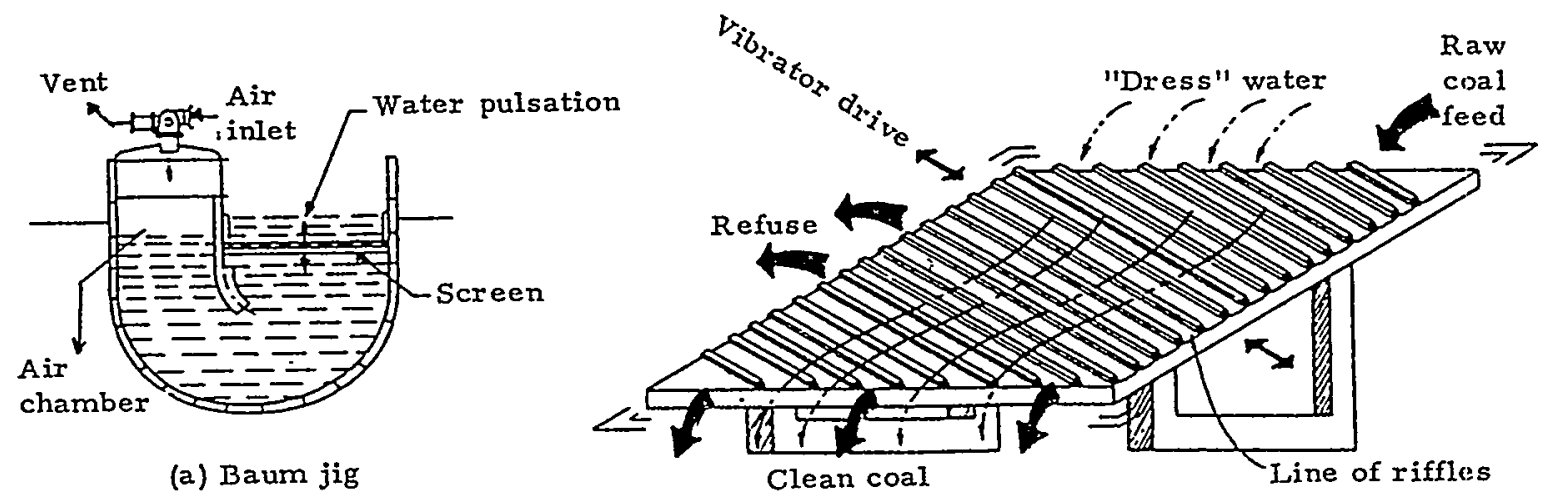

(b) Concentrating table

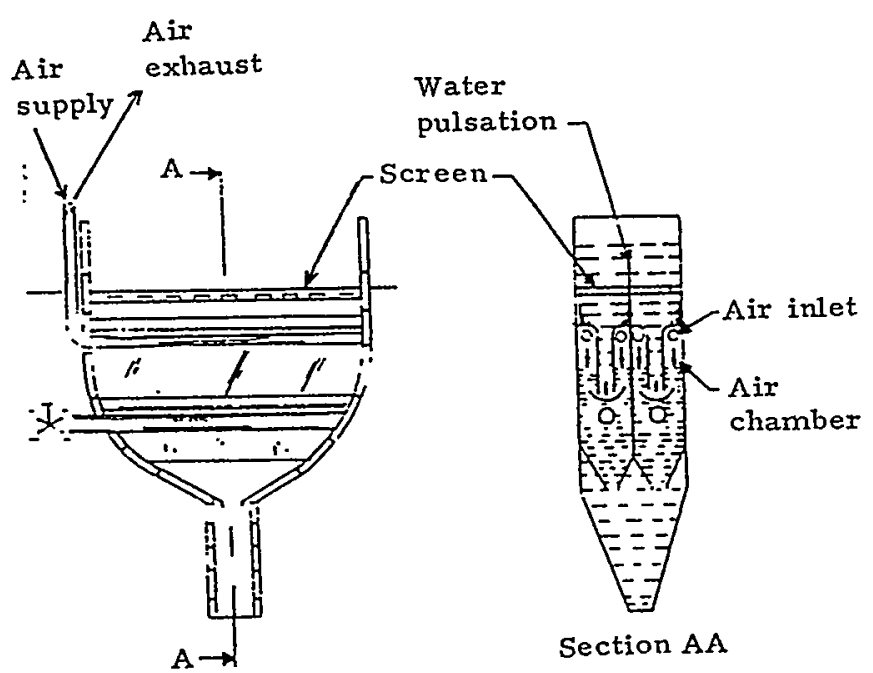

(c) Batac jig

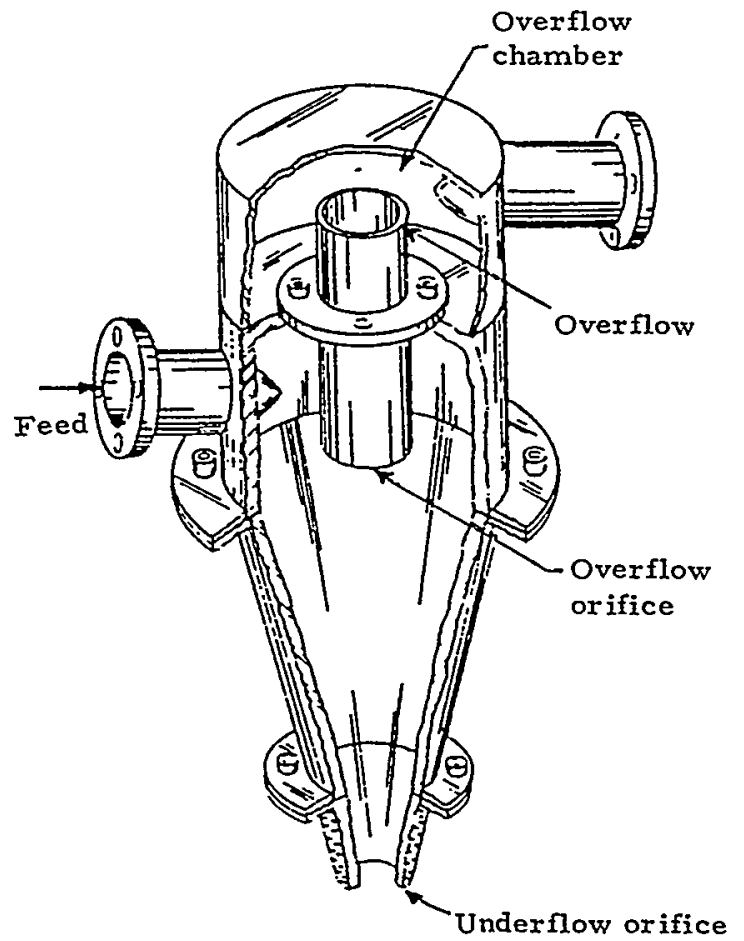

(d) Hydrocyclone

Fig. 10.3. Sketches of typical cleaning equipment used in coal preparation plants. 
Coal-preparation plants use combinations of these unit operations in treating different size fractions of the raw coal, depending on specifications of the coal to be produced. The minimal level of beneficiation consists of size reduction, some size classification, and removal of trash and some mineral matter but essentially no sulfur reduction. At the minimal level, coal yields and energy recovery range from 98 to $100 \%$ of the ROM coal. Full-scale beneficiation consists of a thorough cleaning of the as-mined coal and involves all of the specified operations. Cleaned coal yields at this level range from 50 to $80 \%$, with energy recoveries between 75 and $95 \%$ of the as-mined coal.

Coal-beneficiation costs vary because they are project- and coal-specific. Current coal-preparation plants are largely customized for specific applications. Generally, coal-preparation costs range between $\$ 5$ and $\$ 15$ per ton of cleaned coal, depending on the level of beneficiation.

\section{3. Recent Advances in Coal Cleaning}

Advances in coal cleaning have historically tended to be evolutionary rather than revolutionary. The energy crisis of the $1970 \mathrm{~s}$, together with increased environmental activism, has led to the development of several novel approaches to coal cleaning. Most of the new methods are based on chemical processes to remove more of the impurities from coal than is possible with conventional mechanical techniques. Several novel physical and some microbial methods were also examined during this period. A list of these novel technologies is presented in Table 10.1. However, because of improving market conditions for petroleum products in recent years, the national interest in developing a viable synthetic fuels industry has withered and further $R \& D$ on most of these novel technologies has essentially ceased.

The impetus for recent advances in coal-cleaning methods has come mainly from the drive to produce superclean or ultraclean coal for use in coal-water slurry (CWS) fuels and concerns that emissions from coal-fired power plants are major precursors of acid rain. CWS fuels typically contain 70 to 75 wt\% coal pulverized to -200 mesh, 24 to 29 wt\% water, and $\sim 1$ wt\% chemical additives to provide storage stability and improved flow characteristics. 8 The coal used in CWS fuel must contain only very low levels of ash $(<5 \%)$ and sulfur $(<1 \%)$. As a result, new deep-coal- 
cleaning methods are being developed. Table 10.2 lists some of these. Further details on these new processes may be obtained from Refs. 9-15.

10.4. Conclusions

Coal beneficiation has not received the attention given to coal combustion, gasification, or liquefaction for the following reasons: Beneficiation is often regarded as a part of the overall conversion process. ( $i$ i) Coal preparation lacks the scientific appeal of the other technologies. (iii) Because coal is a commodity, market forces dictate its production at as low a cost as possible. Since beneficiation increases the coal cost, its use is minimized as far as possible.

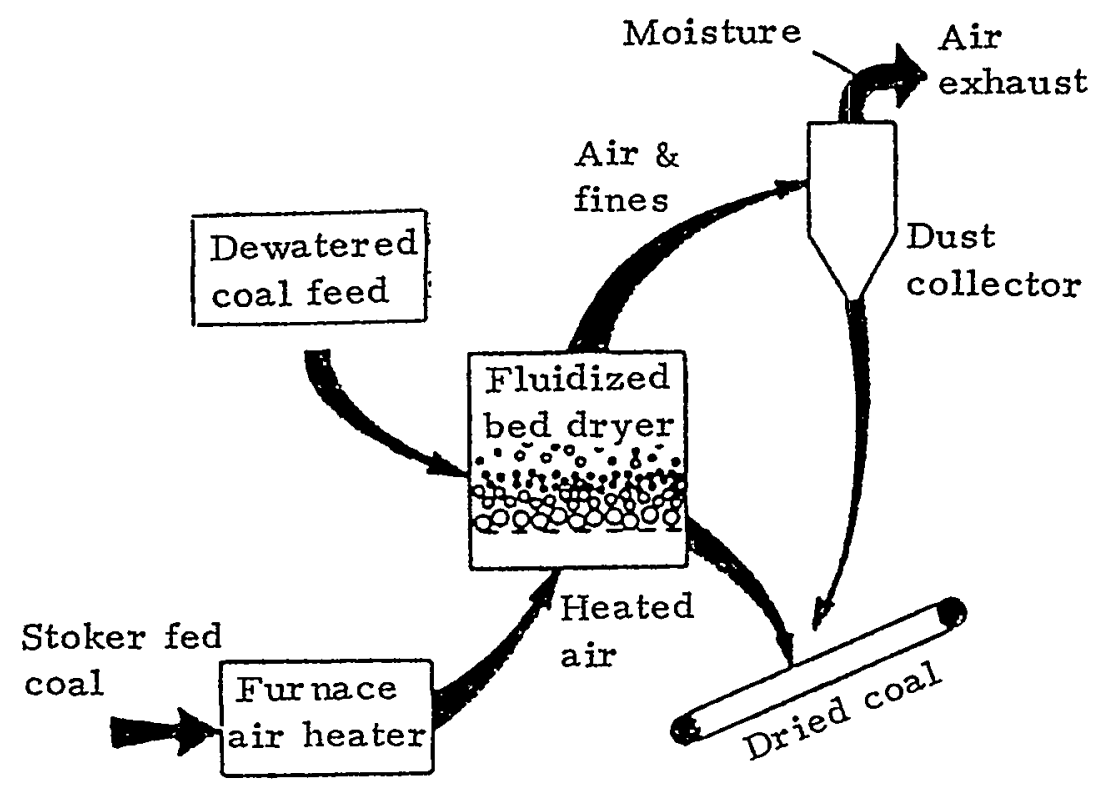

Fig. 10 4. Sketch of a fluidized-bed coal-dryer installation.

(iv) Past emissions regulations could generally be met by installing controls downstream of the conversion step. However, while FGD is a plausible emission-control method, it is expensive and has less-thandesired reliability. As emission regulations are tightened, coal beneficiation may be required. 
Table 10,1. Novel coal-beneficiation technologies developed during the 1970 s and early 1980 s.

Physical beneficiation processes

Dry table separator

Magnex process

High-gradient magnetic separation (wet or dxy)

Chemical comminution

Selective oil agglomeration

Microwave coal cleaning

Two-stage froth flotation

Otisca process
Chemical beneficiation processes

Meyers

Battelle hydrothermal

Ledgemont

KVB

PERC oxidative desulfurization

JPI low-temperature chlorinolysis

ARCO promoted oxydesulfurization

Table 10 2. Novel developmental coal-cleaning processes of recent origin.

\begin{tabular}{|c|c|c|}
\hline Tecl.nology & Developer & Reference (s) \\
\hline \multicolumn{3}{|l|}{ Physical Methods } \\
\hline Ultrasonic comminution & Energy Minerals Research Co. & 9,10 \\
\hline Dry electrostatic separation & $\begin{array}{l}\text { Advanced Energy Dynamics, } \\
\text { Inc. }\end{array}$ & 10 \\
\hline Microbubble flotation & $\begin{array}{l}\text { Bechtel National, Inc. / } \\
\text { Bergbau Forschung GmbH }\end{array}$ & 10 \\
\hline Otisca-T process & Otisca Industries Ltd. & 11 \\
\hline \multicolumn{3}{|l|}{ Chemical Methods } \\
\hline Microwave treatment & General Electric Co. /TRW & 10 \\
\hline Gravimelt process & TRW & 12,13 \\
\hline Supercritical extraction & $\begin{array}{l}\text { Consolidated Natural Gas } \\
\text { Research Co. }\end{array}$ & 14 \\
\hline Aqueous cupric chloride treatment & ORNL & 15 \\
\hline Sodium hypochlorite treatment & Signal Research Co. & 15 \\
\hline \multicolumn{3}{|l|}{ Microbial Methods } \\
\hline $\begin{array}{l}\text { Microbial coal cleaning using thiobacillus } \\
\text { ferrooxidans, sulfolobus acidocaldarius } \\
\text { and other bacteria }\end{array}$ & $\begin{array}{l}\text { Atlantic Research Corp., } \\
\text { Institute of Gas Technology, } \\
\text { Lehigh University }\end{array}$ & 10 \\
\hline
\end{tabular}


Several authors $2,4,16,17$ have shown that coal beneficiation, either alone or in combination with FGD, is a cost-effective sulfur oxide emissions control strategy. The authors of a recent study ${ }^{18}$ have shown that the use of specially beneficiated coal in a moving-bed gasifier leads to sharp (70 to $90 \%$ ) reductions in sulfur-emission levels and tar formation and to significantly higher $(\sim 83 \%)$ gasification efficiency.

While R \& D on chemical coal-cleaning processes has not yet led to a commercial process, $R \& D$ on physical methods is responsible for development of the Rotating Probability (RO-PRO) screens and the BATAC jig. Chemical processes that reduce coal-ash and sulfur contents to very low levels are, at present, too expensive and, therefore, $R$ \& $D$ effort should focus on cost reductions for these technologies.

DoE research efforts should be directed toward two aspects of coal beneficiation: (i) gaining a better understanding of coal morphology and $(i i)$ developing innovative coal-cleaning technologies through the smail (e.g., 20- to 50-lb/hr) pilot-plant scale. Research on coal morphology is important in order to guide the development of more efficient coal-cleaning methods and should receive perhaps $30 \%$ of the funds allocated for coal beneficiation $R \& D$.

\section{$\underline{\text { References }}$}

1. Interagency Task Force on Acid Precipitation, "National Acid Precipitation Assessment Program Annual Report 1984 to the President and Congress," p. 34, Washington, D.C. (1985).

2. L. Hoffman, S.J. Aresco, and E.C. Holt, Jr., "Engineering/Economic Analyses of Coal Preparation with $\mathrm{SO}_{2}$ Cleanup Process for Keeping High Sulfur Coals in the Energy Market," EPA-600/7 -78-002, U.S.

Environmental Protection Agency, Washington, D.C. (1978)

3. N.P. Chironis, Coal Age 21(2), 60 (1986).

4. P.J. Phillips, "Coal Preparation for Combustion and Conversion, Final Report," EPRI-AF-791, EPRI, Palo A1to, CA (May 1978).

5. S.P.N. Singh and G.R. Peterson, "Survey and Evaluation of Current and Potential Coal Beneficiation Processes," ORNL/TM-5953, ORNL, Oak Ridge, TN (March 1979). 
6. T.F. Edgar, Coal Processing and Pollution Control, Gulf Publishing Company, Houston, TX (1983).

7. Y.A. Liu, ed., Physical Cleaning of Coal: Present and Developing Methods, Marcel Dekker, Inc., New York, NY (1982).

8. T. Moore, EPRI J. $\underline{9}(6), 6$ (1984).

9. S.R. Taylor, W.B. Tarpley, Jr., and G.R. Moulder, "Ultrasonically Enhanced Size Reduction of Coal," pp. 256-68, Proceedings of the 5th International Symposium on Coal Slurry Combustion and Technology, Vo1. 1, Tampa, FL (Apri1 25-27, 1983).

10. R.E. Hucko, DoE/PETC, "Monthly Status Report - January 1986," memorandum to G.E. Voelker, DoE Program Manager for Coal Preparation, Feb. 6, 1986.

11. D.V. Keller, Jr., "Coal Refining by Physical Methods for the Preparation of Coal Slurries with Less than One Weigh Percent Ash," pp. 269-78 in Ref. 9.

12. R.A. Meyers, L.C. MCClanathan, and W.D. Hart, "Development of the TRW Gravimelt Process, pp. 112-14 in Proceedings of the 2nd Annual Pittsburgh Coal Conference, Pittsburgh, PA (September 16-20, 1985).

13. J.F. Jones, R.A. Meyers, L.C. McClanathan, and W.D. Hart, "Applicability and Cost of Gravimelt Coal for Coal Liquid Mixtures," in Proceedings of the 3rd Annual Coal Liquid Mixtures Workshop, Technical University of Nova Scotia, Halifax, Nova Scotia, Canada (October 12-14, 1983).

14. G. Carli, "Coal Beneficiation by Expansion of a Supercritical Coal/Water S1urry, pp. 306-15 in Proceedings of the 7th International Symposium on Coal Slurry Fuels Preparation and Utilization, New Orleans, LA (May 21, 1985).

15. Y.A. Attia, ed., Coal Science and Technology 9. Processing and Utilization of High Sulfur Coals, Elsevier Science Publishers, B.V., Amsterdam, The Netherlands (1985).

16. J.D. Kilgroe, "Uses of Coal Cleaning for Air Quality Management," paper presented at the Second Conference on Air Quality Management in the Electric Power Industry at the University of Texas at Austin Center for Energy Studies, Austin, TX (Jan. 22-25, 1980).

17. M.J. Laurila, Coal Mining 22(9), 36 (1985).

18. H.N. Conkle et al., "Experimental Testing of a Catalytically Treated Coal in a Moving Bed Gasifier," EPRI-AP-4506, EPRI, Palo A7to, CA (March 1986). 



\section{CHAPTER 11:}

\section{OPTICAL DIAGNOSTICS FOR IN SITU MEASUREMENTS IN COMBUSTION ENVIRONMENTS CONTAINING COAL PARTICLES*}

Abstract - Much of the recent progress in understanding pulverized coal combustion is attributable to the use of new optical diagnostics for in situ measurements of gas temperatures, concentrations of major and trace gas species, particie-size distributions, particle-surface temperatures, and gasand particle-velocity fields. In addition, advanced methods, which are now undergoing laboratory development and validation, hold promise for measuring in situ the composition of both entrained particulates and deposits on material surfaces exposed to coal-combustion environments. There is great potential for more widespread application of these techniques in the future, particularly in laboratory bench-scale studies. We describe some of the more promising of these new optical methods. This is not intended to be a comprehensive review but rather draws heavily on many of our own experiences. The emphasis is on studies of entrained-flow environments derived from the combustion of pulverized coal. These environments are hostile with regard to in situ optical interrogation in the sense that they are characterized by high temperatures, high particulate loadings and flow turbulence, and require the use of windows that limit optical path lengths and signal-to-noise ratios.

* This chapter has been prepared by D.R. Hardesty and D.K. Ottesen (Sandia National Laboratory, Livermore, CA 94550) and was presented by the authors at a NATO Workshop on "Fundamental Physical Chemical of Pulverized Coal Combustion," Les Arcs, France (July 30, 1986). The instrumentation requirements for coal gasification are similar to those for direct coal combustion and experimental facilities are interchangeable. 
After presenting an outline of diagnostics requirements, we present a framework, in terms of two principal classes of flows, for considering the relevance of various techniques in applications involving combustion flows with pulverized coals. We discuss advantages and limitations of

in situ methods for ( $i$ ) measuring gas-phase temperatures; ( $i$ ) measuring the major and minor gas species concentrations; (iij) measuring particulate properties, including sizes, temperatures, velocities, number densities, and flux; and (iv) measuring gas velocities in the presence of a broad distribution of particle sizes. Special consideration is given to our most recent work on the application of laser spark-spectroscopy for in situ measurement of the elemental composition of entrained particulates.

\subsection{Introduction}

Recent progress in understanding pulverized-coal combustion is attributable, in part, to the use of new optical diagnostics for in situ measurements of gas temperature, concentrations of major and trace-gas species, particle-size distribution, and gas- and particle-velocity fields. There is great potential for more widespread application of these techniques in the future, particularly in laboratory bench-scale studies. In addition, advanced methods, which are now undergoing laboratory development and validation, hold promise for in situ measurement of the composition of both entrained particulates and deposits on material surfaces exposed to coal-combustion environments. We emphasize the features of optical diagnostics that have the greatest potential for near-term application to detect the properties of gaseous or particulate species in small-scale pulverized-coal (PC) combustion experiments. These experiments contain many of the hostile features of practical combustors (e.g., high temperature, high particulate loadings, and flow turbulence).

\subsection{Diagnostics Requirements ${ }^{1,2}$}

Perhaps the key ingredient in defining the applicability of any optical technique for PC studies is the degree of temporal and spatial resolution required. All other requirements are derived from the specific 
parameters to be measured and depend upon the diagnostic system itself. To order this discussion, we define two classes of PC combustion flows as shown schematically in Fig. 11.2-1. Class I includes all wall-bounded, laminar and turbulent duct flows, while Class II refers to mixing, ducted, laminar, or turbulent shear flows. Unconfined, premixed or diffusion flames are special cases of Class I or Class II, respectively. With the notable exception of suspended or electrodynamically-levitated particle experiments, these represent the two limiting cases of the myriad of possible laboratory-scale PC combustion studies. Clearly, some methods are useful in some applications but have little advantage over more conventional methods (e.g., intrusive probes for thermometry and gas or solids extractions) in others. Where the measurement needs suggest that an optical technique be applied, consideration of the key features of the two classes of flows in Fig. 11.2-1 helps to define diagnostics requirements.

\section{2-1. Characteristics of Class I Flows}

The important features of Class I flows include: (i) well mixed gases; (ii) temporal steadiness; (iii) negligible pressure gradients; and (iv) plug flow, where reaction zones extend along the space coordinate or are very small or near zero in extent (e.g., in the post-flame zone). Mean radial gradients in temperature, velocity, or particulate loadings are either negligible (distribution curve $A$ ) or at most are on the order of the transverse duct dimension (distribution curve $B$ ) due to, for example, a nearby bend in the duct. In some cases, smaller characteristic dimensions and steeper gradients arise due to the presence of surfaces inserted in the flow.

The range of gas-phase parameters for Class I flows is: temperature, 1100 to $2000 \mathrm{~K}$; major species concerntrations (in mol\%) from 0.03 $\left(\mathrm{H}_{2} \mathrm{O}\right)$ to $0.8\left(\mathrm{~N}_{2}\right)$; minor species concentrations from a few to $100 \mathrm{ppm}$ for $\mathrm{SO}_{3}$ and less than $2000 \mathrm{ppm}$ for $\mathrm{NO}$ and $\mathrm{SO}_{2}$. Concentrations of $\mathrm{CO}$ due to incomplete combustion may range from a few hundred $\mathrm{ppm}$ to several percent. In addition, at combustion temperatures, volatilization of some mineral species such as vanadium, sodium and potassium occurs. For typical amounts of 

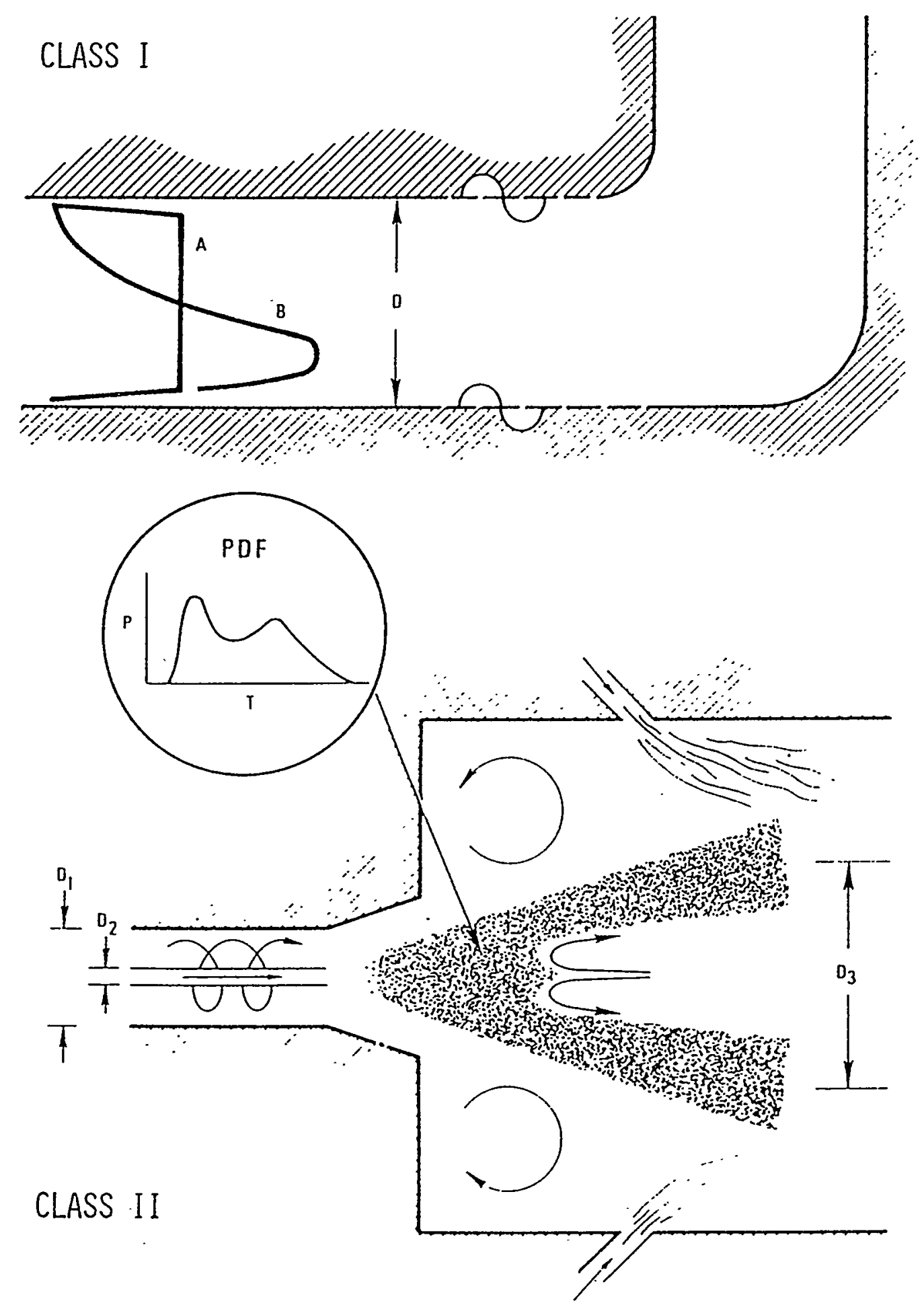

Fig. 11.2-1. Two principal flow regimes for PC combustion. Class I: wallbounded duct flows; Class II: mixing and ducted shear flows. 
these species in the unreacted coal, the highest concentrations to be expected are on the order of $25 \mathrm{ppm}$ for sodium and potassium and $1 \mathrm{ppm}$ for vanadium. Concentrations of these mineral species in the tens to hundreds of ppm will occur after cooling and condensation.

As noted, an important feature of any coal-derived flow is the high loading density of entrained particulates including coal, char, free mineral matter, soot and fly ash. Mass-loading densities are typicially weighted toward the large particle sizes. Of special importance for optical measurements is the wide distribution of both size and particle number densities. Figure 11.2-2 summarizes several recent observations of the number-size distribution of particulates in a variety of typical steady combustion environments. Particle velocity is a function of the mass and size of the particle and may range from a few to a hundred $\mathrm{m} / \mathrm{sec}$. In general, particles of different sizes move at different velocities because of the slip with the gas stream.

\section{2-2. Diagnostics Considerations for Class I Flows}

For these steady flows, requirements on temporal resolution are minimal; time-averaged measurements are adequate. An exception is the case where both the mean value and turbulent fluctuations of velocity are required, e.g., for heat-transfer estimates. Similarly, requirements on spatial resolution are generally not severe, e.g., none for flat(A) profiles or about 0.1 of the duct diameter for a skewed (B) profile. In view of these relaxed requirements on resolution, intrusive isokinetic probes (where sampling velocities match the mean gas flow velocity) may be valid diagnostic candidates. The alternative choice of an optical method would have to be based on other considerations such as the inherent errors and flow disturbances introduced by intrusive probes. For Class I flows, line-of-sight as well as spatially-resolved optical methods are generally applicable. Either may yield the desired information for a flat radial profile $(A)$. However, most of the advance optical methods require tight focusing of laser beams, either in principle or to overcome natural signal to noise limitations. Thus, a spatially resolved measurement is obtained whether it is needed or not. 


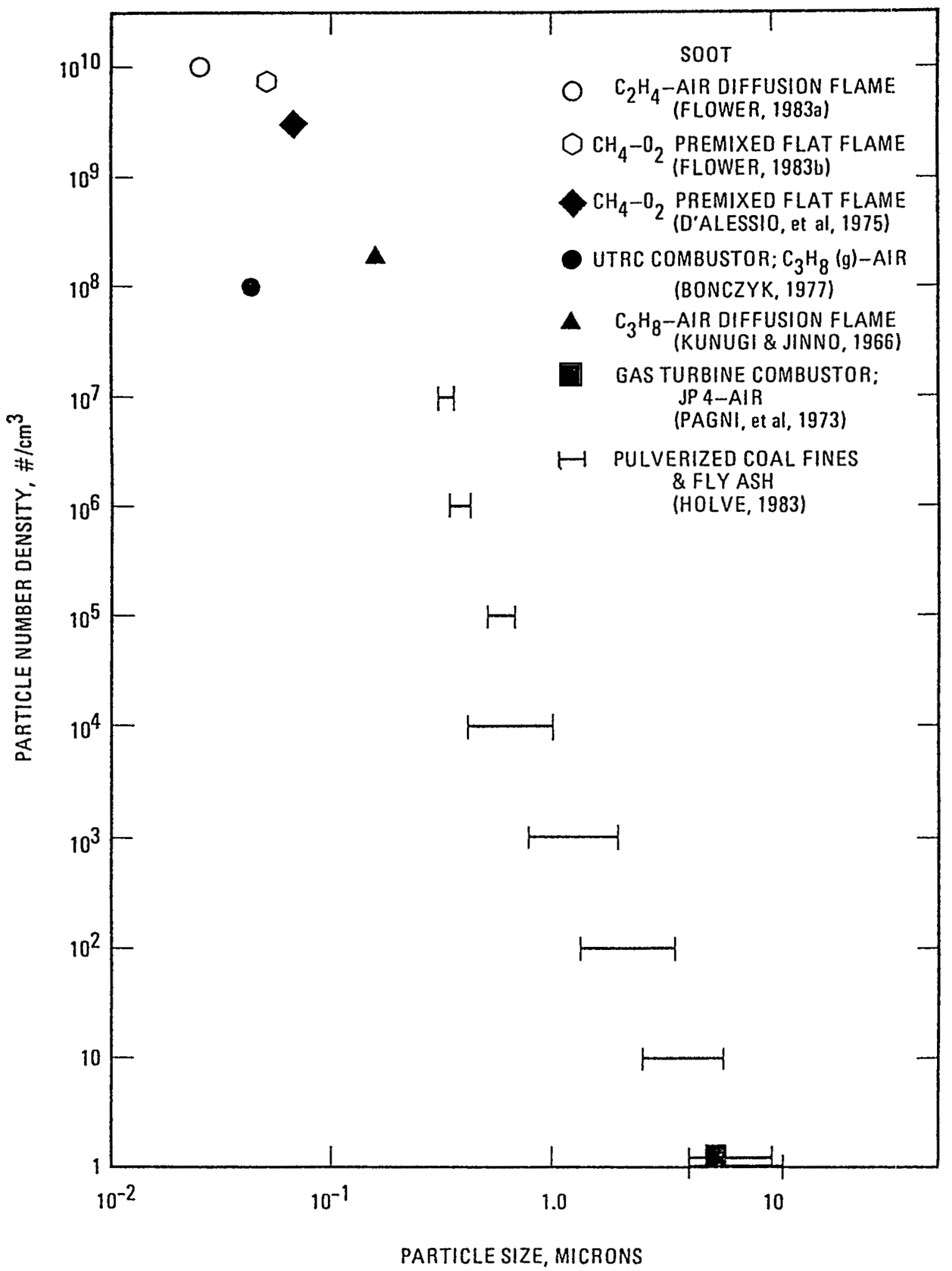

Fig. 11.2-2. Particle number densities and particle sizes for soot, PC fines and fly ash in combustion flows; see Ref. 1 for the literature citations given in the legend. 


\section{2-3. Characteristics of Class II Flows}

The important features of CLass II flows include: (i) locally unmixed gases and particulates with potentially steep gradients in all properties; (ii) locally unsteady flow with substantial turbulent fluctuations; (iii) finite mean pressure gradients and three-dimensional flow, both in the mean and in the turbulent fluctuations; (iv) particle motion may have significant inertial components; and $(v)$ the range of mean values for the concentrations of gaseous and particulate species is from zero to the levels indicated for Class I flows. Local zones of high temperature and high rates of chemical reaction can generate high levels of intermediate species such as the free radicals $\mathrm{OH}$ and $\mathrm{C}_{2}$.

\section{2-4. Diagnostics Considerations for Class II Flows}

The unsteady, three-dimensional, steep gradient character of such flows generally precludes the application of line-of-sight optical diagnostics. The exceptions to this include visualization techniques that may be of use in whole flame observation and line-of-light indicators of gross flame behavior. The existence of regions of steep gradients and high turbulent intensities imposes severe constraints on diagnostics. High spatial resolution is required to measure local properties (on the order of $1 \mathrm{~mm}^{3}$ for small geometries and perhaps $1 \mathrm{~cm}^{3}$ for large flows). As indicated by the schematic of a typical local probability density function (PDF) of, e.g., gas temperature in the reacting shear layer, Class II flows have regions where fluctuations about the local mean value are bimodal; the conventional definition of the mean value may be very misleading. In such regions, high temporal resolution is required in addition to high spatial resolution. Adequate time resolution for Class I flows is likely to be on the order of $50 \mu \mathrm{sec}$. In other words, single-pulse measurements with pulse widths less than $50 \mu$ are dictated; the PDF must be constructed from an ensemble of such single pulse data. In some cases, such as for a singleparticle-counting diagnostic system, this process occurs naturally and the number of counts of particles in each size bin is stored. In other cases, as in any of the Raman scattering techniques, the diagnostic must be 
specially configured to acquire single-pulse information. In still others, as in laser-Doppler velocimetry, an ambiguous jumble of information may be generated due to the difficulty of distinguishing true turbulent fluctuations from variations caused by the size dependence of particle velocity. Locally high concentrations of reaction intermediates (such as $\mathrm{OH}$ and $\mathrm{C}_{2}$ ) may be exploited in some diagnostics to sense local temperature or zones of incipient soot formation. On the other hand, the presence of $\mathrm{C}_{2}$ and other reaction-generated hydrocarbon species can have strong adverse noiseinducing consequences on laser-based-diagnostics.

In Class II flows, probe measurements of local values of gas temperature, species concentrations and particulate loadings are highly questionable from virtually every technical viewpoint. Without exception, it would be advantageous if a suitable, nonintrusive optical diagnostic with the required spatial and temporal resolution were available for measuring each important local property in Class II flows. As is discussed in the following sections, in principle, this is the case. In fact, however, there have been few validated measurements using advanced optical methods in flows where coal or coal slurry fuels have been used.

\subsection{Gas-Phase Temperature Measurement}

In this and in the next section, promising and principally laser-based optical methods for measuring the temperature and concentrations of major and minor gas species in Class I or II PC combustion are summarized.

\section{3-1. Raman Scattering Techniques}

Temperature measurement in flames using Raman spectroscopy has been an active area of research for more than a decade. For most applications of Raman scattering in combustion, temperatures are calculated from vibrational or rotational population distributions in $\mathrm{N}_{2}$, which is at high concentration levels in nearly all regions of air-fed flames. In addition, it has been demonstrated that the rotational and vibrational modes of $\mathrm{N}_{2}$ are close to equilibrium with the translational mode for the great majority of 
combustion situations. Raman scattering has the important advantage that the temperature can be calculated from relative scattering intensities for different transitions.

\section{3-1A. Spontaneous Raman Scattering}

Spontaneous Raman scattering (SRS) is a proven temperaturemeasurement technique and has been widely applied in clean flames. Incident photons (usualiy from a fixed-frequency laser) are scattered at frequencies which are shifted by the energy difference between two vibration-rotation levels. Temperature measurements are typically performed by using the ratios of the intensities of the Stokes (lower frequency) and anti-Stokes (higher frequency) signals or by resolving the Raman signal spectrally (using either Stokes or anti-Stokes lines) and fitting theoretical curves to the data. Application of spontaneous Raman scattering to luminous flames has been complicated by the weakness of the Raman signal relative to background emission. The presence of particles in combustion gases introduces severe problems for any SRS method. Incandescence from hot particles may swamp the weak SRS signal. In some cases, background-subtraction techniques, combined with high-power pulsed lasers and gated detection, may circumvent this continuous background problem. However, excessively high energy laser pulses heat particles above the gas temperature, ${ }^{3}$ causing additional radiation and fluorescence modulated at the laser frequency, radiation which cannot be eliminated by gated-detection and background-subtraction techniques. It appears that only one rather unique approach $^{4}$ is suitable for making time-averaged SRS measurements in luminous, particle-laden flows. The system uses a cavity-dumped argonion laser of intermediate peak power (50-100 W) and short pulse length (20 ns), combined with a high repetition rate $\left(10^{6} \mathrm{sec}-^{1}\right)$ to obtain moderate average power $(0.5-1.0 \mathrm{~W})$. The synchronous detection sampling gate is $25 \mathrm{~ns}$. This system improves the average signal-to-background ration by a factor of 10 relative to a similar system using a $5 \mathrm{~W} \mathrm{CW}$ laser. Flower ${ }^{5}$ validated the feasibility of making time-averaged temperature measurements in highly luminous flows by this method. Application of the technique is restricted to environments 
which are steady over the time period required for the measurement ( 1 to 10 minutes with an optical multichannel detection system.)

\section{3-1B. Stimulated Raman Scattering Techniques}

Stimulated Raman scattering techniques have important advaritages over spontaneous Raman techniques for probing luminous, particle-laden or turbulent flows. In the most widely developed method, coherent anti-Stokes Raman scattering (CARS), the Raman-scattered signal is emitted coherently, i.e., it has the laser-like directionality. Thus, much greater discrimination against background luminosity is possible. Further, signal levels are usualiy sufficiently high that temperature measurements are possible with a single laser pulse for both Class I and Class II flows. CARS requires two lasers, a pump laser and a Stokes laser. A CARS experiment is depicted schematically in Fig. 11.3-1. When the difference frequency between the pump laser $\left(\omega_{p}\right)$ and the Stokes laser $\left(\omega_{s}\right)$ corresponds to a Raman resonance $\left(\omega_{s}\right)$ of the probed species, a signal at the anti-Stokes frequency $2\left(\omega_{p}-\omega_{s}\right)$ is generated. The Stokes laser must be either tunable or broadband and is typically a dye laser. The response of the molecule to the pump and Stokes beams can be described in terms of the third-order resonant susceptibility. The susceptibility can be divided into a resonant part, which has a strong frequency dependance, and a nearly frequency-independent nonresonant component. The resonant and nonresonant signals interfere and the disappearance of the resonant signal into the nonresonant background determines the sensitivity limit for CARS. As will be shown, there are essentially two approaches, scanned CARS, a time-consuming method, and broadband CARS, a rapid and more promising approach for PC combustion studies. Much current research on broadband CARS is devoted to improving the accuracy and precision of single-pulse temperature measurements. The precision of the technique is presently limited by frequency noise in the broadband dye-laser spectrum.

Accurate modeling of CARS spectra is necessary to extract quantitative temperature and concentration information. Such modeling requires molecular linewidths and transition frequencies. The molecular susceptibility must be convoluted with the laser linewidth in order to com-pare theoretical and experimental spectra. The temperature is deduced by 
least-squares fitting of computer-generated spectra to obtain the best match to experimental spectra. Because this least-square fitting is such a timeconsuming procedure, various fast algorithms have been developed for singlepulse broadband CARS temperature measurements:

\section{3-1C. Application of SRS and CARS to Pulverized Coal Combustion}

Although background flame emission is rarely problematical in CARS measurements, the interaction of the high-intensity laser beams used for CARS with particles in the flame causes difficulties. As has been noted, the laser radiation may heat particles to very high temperatures and cause laser-modulated particulate incandescence. Other, more subtle effects occur in particle-laden flows, particularly in the case of soot-laden environments. When soot particles are rapidly heated by laser absorption, $C_{2}$ concentrations increase considerably in the gas phase surrounding the particles. Interferences can arise in the CARS measurements as the result of laser-induced $C_{2}$ fluorescence. In flows seeded with coal slag, Beiting 6 observed a coherent background signal in the region of the nitrogen spectrum, which interferes with CARS thermometry. The source of the background has not been fully explained.

Recently, Lucht ${ }^{7}$ completed the most systematic investigation to date of the applicability of CARS for gas-phase temperature and species concentration measurements in a PC combustion environment. Using a we11controlled, coal-seeded laminar flow reaction, CARS spectra of oxygen and nitrogen were successfully acquired and temperatures were determined from theoretical fits to nitrogen spectra. Significant spectral interferences were observed in the oxygen spectra because of laser-induced particle breakdown at high laser power. Lucht used the system shown in Fig. 11.3-1. The pump and Stokes beams were generated by a Molectron Nd:YAG laser and Quanta-Ray dye laser. The $532 \mathrm{~nm}$, frequency-doubled $10 \mathrm{~Hz}$ output of the Nd:YAG laser serves both as a CARS pump beam and as a pump for the dye laser (bandwidths are 0.1 and $0.2 \mathrm{~cm}^{-1}$, respectively). The pump beam is split into two equal intensity beams; all three beams are focused on a common probe volume $(4 \times 0.2 \times 0.2 \mathrm{~mm})$ by a $238-\mathrm{mm}$ focal length lens. In this work, the narrowband dye-laser frequency was scanned across the Raman resonances of 


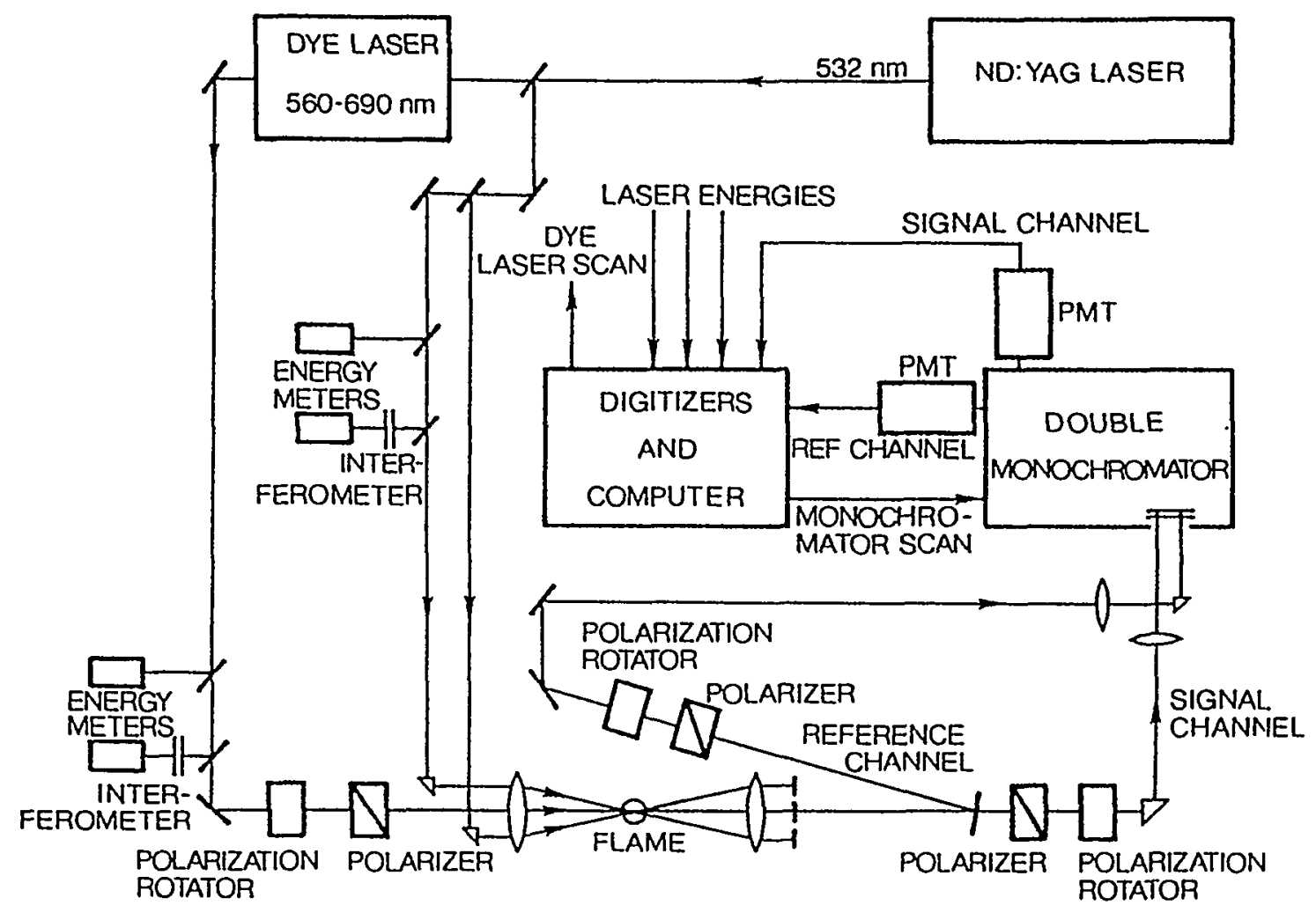

Fig. 11.3-1. Schematic of experimental arrangement for scanned CARS diagnostics with a 2-channel system using in situ referenced background subtraction. 7

oxygen or nitrogen to generate the CARS signal, which is focused on the entrance slit of a 1.5-m monochromator that is scanned synchronously with the dye laser. A photomultiplier (PM) tube detects the CARS signal, which is digitized and stored on a PDP $11 / 24$ minicomputer. This time-consuming approach ( 30 minutes to acquire 600 frequency data points and 30 laser shots averaged at each point) has now been eliminated by using a broadband dye laser to obtain the entire CARS spectra in a single shot, with an optical multichannel analyzer (OMA) for detection rather than a PM tube; the time needed for data acquisition is reduced to a few seconds. The measurements were performed in a densely coal-seeded laminar flow reactor (100X25mm) enclosed with quartz windows. The laser beams traversed the $100-\mathrm{mm}$ length, thus maximizing any effects such as absorption, which arise from propagation through the medium.

Typical results for oxygen and nitrogen spectra are shown in Fig. 11.3-2. With high pulse energies (26 mJ total pump and $5 \mathrm{~mJ}$ Stokes) signif- 

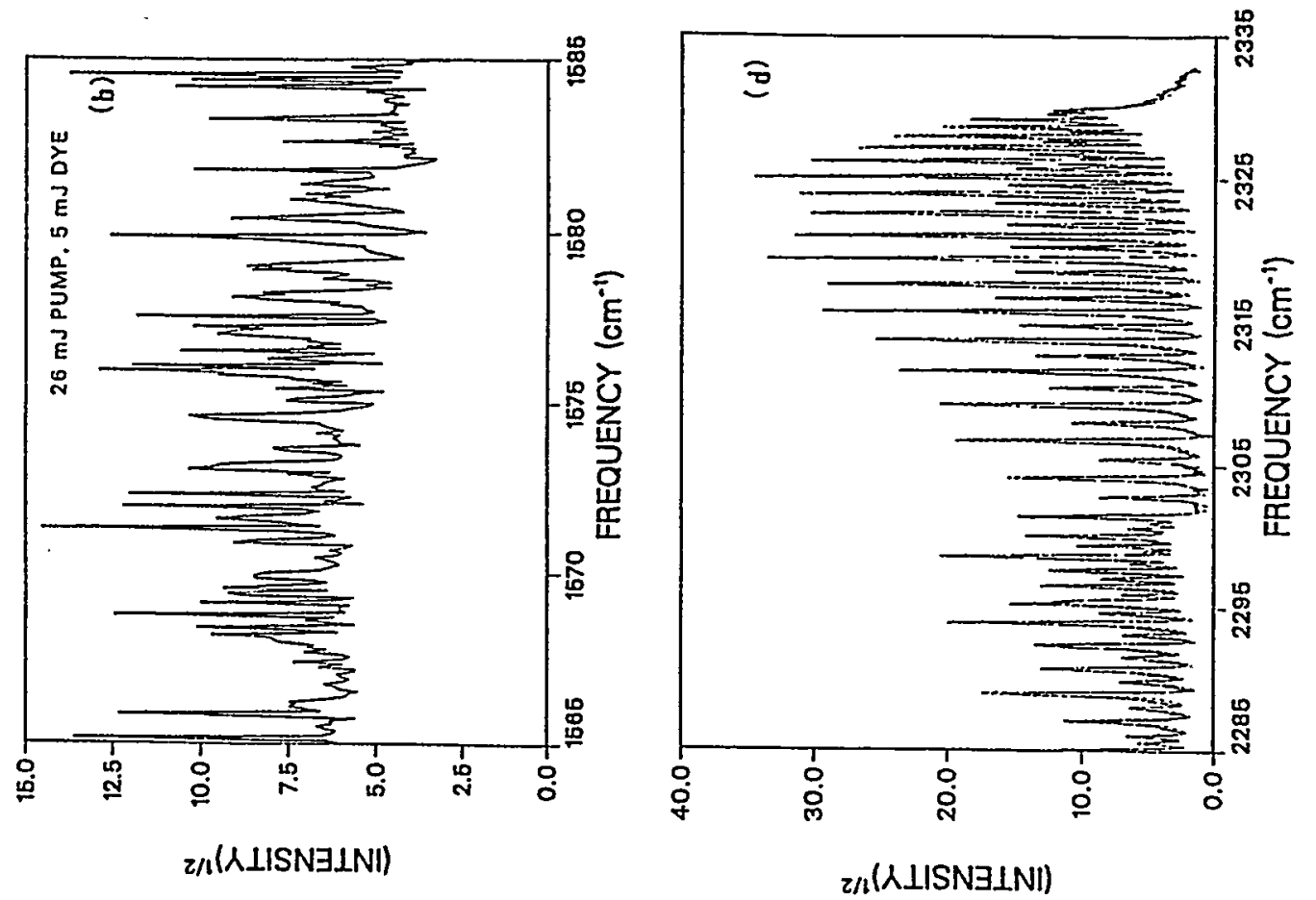

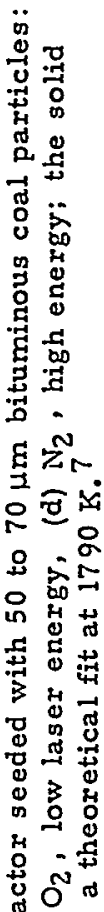

ํㅓㅁ

品实
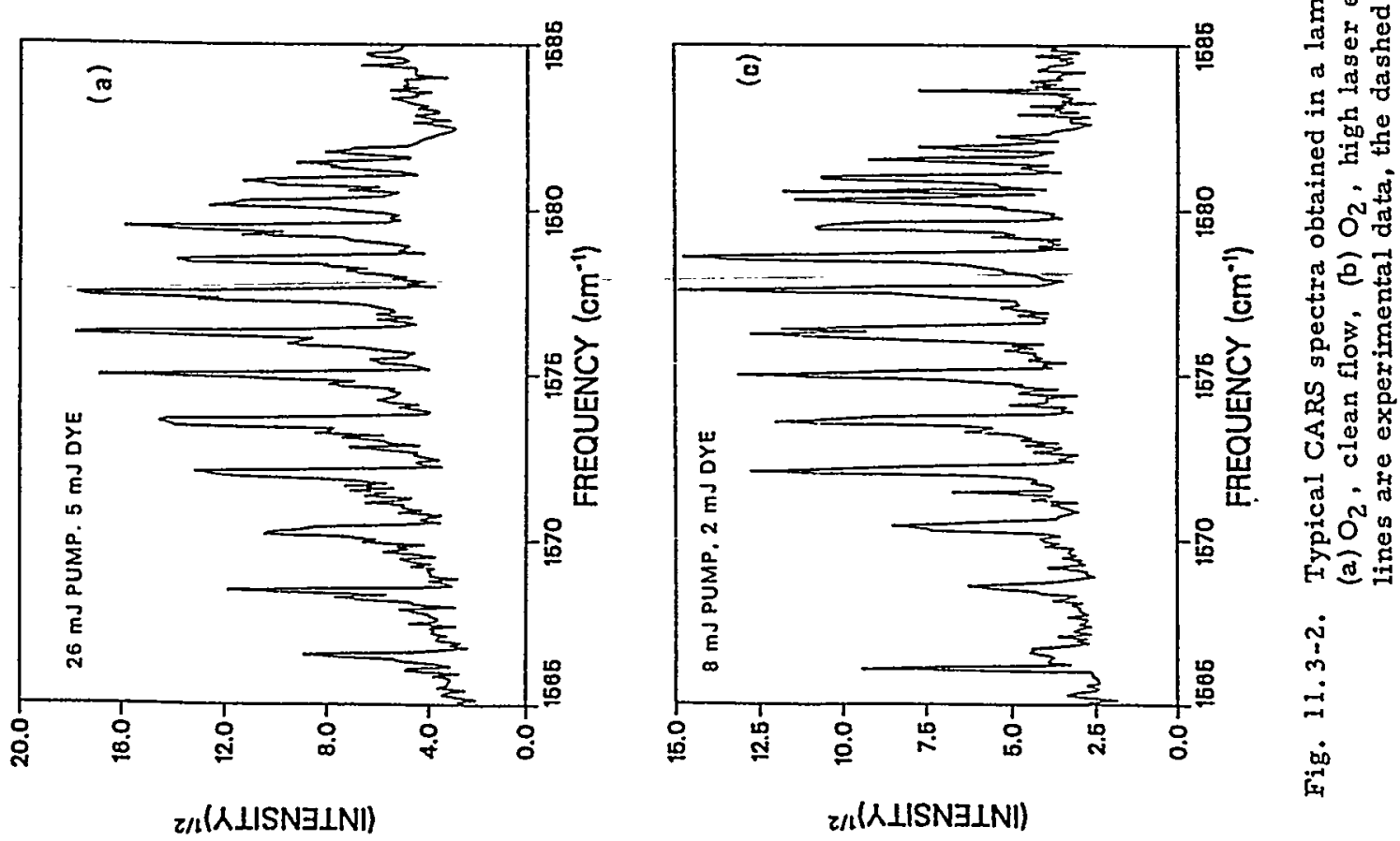
icant interference (random lines) were observed in the spectrum (fig. 11.3-2b) compared to a coai-free spectrum (Fig. 11.3-2a). These spectral interferences are most likely due to laser-induced breakdown at the surfaces of coal particles at random positions along the laser-beam paths. Two approaches, use of a longer focal length focusing lens or use of lower pulse energies, can circumvent this problem. In a large system, the sacrifice of spatial resolution with a longer lens may be acceptable. In this work, lower pulse energies ( $8 \mathrm{~mJ}$ for the pump and $1 \mathrm{~mJ}$ for the Stokes beams) greatly reduced the breakdown, but at the expense of diminishing the CARS signal (fig. 11.3-2c). Lucht successfully implemented a simple conditional sampling system to detect off-axis emission during breakdown and to reject those shots on which breakeown occurs. Time-gating detection electronics synchronously with the lasers discriminatẹs against noise from particle luminosity. Since CARS signals from nitrogen are 100 times stronger than from oxygen, interferences are greatly reduced at the same laser energies. Figure 11.3-2d shows a nitrogen CARS spectrum obtained at high pulse energies with a very good theoretical fit superimposed. In any application, single-shot broadband CARS will eliminate additional systematic uncertain-ties in such slow scans if these are caused, for example, by unsteadiness in the combustion conditions and variation in window transparencies.

In summary, the applicability of Raman scattering techniques, both SRS and CARS, to PC combustion environments is determined by characteristics of the flow such as: (i) the particle size distribution and number density; (ii) the intensity, intermittency and scale of flow turbulence; ( $i i$ ) the size and geometry of the flow; and (iv) the temperature, pressure and composition of the flow. Heavy loadings of luminous particles will be most detrimental to SRS because of the weakness and isotropic nature of the signal; CARS will be most strongly affected by turbulence and combustor size because of beam-overlap requirements and, of course, by beam attenuation at larger path lengths in particle-laden flows.

There is little doubt that, for a variety of Class II flows in laboratory combustors, CARS has potential for achieving local measurements of the probability density function of temperature, from which valid means and fluctuations in gas temperature may be inferred. The limits of applicability of CARS in such flows have not been thoroughly investigated. Beam 
attenuation due to heavy particle loadings and beam steering due to turbulence are expected to be the major limitations on CARS applicability in Class II flows. Beam-steering (especially for long optical path lengths) will cause the three laser beams to diverge from the required common focal volume. If conditional sampiing techniques can be devised to distinguish large beam-steering effects from the real temperature fluctuations due to turbulence, the main effect of beam-steering will be to decrease the data rate, a relatively minor consequence. Only for very clean Class II flows may the same be said for SRS. To date, a systematic demonstration and validation of CARS for local temperature measurements in Class II coal-fired flows has not been done; this is, in fact, one principal objective of current research at our 1 aboratory.

For Class I PC combustion flows, the prospect for successful application of CARS is good. For such flows, time averaging is acceptable because of the low level of temperature fluctuations. Application of SRS is severely limited by the background luminosity level, but time-gating and signal averaging may help.

\section{3-2. Fluorescence and Absorption Techniques}

Laser-induced fluorescence (LIF) and absorption methods (using 1aser diodes or other infrared sources) have been applied extensively to determine gas phase temperature in relatively clean and in soot-laden combustion environments. Fourier transform infrared spectroscopy (FTIR) has emerged only recently as a potentially useful technique for application to bench-scale coa7-combustion studies (see Refs. 8-10). Laser fluorescence and absorption methods require many of the same ingredients as the CARS apparatus shown in Fig. 11.3-1. A laser-pumped tunable dye laser (for LIF) or FTIR source is required, with detection at $90^{\circ}$ with respect to the incident beam for fluorescence or along the beam for absorption. In these measurements, the variable frequency light source is tuned to a real electronic transition of a molecule or atom. The species absorbs laser radiation and is excited to a higher-lying electronic state. The excited state species can decay back to the ground state by spontaneous emission (fluorescence), a process in which a photon is emitted isotropically. The fluorescence or absorption signal is proportional to the exciting state population of the mol- 
ecule or atom. Unfortunately, the excited state population resulting from laser excitation depends not only on the rates of laser absorption and spontaneous emission but also on collisional transfer rates, which must be measured or estimated.

Numerous studies in clean flames have been performed in recent years using LIF (including various special derivatives, such as two-line fluorescence) from the hydroxyl $(\mathrm{OH})$ radical to measure temperatures in flames. Laser-excited $\mathrm{OH}$ fluorescence is attractive as a temperature diagnostic because of signal-strength considerations; $\mathrm{OH}$ is typically present in high concentrations in flames, and several vibrational bands of the first excited electronic transition lie at the frequency-doubled wavelengths of high-efficiency rhodamine laser dyes. In addition, the frequency and radiative transition rates of $\mathrm{OH}$ rotational transitions are unusually we11-characterized. Fluorescence from vaporized atomic species (assumed to be in equilibrium with the combustion gases) can also be used to infer gas temperature. Five methods have been outlined ${ }^{12}$ for measuring flame temperature using atomic fluorescence. Because numerous possible seed atoms (e.g., lithium, sodium, potassium) have electronic transitions in the visible region of the spectrum, where ring dye lasers operate very efficiently, such techniques offer the possibility of temperature measurements at $\mathrm{kHz} d a-$ ta rates.

In a similar way, temperatures of molecular gas-phase species in flames have been determined from absorption spectra. Infrared sources are generally used for absorption measurements because all molecules, except homonuclear diatomics, have strong absorption bands in this spectral regime. As with LIF, temperatures are determined from the assumed equilibrium Boltzmann population distribution among the vibration-rotation energy levels.

\section{3-2A. Application of LIF and FTIR to Pulverized Coal Combustion}

In general, application of LIF or absorption techniques for gas-phase temperature measurement in pulverized coal-combustion environments will be feasible in situations where SRS is only marginally applicable. The strength of the LIF signal will depend on the type of species probed. Because transient species such as $\mathrm{OH}$ will be used for the LIF temperature mea- 
surement in unseeded flows, LIF will be useful as a temperature diagnostic only in relatively high-temperature regions. In such regions, where transient species concentrations may be very high (typically $1000 \mathrm{ppm}$ for $\mathrm{OH}$ ), the strength of the LIF signal is likely to be orders of magnitude higher than the Raman signal. Thus, in situations where temperature and particle loadings are high and SRS cannot be used, LIF temperature measurements may be possible. LIF is an attractive alternative to CARS in some instances since less complex apparatus and data-reduction procedures are involved. Single-pulse LIF temperature measurements may be possible. LIF is an attractive alternative to CARS in some instances since less complex apparatus and data-reduction procedures are involved. Single-pulse LIF temperature measurements will require either a fast-scanning dye laser or laser excitation with two or more distinct frequencies for the so-called two-line methods. No obvious technical obstacles exist for single-pulse, two-line temperature measurements methods, although no such measurements have been reported in flames to date. Seeding the flow with species such as atomic sodium will extend the temperature range of applicability of LIF at the cost of added experimental complexity to ensure uniform seeding, but may possibly introduce some uncertainty about the effect of the seed species on local reaction processes. In many coal-derived flows, sufficient atomic absorbers may already be present. An important consideration for application of LIF in PC combustion studies is the effect of fluorescence trapping or re-absorption of fluorescence emission as it traverses the medium between the probe volume and collecting lens.. In axisymmetric class I flows, the symmetry (or lack of symmetry) of the fluorescence temperature profile should be an excellent indication of these effects. In Class II flows, it may be much more difficult to detect the influence of fluorescence trapping, and serious temperature errors could result.

The feasibility of FTIR absorption thermometry in PC combustion experiments is largely the result of the fact that modern infrared sources are much brighter than the infrared emission of the hot gases in the flame. This is especially true for applications in bench-scale experiments. However, even in situations where the infrared emission from the flame is comparable to that of the infrared source, modulation of the source provides discrimination against the infrared emission of the flame, provided the combined infrared intensities do not saturate the detector. 
11.4. Gas-Phase Species Concentration Measurement

In this section, we comment briefly on the prospects for application of both Raman scattering techniques and laser-induced fluorescence or absorption methods for the detection of gas-phase species concentrations in $P C$ combustion environments.

\section{4-1. Raman Scattering Techniques}

Spontaneous Raman scattering (SRS) is a well-developed technique for measuring concentrations of major species in clean flows, including combustion and turbulent mixing flows. However, SRS has not been applied to measurements in environments laden with coal particles, soot or gas-phase hydrocarbons, due to interferences from particulate luminosity and broadband fluorescence from the gaseous organic species. As noted, CARS has been applied for gas thermometry in a wide variety of combustion systems, but CARS has not been as widely applied for concentration measurements. Concentrations may be calculated from CARS signals, either from the signal intensity or by using the ratio of the resonant and nonresonant CARS signals. The disadvantage of calculating concentrations from signal intensity is that the CARS signal strength is very sensitive to factors such as beam overlap and the temporal structure of the laser pulse, which can vary substantially over the course of an experiment or even from one laser pulse to the next. In principle, more precise and accurate concentration measurements are obtained by using the ratio of the resonant CARS signal from the species of interest to the frequency-independent nonresonant background. Such measuremerits can be performed by using polarization analysis to separate the CARS signals into resonant and nonresonant signals, separately recording the intensities of each signal, and then recording the ratio spectrum. Variations in CARS signal strengths from pulse to pulse are reflected in both the resonant and nonresonant signals, and are approximately cancelled by using signal ratios. Calculations of species concentrations from the ratios is straightforward, provided that the nonresonant susceptibility is a accurately known. Alternatively, broadband CARS spectra can be directly analyzed to obtain species concentrations when the resonant and nonresonant signal magnitudes are approximately equal. 
There have been very few attempts at obtaining species concentration measurements using CARS in heavily particle-laden combustion and gasification environments. A few preliminary demonstrations have been done for Class I flows. $7,13,14$ We are not aware of any, even preliminary validations of CARS for species concentration measurements in coal-fired, Class II

flows. While the few results for the Class I flows have been encouraging (i.e., a CARS signal was detected and a concentration estimated), from the standpoint of proof and validation of the diagnostic technique, much remains to be done, even for well-defined high-temperature environments. In view of the aforementioned uncertainties in interpreting CARS spectra (including such phenomena as pressure narrowing), considerable fundamental diagnostics research on the method is required.

\section{4-2. Fluorescence and Absorption Techniques}

\section{4-2A. Laser-Induced Fluorescence}

In recent years considerable progress has been made in defining the limits of accuracy of various laser-induced fluorescence (LIF) techniques for detecting species concentrations. Species of interest in PC combustion flows, which may be measured by using LIF, can be divided into three basic categories: (i) radical species such as $0, \mathrm{OH}$, and $\mathrm{NH}$ which are important in reaction kinetics and pollutant formation; (ii) pollutant species such as NO, $\mathrm{CO}$ and SO; and ( $\mathrm{i}$ ii) metal atoms such as $\mathrm{Na}, \mathrm{K}$ and $\mathrm{V}$ and compounds such as NaS which are important in corrosion, fouling and slagging.

The use of LIF techniques as a diagnostic for species concentrations in PC combustion has not been actively pursued. One reason for the lack of activity is that the detection of free-radical molecular species, which has been the primary objective of fluorescence investigations in combustion media to date, has not been of particular interest to coal-combustion scientists. However, recent fluorescence investigations of turbulent diffusion flames have shown that the radical pool is far from equilibrium in some portions of the flame. Consequently, accurate predictions of processes such as NO formation and CO burnout may require accurate knowledge of radical concentrations. In addition, there is indication that $\mathrm{OH}$ may be responsible for oxidation of coal volatiles, as well as for direct 
attack on the residual char. Therefore, we expect to see more applications in PC combustion but this will be difficult when particle loadings are high.

Quantitative fluorescence diagnostics of pollutant species such as NO and CO, while certainly feasible, have not yet been demonstrated, even in laboratory flames. Qualitative fluorescence methods may be of use in locating high zones of soot and HC formation. Most HCs, including soot precursors, have strong absorption bands in the visible and near ultraviolet and produce broadband flourescence emission in the visible portion of the spectrum. Fluorescence techniques for the measurement of $\mathrm{Na}$ have been actively pursued for over a decade; in fact, $\mathrm{Na}$ has served as a model atom for the development and demonstration of numerous fluorescence techniques. LIF techniques for measurements of other metal atoms are less we11-developed, but it is anticipated that techniques developed for $\mathrm{Na}$ will also be applicable to numerous other metal atoms. LIF diagnostics of species such as $\mathrm{NaS}$ are handicapped by the lack of a well-developed spectroscopic data base.

\section{4-2B. FTIR Absorption Techniques'}

The commercialization and widespread use of FTIR spectrometers has facilitated their use for quantitative gas analyses. This progress has been aided by the availability of increasingly accurate values for infrared line strengths, as reported in the literature. Furthermore, virtually all gases (except homonuclear diatomics) have at least one strong infrared absorption band in the mid-infrared region $\left(400-4000 \mathrm{~cm}^{-1}\right)$ that is easily accessible to most FTIR instruments. With many different species present in the sample, the mid-infrared region may become congested with many absorption lines. However, in most cases, the features caused by different species may be sorted out if the spectra are taken at sufficiently high resolution $\left(0.5 \mathrm{~cm}^{-1}\right.$ or better), since each species has a unique infrared absorption spectrum. Also, the task of sorting out the spectrum is much easier if only low molecular weight species (those having fewer than 5 atoms of atomic weight greater than hydrogen) are present in the sample. Clearly, lower gas concentrations can be measured if higher signal-to noise (S/N) spectra are obtained. With FTIR, a number of factors influence the maximum attairiable $S / N$. For example, averaging many spectra together improves the $S / N$ by a factor equal to the square root of the number of spectra averaged. The 
price one pays for improved $S / N$ is the increased time required to acquire the data.

In genera1, FTIR spectroscopy is an effective technique for detection of many different species simultaneously over a wide spectral bandwidth when conditions permit time-averaged measurements along a line-of-sight (e.g., in laminar or turbulent, plug-flow flames and reactors). Determination of gas-phase species concentrations using absorption spectroscopy is based on the application of the Beer-Lambert Law of absorption, which relates the intensity of the light transmitted through the sample to the incident light intensity, transition line strength, transition line-shape function, concentration of the absorbing species, and path length of the light through the sample.

Recently, two groups ${ }^{8-10}$ have explored the use of FTIR for gas-phase species concentration measurements in PC combustion studies. Solomon's work is reviewed elsewhere. ${ }^{11}$ 0ttesen's recent work at Sandia 8 has been of the nature of technique demonstration and validation. In this work, he has extended FTIR measurements into the high-resolution domain in order to assess the sensitivity of the technique for the determination of the concentration and rotational temperature of various molecules in a PC combustion environment. Infrared absorption measurements were made with uniformly-sized coal particles entrained in a laminar flow reactor.

Past attempts to make high resolution absorption measurements have been plagued by the infrared emission of hot coal particles passing through the detector field-of-view. Solomon ${ }^{10}$ has attempted to make use of these emissions by inverting the order of the combustion reactor-interferometer apparatus and by extracting the average emittance of the hot particulate ensemble for a given measurement time. These particulate emission signals, however, act as an additional noise source for absorption measurements and are mitigated only somewhat by laborious time-averaging. This problem has prevented the measurement of spectra at a resolution greater than $0.5 \mathrm{~cm}^{-1}$. However, this particle-generated noise occurs at Fourier frequencies lower than the pertinent bandwidth containing infrared spectral information. By electronically filtering the detector output, Ottesen successfully reduced this particulate noise and obtained the first reported measurements of pulverized coal combustion products at a spectral resolution of $0.08 \mathrm{~cm}^{-1}$. Although these measurements are more time consuming than those at 
lower resolution, they allow a more accurate determination of both the molecular rotational temperature and concentration. This advantage results principally from the lessened interferences of nearby absorption lines from other species (mainly water vapor molecules) and higher excited state transitions. These measurements also showed that the measured linewidths of $C O$ and $\mathrm{CO}_{2}$ transitions are considerably greater than the reported values of $0.04 \mathrm{~cm}^{-1}$ at temperatures around $1300 \mathrm{~K}$. Measured widths at half maximum are $0.105 \mathrm{~cm}^{-1}$, and it is postulated that the additional width is caused by collisional broadening due to the large quantity of water present (15 mol\%). A portion of the $C O P$-branch rotation-vibration band produced during the combustion of a pulverized western Kentucky bituminous coal is shown in

Fig. 11.4-1. The co rotational temperature determined from the relative intensities of the absorption lines was $1218 \pm 28 \mathrm{~K}$ and is in good agreement with a temperature of $1247 \pm 22 \mathrm{~K}$ derived from the $\mathrm{CO}_{2} \nu_{3}$, R-branch rotationvibration during the same experimental measurement. Reduction of the noise caused by the particulate emission increased the sensitivity for many small infrared-active molecules $\left(\mathrm{CO}, \mathrm{CH}_{4}, \mathrm{NO}, \mathrm{HCN}, \mathrm{H}_{2} \mathrm{~S}\right)$ to about $100 \mathrm{ppm}$ for a $10 \mathrm{~cm}$ path length at combustion temperatures in the presence in coal particles. Current efforts at detecting minor products of combustion in situ have been hampered by the serious overlap of water-absorption lines with $\mathrm{N}$ and S-containing species of interest.

\subsection{Particle Size, Number Density and Temperature Measurements}

Among the spectrum of diagnostic requirements for examining $P C$ combustion, perhaps the most serious is the need for in situ techniques for real-time detection of the loading and size distribution of entrained particulate matter, including solid coal, char, fly ash, soot particles and liquid droplets or slurry mixtures. In fundamental bench-scale studies of the reactivity of condensed-phase fuels, there is need to obtain simultaneous information on the size, temperature and residence time of reacting particles larger than $10 \mu \mathrm{m}$. In situ optical sizing techniques offer great promise to meet many of these measurement needs. Detailed chemical analysis will probably continue to require extractive sampling; a novel and promising in situ optical method called laser-sparked spectroscopy is discussed in the final section. 


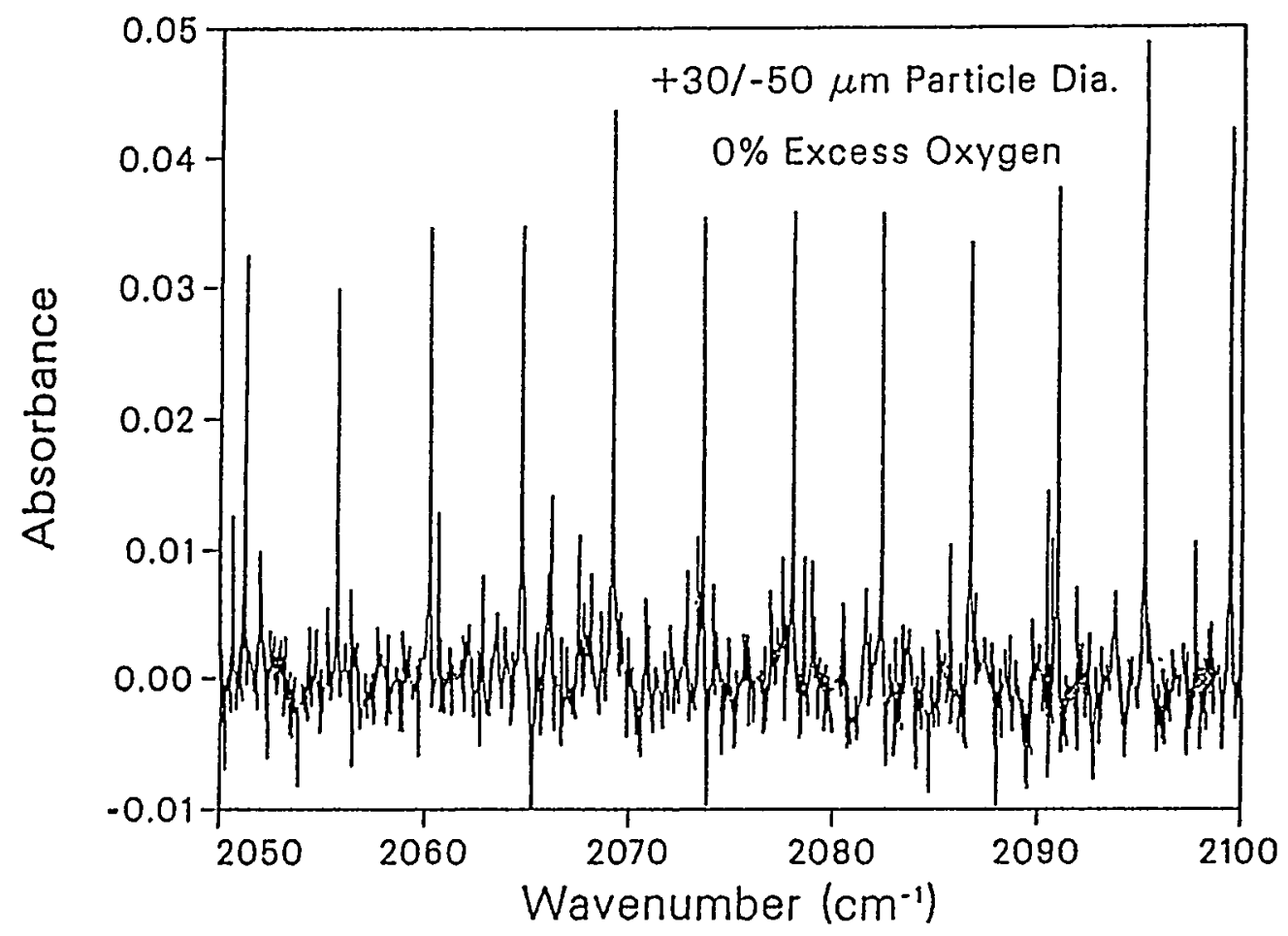

Fig. 11.4-1. The CO P-branch spectrum obtained by FTIR spectroscopy in a coal-seeded laminar flow reactor; rotational $\mathrm{T}=1218 \mathrm{~K} .8$

Optical methods can be characterized as imaging or light scattering. In the case of imaging methods, individual particles are resolved while in the latter they are not. As indicated in Fig. 11.5-1, both methods can be further subdivided into ensemble or single-particle techniques. In all cases, the analysis of particle size relies on the assumption of independent light scattering, which should be valid down to particle separations on the order of four times the particle diameter and number densities up to $10^{10} / \mathrm{d}^{3}$ per $\mathrm{cm}^{3}$, where $\mathrm{d}$ is the particle size in $\mu \mathrm{m}$. Beçause of the need for spatial resolution, real time analysis, and mass resolution (mass is concentrated in the upper end of the size distribution), the emphasis here is on the features of two of the most successful single particle counting (SPC) methods; one is a light scattering method and the other an imaging technique.

\section{5-1. Single Particle Counter, SPC (Scattering) Instruments}




\section{5-1A. User Requirements}

Hardesty ${ }^{1}$ has summarized typical user requirements for application of SPC instruments to PC combustion environments. For many applications, both number and mass-loading densities are of interest. The latter can be inferred from SPC measurements of the former if the material density of the particulates is known. The sizing range required for most studies probably has a lower bound of $0.1 \mu \mathrm{m}$, although soot formation and ash-condensation effects would require monitoring down to $0.01 \mu \mathrm{m}$. However, in all likelihood, the practical limit of SPC in high number density flows is about $0.1 \mathrm{~m}$. Minimum sensitivity to particle refractive index $\left(m=n_{1}+i n_{2}\right)$ and particle-shape variations is desirable in coal-fired flows, where particle properties range from irregularly fractured carbon particles $\left(n_{2} \sim 0.5\right)$ to fused silica fiy ash $\left(n_{2} \sim 0.001\right)$. For comparison, liquid fuel droplets are in general transparent $\left(n_{2} \sim 0\right)$ and spherical. If particle properties and shapes are known and invariant, these restrictions on instrument design become less stringent.

\section{5-1B. Design Constraints}

While many discussions refer to particle measurements as particle sizing, the correct reference is to particle size-distribution measurements. Measurements of particle size alone, without accurate counting of the number in each size class, is insufficient to characterize mean diameters (number, area, mass) or their integrated values. Many discussions have emphasized accurate size characterization with only limited discussion of proper number counting. In practice, accuracy of frequency-distribution measurements and derived averages are equally dependent on sizing and number counting accuracy.

The fundamental relations which constrain the design of SPC diagnostics based on Mie scattering are well known. Of particular concern here are the theoretical results which lead to the variety of in situ SPC diagnostics. First, a monotonic dependency of the scattered light amplitude on the particle size is required, with little dependence on the particle index of refraction or shape. Second, confining all measurements to the forward diffraction lobe for particles larger than about $0.1 \mu \mathrm{m}$ is the most advantageous. Consistent with these considerations, Fig. 11.5-2 shows a schematic 
diagram of a typical SPC instrument with symbols indicating the primary instrument design variables. A laser of wavelength $\lambda$ and beam $f$-number $f_{b}$ is focused through a window of thickness and

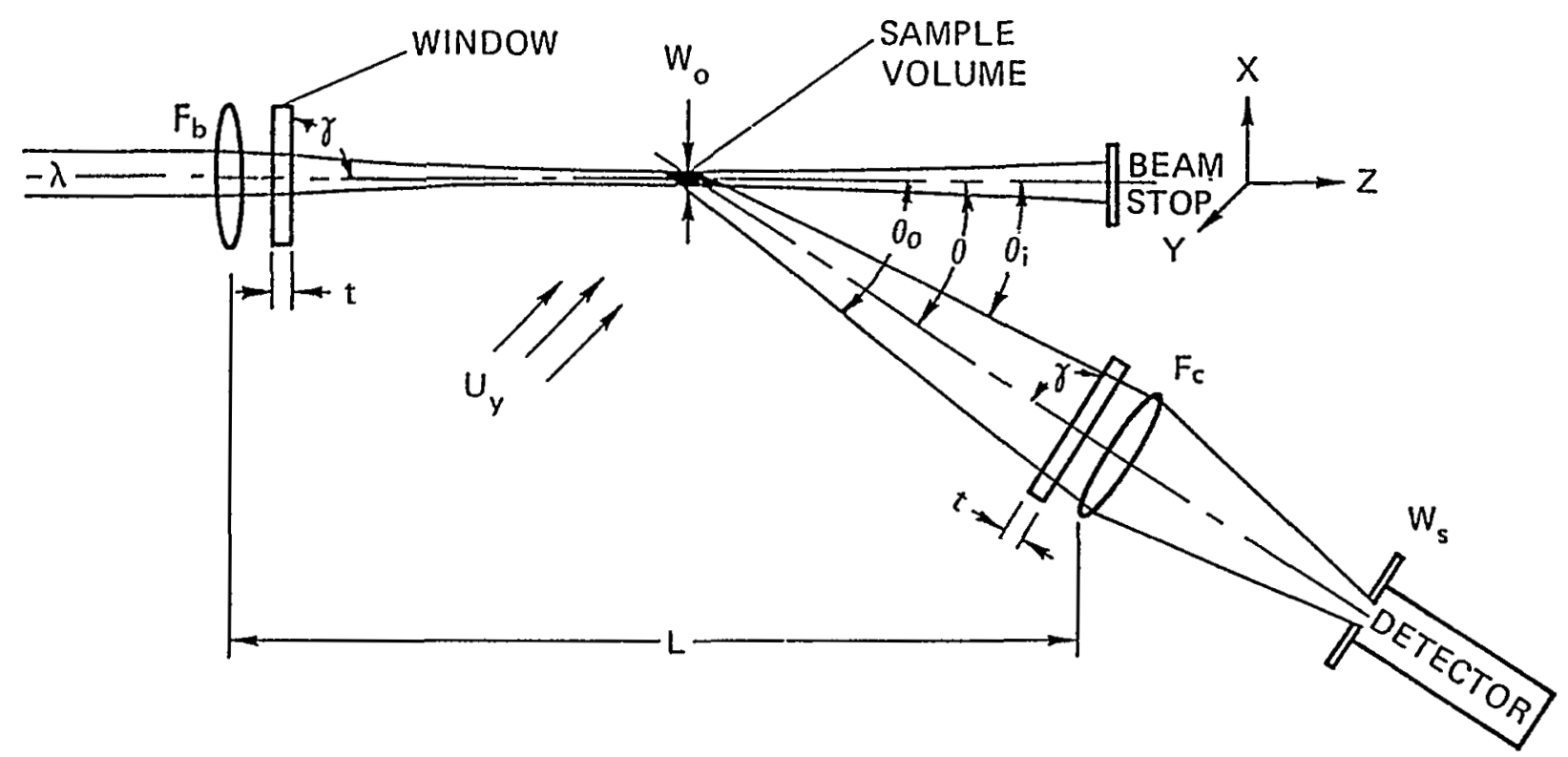

Fig. 11.5-1. Ensemble and single particle optical particlemeasurement techniques.

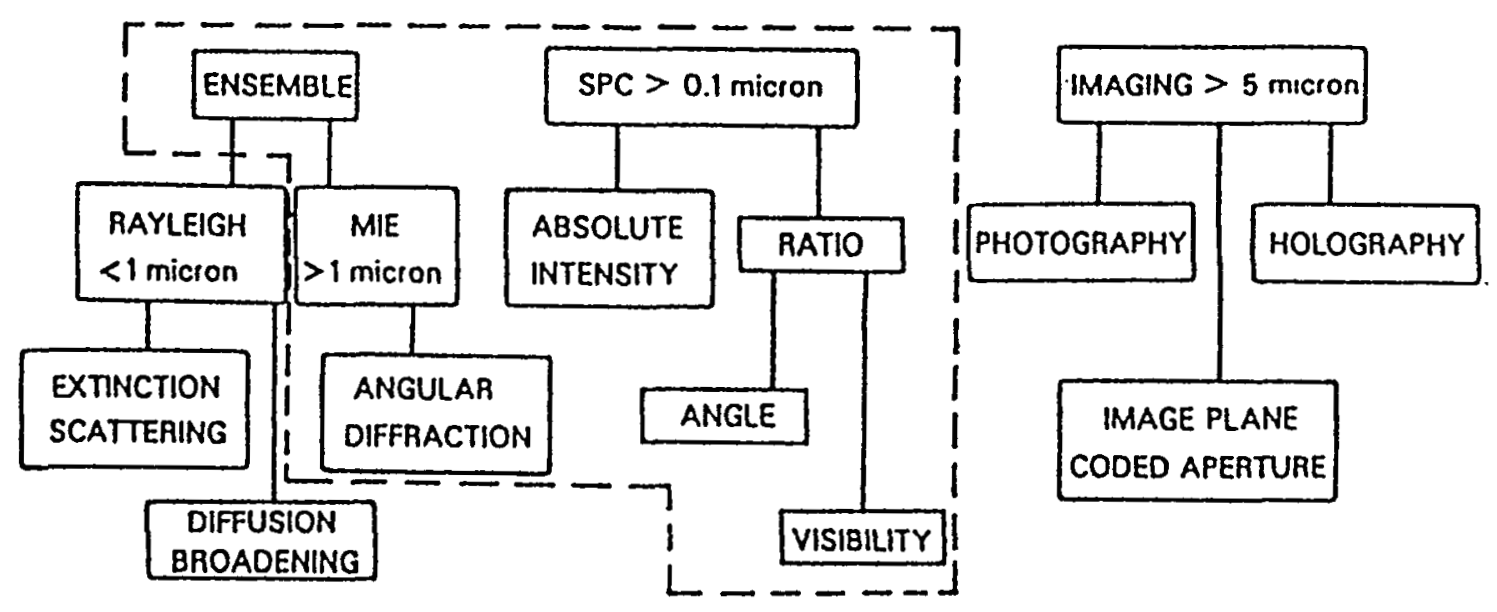

Fig. 11.5-2. Schematic diagram of a typical SPC device employing near-forward Mie scattering. 
angle $\gamma$ to a beam waist $W_{0}$. Scattered light from particles of velocity $U_{y}$ is collected by a lens of open aperture $\left(\theta_{i}-\theta_{0}\right)$ or f-number $F_{c}$ at an angle $\theta$ and focused onto a detector slit assembly of width $W_{s}$. The available working space between the two lenses is denoted by $L$. The sample volume from which scattered light is detected is determined by the intersection of the beam focus and the image of the slit. The single-particle signatures at the detector are processed by a minicomputer to provide amplitude-frequency distributions.

Given this general configuration, there are two basic methods of relating particle size to a scattering signal. One approach ${ }^{15}$ is based on absolute scattering and requires accurate knowledge of the distribution of laser intensity in the sample volume. The second approach ${ }^{16}$ uses the ratio of two independent absolute scattering signals from the same particle. Although ratio methods characterize particle size independently of the illumination intensity, the absolute magnitude of each ratio signal still depends on the local illumination intensity and the absolute response function. In Fig. 11.5-3, a theoretical comparison is shown of the typical absolute scattering response functions for the two classes of SPC methods. In the top half of the figure, the dashed curves refer to the angle-ratio method with different scattering angle pairs, and the solid curve characterizes a typical visibility-response curve with fringe spacing. In general, all such response curves are multivalued, which places undesirable limits on the dynamic range (in particle size) or requires multiple angle ratios to determine the correct particle size. The lower half of Fig. 11.5-3 shows typical absolute scattering response curves for both absolute and ratio scattering methods.

In our original analyses of both types of scattering methods, we considered in detail the basic relations among the elements of the typical SPC optical system, the particles being measured, and various instrument or hardware aspects. These include: (i) the dynamic range; (ii) the sample volume size; ( $i i i)$ the particle number density; (iv) resolution and accuracy; ( $v$ ) laser intensity in the focal volume; ( $v i$ ) windows; ( $v i i$ ) beam steering; and (viii) electronics. The key points are as follows: (i) Enlarging the collection solid angle reduces the dynamic range. The required dynamic range in the signal for a factor of 10 in particle size approaches $10^{4}$. (ii) All SPC methods require knowledge of the absolute scattering response 
function and the distribution of laser intensity in the sample volume. Particles of the same size, which pass through different regions of the focal volume, give rise to different scattering signatures. (iii) The maximum particle number density in the flow that can be accommodated, without having two or more particles in the sample volume simultaneously, is given by $(N<4 P / N)$, where $P$ is the probability of having two or more simultaneous scattering events in the sample volume $V$. The requirement for a small volume dictates a small beam waist $W_{0}$, which produces a non-uniform laser-intensity distribution in the sample volume. (iv) A $95 \%$ confidence level in the particle-count rate requires more than 1000 counts. All SPC instruments require time to acquire sufficient counts in each size bin to meet the accuracy requirement; the time required is a function of the particle loading density and will range from a few seconds to minutes for very lightly loaded flows. Thus, although data are being sensed in a single pulse mode for each particle, the measurement of a size distribution is inherently time-averaged. (v) There are simple interrelationships among the laser wavelength, the foca"l length of the focusing lens, the beam waist size, the depth of field, the size of the largest sensible particle and the maximum number density of the smallest particles that can be sensed. ${ }^{1}$ In practice, these factors dictate that at least two laser beams are required to measure particles from the submicron to $100 \mu \mathrm{m}$ range: one tightly focused to measure the smal1, higher number density particles and the second with a larger focus to measure the larger

particles. ( $v i)$ Most PC combustion experiments require windows for optical access. Displacement of the focal volume along the incident laser direction is proportional to the thickness and index of refraction of the window material; lateral displacement will occur if the beam is not perpendicular to the window. The incident beam must be monitored to account for beam attenuation due to window fouling. (vii) Beam steering, primarily due to gradients in the index of refraction of the combustion gases which are transverse to the laser and scattered beams, can be appreciable and unsteady but may be compensated for by enlarging the entrance slit of the detector. (viii) $\mathrm{Be}^{-}$ cause of the large dynamic range required of the detection and amplification circuit, logarithmic circuits or staged amplifiers are required with at least a $10 \mathrm{MHx}$ frequency response. 


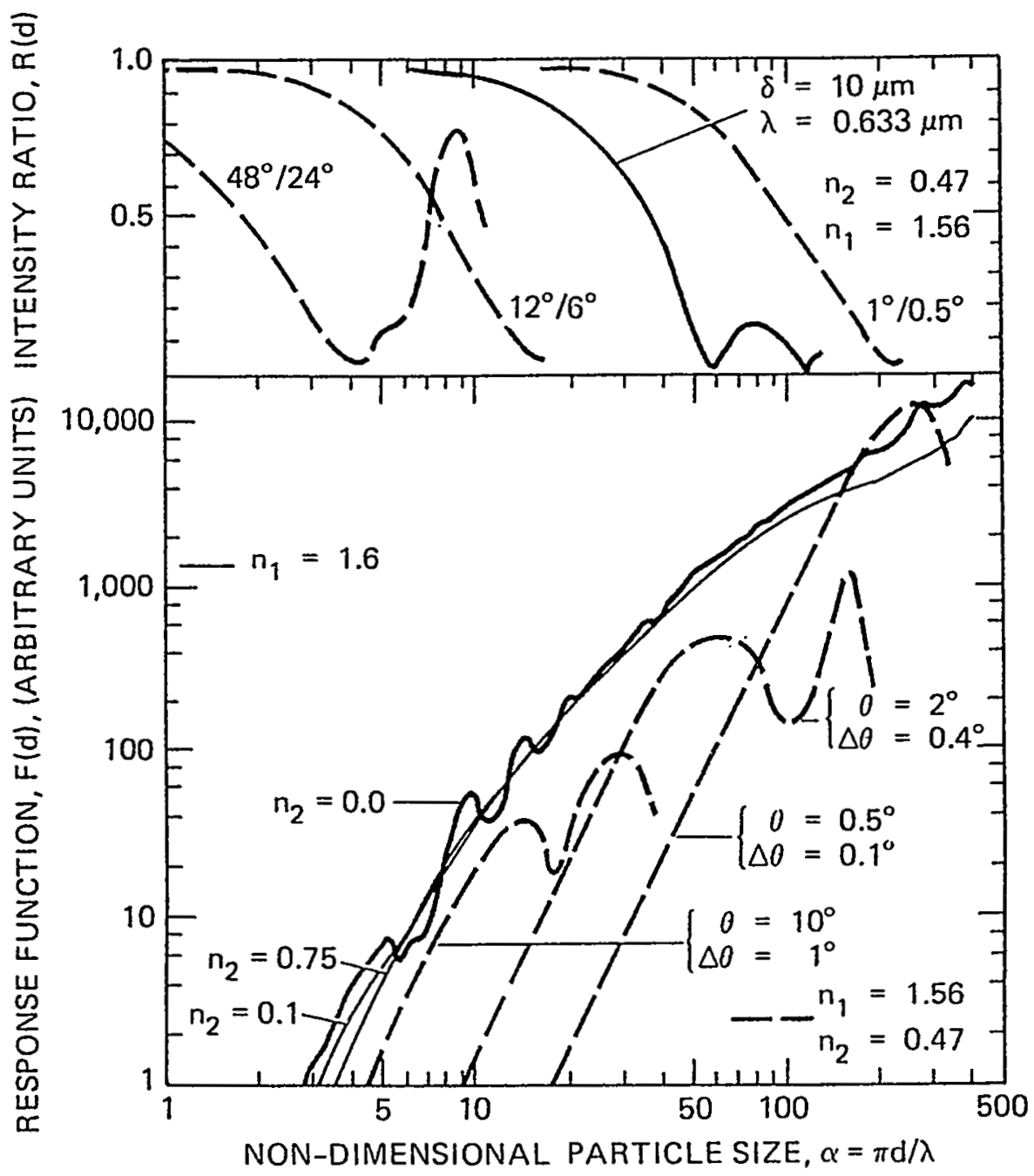

Fig. 11.5-3. Comparison of response functions ${ }^{2}$ for the ratio and absolute SPC scattering methods.

\section{5-1C. SPC Intensity Deconvolution Method}

The only SPC optical method that has been used reliably for measuring particles over the size range $0.1-100 \mu \mathrm{m}$, at number densities from $10{ }_{2} / \mathrm{cm}^{3}$ at the large sizes to $10^{7} / \mathrm{cm}^{3}$ at the small sizes, is a dual-beam absolute intensity deconvolution (SPC/ID) method. ${ }^{17} \mathrm{~A}$ key feature of this method is the use of dual beams to achieve the required small sample-volume size to accommodate the increased particle loadings at the small end of the particle-size distribution. The system uses near-forward scatter, as in 
Fig. 11.5-2, with $\theta_{i}<6^{\circ}$ to minimize refractive-index and particle-shape sensitivities. The choice of inner angle light collection, $\theta_{i}$, depends on the size range of interest. The response functions for $\theta_{i}=0.6^{\circ}$ are the solid curves in Fig. 11.5-3. Because of the variation of the laser beam intensities in the sample volume, the scattered signal is particle-trajectory dependent. A numerical inversion scheme and calibration procedure allows unfolding of the distribution of signal amplitudes and yields and indicated size distribution, which eliminates the dependence on trajectory. The scattered light from particles passing through each of the two sample volumes is collected by a single lens and divided by a beam splitter and focused onto the large and small slits, respectively.

Extensive calibration and validation experiments have been conducted by Holve. ${ }^{15}$ Figure 11.5-4 illustrates recent results obtained for the evolution of particle-size distribution in a laminar flow-reactor study of the combustion of pulverized coal and coal-water slurries. 18

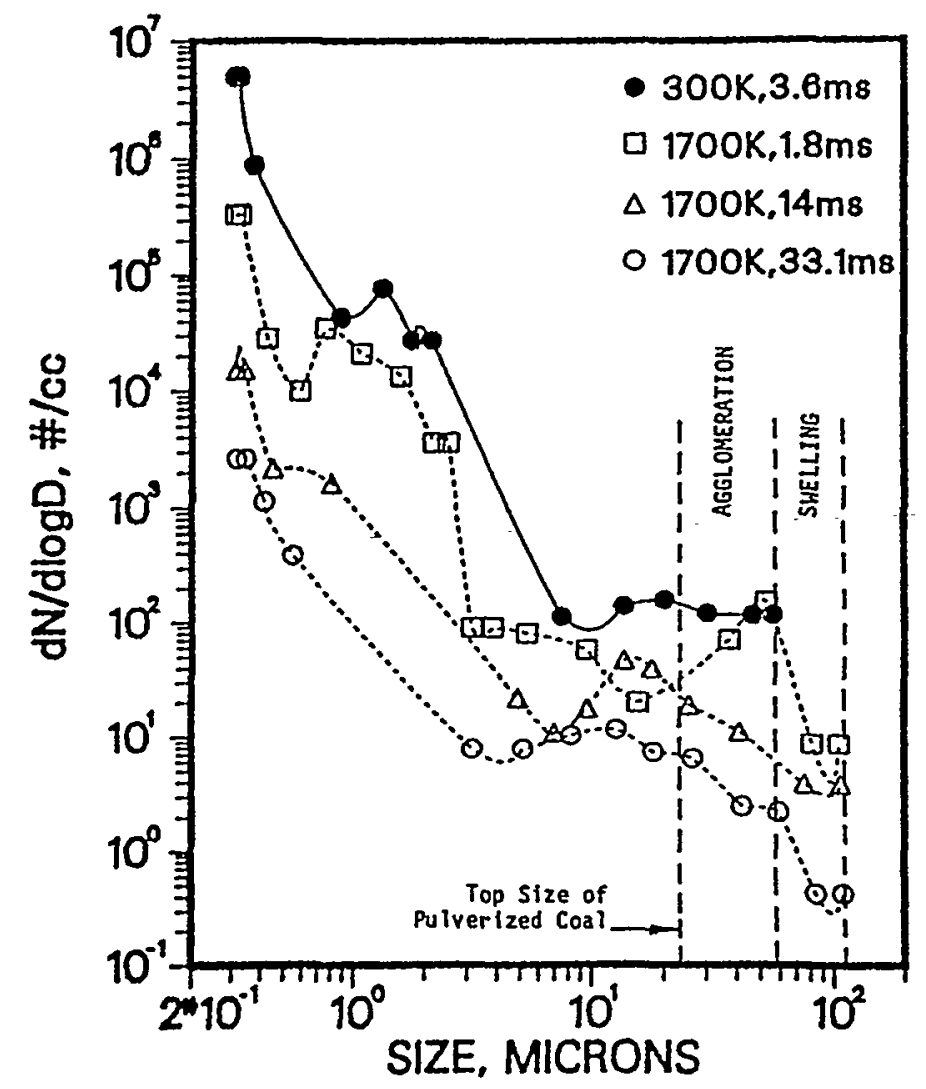

Fig. 11.5-4. Evolution of a bituminous coal-water slurry particle-size distribution as a function of residence time in a laminar flow reactor, obtained by using the SPC/ID system. 18 


\section{5-2. Imaging Methods for Single-Particle Counting}

A11 imaging methods permit, in principle, some degree of particle size-distribution measurement capability. With reference to Fig. 11.5-1, there are three basic types of systems: photographic, holographic, and image-plane coded-aperture methods. Unlike scattering techniques, all are applicable only to particles larger than the diffraction limit of in situ optical systems, typically 5 to $10 \mu \mathrm{m}$. The first two have been extensively reviewed and will not be discussed here. The third method is relatively new. Among the three candidates, it is uniquely amenable to straightforward, real-time, spatially-resolved measurements under certain coal combustion conditions. Under the right conditions, however, it appears to be an extremely powerful method, e.g., for basic studies of the reactivity of pulverized coals, with clear advantages over scattering methods.

\section{5-2A. Image-Plane Coded-Aperture Single-Particle Methods}

Several image-plane coded-aperture systems for application to measurements of both luminous and nonluminous particles during PC combustion have recently been developed at Sandia. ${ }^{19}$ These systems have been evaluated in detail for application to flows where the particle loading density of particles larger than about $10 \mu \mathrm{m}$ does not exceed $10^{4} / \mathrm{cm}^{3}$. In contrast to the light-scattering methods, the image plane methods permit direct and simultaneous measurement of the size and velocity of particles. In addition, if the particles are sufficiently hot, their temperature can also be measured. In contrast to light-scattering methods, the image plane technique permits more direct discrimination against background noise because of the presence of smaller (unsized) particles in the focal volume. In other words, if it is sufficient for a particular application to measure information only on particles larger than say $10 \mu \mathrm{m}$ and if these occur at number densities no greater than about $10^{4} / \mathrm{cm}^{3}$, then the usual higher number densities of smaller particles may not prove limiting since reflecting or emitted, not diffracted, light is employed.

\section{5-2B. The Multiple-Slit Method}


In this method, ${ }^{19}$ the signal that contains the particle-size information is generated by imaging the particle onto a physical mask containing a grid of three slits and detecting the transmitted light. Particles may be illuminated or, in the case of hot or reacting particles, direct emission from the particles may be used to obtain size and velocity information. In general, deconvolution is required to extract information from any image-plane coded-aperture system. It is possible, however, to design the aperture so that the particle size can be retrieved by using only two values in the output waveform. Such an aperture is shown in Fig. 11.5-5. It is composed of two slits for encoding the particle-size

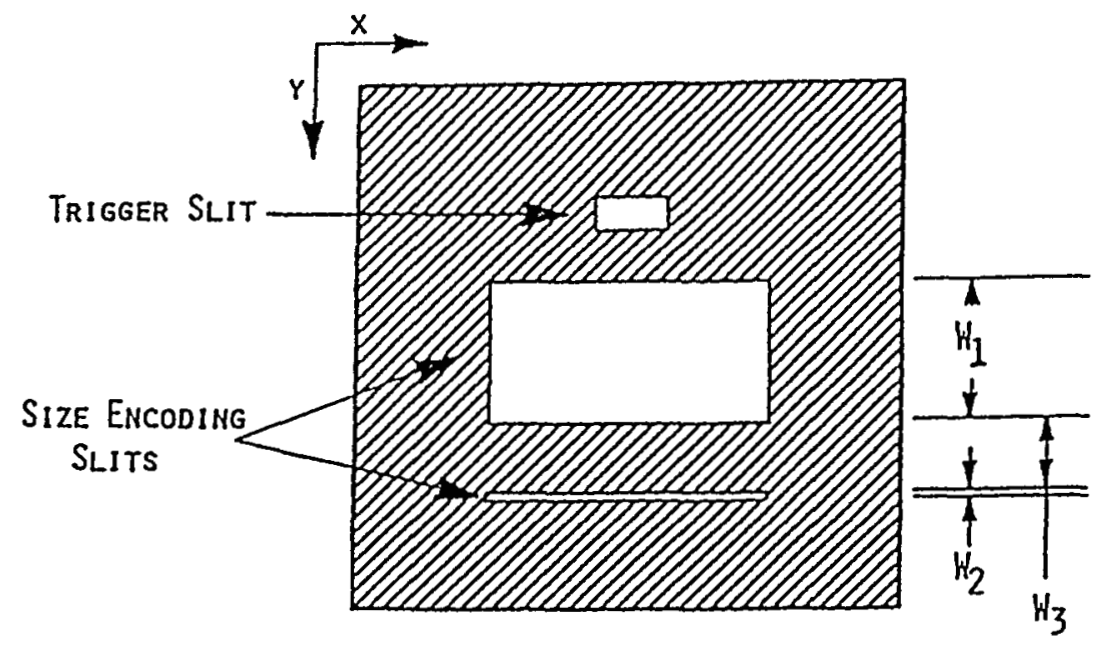

Fig. 11.5-5. Aperture mask used in the image-plane codedaperture (SPC) method. 19

information. A third slit is used in the implementation of a laser trigger to eliminate edge-effect errors and to distinguish further and minimize the size of the focal volume. The large aperture is made bigger than the largest particle to be measured; the small aperture smaller than the sma11est. As the image of the particle scans across the mask, the ratio of the signals from detectors behind the apertures is proportional to the diameter of the particle. In addition to size information, the velocity of the particle can be obtained by measuring the transit time of the particle between the two apertures. Since size and velocity of a particle may be measured simultaneously, velocity-size correlations are readily derived. The method 
is reasonable insensitive to particle shape. For irregular particles, the dimension measured is approximately equal to the particle length in the direction normal to the slits. While the system is insensitive to the particle index of refraction, the particle must be a diffuse surface in order to be sized correctly. This condition is particularly important when coherent illumination is used. In general, white light illumination yields better signals for non-ideal particles. It may be possible to size specular particles by back lighting and operating the system in a schlieren mode.

\section{5-2C. Particle-Sizing Pyrometry Based on the Multiple-Slit Method}

While none of the image-plane techniques can measure particles smaller than $\sim 10 \mu \mathrm{m}$, they do yield an important bonus capability in situations where the particles are sufficiently hot such that their incandescence can be used to obtain size information. Under these conditions, by virtue of its simplicity and ease of implementation in bench scale PC combustion environments, the multiple-slit technique is particularly amenable to integration with a multi-wave-length optical pyrometer system. The integrated system, shown in Fig. 11.5-6, has been developed for the simultaneous detection of particle size, particle velocity, and particle temperature. ${ }^{19}$ In addition, by measuring the absolute magnitude of emitted radiation, once the particle size and temperature have been determined, its emissivity may be estimated. Analysis of the particle size is done by using the ratio of the single particle signatures from the large and small slits. The particle temperature follows from the ratio of the signals from the large slit at two discrete wavelengths (assuming that the particle emits as a gray body). By the use of reflecting optics and extension of the detection system into the near infrared, the lower limits in terms of particle size and temperature may be significantly extended. Particle velocity is determined by timing the signais from the two slits.

The ability of the method to detect simultaneously the size, temperature and velocity of reacting particles is proving invaluable in recent studies of PC combustion. The system is now being routinely applied by Mitche $17^{20}$ to measure these properties for a variety of coals, chars and other reactive solids (and thereby to determine directly global particle reactivities) in a laboratory flow reactor. 


\section{5-3. Ensemble Methods for Analysis of Particulates}

Our discussion has emphasized single-particle counting methods because: (i) these are generally applicable to Class I and Class II flows; (ii) they yield a direct measure of the particle size and number density; (iii) they provide a measure of the flux of particles through the focal volume (by virtue of the fact that the transit time of each particle is sensed). Ensemble methads are inherently line-of-sight measurement, with the exception of diffusion-broadening spectroscopy for local measurement of the total volume of submicron particles in the focal volume of the incident laser beam. As is shown in Fig. 11.5-1, ensemble methods fall into two classes: those that work in the Rayleigh limit of sma 11 particles (generally less than a few tenths of a $\mu \mathrm{m}$ ) and those that work in the Mie Regime (generally larger than $2 \mu \mathrm{m}$ ).

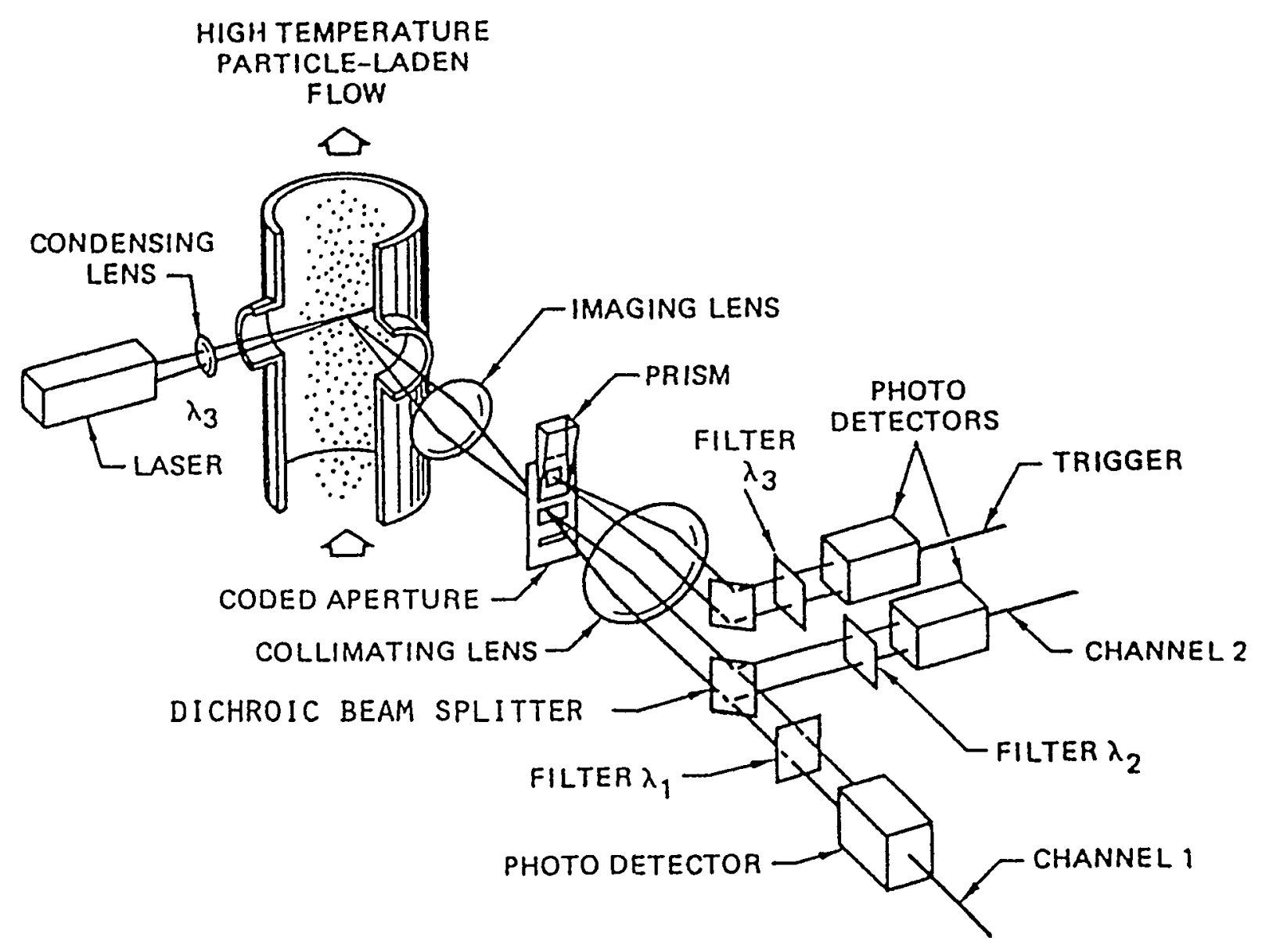

Fig. 11.5-6. An integrated single-particle imaging system for simultaneous particle sizing and temperature and velocity measurement. 19 


\section{5-3A. Ensemble Methods for Large Particles}

To measure the mean size of particles larger than 1 um, two commercial instruments are available, the Malvern instrument ${ }^{21}$ and the Leeds and Northrup instrument. 22 Both devices operate on the principle of detecting Mie scattering from an ensemble of particles or droplets in a relatively large sample volume defined by the width of the duct and the cross section of an incident expanded laser beam. The use of these instruments and their inherent limitations with regard to determining particle-size distributions have been discussed elsewhere. ${ }^{1}$ In general, the ensemble methods inherently yield less information than single-particle methods. In addition to the lack of spatial resolution in the ensemble methods, they provide no measure of velocity or of particle flux. However, if the phenomenon being observed is inherently unsteady, an ensemble device must be used since all SPC instruments average over relatively long times.

\section{5-3B. Ensemble Methods for Measuring Particles $<0.1 \mu \mathrm{m}$ in Size}

High number densities of fine mineral matter particles, less than $0.1 \mu \mathrm{m}$ in size, are common in most PC combustion environments (Fig. 11.2-2). These arise both from the liberation of solid mineral matter during combustion and as a result of condensation of vaporized inorganic species in the combustion and post-flame zones. In addition, high number densities of fine soot particles can be expected in regions where temperatures are high and fuel-rich conditions predominate. Of the various possible methods for obtaining information on particles less than $0.1 \mu \mathrm{m}$ in size, only laser-Doppler-broadening spectroscopy (also called diffusion-broadening spectroscopy, DBS) permits the kind of spatial resolution required in Class II flows. THe DBS technique is unfortunately applicable only to low velocity laminar flows, where particle diffusion velocities due to Brownian motion dominate particle transport through the laser focal volume. The method is extremely useful in bench-scale measurements in laminar flames and flow reactors. ${ }^{23}$ It would appear, however, that there are no near-term candidate methods for obtaining spatially resolved sub-0.1 $\mu \mathrm{m}$ particle size measurements in highly structured Class II flows. 
For Class I flows, where a flat (A) profile of local particle loading density is ensured, the conventional 1 ine-of-sight absorption method may be combined with a scattering technique to infer the total particle volume loading. The method relies on the classical assumptions and results of Rayleigh and Mie scattering and light extinction. In the Rayleigh limit, the method applies for particles which are small compared to the wavelength of light (for visible light, strictly for particles smaller than about $0.05 \mu \mathrm{m})$. In this regime, it can be shown that the ratio of the intensities of 7 ight scattered at $90^{\circ}$ with respect to the incident beam direction to the transmitted light is a strong function of the volume fraction of particles. For larger particles, in the size range of the 0.05 to $0.1 \mu \mathrm{m}$, Mie scattering can be used to advantage.

\subsection{Velocity Measurements in Particle-Laden Flows}

As described earlier, in all single-particle counting diagnostic methods, the velocity of particles passing through the sample volume is measured. The measurement is essentially one of transit-timing. More precise$1 y$, only the magnitude of the component of the particle velocity projected into the plane perpendicular to the axis of the collection optics is sensed. A true velocity is measured only for we11-ordered flows for which the axis of the collection optics can be arranged to be perpendicular to the flow direction. The inversion of the image-plane aperture method has also been used to measure transit times directly; two laser beams are focused in close proximity within the combustion zone and the time for a particle to transit the intervening distance is measured.

Clearly, transit-timing methods are, in principle, applicable to Class I flows. For more complex flows and in most cases where turbulent-intensity information is sought, the method of choice for direct velocity measurement is laser-Doppler velocimetry (LDV). The method is not new; fundamental descriptions of the technique are numerous. In most cases, however, the emphasis in previous work has been on the measurement of gas velocity and turbulent fluctuations associated with the gases. Small particles of uniform size and sphericity in the 1 um size range are typically used to minimize slip between the gas and the particles. Here, we comment briefly on some of the special considerations which pertain to velocity mea- 
surements using LDV in coal-derived flows. In this discussion, basic familiarity with the conventional LDV method is assumed.

\section{6-1. Application of Laser Doppler Velocimetry to Coal-Derived Flows}

Despite the ready availability of commercial LDV systems, interpretation of LDV data from particle-laden, coal-derived flows is anything but a simple matter. Care is required. The two features of such flows which have the greatest impact on straightforward interpretation of LDV signatures are: ( $i$ ) the need to operate with long focal-length optics in large coal-combustion geometries and ( $i i)$ the presence of high number-densities of irregular particles over (typically) a very wide size range. For most bench-scale experiments, the latter effect will dominate.

\section{6-1A. The Effect of Long Focal-Length Optics}

Large combustion-zone dimensions produce long optical path lengths, which require long focal-length optics. As the focal length of the incident lens(es) increases, the length of the sample or probe volume increases in the direction of the input laser beams. Consequently, off-axis (as opposed to backscatter) collection is desirable. For example, for a 50-mm beam spacing with a 120-mm (4.7-inch) focal-length lens, the probe volume length is $0.35 \mathrm{~mm}$; with a $600 \mathrm{~mm}$ ( 2 feet) focal length lens, the probe volume enlarges to $8 \mathrm{~mm}$. This loss of spatial resolution must be considered. While this degree of resolution may be acceptable, the probability of multiple particles in the probe volume poses problems. Another immediate effect is the decrease in efficiency of backscatter due to the decreased solid collection angle.

Multiple particles of the same size and presumably at the same velocity have the effect of degrading S/N. A higher pedestal in the LDV signature occurs due to the increased scattered light intensity, but less modulation occurs since the scattered light from different particles will be somewhat out of phase. If multiple particles of different velocities (sizes) are present simultaneously, the velocity differences will appear as random modulation of the Doppler signal.

The presence of particles in the line of sight between the detec- 
tor and the probe volume can introduce problems with both signal level and noise. The problems are accentuated with longer focal-length systems. Light scattered from a large particle and crossing one of the two laser beams or which passes through the probe volume may undergo secondary scattering by particles along the (increased) line of sight. Finally, the possibility of beam refraction or steering is increased with the longer lever arms involved. Uncrossing of the incident beams causes signal dropout, and relative motion between the two beams introduction a bias error in both the mean velocity and the turbulence intensity.

\section{6-1B. The Effect of Different Particle Sizes}

There are several additional adverse consequences of increasing particle number densities and of an increasing range of particle sizes in the flow. First, the dynamic range of the photodetector is limited. When the detection threshold is set to follow the weak signal from a small particle, the detector may be saturated by the signal from a large particle. A solution may be to use two detectors, which are set at different levels to monitor velocities of small and large particles independently. Secondly, the quality of the Doppler signal in terms of the modulation depth will most likely vary greatly. There is, in principle, an optimum ratio of particle size to fringe spacing; the result is that particles at the small and large ends of the size spectrum may be difficult to detect above the increased noise level. Finally, the single largest cause of low $S / N$ in an LDV system is glare, usually from surfaces and windows. For example, large particles which cross the incident laser beams create glare directly or as the result of scattering off surfaces or other particles.

In summary, the necessity for careful analysis cannot be over-emphasized. Laser-Doppler velocimeter systems, whether packaged or home-grown, will invariably produce Doppler signals. Whether these mean a great deal, especially from a PC combustion flow, is another matter.

\subsection{Particulate Composition Measurement by Laser-Spark Spectroscopy (LASS)}

One of the most challenging areas for coal-combustion diagnostics 
is that of determining the composition of entrained coal, char, and mineral matter particles in the combustion zone. At present, the only means for accomplishing this measurement is to extract a sample by insertion of a generally bulky, water-cooled quench probe and to subject the sample to a battery of off-line analytical techniques. In a new diagnostic research effort, 0ttesen ${ }^{24}$ is extending earlier work in our laboratory ${ }^{25}$ on a technique called laser-spark spectroscopy (also referred to as laser-induced breakdown spectroscopy ${ }^{26}$ ) to obtain in situ measurements of the elemental composition of particles in PC combustion environments. Although the techniques is about 6 years old, Ottesen's results are sufficientiy encouraging to warrant an extended comment in this review.

A schematic diagram of the experimental apparatus ${ }^{24}$ is shown in Fig. 11.7-1. The measurement sequence for single particle uses two cw lasers to provide particle-size measurements and to trigger the laser-breakdown process. A He-Ne laser beam is focused to a $50 \mu \mathrm{m}$ waist

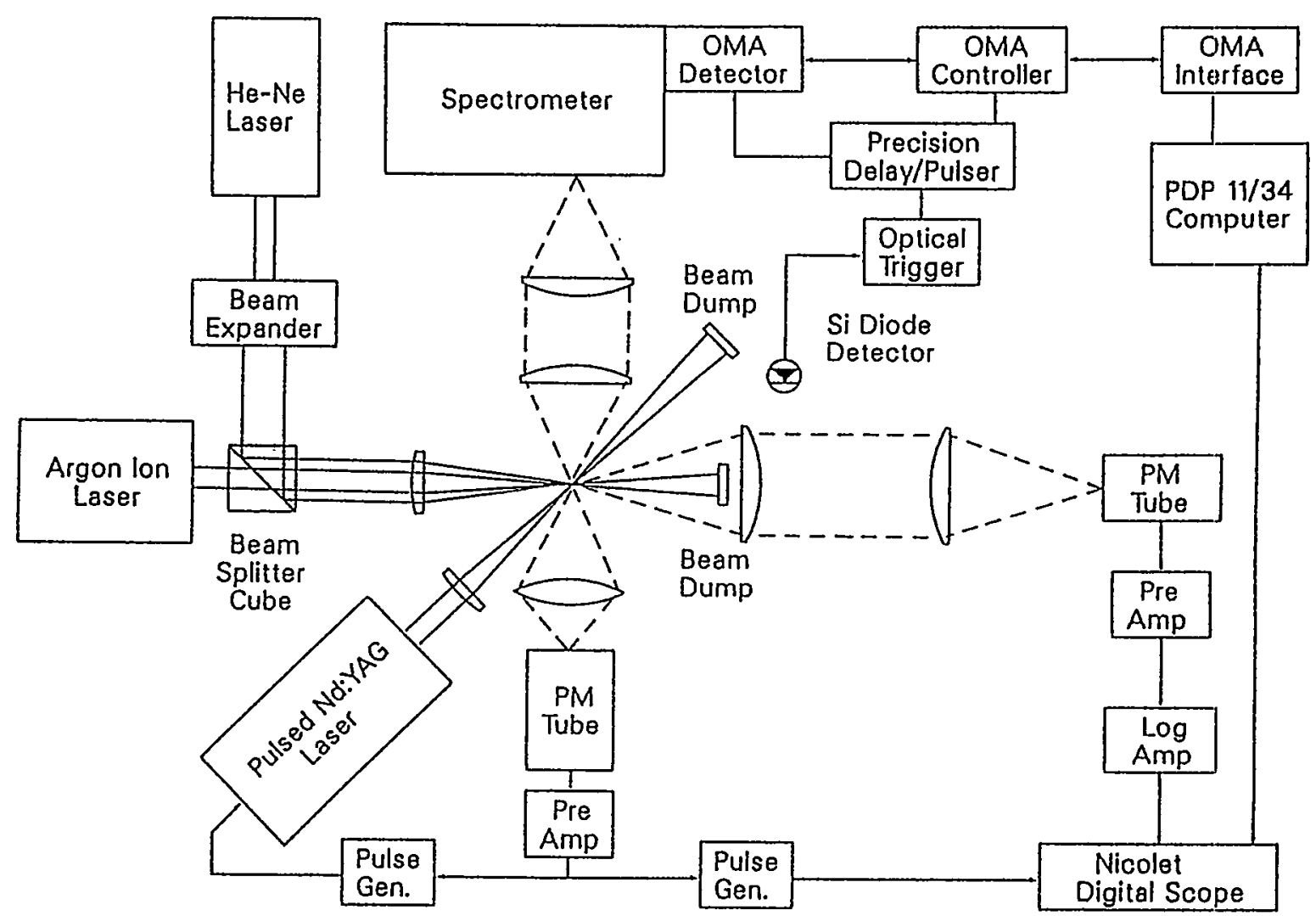

Fig.11.7-1. Schematic diagram of Sandia laser-spark spectroscopy diagnostic system. 24 
size, and the $90^{\circ}$ Mie scattering by individual particles passing through this focal volume is used as a trigger pulse. A co-linear, Ar-ion laser beam with a waist size of $250 \mu \mathrm{m}$ is also scattered by particles passing through the focal volume, and the intensity of the near-forward scattered light is used as a measure of mean particle size. These measurements are calibrated by using precision pinholes and uniform liquid droplets; the particle-sizing method is discussed elsewhere. 27 Incorporating particle-size information into the present emission measurements will help to remove data scatter caused by differences in particle size. It will also be useful in observing systematic trends in mineral composition during combustion as a function of particle size and may permit an absolute elemental mass measurement for each particle.

Immediately following the measurements of particle size, the $\mathrm{He}-\mathrm{Ne}$ laser trigger pulse is used to initiate the laser spark sequence. A Q-switched Nd:YAG 1aser, with a maximum pulse energy of $170 \mathrm{~mJ}$ and a pulse width of 7 nsec at the frequency-doubled wavelength of $5320 \mathrm{~A}$, is used to vaporize part or all of the coal particle. This rapid deposition of energy breaks down the molecular structures in the coal particle and ionizes the resulting atomic species forming a high temperature plasma. ${ }^{26}$ The intense emissions lines from the plasma are viewed with a $0.5-m$ Spex monochromator, equipped with an optical multichannel analyzer capable of time resolution to $0.1 \mu \mathrm{m}$ following the laser pulse. Ottesen's results confirm the expectation that the emission spectrum is extremely complex immediately following the formation of the plasma. ${ }^{25}$ This problem is due to the presence of highly ionized species and results in a poorly characterized spectrum. By delaying the starting time of the observation, we find that a well-defined line spectrum, dominated by neutral and singly-ionized atoms, occurs approximately $2 \mu \mathrm{sec}$ after the pulse. The results discussed here were obtained during a 2 to 4 usec window following this initial delay.

A central concern during the development of any new diagnostic technique is the issue of calibration. To date, a piezo-electric droplet generator has been used to produce uniform diameter liquid droplets, which contain a known concentration of material. For example, breakdown spectra were obtained of uniform droplets generated from dilute aqueous solutions of $\mathrm{NaCl}$. Excellent straight line plots of the sodium $5890 \mathrm{~A}$ emission line vs salt concentration were obtained. The reproducibility of the observed emis- 
sion intensities is of the order of $\pm 10-20 \%$ for salt solutions of 0.05 to $0.5 \mathrm{wt} \%$ and droplet sizes on the order of $70 \mu \mathrm{m}$; this fact is illustrated in Fig. 11.7-2. The dependence of emission intensity on laser energy is not straightforward. Although the $\mathrm{Na}$ emission increases monotonically with laser energy, no clear functional dependence is observed. It is speculated that this result is mainly caused by a complex increase of plasma temperature with incresing laser energy and the incomplete vaporization of the 70 $\mu \mathrm{m}$ droplets, even at the maximum laser energy. 26 This view has not been verified.

In addition to such calibration studies, preliminary investigations of LASS applied to raw coal particles have been completed. Samples of a high-volatility bituminous coal, Kentucky No. 11, with an ASTM ash content of $10 \%$, were used in the particle-size range of $+30 /-50 \mu \mathrm{m}$. A spectrochemical analysis of a bulk sample yielded the following observed mineral species; $>1000 \mathrm{ppm}, \mathrm{Al}$, Fe, Ca, Si; 100-1000 ppm, K, Mg, Na, Ti; $<100 \mathrm{ppm}, \mathrm{Mn}, \mathrm{Cr}$. To date, emission lines using LASS have been recorded for all of these species except $\mathrm{Mn}$ and $\mathrm{Cr}$. Representative spectra for four single particles are shown in Fig. 11.7-3. Additional species identified in the spectra include $\mathrm{C}, \mathrm{N}, \mathrm{O}$ and $\mathrm{CN}$. $\mathrm{CN}$ is observed as a recombination product of carbon atoms from the organic matrix with nitrogen (the entrainment gas). Nitrogen, and oxygen emissions are also observed, although quantitative analysis is not possible for these species since they originate primarily from the entrainment gas and the ambient laboratory atmosphere. Detection of $\mathrm{Na}$ is best done by using the well known emission lines near 5890 .A. Figure 11.7-4a shows four successive single-particle emission spectra. These spectra are representative of a much larger data set and were taken sequentially in approximately $8 \mathrm{sec}$ real time. The small variation in line intensity in Fig. $11.7-4 a$ is typical of the 80 particles which were measured. If these differences in observed intensity are caused primarily by variations in particle size, then one inference from these preliminary data might be that the sodium content is rather evenly distributed in these unreacted coal particles. A similar study for potassium content yielded much larger differences in emission-line intensities (Fig. 11.7-4a). Also of great interest is the correlation of different emission-line intensities in a given spectroscopic region for a set of single particle spectra. This experiment has been done for two iron lines 


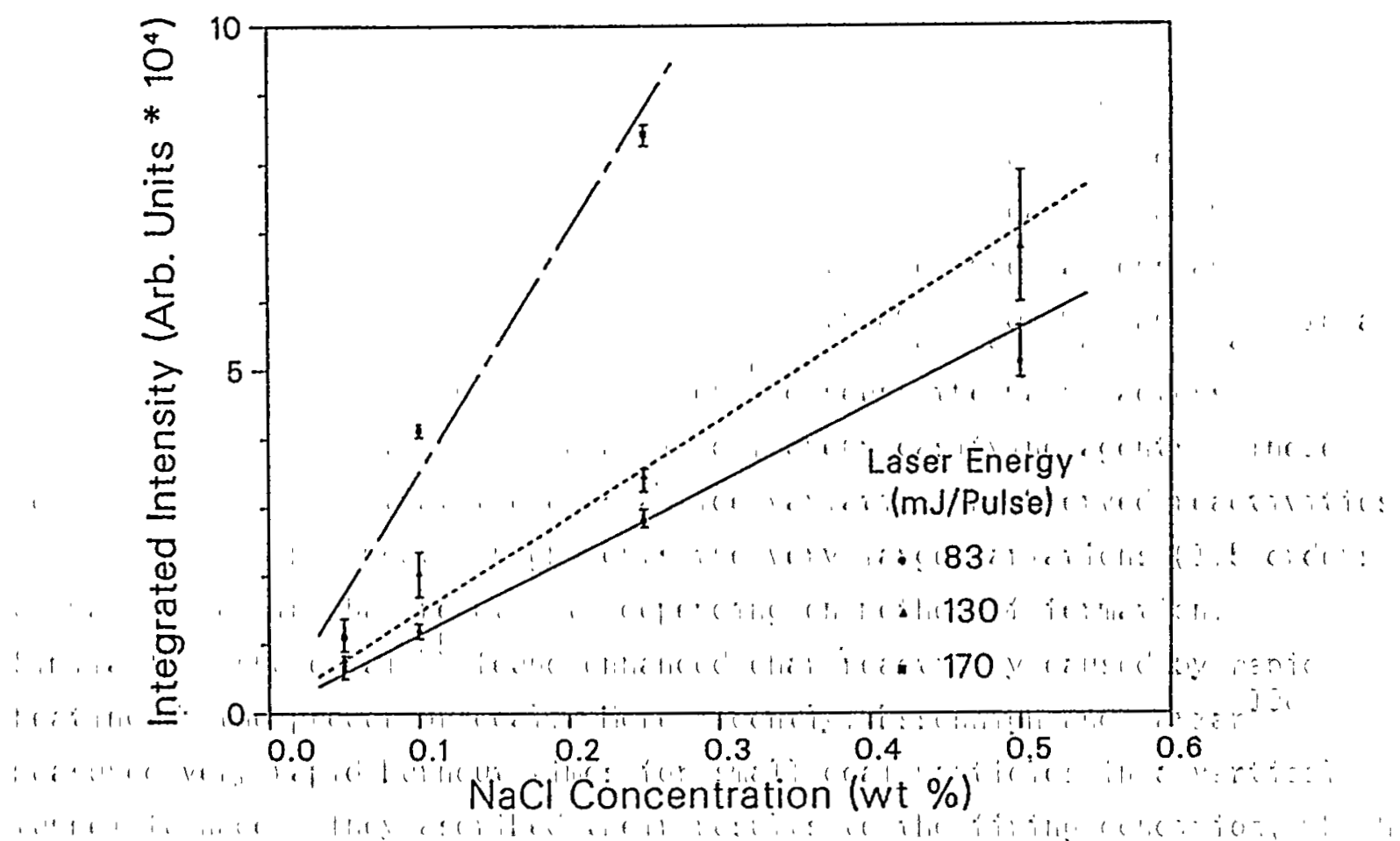

Fig. 11.7-2, Dependencè of Nà emission on solution concentration and laser energy after laser breakdown of a single droplet. ${ }^{24}$

(2601 $A$ and $2634 A)$ as is shown in Fig. $11.7-3 a$, the results are plotted in Fig. 11.7-5a for 80 successive particles To a first approximation this procedure should yield a straight line with a slope equal to the ratio of the line strengths for these two iron transitions. This result is clearly observed for these preliminary data; some of the observed scatter may be accounted for by variations in plasma temperature (caused by differences in particle size and shape, the absorption of 'laser energy, and self-absorption of emission lines). Since these transitions do not originate from the same energy levels, changes in plasma temperature will affect their observed intensity ratios. The intensity of the stronger iron transition (2601 A) is correlated with the intensity of a carbon transition at $2475 \mathrm{~A}$ (as is shown in Fig. 11.7-3a) for the same set of 80 particles. These results are shown in Fig. 11.7-5b. The large scatter in the data points illustrates: the great variability in $\mathrm{Fe}$ distribution in the raw coal particles, possibly caused by various iron-containing mineral inclusions. A much more consistent set of points is observed, however, for particles with Fe transitions of less than 

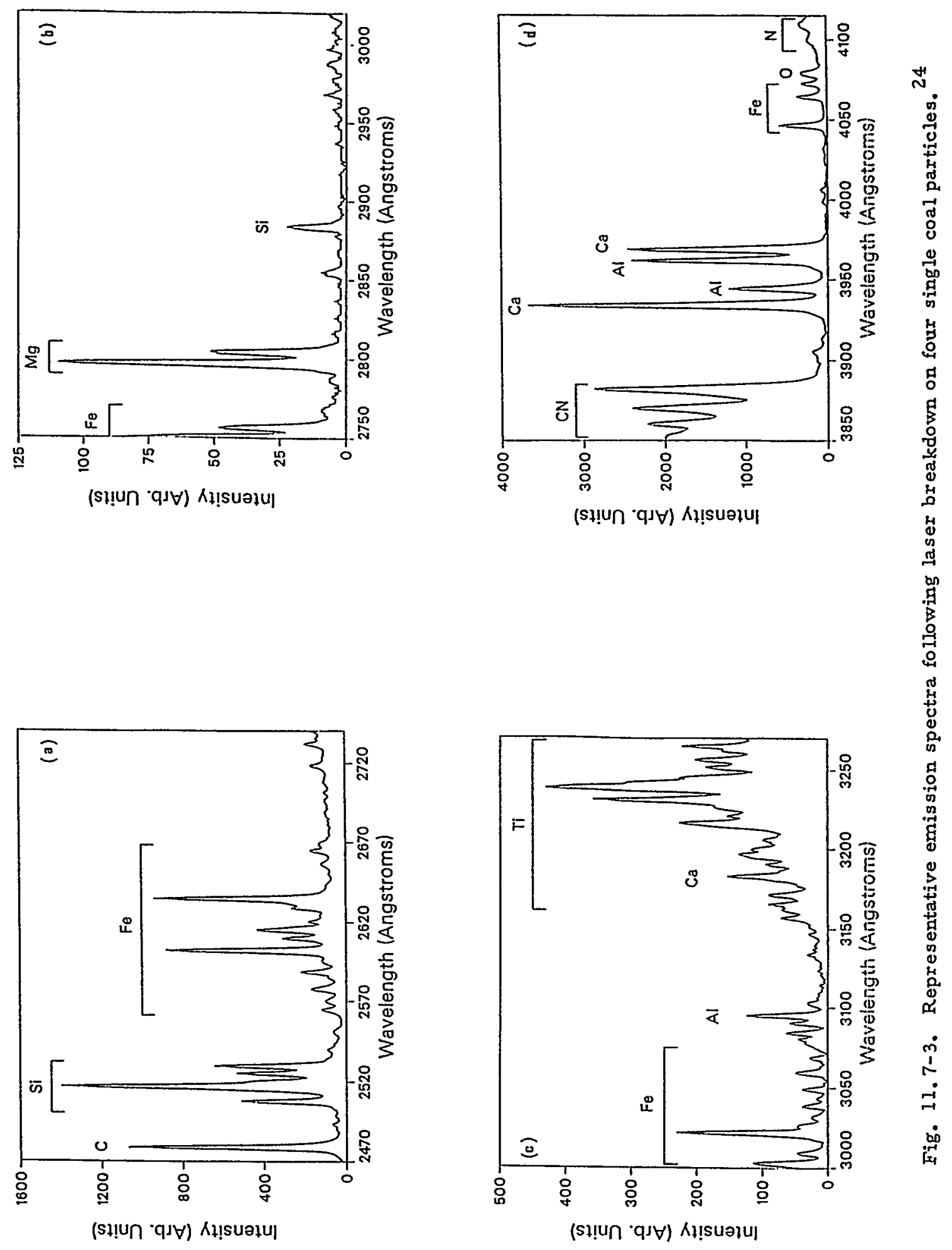

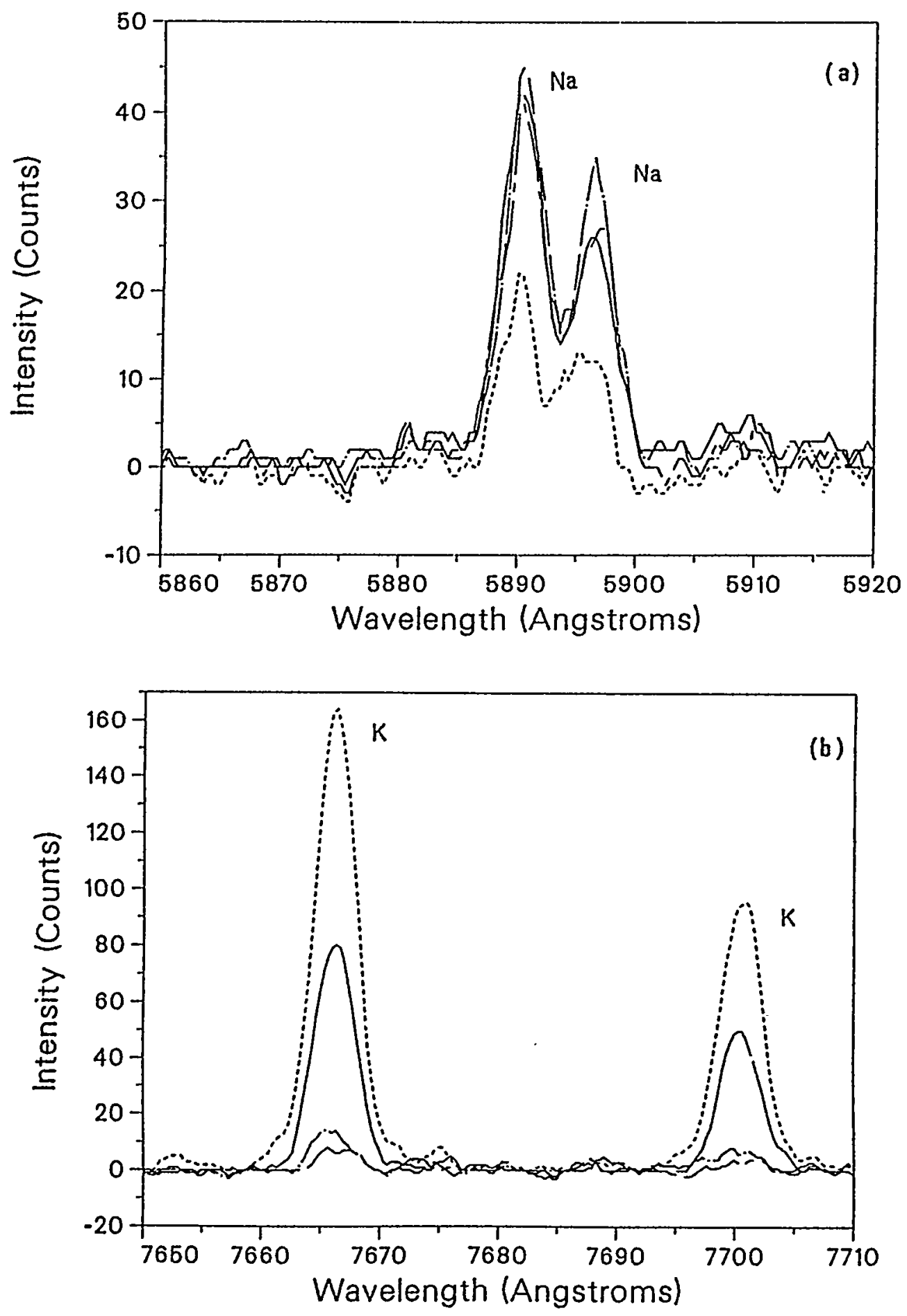

Fig. 11.7-4. Spark emission spectra obtained after laser breakdown of four single coal particles; (a) sodium; (b) potassium. 24 

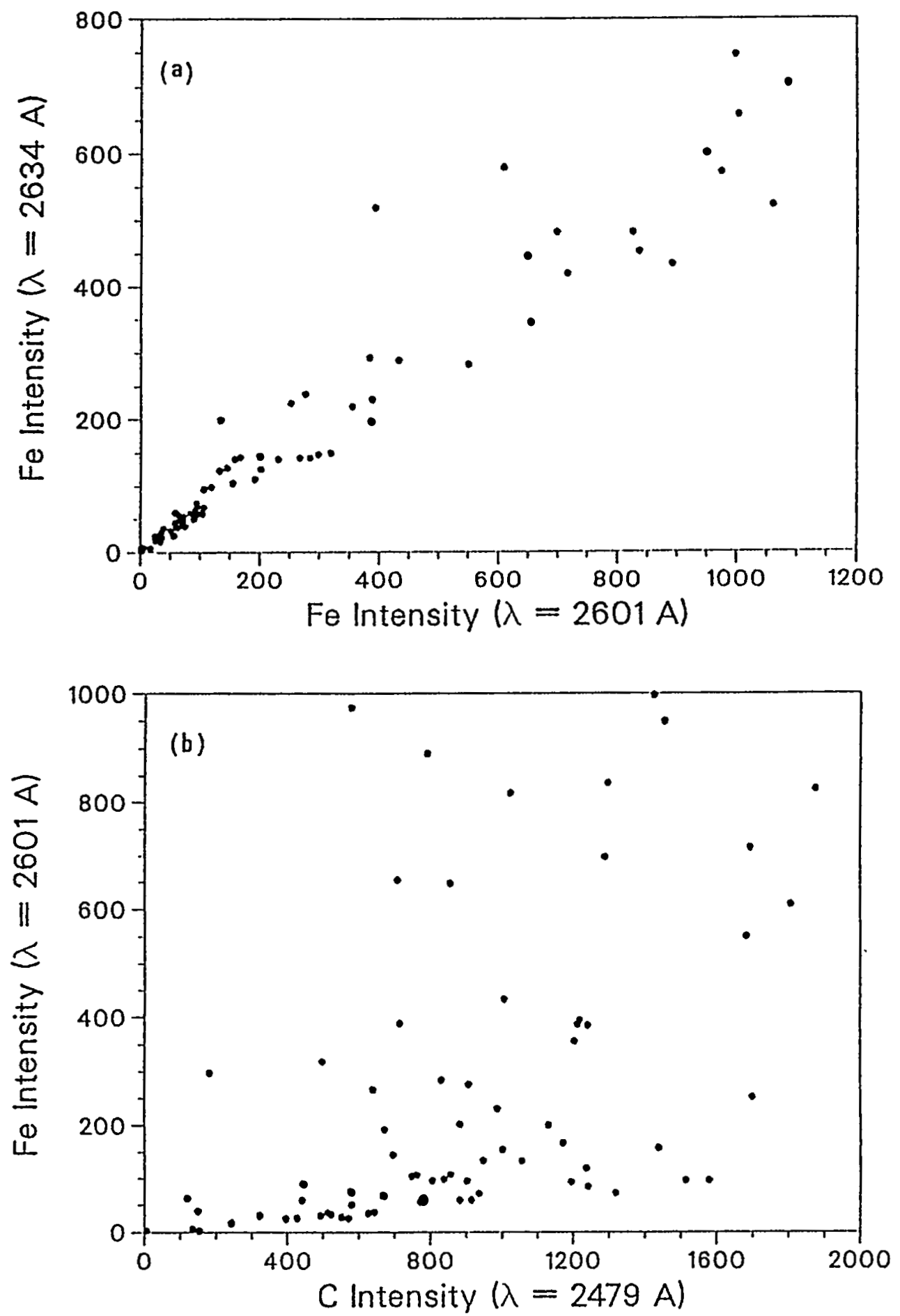

Fig. 11,7-5. Correlation of spark-emission intensities on a particle-byparticle basis in a series of 80 single particles; (a) for two $\mathrm{Fe}$ emission lines; (b) for a single $\mathrm{Fe}$ and a single $\mathrm{C}$ emission line. 24 
200 counts intensity. These points lie near the baseline of Fig. 11.7-5b and may be due to iron bound in the organic matrix of the coal, which would be much more homogeneously distributed than the mineral inclusions.

Although these early studies have shown several very interesting and exciting qualitative results, much work remains to be done in developing LASS as a diagnostic technique and in quantifying the limits of its accuracy under a variety conditions. Current efforts at our laboratory are being directed to the quantification of these emission spectra in the areas of particle size and plasma temperature measurement and emission-intensity calibration.

Laser-spark spectroscopy may also be used to sample the gas phase in a combustion environment, including very small particles which may not produce a measurable Mie-scattering trigger-signal. While some adjustment in laser energy may be required to compensate for the reduced breakdown threshold of the gas or fine, aerosol, ${ }^{26}$ in principle, one needs merely to sample the spark-emission spectra conditionally and to distinguish among those obtained with and without a sensible Mie signal in the particle detection channel. These complementary data are potentially valuable in determining the composition of soot, mineral matter fumes, and condensing in combustion environments. 


\section{References}

1. D. R. Hardesty ed., "Assessment of Optical Daignostics for In Situ Measurements in High Temperature Coal Combustion and Conversion Flows," Sandia Tech. Report No. SAND84-8724, Sandia National Laboratories, Livermore, CA (1984).

2. D. J. Holve, D. A. Tichenor, J. C. F. Wang, and D. R. Hardesty, Optical Engineering 20, 4 (1981).

3. W. L. Flower and J. A. Miller, "An Analysis of Particle-Temperature Modulation Induced by Pulsed-Laser Sources," Sandia Tech. Report No. SAND79-8607, Sandia National Laboratories, Livermore, CA (1979).

4. A. J. Mulac, W. L. Flower, R. A. Hi11, and D. P. Aeschliman, Appl. Opt. 17, 2695 (1978).

5. W. L. Flower, "Raman Scattering Gas Temperature Measurements in Particle Laden Flows," Sandia Tech. Report No. SAND81-8606, Sandia National Laboratories, Livermore, CA (1981).

6. E. J. Beiting, App1. Opt. 24, 18 (1985).

7. R. P. Lucht, "CARS Measurements of Temperature and Species Concentration in Coal Combustion Flows," pp. 367-370, Proceedings, 1985 International Conference on Coal Science, Sydney, NSW, Australia (October 28-31, 1985).

8. D. K. Ottesen, "In Situ Studies of Pulverized Coal Combustion by Fourier Transform Infrared Spectroscopy," pp. 351-354 in Ref. 7.

9. P. R. Solomon, D. G. Hamblen, R. M. Carangelo, and J. L. Krause, 19th Symposium (International) on Combustion, pp. 1139-1149, The Combustion Institute, Pittsburgh, Pa (1982).

10. P. R. Solomon, R. M. Carangelo, P. E. Best, J.R. Markham, and D. G. Hamblen, Am. Chem. Soc. Preprints 31, 141 (1986).

11. P. R. Solomon, "FT-IR Spectroscopy Diagnostic Techniques," paper presented at the NATO Workshop on Fundamental Physical Chemistry of Pulverized Coal Combustion, Les Arcs, France (July 30, 1986).

12. J. D. Bradshaw, N. Omenetto, G. Zizak, J. N. Bower, and J. D. Winefordner, App 1. Opt. 19, 2709 (1980). 
13. D. J. Taylor, "CARS Concentration and Temperature Measurements in Coal Gasifiers," Los Alamos National Laboratory Report No. LA-UR-83-1840, LANL, Los ATamos, NM (1983).

14. A. Ferrario, M. Garbi, and C. Maluicini, "Real-Time CARS Spectroscopy in a Semi-Industrial Furnace," paper presented at the Conference on Lasers and Electro-Optics, Baltimore, MD (1983).

15. D. J. Holve and S. A. Self, Appl. Opt. 18, 10 (1979).

16. E. O. Hirleman, "Optical Techniques for Particle Characterization in Combustion, Multiple Ratio Particle Counter," Ph.D. Thesis, Purdue University, Lafayette, IN (1977).

17. D. H. Holve, "An SPC System for Measuring Fine Particles at High Number Density in Research and Industrial Applications," Sandia Tech. Report No. SAND83-8246, Sandia National Laboratories, Livermore, CA (1983).

18. D. J. Holve, "Comparison of Combustion Studies of Coal-Water Slurries and Pulverized Coal," paper presented at the 7th International Symposium on Coal Slurry Fuels Preparation and Utilization, New Orleans, LA (May 1985).

19. D. A. Tichenor, R. E. Mitche11, K. R. Hencken, and S. Niksa, "Simultaneous In Situ Measurement of Particle Size, Temperature, and Velocity in a Combustion Environment," 20th Symposium (International) on Combustion, pp. 1213 1221, The Combustion Institute, Pittsburgh, PA (1984).

20. R. E. Mitche11 (in press in Comb. Sci. and Tech. 1986).

21. J. Swithenbark, J. M. Beer, D. S. Taylor, D. Abbot, and G. C. McCreath, "A Laser Diagnostic Technique for Measurement of Droplet and Particle Size Distribution," AIAA 14th Aerospace Science Meeting, Paper No. 76-69, NY (1976).

22. A. L. Wertheimer and W. L. Wilcox, App1. Opt. 15, 1616 (1976).

23. W. L. Flower, Phys. Rev. Lett. 51, 2287 (1983).

24. D. K. Ottesen (private communication, 1986).

25. R. W. Schmieder, "Techniques and Applications of Laser Spark Spectroscopy," Sandia Tech. Report No. SAND83-8618, Sandia National Laboratories, Livermore, CA (1983).

26. L. J. Radziemski, T. R. Loree, D. A. Cremers, and N. M. Hoffman, Anal. Chem. 55, 1246 (1983). 
27. J. C. F. Wang and K. R. Hencken, "In Situ Particle Size Measurement Using a Two-Color Laser Scattering Technique," Sandia Tech. Report No. SAND-85-8869, Sandia National Laboratories, Livermore, CA (1985). 


\section{CHAPTER 12:}

FUNDAMENTALS OF COAL CONVERSION AND RELATION

TO COAL PROPERTIES*

\subsection{Introduction}

In order to develop reliable coal-conversion technology, it is important to understand the conversion behavior of coal and the relationship between conversion behavior and measurable sets of coal properties. For example, what is the effect on gasifier performance of normal variations in the organic and mineral properties of a coal from a single mine, of variations in coal particle size, or of switching coals? Unscheduled shutdowns of coal plants are often caused by unexpected and uncontrolled behavior of the coal. What will be the effect of instituting pollution-control strategies such as the injection of sorbents? Can slagging and fouling behavior be predicted from the mineral distribution in the coal and the process conditions? Can the concentration of tars and fines exiting the gasifier be predicted and controlled? Can optimum gasifier operating conditions be predicted for new coals?

The design of new processes or scaling-up of a process should be improved by the availability of a good predictive capability. To design a process for producing condensable products by mild gasification, knowledge of the initial product slate from devolatilization (condensables, char and gas species) and the secondary reactions of the condensables is needed.

* This chapter has been written by P.R. Solomon (Secs. 12.1-12.3 and 12.5) and J.M. Beér (Sec. 12.4); the brief Appendix is by J.P. Longwe11 (M.I.T.). 
The objective of the work on fundamentals of coal-conversion behavior should be the development of accurate predictive capabilities. The steps toward achieving this goal are: (i) development of chemical and physical understanding of coal-conversion phenomena and their relationship to coal properties; ( $i$ i) reduction of data and mechanisms to engineering correlations and submodels; ( $i i j)$ development of comprehensive computersimulation codes for gasification processes incorporating the submodels; and (iv) testing of the models by comparison with we11-instrumented laboratory and pilot-scale experiments.

Important steps in coal conversion are summarized in Table 12.1-1. Coal characterization is discussed in Sec. 12.2. Gasification steps are divided into processes relating to coal organic structure (discussed in Sec. 12.3) and those relating to inorganic mineral matter (Sec. 12.4). Each topic is briefly discussed and the status of research and development in each area is assessed with regard to qualitative or quantitative level of

Table 12.1-1. Requirements relating to better understanding of coalgasification steps.

\begin{tabular}{|c|c|}
\hline Parameters & Problem Area(s) \\
\hline Coal characteristics & Organic structure and minerals. \\
\hline Heat transfer & Heat capacity, emissivity, evolving volatiles, and heats of reaction. \\
\hline Pyrolysis rates & $\begin{array}{l}\text { Variations in literature values, particle temperature measure- } \\
\text { ments. }\end{array}$ \\
\hline $\begin{array}{l}\text { Formation of gases, } \\
\text { condensables and char }\end{array}$ & $\begin{array}{l}\text { Relationship to coal structure, crosslinking, sulfur, nitrogen, } \\
\text { mass transport, vaporization, viscosity, melting, agglomeration, } \\
\text { swelling, pore formation, surface area, and mineral matter } \\
\text { distributions. }\end{array}$ \\
\hline Gasification of char & $\begin{array}{l}\text { Reactivity, active sites, surface area, mineral matter, catalysis, } \\
\text { fragmentation, fines production, reactivity vs extent of conversion. }\end{array}$ \\
\hline $\begin{array}{l}\text { Secondary reactions of } \\
\text { condensables and gases }\end{array}$ & $\begin{array}{l}\text { Cracking, coking, gasification, soot formation, gas phase } \\
\text { reactions }\end{array}$ \\
\hline $\begin{array}{l}\text { Mineral matter trans- } \\
\text { formation in } \\
\text { gasification }\end{array}$ & $\begin{array}{l}\text { Minerals-to-ash transformation, ash properties (optical, thermal, } \\
\text { size), catalytic activity. }\end{array}$ \\
\hline $\begin{array}{l}\text { Behavior of minerals } \\
\text { in conversion devices }\end{array}$ & Slagging \\
\hline
\end{tabular}


understanding and controversial or accepted model availability. The status and needs of computer modeling of gasifiers are discussed briefly in Sec. 12.5 Recommendations are made in Sec. 12.6 for research in important areas where quantitative understanding is lacking.

\subsection{Coal Characterization}

While there are a number of standard characterization procedures for coal, ${ }^{1}$ these often do not provide information appropriate to advanced processes. For example, while the proximate analysis may predict the volatile yield for coke making, it may be as much as $80 \%$ too low for bituminous coals in pulverized-coal combustion or entrained gasification. This increase in volatile yield was discussed by Badzioch and Hawksley. ${ }^{2}$ Similarly, the free-swelling index cannot be easily correlated with swelling behavior, which varies with heating rate and final temperature. 3,4 The ASME has recently noted the need for improvements in the ash-fusion temperature test as an indication of slagging and fouling. ${ }^{5}$ On the other hand, Neavel et $a 7^{6}$ have succeeded in correlating many process variables with the ultimate analysis for a set of low mineral matter vitrinites.

Ideally, the measured characteristics of the coal should allow prediction of the properties important to gasification, as listed in Table 12.1-1. In this section, we consider some recently applied measurement techniques which have been considered to improve predictability. Three symposia provide a good collection of the recent literature. ${ }^{7-9}$ Selected techniques which provide data related to processing behavior are al so considered.

\section{2-1. Organic Structure (Functional Groups)}

The advantage of a coal functional description has been discussed by Gavalas ${ }^{10}$ and Solomon and Hamblen. 4 By providing a description of the conversion behavior of the functional groups as components of the coal, it is possible to develop a general model for coal behavior.

New NMR techniques are starting to provide data on the chemical forms of carbon and hydrogen in coal. A description of the techniques and references may be found in a recent review by Davidson. 11 Among the most recent advances are the techniques of dipolar dephasing ${ }^{12}$ and 2-D and zero-field methods. 13 
Quantitative FTIR methods for determining mineral matter and functional group compositions have been developed. $4,14-22$ Typical KBr pellet spectra for two bituminous coals and a lignite are illustrated in Fig. 12.2-1. Peaks due to their functional groups and mineral components are identified in this figure. In general, all coals have these absorption bands and the major variation with rank is reflected in their relative magnitudes. The gaseous and condensable products produced in pyrolysis have been related to the functional group composition of the coal. 4,10,19,23-29

\section{2-2. Viscosity}

Recent work ${ }^{30,31}$ has provided data on viscosity at high temperatures and heating-rates appropriate to gasification conditions. The viscosity can be correlated with the depolymerization and crosslinking reactions in the coal, and kinetics for these processes are being determined. Knowledge of the viscosity is essential to understand and predict swelling and agglomeration. These properties, in turn, affect char reactivity.

\section{2-3. Pyrolysis}

A number of pyrolysis techniques have been used as a characterization procedure for coal properties and process behavior. $4,32-34$ These are useful in providing information on product distributions in devolatilization.

\section{2-4. Reactivity}

Gasification of char is the slowest process in gasification and, therefore, determines the throughput or size of the reactor. Most work has been performed on oxidation reactivity, which has been shown to correlate with $\mathrm{CO}_{2}$ and $\mathrm{H}_{2} \mathrm{O}$ reactivities. ${ }^{35}$ Reviews of the char-reactivity 1 iterature have been published by Smith, ${ }^{36}$ Essenhigh, ${ }^{37}$ Laurendeau, ${ }^{38}$ and van Heek and Muhlen $^{39}$ Published studies ${ }^{35,40-47}$ have shown that a wide variation in char reactivities is related to coal rank, char-formation conditions, extent of devolatilization and gasification, mineral matter, and reactor conditions.

It is necessary to define a standard laboratory method to characterize char-reactivity parameters for typical reaction conditions. 


\section{2-5. Mineral Matter}

The objective in characterizing the mineral matter in coal is the prediction of its conversion to ash, the properties of the ash (size, composition, optical properties, fluidity), and the disposition of ash in the reactor or in down-stream components. Recent reviews of research on ash in coal have been published. 48,49

In order to study the relation between properties of the ash and mineral constituents in coal, information is required on the spatial distribution of minerals in coal and how these evolve into ash particles and subsequently into wall deposits. Mineral composition and spatial distribution are obtained with a scanning electron microscope (SEM) equipped with an X-ray analyzer. Automated analytical procedures have been employed. ${ }^{50-52}$

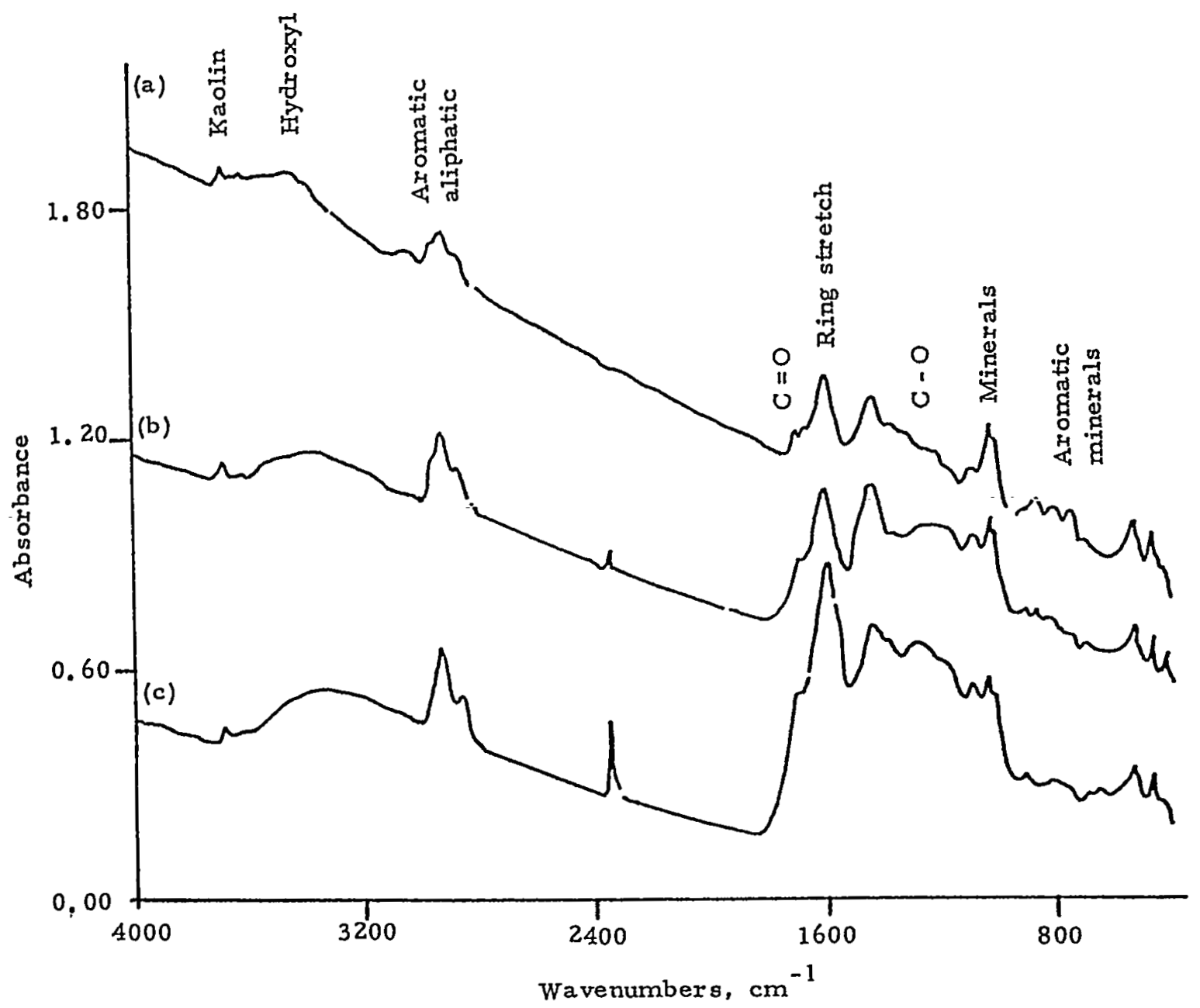

Fig. 12.2-1. FTIR spectra for (a) low-volatility bituminous coal, (b) high volatility bituminous coal, and (c) lignite. 
An example of the sulfur and iron distribution in coal is presented in Fig 12.2-2. The concentration of each element is proportional to the density of dots. This figure shows clusters of iron and sulfur associated with pyrite and a more even distribution of organic sulfur.

\subsection{Fundamental Processes in Gasification and Partial Gasification}

Gasification steps are illustrated in Fig. 12.3-1 with SEM photographs of chars at different stages of gasification. Steps include particle heating and gas, condensables and char formation during primary devolatilization, as well as the subsequent char reaction with $\mathrm{O}_{2}, \mathrm{CO}_{2}$, or $\mathrm{H}_{2} \mathrm{O}$. Figure 12.3-1 illustrates important differences in char formation for thermosetting and swelling coals. This difference affects the size of the char particles, heat-transfer characteristics, aerodynamics, morphology, density, reactivity, and mineral-matter distribution. Coals show a continuum of behavior, depending on rank and gasification conditions.

Among the important properties which must be predicted are: rate of coal heating; rates and amounts of volatile evolution; secondary reactions of the condensables (cracking, coking, soot formation); properties of char during devolatilization (viscosity, agglomeration tendency, repolymerization); resulting physical properties of the char (size, porosity, etc.); intrinsic char reactivity; dependence of reactivity on reaction conditions and extent of reaction; and char fragmentation during reaction. These must be predicted from measurable coal characteristics.

\section{3-1. Heat Transfer}

To predict heat transfer to particles, a number of processes and properties need to be described, including particle heat capacity, emissivity and heats of reaction, as well as the effects of particle trajectories and volatile evolution on the convective heat transfer.

The room-temperature value of the heat capacity has typically been used. Data of Lee ${ }^{53}$ and a model and data reported by Merrick ${ }^{54}$ indicate, however, that the heat capacity is not constant. Predictions from Merrick's mode $1^{54}$ are illustrated in Fig. 12.3-2. The heat capacity increases by about a factor of 2.5 in going from temperature to $773 \mathrm{~K}$. 
(a)

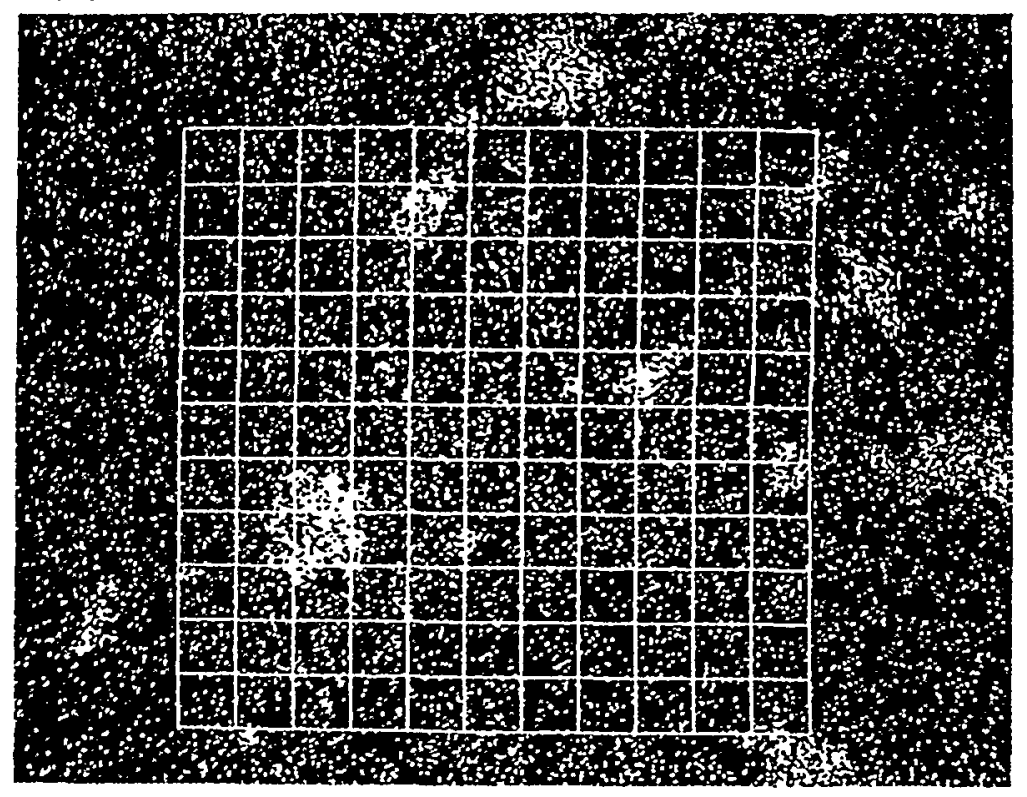

(b)

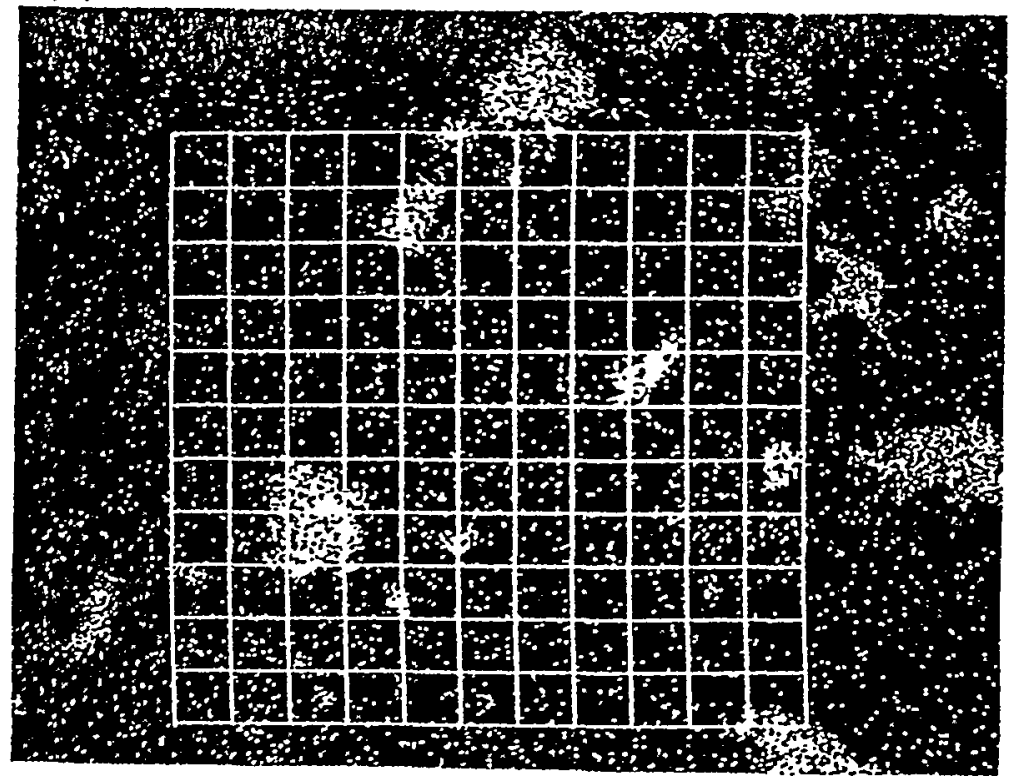

Fig. 12.2-2. X-ray maps for (a) sulfur and (b) iron on a sample of PSOC 330 coal. The grid outlines the subsamples used. Each subsample was $0.6 \mathrm{~mm}$ in dimension. 
To calculate the absorption of radiation by coal particles, coal has typically been assumed to be a gray body with emissivity between 0.8 and 1.0. Recent measurements $55-57$ have shown that, while these values apply to char particles, small coal particles typical of pulverized combustion are not gray and have spectral emittances which depend on particle size, coal rank and the extent of pyrolysis. Figure 12.3-3 shows a comparison between the emitted radiation from char and coal particles and that emitted by a black or gray body. The char is a gray body with an emissivity near 0.7 . As may be seen in Fig. 12.3-3(b), coal particles emit (and absorb) much less radiation than a black body. The average emittance at a typical furrace temperature for the $-200,+325$ mesh fraction of lignite shown in Fig. 12.3-3b is about 0.4. It should be noted that these direct measurements of particle emissivity are in conflict with calculated emissivities based on previously measured optical constants. 58 This problem is discussed Ref. 56 .

A sensitivity analysis was done to examine the importance of various assumptions in the prediction of particle temperatures. ${ }^{59-61}$ Five cases were examined for two temperature levels $\left(800\right.$ and $\left.1600^{\circ} \mathrm{C}\right):(1) \mathrm{c}_{\mathrm{p}}=$ $0.3 \mathrm{cal} / \mathrm{g}-\mathrm{K}$, emissivity $=1.0$, zero heat of pyrolysis, constant mass; (2) as in (1) but with the particle mass (kinetic) submodel included; (3) the heat-capacity submodel is added to (2); (4) the emissivity ( $\varepsilon$ ) submodel is added to (3); and (5) a single particle is used in an infinite gas volume in (4). Results are presented for $200 \times 325$ mesh North Dakota lignite in Fig. 12.3-4 for experiments at 800 and $1600^{\circ} \mathrm{C}$ in an entrained-flow reactor.

At $800^{\circ} \mathrm{C}$, the particle-temperature predictions are most sensitive to variations in the heat capacity with temperature and, to a lesser extent, to emissivity assumptions. These make a difference of $50-100^{\circ} \mathrm{C}$ in the maximum computed temperature. At $1600^{\circ} \mathrm{C}$ (Fig. 12.3-4), the predictions are very sensitive to the emissivity and the heat-capacity models. For this case, the predicted particle temperature during pyrolysis is $800^{\circ} \mathrm{C} 1$ ower for case (4) than for case (1). 

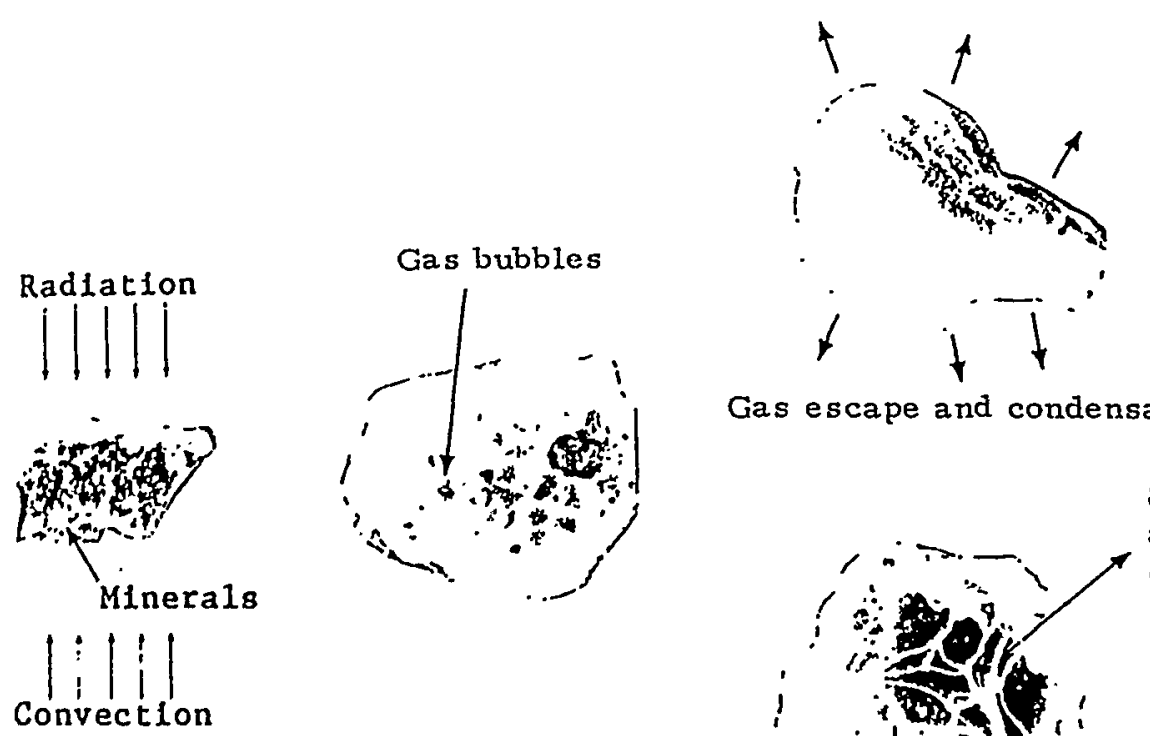

Gas escape and condensables

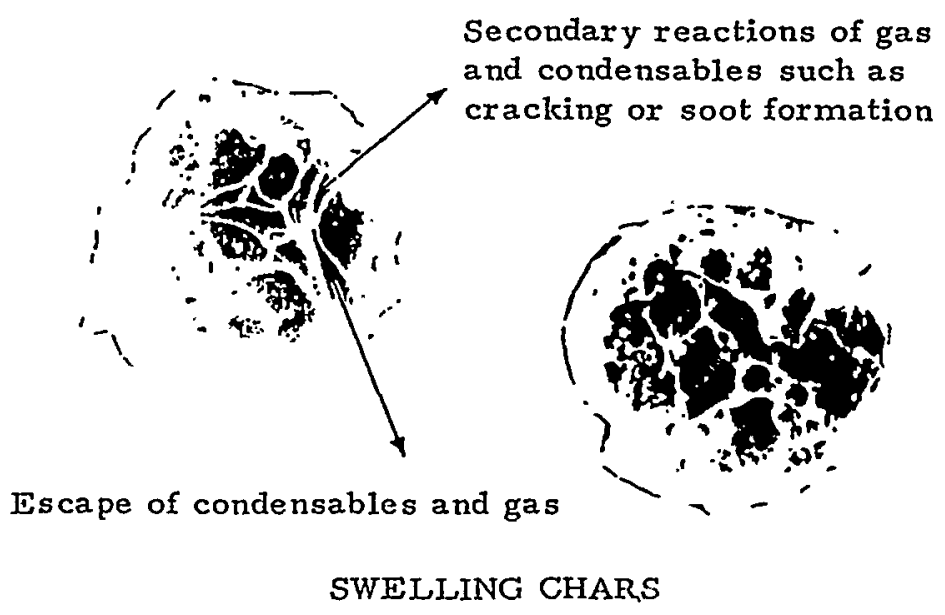

Heat transfer

Formation of gas and condensalsles

Char formation

Char reaction

Fig. 12.3-1. Illustration of gasification steps for thermosetting and swelling chars.

The net pyrolysis heat of reaction was estimated to be between 60 and $80 \mathrm{cal} / \mathrm{g}$ (endothermic) for the experiments at 800 and $1600^{\circ} \mathrm{C}$, respectively. ${ }^{60,61}$ In both cases, the reaction heat had a negligible effect on the calculated particle temperature. This value is, however, controversial and needs to be determined accurately for a wide range of conditions and coals.

For both temperature levels, the heating rate for a single particle introduced without any cold gas (case 5 ) is significantly different from the more typical conditions applying to finite amounts of coal and applicable carrier-gas rates. This result illustrates the sensitivity of particle-temperature models to assumptions concerning mixing and particle loading. Volatiles evolution and its effect on convective heat transfer, particle trajectories and temperature gradients within the particle also need to be assessed. 


\section{3-2. Pyrolysis Rates}

The development of accurate predictive models for coal gasification requires knowledge of the rates and amounts of volatiles released as a function of the particle temperature. The volatiles can account for up to $70 \%$ of the coal weight loss and control the ignition, temperature and stability of the flame, which, in turn, affect the subsequent reactivity of the char. Unfortunately, there is still controversy concerning the rate of coal pyrolysis. For example, at particle temperatures estimated to be $800^{\circ} \mathrm{C}$, rates reported in the 1 iterature for rapid heating conditions (derived by using a single first-order process to define weight loss or tar evolution) vary from less ${ }^{62-65}$ than $1 \mathrm{sec}^{-1}$ to more $2,4,66-70$ than $100 \mathrm{sec}^{-1}$ with values in between. $24,71,72$

Useful gasification models cannot be developed with this wide range of values, as has been emphasized in recent discussions on coal pyrolysis and combustion modeling. These models yield particle temperatures and weight-loss for the assumed rates. Several authors ${ }^{73-75}$ reported reasonably accurate modeling of results using very different pyrolysis kinetics; however, individual results were sensitive to which rates were assumed. For example, Lockwood et a $7^{73}$ found the rates of Badzioch and Hawksley ${ }^{2}$ and of Anthony et a ${ }^{62}$ (distributed rate) acceptable, while the lower rates of Kobayashi et al ${ }^{63}$ and of Anthony et al ${ }^{62}$ (single rate) were not. Truelove ${ }^{74}$ successfully used the high rates of Badzioch and Hawksley, ${ }^{2}$ while Jost et al ${ }^{75}$ employed the lower rates determined by Witte and Gat. 76 Also reported was a rate by Niksa et al, ${ }^{64}$ which was close to that of Anthony (single-rate model), ${ }^{62}$ and another by Maloney and Jenkins, 72 which was close to that of Badzioch and Hawsley. ${ }^{2}$

An important objective of research on fundamentals of coal conversion is to identify the source of variations in these reported rates and provide an accurate separation of the chemical-kinetic, heat-transfer, and mass-transfer rates which combine to produce the observed results.

An overview of measurements is given in Table 12.3-1 and a summary of pyrolysis rates for a number of high heating-rate experiments is presented in Fig. 12.3-5 and in Table 12.3-1. In Fig. 12.3-5, the rates (in $\sec ^{-1}$ ), which describe for various models the weight or tar loss, are plotted as a function of reciprocal particle temperature. The activation energies $E_{0}$ and frequency factors $k_{0}$, which describe rates in Arrhenius 


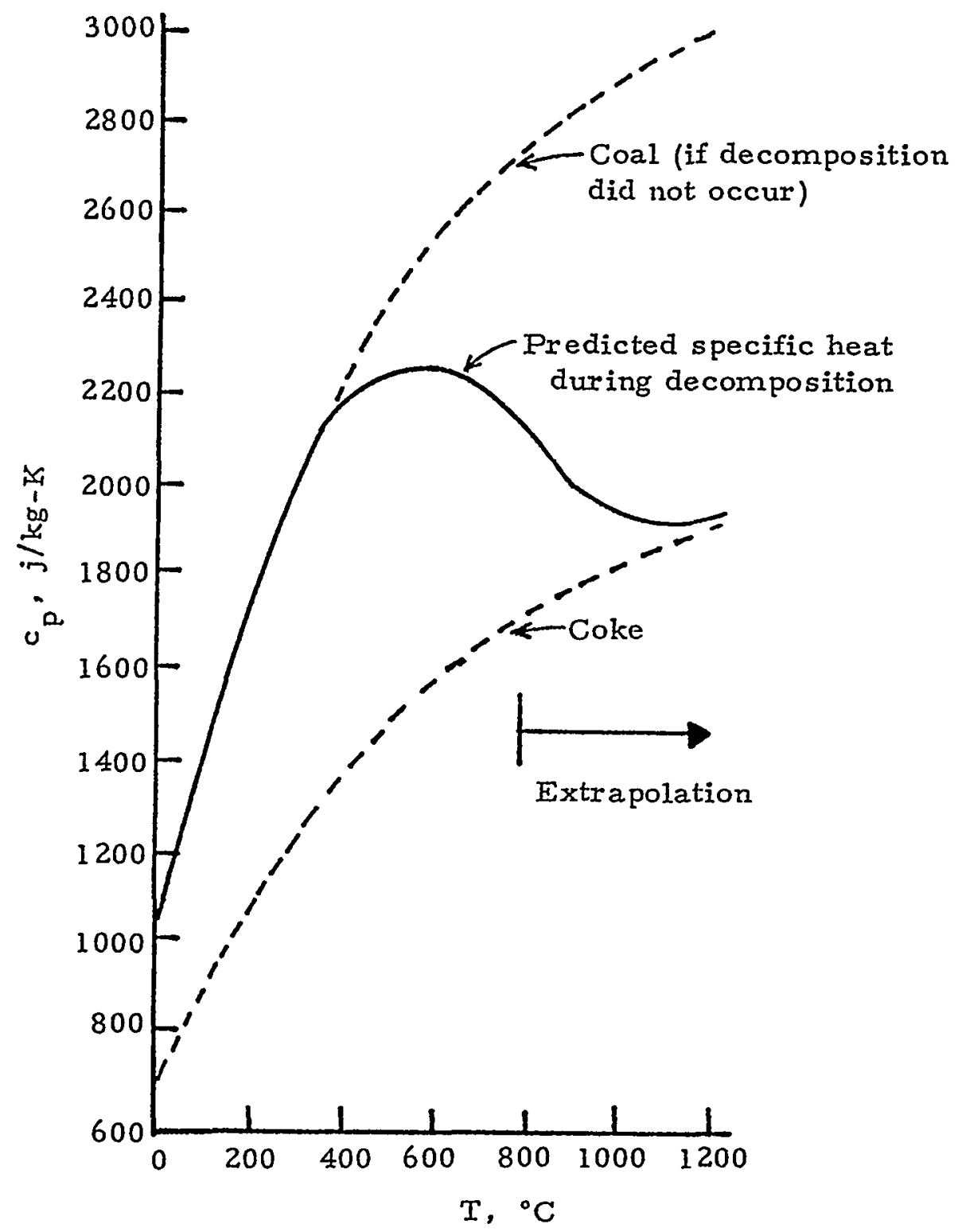

Fig. 12.3-2. Variation in specific heat with temperature for coal and colke according to the model of Merrick, 55 at a heating rate of $3 \mathrm{k} / \mathrm{min}$, DAF Coal, $25 \mathrm{wt} \%$ volatile matter.

expressions, are summarized in Table 12.3-1. In some cases, a Gaussian distribution of activation energies ${ }^{62}$ has been used to describe multiple parallel processes; this model requires the additional parameter o for a description of the width of the distribution. In this case, the rate shown in Fig. 12.3-5 is the mean of the distribution. Data have been included from five different types of experiments: heated grid, entrained-flow reactor, laser-heating, heated-tube reactor, and a thermo-gravimetric and evolved-gas analysis. 
Possible causes for these variations were reviewed in a recent publication, ${ }^{59}$ which dealt with the following factors: (i) variations of rates with coal rank, (ii) variations in rates because of inaccuracies in determinations of weight-loss or residence time, ( $i i i)$ mass-transfer limitations, (iv) influence of heat-transfer model assumptions, (v) inaccuracies in measuring particle temperature, and (vi) influence of model assumptions on the reported rates. The conclusion of this review is that differences in the determinations of particle temperatures appear to be a major source of the variations in rates reported from entrained-flow reactor experiments and direct particle-temperature measurements are essential to provide accurate rates. Also, model assumptions (i.e., single first order kinetics, a Gaussian distribution of activation energies, etc.) account for differences (especially activation energies) in the reported rates. These conclusions are, however, controversial.

\section{3-3. Devolatilization: Formation of Gases, Condensables and Char}

Coal devolatilization is important since it is the initial step in most coal-conversion processes and is the step which is most dependent on coal properties. In addition to the question of devolatilization rates, there are problems concerning the amount, composition and physical form of the devolatilization products. Devolatilization controls the initial yield of condensable products, their molecular weight distribution, and the competitive yields of gas species. Furthermore, the physical form and reactivity of the non-volatile char are controlled by the pyrolysis reactions. In addition to the importance of pyrolysis in coal processing, analysis of pyrolysis products can supply important clues to the structure of the parent coal, especially since many of its structural elements are preserved in the condensable products (tar). 

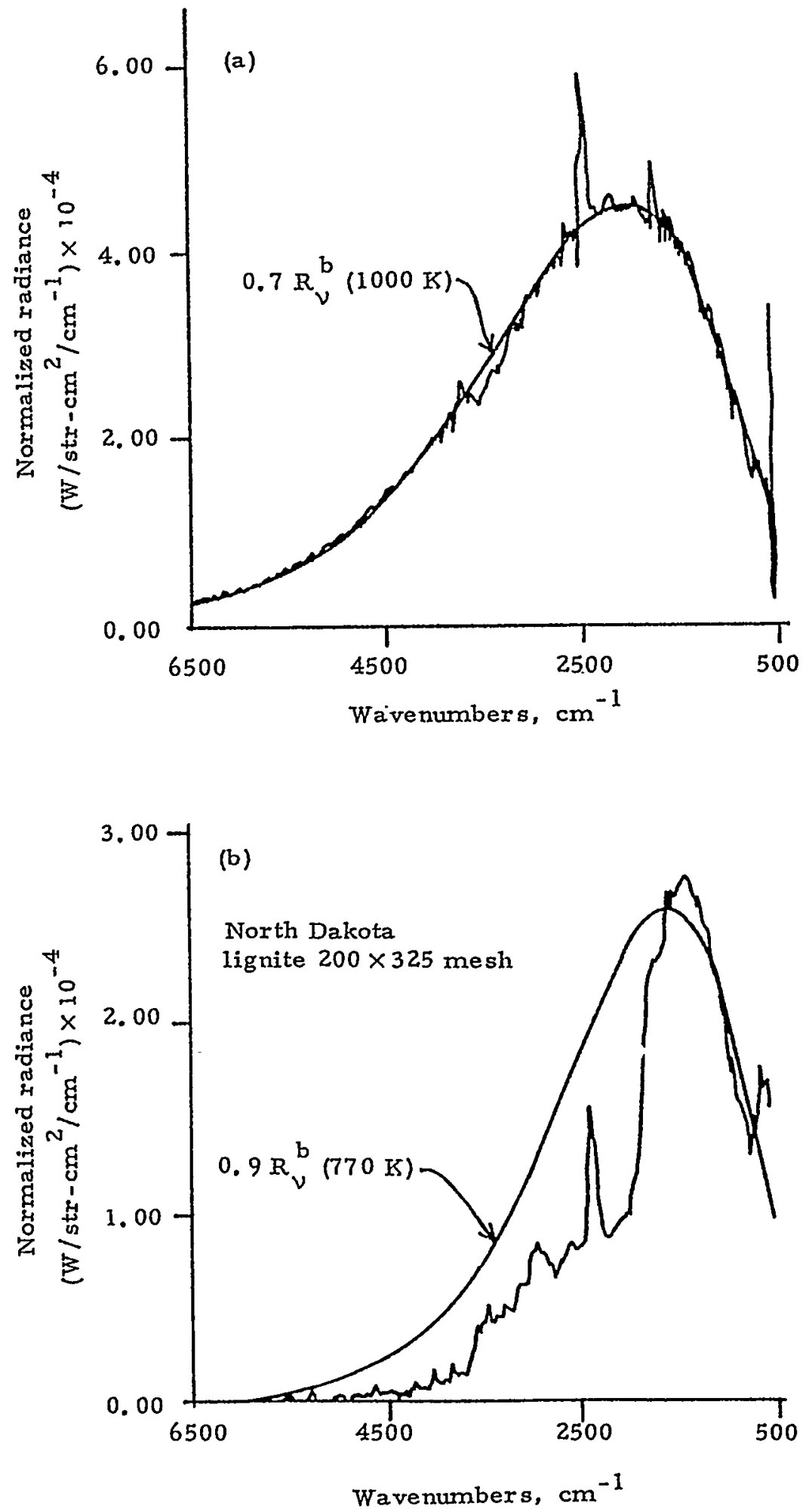

Fig. 12.3-3. Normalized emission spectra compared with theoretical graybody curves for (a) North Dakota char formed at $1573 \mathrm{~K}$ and (b) Nor th Dakota lignite; $200 \times 325$ mesh coal was used. 

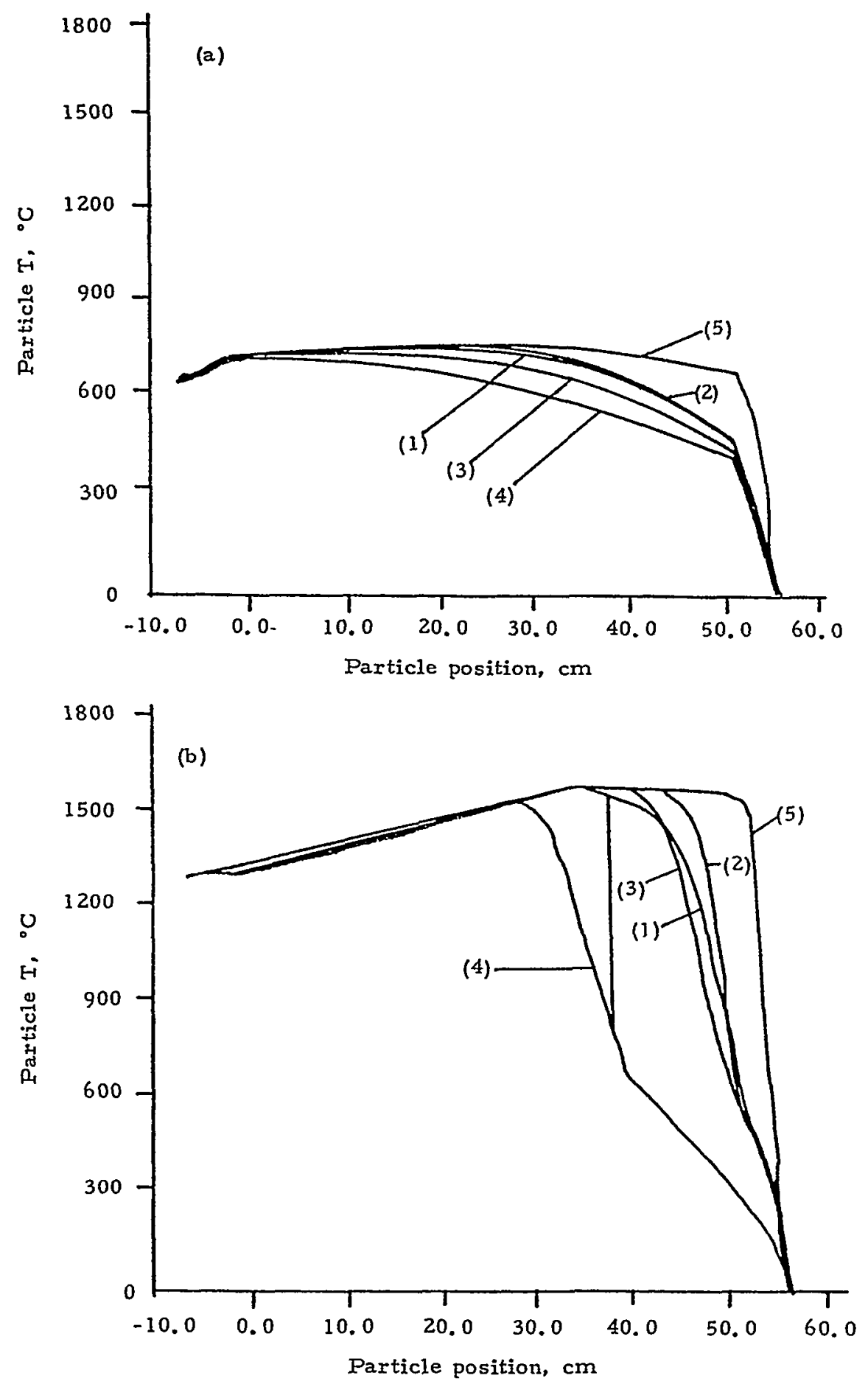

Fig. 12.3-4. Effect of various model assumptions on predicted temperatures in the entrained-flow reactor for North Dakota lignite (200 $\times 325$ mesh), injected $56 \mathrm{~cm}$ above the optical port. Case (1): $c_{p}=0.3 \mathrm{cal} / \mathrm{g}-\mathrm{K}$; $\varepsilon=1.0$; zero heat of pyrolysis, constant mass; cass (2): the particle mass (kinetic) submodel is included in (1); case (3): the heat capacity submodel is included in (2); case (4): the emissjvity submodel is included in (3); case (5): a single particle in an infinite gas volurne is added to (4). Figure (a) refers to $800^{\circ} \mathrm{C}$ and (b) to $1600^{\circ} \mathrm{C} \mathrm{EFR}$ experiments in nitrogen. 
Table 12.3-1. A summary of rate expressions for coal pyrolysis.

\begin{tabular}{|c|c|}
\hline Ref. & $\begin{array}{l}\text { Model Rate } \\
\text { (for) }\end{array}$ \\
\hline $\begin{array}{l}62 \\
62 \\
62 \\
62 \\
62\end{array}$ & $\begin{array}{l}\text { weight loss from lignite at } 10,000 \mathrm{~K} / \mathrm{sec}(1 \mathrm{~atm} \text {, excluding cooling) } \\
\text { weight loss from lignite at } 10,000 \mathrm{~K} / \mathrm{sec}(1 \mathrm{~atm} \text {, including cooling) } \\
\text { weight loss from bituminous coal at } 650 \mathrm{~K} / \mathrm{sec}(1 \mathrm{~atm}) \\
\text { weight loss from lignite (all pressures) } \\
\text { weight loss from bituminous coal }(69 \mathrm{~atm})\end{array}$ \\
\hline 63 & weight loss from lignite and bituminous coals \\
\hline 64 & weight loss from bituminous coal \\
\hline $\begin{array}{l}65 \\
65\end{array}$ & $\begin{array}{l}\text { tar evolution } \\
\text { aliphatic gas evolution }\end{array}$ \\
\hline $\begin{array}{l}2 \\
2\end{array}$ & $\begin{array}{l}\text { weight loss for coal } \mathrm{B} \\
\text { weight loss for coal } \mathrm{F}\end{array}$ \\
\hline $\begin{array}{l}66 \\
66\end{array}$ & $\begin{array}{l}\text { tar evolution from bituminous coal } \\
\text { aliphatic gas evolution from bituminous coal }\end{array}$ \\
\hline $\begin{array}{l}4 \\
4\end{array}$ & $\begin{array}{l}\text { tar evolution from lignite, subbituminous, and bituminous coals } \\
\text { aliphatic gas from lignite, subbituminous, and bituminous coals }\end{array}$ \\
\hline $\begin{array}{l}69 \\
69 \\
69\end{array}$ & $\begin{array}{l}\text { tar from lignite and subbituminous coals } \\
\text { aliphatic gases from lignite, subbituminous, and bituminous coals } \\
\text { weight loss from lignite, subbituminous, and bituminous coals }\end{array}$ \\
\hline 71 & weight-loss rate for $50 \%$ reaction completion, subbituminous coal \\
\hline $\begin{array}{l}24 \\
24\end{array}$ & $\begin{array}{l}\text { tar from lignite, subbituminous, and bituminous coals } \\
\text { aliphatic gas from lignite, subbituminous, and bituminous coals }\end{array}$ \\
\hline 72 & average for initial weight loss \\
\hline $\begin{array}{l}76 \\
76\end{array}$ & $\begin{array}{l}\text { weight loss for subbituminous coal } \\
\text { weight loss for bituminous coal }\end{array}$ \\
\hline $\begin{array}{l}61 \\
61 \\
61\end{array}$ & $\begin{array}{l}\text { tar from lignite, subbituminous, and bituminous coals } \\
\text { aliphatic gases from lignite, subbituminous, and bituminous coals } \\
\text { weight loss from lignite, subbituminous, and bituminous coals }\end{array}$ \\
\hline $\begin{array}{l}77,78 \\
77,78 \\
77,78\end{array}$ & $\begin{array}{l}\text { tar from ethylene-bridged anthracene polymer } \\
\text { tar from ethylene-bridged naphthalene polymer } \\
\text { tar from ethylene-bridged benzene polymer }\end{array}$ \\
\hline 79 & bibenzyl decomposition in tetralin \\
\hline
\end{tabular}


Table 12.3-2. A summary of rate expressions for coal pyrolysis, continued. The following abbreviations apply: EFR, entrained-flow reactor; HTR, heated-tube reactor; Grid, heated grid reactor; Laser, laser-heating experiment; EGA, evolved gas analysis at $0.5 \mathrm{~K} / \mathrm{sec}$; $\mathrm{S}$, single rate model; $\mathrm{G}$, a model using a Gaussian distribution of activation energies; $2 \mathrm{P}$, a model with two parallel rates.

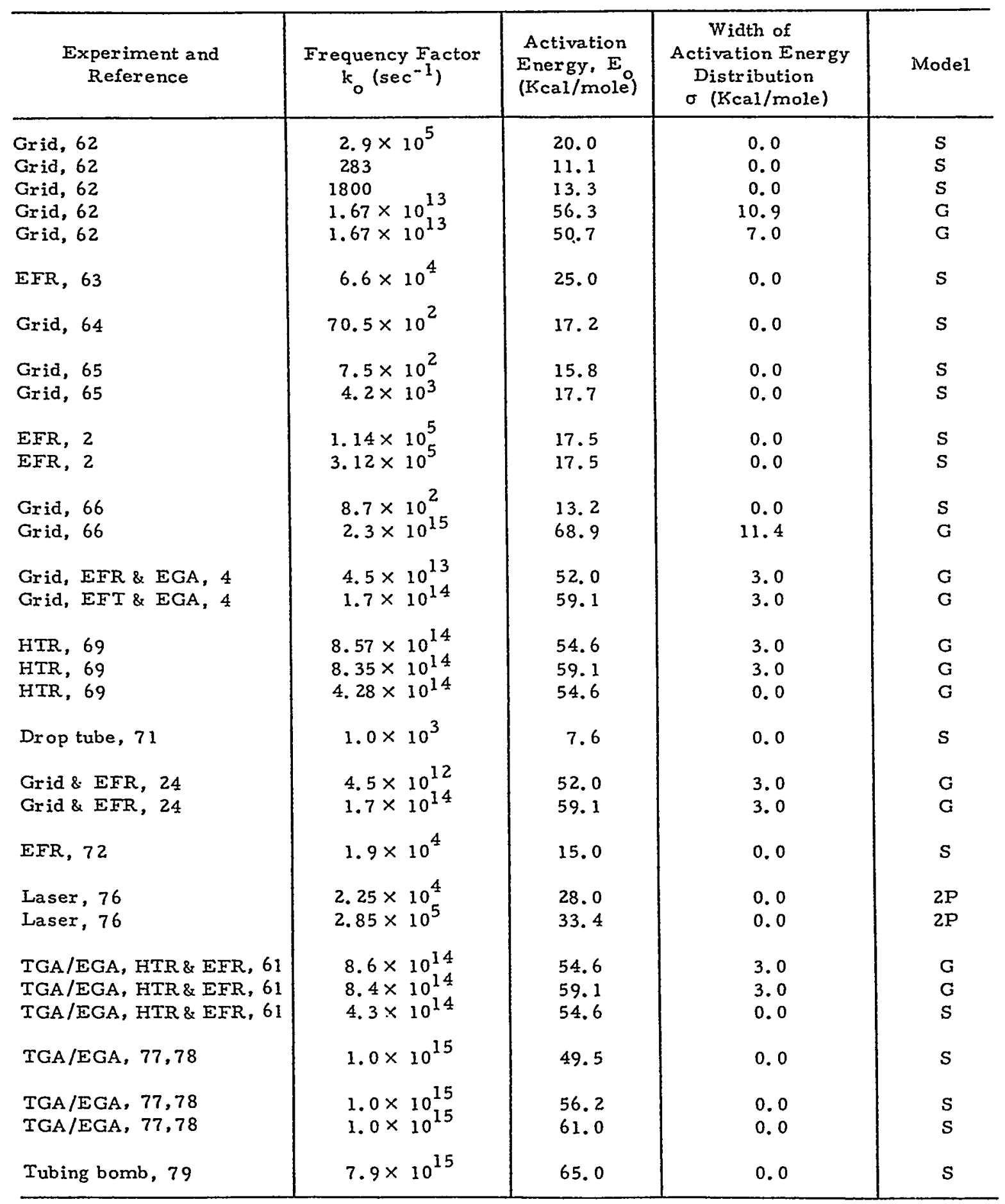




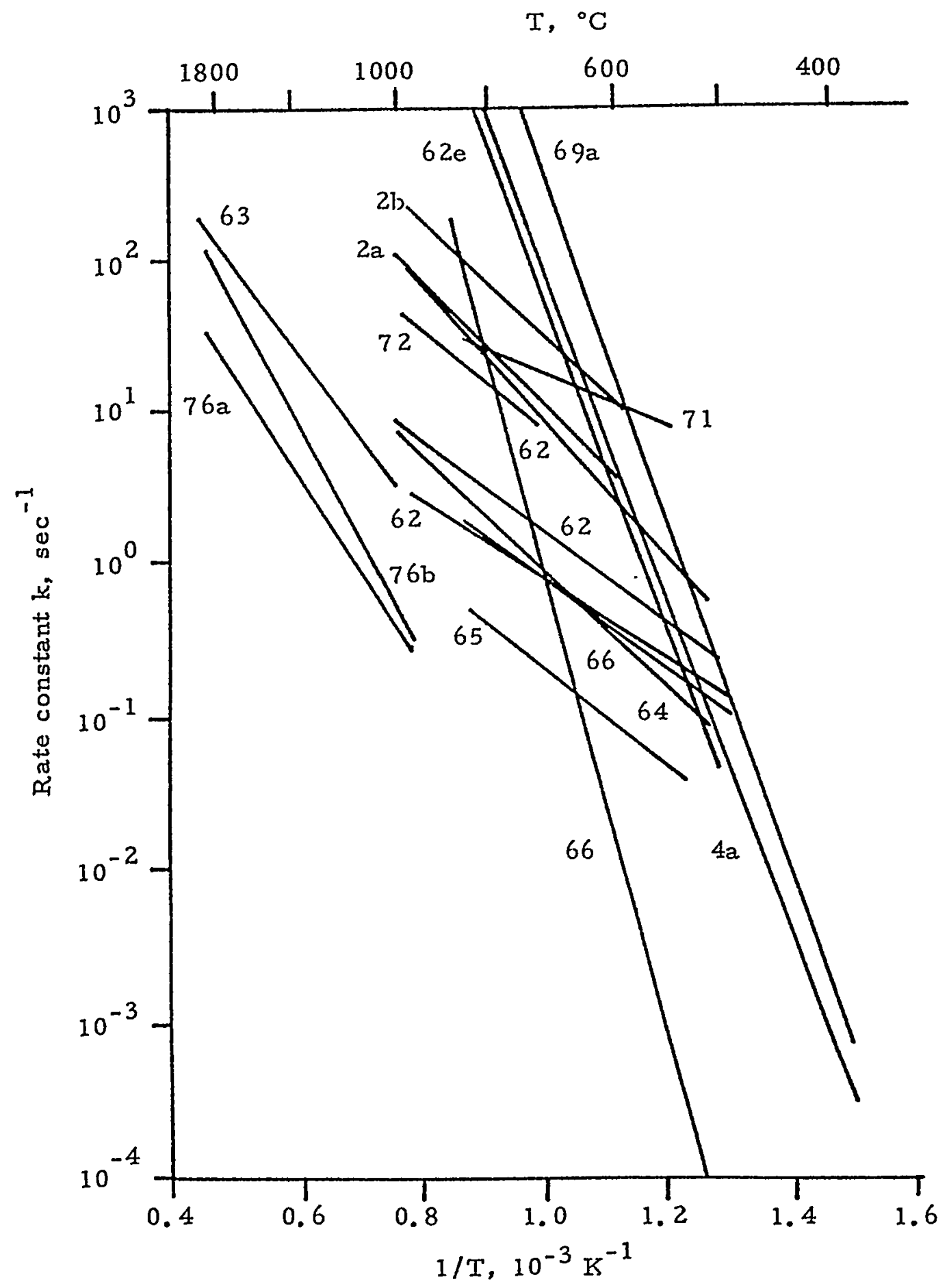

Fig. 12. 3-5. Comparison of kinetic rates for weight loss (or tar loss) from many investigators. The numbers next to each line indicate the reference and case in Table 12.3-1. 
Pyrolysis has been described by the following sequence:

I (coal/metaplast) II (primary pyrolysis) III(secondary pyrolysis)

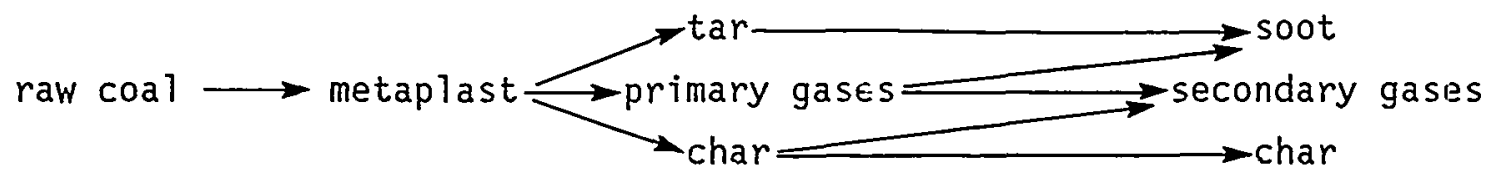

During stage $I$, the coal may undergo some bond-breaking reactions and reduction of hydrogen bonding, which may lead to melting. Some light species, which exist as guest molecules or are formed by the breaking of very weak bonds, are released. During stage II, further bond breaking occurs, leading to evolution of tar and gases and the formation of char. During stage III, the products may continue to react. The char may evolve secondary gases, mainly $\mathrm{CO}$ and $\mathrm{H}_{2}$, while undergoing ring condensation. Ring condensation affects the active-site density. The tars can react to form soot, coke, and gases, and the gases may react to form lighter gases and soot.

A mechanistic description of these stages is shown in Fig. 12.3-6 by a hypothetical picture of the coal organic structure at successive stages of pyrolysis. Figure 12.3-6 represents: (a) the raw coal, (b) formation of tar and light HCs during primary pyrolysis, and (c) char condensation and cross-linking during secondary pyrolysis. The hypothetical structure in Fig. 12.3-6(a) represents the chemical and functional group compositions for a Pittsburgh seam bituminous coal. ${ }^{80}$ which consists of aromatic and hydroaromatic clusters linked by aliphatic bridges. During pyrolysis, the weakest bridges [labeled 1 and 2 in Fig. 12.3-6(a)] may break, producing molecular fragments (depolymerizations). The fragments abstract hydrogen from the hydroaromatics or aliphatics, thus increasing the aromatic hydrogen concentration. These fragments will be released as tar if they reach a surface and vaporize. The two fragments labeled tar are small enough to vaporize under typical pyrolysis conditions, but the other two fragments are not. The other event during primary pyrolysis is the decomposition of functional groups to release $\mathrm{CO}_{2}$, light aliphatic gases, and some $\mathrm{CH}_{4}$ and $\mathrm{H}_{2} \mathrm{O}$. The release of $\mathrm{CH}_{4}, \mathrm{CO}_{2}$ and $\mathrm{H}_{2} \mathrm{O}$ may produce repolymerization, $\mathrm{CH}_{4}$ by a substitution reaction in which the attachment of a larger molecule releases 


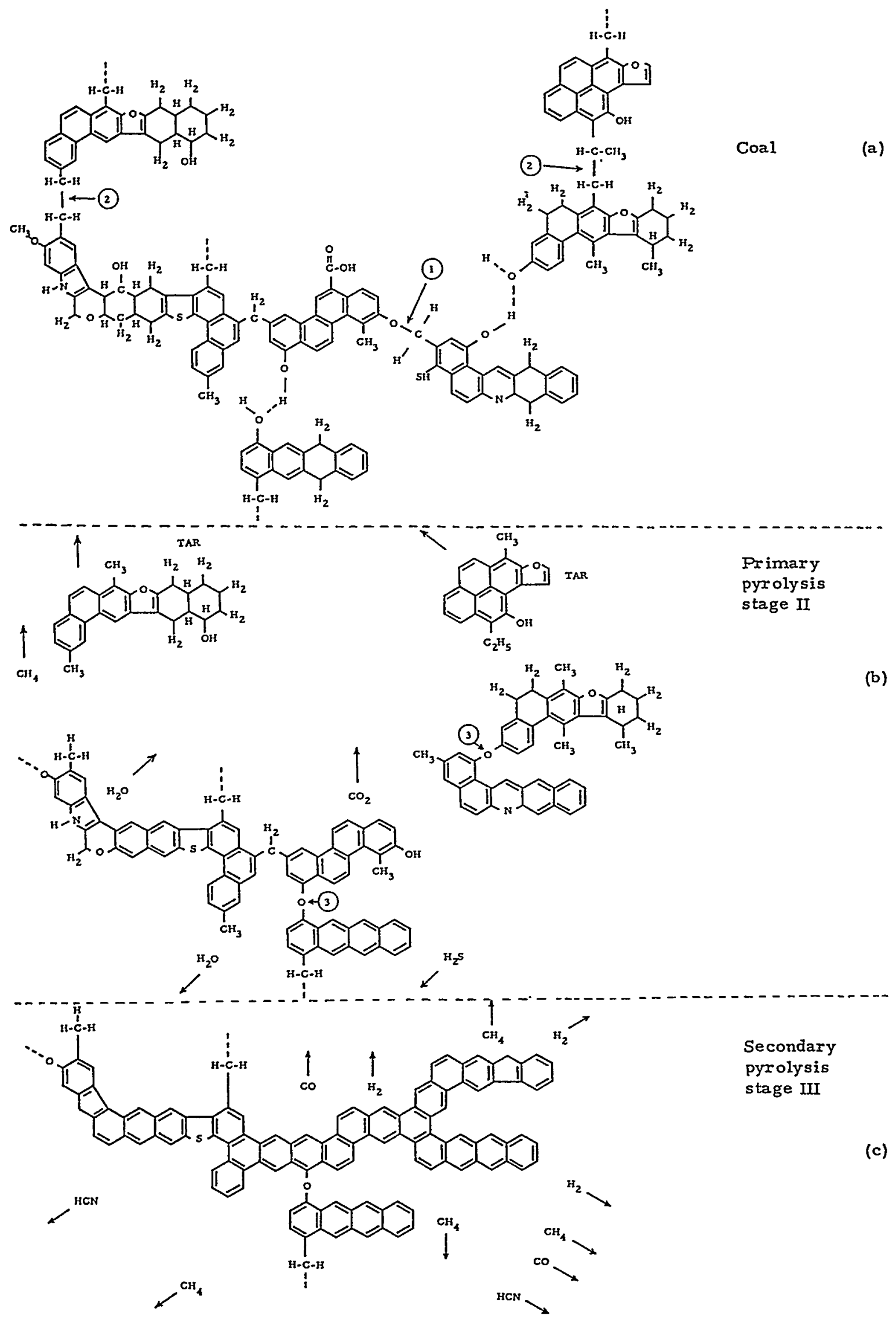

Fig. 12,3-6. A hypothetical coal molecule during three stages of pyrolysis. 
the methyl group, $\mathrm{CO}_{2}$ by radical stabilization after the $\mathrm{CO}_{2}$ evolution creates a radical, and $\mathrm{H}_{2} \mathrm{O}$ by the condensation of two $\mathrm{OH}-g$ roups to produce an ether-link [labeled 3 in Fig. 12.3-6(b)]. The cross-linking is important to determine the tar release and the visco-elastic properties of the char. It may also be important in the rate of loss of active sites. The completion of primary pyrolysis occurs when the available hydrogen from hydroaromatics or aliphatics is depleted. The yield of tar can be correlated with the amount of aliphatic and hydroarmatic hydrogen in the coal. 24

During secondary pyrolysis [Fig, 12.3-6(c)], there is additional evolution of $\mathrm{CH}_{4}$ (from methyl groups), $\mathrm{HCN}$ from ring nitrogen compounds, $\mathrm{CO}$ from ether links, and $\mathrm{H}_{2}$ from ring condensation. The ring condensation reduces the carbon available for oxygen attack and is therefore related to the intrinsic reactivity.

\section{3-3A. Modeling}

In view of the importance of coal pyrolysis in coal processing and in understanding coal structure, an accurate model of this phenomenon is highly desirable. There have been several recent reviews of the pyrolysis literature. 10,81-84 Coals have wide variability of volatile content, tar and soot production, swelling and sticking behavior, char reactivity, and pollutant formation. The behavior of coal depends not only on the chemical and physical properties of the coal but also on the conditions under which pyrolysis occurs. Most models of coal devolatilization have been developed to describe weight loss. While weight loss provides the split between char and volatiles, it does not involve questions about the chemical composition and heating value of the volatiles, release of polluting species, properties of the char (melting, swelling, agglomeration, reactivity), and dependence of these properties on bed geometry, pressure, and heating rate.

A number of more detailed models have recently been developed to address these issues. These range in complexity and include multiple reaction models, which describe the evolution of major species, $4,24-26,65,66,85$ models incorporating the competition between depolymerization, mass transport and crosslinking to describe tar formation 
(Refs. 62, 66, 27-29, 77, 78 and 86-93) and complete models with a detailed chemical description of coal decomposition. $27-29$.

\section{3-3B. Formation of Gas}

Recent reviews of the pyrolysis literature have been presented by a number of authors. $81-84,10$ A few models have been developed to describe the evolution of individual gas species. Individual product formations have been described by independent, first-order reactions, one for each product, have been employed. $85,82,25,66,93$ Some of the products are formed by breaking two or more types of bonds, followed by a corresponding number of reactions. The number of reactions required for each product is judged from the shape of the experimental yield-temperature curves. An example comparing the model of Subberg et a ${ }^{93}$ with heated-grid data is presented in Fig. 12.3-7.

\section{Solomon and coworkers $4,24-26,61,65,69$ have described the parallel} evolution of individual gas species in competition with tar formation. Tars can escape with some of the sources for the gas species. These sources have been related to the functional groups present in the coal by identifying corresponding changes in the functional group composition in the char as the gases evolve. A simplification introduced in this model is the assumption that the kinetics describing the evolution of individual species are insensitive to coal rank. This insensitivity to rank is reviewed in Ref. 94. An example from Ref. 60 of the application of this model to predict gas evolution from three different coals under different pyrolysis conditions is presented in Fig. 12.3-8. The same kinetic rates were used for other coals and temperature histories are varied. 60,61

Most attention has been given to the major species (tar, $\mathrm{CO}, \mathrm{CO}_{2}$, $\mathrm{H}_{2} \mathrm{O}, \mathrm{CH}_{4}$, etc.). There is some work on nitrogen evolution. $23,24,95$ Data or models for sulfur release are scarce. 96

\section{3-3C. Formation of Condensables}

The mechanisms of the formation of condensables (tar) have been considered by a number of investigators. $62,66,27-29,86-93$ A review of current work was recently presented by Subberg. 97 It is generally agreed 
that the process includes the following steps: (i) formation of tar molecules, ( $i i)$ evaporation and transport, ( $i i i)$ possible repolymerization to form char, and (iv) condensation to form soot. There is, however, little

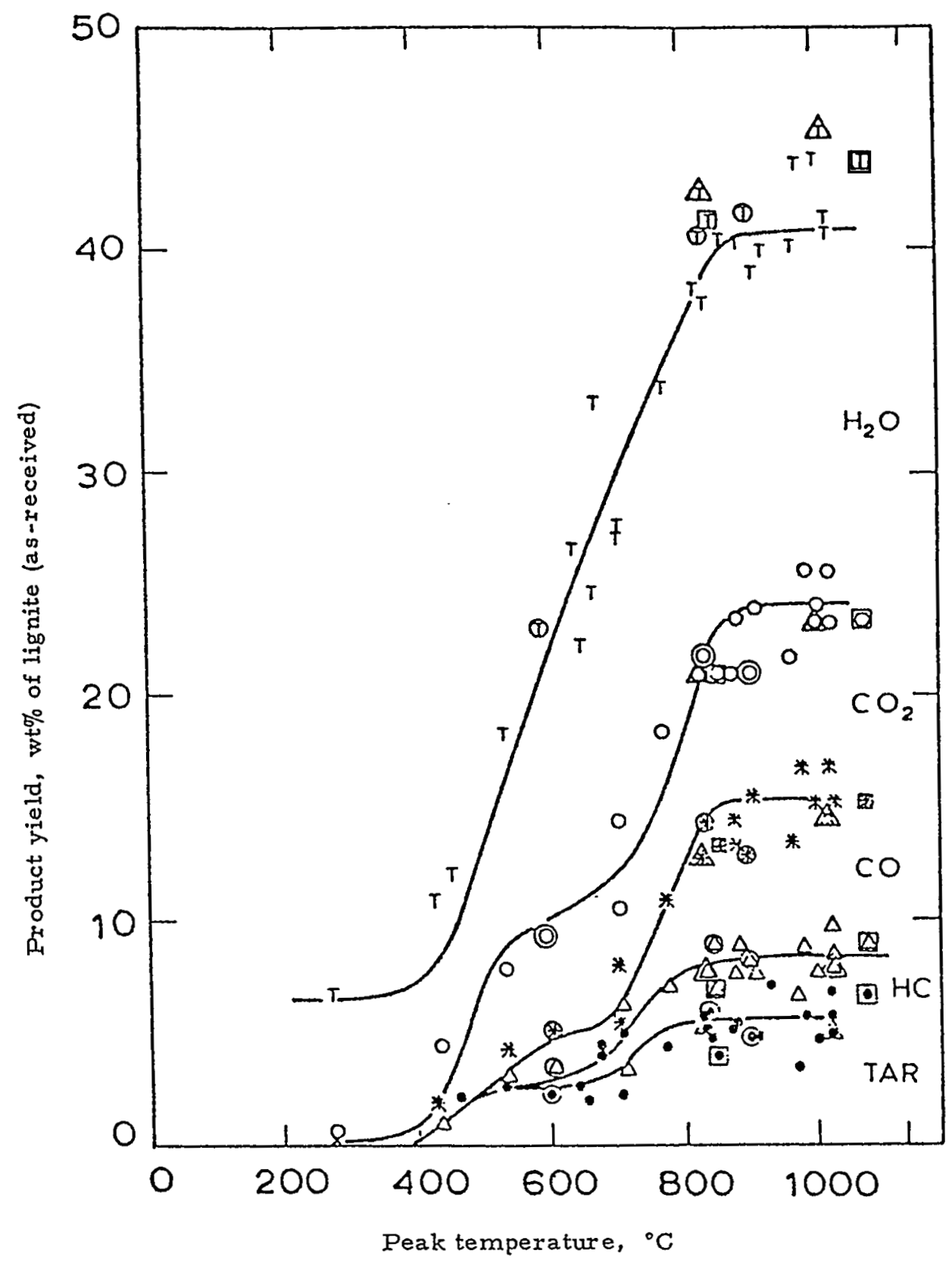

Fig. 12-3-7. Pyrolysis-product distributions from lignite heated to different peak tempexatures $[(-\operatorname{tar} ;(\triangle)$ tar and other hydrocarbons $(H C)$; (*) tar, $\mathrm{HC}$, and $\mathrm{CO}$; $(\mathrm{O})$ tar, $\mathrm{HC}, \mathrm{CO}$, and $\mathrm{CO}_{2} ;(\mathrm{T})$ total, i.e., tar, $\mathrm{HC}, \mathrm{CO}, \mathrm{CO}_{2}$, and $\mathrm{H}_{2} \mathrm{O}$ ]. Pressure $=1$ atm (He); heating rates: basic, $1000^{\circ} \mathrm{C} / \mathrm{s}$; points inside 0,7100 to $10,000^{\circ} \mathrm{C} / \mathrm{s}$; points inside $\Delta, 270$ to $470^{\circ} \mathrm{C} / \mathrm{s}$; points inside $\square, 2$-step heating. These curves are from Ref. 93 and are reprinted with permission. 
agreement on the relative importance of these steps or how they are linked in a model which provides quantitative predictions. One problem is that the mechanisms are likely to change with coal rank.

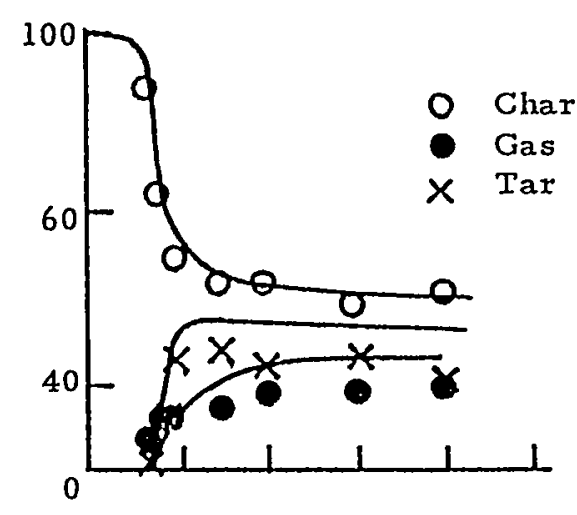

(a)
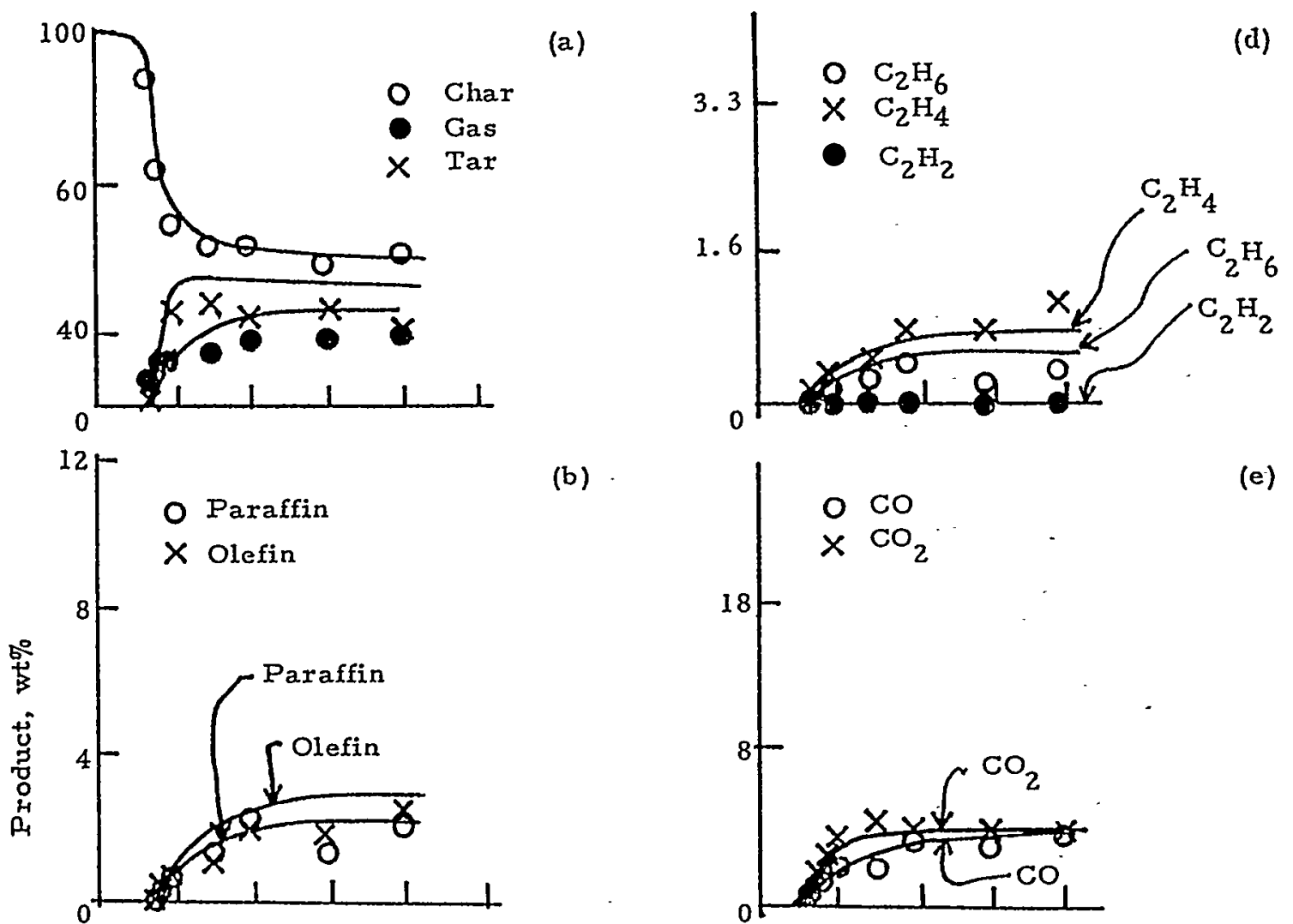

(b)
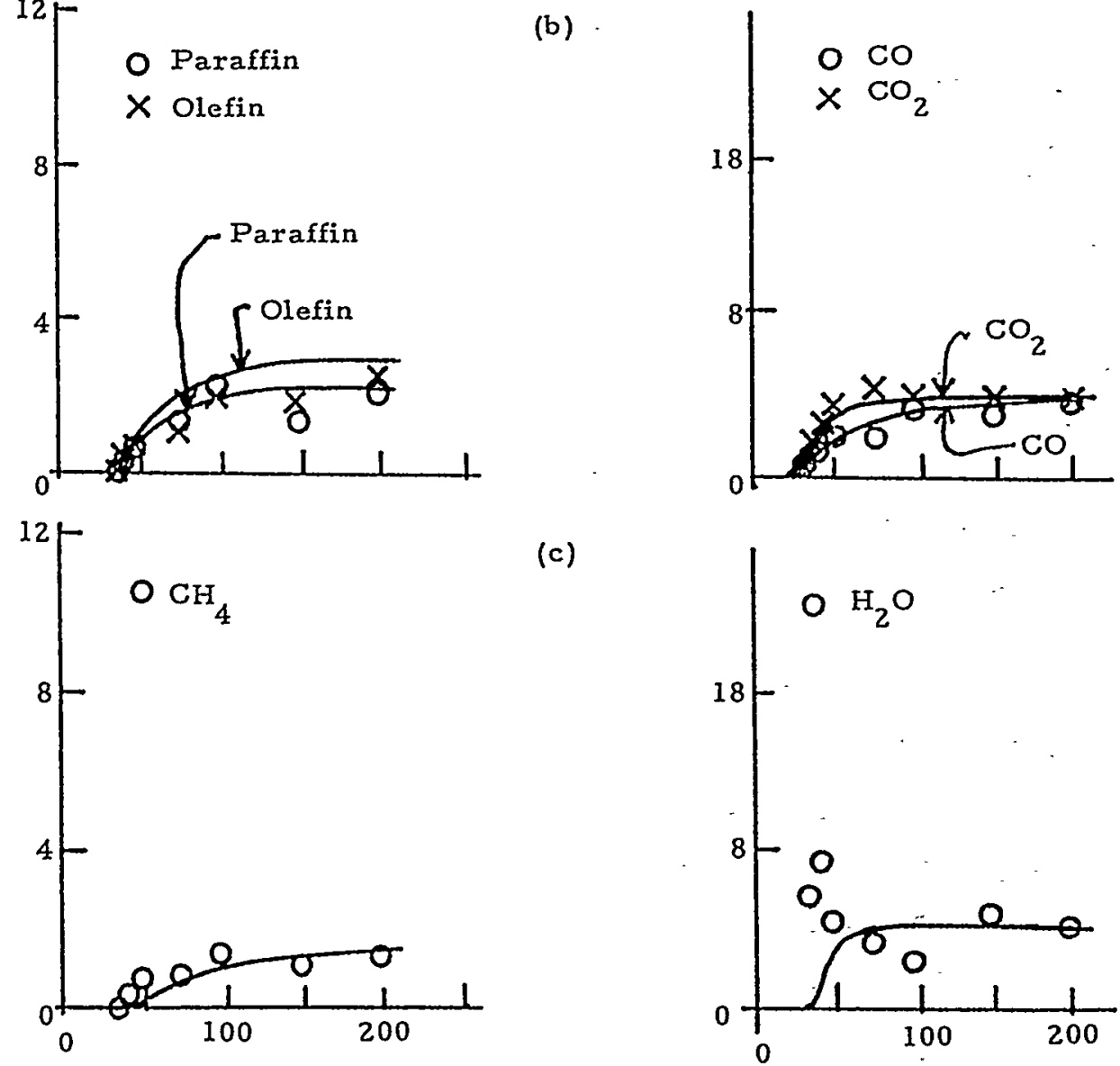

(c)

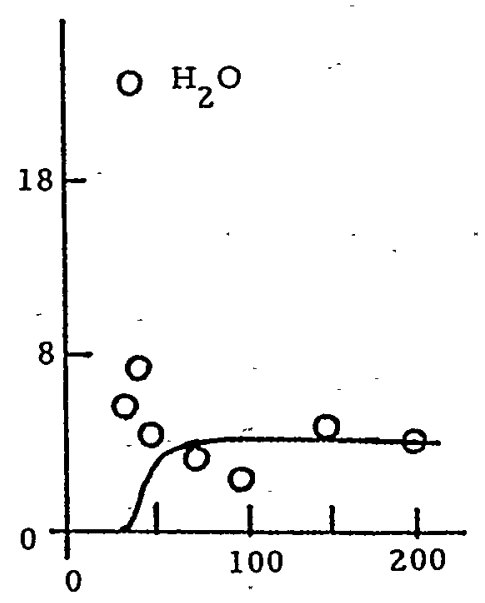

(e)

(f)

Reaction distance, $\mathrm{cm}$

Fig. 12.3-8. Pyrolysis results for Illinois No. 6 coal, $200 \times 325$ mesh, in the heated tube reactor at an equilibrium tube temperature of $800^{\circ} \mathrm{C}$. The solid lines are predictions from the functional group model. The gas and coal flows were $4.4 \mathrm{~g} / \mathrm{min}(\mathrm{He})$ and $0.8 \mathrm{~g} / \mathrm{min}$, res pectively. 
Considering the available evidence reviewed in Ref. 88, tar formation in softening coals may be viewed as a combined depolymerization and evaporation process in which the pyrolytic depolymerization continually reduces the weight of the coal molecular fragments through bond breaking and stabilization of free radicals until the fragments are small enough to be evaporated. Crosslinking resolidifies the material.

Tar molecular weights for softening coals appear to be dominated by their vaporization characteristics. For non-softening coals, the average tar molecular weight, measured under slow heating conditions, is substantially less than predicted from vaporization. 88 It also appears to be much less than for tar measured under rapid heating conditions for the same coal. 89 The explanations, which must be tested, are repolymerization caused by crosslinking and/or transport limitations caused by the rigidity of the pore structure. Both effects will reduce the size of the oligomers that are released. Results of suuberg et al ${ }^{98}$ indicate that low-rank coals undergo substantial crosslinking prior to tar formation.

\section{3-3D. Formation of Char}

A methodology is needed to describe the physical and chemical development of char. This model is most difficult to obtain for a softening coal for which the physical structure changes from a pore system to a fluid medium with gas bubbles and cenospheres (for swelling coals). The required descriptions include an intra-particle transport model such as that of Simons, 99-102 which yields the pressure within the pores. The deformation of the pore walls is determined from this pressure and the viscosity of the melt. This model has been discussed by

Melia and Bowman. 103 Descriptions of bubble transport have been given by Oh et a1. 104 A description of bubble swelling and rupture has been presented by Solomon et al. ${ }^{4}$ Bubble rupture may be the reason for the high-temperature disappearance of swelling at high heating rate. 3,4 Repolymerization and crosslinking effects are described by a number of authors $62,98,66,30,31,27-29,86-93$ and will also be important.

A technique which has been employed to control the swelling properties of char is oxidation. It is important to develop an understanding and quantitative description of the effects of oxidation on swelling and the subsequent reactivity of the char. 


\section{3-3E. Gasification of Char}

Understanding char reactivity is important since the consumption of char is the slowest and, therefore, the controlling process in gasification. Reviews of the char-oxidation literature have been published. 36,37 A comprehensive review of char gasification has been written by Laurendeau, ${ }^{38}$ who discusses qualitative observations and quantitative models for reactions of char with $\mathrm{CO}_{2}, \mathrm{H}_{2} \mathrm{O}, \mathrm{O}_{2}$, and $\mathrm{H}_{2}$. In a more recent review, van Heek and Muhlen ${ }^{39}$ discuss the main factors influencing the reactivity of char in different gasifying agents. These reviews demonstrate that there is a wide variation in observed reactivities. Work described by Smoot ${ }^{44}$ highlights the very large variations ( 1.5 orders of magnitude) in char reactivity depending on method of formation. Similarly, Ashu et a ${ }^{105}$ found enhanced char reactivity caused by rapid heating of the precursor coal. More recently, Essenhigh and Farzar 106 measured very rapid burnout times for small coal particles in a vertical tunnel furnace. They ascribed their results to the firing condition, which gave heating rates in the $10^{6} \mathrm{~K} / \mathrm{sec}$ regime, compared with the more usual value of $10^{4} \mathrm{~K} / \mathrm{sec}$ in slower burning flames.

Both the formation conditions and reactivity vary with coal rank. Variations with coal type and pyrolysis conditions may be understood in terms of variations in active-site density, accessible surface area, and the catalytic effects of minerals. The active-site density is determined by the concentration of carbon edge sites and defects and by the concentration of hydrogen and oxygen (to some extent, also by sulfur and nitrogen) in the char. These chemical factors, combined with the mineral content and the pore structure, account for differences in char reactivity. Minerals have a significant positive effect on reactivity for low-rank coals. For most high-rank coals, minerals do not contribute greatly to the reactivity and may even have a negative impact because of pore blockage. Some minerals react with added catalysts and render them ineffective. 39

The gasification or combustion reactions of char are generally described as falling into three rate-controlling regimes for which the reaction is limited by (i) intrinsic reactivity of the char itself, (ii) diffusion of reactants within the char pores, and ( $i i i$ ) diffusion of reactants between the char surface and the ambient atmosphere. These regimes are traversed successively as the temperature increases. At high 
temperatures, the rate of chemical reaction may exceed the rate of transport of reactants to the surface, which is especially true for oxidation reactions. The mass-transport rate will be controlled by the char properties (porosity, pore-size distribution, and particle size), as well as the reaction conditions (pressure, temperature, and turbulence).

Research in this area should be directed at (i) defining appropriate characterization procedures for the char structure through reactivity measurements at temperature appropriate to gasifier conditions, (ii) developing a description of the varying reactivity during char gasification and (iii) developing a better understanding of the role of mineral matter and added catalysts.

\section{3-3F. Secondary Reactions of Condensables}

Secondary reactions of tars may be of the cracking type, which forms lighter tars, light oils $\left(<C_{10}\right)$ and/or light gases $\left(<C_{5}\right)$, or of the polymerization-condensation type, which leads to heavier tars, or, ultimately, coke and soot (although small amounts of light gases are eliminated). The nature and extent of the secondary tar reactions are influenced by coal type, temperature, ambient gas composition, mass transfer of the primary tars away from their source, and the characteristics of any surfaces that may be encountered. Depending on the process, operating conditions, and coal type, secondary tar reactions will have a minor or major impact in the following areas: (i) product distribution (between solid, liquid, and/or gas); (ii) product heating value; (iii) char reactivity (by obstruction of pores or active sites); (iv) disposition of sulfur, nitrogen, and oxygen among the products of coal pyrolysis; (v) formation of soot and polycyclic aromatic hydrocarbons (PAH); (vi) particle ignition and flame stability; (vii) coal plasticity and coke properties; and ( $v i i j$ ) evolution of unreacted tars from the gasifier.

For mild gasification, secondary reactions are desirable to the extent that they improve the quality of the liquids produced, although they also reduce the overall yield of the liquids. Better knowledge of the fundamental nature of the secondary reactions is required in order to optimize the yields of these processes. Some information on homogeneous 
tar-cracking reactions is available from previous work. ${ }^{107-110}$ There is currently only qualitative information on heterogeneous reactions $107,108,111$ and on the transformation of tar to soot. 112

12.4. The Behavior of Coal Mineral Matter in Gasification

Inorganic constituents of coal consist of both discrete mineral particles (inclusions) and elements that are bonded to organic molecules. As the organic matter in the coal is gasified, the inorganic constituents form increasingly the bulk of the residual material of the gasification process. Depending on the type of process, this inorganic residue is removed as a dry, powdery fly ash, sintered ash, or molten slag. The physico-chemical transformations of the coal mineral matter depend on its chemical and mineralogical composition and its temperature-concentration history in the gasification process. Most of the information about coal mineral-matter transformation comes from coal-combustion studies, mainly because of the troublesome slagging and fouling of heat exchangers in coal-fired boilers. While heat-exchanger fouling is a lesser problem in coal gasification, removal of the ash from the gasifier and cleaning of the gas require knowledge of the state, chemical, and mineralogical composition of the ash and the particle size of the fly ash carried over from the gasifier with the product gas.

\section{4-1. The Nature of Mineral Matter in Coal and Its Characteristics}

Coal is a sedimentary deposit, which explains its widely variable overall composition. As mined, most coals contain shales, sandstones from adjoining strata, and also inorganic matter such as alkali- and alkaline-earth metals and sulfur, which were part of the coalified vegetation, are associated with the organic material, and are dispered on an atomic scale in the coal. These may be chemically combined with the carbonaceous material or as ions absorbed from groundwaters. Other minerals, such as sulfides and carbonates, form inclusions in voids in the coal seam between fracture surfaces of hard coals by deposition from percolating water. Table 12.4-1 lists some of the mineral compounds found in coals, along with their usual manner or mode of occurrence. ${ }^{114}$ 
Traditionally, ash chemistry was used for coal mineral-matter characterization. In recent years, new analytical methods have become available, which are capable of much more detailed and useful characterizations. Computer-controlled scanning electron microscopy (CCSEM), scanning transmission electron microscopy (STEM), and $x$-ray diffraction (XRD) have been used to determine the types, amounts, and size distributions of mineral matter in coal. Types of iron-bearing minerals can be distinguished quatitatively by Mossbauer spectroscopy. The electronic bonding structure and local atomic environment of inorganic species that are organically bonded within the coal macerals, such as sulfur, calcium and alkalies, may be identified by $x$-ray absorption fine-structure spectroscopy (EXAFS) and energy-loss spectroscopy (EELS). Other techniques, which have been used successfully, include Fourier-transform infrared (FTIR) spectroscopy, use of an electron microprobe, electron spectroscopy for chemical analysis (ESCA), proton-induced x-ray emmission (PIXE), etc. While in recent years significant progress has been made in the development of these new analytical techniques, their further development is essential for detailed characterization of the types, amounts, size distributions, and structures of inorganic matter in coal.

\section{4-2. Behavior During Heating}

In the initial stages of heating, the mineral matter undergoes a number of changes, some of which are shown in Fig. 12.4-1. First, at temperatures below $500 \mathrm{~K}$, the water absorbed on the coal substance or combined with the mineral matter is dried off. At temperatures ranging from 500 to $1000 \mathrm{~K}$, carbonates and sulfates decompose with significant associated weight loss in the ash as $\mathrm{CO}_{2}, \mathrm{SO}_{2}$, and $\mathrm{SO}_{3}$ are evolved.

The organic material in the coal substance also undergoes thermal decomposition, yielding hydrocarbon vapors. Some elements, which are physically adsorbed or are organically combined in the coal such as chlorine and sulfur, evolve as volatiles; the organic sulfur may pyrolyze to give a elemental sulfur and its hydrites and the chlorine are probably released as $\mathrm{HCl} .116$

Because of the weight loss associated with thermal decomposition of the ash, the weight of the ash determined by the ASTM test is usually lower than that of the original mineral content of the coal. The weight of 
the original mineral matter is better approximated by the low-temperature ash determination ${ }^{117}$ and is of the order of $20 \%$ greater than that of the ASTM ash.

A summary of minerals identified in coals is given in Table 12.4-1.

\section{4-3. Mineralogical Transformations at High Temperatures}

As the temperature exceeds $1300 \mathrm{~K}$, alkalies in the form of salts ( $\mathrm{NaCl}$ and $\mathrm{KCl}$ ) are volatilized. Those bound in complex aluminum silicates are less likely to vaporize and, in these mineralogical forms, alkalies are less active in a slagging-fouling processes.

Sintering in the mineral matter begins to take place at temperatures as low as $1000 \mathrm{~K}$. Because of interaction of the ash constituents and the formation of low melting-point eutectics, the melting point of the ash is usually lower than that of the pure mineral compounds. For example, at temperatures between 1150 and $1500 \mathrm{~K}$, illite $\left(2 \mathrm{~K}_{2} \mathrm{O} 3 \mathrm{MgO} \mathrm{Al}_{2} \mathrm{O}_{3}\right.$ $24 \mathrm{SiO}_{2} 12 \mathrm{H}_{2} \mathrm{O}$ ) undergoes dehydration leading to the formation of spinel (crystalline magnesium-iron-aluminates) while the alkali, the silica, and the remainder of the alumina produce a glassy mass. The spinel then dissolves in this glassy mass. Parallel with these reactions and at about $1400 \mathrm{~K}$, mullite $\left(3 \mathrm{AL}_{2} \mathrm{O}_{3} 2 \mathrm{SiO}_{2}\right)$ begins to form. Mullite also dissolves in the glassy melt and forms a liquid phase in the presence of alkalies.

Because of the eutectics formed during the reactions in the slag, slag-melting temperatures may sometimes be reduced by high meiting-point compounds, as for example $\mathrm{CaO}$ and $\mathrm{MgO}$ in acidic slags in $\mathrm{SiO}_{2}$ in Time-containing basic slags.

Because of the complexities of the physico-chemical processes in slags, efforts to predict softening -melting behavior from the chemical composition of the ash have not met with much success. It is one of the challenging problems to determine the softening-sintering-melting behavior under the conditions found in the gasification process from the chemical and mineralogical composition of the mineral matter in the coal.

\section{4-4. Ash Agglomeration}

At elevated temperatures as in slagging gasifiers, the mineral inclusions in coal decompose, melt and form small spherical particles that 
attach themselves to the receding carbonaceous particles. ${ }^{118}$ Even though molten ash does not appreciably wet carbon surfaces, ${ }^{119}$ only slight melting is needed to provide ash adherence since its surface tension is high ( 320dyne/cm). ${ }^{119}$ Because the ash is not separated from the carbon matrix during combustion, the ashed mineral particles will be drawn together and coalesce as the carbon surface recedes. $118,120,121$

The ash particle-size distribution depends on the processes of ash agglomeration, but it is also strongly influenced by the fragmentation of the char as it undergoes gasification. Recent research on heterogeneous reactions involving coal char indicate that the solid particle undergoes percolative fragmentation during its reaction. In the course of the reaction, the particle is penetrated by the gaseous reactant and becomes increasingly porous. At a critical porosity of about 0.7-0.8, the layer of the particle loses its structural integrity and breaks off as a fragment. In the regime controlled by chemical kinetics, the whole particle may be uniformly penetrated by the gaseous reactant and may disintegrate into fragments when the critical porosity is reached.

\subsection{Mathematical Modeling}

In order to understand and obtain quantitative predictions of how the individual chemical and physical steps described in Sec. 12.3 and 12.4 affect the overall gasification process, it is necessary to develop computational procedures which incorporate these steps in a comprehensive gasifier model. Models which are common to both gasification and combustion are being developed, and an extensive review of their status was presented by Smoot, ${ }^{122,123}$ who noted that modeling of coal-reaction processes has not reached the point where significant use is made of it in process development for coal utilization.

\section{5-1. Status of Model Development}

We refer to Smoot ${ }^{122,123}$ for review of this problem. Modeling of turbulent reaction processes is still in a state of development. At least 6 fixed-bed, 10 fluidized-bed and 14 pulverized-coal conversion models have been developed since 1970. In general, the approach used in advanced combustion models is sound. However, unresolved fundamental issues remain. 
Table 12.4-1. Minerals identified in coals (after Gluskoter ${ }^{113}$ ).

\begin{tabular}{|c|c|c|}
\hline Mineral & Chemical Formula & Association with Coal \\
\hline $\begin{array}{l}\text { Clay minerals } \\
\text { Montmorillonite } \\
\text { Illite-sericite } \\
\text { Kaclinite } \\
\text { Halloysite } \\
\text { Chlorite (prochlorite, } \\
\text { penninite) } \\
\text { Mixed-layer clay } \\
\text { minerals }\end{array}$ & $\begin{array}{l}\mathrm{Al}_{2} \mathrm{Si}_{4} \mathrm{O}_{10}(\mathrm{OH})_{2} \times \mathrm{H}_{2} \mathrm{O} \\
\mathrm{KAl}_{2}\left(\mathrm{AlSi} \mathrm{O}_{10}\right)(\mathrm{OH})_{2} \\
\mathrm{Al}_{2} \mathrm{Si}_{4} \mathrm{O}_{10}{ }^{(\mathrm{OH})_{8}} \\
\mathrm{Al}_{4} \mathrm{Si}_{4} \mathrm{O}_{10}(\mathrm{OH})_{8} \\
\mathrm{Mg}_{5} \mathrm{Al}^{\left(\mathrm{AlSi}_{3} \mathrm{O}_{10}\right)(\mathrm{OH})_{8}}\end{array}$ & $\begin{array}{l}\text { This material is finely-dispersed } \\
\text { in coal substance. It is the prin- } \\
\text { cipal constituent of shales. } \\
\text { Crystals are }<1 \mu \mathrm{m} \text {. Impregna- } \\
\text { tion occurs in joints in brown } \\
\text { coal. }\end{array}$ \\
\hline $\begin{array}{l}\text { Sulfide minerals } \\
\text { Pyrite } \\
\text { Marcasite } \\
\text { Sphalerite } \\
\text { Galena } \\
\text { Chalcopyrite } \\
\text { Pyrrhotite } \\
\text { Arsenopyrite } \\
\text { Millerite }\end{array}$ & $\begin{array}{l}\mathrm{FeS}_{2} \\
\mathrm{FeS}_{2} \\
\mathrm{ZnS} \mathrm{PbS} \\
\mathrm{CuFeS}_{2} \\
\mathrm{Fe}_{1-\mathrm{S}} \\
\mathrm{FeAsS} \\
\mathrm{NiS}\end{array}$ & $\begin{array}{l}\text { The minerals occur in modules } \\
\text { and crystals }(10 \mathrm{~cm} \text { to }<1 \mu \mathrm{m}) \\
\text { in coal substance and in joints } \\
\text { and cleats. Pyrite and marcasite } \\
\text { are the principal sulphides. This } \\
\text { is the principal form of iron in } \\
\text { most hard coals. }\end{array}$ \\
\hline $\begin{array}{l}\text { Carbonate minerals } \\
\text { Calcite } \\
\text { Dolomite } \\
\text { Siderite } \\
\text { Ankerite (ferroan } \\
\text { dolomite) } \\
\text { Witherite }\end{array}$ & $\begin{array}{l}\mathrm{CaCO}_{3} \\
(\mathrm{Ca}, \mathrm{Mg}) \mathrm{CO}_{3} \\
\mathrm{FeCO}_{3} \\
(\mathrm{Ca}, \mathrm{Fe}, \mathrm{Mg}) \mathrm{CO}_{3} \\
\mathrm{BaCO}_{3}\end{array}$ & $\begin{array}{l}\text { The minerals occur in hard coals } \\
\text { that are present mainly in joints } \\
\text { and cleats. They constitute the } \\
\text { principal form of calcium and } \\
\text { magnesium and the secondary } \\
\text { form of iron. }\end{array}$ \\
\hline $\begin{array}{l}\text { Sulfate minerals } \\
\text { Barite } \\
\text { Gypsum } \\
\text { Anhydrite } \\
\text { Bassanite } \\
\text { Jarosite } \\
\text { Szomolnokite } \\
\text { Rozenite } \\
\text { Melanterite } \\
\text { Coquimbite } \\
\text { Roemerite } \\
\text { Mirabilite } \\
\text { Kieserite } \\
\text { Sideronatrite }\end{array}$ & 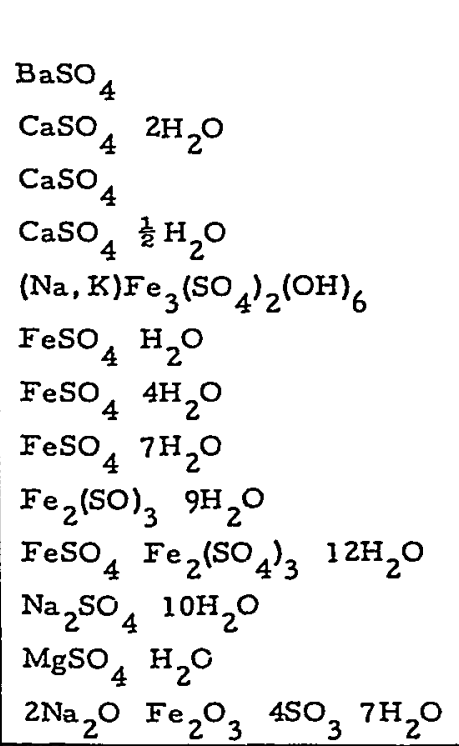 & $\begin{array}{l}\text { These are principally } \\
\text { formed as a result of weath- } \\
\text { ering (aqueous oxidation of } \\
\text { sulphides). }\end{array}$ \\
\hline $\begin{array}{l}\text { Chloride minerals } \\
\text { Halite } \\
\text { Sylvite } \\
\text { Bischofite }\end{array}$ & $\begin{array}{l}\mathrm{NaCl} \\
\mathrm{KCl} \\
\mathrm{MgCl}_{2} \quad 6 \mathrm{H}_{2} \mathrm{O}\end{array}$ & $\begin{array}{l}\text { These are occasionally present as } \\
\text { discrete crystals, often as ions } \\
\text { adsorbed on coal substance (vitri- } \\
\text { nite). They can be recrystallized } \\
\text { from solution after wetting. }\end{array}$ \\
\hline
\end{tabular}


Table 12.4-1. Continued

\begin{tabular}{|c|c|c|}
\hline Mineral & Chemical Formula & Association with Coal \\
\hline $\begin{array}{l}\text { Silicate minerals } \\
\text { Cuartz } \\
\text { Biotite } \\
\text { Zircon } \\
\text { Tourmaline } \\
\text { Garnet } \\
\text { Kyanite } \\
\text { Staurolite } \\
\text { Epidote } \\
\text { Albite } \\
\text { Sanidine } \\
\text { Orthoclase } \\
\text { Augite } \\
\text { Hornblends } \\
\text { Topaz }\end{array}$ & 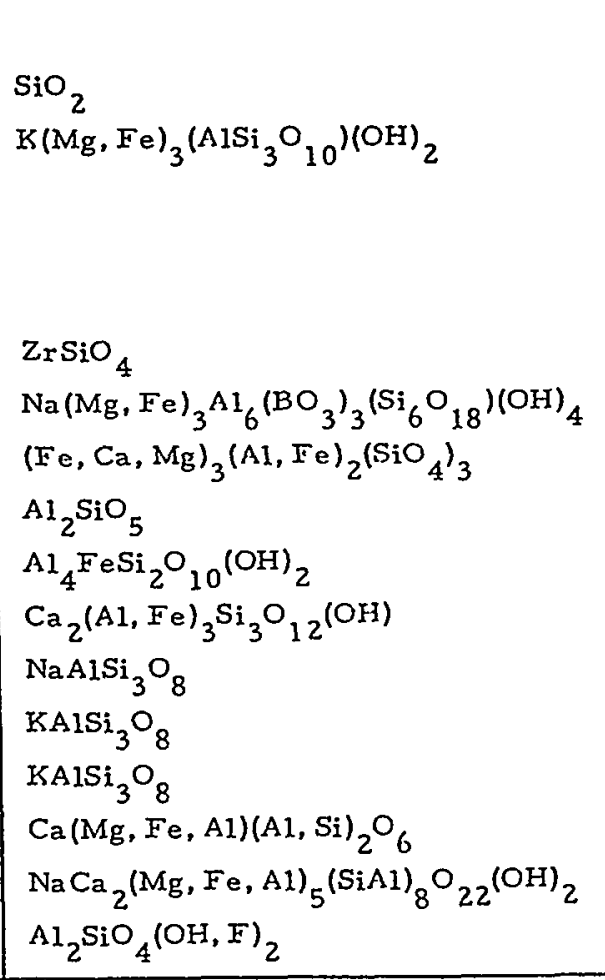 & $\begin{array}{l}\text { Major silicates occur with clay } \\
\text { minerals. Biotite is the prin- } \\
\text { cipal compound of potassium. } \\
\text { Quartz is present as sediment } \\
\text { in round to angular grains of } \\
\sim 1 \text { mm to }<1 \mu m \text {. Impregna- } \\
\text { tion of joints occurs in brown } \\
\text { coal. } \\
7\end{array}$ \\
\hline $\begin{array}{l}\text { Oxide and hydroxide mine } \\
\text { Hematite } \\
\text { Magnetite } \\
\text { Rutile } \\
\text { Limonite } \\
\text { Goethite } \\
\text { Lepidocrocite } \\
\text { Diaspore }\end{array}$ & $\begin{array}{l}\mathrm{Fe}_{2} \mathrm{O}_{3} \\
\mathrm{Fe}_{3} \mathrm{O}_{4} \\
\mathrm{TiO}_{2} \\
\mathrm{FeO}^{\mathrm{OH}} \quad \mathrm{nH}_{2} \mathrm{O} \\
\mathrm{EeO} \mathrm{OH} \\
\mathrm{FeO} \mathrm{OH} \\
\mathrm{AlO} \mathrm{OH}\end{array}$ & $\begin{array}{l}\text { These minerals are } \\
\text { products of weathering. }\end{array}$ \\
\hline $\begin{array}{l}\text { Phosphate mineral } \\
\text { Apatite (fluorapatite) } \\
\text { Combined with or } \\
\text { adsorbed on organic } \\
\text { matter } \\
\text { Calcium } \\
\text { Magnesium } \\
\text { Sodium } \\
\text { Sulphur } \\
\text { Vanadium } \\
\text { Nickel } \\
\text { + numerous other } \\
\text { "trace" elements }\end{array}$ & $\begin{array}{l}\mathrm{Ca}_{5}\left(\mathrm{PO}_{4}\right)_{3}(\mathrm{~F}, \mathrm{Cl}, \mathrm{OH}) \\
\mathrm{Ca} \\
\mathrm{Mg} \\
\mathrm{Na} \\
\mathrm{S} \\
\mathrm{V} \\
\mathrm{Ni}\end{array}$ & $\begin{array}{l}\text { Some of these elements are } \\
\text { particularly associated with } \\
\text { specific coal minerals. }\end{array}$ \\
\hline
\end{tabular}




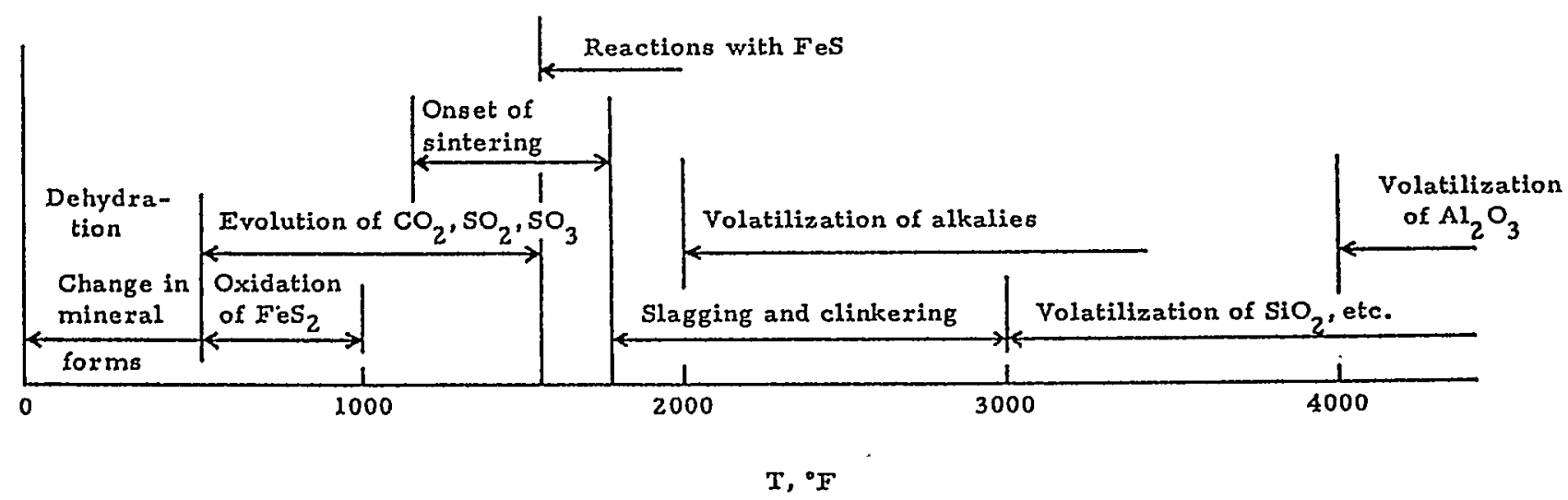

Fig. 12.4-1. Temperature ranges over which ash undergoes various chemical and physical transformations. 115

Important among these are the progress of gasification reactions in porous char particles, fluid and particles dynamics, interactions of turbulence and chemical reactions, and the spatial dispersion of reacting particles in hot gas flows.

For the evaluation of computer codes, laboratory and pilot plant experiments are necessary, in which the effects of fluid dynamics, heat transfer and chemical kinetics on the progress of carbon conversion in the reactor may be studied independently. This approach requires special experimental facilities and measurements at levels of sophistication and detail that are not practicable in full-size plants. Such rigorous testing of models proved to be most useful for the introduction of computer codes of radiative heat-flux distribution into utility-boiler design-practice in the 1970 s. 124

\subsection{Research Recommendations}

We now present brief comments on the research recommendations for the gasification problem areas listed in Table 12.1-1 that have been discussed in this chapter.

\section{6-1. Coal Characterization}

While there are a number of standard characterization procedures for coal, they often do not provide information appropriate for advanced 
processes. Methods are needed to provide organic structure, viscosity and reactivity parameters from which coal behavior in gasification can be accurately predicted.

Work is required to define mineral-characterization procedures and methodology to relate the test results to ash behavior under gasifier operating conditions.

\section{6-2. Fundamental Processes in Gasification and Partial Gasification}

The objective is to gasify coals of different rank reliably in the shortest time under the lowest severity conditions and with small amounts of tars or fines exiting from the reactor. For mild gasification, the objective is a high yield of quality products. These processes are controlled by heat transfer, pyrolysis rates, devolatilization, char gasification, and secondary reactions of condensables and gases.

\section{6-2A. Heat Transfer}

There is a lack of data on the fundamental parameters involved in heat transfer (heat capacity, emissivity, heats of reaction, effects of volatile evolution on convective heat transfer, coal thermal conductivity, etc.). While some data have been obtained and models have been developed for determination of heat capacity and emissivity, experiments should be performed to determine these properties for a variety of coals and conditions. Work relating to heats of reaction and parameters affecting convective heat transfer needs to be initiated. Heat-transfer calculations employing measured parameters should be validated under gasification conditions by employing well-instrumented laboratory-scale experiments which allow coal-particle temperature measurements.

\section{6-2B. Pyrolysis Rates}

Accurate determinations of the important chemical kinetic rate(s) in pyrolysis must be performed in experiments where coal-particle temperatures are directiy measured or can be accurately determined. At heating rates above $10,000^{\circ} \mathrm{C} / \mathrm{sec}$, attention must be given to temperature gradients within the particle. Experiments should be compared by using an 
agreed-upon standard model. This model may include one or more rate expressions, which are independent of heating rate or experimental geometry. The use of a small set of standard coal samples by several investigators should be encouraged.

12.6-2C. Devolatization, Formation of Gases, Condensables and Char

Work should proceed towards finding an acceptable standard model to describe the devolatilization process. Experimental and theoretical work is particularly needed on sulfur evolution, on tar formation and char viscosity (including depolymerization, mass transport, and crosslinking processes), and on the formation of char (swelling, pore structure and reactivity).

\section{6-2D. Gasification of Char}

There is a need to develop a better understanding of the chemical factors (i.e., functional group composition, minerals) which influence intrinsic reactivity and how the observed reactivity is affected by physical factors (pore structure). For catalytic gasification, the dispersion of catalyst in the char is an important issue, along with interactions of added catalysts with minerals already present in the char. The elutriation of highly unreactive carbon in the form of fines from gasifiers is a problem, the solution of which would benefit from a-more fundamental understanding of gasification reactions.

Studies should include work on model chars made from pure compounds. Better measurements of surface area, active area, pore size, pore-size distribution, and density must be developed. The application of analytical techniques used in surface science and catalysis research would be beneficial, along with development of better mathematical representations of pore structures. Of importance is the extension of measurements of the fundamental phenomena to higher temperature ranges, which requires in situ measurements of particles by using probes for the purpose of surface characterization. 


\section{6-2E. Secondary Reaction of Condensables}

There is a need for kinetic data and models for product evolution from the gas-phase cracking of tars for a wide range of coals. There is also need for information on the kinetics of soot formation from tar. Information is required on mechanisms and kinetics of secondary repolymerization reactions of tars, which occur on surfaces inside and outside of the parent coal particle. This work is important in understanding the yields and quality of co-products generated in mild gasification.

\section{6-2F. Mineral-Matter Transformation}

A quantitative understanding is needed of residual ash-particle formation. Theoretical developments, such as the recent application of percolation theory to the problem of char fragmentation, may be useful. Detailed characterizations of mineral distribution in coal and char at progressive stages of gasification are necessary for the development of a predictive model of mineral-matter transformation. Wel1-characterized coals and synthetic coal or char-like materials are essential in the critical evaluation of fundamental models of ash dynamics. Methods for the measurement of particle properties in the hot gasification environment require further work. The development of techniques to measure physical properties, such as viscosity and degree of sintering, at gasifier temperatures is important since the cooling which occurs on sampling may seriously alter these properties. Measurement methods for vapor-species concentrations are needed, as are also methods for correcting measurements of ash-chemical compositions during the condensation of vapor-phase compounds occurring in the sampling process. Particle temperature-time history measurements in practical gasifiers are needed as inputs to the ash-evolution model-development efforts.

\section{6-3. Mathematical Modeling of Gasification Processes}

We refer to Refs. 122 and 123 for elaboration of coal-combustion models relating to direct coal use. The requirements for gasification modeling are generally similar. We recommend studies on fixed-bed models 
because of their importance in gasification and partial gasification. Support should also be provided for well-instrumented and flexible laboratory-scale experiments, which can be employed to validate selected aspects of the comprehensive codes. 59,124

\section{References}

1. Annual Book of ASTM Standards, Sec. 5, Vo1. 05.05, "Gaseous Fuels; Coal and Coke," ASTM, Philadephia, PA (1985).

2. A. Badzoich and P. G. W. Hawksley, Ind. Eng. Chem. Proc. Res. Dev. 9, 521 (1970).

3. J.M. Poh1, H. Kobayashi, and A.F. Sarofim, "The Effects of Temperature and Time on the Swelling of Pulverized Coal Particles," M.I.T. Industrial Liaison Program, Symp. Paper, Cambridge, MA (Oct. 2, 1979).

4. P.R. Solomon and D. G. Hamblen, in Chemistry of Coal Conversion, p. 121, R. H. Schlosberg ed., Plenum Press, NY (1985).

5. ASME Research Committee on Corrosion and Deposits from Combustion Gases, "Recommendation for Research Leading to New Bench-Scale Experiments for the Prediction of Slagging and Fouling Behavior" (1986).

6. R.C. Neave1, S.E. Smith, E.J. Hippo, and R.N. Miller, Fuel $\underline{65}, 312$ (1986).

7. Coal and Coal Products: Analytical Characterization Techniques, ACS Symp. Series No. 205, ACS, Washington, D.C. (1982).

8. Symposium on Physical Methods for Fossil Fuels Characterization, ACS Div. of Fuel Chem. Preprints 30 (1), 1-220 (1985).*

9. Symposium on New Applications of Analytical Techniques of Fossil Fuels, ACS Div. of Fuel Chem. Preprints 31, (1), 1-272 (1986).

10. G.R. Gavalas, Coal Science and Technology 4: Coal Pyrolysis, Elsevier Scientific Publ. Co., NY (1982).

* When multiple references appear to (symposium) volumes, these are not repeated. Instead, they are identified in this reference 1 ist by simply referring to the reference number that is used with the first-named entry referring to the (symposium) volume. 
11. R.M. Davidson, "Nuclear Magnetic Resonance Studies of Coal," IEA Coal Research, Report No. ICTIS/TR32, London (Jan. 1986).

12. M. A. Wilson, R.J. Pugmire, J. Karas, L.B. Alemany, W.R. Woolfenden, D.M. Grant, and P.H. Given, Ana1. Chem. 56, 993 (1984).

13. K.W. Zilm and G.G. Webb, P. 200 in Ref. 9.

14. P.C. Painter, R.W. Snyder, M. Starsinic, M.M. Coleman, D.W. Keuhn, and A. Davis, App 1. Spectros, 35, 475 (1981).

15. M. Sobkowiak, E. Riesser, R. Given, and P. Painter, Fuel 63, 1245 (1984).

16. B. Riesser, M. Starsinic, E. Squires, A. Davis, and P.C. Painter, Fue1 63, 1253 (1984).

17. D. W. Kueh, R.W. Snyder, A. Davis, and P.C. Painter, Fuel $\underline{61}, 682$ (1982).

18. P.C. Painter, M. Starsinic, E. Squires, and A.A. Davis, Fuel 62, 742 (1983).

19. P.R. Solomon, "Coal Structure," p. 95, ACS Advances in Chemistry Series, No. 192, ACS, Washington, D.C. (1981).

20. P.R. Solomon, D.B. Hamblen, and R.M. Carangelo, "Coal and Coal Products: Analytical Characterization Techniques," p. 77 in Ref. 7.

21. P.R. Solomon and R.M. Carangelo, Fuel 61, 663 (1982).

22. P.R. Solomon, D.G. Hamblen, R.M. Carangelo, J.R. Markham, and M.R. Chaffee, p. 1, in Ref.

23. P.R. Solomon and M.B. Colket, Fuel 57, 748 (1978).

24. P.R. Solomon, D.G. Hamblen, R.M. Carangelo, and J.L. Krause, 19th Symposium (Int1.) on Combustion, pp. 1139-1149 (1982).

25. E.M. Suuberg, W.A. Peters, and J.B. Howard, Thermal Hydrocarbon Chemistry, ACS Advances in Chemistry Series, No. 183, p. 239, ACS, NY (1979).

26. P.R. Solomon, R. H. Hobbs, D.G. Hamblen, W.Y. Chen, A. La Cava, and R.S. Graff, Fuel 60, 342 (1981).

27. R. Jain, Ph.D. Thesis, Calif. Inst. Tech., Pasadena, CA (1979).

28. G.R. Gavalas, P.H. Cheong, and R. Jain, Ind. Eng. Chem. Fund. 20, 113 (1981).

29. G.R. Gavalas, R. Jain, and P.H. Cheong, ibid 20122 (1981).

30. W.S. Fong, Y.F. Khali1, W.A. Peters, and J.B. Howard, pp. 1-115 in Ref. 8.

31. W.S. Fong, Y.F. Khali1, W.A. Peters, and J.B. Howard, Fue $1 \underline{65}, 195$ (1986). 
32. C.J. Chu, R.H. Hauge, and J.L. Margrave, p. 87 in Ref. 9.

33. H.L.C. Meuzelaar, W. Windig, and G.A. Metcalf, p. 200 in Ref. 8.

34. R.M. Carangelo, P.R. Solomon, and D.J. Gerson, p. 152 in Ref. 9.

35. Om. P. Mahajan, R. Yarzab, and P.L. Walker, Jr., Fuel 57, 643 (1978).

36. I.W. Smith, pp. 1045-1065 in Ref. 24.

37. R.H. Essenhigh, Chemistry of Coal Utilization 2nd Supplementary Vol., M.A. Elliot ed., p. 1162, John Wiley \& Sons, NY (1981).

38. N.M. Laurendeau, Progr. Energy Comb. Sci. 4, 221 (1978).

39. K.H. Van Heek and H.J. Muhlen, Fuel 64, 1405, (1985).

40. R.G. Jenkins, S.P. Nandi, and P.L. Walker, Jr., Fuel 52, 288 (1973).

41. L.R. Radovic and P.L. Walker, Jr., Fuel 62, 849 (1983).

42. B.W. Brown, L.D. Smoot, and P.0. Hedman, Fuel 65, 673 (1986).

43. W.F. Wel1s, S.K. Kramer, and L.D. Smoot, 20th Symposium (Int1.) on Combustion, p. 1539 THe Combustion Institute, Pittsburgh, PA (1984).

44. N.Y. Nsakala, R. Patel, and T.C. Lao, "Combustion and Gasification Characteristics of Chars from Four Commercially Significant Coals at Different Rank," Report No. 1654-6, ERPI, Palo A7to, CA (1982).

45. E.M. Suuberg, J.M. Calo, and M. Wojowicz, p. 186 in Ref. 9.

46. J.L. Johnson, ACS Div. of Fuel CHem. Preprints, 20 (4), 85 (1975).

47. P.R. Solomon, M.A. Serio, and S.G. Heninger, ACS Div. of Fuel Chemistry Preprints 31, (3), 200 (1986).

48. E. Raask, Mineral Impurities in Coal Combustion: Behavior, Problems, and Remedial Measures, Hemisphere Publ. Corp., Washington, DC (1985).

49. K.S. Vorres, Mineral Matter and Ash in Coal, ACS Symposium Series No. 301, ACS, Washington, DC (1986).

50. F.E. Huggins, G.P. Huffman, and R.J. Lee, pp. 239-258 in Ref. 7.

51. W.E. Straszheim and R. Markuszewski, p. 47 in Ref. 8.

52. D.G. Hamblen, P.R. Solomon, and P.E. Best, "Analysis of Mineral Constituents, Sulfur Forms, and Beneficiation Potential of Coal Using Electron Beam Microanalysis," presented at the Joint ASME/IEEE Power Generation Conference, Milwaukee, WI (Oct. 20-24, 1985).

53. A.L. Lee, ACS Div. Fuel Chem. Preprints 12 (3), 19 (1979).

54. D. Merrick, Fuel 62540 (1983).

55. P.R. Solomon, R.M. Carangelo, P.E. Best, J.R. Markham, and D.G. Hamblen, "Analysis of Particle Combustion, Size, and Temperature by FT-IR Emission/Transmission Spectroscopy," p. 141 in Ref. 9. 
56. P.R. Solomon, R.M. Carange10, P.E. Best, J.R. Markham, and D.G. Hamblen, "The Spectral Emittance of Pulverized Coal and Char," presented at the 21st Symposium (Int1.) on Combustion, Munich, FFG (1986).

57. P.E. Best, R.M. Carangelo, J.R. Markham, and P.R. Solomon, Combustion and Flame 66, 47 (1986).

58. P.J. Foster and C.R. Howarth, Carbon 6, 719 (1968).

59. P.R. Solomon and M.A. Serio, "Evaluation of Coal Pyrolysis Kinetics," presented at NATO Workshop on Fundamentals of Physical-Chemistry of Puiverized Combustion, Les Arcs, France (July 28-Aug. 1, 1986).

60. P.R. Solomon, M.A. Serio, D.B. Hamblen, P.E. Best, K.R. Squire, R.M. Carangelo, and J.R. Markham, "Coal Gasification Reactions with on-Line FT-IR Analysis," Final Report DoE METC Contract No. DE-AC21-81FE05122, Advanced Fuel Research, East Hartford, CT (1986).

61. M.A. Serio, D.B. Hamblen, J.R. Markham, and P.R. Solomon, Energy and Fuels (in press 1987); see also M.A. Serio, P.R. Solomon, D.B. Hamblen, J.R. Markham, and R.M. Carangelo, "Coal Pyrolysis Kinetics and Heat Transfer in Three Reactros," Poster Session, 21st Symposium on Combustion, Munich, FRG (1986).

62. D.B. Anthony, J.B. Howard, H.C. Hottel, and H.P. Meissner, 15th Symposium (Int1.) on Combustion, p. 1303, The Combustion Institute, Pittsburgh, PA (1975); see also D.B. Anthony, Sc. D Thesis, M.I.T., Dept. of Chemical Engineering, Cambridge, MA (1974).

63. H. Kobayashi, J.B. Howard, and A.F. Sarofim, 16th Symposium (Int1). on Combustion, p. 1445, The Combustion Institute, Pittsburgh, PA (1984).

64. S. Niksa, L.E. Heyd, W.B. Russe1, and D.A. Saville, 20th Symposium (Int1.) on Combustion, p. 1445, The Combustion Institute, Pittsburgh, PA (1984).

65. P.R. Solomon and M.B. Colket, 17th Sumposium (Intl.) on Combustion, p. 131, The Combustion Institute, Pittsburgh, PA (1978).

66. E.M. Suuberg, W.A. Peters, and J.B. Howard, p. 117 in Ref. 65.

67. P.R. Solomon and D.G. Hamblen, EPRI Final Report for Project RP 1654-8, EPRI, Palo Alto, CA (1983).

68. P.R. Solomon and D.G. Hamblen, Progr. Energy Comb. Sci. 9, 323 (1984).

69. P.R. Solomon, M.A. Serio, R.M. Carangelo, and J.R. Markham, Fuel 65 , 182 (1986). 
70. P.R. Solomon, M..A Serio, R.M. Carangelo, and J.R. Markham, pp. 1-266 in Ref. 8.

71. J.D. Freihaut, Ph.D. Thesis, Penn. State Univ., College Park, PA (1980).

72. D.J. Maloney and R.G. Jenkins, p. 1435 in Ref. 64.

73. F.C. Lockwood, S.M.A. Rizvi, G.K. Lee, and H. Whatey, p. 513 in Ref. 64.

74. J.S. Truelove, p. 523 in Ref. 64.

75. M. Jost, I. Leslie, and C. Kruger, p. 1531 in Ref. 64.

76. A.B. Witte and N. Gat, "Effect of Rapid Heating on Coal Nitrogen and Sulfur Release," presented at the DoE Direct Utilization AR \& TD Contractors' Meeting, Pittsburgh, PA (1983).

77. P.R. Solomon and H.H. King, Fuel 63, 1302 (1984).

78. K.R. Squire, P.R. Solomon, R.M. Carange1o, and M.B. DiTaranto, Fuel $\underline{65}$, 833 (1986).

79. S.E. Stein, New Approaches in Coal Chemistry, pp. 97-129, B.D. Blaustein, B.C. Bockrath, and S. Friedman eds., ACS Symposium Series No. 169, ACS, Washington, DC (1981).

80. P.R. Solomon, p. 61, in Ref. 79.

81. D.B. Anthony and J.B. Howard AIChE J. 22, 625 (1976).

82. J.B. Howard, W.A. Peters, and M.A. Serio, "Coal Devolatilization Information for Reactor Modeling," Final Report AP-1803 for EPRI Project No. 986-5, EPRI, Palo Alto, CA (1981).

83. J.B. Howard, Chapter 12 in Ref. 37.

84. A.T. Talwaker, "Topical Report on Coal Pyrolysis," DoE Contract No. DOE/MC/19316-1408(DE83006592), (1983).

85. H. Juntgen and K.H. van Heek, Fuel Proc. Tech. 2, 261 (1979).

86. P.E. Unger and E.M. Suuberg, 18th Symposium (Intl.) on Combustion, p. 1203, The Combustion Institute, Pittsburgh, PA (1981).

87. P.E. Unger and E.M. Suuberg, Fuel 63, 606 (1984).

88. P.R. Solomon and H.H.King, Fuel 63, 1302 (1984).

89. P.R. Solomon and K.R. Squire, ACS Division of Fuel Chemistry Preprints 30 (4), 347 (1985).

90. S. Niksa, A.R. Kerstein, and T.H. Fletcher, p. 237 in Ref. 9.

91. S. Niksa and A.R. Kernstein, Combustion and Flame (in press, 1986).

92. W.S. Fong,W.A. Peters, and J.B. Howard, Fuel 65, 251 (1986). 
93. E.M. Suuberg, W.A. Peters, and J.B. Howard, Ind. Eng. Chem. Proc. Design Dev. 17, 34 (1978); see also E.M. Suuberg Ph.D. Thesis, M.I.T., Cambridge, MA (1977).

94. P.R. Solomon and D.B. Hamblen, Progr. Energy Comb. Sci. 9, 323 (1983).

95. J.D. Freihaut and D.J. Seery, ACS Div. of Fuel Chem. Preprints $\underline{2} 8$ (4), 265 (1983).

96. A. Attar and G.G. Hendrickson, in Coal Structure, pp. 131-198, R.L. Meyers ed., Academic Press, NY (1982).

97. E.M. Suuberg, Chemistry of Coal Conversion, Chapter 4, p. 67, R.H. Schlosberg ed., Plenum Press, NY (1982).

98. E.M. Suuberg, J. Larsen, and A.L. Lee, Fuel 64, 1668 (1985).

99. G.A. Simons, Combustion and Flame $\underline{53}, 83$ (1983).

100. G.A. Simons, Combustion and Flame 55, 181 (1984).

101. G.A. Simons, "The Influence of Fluid Transport During Pyrolysis," Proceedings of the International Conference on Coal Science, p. 479, Pittsburgh, PA (1983).

102. G.A. Simons, Progr. Energy and Comb. Sci. 9, 269 (1983).

103. P.R. Melia and C.T. Bowman, paper presented at the Western States Section Conference Combustion Institute, Spring Meeting, University of Utah, Salt Lake City, UT (1982).

104. M. Oh, W.A. Peters, and J.B. Howard, "Modeling Mass Transport and Plasticity in Bituminous Coal Pyrolysis," p. 483 in Ref. 101.

105. J.R. Ashu, N.Y. Nsakala, O.P. Mahajan, and P.L. Walker, Jr., Fuel $\underline{57}$, 251 (1978).

106. R.H. Essenhigh and H. Farzan, p. 1105 in Ref. 24.

107. M.A. Serio, Ph.D. Thesis, M.I.T. Cambridge, MA (1984).

108. M.A. Serio, W.A. Peters, K. Sawada, and J.B. Howard, "Secondary Reactions of Nascent Coal Pyrolysis Tars," p. 533 in Ref. 101.

109. M.A. Serio, W.A. Peters, K. Sawada, and J.B. Howard, ACS Div. of Fuel Chem. Preprints 29 (2), 65 (1984).

110. K.R. Doolan, J.C. Mackie, and R.J. Tyler, Proceedings of the International Conference on Coal Science, p. 961, Sydney, N.S.W., Australia (1985).

111. M.R. Kahn, "Characterization of Mechanisms of Mild Gasification Processes and Catalytic Fuel Gas Conversion Low-Temperature Devolatization Studies," Fifth Annual Gasification Projects Contractors' Meeting, METC, Morgantown, WV (1985). 
112. R.D. Nenninger, J.B. Howard, and A.F. Sarofim, p. 521 in Ref. 101.

113. H.J. Gluskoter, Ash Deposits and Corrosion due to Impurities in Combustion Gases, Hemisphere Publishing Co., Washington, DC (1977).

114. P.J. Jackson, Pulverized Coal Firing Workshop, L9 and L10, The University of Newcastle, NSW, Australia (1974).

115. W.T. Reid, External Corrosion and Deposits, J.M. Beer ed., Elsevier, NY (1971).

116. P.J. Jackson, "Combustion of Pulverized Coal. The Effect of Mineral Matter," Workshop, Dept. Chem. Eng., Univ. New Castle, NSW, Australia (1979).

117. H.J. Gluskoter, Fuel 44, 285 (1965).

118. A.R. Ramsden, Fuel 48, 121 (1969).

119. E. Raask, ASME Trans. Eng. Pwr. 88, 40 (1966).

120. E.L. Mitchell and G.K. Lee, Trans. Con. Inst. Min. Met. $\underline{65}, 360$ (1962).

121. P. Lightman and P.J. Street, Fuel 47, 7 (1968).

122. L.D. Smoot, Progr. Energy Comb. Sci. 10, 229 (1984).

123. S.S. Penner et al., Ref. 1 in Sec. 2.1.

124. T.R. Johnson, T.M. Lowes, and J.M. Beer, J.Inst. Fuel 47, 39 (1974). 
APPENDIX: EFFECT OF CaO COMBINED FLUIDIZED-BED GASIFICATION AND PYROLYSIS*

If coal is pyrolyzed to produce gas and liquid products prior to combustion and gasification, higher thermal efficiency and decreased cost can be achieved as compared to gasification of the whole fresh coal. This observation applies when pyrolysis gas and liquids are of equal or higher value than heat or gas from whole coal. Figure 12A-1 illustrates a fluidized bed process with heat supplied by combustion. Medium heating value gas is produced by steam gasification of char and the coal is pyrolyzed in a third reactor, where heat is supplied by hot solids from the combusion reactor. In such a system, it is advantageous to use limestone to capture sulfur in all three reactors and to improve the heating value of gas produced by $\mathrm{CO}_{2}$ capture and also the tar properties. The following are reactions involving $\mathrm{CaO}: \mathrm{CaO}+$ multi-ring aromatics $\longrightarrow$ char + gas to reduce tar molecular weight, improve compatibility, reduce mutagenicity; $\mathrm{CaO}+$ phenols $\longrightarrow$ char + gas to reduce owygen content and toxicity; $\mathrm{CaO}+\mathrm{H}_{2} \mathrm{~S} \longrightarrow \mathrm{CaS}+\mathrm{H}_{2} \mathrm{O}$ to produce low-sulfur gas; $\mathrm{CaO}+\mathrm{CO}_{2}$ $\mathrm{CaCO}_{3}$ to increase the gas-heating value and hydrogen content; $\mathrm{CaO}+\mathrm{SO}_{2}+\left(\frac{1}{2}\right) \mathrm{O}_{2} \longrightarrow \mathrm{CaSO}_{4}$ to form non-polluting flue gas. The sulfur compound and $\mathrm{CO}_{2}$ reactions have been studied in a number of applications; however, selective reactions with multi-ring aromatics have been discovered relatively recently and their potential for improvement of tar properties and reduction of the amount of tar has received only limited laboratory study. Table 12A-1 shows results of studies on pyrolysis of pure HCs over $\mathrm{CaO}_{\mathrm{O}}$ compared with pyrolysis over an inert material (quartz). For the aromatic compounds, the temperature for a given conversion to char and gas is reduced, while there is relatively little change in heptane conversion. This selectivity for multi-ring aromatic removal is also observed for pyrolysis of coal tar, as is shown by the data in Table $12 \mathrm{~A}-2$.

* Prepared by J.P. Longwe11, Department of Chemical Engineering, Massachusetts Institute of Technology, Cambridge, MA 02139. 


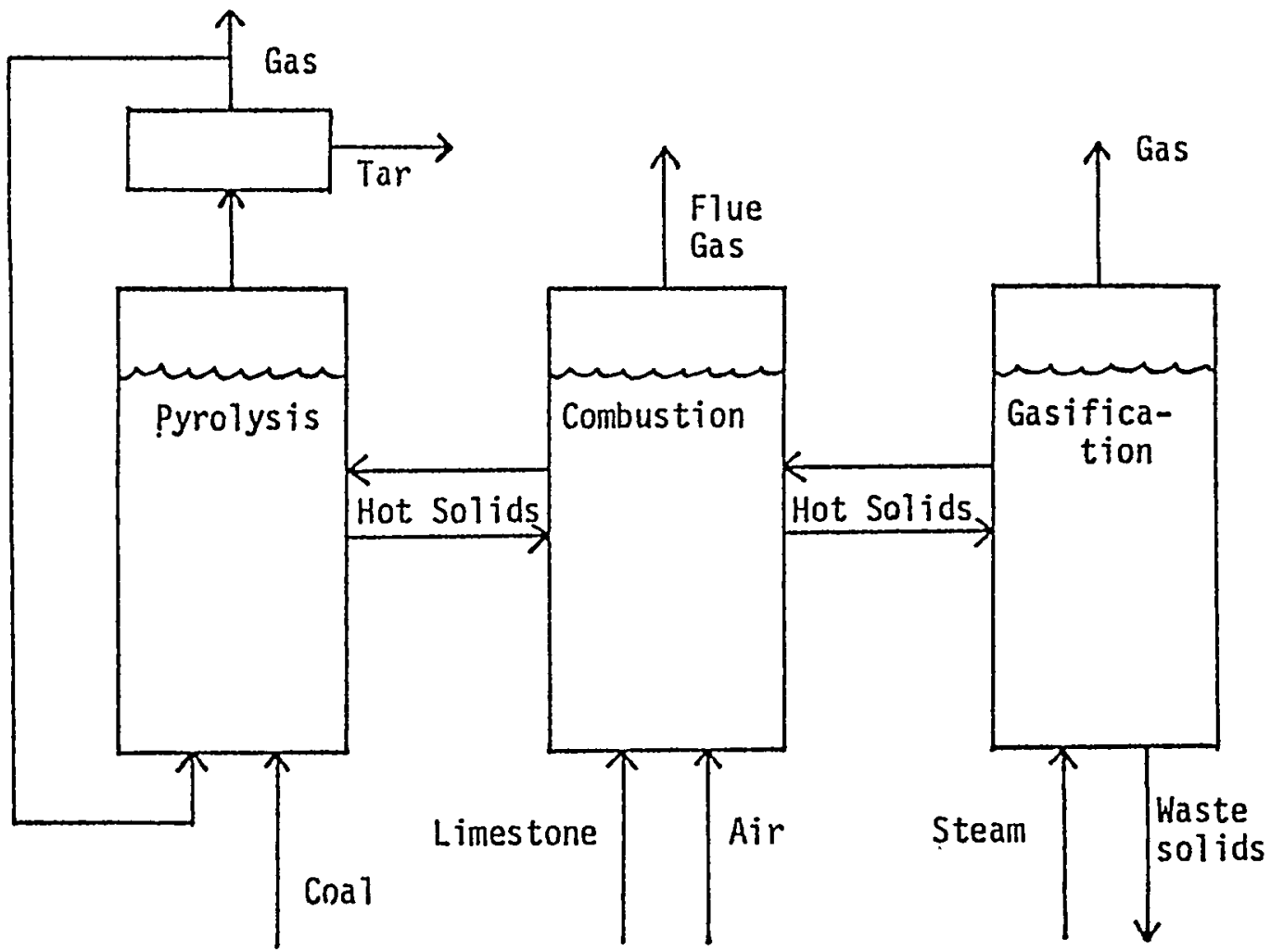

Fig. 12A-1. Schematic of a coal-gasification process following pyrolysis and combustion to obtain higher thermal efficiencies. 
Table 12A-1. Results on pyrolysis of aromatic compounds over $\mathrm{CaO}$ and quartz.

\begin{tabular}{|c|c|c|c|c|}
\hline \multirow[b]{2}{*}{ Compound } & \multicolumn{2}{|c|}{$\begin{array}{l}408 \text { conversion } \\
\text { temperature, }{ }^{\circ} \mathrm{C}\end{array}$} & \multicolumn{2}{|c|}{$\begin{array}{l}\text { Activation energy, } \\
\mathrm{kcal} / \mathrm{mole}\end{array}$} \\
\hline & $\mathrm{CaO}$ & Quartz & $\mathrm{CaO}$ & Quartz \\
\hline $\begin{array}{l}\text { Toluene } \\
\text { 1-Methylnaphthalene } \\
\text { l-Methylanthracene } \\
\text { n-Heptane }\end{array}$ & $\begin{array}{l}710 \\
600 \\
490 \\
600\end{array}$ & $\begin{array}{l}850 \\
775 \\
730 \\
640\end{array}$ & $\begin{array}{l}46.2 \\
25.4 \\
12.0 \\
40.6\end{array}$ & $\begin{array}{l}79.5 \\
43.4 \\
46.0 \\
48.7\end{array}$ \\
\hline
\end{tabular}

Table 12A-2. Effect of $\mathrm{CaO}$ on tar conversion.

\begin{tabular}{lccc}
\hline \multicolumn{1}{c}{ Parameter } & \multicolumn{2}{c}{ Tar Properties } & \\
\cline { 2 - 3 } & $\begin{array}{c}\text { Untreated } \\
\text { tar }\end{array}$ & $\begin{array}{c}\text { Thermal } \\
\text { conversion }\end{array}$ & $\begin{array}{c}\text { CaO } \\
\text { conversion }\end{array}$ \\
\hline Temperature, ${ }^{\circ} \mathrm{C}$ & -- & 800 & 550 \\
Tar yield, \& & 100 & 60 & 60 \\
Fraction of aromatic C & 0.67 & 0.78 & 0.67 \\
Weighted average molecular & & & 530 \\
$\quad$ weight & 600 & 540 & 3.5 \\
Phenolic 0, wto & 5 & 3.0 & 0.9 \\
Relative mutagenicity & 1 & 10 & \\
\hline
\end{tabular}


CHAPTER 13:

GAS SUPPLIES AND SEPARATION: ASH DISPOSAL; MATERIALS FOR GASIFIERS

13.1. Gas Supplies and Separation ${ }^{*}$

13.1-1. Introduction

Future efficient gasification systems are expected to utilize $\mathrm{O}_{2}$-blown gasification rather than air-blown gasification. The advantages of having $\mathrm{O}_{2}$ as the oxidation agent include a cleaner, higher-quality gasifier-product gas, smaller system sizes and less demanding gas clean-up requirements. However, these advantages must be constantly balanced against the cost associated with building and operating an air-separation plant to separate oxygen from air, which may become a significant part of the overal1 plant cost and usually requires large amounts of electricity. Thus, a careful evaluation of dominant parameters imposed on the air-separation plant and their relation to output-gas quality must be performed in order to optimize total system economics. Factors affecting the air-separation plant are $\mathrm{O}_{2}$-purity, $\mathrm{O}_{2}$-pressure, $\mathrm{H}_{2} \mathrm{O}$ and $\mathrm{CO}_{2}$ levels of the input air, turndown percentage, number of trains and, of course, plant size. ${ }^{1}$ The impact of these variables on $0_{2}$-cost is shown in Table 13.1-1. There are several air-separation techniques that are applicable to coal gasifiers. A listing of these is given in Table 13.1-2, along with their present development and availability status. At present, cryogenic separation is the only commercially available technique for the large requirements of coal

* Unless otherwise indicated, information in this section has been abstracted by S.S. Penner and D.F. Wiesenhan from viewgraphs and references supplied to COGARN on July 11, 1986 by A. Smith of Air Products and Chemicals, Inc., P.0. Box 538, Allentown, PA 18105. 
gasifiers. The MOLTOX* system will probably see application of large-scale coal-gasification systems by the mid-1990s. A brief overview of these technologies follows.

\section{1-2. Cryogenic Air Separation}

Cryogenic air separation is the most widely used procedure for large-scale (>100 tons of $\mathrm{O}_{2}$ per day) applications. This procedure has relatively low specific energy consumption and may be readily used to achieve high gas purity while $\mathrm{N}_{2}$ and Ar by-products are easily recovered. Cryogenic air separation is a mature technology but improvements leading to lower costs may be possible. For $0_{2}$-plants producing more than 200 TPD of $0_{2}$, power requirements account for more than $50 \%$ of the oxygen cost. ${ }^{1}$ As the size of the plant is increased, the fraction of oxygen cost attributable to energy consumption also increases (see Fig. 13.1-1). The energy requirements for cryogenic air-separation plants may become a significant fraction of the total energy output of a coal-gasification plant, up to $15 \%$ in some cases. 1

A schematic diagram of a dual-distillation column, low-pressure cryogenic air-separation cycle, as commonly used to provide purities better than 99.5\%, is shown in Fig. 13.1-2. Water and $\mathrm{CO}_{2}$ enter with the air and are removed by using either a reversing heat exchanger (which combines impurity removal with primary heat exchange) or a molecular sieve adsorption system.

A problem endemic to $\mathrm{O}_{2}$-plants located near coal gasifiers is higher than normal ambient $\mathrm{CO}_{2}$ concentrations ( 2000 ppm vs $\sim 350 \mathrm{ppm}$ ). This excess $\mathrm{CO}_{2}$ prevents the use of adsorption clean-up and results in higher equipment and energy costs.

The specific power requirements remain constant for purities $\leq 95 \%$. Typical energy-use rates for delivering $\mathrm{O}_{2}$ at $615 \mathrm{psia}$ are $500 \mathrm{kWh} / \mathrm{ton}$ of $\mathrm{O}_{2}$ for existing plants and $\sim 360 \mathrm{kWh} /$ ton of $\mathrm{O}_{2}$ for newer cryogenic plants. ${ }^{2}$

* MOLTOX is a trademark of Air Products and Chemicals, Inc. 


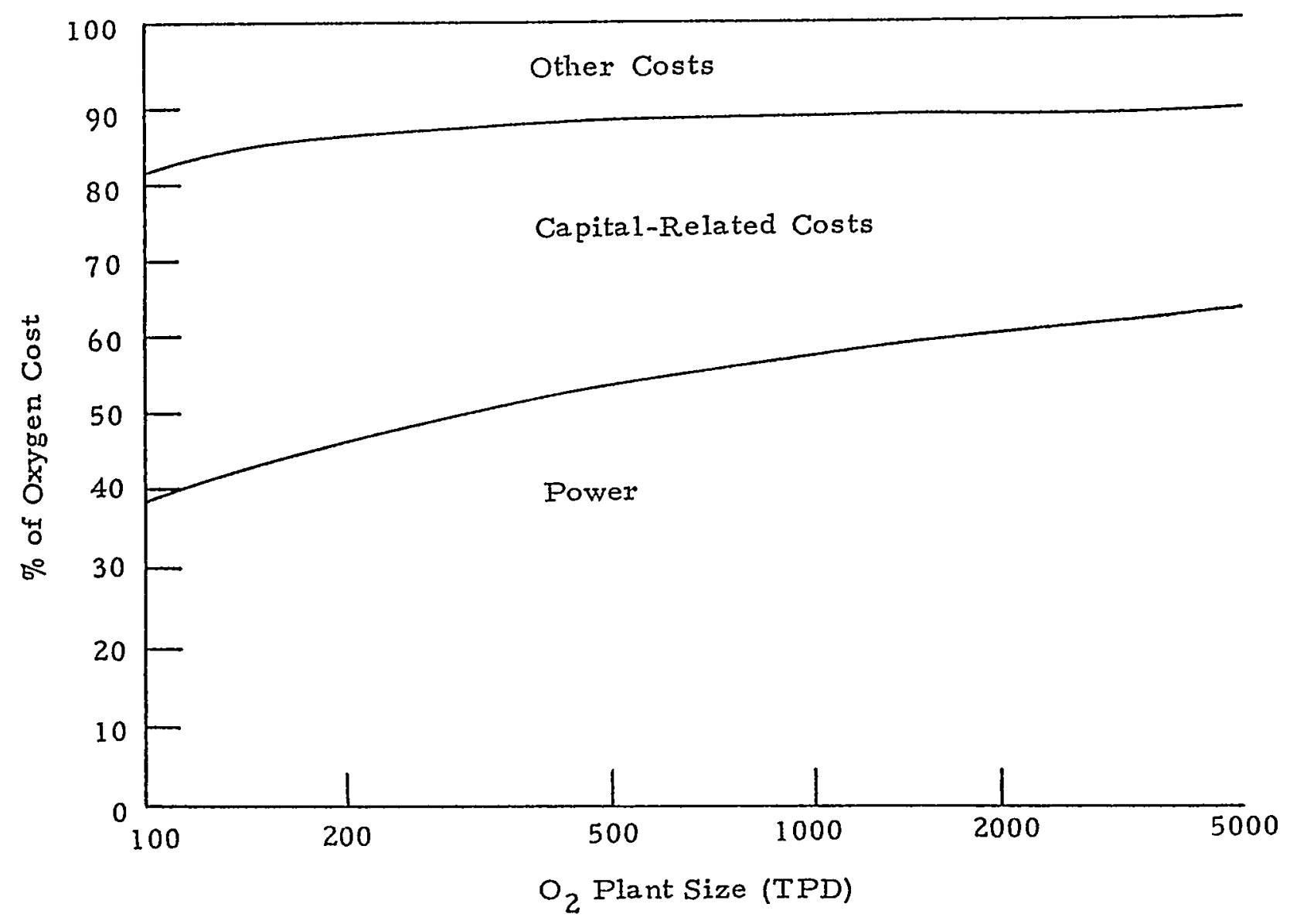

Fig. 13.1-1. Components of the oxygen cost for cryogenic air-separation; reproduced from Ref. 1.

Table 13.1-1. Effects of oxygen plant/gasifier interface variables on oxygen cost; reproduced from data presented by Air Products and Chemicals, Inc.

\begin{tabular}{l|c|c}
\hline Variable & Change in variable & $\mathrm{O}_{2}$-cost impact \\
\hline Purity & 99.5 vs $90 \%$ & $5-15 \%$ \\
Pressure & 1200 vs $100 \mathrm{psig}$ & $15-20 \%$ \\
Plant size & 1000 TPD vs $6000 \mathrm{TPD}$ & $18 \%$ \\
Turndown & $65 \%$ vs $85 \%$ & $3-5 \%$ \\
No. of trains & Single vs 2 to 6 & $3-8 \%$ \\
\hline
\end{tabular}




\section{1-3. The MOLTOX System}

A promising new air-separation method being developed is the MOLTOX system. A MOLTOX plant will use electricity at about half the rate of existing cryogenic plants. ${ }^{2}$ This improvement is accomplished with a molten mixture of alkali nitrates and nitrites which react chemically with $\mathrm{O}_{2}$ in the compressed air. About $99.8 \%$ purity is reached after a reversible reaction in the required heating and/or depressurization step. Heat removal from the waste $\mathrm{N}_{2}$-exhaust recovers a major portion of the energy used to compress or heat the input air. Recent funding by DoE has culminated in the construction of a $0.25 \mathrm{TPD}_{2} \mathrm{O}_{2} \mathrm{plant}$, which has been operating since March 1986.

Two operating modes are possible: pressure-swing absorption (PSA) or thermal-swing absorption (TSA). The former is best suited to integration with pressurized gases of gas-turbine power plants. The TSA mode is applied by using the heat recovery and steam generation section of industrial and utility steam boilers. A combination of these two modes is

Table 13.1-2. Air separation technologies and their development status; reproduced from data presented by Air products and Chemicals, Inc.

\begin{tabular}{|c|c|}
\hline Technology & status \\
\hline Cryogenics & Mature \\
\hline Absorption & Mature \\
\hline Membranes & $\begin{array}{l}\text { Developing (small } \\
\text { units are available) }\end{array}$ \\
\hline Chemical (MOLTOX ${ }^{\mathrm{TM}}$ ) & $\begin{array}{l}\text { Developing (pilot- } \\
\text { plant stage) }\end{array}$ \\
\hline $\begin{array}{l}\text { Others: } \\
\text { solid membrane } \\
\text { electrochemical } \\
\text { bench scale studies }\end{array}$ & $\begin{array}{l}\text { Developing ( } R \& D \\
\text { stage) }\end{array}$ \\
\hline
\end{tabular}




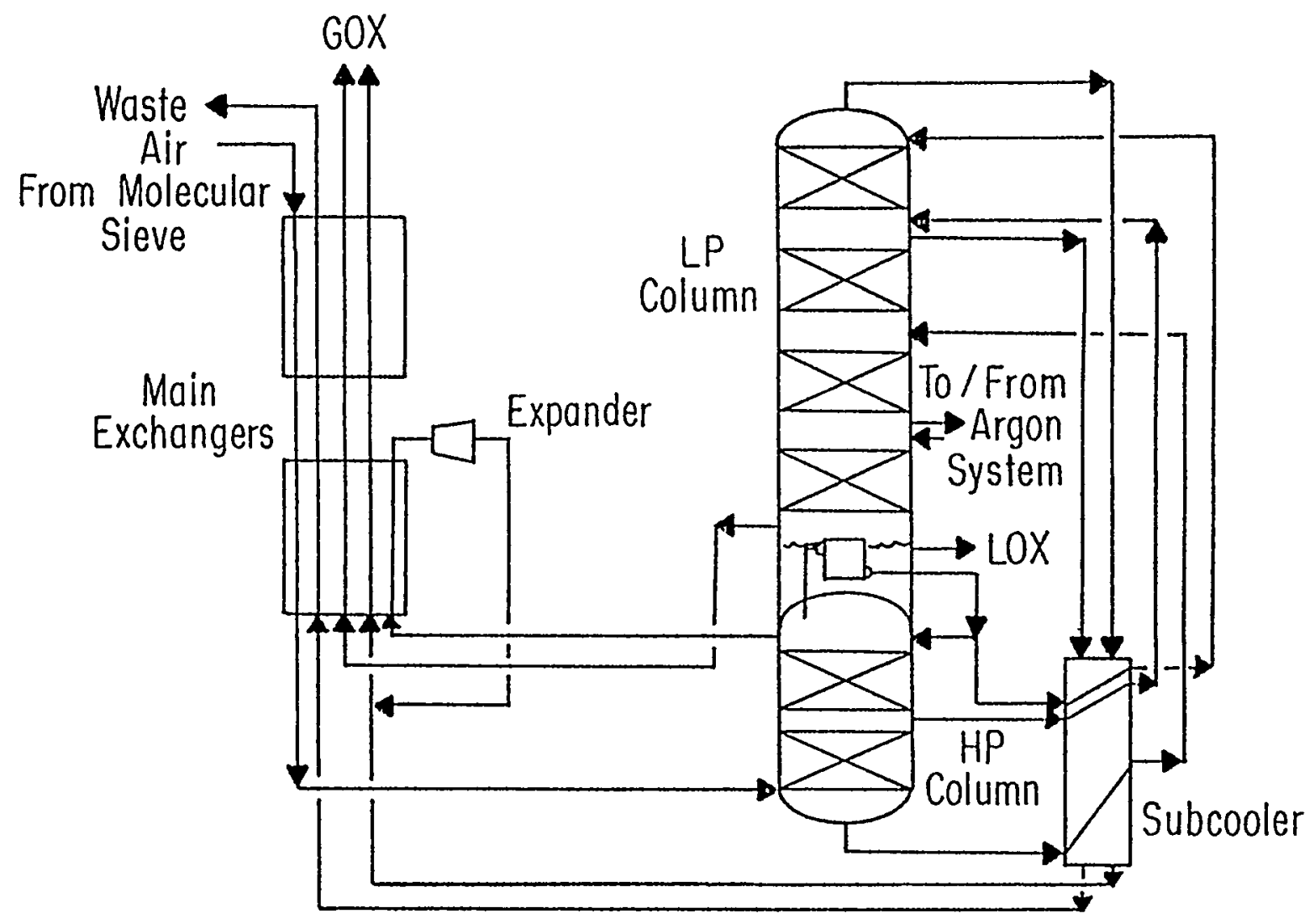

Fig. 13.1-2. Schematic diagram of a dual-distillation column, low-pressure cryogenic air-separation system; reproduced from Ref. 1 .

practical when both heat and pressure head are available for recovery. Schematic diagrams showing PSA and TSA are found in Fig. 13.1-3.

Prior to entering the MOLTOX unit, the air is dried and the $\mathrm{CO}_{2}$ is removed. The inlet temperatures and pressures are either 510 or $650^{\circ} \mathrm{C}$ and 0.41 or $1.2 \mathrm{MPa}$, respectively, depending on the operating mode. In the absorber, the air contacts the molten salt (a mixture based on $\mathrm{Na}$ and $\mathrm{K}$ ) and reacts according to the process $\mathrm{MNO}_{2}^{-}+(1 / 2) \mathrm{O}_{2} \rightarrow \mathrm{MNO}_{3}{ }^{-}$. The oxygen is thus removed with the salt from the bottom of the absorber. The molten salt then flows to the desorber where the reverse reaction $\mathrm{MNO}_{3}{ }^{-} \rightarrow \mathrm{MNO}_{2}{ }^{-}+(1 / 2) \mathrm{O}_{2}$ occurs, thus liberating gaseous oxygen. This last step requires either a pressure reduction (PSA) or a temperature increase (TSA). Nitrogen, inert gases, and unreacted oxygen leave the absorber at essentially the same temperature and pressure at which they entered.

Depending on the amount of heat input available to the MOLTOX unit, energy requirements will be less than for a new cryogenic plant. At 
zero available heat input, energy requirements are $\sim 300 \mathrm{kWh} /$ ton of $\mathrm{O}_{2} .^{2}$ With $8 \times 10^{6}$ Btu/ton of $0_{2}$ available, this value is reduced to slightly more than $200 \mathrm{kWh} /$ ton of $\mathrm{O}_{2}{ }^{2}$ These savings are important, especially since the MOLTOX system has higher capital costs and higher operation and maintenance costs (see Table 13.1-3) than a cryogenic plant.

Compared with cryogenic systems, a $1000 \mathrm{TPD}^{-\mathrm{O}_{2}}$ MOLTOX Plant producing 600 psig of $\mathrm{O}_{2}$ at $99.5 \%$ purity and operating at $100 \%$ capacity for 340 days per year over 15 years is economically advantageous for electricity costs greater than $4 \$ / \mathrm{kWh} .^{2}$ For the projected mid 1990 s electricity price of $7.5 \$ / \mathrm{kWh}$, present MOLTOX units offer a $12 \%$ cost reduction over nely cryogenic systems. These savings are expected to increase to $23 \%$ for future MOLTOX units. ${ }^{2}$ At $7.5 \$ / \mathrm{kWh}$, the MOLTOX Process will yield a lower-bound estimate of $\$ 33 /$ ton of $\mathrm{O}_{2}$.

Approval for construction of a small ( $\left.0.25 \mathrm{TPD}^{-\mathrm{O}_{2}}\right)$ plant was given in January 1985. This plant was built to assess and rectify problems in the following areas: TSA/PSA and TSA-only operational modes; salt losses through vapor or corrosion; salt stability; absorption/desorption kinetics; salt-loop equipment designs and adequacy of construction materials; long-term operability; and gas purities, impurities, and by-products. A simplified experimental system capable of addressing these issues was implemented.

A particular difficulty is the high corrosiveness of the salt. Extensive monitoring equipment was installed and different alloys and ceramic materials have been or will be tested to find optimal materials for salt exposure.

The plant began operation in March 1986. At a production rate of $0.12 \mathrm{TPD}^{-\mathrm{O}_{2}}$, $99.9 \%$ pure $\mathrm{O}_{2}$ was obtained, which was within $92 \%$ of theoretical equilibrium recovery for the operating conditions employed. After four days of good operation, a centrifugal pump constructed out of 316 SS failed. This failure was attributed to corrosion, cavitation, or a combination of these two effects. A redesigned pump was constructed out of new materials and has been incorporated.

Future plans call for a $50 \mathrm{TPD}-\mathrm{O}_{2}$ plant, partly financed by oxygen users or by other oxygen suppliers. Especially sought after is metaliurgical expertise to solve the corrosion problems. Other factors to 
be studied in this plant are the heat-integration systems and plant scaleup. Another aspect to be examined that may lead to lower costs is the reduction of required input $\mathrm{H}_{2} \mathrm{O}$ and $\mathrm{CO}_{2}$ from the present levels of $1 \mathrm{ppm} .^{3}$ Plants capable of producing 500 TPD of $\mathrm{O}_{2}$ are expected to be available in the early 1990s.

(a)

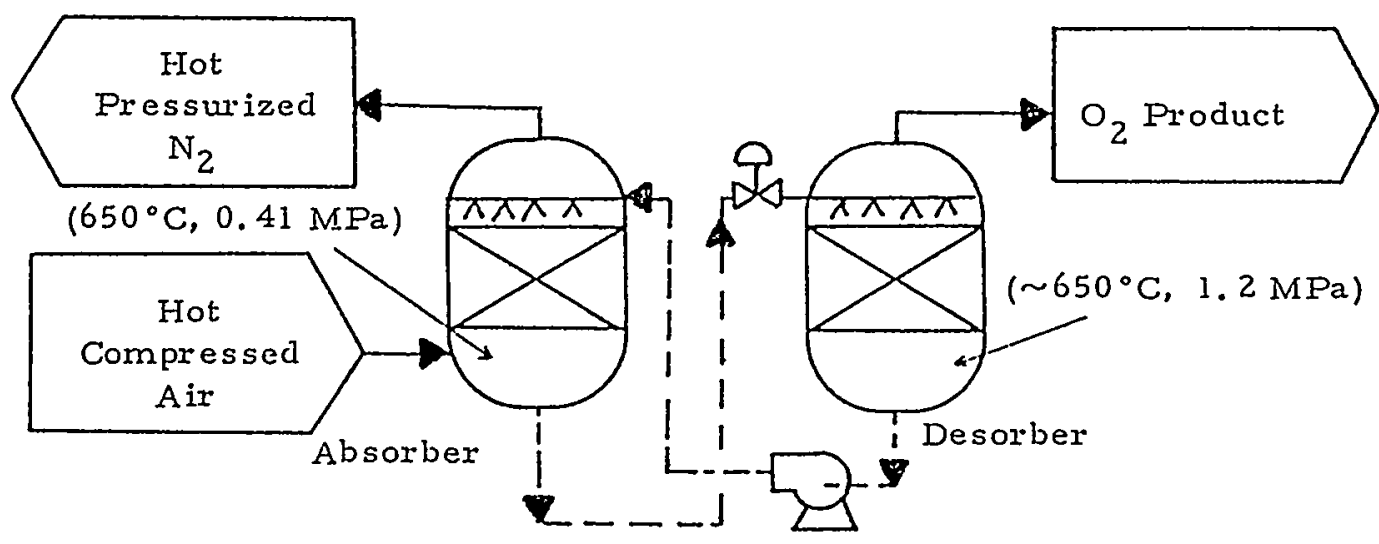

(b)

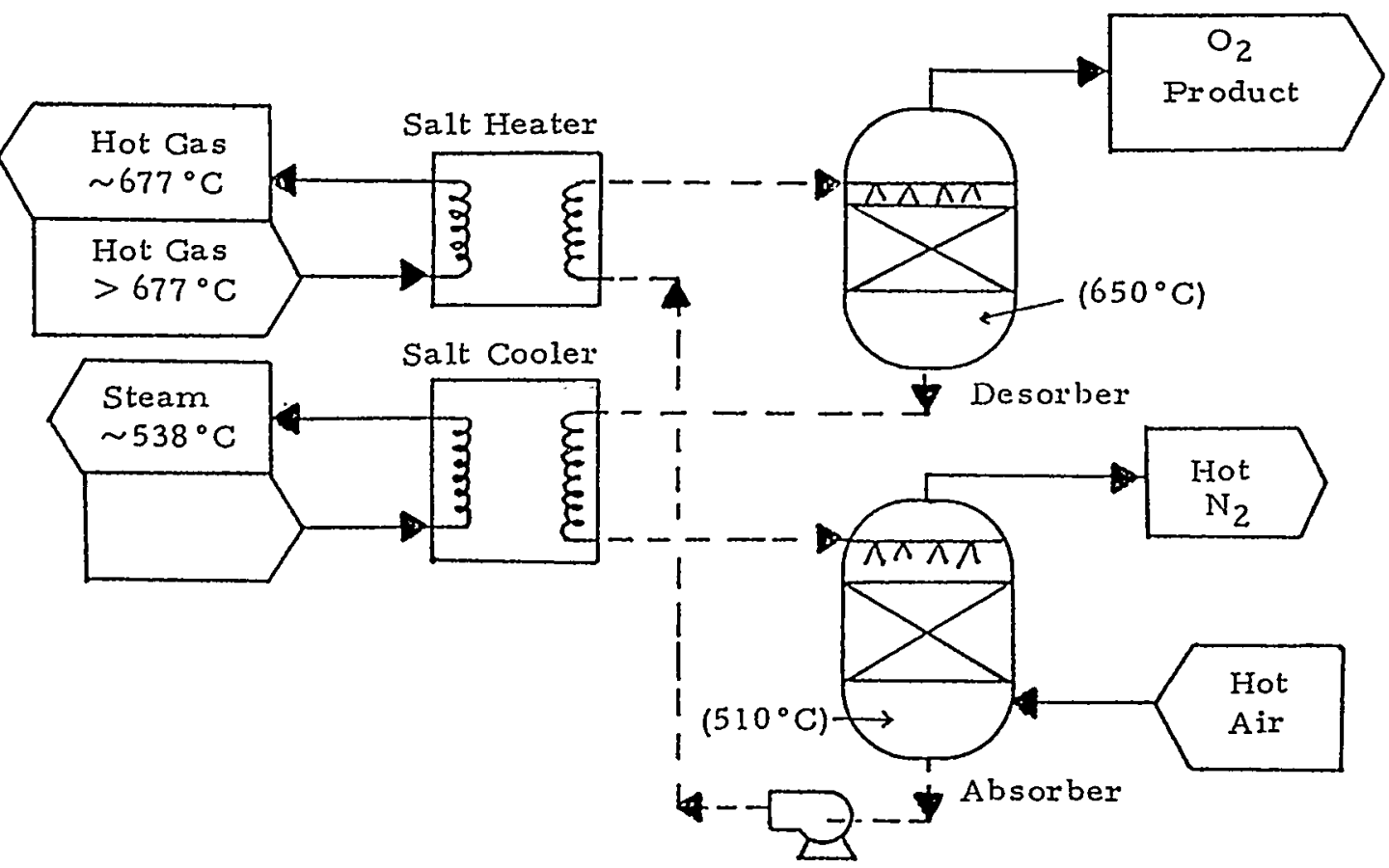

Fig. 13.1-3. The two operating modes of the MOLTOX air-separation system are shown: (a) pressure-swing absorption (PSA), (b) temperature-swing absorption (TSA); reproduced from Ref. 2 . indicates integration with an external process. 
Table 13.1-3. Cost comparison between a new cryogenic plant and a MOLTOX plant, both producing $99.5 \%$-pure $\mathrm{O}_{2}$ at 600 psig, 1000 TPD, and operating for 340 days per year; the cryogenic data refer to the reference task 1 report, May 1985, DoE/CE/40544-TI.

\begin{tabular}{|c|c|c|}
\hline & Cryogenic plant & MOLTOX plant \\
\hline Capital investment & $\$ 18.6 \mathrm{MM}$ & $+10 \%$ to $35 \%$ \\
\hline Cost component & $\begin{array}{l}\text { Oxygen cost } \\
(\$ / T)\end{array}$ & $\begin{array}{l}\text { Cost differential } \\
\text { from cryogenic } \\
\text { plant } \\
(\$ / T)\end{array}$ \\
\hline $\begin{array}{c}\text { Capital related } \\
\text { O \& } M\end{array}$ & $\begin{array}{r}\$ 12.03 \\
4.74\end{array}$ & $\begin{array}{r}+\$ 1.00 \text { to } 4.50 \\
+\quad 1.00 \text { to } 2.50\end{array}$ \\
\hline $\begin{array}{l}\text { Electricity at } \\
7.5 / 10.0 \mathrm{G} / \mathrm{kWh}\end{array}$ & $27.58 / 36.77$ & -12.00 to -16.00 \\
\hline $\begin{array}{l}\% \text { savings for } \\
\text { totaI } \mathrm{O}_{2} \text { cost }\end{array}$ & $44.35 / 53.54$ & -5.00 to -14.00 \\
\hline
\end{tabular}

13.1-4. Other Air-Separation Systems

Systems using membranes, adsorption, or other techniques exist and may be useful as oxygen generators for coal gasifiers. However, many factors prevent their application. Because of their low state of maturity, these techniques are not yet suitable for large-scale applications. They will probably also require more electrical energy per unit product than the two techniques previously discussed.

\section{1-5. Research Needs}

Cryogenic air-separation units are the only $\mathrm{O}_{2}$-supply systems presently available for coal gasifiers. Associated costs for these systems may be reduced by using improved compressor design, improved air pretreatment techniques, or reduction of the sensitivity of the cost to 
$\mathrm{O}_{2}$-quality. Since this is a mature technology, large gains are not likely to be achieved.

Since the primary cost associated with air-separation systems is energy consumption, efficient processes using less electricity are desirable. Gains can be made by optimizing mechanical systems, but significant gains are realized if the waste heat from another process is used as an energy source, as is done in the MOLTOX process. The MOLTOX system will soon become applicable in coal-gasification plants, where sufficient amounts of waste heat are available.

The following problems need to be assessed in the MOLTOX system: (i) Material selection leading to corrosion reduction. (ii) Efficient integration of the heat-transfer systems of the MOLTOX plant with the heat-export systems of the host plant. (iii) Increasing the level of input $\mathrm{CO}_{2}$ that can be effectively handled, especially when the MOLTOX plant is located near a coal gasifier. (iv) General problems involved in scaling up to the large requirements of a coal-gasification plant must be identified and assessed. ( $v$ ) Research leading to increased understanding of the molten salt is necessary, e.g., salt losses, kinetics, and salt-loop equipment design.

When an oxygen plant is integrated with a coal gasifier, it is frequently difficult to optimize the plant and meet changing requirements such as purity, amount, turndown time, etc. Different gasification systems (SNG, IGCC, etc.) wil1 have different demands. Proper optimization routes are not clear at this time and should be pursued.

The study of alternative air-separation techniques should be continued. The most promising new procedure for coal-gasification applications will probably be a process based on membrane technology.

\section{References for Section 13.1}

1. J. Klosek, A. R. Smith and J. Solomon, :The Role of Oxygen in Coal Gasification, unpublished, Air Products and Chemicals, Inc., Allentown, PA (1986).

2. D. C. Erickson, W. R. Brown, B. R. Dunbobbin, and R. G. Massey, "MOLTOX ${ }^{T M}$ Chemical Air Separation System - A Progress Report," unpublished, see Ref. 1 (1986). 
3. Air Products and Chemicals, Inc., "MOLTOX ${ }^{T M}$ Oxygen System Status Report, April 1986," unpublished, see Ref. 1 (1986).

13.2. Utilization and Disposal of Ash From Gasifiers*

A considerable amount of testing has been performed on ash products from coal-gasification processes at pilot- and commercial-size plants. Regulations regarding permissible leachates into water are set by Federal and state standards and allow for the quantities of ions in the water that may be leached from the ash. In all instances, EPA standards have been easily achieved for ash samples from the Texaco, Shell, KRW, Lurgi, and British Gas/Lurgi gasification processes. It should be noted that more severe standards for metal ions in water may be set by state than by Federal regulations. The ash product from the Cool Water, Texaco-based plant was declared to be non-hazardous by the California State Departinent of Health when it was tested according to the severe standards of California. During coal gasification, the ash in the coal is melted in the gasifiers (She11, Texaco, Lurgi, Dow, etc.) The resultant ash product is a glassy, hard solid. This material has been heated to relatively high surface temperatures and is relatively impervious to leaching by ground water percolating through deposits in landfills.

In the US, coal ash from pulverized fuel combustion has established local markets for a number of special applications. Table 13.2-1 shows the amount of ash from pulverized coal plants that is produced. Coal ash from pulverized fuel plants is produced in the form of (i) light, fluffy fly ash that is carried out of the furnace by the combustion gases and ( $i i)$ bottom ash that represents ash that has been melted in the furnace. In the US, markets for low-density fly ash absorbs only about $15 \%$ of the available ash, whereas a larger portion of the denser bottom ash is used commercially for a wide number of applications (Table 13.2-2). Markets for ash from coal are site-specific since the selling price is relatively low $(\$ 2-8 /$ ton $)$. For a 11 uses, shipping costs affect the distance that the ash

* This section has been written by S.B. Alpert. 
can be transported before its use becomes eonomically unattractive. Table 13.2-2 also shows representative markets for US coal ash.

In the US, coal-gasification plants have only recently been operated on a scale at which representative ash is being produced. A major incentive in developing markets for this by-product is to avoid the expense of land-fill disposal at costs of $\$ 5-20 /$ ton, depending on location and other site-specific factors.

Table 13.2-1. Coal ash from conventional us combustion plants in $10^{6} \mathrm{mt} / \mathrm{yr}$ ).

\begin{tabular}{l|c|c|c}
\hline Ash Year & 1979 & 1983 & 1995 (estimated) \\
\hline Fly ash & 52.2 & 52.4 & 82 \\
Bottom ash and boiler slag & 16.1 & 17.9 & 28 \\
\hline Total & 68.3 & 70.3 & 110 \\
\hline
\end{tabular}

Table 13.2-2. Ash utilization in the US during 1983, in $10^{6} \mathrm{mt} / \mathrm{yr}$.

\begin{tabular}{l|c|c|c}
\hline \multicolumn{1}{c|}{ Application } & Fly Ash & Bottom Ash & Slag \\
\hline & 3.5 & 0.4 & 0.3 \\
Cement & 1.4 & 1.1 & 0.2 \\
Structural fill & 0.5 & 0.3 & 0.1 \\
Road base & 0.1 & 0.1 & 0.1 \\
Asphalt mix & 0.1 & 0.4 & 0.2 \\
Snow and ice control &.- &.- & 1.5 \\
Grit, roofing, gravels & 0.2 & 0 & 0 \\
Grouting & 0.2 & 0.1 &.- \\
Coal mining & 1.5 & 0.4 & 0.1 \\
Miscellaneous & & & \\
\hline Total utilized & 7.5 & 2.8 & 2.5 \\
\hline Total disposal & 44.8 & 11.2 & 1.4 \\
\hline Total produced & 52.4 & 14.0 & 3.9 \\
\hline
\end{tabular}


Table 13.2-3. Representative applications for coal-gasification ash.

\begin{tabular}{|c|c|}
\hline Market & Applications \\
\hline Agricultural use & $\begin{array}{l}\text { Soil stabilization, soil conditioner, soil } \\
\text { neutralization, acid water treatment }\end{array}$ \\
\hline Industrial use & $\begin{array}{l}\text { Sandblasting, roofing granules, industrial } \\
\text { fillers, mineral wool, sludge stabilization }\end{array}$ \\
\hline Cement, concrete & Concrete aggregate and concrete extender \\
\hline Road construction & $\begin{array}{l}\text { Road ballast, base, asphalt, construction } \\
\text { material }\end{array}$ \\
\hline Soil stabilization & Landfill \\
\hline Resource recovery & $\begin{array}{l}\text { Concentrate and recover minerals (this is a } \\
\text { long-term potential) }\end{array}$ \\
\hline
\end{tabular}

New generic applications may be developed by comparing the properties of ash products from coal gasification with required specifications for mineral products. Considerable screening work is generally required. Representative markets are summarized in Table 13.2-3.

A DoE program to evaluate ash utilization from a number of representative gasifiers and using a variety of US coals is recommended. Test work on applications should be performed cooperatively with producers, using ash products from operating plants.

\section{2-1. Environmenta 7-Impact Studies}

Technology exists for acceptable disposal of coal-ash wastes. Environmental issues in handling and disposal of ash are: (i) air-related issues involving fugitive dust emissions from ash piles and handling; (ii) groundwater contamination and contamination resulting from run-off and percolation; ( $i i j)$ land-use related considerations, including ash stability, pile erosion, and structural stability; and (iv) ecological and biological impacts. All of these issues are site-specific. Acceptable environmental controls should be achievable because of the relatively benign character of the ash produced from coal-gasification plants. 
Long-term testing and evaluation of sites where ash is stored are being performed. DoE should review these programs but a generic environmental program may not be appropriate because of the site-specific nature of environmental controls.

13.3. Construction Materials for Coal Gasification *

13.3-1. Introduction

The materials used for construction in coal-gasification plants are subjected to highly aggressive environments at elevated temperatures under conditions of severe erosion, corrosion, and mechanical and thermal stresses. During the past decade, progress has been made in studies of the candidate materials, in both laboratory experiments and under operating conditions in coal-gasification plants. The following are the major materials problems that must be addressed: ( $i$ ) gaseous corrosion of metals and refractories; ( $i i)$ slag corrosion of refractories; ( $i i i$ ) erosive wear; (iv) the materials/design interface and economic considerations including life-cycle costs; and ( $v$ ) nondestructive examination. Several excellent reviews have been published in recent years. The following summary is based on information presented in Refs. 1-7.

\section{3-2. High-Temperature Corrosion}

Degradation of materials at elevated temperatures results from both corrosion wastage and loss of structural integrity. Chemical reactions with the ambient environment may cause rapid wastage or intense localized attack, which limits component life. This process leads to serious losses in plant performance and availability, as well as to increased costs.

Gaseous corrosion of metallic materials leads to oxidation, sulfidation, carburization, and nitridation. These reactions are complex because of interactions between the multiple reactive species present in the

* This section has been written by M.T. Simnad, Center for Energy and Combustion Research and Dept. of Applied Mechanics and Engineering Science, University of California, San Diego, La Jolla, CA 92038. 
environment and the alloying elements in alloy components. Predictions of alloy performance are based on thermochemistry and kinetic factors, which include time-dependent considerations of the nature of the reaction products.

The composition of the gas phase depends on coal feedstock, gasification agent (air, oxygen, or steam), type of reactor, and operating temperature and pressure (Table 13.3-1). Natesan ${ }^{1,2}$ has presented a generalized approach for the evaluation of reaction potentials in complex gas mixtures and concluded that, in coal-gasification atmospheres involving reactive species such as oxygen, sulfur, and carbon, sulfidation of the alloy is the major mode of material degradation. Alloys that develop protective oxide scales are needed to limit corrosion rates to acceptable levels. High chromium and aluminum contents in the iron-, nickel-, arid cobalt-base alloys lead to the formation of relatively stable oxide films. High-nickel alloys form low-melting $\mathrm{Ni}$-sulfide eutectics in the scale or interior of the base alloy even in gas environments with low to moderate sulfur partial pressures. For this reason, alloys with high chromium and fairly low nickel contents are selected for use in coal-gasification systems' (Table 13.3-2). The inter-relationships among oxygen and sulfur partial pressures in the gas phase, the alloy composition, and the test temperature and pressure have been determined. ${ }^{2}$. These data have provided information needed to establish the critical oxygen pressures that allow the formation of stable protective oxide scales on alloy surfaces (see Figs. 13.3-1 and 13.3-2, Table 13.3-3).

There is a need for more detailed studies of nucleation and lateral growth of chromium-rich oxides for high-chromium alloys on exposure to environments with low partial pressures of oxygen and in the presence of sulfidation. The oxidation-sulfidation behavior of candidate alloys has been examined in different mechanistic regimes defined by the temperature and oxidant (oxygen and sulfur) potentials. ${ }^{2}$ A number of reaction sequences have been postulated as a result of these studies and are depicted in Fig. 13.3-3. The higher growth rate of the sulfide gives rise to sulfide overgrowth above the oxide and sulfide nuclei. Outward cation diffusion through the scale leads to the formation of voids in the subscale. The presence of high $A T$ and $T i$ in the alloy stabilizes the oxide nuclei relative to the sulfide by preferential oxide formation. 
The refractory materials used for linings and components of coal-gasification plants are also subject to corrosion at elevated temperatures (Table 13.3-4). The refractories are aggregates of ceramic grains bonded with sintered cement or fused matrices (Tables 13.3-5 and 13.3-6). For conditions of severe erosion, high alumina-type refractories are used. When high thermal conductivity is required, silicon carbide refractory shapes are employed. Gaseous SiO will form in the presence of hydrogen or water vapor in the gas phase. The process causes loss of silica from the refractory bricks containing silicates (such as firebrick) and deterioration of the bricks by erosion and mechanical weakening.

Low-silica refractories are used in the working linings of non-slagging regions in order to mitigate losses of silica by reactions with hydrogen and/or steam. The preferred refractories are dense castables of high-fired, dense fireclay aggregates, bonded with high-purity alumina cements or dense high-alumina fireclay brick.

Table 13,3-1. Comparison of operating conditions in coal gasifiers and other industrial processes; reproduced from Ref. 1. Unless indicated otherwise, compositions are given in vol\%.

\begin{tabular}{|c|c|c|c|c|c|c|c|c|}
\hline $\begin{array}{l}\text { Compound or } \\
\text { Parameter }\end{array}$ & $\begin{array}{l}\text { Low-Btu } \\
\text { Lurgi }\end{array}$ & $\begin{array}{l}\text { Low-Btu } \\
\text { Winkler }\end{array}$ & $\begin{array}{l}\text { High-Btu } \\
\text { Synthane }\end{array}$ & $\begin{array}{c}\text { Fligh-Btu } \\
\text { Hygas } \\
\text { (Bteam-iron) }\end{array}$ & $\begin{array}{l}\text { Fluid- } \\
\text { catalyst } \\
\text { cracking-unit } \\
\text { regenerator }\end{array}$ & $\begin{array}{l}\text { Ammonia- } \\
\text { plant } \\
\text { secondary- } \\
\text { reformer }\end{array}$ & $\begin{array}{l}\text { Slagging } \\
\text { Texaco }\end{array}$ & $\begin{array}{c}\text { Slagging } \\
\text { Bi-Gas }\end{array}$ \\
\hline co & 13.3 & 19.0 & 10.5 & 7.4 & 7 & 6.4 & 35.6 & 12.0 \\
\hline $\mathrm{CO}_{2}$ & 13.3 & 6.2 & 18.5 & 7.1 & 9 & 3.9 & 12.8 & 13.0 \\
\hline $\mathrm{H}_{2}$ & 19.6 & 11.7 & 17.5 & 22.5 & - & 28.0 & 24.8 & 15.0 \\
\hline $\mathrm{H}_{2} \mathrm{O}$ & 10.1 & 11.5 & 37.1 & 32.9 & 17 & 50.8 & 26.2 & 52.0 \\
\hline $\mathrm{CIH}_{4}$ & 5.5 & 0.5 & 15.4 & 26.2 & - & 0.1 & 0.07 & 7.0 \\
\hline $\mathrm{C}_{2} \mathrm{HI}_{6}$ & - & - & 0.5 & 1.0 & Irnce & - & - & - \\
\hline $\mathrm{H}_{2} \mathrm{~S}(\mathrm{ppm})$ & 0.6 & 1300 & 0.3 & 1.5 & - & - & 0.11 & 0.5 \\
\hline Other & $37.5 \mathrm{~N}_{2}$ & $51.1 \mathrm{~N}_{2}$ & - & - & $61 \mathrm{~N}_{2}$ & $10.8 \mathrm{~N}_{2}$ & $0.28 \mathrm{~N}_{2}$ & - \\
\hline Procesa $\mathrm{T},{ }^{\circ} \mathrm{C}$ & $621-760$ & $815-1010$ & 982 & Alove 500 & Above 700 & 787 & 1550 & 1650 \\
\hline Procena $\mathrm{p}, \mathrm{MlPa}$ & $2.41-3.10$ & 0.101 & 6.89 & 6.89 & 0.28 & $1.38-2.07$ & 3 & 7 \\
\hline
\end{tabular}


Table 13.3-2. Candidate metallic materials for application in coal-gasification plants; from the National Materials Board (1977). The data are from A. M. Hall, Battelle Columbus Laboratories, Columbus, Ohio, and are reproduced from Ref. 1.

\begin{tabular}{|c|c|c|c|c|c|c|c|c|c|}
\hline \multirow{2}{*}{ Designation } & \multirow{2}{*}{ Classification } & \multicolumn{7}{|c|}{ Nominal composition, $\%$} & \multirow{2}{*}{ Application } \\
\hline & & C & $\mathrm{Mn}$ & $\mathbf{S i}$ & $C x$ & $\mathrm{Ni}$ & Mo & Others & \\
\hline $15 \mathrm{Cr}-3 \mathrm{MO}$ & $\begin{array}{l}\text { Alloy white } \\
\text { iron }\end{array}$ & 4.00 & 0.85 & 0.50 & 15.00 & & 2.75 & & $\begin{array}{l}\text { Wear parts for } \\
\text { pumps, valves, } \\
\text { fecelers }\end{array}$ \\
\hline $\begin{array}{l}\text { Stellite } 12 \text { (trade- } \\
\text { mark of the } \\
\text { Stellite Division } \\
\text { of Cabot Corp.) }\end{array}$ & $\begin{array}{l}\text { Fard facing } \\
\text { alloy }\end{array}$ & 1.80 & - & - & 29.00 & & - & $\begin{array}{c}59.0 \mathrm{Co} \\
9.0 \mathrm{~W}\end{array}$ & \\
\hline A-387 (Grade D) & $\begin{array}{l}\text { Cr-Mo plate } \\
\text { ster: }\end{array}$ & 0.15 & 0.40 & 0.40 & 2.25 & & 1.00 & & $\begin{array}{l}\text { Shells, heads, } \\
\text { ducts }\end{array}$ \\
\hline$\Lambda-516$ & $\begin{array}{l}\text { C-Si plate } \\
\text { steel }\end{array}$ & 0.27 & 0.70 & 0.25 & - & - & - & & \\
\hline A-533 & $\begin{array}{l}\text { Mn-Mo-Ni } \\
\text { plate steel }\end{array}$ & 0.25 & 1.25 & 0.25 & - & 0.85 & 0.50 & & \\
\hline 310 & $\begin{array}{l}25 / 20 \text { stain- } \\
\text { less stecl }\end{array}$ & 0.20 & 1.00 & 1.00 & 25.00 & 20.00 & - & & $\begin{array}{l}\text { Exposed internals, } \\
\text { and penetrations, } \\
\text { high-temperature } \\
\text { cyclones }\end{array}$ \\
\hline $50 \mathrm{Ni}-50 \mathrm{Cr}$ & $\begin{array}{l}\text { Wrought heat- } \\
\text { resistant } \\
\text { alloy }\end{array}$ & - & - & - & 50 & Bal & - & & \\
\hline Alloy 400 & $\begin{array}{l}\text { Formerly } \\
\text { monel }\end{array}$ & 0.12 & 0.90 & 0.15 & - & Bal & - & $31.5 \mathrm{Cu}$ & Shell diner \\
\hline
\end{tabular}

From the National Materials Advisory Board (1977). The data are from A. M. Hall, Battelle Columbus Laboratories, Columbus, Ohio, and are reproduced from Ref. 1.

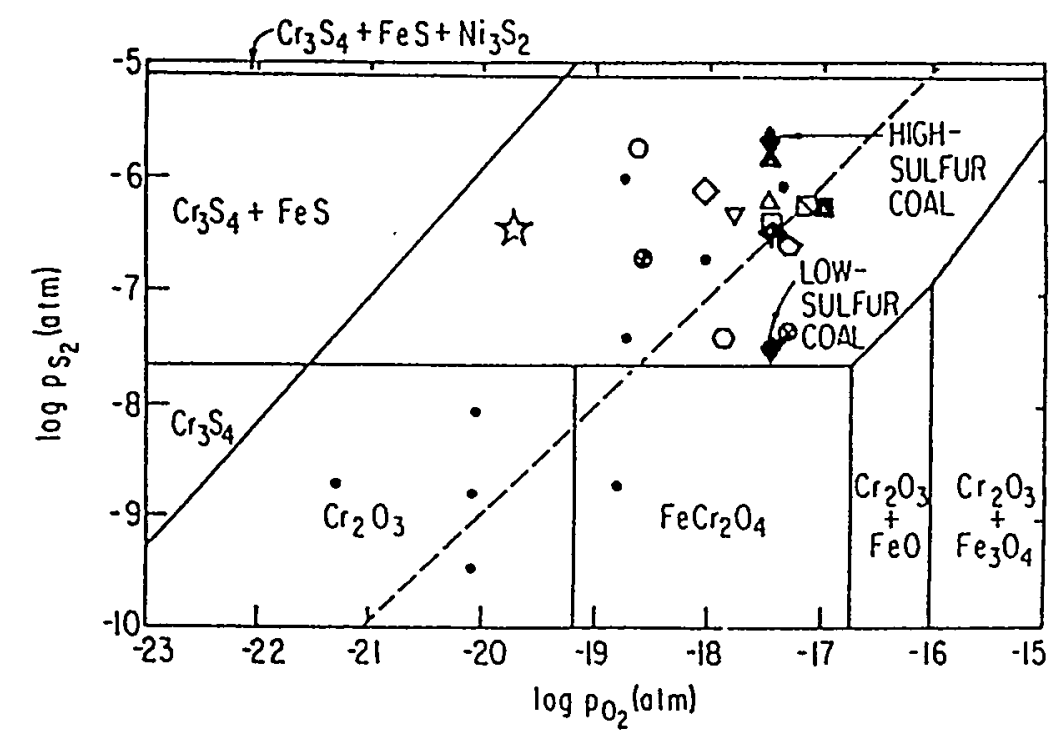

Fig. 13.3-1. Thermochemical diagram for Type 310 stainless steel at $871^{\circ} \mathrm{C}$, showing a $n$ experimentally-determined kinetic boundary (dashed line). Open and solid symbols represent low - and medium-Btu gasifier conditions, respectively; black dots are experimental gas potentials (reproduced from Ref. 2). 


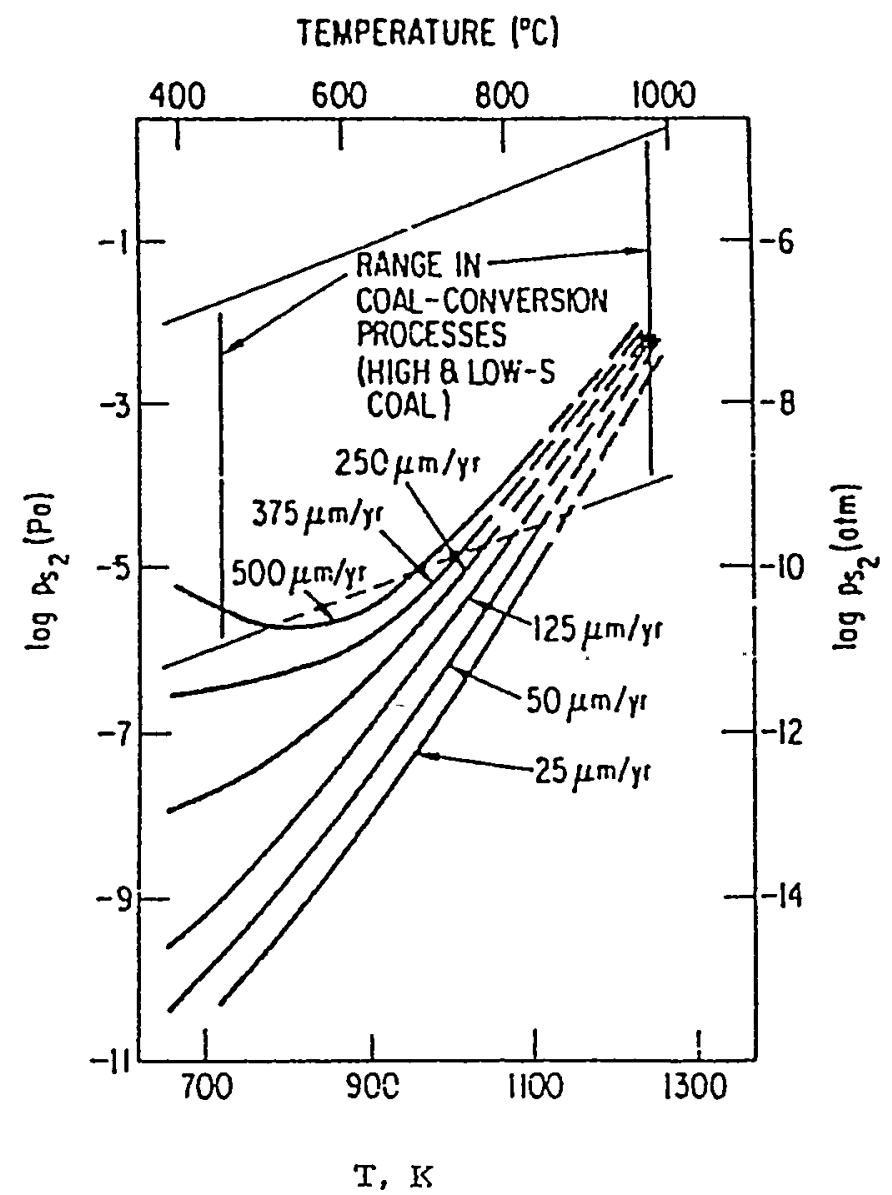

Fig. 13.3-2. Isocorrosion rate curves for types 304 and 316 stainless steel as a function of sulfur potential; reproduced from Ref. 1 .

Table 13.3-3. Stability of alloy elements in medium $\left(27 \% \mathrm{H}_{2}, 28 \% \mathrm{H}_{2} \mathrm{O}\right.$, $\left.31 \% \mathrm{CO}, 13 \% \mathrm{CO}_{2}, 1 \% \mathrm{H}_{2} \mathrm{~S}\right)$ and low $\left(12 \% \mathrm{H}_{2}, 8 \% \mathrm{H}_{2} \mathrm{O}\right.$, $\left.20 \% \mathrm{CO}, 8 \% \mathrm{CO}_{2}, 4 \% \mathrm{CH}_{4}, 47 \% \mathrm{~N}_{2}, 1 \% \mathrm{H}_{2} \mathrm{~S}\right) \mathrm{BTU}$ coalgasification atmospheres: reproduced from Ref. 5 .

\begin{tabular}{|c|c|c|c|c|c|}
\hline & \multicolumn{5}{|c|}{ Phase stability (phase can be formed in the gas between 300 and $1200^{\circ} \mathrm{C}$} \\
\hline & Element & $\begin{array}{l}\text { Oxide } \\
\text { (MO) }\end{array}$ & $\begin{array}{l}\text { Sul phide } \\
\text { (MS) }\end{array}$ & $\begin{array}{l}\text { Carbide } \\
\text { (MC) }\end{array}$ & $\begin{array}{l}\text { Equilibrium phase } \\
\text { in stable } \\
\text { equilibrium } \\
\text { with gas }\end{array}$ \\
\hline Alloy bases & $\begin{array}{l}\mathrm{Fe} \\
\mathrm{Ni} \\
\mathrm{Co}\end{array}$ & $\mathbf{X}$ & $\begin{array}{l}x \\
x \\
x\end{array}$ & & $\begin{array}{l}\text { MS } \\
\text { MS } \\
\text { MS }\end{array}$ \\
\hline Desulphurizer & $M \mathbf{n}$ & $\mathbf{x}$ & $\mathrm{X}$ & & MS \\
\hline Deoxidizer & Si & $\mathbf{x}$ & $\mathrm{X}$ & & MO \\
\hline Reactive additions & $\begin{array}{l}\mathrm{Cr} \\
\mathrm{Al} \\
\mathrm{Ti}\end{array}$ & $\begin{array}{l}x \\
x \\
x\end{array}$ & $\begin{array}{l}X \\
X \\
X\end{array}$ & $\begin{array}{l}x \\
x\end{array}$ & $\begin{array}{l}\text { MO } \\
\text { MO } \\
\text { MO }\end{array}$ \\
\hline Solute strengtheners & Mo & & $\mathrm{X}$ & & MS \\
\hline
\end{tabular}




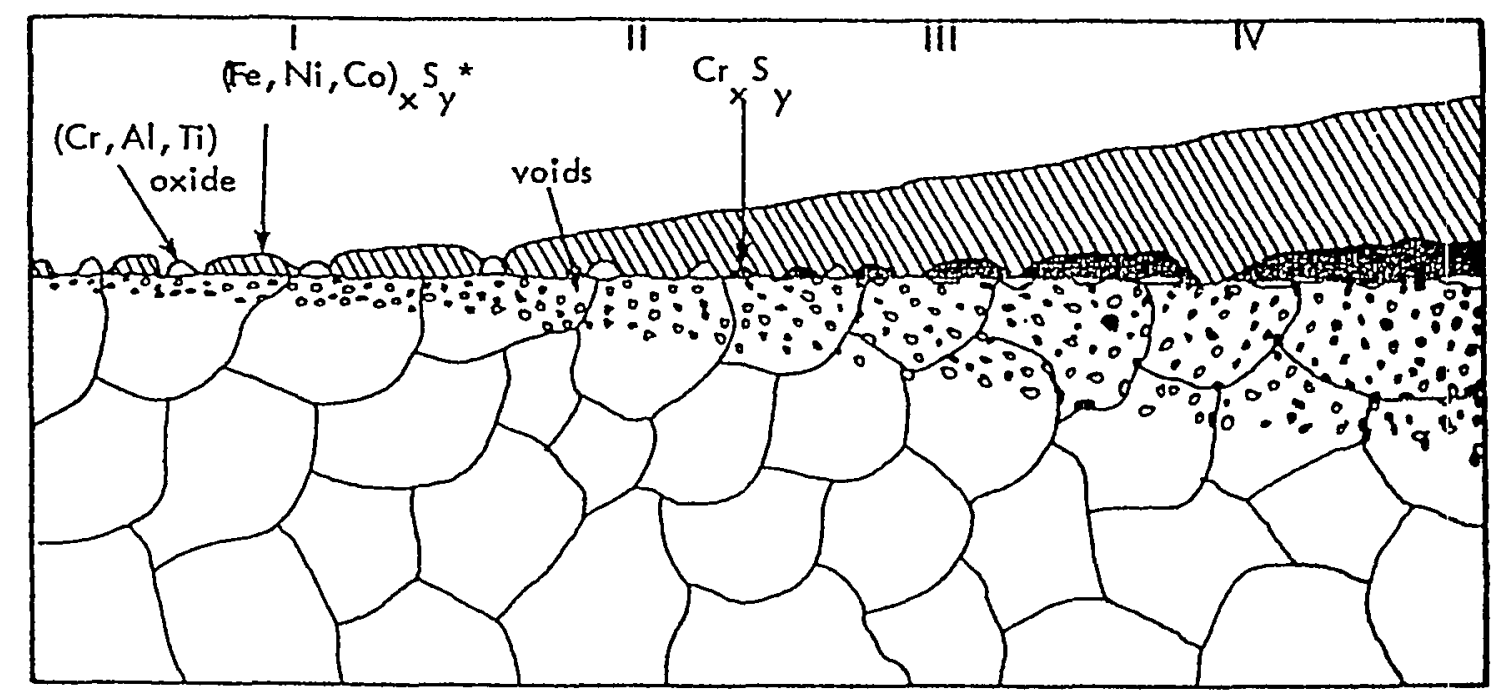

I Competition; II Overgrowth: III $\mathrm{Cr}_{\mathrm{x}} \mathrm{S}$ Formation; IV Dissociation \& Internal Sulfidation

Fig. 13.3-3. Reaction model for oxidation-sulfidation in mixed oxidant environments; reproduced from Ref. 1. An asterisk ( $*$ indicates that, if the base metal sulfide is molten at the test temperature, islands of $\mathrm{Cr}_{\mathrm{x}} \mathrm{S}_{\mathrm{y}}$ oxides and $\mathrm{Cr}$-depleted alloy exist in the outer scale after cooling due to grain boundary attack by the liquid.

Table 13.3-4. Forms of gaseous corrosion of ceramic materials; reproduced from Ref. 1 .

\begin{tabular}{|c|c|}
\hline Reaction & Result \\
\hline Reaction with steam & Leaching of $\mathrm{SiO}_{2}, \mathrm{AlPO}_{4}, \mathrm{Ca}$ \\
\hline Reaction with hydrogen & $\begin{array}{l}\text { Reduction of solid } \mathrm{SiO}_{2} \text {, and } \mathrm{Fe}_{2} \mathrm{O}_{3} \\
\text { to gaseous } \mathrm{SiO} \text { and } \mathrm{Fe} / \mathrm{FeO}\end{array}$ \\
\hline Reaction with carbon & $\begin{array}{l}\text { Disintegration by CO attack through } \\
\text { deposite of } \mathrm{C} \text { near Fe in refractory } \\
\text { causing highly local stresses }\end{array}$ \\
\hline Reaction with alkali vapor $(\mathrm{Na}, \mathrm{K})$ & $\begin{array}{l}\text { Change in refractory/ceramic } \\
\text { composition through direct } \\
\text { reaction with } \mathrm{Na}, \mathrm{K}\end{array}$ \\
\hline
\end{tabular}


Table 13.3-5. Candidate structural ceramic materials and their properties; reproduced from Ref. 1 and based on data of M. G. Coombs and D. M. Kotchick (1979).

\begin{tabular}{|c|c|c|c|c|c|c|c|}
\hline \multirow[t]{2}{*}{$\begin{array}{l}\text { Candidate } \\
\text { materials }\end{array}$} & \multirow[t]{2}{*}{ Strength } & \multicolumn{2}{|c|}{$\begin{array}{l}\text { Linear thermal } \\
\text { expansion } \times 10^{6}\end{array}$} & \multicolumn{2}{|c|}{$\begin{array}{l}\text { Thermal } \\
\text { conductivity } \\
\text { at } 982^{\circ} \mathrm{C}\left(1800^{\circ} \mathrm{F}\right)\end{array}$} & \multirow{2}{*}{$\begin{array}{c}\text { Maximum use } \\
\text { temperature, } \\
{ }^{\circ} \mathrm{C}\left({ }^{\circ} \mathrm{F}\right)\end{array}$} & \multirow[t]{2}{*}{ Fabricability } \\
\hline & & $\mathrm{cm} / \mathrm{cm}-{ }^{\circ} \mathrm{K}$ & $\left(10^{6} \mathrm{in} / \mathrm{in}-{ }^{\circ} F\right)$ & Watts $/{ }^{\circ} \mathrm{K}-\mathrm{m}$ & $\left(\mathrm{Btu} / \mathrm{hr}-{ }^{\circ} \mathrm{F}-\mathrm{ft}\right)$ & & \\
\hline $\begin{array}{l}\text { LAS, MAS } \\
\text { and AS }\end{array}$ & Moderate & $\begin{array}{l}0.4 \text { to } \\
5.4\end{array}$ & $\begin{array}{l}\text { Low to } \\
\text { moderate } \\
(0.2 \text { to } 3.0)\end{array}$ & $\begin{array}{l}\text { Low } \\
3.46\end{array}$ & $\begin{array}{l}\text { Low } \\
(2.0)\end{array}$ & $\begin{array}{l}982(1800) \\
16\end{array}$ & Good \\
\hline $\mathrm{Al}_{2} \mathrm{O}_{3}$ & $\begin{array}{l}\text { Moderate } \\
\text { to good }\end{array}$ & 8.1 & $\begin{array}{l}\text { High } \\
(4.5)\end{array}$ & 10.38 & $\begin{array}{l}\text { Low } \\
(6.0)\end{array}$ & $1648(3000+)$ & Good \\
\hline Mullite & Moderate & 4.5 & $\begin{array}{l}\text { Moderate } \\
(2.5)\end{array}$ & 4.3 & $\begin{array}{l}\text { Low } \\
(2.5)\end{array}$ & $1648(3000+)$ & Good \\
\hline $\begin{array}{l}\mathrm{Si}_{3} \mathrm{~N}_{4} \\
\text { hot-pressed }\end{array}$ & High & 3.2 & $\begin{array}{l}\text { Moderate } \\
((1.8)\end{array}$ & 15.6 & $\begin{array}{l}\text { Moderate } \\
\text { (9) }\end{array}$ & $1537(2800)$ & ṗoor \\
\hline $\begin{array}{l}\mathrm{Si}_{3} \mathrm{~N}_{4} \\
\text { reaction- } \\
\text { bonded }\end{array}$ & Moderate & 3.2 & $\begin{array}{l}\text { Moderate } \\
(1.8)\end{array}$ & 8.7 & $\begin{array}{l}\text { Low } \\
\text { (5) }\end{array}$ & $1537(2800)$ & Good \\
\hline $\begin{array}{l}\mathrm{Si}_{3} \mathrm{~N}_{4} \\
\text { sintered }\end{array}$ & High & 3.6 & $\begin{array}{l}\text { Moderate } \\
(2.0)\end{array}$ & 17.3 & $\begin{array}{l}\text { Moderate } \\
\text { (10) }\end{array}$ & $1371(2500)$ & Good \\
\hline $\begin{array}{l}\text { SiC } \\
\text { hot-preased }\end{array}$ & High & 4.3 & $\begin{array}{l}\text { Moderate } \\
(2.4)\end{array}$ & 39.8 & $\begin{array}{l}\text { Good } \\
\text { (23) }\end{array}$ & $1537(2800)$ & Poor \\
\hline $\begin{array}{l}\mathrm{SiC} \\
\text { Bintered }\end{array}$ & $\begin{array}{l}\text { Moderate } \\
\text { to high }\end{array}$ & 4.5 & $\begin{array}{l}\text { Moderate } \\
(2.5)\end{array}$ & 19.0 & $\begin{array}{l}\text { Moderate } \\
\text { (11) }\end{array}$ & $1537(2800)$ & Good \\
\hline $\begin{array}{l}\text { SiC } \\
\text { siliconized }\end{array}$ & Moderate & 5.0 & $\begin{array}{l}\text { Moderate } \\
(2.8)\end{array}$ & $19.0-34.6$ & $\begin{array}{l}\text { Good } \\
(11-20)\end{array}$ & $1343(2540)$ & Good \\
\hline
\end{tabular}

Table 13,3-6. Chemical composition (in wt\%) of several refractories; reproduced from Ref, 1 and based on data of R. E. Dial-(1975). Castables are items 1 to 5 and shapes are 6 to 13 .

\begin{tabular}{|c|c|c|c|c|c|c|c|c|c|c|c|c|c|}
\hline \multirow{2}{*}{ Refractory } & \multicolumn{2}{|c|}{ Bubble $\mathrm{Al}_{2} \mathrm{O}_{3}$} & \multicolumn{2}{|c|}{ Dense $\mathrm{Al}_{2} \mathrm{O}_{3}$} & \multirow{2}{*}{$\frac{\mathrm{SiC}}{5}$} & \multicolumn{2}{|c|}{$\mathrm{Al}_{2} \mathrm{O}_{3}$} & \multicolumn{4}{|c|}{ Fused cast $\mathrm{Al}_{2} \mathrm{O}_{3}$} & \multicolumn{2}{|c|}{ SiC } \\
\hline & 1 & 2 & 3 & 4 & & 6 & 7 & 8 & 9 & 10 & 11 & 12 & 13 \\
\hline $\mathrm{Al}_{2} \mathrm{O}_{3}$ & 94.6 & 94.1 & 96.0 & 96.7 & 6.6 & 99.2 & 99.4 & 99.3 & 98.7 & 94.5 & 94.5 & 0.7 & 0.3 \\
\hline $\mathrm{SiO}_{2}$ & 0.5 & 0.5 & 0.1 & 0.1 & 2.2 & 0.5 & 0.3 & 0.1 & 0.5 & 1.1 & 0.1 & 8.5 & 1.3 \\
\hline $\mathrm{Fe}_{2} \mathrm{O}_{3}$ & 0.2 & 0.2 & 0.1 & 0.1 & 1.8 & 0.1 & 0.1 & 0.1 & 0.1 & 0.1 & 0.1 & 0.7 & 0.3 \\
\hline $\mathrm{CaO}$ & 4.2 & 4.7 & 3.6 & 2.7 & 5.5 & 0.1 & 0.1 & 0.1 & 0.1 & 0.3 & 0.1 & 0.2 & 0.2 \\
\hline Alkalis & 0.4 & 0.4 & 0.2 & 0.3 & & 0.1 & 0.1 & 0.4 & 0.04 & 3.9 & 5.2 & & \\
\hline Other & & & & & & & & & & & & & \\
\hline & & & \multicolumn{5}{|c|}{$82.7(\mathrm{SiC})$} & \multicolumn{4}{|c|}{$0.5\left(\mathrm{~B}_{2} \mathrm{O}_{3}\right)$} & \multicolumn{2}{|c|}{$\begin{array}{l}89.6(\mathrm{SiC}) \\
18.5\left(\mathrm{Si}_{3} \mathrm{~N}_{4}\right) \\
79.1\left(\mathrm{SiC}_{4}\right)\end{array}$} \\
\hline
\end{tabular}


Refractories containing free iron or iron-oxide-bearing compounds are subject to disintegration by carbon deposition (via decomposition of co to $\mathrm{C}$ and $\mathrm{CO}_{2}$ ), which leads to high local stresses that spall the refractory. This phenomenon occurs in the temperature range $400-650^{\circ} \mathrm{C}$. Another cause of destruction of alumina-silica refractories is reaction with alkalies, which results in a $30 \%$ volume expansion that causes the refractory to spall. Western lignite coals contain sodium and have been reported to cause alkali-attack failure in a slagging-type gasifier, where a mullite refractory failed after 125 hours of exposure at about $1000^{\circ} \mathrm{C}$.

In slagging coal-gasification systems, corrosion of refractories by molten slag occurs by a complex physiochemical process. The rate of corrosion is governed by mass transport of material across the boundary layer, which thus involves fluid flow and diffusion. Both thermodynamic and kinetic processes must be considered, as well as the pore structure and grain boundaries of the refractory and the nature of the reaction products. The physical, chemical and thermal properties of the liquid slag, refractory, and reaction products determine the corrosion of the refractories by liquid slags. The solubility of the refractory in the molten slag is an important parameter, especially the solubility of the grain boundary or bonding phases. It has been reported that alumina-silica and lime-silica refractories are suitable for use only up to about $1500^{\circ} \mathrm{C}$ and that, with high silica slags, the zirconia and chromium oxide refractories are more suitable. ${ }^{1}$ For the more fluid low-silica slags, the chrome-magnesite and pure magnesia refractories are preferred.

The falling temperature gradients in the liner affect the composition gradients. The solubility of the refractory in the slag decreases with decreasing temperature, while the slag viscosity increases and diffusion decreases. These changes cause the corrosion, material transport, and penetration rates to decrease and eventually stop. ${ }^{1}$ As a result, an equilibrium thickness of water-cooled refractory lining is established, which depends on the thermal conductivity of the refractory and the minimum temperature of the chemical reactions. High thermal conductivity and high minimum reaction temperatures are desirable under slagging conditions. Also, good resistance to abrasion, cracking, and spalling are important criteria in the selection of refractories for slagging gasifiers. Cooling plates penetrating into the refractory lining 
are effective in forming a chilled slag layer or reducing solubility, material transport, and slag penetration, thereby greatly increasing operating life. Thin refractory linings on water-cooled walls are used in commercial slagging gasifiers, with the linings applied over studded metal tubes forming part of the metal wa11. Candidate linings include fireclay, chrome ore, silicon carbide, alumina, and zircon sand ( $Z r$ silicate). The bonding agents that are used in applying the liners include calcium aluminum cement, phosphate compounds, sodium silicates, clay, boric acid, sulfur cement, and organic compounds. The water-cooled thin linings last 1-2 years; the longest lifetimes have been achieved with silicon-carbide containing vanadium additions, because of the high thermal conductivities and abrasion resistance.

The presence of particulate matter in the gas stream will enhance the degradation of alloy components by erosion-corrosion and sulfidation. Char-particle deposits act primarity by lowering the oxygen pressure in their vicinity and thereby promote suifidation reactions.

\section{3-3. Low-Temperature Corrosion}

The aqueous solutions in coal-gasification systems are highly corrosive to the structural materials in components such as heat exchangers, fractionation columns, condensers, slurry pipelines, scrubbers and quench systems. These solutions contain dissolved aggressive gases, alkalis, salts, and organic acids, which may give rise to intense localized corrosion such as pitting, crevice corrosion, and stress-corrosion cracking. The selection of alloys under these service conditions depends on the specific impurities that are present in the aqueous media. In extensive, statistically designed, environmental tests, the concentrations of the different chemical species were varied systematically over a temperature range of 121 to $239^{\circ} \mathrm{C} .{ }^{1}$ The results indicate that the corrosion rates ranged from a low of less than $0.025 \mathrm{~mm} / \mathrm{yr}$ for high-nickel alloys, austenitic stainless steels, and titanium, to rates exceeding $2.5 \mathrm{~mm} / \mathrm{yr}$ for carbon steel, 410 SS and $430 \mathrm{SS}$, and above $5 \mathrm{~mm} / \mathrm{yr}$ for copper- and aluminum-base alloys. Stress-corrosion cracking is particulary severe in (i) austenitic stainless steels that have been heat-treated in the sensitizing temperature range of 450 to $700^{\circ} \mathrm{C}$ and (ii) in weld areas. 
The presence of hydrogen in coal-gasification product streams may lead to degradation of the pressure-vessel materials (generally low $\mathrm{Cr}$-Mo steels such as $\mathrm{Fe}-2.25 \mathrm{Cr}-1 \mathrm{Mo})$. Hydrogen attack of the steel results in loss of ductility and fracture toughness. The conventional approach in determining the operating limits for these vessels is to use Nelson curves. These curves are based on an empirical compilation of failure data from the petrochemical industries. However, recent studies of hydrogen attack in pressure-vessel steel have addresssed the influence of environmental and metallurgical parameters. The goal of these studies is to provide models that can be used to correlated engineering and laboratory data and also to predict eventually the behavior under operating conditions. However, reliable fracture analysis can only be carried out when additional data are generated on the effects of hydrogen on residual stresses, plasticity, fatigue crack-growth rate, creep, and creep-fatigue interactions.

\section{3-4 Erosive Wear}

Erosive wear by solid particles entrained in gas streams is usually explained in terms of two models. One model is applicable to ductile materials and involves the mechanism of plastic flow. The second model explains wear for brittle materials in terms of micro-fracture. Both models include a number of parameters related to both the impacting particles and the impacted materials.

The properties of the impacting particles include size, shape, hardness, velocity, angle of particle impingement, and the loading density of the particles in the flowing stream. The properties of the impacted materials that influence wear include microstructure and mechanical properties and hardness. For example, for stainless steels, the resistance to wear decreases with increasing temperature because the ductility decreases correspondingly. Alloys having a well-dispersed carbide in a high-yield strength matrix show the least wear ${ }^{3}$. In ductile materials, erosion resistance is inversely proportional to the flow resistance of the material.

In brittle materials, erosion is influenced by porosity, as well as by hardness and toughness. Hence, high-density material has superior 
wear resistance (Figs. 13.3-4 and -5 ). The wear model for brittle materials is based on the suggestion that surface cracks formed by particle impingement nucleate larger cracks, which results in material being removed by localized fracture. There is a need for information on the variation of hardness, ductility, and toughness of the refractory materials as a function of temperature. The best correlation appears to be between erosion rate and compressive strength of refractories (Table 13.3-7). Erosion rates may also be improved by enhancing the properties of the bonding material.

The mechanism of erosion is also influenced by the size of the impinging particles. Large particles tend to bridge the distance between the aggregate grains in refractories, whereas fine particles undercut the aggregate and cause much higher erosion rates. At elevated temperatures where the refractories have some ductility, their erosion behavior is similar to that of a metal rather than a brittle ceramic. Erosion rates are also influenced by flow conditions, fluid mechanics of the gas stream, temperatures, and corrosiveness of the ambient environment.

\section{3-5. Mechanical Properties}

The complex gas environment affects the mechanical properties of the materials, both by intergranular penetration of sulfur and by breakaway corrosion. These corrosion rates are difficult to predict for long-term service. Experimental studies on the mechanical properties of the materials in gas environments include measurements of uniaxial tensile strength, uniaxial and biaxial creep rupture, low-cycle fatigue, impact, and stress-corrosion cracking.

Tensile tests of candidate alloys after exposures of $1000 \mathrm{hr}$ at $649^{\circ} \mathrm{C}$ to air and gas mixtures with $0.5 \% \mathrm{H}_{2} \mathrm{~S}$ at $68 \mathrm{~atm}$ have been reported. 1 The results indicate that, with gas compositions which allow the formation of oxide films, there is a negligible effect on the tensile properties and impact strength of all of the selected alloys except for IN-657 $(48 \mathrm{C}-50 \mathrm{Ni}-1.5 \mathrm{Nb})$, which had an elongation value of zero after exposure to the gas environment. On the other hand, the similar alloy IN-671 (48C $-51.5 \mathrm{Ni}-0.4 \mathrm{Ti})$ showed no significant loss of ductility after exposure to the mixed-gas environments. These results illustrate the striking 
difference caused by $\mathrm{Ti}$ and $\mathrm{Nb}$ additions. Other high-Cr alloys (Incoloy-800 and type $310 \mathrm{SS}$ ), when exposed for $1000 \mathrm{hr}$ to gas mixtures with a wide range of oxygen and sulfur partial pressures between 750 and $982^{\circ} \mathrm{C}$, show a decrease in strength with a decrease in oxygen partial pressure in the preexposure environment.

The results of creep-rupture tests indicate that, if the oxygen partial pressure is below a threshold value, the creep-rupture life and rupture strain are significantly lowered. Susceptibility to stress-corrosion cracking of several alloys was tested in oxidizing-sulfidizing and oxidizing-sulfidizing-carburizing atmospheres. The results are summarized in Fig. 13.3-6.

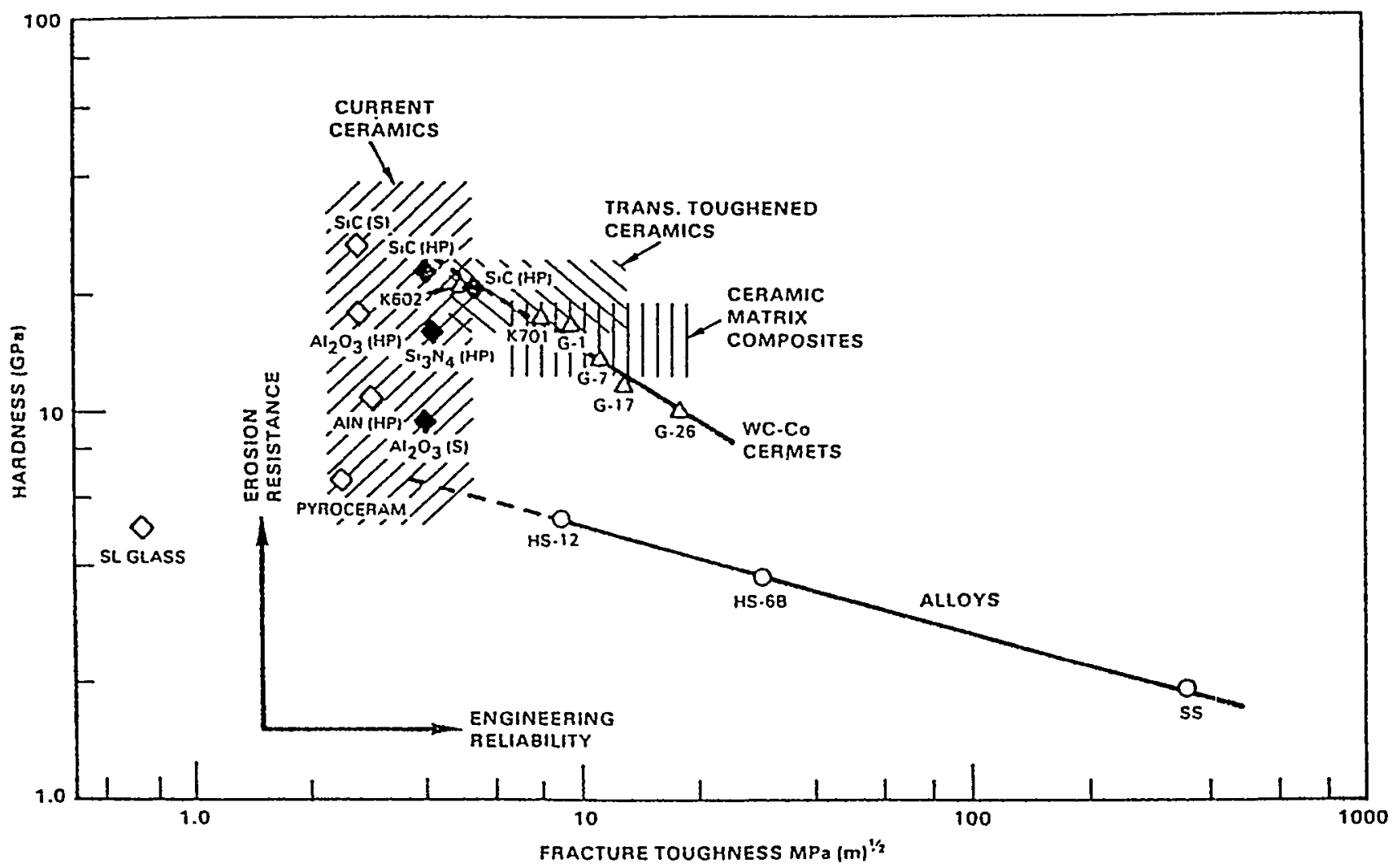

Fig. 13.3-4. Summary of ranges of properties pertinent to erosion resistance for different classes of materials; reproduced from Ref. 3. 


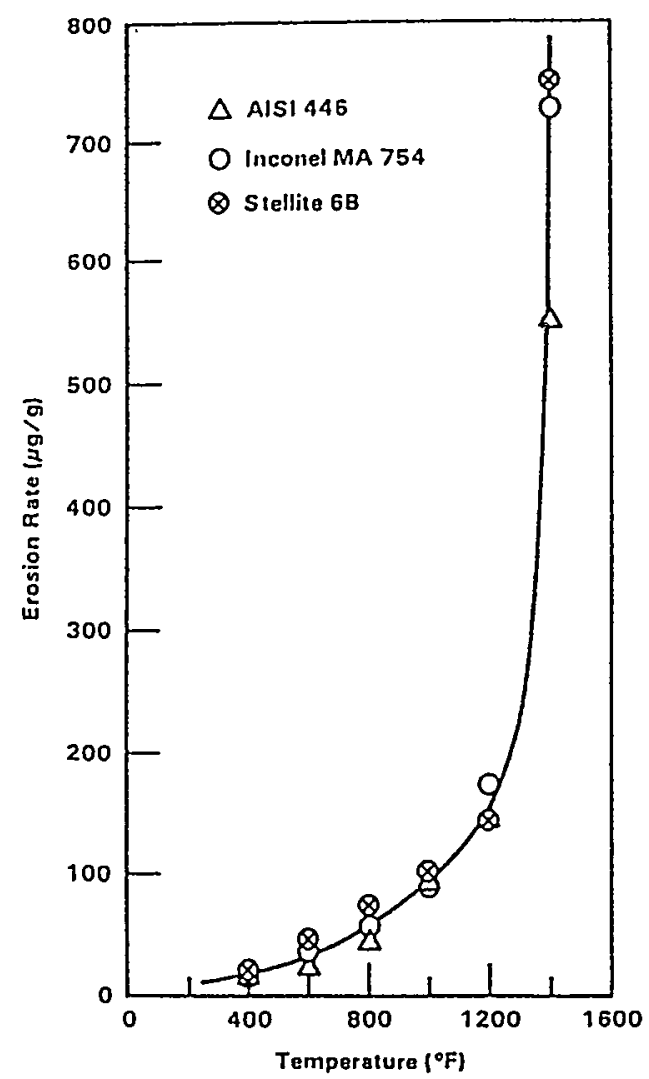

Fig. 13.3-5. Temperature dependence of exosion of high-temperature alloys (flue gas, $12 \mu \mathrm{m}$ alumina particles at nominally $30^{\circ}$ ); reproduced from Ref. 3 and based on EPRI data.

Table 13.3-7. Properties and erosion characteristics of selected ceramics; reproduced from Ref. 3.

\begin{tabular}{|c|c|c|c|c|c|}
\hline Ceramic & Grade & $\begin{array}{l}\text { Hardness } \\
\text { (GPa) }\end{array}$ & $\begin{array}{l}\text { Fracture } \\
\text { toughness } \\
(\text { MPaml/2) }\end{array}$ & $\begin{array}{c}\text { Erosion } \\
\text { characteristics }\end{array}$ & $\begin{array}{c}\text { Erosion } \\
\text { rate } \\
(\Delta v / v) \times 10^{10}\end{array}$ \\
\hline $\begin{array}{l}\text { Soda-lime } \\
\text { gla's }\end{array}$ & Float glass & 5.2 & 0.75 & $\begin{array}{l}\text { Micxocutting/ } \\
\text { latexal cracking }\end{array}$ & 2200 \\
\hline $\begin{array}{l}\text { Glass- } \\
\text { ceramic }\end{array}$ & & 6.6 & 2.4 & $\begin{array}{l}\text { Microcutting/ } \\
\text { microflaking } \\
\text { (transgranular) }\end{array}$ & 210 \\
\hline AlN & Hot-pressed & 10.9 & 2.9 & & 1.6 \\
\hline $\mathrm{Al}_{2} \mathrm{O}_{3}$ & Hot-pressed & 17.7 & 2.7 & Micr oflaking & 1.4 \\
\hline $\mathrm{SiC}$ & Sintered & 26.1 & 2.7 & (transgranular) & 0.7 \\
\hline $\mathrm{B}_{4} \mathrm{C}$ & Hot-pressed & 31.0 & - & & 0.3 \\
\hline $\mathrm{SiC}$ & Hot-pressed & 22.7 & 4.0 & & 19 \\
\hline $\mathrm{SiC}$ & Hot-pressed & 20.7 & 5.3 & Intergranular & 10 \\
\hline $\mathrm{Si}_{3} \mathrm{~N}_{4}$ & Hot-pressed & 15.9 & 4.2 & wear & 5 \\
\hline $\mathrm{Al}_{2} \mathrm{O}_{3}$ & Sintered & 9.4 & 4.0 & & 6.5 \\
\hline
\end{tabular}


Pressure vessels in second-generation coal-gasification plants being developed in the US require higher temperatures and/or pressures than the early systems. Fabrication technology imposes limitations on pressure-vessel size and wall thickness. An example of the relation between design pressure and wall thickness for a pressure-vessel steel is shown in Fig. 13.3-7. Table 13.3-8 and Figs. $13 \cdot 3-8$ and $13 \cdot 3-9$ show allowable stress values for low alloy steels based on the ASME Boiler and Pressure Cocle, Section VIII, Division 1 and 2. In thick-section fabrication, quenching and tempering are required to meet code requirements. The problem of hydrogen attack on pressure-vessel steels must be addressed in operations at higher temperatures and pressures. Refractory linings have to be used in the vessels in order to limit the wall temperatures to less than about $325^{\circ} \mathrm{C}$. Monolithic linings are preferred and are also said to be relatively cost-effective.

Heat exchangers are used for the recovery of sensible heat from hot gases produced by gasifiers prior to such operations as scrubbing, in preheating gasification air or raw materials, or to generate steam. The heat-exchanger materials function with oxidizing gases on one side and complex reducing gases on the other. Boiler-tubing-alloy recommendations are listed in Table 13.3-9. The use of structural ceramics for high-temperature heat-exchangers has been limited by the need for a statistical approach to the design and the lack of ASME codes for structural ceramics. Recent advances in the development of structural ceramics for heat exchangers may be of importance to future coal-gasification technology.

\section{3-6. Materials for Syngas Coolers of Slagging Gasifiers}

The development of entrained-flow, slagging coal-gasifiers is of interest for the production of electric power with gas turbines and steam-generating systems in integrated, combined-cycle power plants. The results of recent studies on materials for syngas coolers in slagging gasifiers have been described. ${ }^{5}$ At temperatures above $650^{\circ} \mathrm{C}$, few materials resist rapid corrosion by the gases with higher sulphur and lower oxygen activities found in the medium- or low-BTU atmospheres (Table 13.3-10) because the $\mathrm{Fe}-\mathrm{Ni}$ sulphides melt above this temperature. Thermodynamic and 
kinetic factors favor the formation of sulfide-reaction products on many of the candidate metals and alloys. Guidance in the selection of materials is provided by thermodynamic and kinetic data, as well as by analyses of gas equitibria.

In the combined-cycle coal gasification plant, the tubular heat exchanger metal walls are maintained at $250-500^{\circ} \mathrm{C}$, with gas inlet temperatures of $1100-1200^{\circ} \mathrm{C}$. A minimum of $23-25 \% \mathrm{Cr}$ is required in ferritic chromium steels for good resistance to corrosion at $400-500^{\circ} \mathrm{C}$ (Fig. 13.3-10). A clad or overlay of an alloy such as $\mathrm{Fe}-19 \mathrm{Cr}-6 \mathrm{Al}-0.8 \mathrm{Hf}$ provides excellent protection on low alloy steels. Even better corrosion resistance to sulfidation at $400-500^{\circ} \mathrm{C}$ is exhibited by high- $\mathrm{Cr}$ austenitic stainless steels such as types 309 and 310 and also by the cast alloy HK40. Titanium and $T i-6 A 1-4 V$ alloys are reported to have the best resistance to corrosion among 211 of the materials tested at $300-500^{\circ} \mathrm{C}$. They should be more cost-effective in use on a life-cycle basis than coated low alloy steels for long-term service at temperatures below $400^{\circ} \mathrm{C}$ in syngas coolers (Table $13.3-11) .^{5}$

METAL TEMPERATURE ("F)

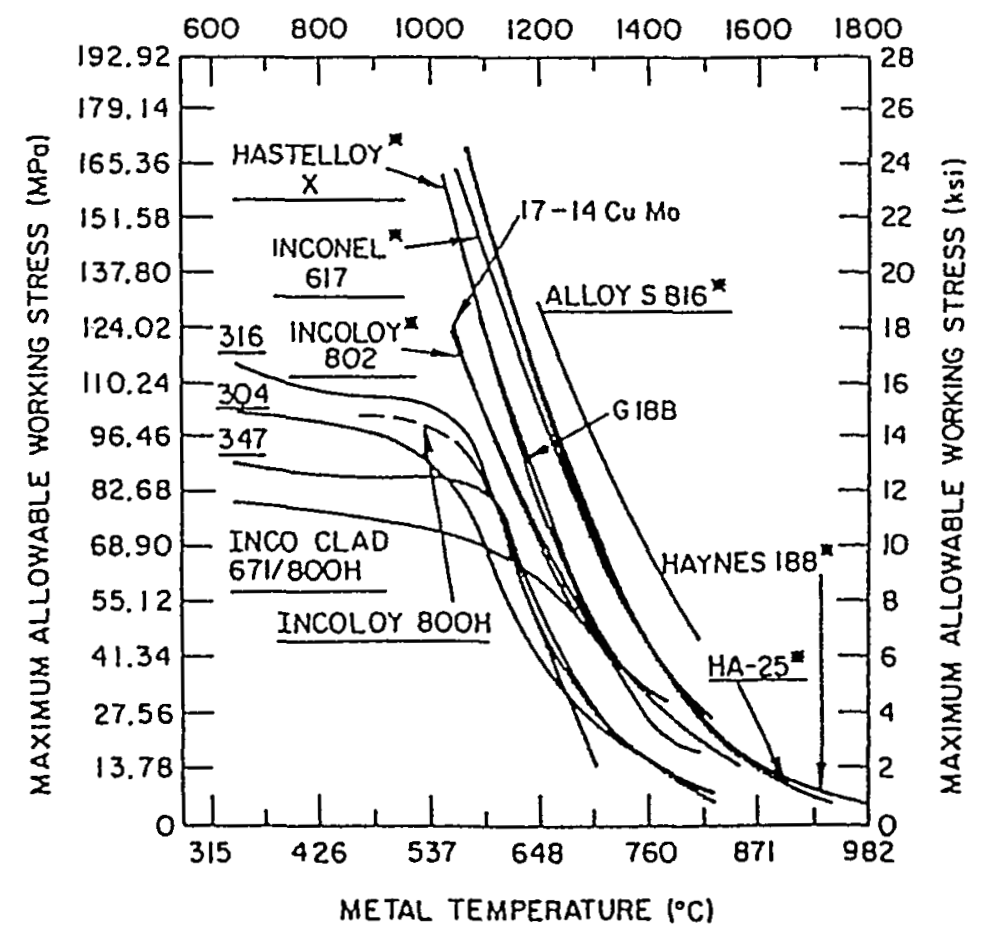

Fig. 13,3-6. Maximum allowable working stress for several candiclate tubing materials for fossil gas applications; reproduced from Ref. 1 and based on data of D. E. Thomas et al (1976). 


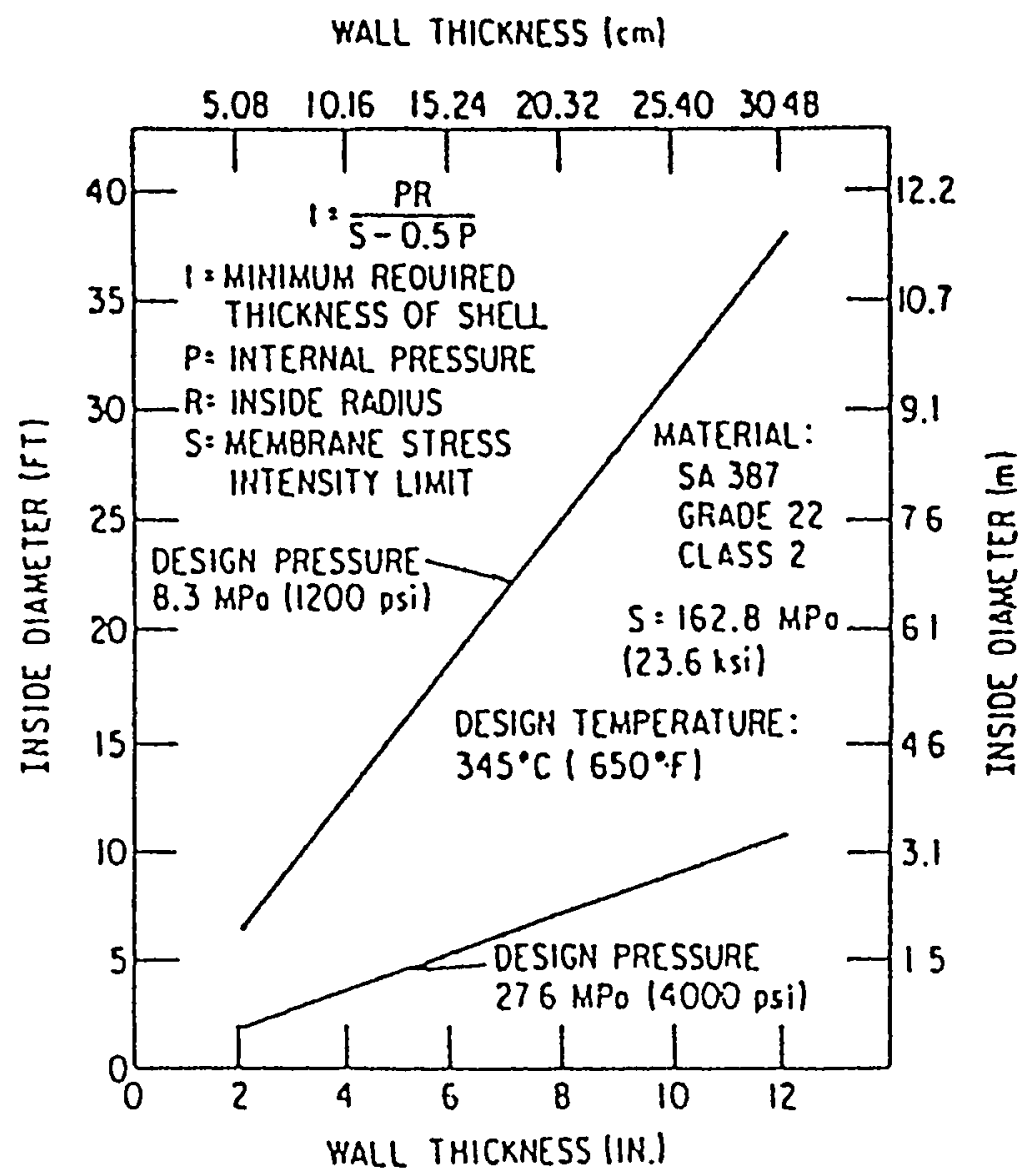

Fig. 13,3-7. Relationship of design pressure to inside diameter and wall thickness of pressure vessels, based on limits of current technology; reproduced from Ref. I and based on data of D. A. Canonico et al (1978).

\section{3-7. Nuclear Heat Steam-Gasification of Coal}

There has been much interest in several countries in coupling the steam-gasification process with a high-temperature nuclear reactor (HTGR). 6,7 The fluidized bed is now contained in a pressure vessel made of boiler steel with inside insulation. The intermediate heat exchanger between the primary reactor-coolant helium and the coal gasifier is subjected to high temperatures and is also in direct contact with the coal/steam fluidized bed. Special high-temperature alloys have been developed for this type of application, with the heat exchanger subjected to aggressive conditions. The heat exchanger is immersed in the fluidized-gas 
generator at temperatures ranging from 750 to $950^{\circ} \mathrm{C}$ and at a pressure of about 40 bars. The fluidized bed consists of finely ground coal which is fluidized by steam. The commercial alloy Incoloy- 800 was selected in Germany as base composition for 70 experimental alloys, with and without the addition of minor alloying elements to improve its corrosion resistance to an acceptable level under these conditions. The wet crude gas contains about 50 vol\% of steam and the dry gas contains $\mathrm{H}_{2}, \mathrm{CO}_{2}, \mathrm{CO}, \mathrm{CH}_{4}$, and traces of $\mathrm{H}_{2} \mathrm{~S}$. The alloy, which was found to be acceptable after 10,000 hr of exposure, has a composition (in wt\%) of 25-27 $\mathrm{Cr}, 30-32 \mathrm{Ni}, 0.06-0.12 \mathrm{Ce}$, with the balance made up of $\mathrm{Fe}$. The Ce serves to mitigate spalling of the oxide film during thermal cycling by improving the adherence of the scales. It also improves the resistance to corrosion and internal oxidation.

Table 13.3-8. Design stress values for typical gasifier plate steels; reproduced from Ref. 1 and based on data of $D$. A. Canonico et al (1978).

\begin{tabular}{|c|c|c|c|c|c|c|}
\hline \multicolumn{2}{|c|}{ Material } & \multirow{2}{*}{$\begin{array}{c}\text { Minimum } \\
\text { tensile } \\
\text { strength, } \\
\text { MPa (ksi) } \\
482(70)\end{array}$} & \multirow{2}{*}{$\begin{array}{c}\begin{array}{c}\text { Minimum } \\
\text { yield } \\
\text { strength, } \\
\text { MPa (ski) }\end{array} \\
262 \text { (38; }\end{array}$} & \multirow{2}{*}{$\begin{array}{l}\text { Maximum } \\
\text { allowable stress } \\
\text { (Sect. VIU Div. 1), } \\
-29 \text { to } 343^{\circ} \mathrm{C} \\
\text { MPa (ksi) } \\
121(17.5)\end{array}$} & \multirow{2}{*}{$\begin{array}{c}\frac{T}{\circ} \mathrm{C}\left({ }^{\circ} \mathrm{F}\right) \\
260(500) \\
343(650) \\
371(700)\end{array}$} & \multirow{2}{*}{$\begin{array}{c}\begin{array}{c}\text { Design stress } \\
\text { intensity } \\
\text { (Sect. VHI Div. 2), } \\
\text { MPa (ksi) }\end{array} \\
141(20.5) \\
127(18.4) \\
126(18.3)\end{array}$} \\
\hline$A-516-70$ & CS & & & & & \\
\hline$A-204-B$ & $\mathrm{C}-\frac{1}{2} \mathrm{Mo}$ & $482(70)$ & $276(40)$ & $121(17.5)$ & $\begin{array}{l}260(500) \\
343(650) \\
371(700)\end{array}$ & $\begin{array}{l}155(22.5) \\
148(21.4) \\
145(21.0)\end{array}$ \\
\hline$A-204-C$ & $\mathrm{C}-\frac{1}{2} \mathrm{Mo}$ & $517(75)$ & $296(43)$ & $129(18.7)$ & $\begin{array}{l}260(500) \\
343(650) \\
371(700)\end{array}$ & $\begin{array}{l}167(24.2) \\
158(22.9) \\
156(22.6)\end{array}$ \\
\hline$A-302-B$ & $M n-\frac{1}{2} M o$ & $552(80)$ & $345(50)$ & $138(20.0)$ & $\begin{array}{l}260(500) \\
343(650) \\
371(700)\end{array}$ & $\begin{array}{l}184(26.7) \\
184(26.7) \\
184(26.7)\end{array}$ \\
\hline$A-533-A, B, C$ & $\mathrm{Mn}-\mathrm{Mo}-\mathrm{Ni}$ & $552(80)$ & $345(50)$ & $138(20.0)$ & $\begin{array}{l}260(500) \\
343(650) \\
371(700)\end{array}$ & $\begin{array}{l}184(26.7) \\
184(26.7) \\
184(26.7)\end{array}$ \\
\hline$A-387-22 C 12$ & $2{ }_{4}^{1} \mathrm{Cr}-1 \mathrm{MO}$ & $517(75)$ & $310(45)$ & $119(17.2)$ & $\begin{array}{l}260(500) \\
343(650) \\
371(900)\end{array}$ & $\begin{array}{l}159(23.0) \\
158(22.9) \\
117(17.0)\end{array}$ \\
\hline
\end{tabular}


TEMPERATURE $\left({ }^{\circ} \mathrm{C}\right)$

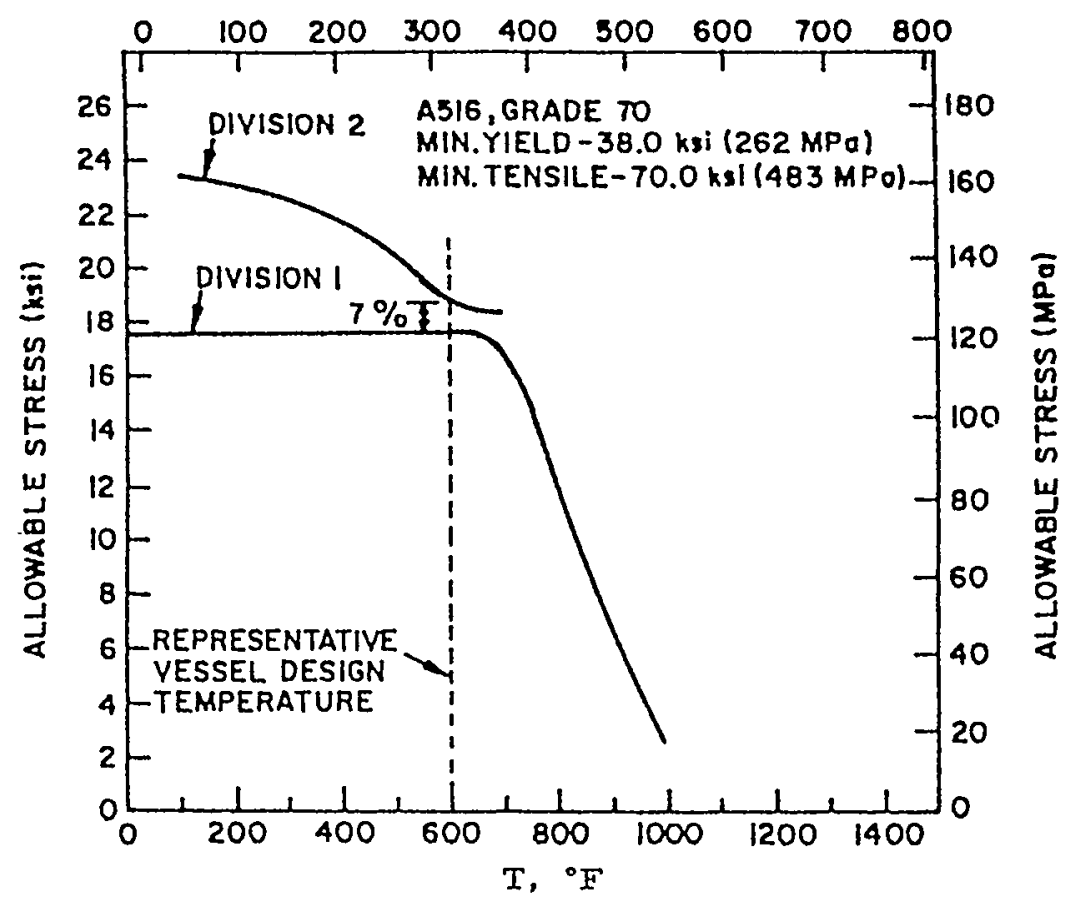

Fig. 13,3-8. Comparison of the allowable stresses os Section VIII, Division 1 and the allowable stress intensities of Section VIII, Division 2 for SA 516 grade 70 steel; reproduced from Ref. 1 and based on data of D. A. Canonico et al (1978).

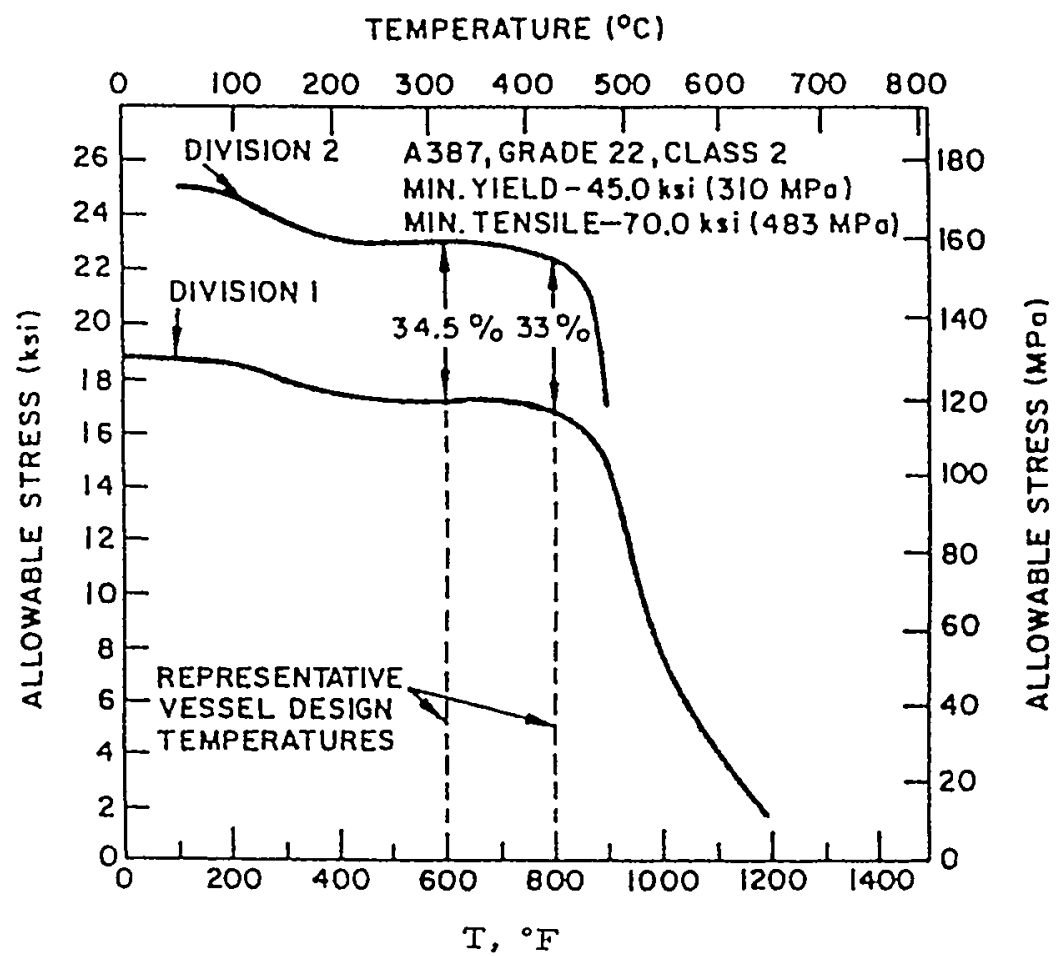

Fig. 13,3-9. Comparison of the allowable stresses of Section VIII, Division 1 and the allowable stress intensities of Section VIII, Division 2, for SA 387 grade 22 class 2 steel; reproduced from Ref. 1 and based on data of D. A. Canonico et al (1978). 
Table 13.3-9. Boiler tubing alloy recommendations (based on stress and fireside/steam side corrosion); reproduced from Ref. 1 D. E. Thomas et al (1976).

\begin{tabular}{|c|c|c|c|}
\hline \multirow{2}{*}{ Pressure, $\mathrm{MPa}$ (psi) } & \multicolumn{3}{|c|}{ Temperatures } \\
\hline & $538^{\circ} \mathrm{C}\left(1000^{\circ} \mathrm{F}\right)$. & $649^{\circ} \mathrm{C}\left(1200^{\circ} \mathrm{F}\right)$ & $.760^{\circ} \mathrm{C}\left(1400^{\circ} \mathrm{F}\right)$ \\
\hline $2.41(350)$ & $2 \frac{1}{4} \mathrm{Cr}-1 \mathrm{Mo}$ & & $\begin{array}{l}347 \text { SS } \\
\text { Inco Clad } 671 / 800 \mathrm{H} \\
\text { Incoloy } 802\end{array}$ \\
\hline $3.10(450)$ & - & & Incoloy 82 \\
\hline $4.10(600)$ & $2 \frac{1}{4} \mathrm{Cr}-1 \mathrm{MO}$ & $\begin{array}{l}304 \mathrm{SS} \\
\text { Incoloy } 800 \mathrm{H} \\
\text { Incoloy } 802\end{array}$ & Incoloy 802 \\
\hline $4.31(625)$ & $2 \frac{1}{4} C x-1 M o$ & & - \\
\hline $7.58(1100)$ & $2 \frac{1}{4} \mathrm{Cr}-1 \mathrm{Mo}$ & $\begin{array}{l}304 \mathrm{SS} \\
\text { Incoloy } 800 \mathrm{H} \\
\text { Incoloy } 802\end{array}$ & $\begin{array}{l}\text { Inco Clad } 671 / 800 \mathrm{H} \\
\text { Incoloy } 802 \\
\text { Inconel } 617\end{array}$ \\
\hline $8.96(1300)$ & - & Incoloy 802 & - \\
\hline $12.40(1800)$ & - & Incoloy 802 & - \\
\hline $13.78(2000)$ & - & $\begin{array}{l}316 \mathrm{SS} \\
347 \mathrm{SS} \\
\text { Incoloy } 802\end{array}$ & $\begin{array}{l}- \\
-\end{array}$ \\
\hline $15.16(2200)$ & - & Incoloy 802 & $\begin{array}{l}\text { Incoloy } 802 \\
\text { Inconel } 617\end{array}$ \\
\hline $16.54(2400)$ & 304 SS/Incoloy $800 \mathrm{H}$ & $\begin{array}{l}304 \mathrm{SS} \\
\text { Incoloy } 800 \mathrm{H} \\
\text { Incoloy } 802\end{array}$ & $\begin{array}{l}\text { Incoloy } 802 \\
\text { Inconel } 617 \\
\text { HA } 188\end{array}$ \\
\hline $24.12(3500)$ & 304 SS/Incoloy $800 \mathrm{H}$ & $\begin{array}{l}304 \text { SS } \\
\text { Incoloy } 800 \mathrm{H} \\
\text { Incoloy } 802\end{array}$ & $\begin{array}{l}\text { Inconel } 617 \\
\text { HA } 188 \\
\text { S } 816\end{array}$ \\
\hline $31.00(4500)$ & 304 SS/Incoloy $800 \mathrm{H}$ & $\begin{array}{l}\text { Incoloy } 802 \\
\text { Incoloy } 617\end{array}$ & S 816 \\
\hline $34.45(5000)$ & 304 SS/Incoloy $800 \mathrm{H}$ & Incoloy 617 & S 816 \\
\hline
\end{tabular}


Table 13.3-10. Representative coal-gasification atmos pheres; reproduced from Ref. 5. The product gas compositions axe given in vol\%.

\begin{tabular}{l|c|c|c}
\hline \multicolumn{1}{c|}{ Compounds } & $\mathrm{MPC}^{\mathrm{a}}$ & Medium BTU $^{\mathrm{b}}$ & Low BTU $^{\mathrm{c}}$ \\
\hline $\mathrm{H}_{2}$ & 24 & 30 & 12 \\
$\mathrm{H}_{2} \mathrm{O}$ & 39 & 14 & 8 \\
$\mathrm{5O}$ & 18 & 44 & 20 \\
$\mathrm{CO}_{2}$ & 5 & 10 & 8 \\
$\mathrm{CH}_{4}$ & $\left(\mathrm{NH}_{3}-1\right)$ & - & 4 \\
$\mathrm{~N}_{2}$ & 1 & 2 & 47 \\
$\mathrm{H}_{2} \mathrm{~S}$ & 1.62 & 0.6 & 1 \\
$\mathrm{H}_{2} \mathrm{O}: \mathrm{H}_{2}$ & 0.66 & 0.47 & 0.67 \\
$\mathrm{CO}_{2}: \mathrm{CO}$ & 51 & 0.23 & 0.40 \\
$\mathrm{H}_{2} \mathrm{O}+\mathrm{CO}$ & 24 & 16 \\
\hline $\mathrm{a}$ & & & 16 \\
\hline
\end{tabular}

${ }^{\mathrm{M}} \mathrm{MPC}$ laboratory test atmosphere modelled after the Hygas pilot-plant product gas.

${ }^{b}$ Oxygen-blown slagging gasifier.

Air-blown gasifier.

Table 13.3-11. Based on the results of $1500-3000 \mathrm{hr}$ tests. The listed materials and coatings are considered to have good potential for further testing, evaluation, or development as syngas-cooler components; xe produced from Ref. 5 .

\begin{tabular}{l|c|c|c|c}
\hline \multirow{2}{*}{ Alloy coating } & \multicolumn{3}{|c}{ Maximum temperature, ${ }^{\circ} \mathrm{C}$} \\
\cline { 2 - 5 } T-11.22 steels & $<300$ & 300 & 400 & 500 \\
16-18Cr steels & $\mathrm{X}$ & & & \\
23-25Cr steels & & $\mathrm{X}$ & & \\
Types 304, 347SS & & & $\mathrm{X}$ & \\
Types 309 and 310SS, HK40 & & & & $\mathrm{X}$ \\
Titanium & & & & $\mathrm{X}$ \\
T-11 alonized & & & & $\mathrm{X}$ \\
T-11 chromized & & & & $\mathrm{X}$ \\
T-11 sprayed aluminum & & & & \\
\hline
\end{tabular}


Matexials for syngas coolers of entrained slagging gasifiers

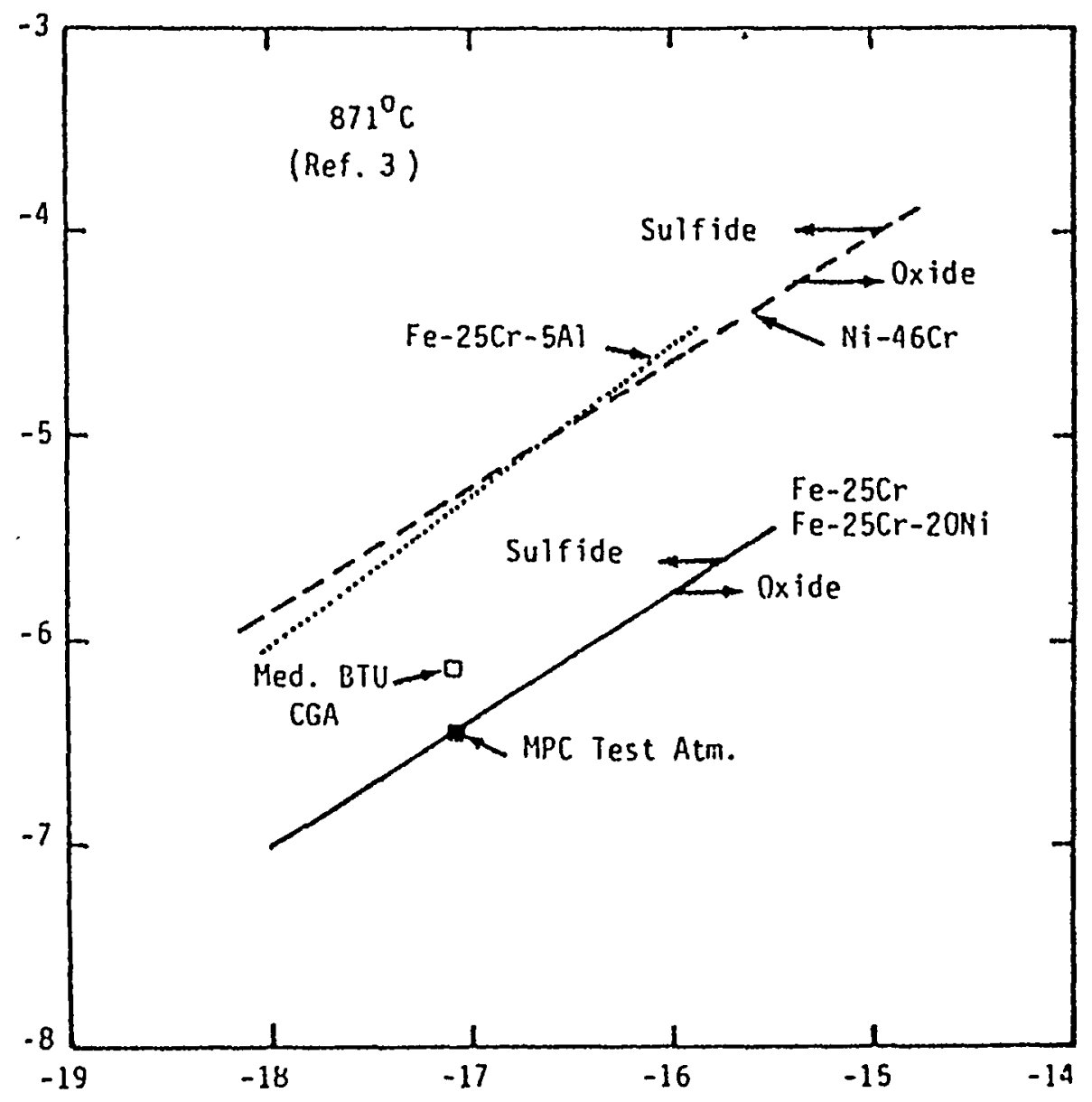

Fig. 13.3-10. Oxide-sulphide transition boundaries (ordinate $=\log \mathrm{P}_{\mathrm{S}_{7}}$, abscissa $=$ $\left.\log \mathrm{PO}_{2}\right)$, pressures in atmospheres. Reproduced from Ref. 5 and based on data of R.A. Perkins and S. J. Vonk (1979).

\section{References for Section 13.3}

1. W.A. Ellingson, K. Natesan, and T. Vojnovich, "Materials of Construction," pp. 488-610 in The Science and Technology of Coal and Coal Utilization, B.R. Cooper and W.A. Ellingson eds., Plenum Press, NY and London (1984).

2. K. Natesan and W.T. Bakker, "Corrosion in Coal Gasification Systems," pp. 185-194 in Proc. Conf. on "Materials for Future Energy Systems," 1-3 May, 1984, Washington, DC, American Society for Metals, Metals Park, Ohio (1985). 
3. I.G. Wright, A.R. 01 sen, and S. Ibarra, "Erosion-Resistant Materials for Critical Areas of Coal Liquefaction and Coal Gasification Systems," ibid. pp. 205-216.

4. A.G. Imgram and R.A. Swift, "Pressure Vessel, Piping, and Welding Needs for Coal Conversion Systems," ibid. pp. 217-233.

5. R. A. Perkins, "Materials for Syngas Coolers of Entrained Slagging Gasifiers," pp. 219-258 in Corrosion Resistant Materials for Coal Conversion Systems, D.B. Meadowcroft and M.I. Manning eds., Applied Science Publishers, London and NY (1983).

6. H.J. Schroter and K.H. Van Heek, "Status of Coal Gasification in Europe and Related Requirements on Materials," ibid. pp. 181-218.

7. W. Schendler, "High Temperature Corrosion of Materials for Steam-Coal Gasification Utilizing Nuclear Process Heat," ibid. pp. 201-218. 
CHAPTER 14:

\section{INTRODUCTION TO COSTING*}

Capacity-factored estimating and equipment-factored estimating represent the two primary techniques used in the conceptual-estimation of synfuels projects. These two techniques and their limitations will be discussed. We conclude with an overview of the assessment of risk associated with an estimate. Before describing these approaches to conceptual estimating, cost definition must be established. Our objective in estimating is to establish the selling price or installed cost of a new facility. The selling price is composed of the following four major cost elements: (i) Direct field costs are those of the permanent physical plant facilities and include field material, subcontracts, and labor. (ii) Indirect field costs include 211 of the construction support of the permanent facility. (iii) Home-office costs include all labor and expenses associated with engineering of the facility. (iv) Other costs include sales taxes, escalation, and contingency.

Figure 14-1 shows a typical distribution of project costs between the four major cost elements. The largest cost element is the direct field cost. This is the primary element we focus on in defining the data base used for conceptual estimation. The variable nature of the remaining costs elements causes us to treat these items only at the total project level, after the direct field costs have been established for all processes, utilities, and offsites.

Capacity-factored estimates for new process units are derived from the battery-limit costs of similar units of the same or different capacities (i.e., coal gasification, gas cooling and scrubbing, steam generation, etc.). Through the use of normalized historical data, the capacityfactored estimating technique can be used to scale the costs of similar

* This chapter has been written by D. Pescarolo, Fluor Technology, Inc., 3333 Michelson Drive, Irvine, CA 92780. 
process plants to arrive at the direct field costs within the battery limits of the new process facility. Direct field costs within the data base contain normalized man-hours and material dollars. After scaling to the new plant capacity, labor efficiencies, wage rates, and material escalation can be applied to adjust for new plant location and timing.

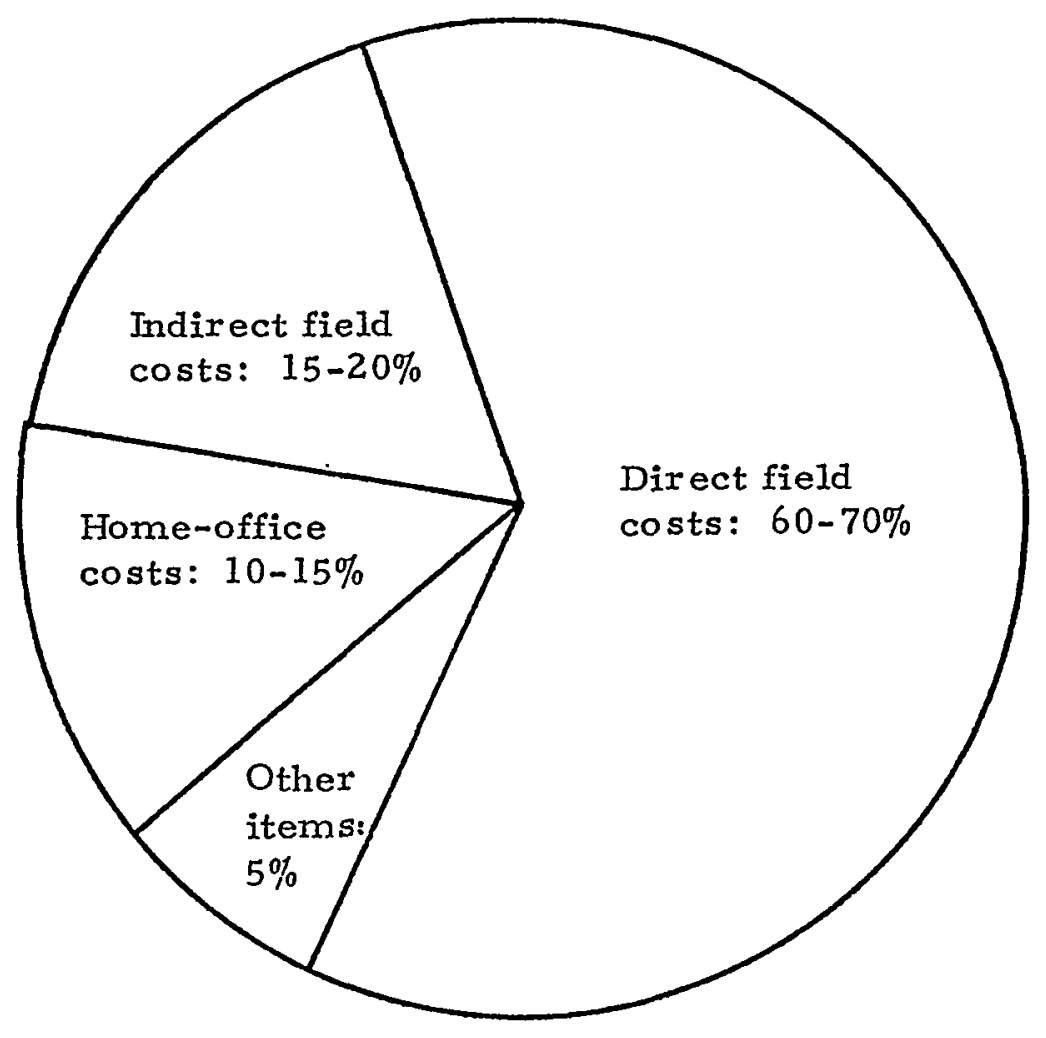

Fig. 14-1. Relative costs of the four major cost elements in the total project cost.

The accuracy associated with the capacity-factored estimate depends on several key factors. Most critical is the similarity of the base or reference plant to the new plant. Significant differences in configuration, operating conditions, or feedstock will greatly reduce the accuracy of the estimate. Coal composition and legislated environmental constraints are some of the major items driving the design configuration and the costs associated with early synfuels studies. The accuracy of the estimate is related to our confidence in the design basis. 
In the absence of a closely-matched process plant that may be used in capacity-factored estimating, an equipmeht-factored estimating approach is used. Here, each piece of equipment represents a module. The equipment modules become building blocks of a process 'unit. Each equipment module includes all costs required to install that piece of equipment at the direct field-cost leve1. Each equipment item must be defined in terms of capacity, metallurgy, and design pressure and temperature. These are the mandatory data elements needed to establish the direct field costs associated with equipment items. The accuracy associated with the cost of a process unit estimated through this approach is related to our ability to recognize all equipment items required to operate the process unit at the required stream factor. Table 14.1 summarizes data required to support EXPONE, an equipment-factoring estimating tool.

The firmer the design, the greater the confidence in the estimate. Soft areas in process or design definition must be clearly segregated and analyzed for cost-growth potential. The quality of an estimate then depends on the information known at the time of the estimate. Contingency is normally applied to mitigate the cost-growth potential associated with the unknown. Items that must be considered in establishing contingency are project definition, labor efficiency, materials pricing, subcontractor performance, estimated tolerances, minor scope changes, minor schedule delays, process uncertainties, wage rates, and environmental impositions.

One of the most important factors causing estimate uncertainty for conceptual facilities is the level of process and project definition when the estimate is made. Uncertainty and risk in an estimate can be defined and measured through the use of probability models. If properly performed, this analysis results in a valuable tool for management. Management thus has a vehicle to go from qualitative to quantitative statements about uncertainty in terms of probability of underruning the estimated cost. The proper use of a risk model enables us to identify weak links, thereby quantifying cost-growth potential. Management may then concentrate on design issues causing greatest uncertainty.

For a $\$ 300$ million plant, Fig. 14-2 shows the probability of underrun curve for a capacity-factored estimate. The factored or conceptual estimate confidence of underrun is less than $30 \%$. To increase this value to $50 \%, 13 \%$ contingency would have to be added; $31 \%$ additional contingency 
would yield a $75 \%$ confidence of underrun. Bringing conceptual studies to $50 \%$ probability of underrun is the norm.

Figure 14-3 shows the probability of an underrun curve for a detailed estimate. For this case, the engineering of the $\$ 300$ million plant is $40 \%$ complete; orders have been placed for $90 \%$ of the machinery and equipment. The resulting curve shows a greater probability of underrun, and the $50 \%$ probability is achieved with $3 \%$ contingency.

Figure 14-4 shows both the capacity-factored-estimate and the detailed-estimate probability of underrun curves. The greater confidence in underrun shown on the detailed estimate is a function of the maturity of design. Figure 14-4 clearly shows the influence of design development on confidence in the estimate. The absolute cost difference between the conceptual and detailed estimates is not great in this example. This type of result is obviously not always obtained, but if it is accepted that one of the major uses of conceptual estimates is to determine process configuration alternatives; then, the absolute cost is not critical. Instead, cost differences are important. Thus, the ability to use consistent data and estimating tools for each design case is of paramount importance in conceptual estimating. If properly done, costs are then driven by design configuration alone and not by differences in estimating techniques.

Table 14-1. Mandatory and desired input data for the EXPONE equipment-factored estimate.

Mandatory Data: equipment definition, capacity, metallurgy, design
pressure, design temperature.

Desired Data: mechanical flow diagrams, project specifications, piping transpositions, equipment-data sheets, equipment-price quotations, major electrical equipment pricing, electrical one-line diagrams, plot plans, building and structure sketches. 


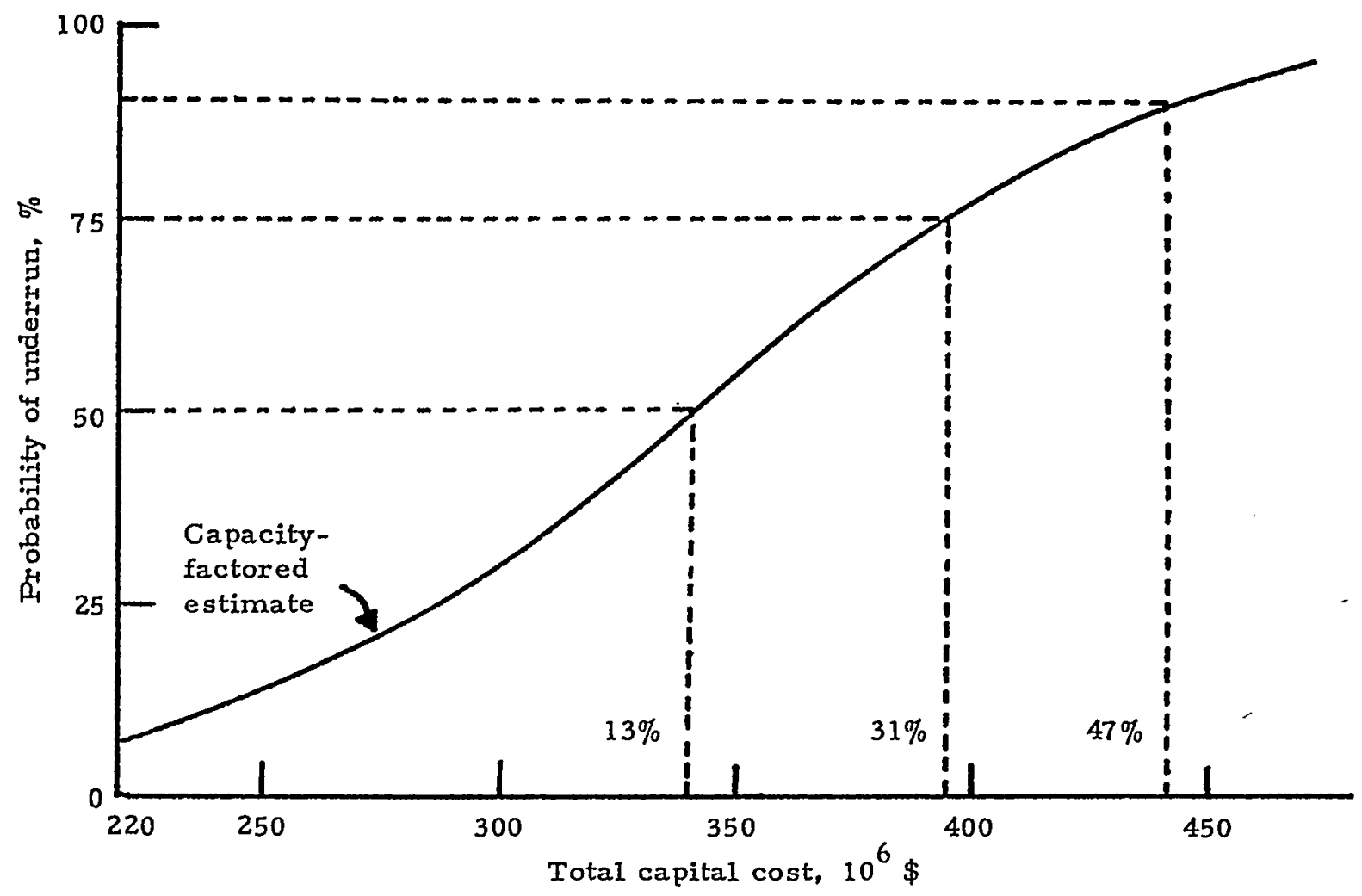

Fig. 14-2. Cumulative probability for a capacity-factored estimate of a $\$ 300$ million plant.

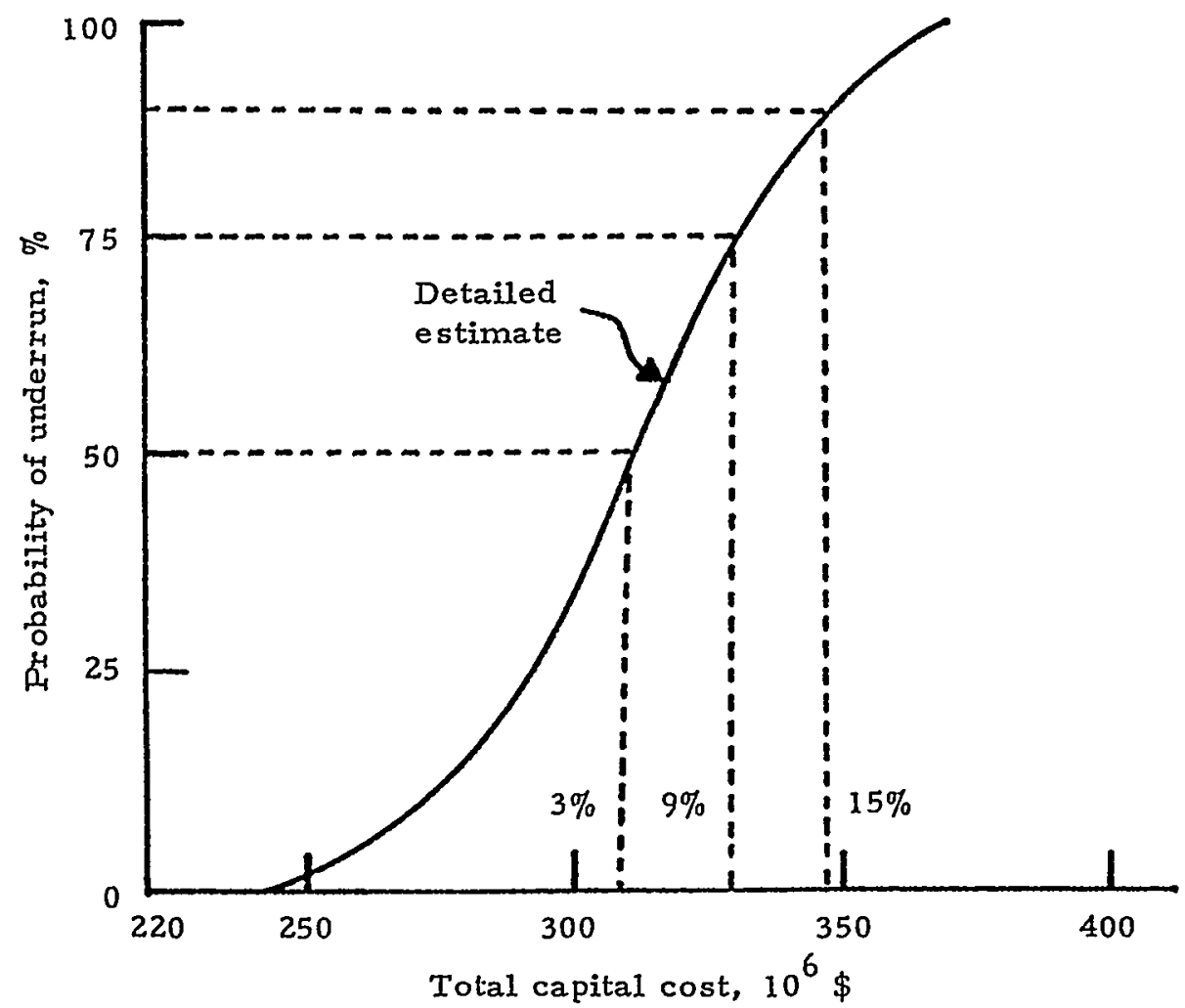

Fig. 14-3. Cumulative probability for a detailed estimate of a $\$ 300$ million plant. 


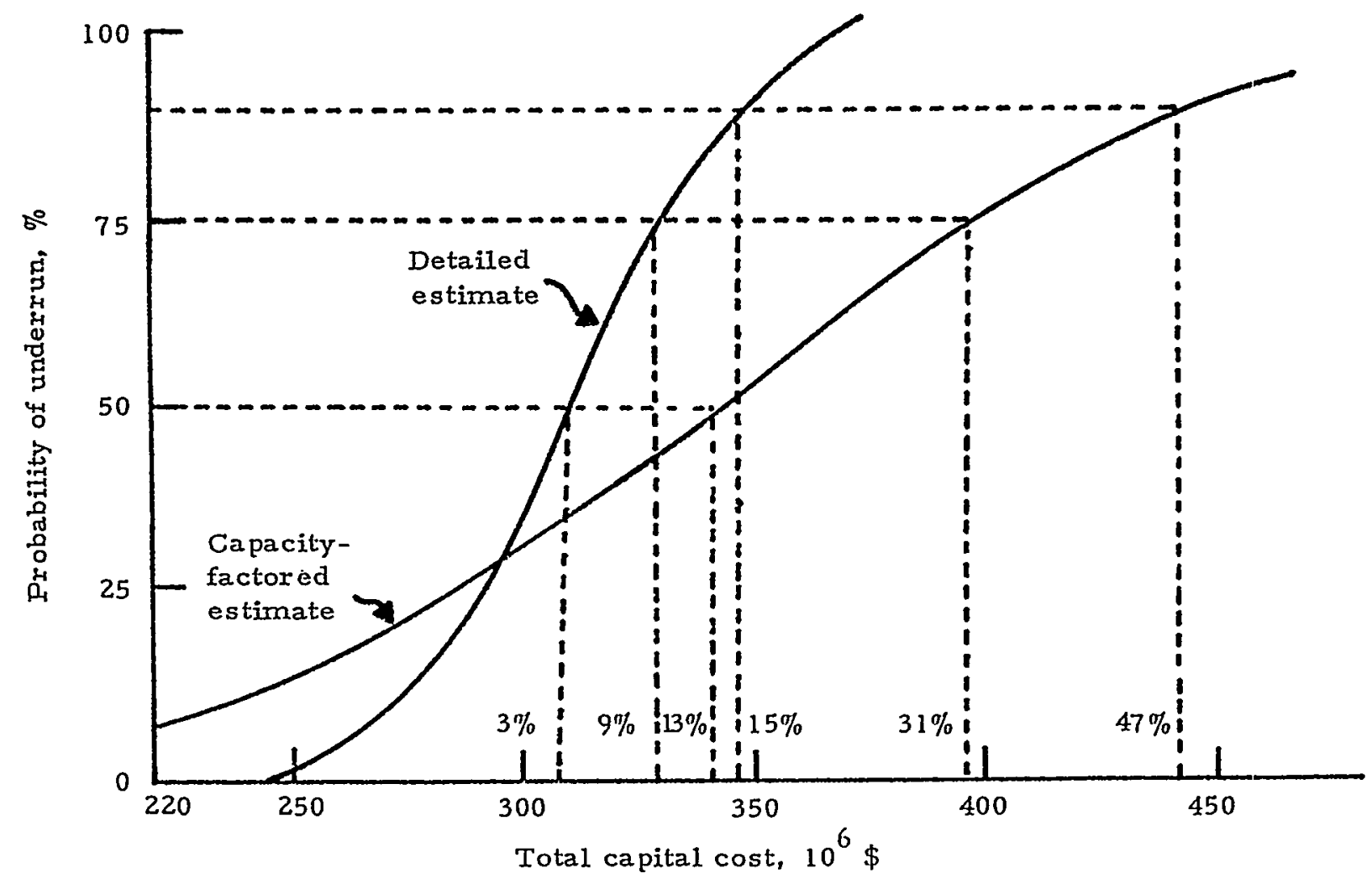

Fig. 14-4. Cumulative probabilities for a $\$ 300$ million plant based on a detailed estimate and a capacity-factored estimate.

In summary, conceptual estimating data and tools, when properly used with probability simulations, are major contributors to the decisionmaking process between design alternatives and in determining plant economics. 
APPENDIX: GENERAL REMARKS ON COAL-GASIFICATION SYSTEMS*

A convenient manner of viewing gasifiers is illustrated in Fig. A-1. ${ }^{1}$ In the gasification zone, product $t^{z}$ gas and ash are formed by reactions involving oxygen, steam and coal (a). The gasification zone is intimately coupled with the devolatilization region (b) and (c).

Devolatilization is accomplished either by mixing the feed coal with hot gas in a countercurrent flow (b) or by creating a completely stirred mixing region (c). In both cases, heating is accomplished by hot gases from the gasification zone, char is returned to the gasification zone, and hot exit gases are removed from the devolatilization zone.

R.V. Shinnar ${ }^{1}$ defines an ideal gasifier as a unit in which the heats of combustion and gasification are exactly balanced, whereas practical gasifiers are non-adiabatic and operate with heat removal. In practice, excess steam, gas and fines recycle are used at high gasifier outlet temperatures, with or without a waste-heat boiler (as in the Winkler).

An extensive overview of gasifier performance based on stoichiometric, kinetic, and thermodynamic considerations is given by Denn and Shinnar in Ref. 2. Deviations from optimum conditions imposed by process constraints are detailed, and further insight into the operation of the three basic gasifier types (moving-bed, entrained-flow, and fluidized-bed) is obtained by computer modeling. ${ }^{2}$ Comparisons between actually operating gasifiers are made and ideal operating conditions are identified. ${ }^{2}$

\section{A-1. Stoichiometry of Coal Conversion ${ }^{1}$}

The conversion of coal with elemental composition $\mathrm{CH}_{\mathrm{a}} \mathrm{O}_{\mathrm{b}}(\mathrm{a} \simeq 0.8$, $b=0.1$ to 0.2 ) by oxygen (in the ratio $R$ moles of $O_{2}$ per mole of $C$ ) and water ( $\mathrm{Su}+\mathrm{Sp}$ moles of $\mathrm{H}_{2} \mathrm{O}$ per mole of $\mathrm{O}_{2}$ ) is described by the following stoichiometric equation if $\mathrm{m}$ moles of $\mathrm{CH}_{4}$ are formed per mole of $\mathrm{C}$ and RSp moles of $\mathrm{H}_{2} \mathrm{O}$ remain per mole of $\mathrm{C}$ :

* Based on a presentation by R. Shinnar (Department of Chemical Engineering, CUNY, NY 10031) at the Fourth Technical Meeting of COGARN. ${ }^{1}$ This Appendix has been prepared by S.S. Penner and D.F. Wiesenhahn. 


$$
\begin{aligned}
\mathrm{CH}_{a} \mathrm{O}_{b}+\mathrm{RO}_{2}+\mathrm{R}(\mathrm{Su}+\mathrm{Sp}) \mathrm{H}_{2} \mathrm{O} & \rightarrow(2-2 \mathrm{R}-\mathrm{SuR}-\mathrm{b}-2 \mathrm{~m}) \mathrm{CO}+[\mathrm{SuR}+(\mathrm{a} / 2)-2 \mathrm{~m}] \mathrm{H}_{2} \\
& +(2 \mathrm{R}+\mathrm{SuR}+\mathrm{b}+\mathrm{m}-1) \mathrm{CO}_{2} \\
& +\mathrm{m} \times \mathrm{CH}_{4}+\mathrm{RSp} \times \mathrm{H}_{2} \mathrm{O},
\end{aligned}
$$

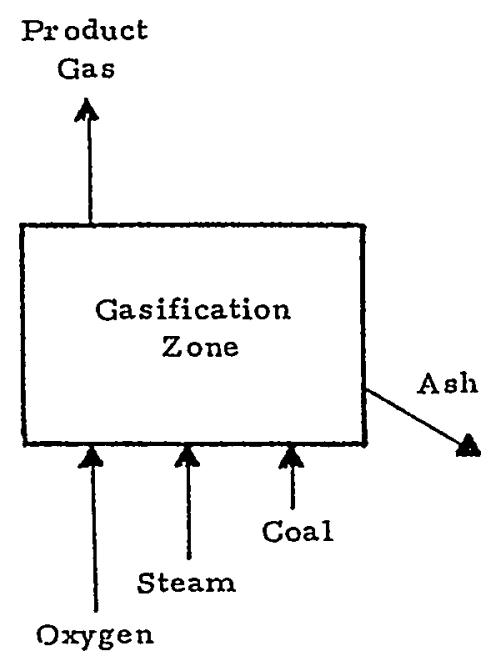

(a)

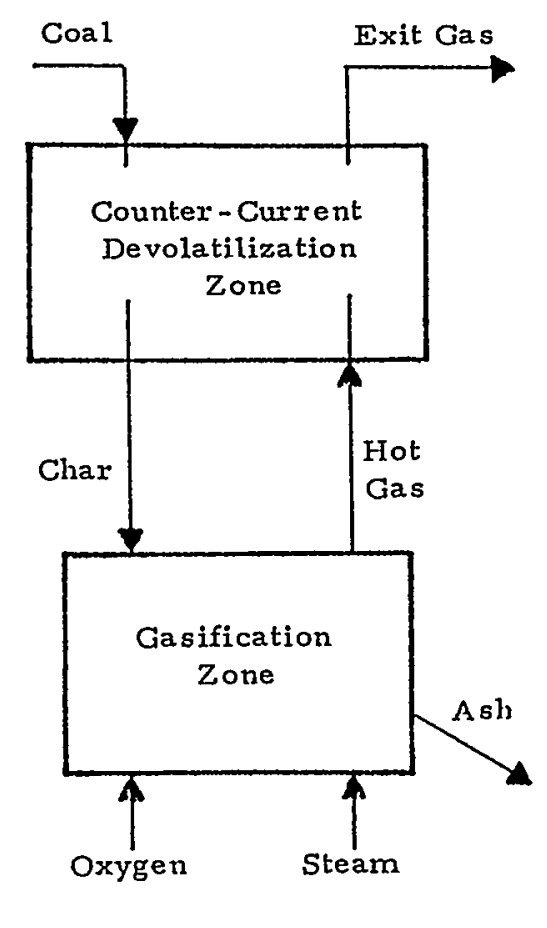

(b)

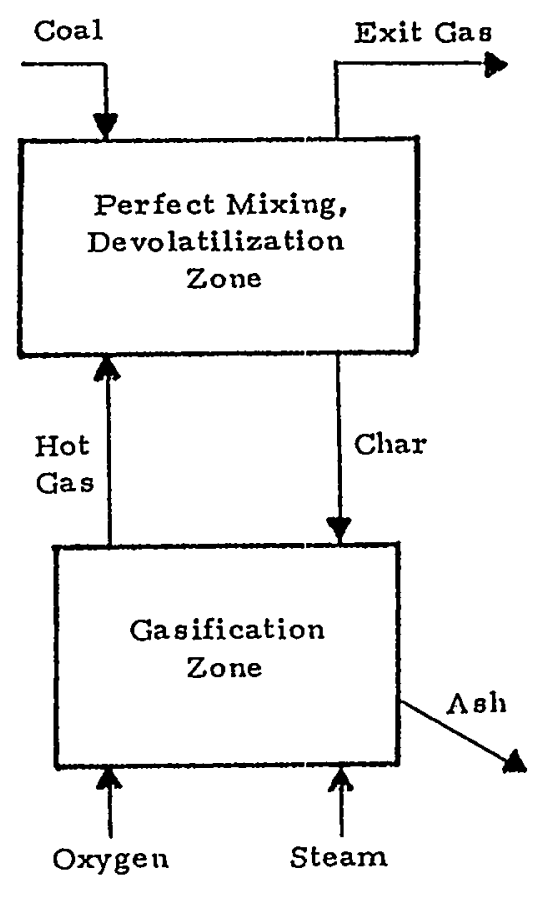

(c)

Fig. A-1. Schematic representation of gasifiers; from Ref. 1.

where the coefficients multiplying $\mathrm{CO}, \mathrm{CO}_{2}$ and $\mathrm{H}_{2}$ follow immediately from mass conservation in view of the stoichiometric inputs of reactants. A parameter that does not depend on either the water-feed or methane-production rates may be formed by adding the overall stoichiometric coefficients of $\mathrm{CO}$ and $\mathrm{H}_{2}$ per mole of $\mathrm{CH}_{a} \mathrm{O}_{\mathrm{b}}$ to $4 \mathrm{~m}$. The result has been termed a stoichiometric invariant and is given by

$$
\begin{aligned}
I=(2-2 R & -S U R-b-2 m) \\
+ & {[S u R+(a / 2)-2 m]+4 m=2-b+(a / 2)-2 R . }
\end{aligned}
$$


The parameter $I$ is seen to depend only on the oxygen-feed ratio $R$ and on the coal composition ( $a$ and $b$ ). In the absence of methane formation $(m=0)$ and without feed $\mathrm{CO}_{2}$ or the addition of $\mathrm{H}_{2} \mathrm{O}$ to effect gas conversion ( $S u=0$ or $S u+S p=S p=0$ ), all of the carbon is converted to $C O$ when the coefficient of $\mathrm{CO}_{2}$ in Eq. (A-1) vanishes, i.e.,

$$
R=R_{c}=(1 / 2)(1-b) \text { or } 2-2 R_{c}-b=1 \text {. }
$$

This limiting value of $R=R_{C}$ represents the minimal oxygen-to-carbon ratio for complete conversion of $C$ to $C 0$; with $b=0.1$ to $0.2,0.40 \leq R_{C} \leq 0.45$. For $R>R_{C}$, some of the carbon must be converted to $\mathrm{CO}_{2}$. In terms of $I$ [compare Eq. $(A-2)]$, the difference between $R$ and $R_{C}$ becomes

$$
R-R_{c}=(1 / 2)\{[1+(a / 2)]-I\} .
$$

The molar heat of combustion of $\mathrm{CO}$ to form $\mathrm{CO}_{2}$, the HHV for the molar heat of combustion of $\mathrm{H}_{2}$, and one third of the molar heat of combustion of $\mathrm{CH}_{4}$ when using the HHV for the water formed are all nearly equal ( $\approx 68 \mathrm{kcal})$. Thus, the total heat of combustion of the product gases, measured in units of 68 kcal, is approximately

$$
h=2-2 R-S U R-b-2 m+S U R+(a / 2)-2 m+3 m=I-m,
$$

where we have used Eq. (A-2). It is apparent from Eq. (A-5) that methane formation reduces the reaction heat unless it affects $I$. That methane formation increases I follows immediately from the fact that carbon conversion to methane reduces oxygen requrements (i.e., it reduces $R$ ) and hence increases I according to Eq. (A-2).

Shinnar has emphasized the importance of minimizing the costs of feed steam and oxygen. This cost is roughly proportional to $\mathrm{R}(4.1+\mathrm{Su}+$ $\mathrm{Sp}$ ) since oxygen feed costs roughty 4.1 times as much as steam feed. Cost minimization requires minimizing the unused steam in the product gases (RSp) per mole of $\mathrm{CH}_{\mathrm{a}} \mathrm{O}_{\mathrm{b}}$. In the absence of methane production $(\mathrm{m}=0)$, the steam feed rate for gasification and shift is bounded by the requirements that it must less than or equal to the value that makes the coefficient of $\mathrm{CO}$ in Eq. (A-1) greater than or equal to zero and it must be greater than 
or equal to the value required to make the coefficient of $\mathrm{CO}_{2}$ in Eq. $(\mathrm{A}-1)$ greater than or equal to zero, i.e.,

$$
\operatorname{SUR} \leq 2-2 R-b, \quad \operatorname{SUR} \geq 1-b-2 R ;
$$

combining these two inequalities and replacing $b$ according to Eq. (A-3), we find that

$$
(2 / R)\left(R_{c}-R\right) \leq S u \leq(2 / R)\left[R_{c}-R+(1 / 2)\right] .
$$

Easily measurable gasifier parameters are the cold-gas composition and the flow rates of oxygen, coal and product gas. The extent of carbon and steam conversion and the fines flow rate are difficult to measure.

A-2. Gasifier Efficiency

Shinnar and $\mathrm{KuO}^{3}$ measure the gasifier efficiency by the ratio of non-recoverable energy in the feed to the LHV of the product gases. This ratio, per mole of $\mathrm{CH}_{a} \mathrm{O}_{b}$, is proportional to

$$
\begin{aligned}
& E_{L}=[R(S u+S p)+4.1 R] / \\
& {[(2-2 R-S u R-b-2 m)+0.85[S u R+(a / 2)-2 m]+2.85 m] }
\end{aligned}
$$

since the relative LHVs of $\mathrm{CO}, \mathrm{H}_{2}$ and $\mathrm{CH}_{4}$ are proportional to $1,0.85$ and 2.85 , respectively. In terms of moles of reactants and products per mole of $\mathrm{CH}_{a} \mathrm{O}_{b}$, the quantity $E_{L}$ may be written as

$$
E_{L}=\left[\left(\mathrm{H}_{2} \mathrm{O}\right)+4.1\left(\mathrm{O}_{2}\right)\right] /\left[(\mathrm{CO})+0.85\left(\mathrm{H}_{2}\right)+2.85\left(\mathrm{CH}_{4}\right)\right]
$$

where quantities in parentheses denote moles per mole of $\mathrm{CH}_{a} \mathrm{O}_{b}$. For an SNG plant, the applicable heating values are the HHVs, which are in the ratio 1 , \#1 and 3 for $\mathrm{CO}, \mathrm{H}_{2}$ and $\mathrm{CH}_{4}$, respectively, and the denominator in Eq. (A-7) therefore becomes $(\mathrm{CO})+\left(\mathrm{H}_{2}\right)+3\left(\mathrm{CH}_{4}\right)$; the resulting value of $E$ for this system is designated as $\mathrm{E}_{\mathrm{CH}_{4}}$. The lower $\mathrm{E}_{\mathrm{L}}$ or $\mathrm{E}_{\mathrm{CH}_{4}}$, the higher the net gasifier efficiency. 
For practical systems, Shinnar ${ }^{1}$ defines a revised oxygenconsumption ratio as

$$
R=\left(O_{2}\right) /(C) x,
$$

where $x=$ fractional carbon conversion and $\mathrm{R}$ (in mole/mole) represents. the moles of $\mathrm{O}_{2}$ required in practice per mole of carbon converted. Furthermore, with $\mathrm{CO}_{2}$ feed, Shinnar ${ }^{1}$ replaces the stoichiometric invariant I of Eq. $(A-2)$ by the following invariant:

$$
\begin{aligned}
& \left(\mathrm{X}_{\mathrm{CO}}+\mathrm{X}_{\mathrm{H}_{2}}+3 \mathrm{X}_{\mathrm{CH}_{4}}\right) /\left[\mathrm{X}_{\mathrm{CO}}+\mathrm{X}_{\mathrm{CO}_{2}}+\mathrm{X}_{\mathrm{CH}_{4}}-\left(\mathrm{CO}_{2}\right) / \dot{M}\right]= \\
& 2+(a / 2 x)-(b / x)-2 R \text {, }
\end{aligned}
$$

where $X_{i}=$ mole fraction of species $i$ in the net dry product gas, $\left(\dot{C O}_{2}\right)=$ $\mathrm{CO}_{2}$ feed rate $(\mathrm{lb}-\mathrm{mole} / \mathrm{hr}$ ), and $\dot{M}=$ net dry product-gas flow rate ( $\mathrm{bb}-\mathrm{mole} / \mathrm{hr}$ ). Here, the numerator on the left side of Eq. $(A-8)$ is proportional to the product-gas heating value, while the denominator represents carbon-species conservation.

Practical gasifiers operate with $R_{C}-R$ close to zero, with both positive and negative values occurring (see Tables $A-1$ and $A-2$ ). Thus, the Lurgi dry ash and slagger gasifiers should be viewed as the only true gasifiers; future design calculations for the KRW show that it may also become a true gasifier. In terms of feed costs for oxygen and steam, the Lurgi slagger and KRW design are cheaper than the Texaco and Shell gasifiers which, in turn, are superior to the Lurgi dry ash and KRW PDU for Illinois No. 6 coal (Table A-1). Similar data for German Braunkohle are also given in Table $\mathrm{A}-2$.

The parameter $E_{L}$ defined in $E q .(A-7)$ represents the steam and oxygen feed cost per unit of syngas produced. It generally decreases rapidly as the temperature is raised above about $1200^{\circ} \mathrm{F}$ and then levels off at higher temperatures. Because of the large effect of $E_{L}$ on gasification cost, gasifier operating temperatures tend to be determined by the minimum temperature above which $E_{L}$ no longer decreases with rising $T$. This statement is consistent with the fact that costs related to steam and oxygen may be as high as $50 \%$ of total syngas-production costs, whereas 
gasification costs alone fall in the range of 10 to $20 \%$. Critical gasifier parameters are coal conversion, thermal efficiency, tar formation, and gas requirements.

Because of its large steam requirement (which is needed for the gasifier to remain below the ash-fusion temperature), the Lurgi dry ash gasifier has a relatively large value of $E_{L}$ (2.6 for Illinois No. 6 coal). The Lurgi slagging gasifier requires less steam and has a resultant lower value of $E_{L} \cdot{ }^{2}$ Steam requirements for the Lurgi dry ash gasifier are lower for higher-reactivity coals (compare Tables $A-1$ and $A-2$ ), resulting in a relatively lower value of $E_{L}$ for reactive coals.

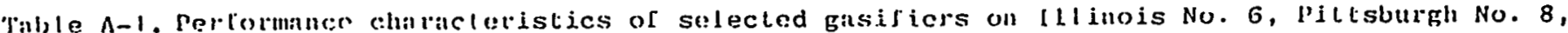
and liest: Kent conls.t

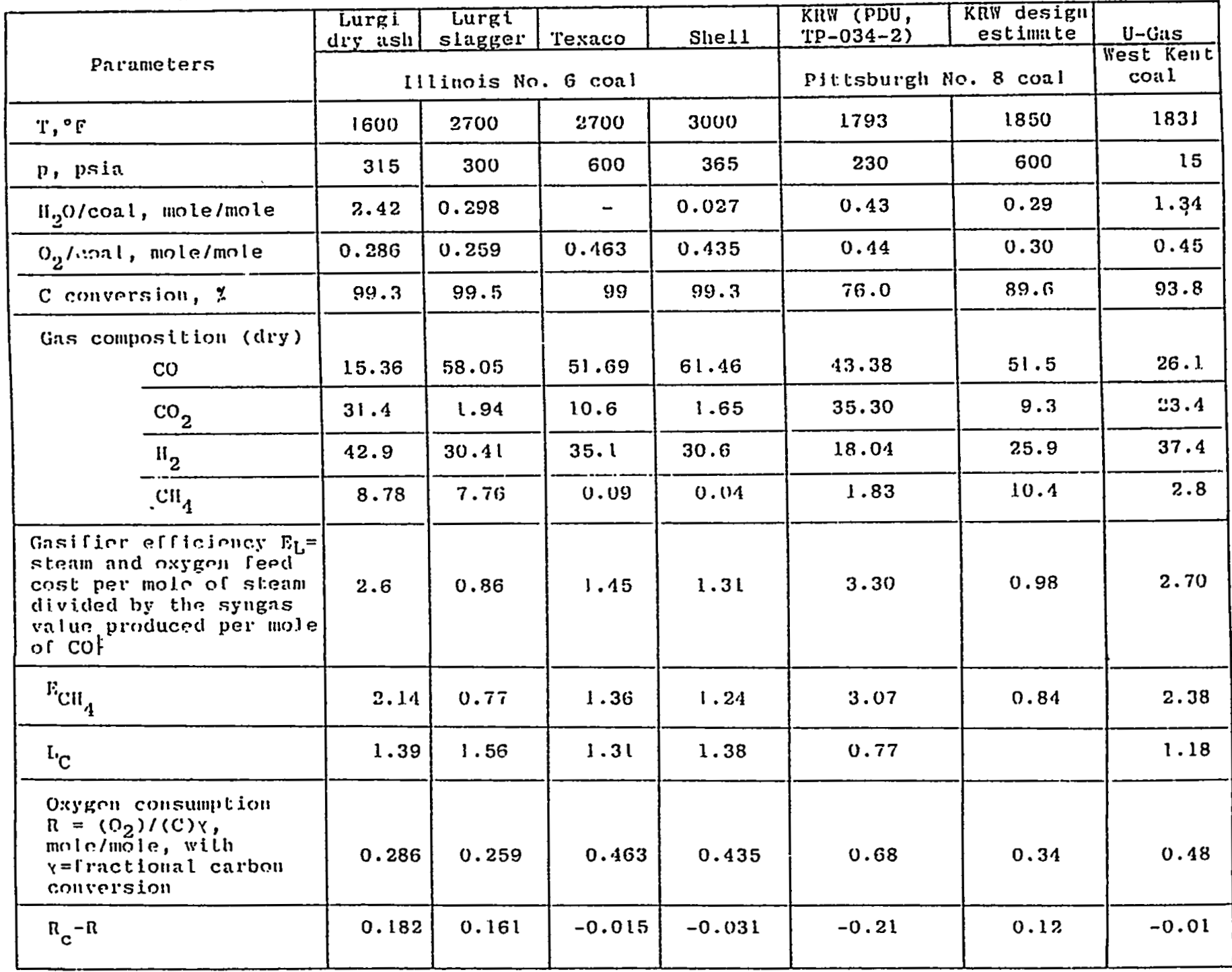

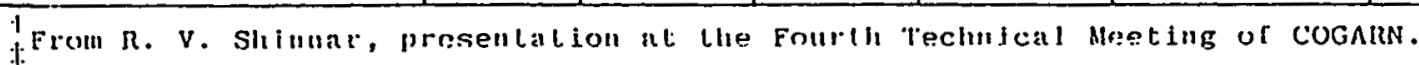

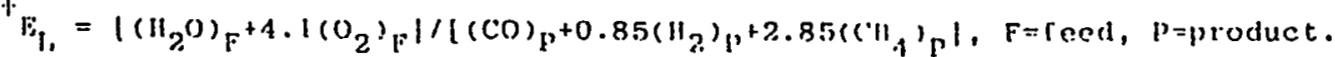


Table A-2. Performance characteristics of selected gasifiers for US Western and German Braunkohle.t

\begin{tabular}{|c|c|c|c|c|c|c|}
\hline Parameters & $\begin{array}{l}\text { Lurgi } \\
\text { dry ash }\end{array}$ & Shell & $\mathrm{KRW}$ & U-Gas & Winkler & HTW \\
\hline Coal Type & Wyoming & $\begin{array}{l}\text { Texas } \\
\text { Iignite }\end{array}$ & $\begin{array}{l}\text { N.D. } \\
\text { lignite }\end{array}$ & Wyoming & $\begin{array}{l}\text { German } \\
\text { Braun- } \\
\text { kohle }\end{array}$ & $\begin{array}{l}\text { German } \\
\text { Braun- } \\
\text { kohle }\end{array}$ \\
\hline $\mathrm{T},{ }^{\circ} \mathrm{F}$ & 900 & 2530 & 1566 & 1570 & 1300 & \\
\hline $\mathrm{p}, \mathrm{psia}$ & 460 & 160 & 230 & 30 & 30 & 150 \\
\hline $\begin{array}{l}\mathrm{H}_{2} \mathrm{O} / \mathrm{coal} \\
\text { mole/mole }\end{array}$ & 1.74 & - & 0.31 & 0.65 & 0.69 & \\
\hline $\begin{array}{l}\mathrm{O}_{2} / \mathrm{coal}, \\
\text { mole/mole }\end{array}$ & 0.23 & 0.45 & 0.37 & 0.29 & 0.33 & 0.34 \\
\hline C conversion, $\%$ & 96 & 98.4 & 88.1 & 89.9 & 89.2 & 96 \\
\hline $\begin{array}{l}\text { Gas composition } \\
\text { (dry) }\end{array}$ & 18.8 & 52.4 & 39.0 & 33.6 & 34.7 & \\
\hline $\mathrm{CO}_{2}$ & 29.6 & 6.2 & 31.6 & 15.6 & 19.4 & \\
\hline $\mathrm{H}_{2}$ & 38.8 & 28.8 & 24.2 & 36.6 & 41.7 & \\
\hline $\mathrm{CH}_{4}$ & 11.9 & 0.1 & 4.2 & 3.8 & 3.1 & \\
\hline $\mathrm{E}_{\mathrm{L}}$ & 1.64 & 1.43 & 1.73 & 1.44 & 2.1 & \\
\hline $\mathrm{E}_{\mathrm{CH}_{4}}$ & 1.34 & 1.36 & 1.54 & 1.27 & 1.9 & \\
\hline $\mathrm{L}_{\mathrm{C}}$ & 1.63 & & & 1.28 & & \\
\hline$R=\left(O_{2}\right) /(C) x$ & 0.23 & 0.46 & 0.42 & 0.33 & 0.37 & 0.36 \\
\hline$R_{c}-R$ & +0.17 & -0.06 & -0.06 & $\begin{array}{c}+0.07 \\
(-0.05)\end{array}$ & +0.03 & -0.02 \\
\hline
\end{tabular}

From R. V. Shinnar, presentation at the Fourth Technical Meeting of COGARN. 
Results for equilibrium calculations of $E_{L}$ as a function of temperature are shown in Fig. A-2 under four sets of assumptions for an Eastern US coal. Similar results are shown in Fig. A-3 for a Western US coal. The values of $E_{L}$ for actually operating gasifiers are also indicated on these figures. All gasifiers, except for the Lurgi slagger and the Lurgi dry ash gasifier (with Western US coal), operate well above the theoretical equilibrium value of $E_{L}$. The calculations show a broad minimum for $E_{L}$ and little gain in efficiency if temperatures are raised above $\sim 1300 \mathrm{~K}$. Also predicted is sensitivity of the value of $E_{L}$. at low temperature when methane production is ignored (curves $A$ and $B$ ). Thus, operation at $T \leqq$ $1300 \mathrm{~K}$ requires methane formation for efficient operation. ${ }^{2}$

A-3. $\quad$ Fluidized-Bed Gasifiers ${ }^{1}$

Fluidized-bed gasifiers are distinguished by their utility in handling a wide variety of coals, including subbituminous coals, lignites, and coal fines. They are relatively safe and adaptable to two-stage countercurrent operation. However, they yield low conversion, require dilute oxygen for operation, fines recirculation is difficult to achieve, and the returned fines have short residence times and low reactivity. clinkering and agglomeration of caking coals are problems, especially in the vicinity of the feed systems.

In the absence of tar and with pure carbon as char, a gasifier has 7 major components $\left(\mathrm{CO}, \mathrm{CO}_{2}, \mathrm{H}_{2} \mathrm{O}, \mathrm{O}_{2}, \mathrm{H}_{2}, \mathrm{C}, \mathrm{CH}_{4}\right)$ and 3 major elements that undergo chemical changes $(\mathrm{C}, \mathrm{H}, \mathrm{O})$, which leaves 4 degrees of freedom. Of these, one is represented by the constraint that there should be no oxygen in the product and another by the existence of shift equilibrium $\left(\mathrm{H}_{2} \mathrm{O}+\mathrm{CO}\right.$ $\left.\rightleftarrows \mathrm{CO}_{2}+\mathrm{H}_{2}\right)$. Hence, there remain two free operating parameters. 


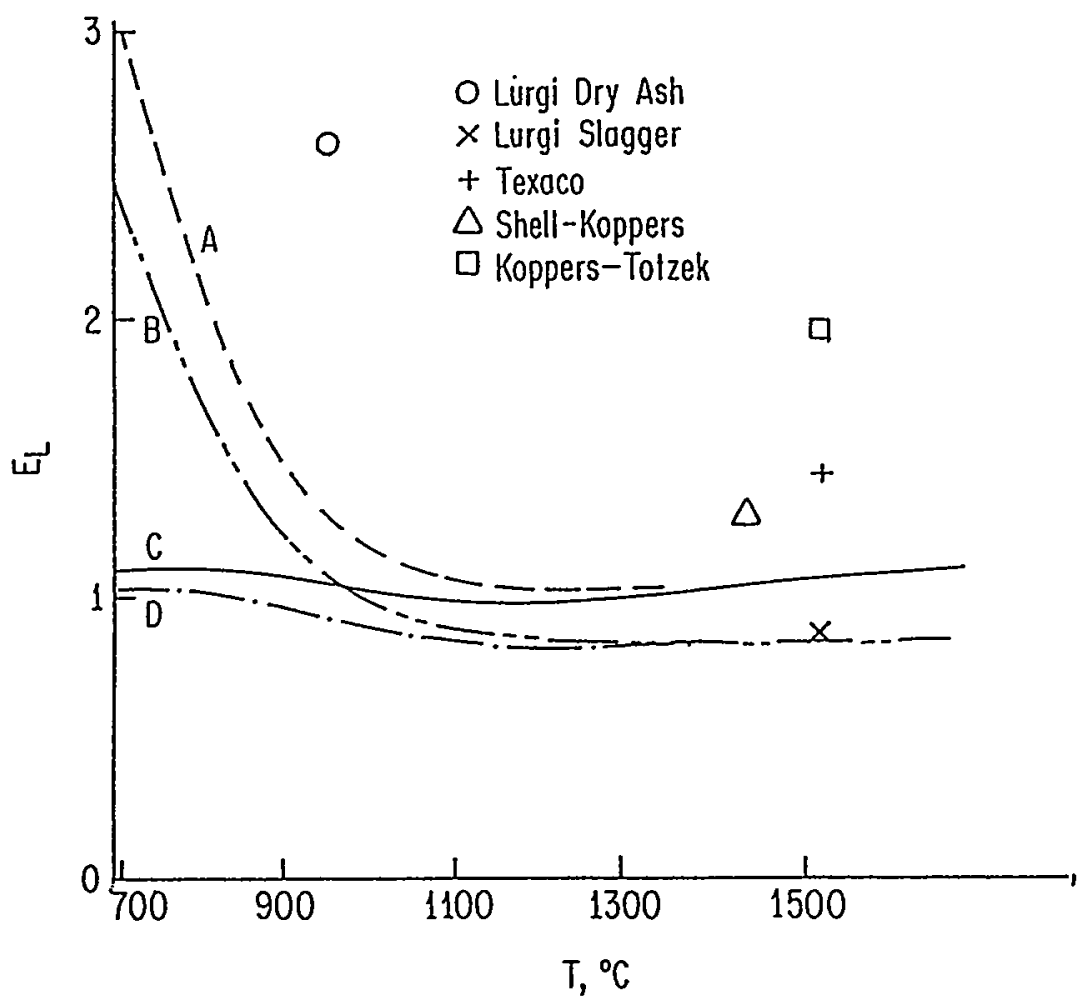

Fig. A-2. Calculated equilibrium and actual values of $E_{L}$ for an Eastern US coal; reproduced from Ref. 2. The following assumptions apply to the calculated curves; $A$, well-mixed reactor, no methane formation; $B$, counter current reactor, no methane formation; $C$, well-mixed reactor, methane at equilibrium; D, counter current reactor, methane at equilibrium; from Ref. 2 .

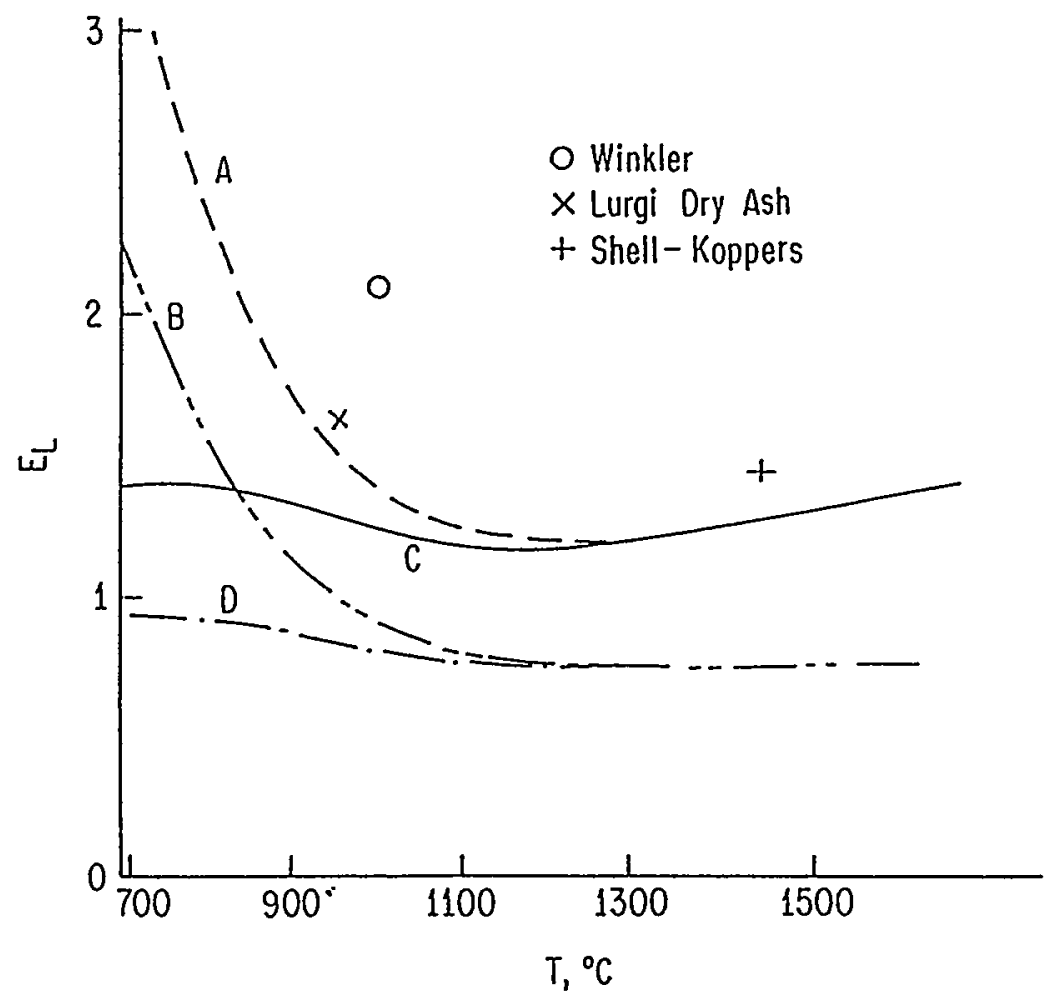

Fig. A-3. As in Fig. A-2 but using a Western US coal; from Ref. 2. 


\section{References}

1. R.V. Shinnar, presentation at the Fourth Technical Meeting of COGARN, May 1986.

2. M.M. Denn and R.V. Shinnar, "Coal Gasification Reactors" in Chemical Reactor \& Reaction Engineering, pp. 499-543, Carberry and Varma eds., Marcel Dekker, New York, NY (1986).

3. R.V. Shinnar and J.C. Kuo, "Gasifer Study for Mobil Coal to Gasoline Processes," Final Report, FE-2766-13/UC-90D, US DoE, Germantown, MD (1978). 
GLOSSARY OF SYMBOLS AND ABBREVIATIONS

\begin{tabular}{|c|c|}
\hline $\begin{array}{l}A \\
\AA \\
\AA\end{array}$ & $\begin{array}{l}=\text { ampere } \\
=\text { Angstrom }=10^{-10} \text { meter }\end{array}$ \\
\hline AAQS & $=$ Ambient Air Quality Standards \\
\hline$A C$ & $=$ alternating current \\
\hline $\operatorname{AFC}(s)$ & $=$ alkaline fuel cell(s) \\
\hline AI & $=$ artificial intelligence \\
\hline ANL & = Argonne National Laboratory \\
\hline ASTM & $=$ American Society for Testing Materials \\
\hline atm & $=$ atmosphere \\
\hline$B G C$ & $=$ British Gas Corporation \\
\hline BOD & $=$ biological oxygen demand \\
\hline BPD & $=$ barrel(s) per day \\
\hline BPY & $=$ barrel $(s)$ per year \\
\hline BTU & $=$ British thermal unit(s) \\
\hline BTX & $=$ benzene $(s)$, toluene $(s)$, and $x y$ lene $(s)$ \\
\hline${ }^{\circ} \mathrm{C}$ & $=$ degree $(s)$ Celsius \\
\hline cal & $=$ calorie \\
\hline CARS & $=$ coherent anti-Stokes Raman scattering \\
\hline $\mathrm{cc}$ & $=$ cubic centimeter \\
\hline CCG & $=$ catalytic coal gasification \\
\hline$C F$ & $=$ cubic foot (feet) \\
\hline $\mathrm{Ci}$ & $=$ Curie \\
\hline $\mathrm{cm}$ & $=$ centimeter $=10^{2}$ meter \\
\hline CNG & $=$ Consolidated Natural Gas \\
\hline COD & $=$ chemical oxygen demand \\
\hline COGARN & $\begin{aligned}= & \text { (Working Group for) Coal Gasification Research } \\
& \text { Needs }\end{aligned}$ \\
\hline $\begin{array}{l}C_{s} \\
\text { CWCGP }\end{array}$ & $\begin{array}{l}=\text { sulfide capacity defined in Eq. }(8 \mathrm{~A}-4) \\
=\text { Cool Water Coal Gasification Program }\end{array}$ \\
\hline$d$ & $=$ day or particle diameter \\
\hline D & $=$ diesel fuel(s) \\
\hline
\end{tabular}




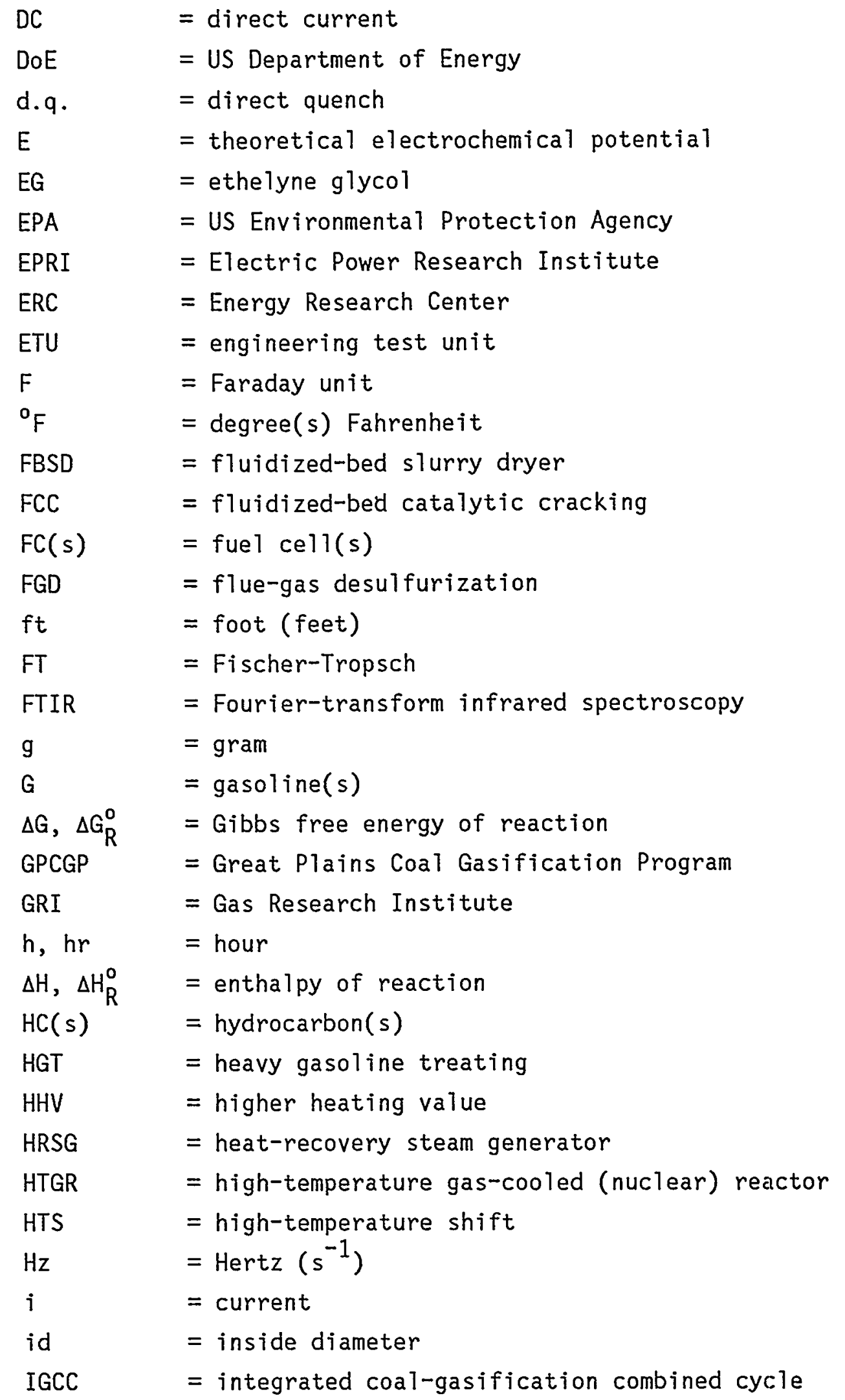




\begin{tabular}{|c|c|}
\hline IGT & $=$ Institute of Gas Technology \\
\hline in & $=$ inch \\
\hline IRMCFC & $=$ internal-reforming molten-carbonate fuel cell \\
\hline K & $=$ degree $(\mathrm{s})$ Kelṽin or equilibrium constant \\
\hline KRW & $=$ Kellogg-Rust-Westinghouse (gasifier) \\
\hline$\ell$ & $=1 i \operatorname{ter}(s)$ \\
\hline LASS & $=$ laser spark spectroscopy \\
\hline $1 \mathrm{~b}$ & $=\operatorname{pound}(s)$ \\
\hline LCD & $=$ levelized constant dollars \\
\hline LDV & $=$ laser-doppler velocimetry \\
\hline LHV & $=$ lower heating value \\
\hline LIF & $=1$ aser-induced fluorescence \\
\hline LTS & $=$ low-temperature shift \\
\hline m & $=$ meter \\
\hline $\operatorname{MCFC}(s)$ & $=$ molten-carbonate fuel cell(s) \\
\hline Me & $=$ methanol \\
\hline METC & $=$ Morgantown Energy Technology Center \\
\hline $\operatorname{mil1}$ & $=10^{-3}$ do $11 \mathrm{ar}$ \\
\hline MOGD & $\begin{aligned}= & \text { Mobil's process for the conversion of olefins } \\
& \text { to gasolines and diesel fuels }\end{aligned}$ \\
\hline moß\% & $=$ mole percent \\
\hline $\mathrm{mt}$ & $=$ metric ton \\
\hline MTBE & $=$ methy 1 tert-buty 1 ether \\
\hline MTG & $=$ methanol-to-gasoline (conversion) \\
\hline MTO & $=$ methanol-to-olefin(s) (conversion) \\
\hline $\mathrm{n}$ & $=$ number of equivalents per mole \\
\hline NESHAP & $\begin{aligned}= & \text { National Emissons Standards for Hazardous } \\
& \text { Pollutants }\end{aligned}$ \\
\hline NG & $=$ natural gas \\
\hline NMR & $=$ nuclear magnetic resonance \\
\hline NSPS & $=$ New Source Performance Standards \\
\hline ORNL & $=$ Oak Ridge National Laboratory \\
\hline $\mathrm{p}$ & $=$ pressure \\
\hline $\begin{array}{l}p_{i} \\
\operatorname{PAFC}(s)\end{array}$ & $\begin{array}{l}=\text { partial pressure of component } i \\
=\text { phosphoric-acid fuel cell(s) }\end{array}$ \\
\hline
\end{tabular}




$$
\begin{aligned}
& \operatorname{PAH}(s) \quad=\text { Polycyclic aromatic hydrocarbon(s) } \\
& \text { PC = pulverized coal } \\
& \text { PDF } \quad \text { probability density function } \\
& \text { PDU }=\text { process development unit } \\
& \text { PETC = Pittsburgh Energy Technology Center } \\
& \text { PM = photomultiplier } \\
& \operatorname{PNA}(s) \quad=\text { polynuclear aromatic(s) } \\
& \text { ppm (ppmv) = parts per million (by volume) } \\
& \text { PSA }=\text { pressure-swing absorption } \\
& \text { psia }(p s i g)=\text { pounds per square inch absolute (gauge) } \\
& \mathrm{R}=\text { molar gas constant } \\
& \text { RCRA = Resource Conservation Recovery Act } \\
& \text { RGS = raw gas shift } \\
& \text { ROM = run-of-mine } \\
& \text { RON = research octane number } \\
& \mathrm{s} \quad=\text { seconds } \\
& \triangle S \quad=\text { entropy of reaction } \\
& \text { SASOL = city in South Africa where the South African } \\
& \text { Coal, 0i1 and Gas Corporation built its } \\
& \text { initial plant for syncrude production from coal } \\
& \text { SCE = Southern California Edison Company } \\
& \text { SCF } \quad=\text { standard cubic foot (feet) } \\
& \text { SCGP = Shell Coal Gasification Process } \\
& \text { SEM = scanning electron microscope } \\
& \text { SG = synthesis gas } \\
& \text { SI = swelling index } \\
& \text { SMDS = Shell middle-distillate synthesis } \\
& S / N=\text { signal-to-noise ratio } \\
& \text { SNG = substitute (or synthetic) natural gas } \\
& \text { SPC = single-particle counter } \\
& \operatorname{SPEFC}(\mathrm{s})=\text { solid polymer electrolyte fuel cell(s) } \\
& \text { SRS = stimulated Raman scattering } \\
& \text { SS } \quad=\text { stainless steel } \\
& \mathrm{T} \quad \text { = temperature }
\end{aligned}
$$




$\begin{array}{ll}\text { TARGET } & =\text { Team to Advance Research on Gas Energy } \\ & \text { Transformation } \\ \text { TBE } & \text { tert-butyl ether } \\ \text { TCGP } & =\text { Texaco Coal Gasification Process } \\ \text { TDS } & =\text { total dissolved solids } \\ \text { TSA } & =\text { temperature-swing absorption } \\ \text { TSCA } & =\text { Toxic Substances Control Act } \\ \text { TOC } & =\text { total organic carbon } \\ \text { TPD } & =\text { ton(s) per day } \\ \text { TPY } & =\text { ton(s) per year } \\ \text { TSP } & =\text { total suspended particulates } \\ \text { TSS } & =\text { total suspended solids } \\ \text { TVA } & =\text { Tennessee Valley Authority } \\ \text { UPA } & =\text { United Power Association } \\ \text { UTC } & =\text { United Technologies Corporation } \\ V & =\text { volt(s) } \\ \text { VA } & =\text { vinyl acetate } \\ \text { vol\% } & =\text { percent by volume } \\ W / W & =\text { weight divided by weight } \\ W H & =\text { watt-hour } \\ \text { WGS } & =\text { water-gas-shift reaction } \\ W t \% & =\text { weight percent }\end{array}$

\section{Greek Symbol-s.}

\begin{tabular}{|c|c|}
\hline$\varepsilon$ & $=$ emissivity, Carnot efficiency \\
\hline$\eta$ & = overpotential \\
\hline$\theta_{\mathbf{i}}$ & $=$ angle defined in Fig. $11.5-2$ \\
\hline$\lambda$ & $=$ wavelength \\
\hline$\phi$ & $=$ pheny 1 radical \\
\hline$\omega_{p}$ & $=$ pump-laser frequency \\
\hline$\omega_{s}$ & = Stokes-laser frequency \\
\hline
\end{tabular}




\section{Prefixes}

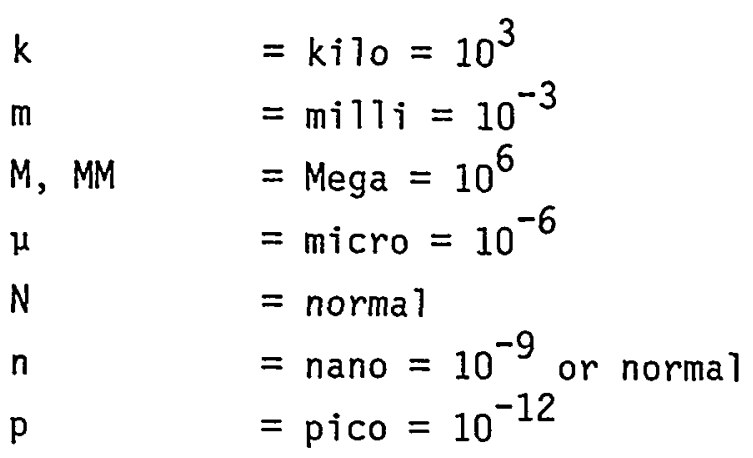


FORMAL REVIEWS OF THE COGARN REPORT

At the request of the DoE Project Officer for this study, the COGARN report was submitted for independent review and comments to the following experts on coal science and gasification: H. Heinemann (Lawrence Berkeley Laboratory, University of California, Berkeley), J.P. Henley (Dow Chemical, Plaquemine, LA), G.R. Hill (University of Utah, Salt Lake City), J.D. Holmgren (KRW Energy Systems Inc., Madison, PA), W.E. Schlinger (Texaco Inc., Universal City, CA), and R. Shinnar (City University of New York, NYC). Insofar as the reviewers' comments dealt with corrections or specific changes, these have been incorporated in the final text. Policy recommendations are reproduced here because they may be of general interest and complementary to the views of COGARN members. The writers addressed their reviews to the COGARN chairman.

H. Heinemann, Senior Scientist, Lawrence Berkeley Laboratory, 1 Cyclotron Road, Berkeley, CA 94720

I have had an opportunity to review the draft of the COGARN report, which you sent me with your letter of December 25, 1986. This is an excellent and very helpful report.

I believe that the recommendations are clear and acceptable. As stated in the report, the priorities will vary from individual to individual, depending on his outlook and interests. Perhaps one should distinguish in the recommendations between developmental reeds and research needs. Items 2 and 11 are obviously urgent for further development and should receive highest priority in that category. Items 5 and 6 would fall into the same group. By listing priorities for research separately, the impression of greater urgency might be created by giving them ratings on the 1 to 10 scale which would compete with ratings in the developmental area.

I have not read all the tutorials, but am particularly impressed with Chapter 5 , which presents a survey which can serve as guidelines for the future and will even be helpful in teaching. As a minor criticism of this chapter, I miss references to our work on the slurry reactor, 
particularly the papers by Stern et a1. in Chemical Engineering Science [40, No. 10, 1917 (1985)] and I and EC Process Design and Development [24, $12-13(1985)]$.

I had previously seen a draft of Chapter 7, which includes our own work on gasification. Since I had previously approved of it, I can only repeat that it states matters fairly.

I believe that this report will be very useful in our own work on coal gasification, as well as in the obvious need to persuade funding organizations to support work in the area if at all possible on an expanded scale. I am deeply concerned about the continuing efforts to disregard and deemphasize this very important area at a time when research should be emphasized, perhaps over development, because we may have a period during which novel ideas and concepts can be brought forward toward commercialization without working under the pressure of immediate needs.

John P. Henley, Research Associate, Louisiana Applied Science and Technology Laboratories, Dow Chemical USA, P.O. Box 150, P1aquemine, LA 70765-0150

I certainly appreciate the opportunity to review the document produced by the COGARN group on research need for coal gasification. This type of project is most valuable in light of our shifting emphasis in synthetic fuel research.

The tutorial sections of the report were excellent in describing each area of technology. Each section was both thoroughly researched and well written. The respective authors should be commended for their work.

After reading the executive summary containing the prioritized list, I went through the exercise of ranking these in the order as I saw them. As one might expect, my background being private development, the order was rather different. From this I concluded that I would agree completely with your statement on page 8 , "priority assignments reflect the background and problem areas faced by individual investigators . . .". To get a better idea of what experts in each area believe is important, I think it would have been most informative to have at least four separate priority lists, one each representing academia, industry, not-for-profits 
(EPRI, GRI, etc.), and government-financed institutions. While no particular one could ever be considered "best," this would allow the researcher to evaluate each group's consensus with regard to his own specific are of interest.

In general, I would like to say that the report should be quite useful as a reference source to evaluate research needs. The COGARN group should be commended for their fine work.

G.R. Hill, Dept. of Fuel Chemistry, University of Utah, Salt Lake City, UT 84108

The volume "Coal Gasification" is a very thorough review of research and development of coal-gasification processes and might well constitute a major section of a new supplement of Lowry's "The Chemistry of Coal Utilization," the coal R\&D "Bible." The Assessment of Research needs, per se, is stated briefly, almost perfunctorily, in the executive summary. It would be very useful to have the volume (even minus the executive summary) published and made available to those involved in coal gasification research and development.

If this use of the volume is possible, there should be added an important section on co-production of gas and oil, i.e., of primary coal liquid distillates. Because of the historical classification of coal conversion into gasification and liquefaction, process paths for the production of qas and oil or of char and oil have been orphans. Research and development done under special designations (e.g., mild gasification or partial liquefaction), have largely fallen through the cracks between the total conversion processes, in reviews such as this. Since these processes appear to require much milder conditions, they are less costly. It is essential that they not be overlooked.

Chapter 2 in the present volume is a very detailed summation of the possible and necessary research programs needed in each of the areas described in detail in Chapters 3 through 14 . The great simplification in the Table ES-1 list of priority research and development areas is readily apparent as one studies detailed recommendations in all 12 areas in Chapter 2. Chapters 3 through 14 will be invaluable references for those planning for or engaged in coal gasification and its applications. 
The authors of the treatise are to be commended for the thoroughness of their comprehensive work.

J.D. Holmgren, Vice President - Technology Development, KRW Energy Systems, Inc., P.0. Box 334, Madison, PA 15663-0334

Overall, I think the document is an excellent summary on coal-processing technologies, applications, and research and development needs. In my opinion, the first two chapters are really the heart and muscle of the report. The Executive Summary is brief and to the point and the use of Table ES-1 provides a simplified way of identifying R\&D priorities. One suggestion that might provide a little more data would be to use a matrix table in which the priorities could be 1 isted in row form and the scale at which activities would be conducted, such as bench, laboratory, pilot, demonstration, etc., would be listed in columnar form.

Chapter 2, "Overview of Coal-Gasification R\&D Needs" is a good companion to the Executive Summary and, in genera1, one obtains a good synopsis of each of the subsequent chapters to follow. Some sections are more detailed than others and Sec. 2.5 on "Gasification for Synthesis of Fuels and Chemicals" could be abbreviated.

Chapter 3, "Gasification for Electricity Generation," provides a good summary for power-generation applications and the Cool Water details are very appropriate. The description of gasification systems that could be used is good for the Shell and Texaco gasifiers; however, the information for U-GAS is much too detailed and relates largely to R\&D results.

Chapter 4, "Coal Gasification for SNG Production," is an excellent chapter. It has good organization and good balance of fundamentals, technologies, specific processes, and economics.

Chapter 5, "Gasification for the Synthesis of Fuels and Chemicals," is a good chapter but is much more detailed than most of the other chapters in the publication. The information could be summarized to provide a more concise and effective text. In addition, the outline could make better use of numerical paragraph indexing to help the reader understand where he is within the text. 
Chapter 6, "Coal Gasification in Fuel-Cell Applications," is a good, short and hard-hitting chapter.

Chapter 7, "Use of Catalysts During Gasification," is another short, good, and effective chapter with good use of visual and tabular summaries and good references.

Chapter 8, "Gas-Cleaning Processes for Coal Gasification," is much too brief in view of the importance of gas cleaning for coal gasification. There is some duplication on acid-gas removal with Chapter 4, Sec. 4.4, but this is not distracting.

Chapter 9, "Environmental Issues," is a good chapter, which identifies requirements and presents information regarding environmental characteristics for various gasification systems. For the amount of information presented, the list of references is rather brief.

Chapter 10, "Coal Beneficiation," is another area that I believe to be extremely important for the utilization of coal and this particular chapter is much too brief. The information presented relates primarily to old technologies and the discussion is extremely brief on the development that are currently underway. I believe that it would be helpful to have more information presented on advanced clean-coal technologies that are currently under development and demonstration.

Chapter 11, "Optical Diagnostics for In Situ Measurements in Pulverized-Coal Combustion Environments," is an excellent chapter, particularly for people who are involved in R\&D studies. In the future, some of these technologies will be used on commercial systems to provide better control and system diagnostics.

Chapter 12, "Fundamentals of Coal Conversion and Relation to Coal Properties," is an excellent chapter that summarizes a great deal of information with tables and charts and correlates this information with a significant reference list.

Chapter 13 deals with "Gas Supplies and Separation; Ash Disposal; Materials for Gasifiers." The section on oxygen systems should include some specific information of pressure-swing absorption systems that have been developed and are applicable for smaller gasification applications or for systems with lower oxygen-purity requirements. The other sections on ash and materials of construction are adequate. 
Chapter 14, "Introduction to Costing," was a disappointment to me in that the material did not relate to economics of coal gasification and utilization. There have been many economic studies completed for EPRI and GRI that could have been used to provide detailed information for this particular chapter. The important problem is not so much the probability of over- and under-runs on cost estimation, but rather what are some of the real projected costs for coal-gasification applications. I would hope that this chapter could be redone and information provided in at least the following three areas: (i) summary of techniques (models) used to generate economic cost data; ( $i i)$ a general summary showing capital and product. costs for various coal-gasification applications; (iii) a general summary showing the distribution of capital and operating costs by components/ systems for specific coal-gasification applications.

The Appendix includes information prepared by Shinnar. We have worked closely with Shinnar over the past few years, and I am quite familiar with his approach for evaluating different gasification technologies. I certainiy think this information should be included; however, I feel there should be a more detailed preamble on how his technique fits with other gasification-evaluation schemes.

Again, I thought the efforts were outstanding and the report will be extremely useful to many people. I realize that many of my comments are quite general, but I do hope that they will provide some feeling regarding the balance of material within this document.

W.G. Schlinger, Associate Director, Gasification, Alternate Energy and Resource Department, Texaco Inc., 10 Universal City Plaza, Universal City, CA $91608-1097$

I have made an attempt to review the rather impressive docunnent you put together for DOE on the assessment of research needs for coal gasification. I must confess, I concentrated primarily on the first three sections. A few specific comments are detailed below.

As far as the overall report is concerned, the consensus appears to be that work in 211 areas that you have identified is needed. You do not identify any areas where effort should be discontinued or significantly reduced. DOE, with their limited funding, probably should concentrate the 
funds they have in areas which are most likely to solve some of the energy shortfall problems of the future.

One of the most important items in your report is Table ES-1, in which you assign priorities based upon the consensus of COGARN members. In general, the areas of highest priority (those rated above 6.0) are in agreement with our thinking. Some of the items, however, are much more costly than others to pursue on a high-priority basis. Some indication of cost effectiveness needs to be identified.

Chapter 2 ("Overview of Coal Gasification R\&D Needs") is a we11-written summary. The need to decrease the cost of an IGCC plant is certainly important and well recognized by the Committee. As I told your Committee in Morgantown, hot gas cleanup and more efficient and less costly air-separation plants are two areas which could accomplish such a cost reduction.

You have done a very creditable job of assembling a mass of information. All of your Committee members should be congratulated.

R. Shinnar, School of Engineering, Department of Chemical Engineering, The City College, The City University of New York, New York, NY 10031

Table ES-1 (p. 2) I find it hard to understand why item $\underline{9}$ got such low priority. Why is it not tied to item 13? Also, how can we summarize present results without a reasonable model for comparison? (i) I find no comment on the fluidized-bed gasification program. It was the heart of my DoE paper and received most of the support in the past. Should this effort be completed and summarized or should it be abandoned? I am strongly for the first option. This aspect should have been more thoroughly discussed.

Fig. 4.5-1 (p. 62) The report gives some economic estimates comparing KRW to Lurgi. As I pointed out in my inputs, there is absolutely no experimental or theoretical basis for the mass balances on which these estimates are prepared. The same holds for similar estimates made for U-GAS. Furthermore, a dry bottom in Lurgi is a totally nonrealistic base case for Eastern coal. A more realistic base case would be a BGC slagger, 
which is practically the only presently available viable option for SNG from Eastern coal.

pp. 29-37 No mention is made of the fact that the U-GAS pilot plant operated at $50 \mathrm{psi}$, which is totally unsuitable for a combined-cycle power plant. There is no way to predict the operation of such a gasifier at higher pressures. The only way is to operate a pilot plant at the desired pressure, which is about 300 psi for a combined-cycle power plant. On the other hand, KRW has operated the gasifier at $300 \mathrm{psi}$ in an airblown mode. This operation with added limestone at $2000^{\circ} \mathrm{F}$ was their most successful overall run in any mode and could be useful for a combined-cycle power plant.

Appendix (p. 267) The comment on fiuid-bed gasifiers is much more negative than I intended. It is correct as applied to present-day pilot plants. I would suggest to add the following paragraph:

The advantages of fluid-bed gasifiers are: (a) ability to handle low-grade coals (for some coals, it is the only suitable gasifier); (b) higher safety than entrained-bed gasifiers.

There is a substantial hope that the disadvantages of present fluid-bed gasifiers for Eastern coal will be overcome by proper use of cheap catalysts such as limestone. The results of KRW with lime in an airblown operation are very promising. Limestone reduces agglomeration and allows operation at higher temperature, which could substantially reduce the need for dilution of the oxygen. Catalysis could also lead to high carbon conversion. Since a substantial effort has been devoted to fluid-bed gasifiers, it is highly desirable to investigate the effect of catalysts on oxygen-blown fluid-bed gasifiers. 